 \\ UNIVERSITY OF \\ TECHNOLOGY
}

\section{Positive Organizational Interventions}

Citation for published version (APA):

van Zyl, L. E., \& Rothmann, Sr., S. (Eds.) (2021). Positive Organizational Interventions: Contemporary Theories, Approaches and Applications. Frontiers Media S.A. https://doi.org/10.3389/978-2-88966-345-3

DOI:

10.3389/978-2-88966-345-3

Document status and date:

Published: 05/01/2021

\section{Document Version:}

Publisher's PDF, also known as Version of Record (includes final page, issue and volume numbers)

\section{Please check the document version of this publication:}

- A submitted manuscript is the version of the article upon submission and before peer-review. There can be important differences between the submitted version and the official published version of record. People interested in the research are advised to contact the author for the final version of the publication, or visit the $\mathrm{DOI}$ to the publisher's website.

- The final author version and the galley proof are versions of the publication after peer review.

- The final published version features the final layout of the paper including the volume, issue and page numbers.

Link to publication

\section{General rights}

Copyright and moral rights for the publications made accessible in the public portal are retained by the authors and/or other copyright owners and it is a condition of accessing publications that users recognise and abide by the legal requirements associated with these rights.

- Users may download and print one copy of any publication from the public portal for the purpose of private study or research.

- You may not further distribute the material or use it for any profit-making activity or commercial gain

- You may freely distribute the URL identifying the publication in the public portal.

If the publication is distributed under the terms of Article $25 \mathrm{fa}$ of the Dutch Copyright Act, indicated by the "Taverne" license above, please follow below link for the End User Agreement:

www.tue.nl/taverne

Take down policy

If you believe that this document breaches copyright please contact us at:

openaccess@tue.nl

providing details and we will investigate your claim. 


\section{POSITIVE ORGANIZATIONAL INTERVENTIONS: CONTEMPORARY THEORIES, APPROACHES AND APPLICATIONS}

EDITED BY: Llewellyn Ellardus Van Zyl and Sebastiaan Rothmann PUBLISHED IN: Frontiers in Psychology



frontiers Research Topics 


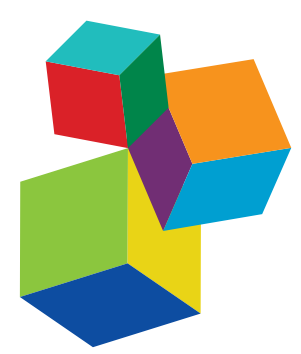

Frontiers eBook Copyright Statement

The copyright in the text of individual articles in this eBook is the property of their respective authors or their respective institutions or funders. The copyright in graphics and images within each article may be subject to copyright of other parties. In both cases this is subject to a license granted to Frontiers.

The compilation of articles constituting this eBook is the property of Frontiers.

Each article within this eBook, and the eBook itself, are published under the most recent version of the Creative Commons CC-BY licence. The version current at the date of publication of this eBook is CC-BY 4.0. If the CC-BY licence is updated, the licence granted by Frontiers is automatically updated to the new version.

When exercising any right under the CC-BY licence, Frontiers must be attributed as the original publisher of the article or eBook, as applicable.

Authors have the responsibility of ensuring that any graphics or other materials which are the property of others may be included in the

CC-BY licence, but this should be checked before relying on the

CC-BY licence to reproduce those materials. Any copyright notices relating to those materials must be complied with.

Copyright and source acknowledgement notices may not be removed and must be displayed in any copy, derivative work or partial copy which includes the elements in question.

All copyright, and all rights therein, are protected by national and international copyright laws. The above represents a summary only.

For further information please read Frontiers' Conditions for Website

Use and Copyright Statement, and the applicable CC-BY licence.

ISSN 1664-8714

ISBN 978-2-88966-345-3

DOI 10.3389/978-2-88966-345-3

\section{About Frontiers}

Frontiers is more than just an open-access publisher of scholarly articles: it is a pioneering approach to the world of academia, radically improving the way scholarly research is managed. The grand vision of Frontiers is a world where all people have an equal opportunity to seek, share and generate knowledge. Frontiers provides immediate and permanent online open access to all its publications, but this alone is not enough to realize our grand goals.

\section{Frontiers Journal Series}

The Frontiers Journal Series is a multi-tier and interdisciplinary set of open-access, online journals, promising a paradigm shift from the current review, selection and dissemination processes in academic publishing. All Frontiers journals are driven by researchers for researchers; therefore, they constitute a service to the scholarly community. At the same time, the Frontiers Journal Series operates on a revolutionary invention, the tiered publishing system, initially addressing specific communities of scholars, and gradually climbing up to broader public understanding, thus serving the interests of the lay society, too.

\section{Dedication to Quality}

Each Frontiers article is a landmark of the highest quality, thanks to genuinely collaborative interactions between authors and review editors, who include some of the world's best academicians. Research must be certified by peers before entering a stream of knowledge that may eventually reach the public - and shape society; therefore, Frontiers only applies the most rigorous and unbiased reviews.

Frontiers revolutionizes research publishing by freely delivering the most outstanding research, evaluated with no bias from both the academic and social point of view. By applying the most advanced information technologies, Frontiers is catapulting scholarly publishing into a new generation.

\section{What are Frontiers Research Topics?}

Frontiers Research Topics are very popular trademarks of the Frontiers Journals Series: they are collections of at least ten articles, all centered on a particular subject. With their unique mix of varied contributions from Original Research to Review Articles, Frontiers Research Topics unify the most influential researchers, the latest key findings and historical advances in a hot research area! Find out more on how to host your own Frontiers Research Topic or contribute to one as an author by contacting the Frontiers Editorial Office: researchtopics@frontiersin.org 


\title{
POSITIVE ORGANIZATIONAL INTERVENTIONS: CONTEMPORARY THEORIES, APPROACHES AND APPLICATIONS
}

\author{
Topic Editors: \\ Llewellyn Ellardus Van Zyl, North-West University, South Africa \\ Sebastiaan Rothmann, North-West University, South Africa
}

Citation: van Zyl, L. E., Rothmann, S., eds. (2021). Positive Organizational Interventions: Contemporary Theories, Approaches and Applications. Lausanne: Frontiers Media SA. doi: 10.3389/978-2-88966-345-3 


\section{Table of Contents}

04 Editorial: Positive Organizational Interventions: Contemporary Theories, Approaches and Applications

Llewellyn E. van Zyl and Sebastiaan Rothmann

10 Providing Services During Times of Change: Can Employees Maintain Their Levels of Empowerment, Work Engagement and Service Quality Through a Job Crafting Intervention?

Inge L. Hulshof, Evangelia Demerouti and Pascale M. Le Blanc

25 Coaching-Based Leadership Intervention Program: A Controlled Trial Study María Josefina Peláez Zuberbuhler, Marisa Salanova and Isabel M. Martínez

47 Positive Psychological Micro-Interventions to Improve the Work-Family Interface: Use Your Resources and Count Your Blessings

Maria C. W. Peeters, Elianne F. van Steenbergen and Jan Fekke Ybema

59 An Intervention Framework to Facilitate Psychological Trauma Management in High-Risk Occupations

Bouwer E. Jonker, Lene llyna Graupner and Lizelle Rossouw

75 Positive Psychological Coaching Definitions and Models: A Systematic Literature Review

Llewellyn E. van Zyl, Lara C. Roll, Marius W. Stander and Stefanie Richter

94 A Three-Wave Longitudinal Study of Moderated Mediation Between High-Performance Work Systems and Employee Job Satisfaction: The Role of Relational Coordination and Peer Justice Climate

Sajid Haider, Carmen De-Pablos-Heredero and Monica De-Pablos-Heredero

109 The Concept and Components of Engagement in Different Domains Applied to eHealth: A Systematic Scoping Review Saskia M. Kelders, Llewellyn Ellardus van Zyl and Geke D. S. Ludden

123 Testing a Self-Compassion Intervention Among Job Seekers: Self-Compassion Beneficially Impacts Affect Through Reduced Self-Criticism

Loes M. Kreemers, Edwin A. J. van Hooft, Annelies E. M. van Vianen and Sophie C. M. Sisouw de Zilwa

137 The Implementation and Evaluation of the South African Adaptation of the JOBS Program

Rachele Paver, Hans De Witte, Sebastiaan Rothmann, Anja Van den Broeck and Roland Willem Bart Blonk

150 The Effect of Strengths-Based Performance Appraisal on Perceived Supervisor Support and the Motivation to Improve Performance Marianne van Woerkom and Brigitte Kroon

162 Feasibility and Process Evaluation of a Need-Supportive Physical Activity Program in Aged Care Workers: The Activity for Well-Being Project Merilyn Lock, Dannielle Post, James Dollman and Gaynor Parfitt

177 Will Happiness-Trainings Make Us Happier? A Research Synthesis Using an Online Findings-Archive

Ad Bergsma, Ivonne Buijt and Ruut Veenhoven 


\title{
Editorial: Positive Organizational Interventions: Contemporary Theories, Approaches and Applications
}

\author{
Llewellyn E. van Zyl ${ }^{1,2,3,4 *}$ and Sebastiaan Rothmann ${ }^{2}$ \\ ${ }^{1}$ Department of Industrial Engineering, University of Eindhoven, Eindhoven, Netherlands, ${ }^{2}$ Optentia Research Focus Area, \\ North-West University, Vaal Triangle Campus (VTC), Vanderbijlpark, South Africa, ${ }^{3}$ Department of Human Resource \\ Management, University of Twente, Enschede, Netherlands, ${ }^{4}$ Department of Social Psychology, Institut für Psychologie, \\ Goethe University, Frankfurt am Main, Germany
}

Keywords: positive organizational interventions, positive psychological interventions, strengths based development, positive psychological coaching, talent management

\section{Editorial on the Research Topic}

Positive Organizational Interventions: Contemporary Theories, Approaches and Applications

\section{INTRODUCTION}

Positive Organizational Interventions (POIs) have emerged as popular mechanisms to facilitate the personal/professional development and well-being of individuals as well as optimizing the growth potential of organizations (van Zyl and Rothmann, 2019a). These interventions draw from positive psychological principles, processes, and practices in order to produce positive outcomes for the individual (e.g., work engagement), the team (e.g., collaboration, team flow) and ultimately, the organization (e.g., innovative work behaviors) (Costantini et al., 2019). Through the optimization, utilization and application of an entity's strengths, POIs are not aimed at fixing what is proverbially "wrong," or correcting deviant behaviors, but rather focus on enhancing what is already working well (van Zyl and Rothmann, 2019b). This positive approach toward individual and organizational development has gained mass-appeal within the popular psychological press circuit ("Pop Psych") and is readily implemented within organizational contexts (Haberlin, 2019; van Zyl et al.).

Pop Psych has increased the visibility of POIs within the broader population through providing access to scientific content in an easily digestible format (Seligman, 2012). Pop Psych authors promise "ten scientifically proven ways" or "five easy evidence-based practices" to build flourishing organizations, optimal functioning teams, positive leaders and thriving employees through translating "scientifically proven interventions" into consumer-friendly terms (Ausch, 2016). However, the scientific merits of these portrayals within the Pop Psych press are questionable as authors miscommunicate findings, provide erroneous "summaries" of papers, and fundamentally alter both the context of- and POIs protocols published within the scientific literature (Ferguson, 2015, 2019). Therefore, when these interventions are implemented within practice, they rarely yield functional returns and do not deliver on their promises (Ausch, 2016). This in turn has a negative impact on the perceptive value of POIs within both the public domain and the broader discipline of psychology.

Scientists within the broader discipline of psychology have also questioned the effectiveness of POIs and shown to be critical of the underlying paradigm (i.e., positive psychology) (c.f. Brown et al., 2014; Friedman and Brown, 2018; Wong and Roy, 2018; Trask-Kerr et al., 2019). Academic 
authors have highlighted that POIs produce mixed results outside of clinical contexts (Bolier et al., 2013; Roll et al., 2019), that intervention effects are rarely replicable (Mongrain and Anselmo-Matthews, 2012; Khanna and Singh, 2019) or sustained (Turnes et al., 2020; van Zyl et al., 2020), that reported effect sizes are usually small (Bolier et al., 2013) and that the effectiveness of POIs are highly dependent upon contextual factors (Parks and Schueller, 2014; Wong and Roy, 2018).

Contemporary literature suggests the lack of effectiveness of POIs is a function of a plethora of factors ranging from insufficient duration of the intervention, inappropriate dissemination methods, inadequate consideration of cultural and contextual factors, to a failure to build interventions around validated theoretical models, poor measurement strategies and person-activity misfit (Stander and van Zyl, 2019; van Zyl et al., 2019). In essence, the problem stems from poor POI design, implementation and evaluation methods which is exasperated by a lack extensive POI intervention protocols and methodologies within the academic literature. In those instances where POIs have shown to be effective, intervention content is usually condensed into a single paragraph in the methods' section or removed in its entirety in the final manuscript. This severely limits or deludes its potential transferability into practice.

In order to address these challenges, practitioners and researchers need to develop a shared understanding as to how POIs need to be designed, how content needs to be aligned to the strengths of participants, how to effectively evaluate such and finally how to maintain the positive effects over time. Similarly, clear intervention protocols need to be established, practice friendly process models need to be provided and the models on which interventions are built needs to be expanded. As such, the purpose of this Research Topic and e-book was to address these challenges through curating innovative theoretical and empirical POI research relating to modern intervention designs, methodologies, models, content, and evaluation methods.

\section{STRUCTURE AND CONTRIBUTION OF THIS SPECIAL ISSUE}

The primary aim of this manuscript was to collate a collection of contemporary approaches toward the development, implementation and evaluation of POIs which could easily be translated into practical, viable instruments for others to employ. The 12 manuscripts in this special issue, summarized in Table 1, are classified into four sections:

(1) Empirically validated positive organizational intervention strategies. Here the focus is on determining the effectiveness of POIs and to present readers with intervention protocols.

(2) Empirical models for positive organizational interventions. In this section, authors aimed to provide a proverbial "roadmap" on which POIs can be built, and to show how adopting a certain type of intervention approach may impact organizational outcomes.

(3) Positive organizational intervention strategies and frameworks. Here the focus was on providing broad practice friendly POI strategies and frameworks.
(4) Online POI design principles. In this section, the authors attempted to provide an overview of important components to consider when designing engaging online POIs.

The papers in each of these respective sections advances our understanding as to what constitutes a POI, as well as how such should effectively be designed and implemented. On a meta-level, this special issue highlights the following:

(1) POIs largely involve a structured set of intentional developmental initiatives that are initiated by an organization, that are built upon the positive psychology paradigm with the specific aim to promote positive states, traits, behaviors and to facilitate a positive organizational climate and culture.

(2) POIs could take the form of self-administered intentional activities (e.g., counting one's blessings), group-based development initiatives (e.g., happiness trainings), organizational level interventions (e.g., strengthsbased performance management) and strengths- or positive coaching.

(3) POIs that do not produce the desired effects are largely the result of poor empirical models underpinning interventions, interventions focusing on enhancing outcomes rather than specifically targeted mediators/moderators, poor intervention design and unreliable measuring instruments, as well as person-activity misfit and when basic behavioral change models are ignored.

(4) In terms of POI design, the focus should be placed on the duration of the intervention, participants intention-totreat, appropriate dissemination methods or tools should be employed, and the culture and context of participants need to be taken into consideration.

(5) Effective POIs focus on aligning the features of the intervention and the methodology of its dissemination, to the personal features of the participants and

(6) Participants and facilitators need to be debriefed after the completion of the intervention.

\section{GUIDELINES FOR DESIGNING POSITIVE ORGANIZATIONAL INTERVENTIONS}

This special issue further highlights that the effectiveness of POIs is fundamentally a function of its intentional design. Although various attempts have been made to provide structured guidelines on designing POIs and Positive Psychological Interventions (van Zyl et al., 2019), no clearly validated frameworks or protocols for such exist. This special issue highlights six elements of designing impactful POIs (see Figure 1).

When designing POIs, researchers and practitioners should consider the following:

a. Defining the scope and context of the intervention. Here the focus is on understanding the nature of the underlying problem within the population and determining the way to effectively address and approach such. Practitioners should first conduct a needs analyses to determine the underlying needs of participants. These needs need to 
TABLE 1 | Summary of the contributions to this special topic.

\begin{tabular}{|c|c|c|c|}
\hline No & Author & Title of contribution & Main objective \\
\hline \multicolumn{4}{|c|}{ SECTION 1: EMPIRICALLY VALIDATED POSITIVE PSYCHOLOGICAL INTERVENTION STRATEGIES } \\
\hline 1 & Paver et al. & $\begin{array}{l}\text { The implementation and evaluation of the } \\
\text { South African adaptation of the JOBS program }\end{array}$ & $\begin{array}{l}\text { The purpose of this paper was to evaluate the effectiveness of a POI aimed } \\
\text { at enhancing the job-related search behaviors of unemployed individuals } \\
\text { within the South African context. The JOBS program aimed to enhance the } \\
\text { self-efficacy, amotivation and self-esteem of job-seekers. }\end{array}$ \\
\hline
\end{tabular}

\section{$2 \quad$ Lock et al.}

Feasibility and process evaluation of a need-supportive physical activity program in aged-care workers: the Activity for well-being project
In this paper, the authors implemented a mixed-methods process evaluation and feasibility study for a need-supportive physical activity program that was piloted in a single-group pre-post study. The piloted program was designed to support participant needs of autonomy, competence and relatedness through evidence-based and theory-informed behavior change strategies including a Motivational Interviewing style appointment, education on self-management tools, and Self-Determined modes of regulating physical activity intensity. The program aimed to positively impact physical activity behavior, psychological well-being and associated motivational processes.

In this paper, the authors examined whether state self-compassion can be increased among job seekers through writing exercises in which job seekers are instructed to reflect with self-compassion on their negative job search experiences. Further, they wanted to determine if a self-compassion intervention benefited job seekers' affective responses, through reducing self-criticism.

The authors aimed to investigate the effectiveness of two micro-interventions which aimed to improve the work-family interface. One intervention focused on aiding individuals to optimize the use of their resources and the other focused on becoming consciously aware of one's "blessings." improve psychological micro-interventions to resources and count your blessings

"This paper foc

$\begin{array}{ll}5 & \text { Hulshof et al. } \quad \text { Providing services during times of change: can } \\ & \text { employees maintain their levels of } \\ & \text { empowerment, work engagement and service } \\ \text { quality through a job crafting intervention? }\end{array}$

This paper focused on how a job crafting training programme could aid organizations to maintain empowerment, work engagement and performance during times of organizational change.

$\begin{array}{ll}\text { Peláez-Zuberbuhler } & \text { Coaching-based leadership intervention } \\ \text { et al. } & \text { program: a controlled trial study }\end{array}$

The authors of this paper implemented and evaluated a coaching-based et al. program: a controlled trial study leadership intervention program comprised of training and three coaching sessions. The results showed that the intervention was successful in enhancing one's coaching-based leadership skills, psychological capital, work engagement and performance.

\begin{tabular}{ll}
\hline Bergsma et al. & Will happiness-trainings make us happier? A \\
& research synthesis using an online \\
& findings-archive
\end{tabular}

The authors investigated the effectiveness of happiness trainings using an online research repository. Specifically, they provided an overview of the techniques that can be used to enhance happiness, the duration of how long happiness trainings effects the happiness of participants, and what kind of individual could benefit from happiness trainings.

\section{SECTION 2: EMPIRICAL MODELS FOR POSITIVE ORGANIZATIONAL INTERVENTIONS}

\section{$8 \quad$ Haider et al.}

A three-wave longitudinal study of moderated mediation between high-performance work systems and employee job satisfaction: the role of relational coordination and peer justice climate
The authors provided an extensive exploration for an empirical model on which to build positive organizational level interventions aimed at enhancing job satisfaction. Through a three-wave longitudinal design, the authors found that organizations should foster practices that help foster relational coordination between employees in order to increase their job satisfaction. Further, managers should focus on optimizing rewards/recognition systems, performance management and meetings in order to create a positive and supportive work environment.

\begin{tabular}{ll}
\hline van Woerkom and & $\begin{array}{l}\text { The effect of strengths-based performance } \\
\text { appraisal on perceived supervisor support and } \\
\text { the motivation to improve performance }\end{array}$
\end{tabular}

\section{SECTION 3: POSITIVE ORGANIZATIONAL INTERVENTION STRATEGIES AND FRAMEWORKS} relatively low.
Positive psychological coaching definitions and models: a systematic literature review
The authors examined the effect of strengths-based performance appraisals on the relationship between the support supervisors provide and its impact on motivation to enhance performance. The findings indicate that a focus on strengths in the performance appraisal may boost employees' optimism regarding future successes, which is especially important to safeguard a supportive relationship with the supervisor when the performance rating is

$\begin{array}{ll}10 \text { van Zyl et al. } & \text { Positive psychological coaching definitions and } \\ \text { models: a systematic literature review }\end{array}$

The authors attempted to consolidate the literature on positive psychological coaching in order to provide an integrated definition and practice-orientated model. 
TABLE 1 | Continued

\begin{tabular}{|c|c|c|c|}
\hline No & Author & Title of contribution & Main objective \\
\hline 11 & Jonker et al. & $\begin{array}{l}\text { An intervention framework to facilitate } \\
\text { psychological trauma management (PTMP) in } \\
\text { high-risk occupations }\end{array}$ & $\begin{array}{l}\text { This study provided a qualitatively explored the experiences of PTMPs from } \\
\text { the perspective of employees working in three high-risk occupations. The } \\
\text { study explored the experiences of the participants in order to compile a } \\
\text { framework that supports and improves the productivity and well-being of } \\
\text { employees affected by work-related trauma. }\end{array}$ \\
\hline
\end{tabular}

\section{SECTION 4: ONLINE POSITIVE ORGANIZATIONAL INTERVENTION DESIGN PRINCIPLES}

$12 \quad$ Kelders et al. The concept and components of engagement in different domains applied to ehealth: a systematic scoping review
The aim of this study was to determine what constitutes "engagement" in order to effectively translate such into effective e-Health designs. The authors attempted (a) to investigate in which domains engagement features, (b) to determine what constitutes engagement in these different fields, and (c) to determine whether there are any common components that seem to be important.

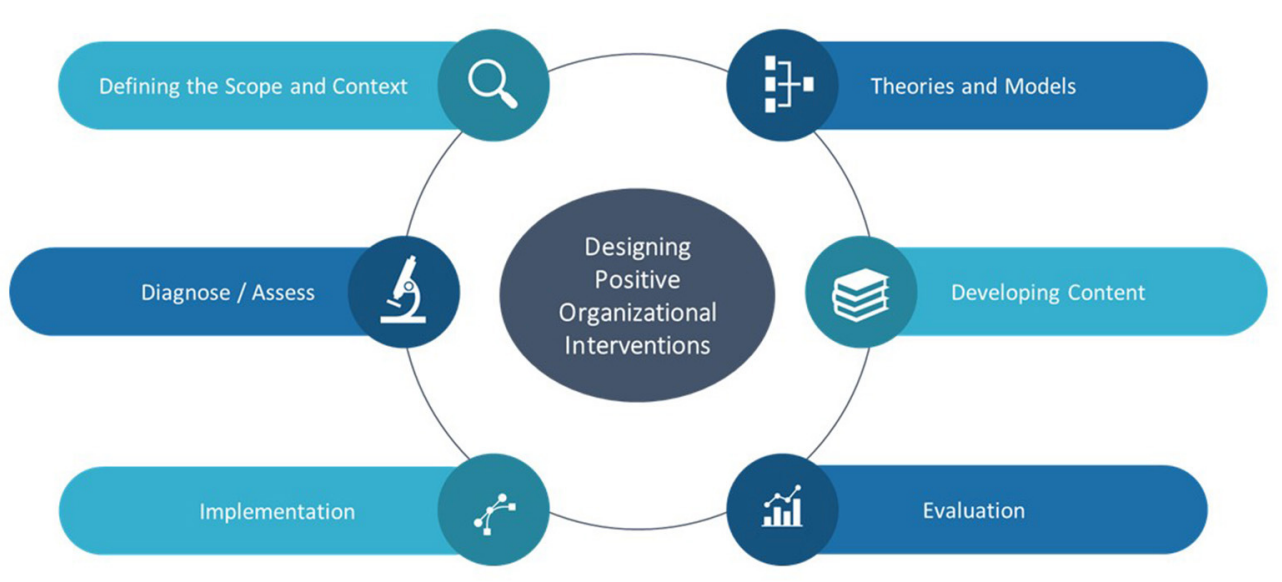

FIGURE 1 | Elements to consider when designing POls.

be reformulated/categorized into specific positive states, traits and behaviors that need to be targeted by the intervention. Practitioners should therefore carefully consider the appropriateness and relevance of these factors/constructs for the specific context (Alexandrova, 2017) as such would influence the effectiveness of the intervention. The specific context in which the intervention is to take place, plays a major role in both the adoption of- and adherence to intervention content and should therefore be an essential element of investigation during the scoping/panning process. In essence, the purpose of the intervention, the target population group, the level of the intervention, the needs/context of participants and the specific positive factors to be targeted needs to be considered in this phase.

b. Building interventions around positive psychological theories and models. Effective interventions start with a clarifying a core positive outcome to be achieved and be aligned to an appropriate positive psychological theory or model. This model is used to provide a roadmap on which the developmental practices can be built. Here one needs to ensure that the positive psychological outcome to be achieved is aligned to the nature, scope and treatment trajectory. Further an appropriate behavioral change model needs to be selected to understand the facilitators and barriers that impacts changes in behaviors. These models should clearly articulate both the positive states/traits/behaviors to be targeted as well as the specific repertoire of skills, capabilities and resources required to enhance such (Oades et al., 2020).

c. Validated diagnostic frameworks and assessment techniques/tools need to be employed. Validated positive psychological assessment techniques/instruments need to be used to assess the core components of the theoretical model being tested. The entire measurement/diagnostic model needs to be tested in the beginning and end of the intervention. Practitioners should further assess participants' intention to treat and willingness to participate. Clear goals for the intervention and an appropriate evaluation strategy needs to be developed before the start of the intervention.

d. Developing intervention content aligned to the empirical model and that "fits" the participant. Intervention content needs to be aligned to the components of the empirical model, with functional developmental activities designed to enhance the specific state/behaviors being targeted. Intervention activities should be designed to develop specifics skills 
and capabilities within real-world environments; actively considering the contextual resources and constraints of participants. Intervention content should be novel and not repetitive, but also be challenging, and provide opportunities for autonomous practice. Intervention should also be designed around the utilization of individual strengths, and optimal usage of currently available personal/social resources in order to enhance the effectiveness and sustainability of its positive effects over time. Further, attempts need to be made to align intervention content to personal characteristic of participants to enhance intervention adherence. Specific focus needs to be placed on ensuring both person-intervention fit, as well as context-intervention fit to increase adherence and engagement. Finally, the means through which the content is to be delivered and the time frame for delivery needs to be defined. The mode of delivery needs to be aligned to the personal characteristics and capabilities of participants. All these elements need to culminate in the development of a structural intervention protocol.

e. Interventions need to be structurally implemented and appropriately managed. The effectiveness of an intervention is not only dependent upon the design, but also in how it is executed. Practitioners should ensure adherence to the intervention protocol, and only intervene if participants are showing adverse reactions to the content. Practitioners should

\section{REFERENCES}

Alexandrova, A. (2017). A Philosophy of Science for Well-Being. London: Oxford University Press.

Ausch, R. (2016). Methodological Problems With the Academic Sources of Popular Psychology: Context, Inference, and Measurement. London: Lexington Books.

Bolier, L., Haverman, M., Westerhof, G. J., Riper, H., Smit, F., and Bohlmeijer, E. (2013). Positive psychology interventions: a meta-analysis of randomized controlled studies. BMC Public Health 13:119. doi: 10.1186/1471-2458-13-119

Brown, N. J. L., Sokal, A. D., and Friedman, H. L. (2014). Positive psychology and romantic scientism. Am. Psychol. 69, 636-637. doi: 10.1037/a0037390

Costantini, A., Ceschi, A., Viragos, A., De Paola, F., and Sartori, R. (2019). The role of a new strength-based intervention on organisationbased self-esteem and work engagement. J. Workplace Learn. 31, 194-206. doi: 10.1108/JWL-07-2018-0091

Ferguson, C. J. (2015). "Everybody knows psychology is not a real science": public perceptions of psychology and how we can improve our relationship with policymakers, the scientific community, and the general public. Am. Psychol. 70, 527-542. doi: 10.1037/a0039405

Ferguson, C. J. (2019). The fame monster: unintended consequence of fame for psychological science. New Ideas Psychol. 54, 35-39. doi: 10.1016/j.newideapsych.2019.01.003

Friedman, H. L., and Brown, N. J. (2018). Implications of debunking the "Critical Positivity Ratio" for humanistic psychology: introduction to special issue. J. Humanis. Psychol. 58, 239-261. doi: 10.1177/0022167818762227

Haberlin, S. (2019). Something always works: a self-study of strengths-based coaching in supervision. J. Educ. Superv. 2, 38-57. doi: 10.31045/jes.2.1.3

Khanna, P., and Singh, K. (2019). Do all positive psychology exercises work for everyone? Replication of Seligman et al.'s (2005) interventions among adolescents. Psychol. Studies 64, 1-10. doi: 10.1007/s12646-019-00477-3

Mongrain, M., and Anselmo-Matthews, T. (2012). Do positive psychology exercises work? A replication of Seligman et al. (2005). J. Clin. Psychol. 68, 87-99. doi: 10.1002/jclp.21839

Oades, L. G., Ozturk, C., Hou, H., and Slemp, G. R. (2020). Wellbeing literacy: a language-use capability relevant to wellbeing outcomes of positive psychology interventions. J. Posit. Psychol. 15, 696-700. doi: $10.1080 / 17439760.2020 .1789711$ actively monitor both the effect of the intervention and participant engagement/adherence.

f. POIs need to be appropriately evaluated. Changes in the positive psychological outcome (dependent variable) need to be actively monitored. Both quantitative and qualitative assessment measures need to be employed. Direct feedback during the intervention process need to be solicited from participants.

\section{CONCLUSION}

Despite significant advancements in the field of applied positive psychology, and the popularization of a "positive approach toward people and organizational development" in practice, intervention research still seems to be in its infancy. We therefore hope that this special issue will provide the reader with some context as to our current understanding of POIs and stimulate future researchers to further investigate how such can be optimally designed, implemented, and evaluated.

\section{AUTHOR CONTRIBUTIONS}

Both authors listed have made a substantial, direct and intellectual contribution to the work, and approved it for publication.

Parks, A. C., and Schueller, S. (Eds.). (2014). The Wiley Blackwell Handbook of Positive Psychological Interventions. Hoboken, NJ: John Wiley \& Sons.

Roll, L. C, van Zyl, L. E., and Griep, Y. (2019). "Brief positive psychological interventions within multi-cultural organisational contexts: a systematic literature review,". in Theoretical Approaches to Multi-cultural Positive Psychological Interventions, eds L. E. van Zyl and S. Rothmann New York, NY: Springer.

Seligman, M. E. (2012). Flourish: A Visionary New Understanding of Happiness and Well-Being. New York, NY: Simon and Schuster.

Stander, F. W., and van Zyl, L. E. (2019). "The talent development centre as an integrated positive psychological leadership development and talent analytics framework," in Positive Psychological Intervention Design and Protocols for Multi-Cultural Contexts, eds L. E. van Zyl, \& S. Rothmann Sr (Cham: Springer), 33-56. doi: 10.1007/978-3-03020020-6_2

Trask-Kerr, K., Quay, J., and Slemp, G. R. (2019). A Deweyan positive education: psychology with philosophy. Oxford Rev. Educ. 45, 786-801. doi: 10.1080/03054985.2019.1625761

Turnes, P. B., Petty, R. E., Gandarillas, B., and Moreno, L. (2020). Are positive interventions always beneficial? Spanish J. Psychol. 23, 1-9. doi: 10.1017/SJP.2020.21

van Zyl, L. E., Efendic, E., Rothmann, Sr,., S., and Shankland, R. (2019). "Bestpractice guidelines for positive psychological intervention research design," in Positive Psychological Intervention Design and Protocols for Multi-Cultural Contexts, eds L. E. van Zyl, \& S. Rothmann Sr (Cham: Springer), 1-32. doi: 10.1007/978-3-030-20020-6_1

van Zyl, L. E., and Rothmann, S. (2019a). Positive Psychological Intervention Design and Protocols for Multi-Cultural Contexts. Cham: Springer.

van Zyl, L. E., and Rothmann, S. (2019b). Theoretical Approaches to Multi-Cultural Positive Psychological Interventions. Cham: Springer.

van Zyl, L. E., Zondervan-Zwijnenburg, M. A. J., Dickens, L. R., and Hulshof, I. (2020). Exploring meaning in life through a brief photo-ethnographic intervention using Instagram: a bayesian growth modelling approach. Int. Rev. Psychiatry. doi: 10.1080/09540261.2020.1809357. [Epub ahead of print].

Wong, P. T. P., and Roy, S. (2018). "Critique of positive psychology and positive interventions," in Routledge International Handbooks. The Routledge 
International Handbook of Critical Positive Psychology, eds N. J. L. Brown, T. Lomas, \& F. J. Eiroa-Orosa (London: Routledge/Taylor \& Francis Group), 142-160.

Conflict of Interest: The authors declare that the research was conducted in the absence of any commercial or financial relationships that could be construed as a potential conflict of interest.
Copyright $\odot 2020$ van Zyl and Rothmann. This is an open-access article distributed under the terms of the Creative Commons Attribution License (CC BY). The use, distribution or reproduction in other forums is permitted, provided the original author(s) and the copyright owner(s) are credited and that the original publication in this journal is cited, in accordance with accepted academic practice. No use, distribution or reproduction is permitted which does not comply with these terms. 
OPEN ACCESS

Edited by:

Sebastiaan Rothmann

North-West University, South Africa

Reviewed by:

Gavin Robert Slemp,

The University of Melbourne, Australia

Rachele Paver

North-West University, South Africa

*Correspondence: Inge L. Hulsho i.l.hulshof@tue.nl

Specialty section: This article was submitted to Organizational Psychology, a section of the journal Frontiers in Psychology

Received: 11 September 2019 Accepted: 13 January 2020 Published: 28 January 2020

Citation: Hulshof IL, Demerouti E and Le Blanc PM (2020) Providing Services During Times of Change: Can Employees Maintain Their Levels of Empowerment, Work Engagement and Service Quality Through a Job

Crafting Intervention?

Front. Psychol. 11:87.

doi: 10.3389/fpsyg.2020.00087

\section{Providing Services During Times of Change: Can Employees Maintain Their Levels of Empowerment, Work Engagement and Service Quality Through a Job Crafting Intervention?}

\author{
Inge L. Hulshof*, Evangelia Demerouti and Pascale M. Le Blanc \\ Human Performance Management Group, Eindhoven University of Technology, Eindhoven, Netherlands
}

By means of a quasi-experimental study, the effects of a tailor-made job crafting intervention for employees of a Dutch unemployment agency were evaluated. The intervention was designed to prevent a decrease in employee empowerment, work engagement and employee performance (i.e., the provision of services) due to organizational changes. Seventy-four employees received a 1-day training in which they set four job crafting goals for the subsequent weeks. After 6 weeks a reflection session was organized. Repeated measures ANOVA's showed that the intervention prevented a decrease in employees' feelings of empowerment. Furthermore, pre-post comparison tests showed that the control group $(N=89)$ experienced a significant decrease in work engagement, whereas the intervention group did not. Results showed no effect on customer-rated employee service quality. However, 1 year after the intervention, customer ratings of employee service quality were significantly higher for the intervention group compared to the control group. Although further research is needed, our results demonstrate that a job crafting intervention may be a promising tool to combat a decline in employee empowerment and work engagement during times of organizational change.

\footnotetext{
Keywords: customer ratings, empowerment, job crafting intervention, organizational change, service quality, work engagement
}

\section{INTRODUCTION}

The nature of work has undergone some major changes in the last couple of decades. It has, for example, become more service-oriented (Dall'erba et al., 2009) influencing the type of performance that employees need to deliver. In the past, employee performance mainly referred to the number of products made, whereas nowadays it has gradually changed toward the quality of services provided (Oliva and Sterman, 2001). Employee performance is not the only thing that has changed: new technologies, economic forces, social innovations, new ways of working, they all force employees to adapt at a high pace (Kompier, 2006). Organizations have to innovate, change and improve themselves time after time to stay ahead of the competition and to keep their customers satisfied. However, adapting to a changing environment is not always easy. Employees may be insecure or 
even cynical about upcoming changes, which may in turn inadvertently - affect their performance (Cartwright and Holmes, 2006). To prevent this from happening, it is extremely important to examine ways in which employees can adapt to changes in a positive way. In this article we focus on a promising bottom-up approach through which employees can make small changes in their work to align it more with their personal wishes and preferences: job crafting (Wrzesniewski and Dutton, 2001). Job crafting is defined as "the physical and cognitive changes individuals make in the task or relational boundaries of their work" (p. 179). It describes how employees proactively shape their work context by changing (a) the type and number of tasks they carry out, (b) the way they interact with others at work and (c) the way they think about their work (Wrzesniewski and Dutton, 2001). In the present study, we will explore the effects of a job crafting intervention during times of organizational change. The intervention focuses on increasing job crafting behavior, in order to prevent a decrease in work engagement, empowerment, and the provision of highquality services.

This study contributes to the literature in several ways. First, it was conducted during times of organizational change. Employees nowadays have to adapt to many changes (e.g., innovations, advanced technologies, new ways of working) as our world is ever-changing (Van den Heuvel et al., 2010). Adapting to these changes may be challenging, as it can cause stress, increase insecurity and reduce motivation, all potentially undermining employee performance (Callan, 1993; Caldwell et al., 2004; Gilley et al., 2009). Therefore, it seems worthwhile to not only examine the effects of interventions during 'quiet' times, but also explore their effects during times of change to see if they enable employees to adapt more easily (Demerouti et al., 2017). Second, as providing high quality services is a key performance indicator in the service sector (Bowden, 2009), developing and validating interventions that stimulate this is extremely valuable. The current intervention does so by focusing on enhancing service-oriented task performance (i.e., performing one's service-related tasks optimally) and empowering services (i.e., providing services that enhance customers to feel confident to take care of their own (work-related) affairs). Although the current study focuses on the unemployment sector, the results are valuable for other service organizations as well, since both components of performance/service quality focus on helping customers in the best way possible. Third, by taking customer satisfaction into account, this study uses a unique research design. We do not only rely on self-report measures of service quality, but also examine whether the effects of the intervention are noticeable for others (Gordon et al., 2018). As customer satisfaction is of vital importance for serviceorganizations (Taylor and Pandza, 2003), the current job crafting intervention aims to directly contribute to this key performance indicator in the sector too. Lastly, although job crafting has limitedly been investigated in the service sector (e.g., McCelland et al., 2014; Hulshof et al., 2019), we are unaware of any job crafting intervention studies in this sector. As more and more organizations nowadays are providing services (Dall'erba et al., 2009), examining the effects of job crafting in this sector is not only of theoretical value (broadening its generalizability) but also of great practical value.

\section{Job Crafting and the Job Crafting Intervention}

Job crafting has been framed within the Job Demands-Resources (JD-R) model (Tims and Bakker, 2010). This model describes the relationship between work characteristics and employee wellbeing (Demerouti et al., 2001) and proposes that each work environment has its own unique configuration of job demands and job resources (Bakker and Demerouti, 2017). Job demands refer to those aspects of the work (either social, psychological, physical or organizational) that require sustained physical or psychological (emotional or cognitive) effort. Job resources are those aspects of the work (either social, psychological, physical or organizational) that help achieve work related goals, reduce the effects of job demands and stimulate personal growth, learning and development (Demerouti et al., 2001). Although all job demands require the investment of effort and are associated with certain costs, we distinguish between two types of job demands: hindering job demands and challenging job demands (Crawford et al., 2010). Hindering demands refer to demands that involve excessive or undesirable constraints that interfere with or hinder an individual's ability to achieve valued goals' (Cavanaugh et al., 2000, p. 67). Challenging demands are those demands that may cause a stress response while pursuing, but in the end are seen as rewarding and worth the effort (Cavanaugh et al., 2000).

When crafting their job, employees can make changes to their job demands and job resources using three strategies: (1) decreasing hindering demands (e.g., making the work emotionally less intense or avoiding making difficult decisions), (2) seeking challenging demands (e.g., starting a new project or following a course on a topic of interest) and (3) seeking resources (e.g., asking for feedback or increasing the variety of tasks) (Petrou et al., 2012). Some researchers (e.g., Tims et al., 2012) further specified seeking resources into two categories: social resources and structural resources. Social resources are resources related to the social aspects of the job (e.g., support and feedback) while structural resources are resources that are related to the job design (e.g., autonomy and opportunities for development). In the present study, we will make this distinction too.

A job crafting intervention may be beneficial, especially during times of change, as job crafting enhances the person environment (P-E) fit (Tims et al., 2012). Due to topdown organizational changes, the P-E fit of employees is shifting, possibly leading to a less optimal fit and consequently performance (Caldwell et al., 2004). Providing people with tools (i.e., job crafting strategies) to - at least to some extent restore their P-E fit may be a valuable bottom-up approach for employees to deal with their changing environment. Training people to craft their job may enhance feelings of control, as job crafting behaviors are unsupervised, voluntary and beneficial for the employee (Wrzesniewski and Dutton, 2001). Thus, although people cannot prevent the top-down organizational changes from happening, they may, through job crafting, 
expand strategies that are needed to stay in control and to adapt to the changes.

Previous job crafting interventions have provided valuable results in different organizational settings. For example, Van den Heuvel et al. (2015) showed that a job crafting intervention is a promising means to enhance personal resources (i.e., selfefficacy) and well-being for police officers. Moreover, Gordon et al. (2018) showed that a job crafting intervention enhances employee performance in healthcare, whereas Dubbelt et al. (2019) showed that a job crafting intervention, executed in an educational setting, was able to enhance employee work engagement. Lastly, Demerouti et al. (2017) showed that the intervention was effective to increase positive affect and openness to change among municipality employees during organizational change due to austerity. In general, results suggest that the job crafting intervention is effective in stimulating aspects of job crafting behavior, although the effects cannot always be detected with multivariate tests (Demerouti et al., 2019). Demerouti et al. (2019) suggested that it might be difficult to detect the effect of the intervention on job crafting behaviors because the scale may not include the whole range crafting behavior or there might be a ceiling effect of behaviors that individuals are involved prior to the intervention such as seeking resources. However, a recent meta-analysis of 14 job crafting interventions concluded that the intervention has significant on overall job crafting but also on seeking challenges and somewhat stronger on reducing demands (Oprea et al., 2019).

Our intervention is in line with earlier job crafting interventions and is designed based on experiential learning theory (Kolb and Kolb, 2011). Experiential learning theory emphasizes the importance of past experiences in learning and behavioral change. All four stages relevant for learning to apply job crafting techniques and to initiate actual behavioral change were incorporated in the intervention (for an overview of the intervention see Tables 1A,B). The learning process begins with concrete experiences with the behavior, followed by reflection (stage 1 and 2) (Kolb et al., 2000). In the third stage, individuals have abstract ideas about the new behavior and how to benefit from it (Kolb and Kolb, 2011). In this stage it is important to emphasize the added value of the new behavior to enhance individual's motivation to invest time and energy trying to implement it. In the fourth and last stage, employees actively experiment with the behavior to create new experiences (Kolb et al., 2000). In order to stimulate the implementation of the newly learned behavior, goal setting is extremely important (Schunk, 1990), so we explicitly focused on that too during the intervention. As learning is an ongoing process, after stage four, individuals start again in stage 1 (Kolb et al., 2000; Kolb and Kolb, 2011). Thus, building on the experiential learning theory we expect that our job crafting intervention will stimulate employees in the intervention group to learn to apply and integrate job crafting techniques into their work routines.

H1: Employees participating in the job crafting intervention will show increased levels of (a) increasing structural resources, (b) increasing social resources, (c) decreasing hindering demands and (d) increasing challenging demands after the intervention compared to employees in the control group.

\section{Well-Being During Times of Change}

Providing high quality services is a key performance indicator in the service sector, regardless of organizational changes going on. Therefore, finding ways to stimulate this type of performance seems worthwhile. In our intervention we did so by focusing on work engagement and empowerment, both factors that are related to intrinsic motivation (Thomas and Velthouse, 1990; Bakker and Demerouti, 2009). Intrinsically motivated people are willing to pursue time and energy into the tasks at hand, leading to higher levels of performance. When people are engaged in their work, they are enthusiastic and feel energized while working (Schaufeli et al., 2002). When empowered, employees feel they are able to proactively shape their work role and context in order to carry out their work (Spreitzer, 1995). These factors differ in that work engagement is related to interest and excitement, whereas empowerment is related to confidence.

Work engagement consists of three dimensions: vigor, dedication and absorption. When vigorous, people feel energized by their work and are resilient during setbacks. When dedicated, people are enthusiastic and continue until the job is done. When absorbed, people are highly focused and lose track of time (Schaufeli et al., 2002). Work engagement has extensively been linked to performance (for a review, see Christian et al., 2011), in that employees who are more engaged, have the energy and the willingness to devote their attention to their tasks and perform them better. Recent research has shown that job crafting seems a promising tool to enhance work engagement even during organizational change (e.g., Petrou et al., 2018). Employees who proactively craft their job, experience an increased fit between themselves and their work (Bakker et al., 2012) by focusing on those aspects of the work that are significant and important to them (Pratt and Ashforth, 2003), resulting in higher levels of energy and enthusiasm about their work; they become more engaged. Engagement may be especially beneficial during times of change, as engaged employees are more creative and willing to go the extra mile (Van den Heuvel, 2013). As organizational change is hardly ever a smooth process (Cartwright and Holmes, 2006; Kompier, 2006), creativity and extra effort may be extremely valuable to be able to handle unforeseen, difficult or challenging situations (Petrou et al., 2018). Furthermore, work engagement is contagious (Bakker and Demerouti, 2009), which implies that as one person is engaged, his/her engagement may crossover to another person. This crossover effect may be especially valuable in times of change. Work engagement, as a counterforce to possible cynicism regarding the organizational changes, may help employees adapt to changes in a positive way. Moreover, this positive adaptation may crossover to others, amplifying its effects (Van den Heuvel et al., 2010).

Empowerment refers to increased intrinsic task motivation through delegation of responsibilities and authority to the lowest organizational level possible (Thomas and Velthouse, 1990). There are four underlying mechanisms to empowerment: meaning, impact, competence, and self-determination. Meaning is described as the value an individual gives to a task goal or 
TABLE 1A | Overview of the intervention at day 1.

\begin{tabular}{|c|c|c|}
\hline Time spent* & Steps & Aspects of the intervention reflecting experiential learning theory \\
\hline $15 \mathrm{~min}$ & 1: Concrete experiences & $\begin{array}{l}\text { - Providing real-life examples of job crafting and empowering service, based on interviews conducted } \\
\text { with employees of the unemployment agency. }\end{array}$ \\
\hline $85 \min$ & 2: Reflection & $\begin{array}{l}\text { - Mapping exercise (Davies, 2011) in which participants mapped a normal work week and } \\
\text { distinguished between energizing aspects (resources) and aspects that cost energy (demands) } \\
\text { based on the JD-R model (Bakker and Demerouti, 2017). } \\
\text { - Learning by analogy exercise (Carbonell, 1983) in which participants retrieved past (successful) } \\
\text { experiences with job crafting and empowering service and reflected (in small groups) upon the value } \\
\text { of these experiences for current situations. }\end{array}$ \\
\hline $40 \min$ & 3: Abstract concepts & $\begin{array}{l}\text { - Using the JD-R model (Bakker and Demerouti, 2017), explaining participants how job crafting } \\
\text { benefits work-related outcomes, such as performance (Bakker et al., 2012) and work engagement } \\
\text { (Demerouti et al., 2015). Explaining the concept of empowering service. }\end{array}$ \\
\hline $95 \min$ & 4: Creating new experiences & $\begin{array}{l}\text { - Setting } 4 \text { SMART (specific, measurable, attainable, realistic and time-bound) goals (Doran, 1981) for } \\
\text { the weeks after the first day of the intervention (i.e., week 1: seeking (social) resources, week 2: } \\
\text { reducing demands, week 3: seeking challenges, week 4: seeking (structural) resources). By setting } \\
\text { these goals, participants could practice with all job crafting strategies at least once. } \\
\text { - In couples: thinking about possible facilitating factors and obstacles for the goals that were set. This } \\
\text { helped participants explore possible obstacles (how to deal with them) and facilitating factors (how } \\
\text { to optimally use them) in reaching their goals. } \\
\text { - Weekly reminders (per e-mail) were sent to encourage goal achievement (Fry and Neff, 2009) }\end{array}$ \\
\hline
\end{tabular}

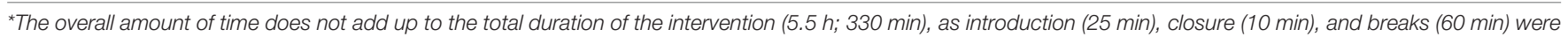
included in the total duration of the intervention, but are excluded in this overview as they do not resemble a specific element of experiential learning theory.

TABLE 1B | Overview of the intervention at day 2 (evaluation session).

\begin{tabular}{|c|c|c|}
\hline Time spent ${ }^{*}$ & Steps & Aspects of the intervention reflecting experiential learning theory \\
\hline $25 \min$ & 1: Concrete experiences & - The real-life job crafting goals and experiences in the weeks between day 1 and 2 . \\
\hline $45 \min$ & 2: Reflection & $\begin{array}{l}\text { - Celebrating successes to enhance ownership and self-confidence (e.g., Sawyer et al., 2007) } \\
\text { - In small groups: reflecting upon the goals set in the weeks between day } 1 \text { and 2. Finding obstacles, } \\
\text { discussing how to deal with them and explore ways in which facilitating factors can be used to } \\
\text { reach the desired goal(s). }\end{array}$ \\
\hline $10 \mathrm{~min}$ & 3: Abstract concepts & $\begin{array}{l}\text { - Emphasizing again the benefits of job crafting based upon the JD-R model (Bakker and Demerouti, } \\
\text { 2017) }\end{array}$ \\
\hline $15 \min$ & 4: Creating new experiences & $\begin{array}{l}\text { - Looking ahead: discussing with participants how to implement the use of job crafting strategies into } \\
\text { their (daily) work routines. }\end{array}$ \\
\hline
\end{tabular}

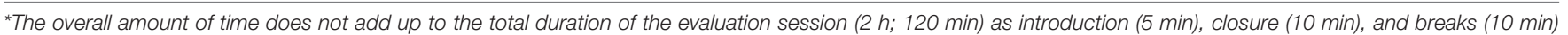
were included in the total duration of the intervention, but are excluded in this overview as they do not resemble a specific element of experiential learning theory.

purpose, based on the individual's ideals and standards (Thomas and Velthouse, 1990). Impact is described as the influence an individual has to control strategic, operational or administrative organizational outcomes (Ashforth, 1989). Competence (or selfefficacy) is described as the belief an individual has to be capable to complete the tasks at hand (Gist, 1987). Self-determination is described as the sense of having a choice to initiate and regulate behaviors, for example making decisions about work pace and the order in which tasks are carried out (Spreitzer, 1995). Thus, when people get adequate responsibilities and authority in their work, they can feel empowered and are intrinsically motivated to carry out their work-related tasks through a sense of meaning, impact, competence and selfdetermination. Empowerment has been linked to performance (e.g., Chen et al., 2007; Seibert et al., 2011), in that people who feel more empowered, perform better. Empowerment may also boost customer satisfaction, as empowered employees have the confidence to handle customer needs and problems efficiently (Chiang and Jang, 2008). Since the service sector is peopleoriented in essence, empowerment, especially during times of change, may be a promising 'tool' to enhance the sector's key performance indicator: the provision of services. We expect that empowerment can be stimulated through the job crafting intervention. When people craft their job, they enhance the fit between themselves and their job (Bakker et al., 2012) by focusing on those aspects of the work that are significant and important to them (Pratt and Ashforth, 2003). This results in higher levels of intrinsic (task) motivation (Ryan and Deci, 2000) through a sense of meaning, impact, competence and self-determination. That is, they become empowered. Empowering employees during organizational change may be beneficial, as it helps employees feel less powerless (Conger and Kanungo, 1988) when adapting to the organizational changes. This way, they can maintain their service quality level.

Organizational change may negatively impact employee health and well-being, as it causes stress, anxiety and ambiguity (Callan, 1993; Cartwright and Holmes, 2006). Having to deal with the additional demands from the implemented changes and providing employees with insufficient resources, may negatively affect their work engagement and empowerment 
(Lamm and Gordon, 2010; Bakker and Demerouti, 2017). In our study population, management decided to double all targets, leaving employees with twice as many clients to provide services to. Moreover, employees did not get additional resources (personnel, time, etc.). Therefore, we expected employee wellbeing to decline. However, employees may be able to temper this process through job crafting, as organizational change from a JD-R perspective refers to a shift in job demands and job resources to which employees have to adapt (Van den Heuvel et al., 2010). Job crafting is targeted at maximizing job resources and challenges and minimizing hindering job demands. Thus, as a means to restore the configuration of job demands and job resources, job crafting may help to uphold work engagement and empowerment during times of change (Miller, 2015; Petrou et al., 2016, 2018). Therefore, we expect that during times of change employees participating in the job crafting intervention will be able to maintain their levels of work engagement and empowerment, whereas employees in the control group will experience a decrease as a result of the heightened demands.

H2: Employees in the control group will experience a decrease in (a) work engagement and (b) empowerment, whereas employees in the intervention group will not.

\section{Employee Service Quality in Times of Change}

In a people- or customer-oriented sector like the service sector, providing high quality services is of vital importance (Chiang and Jang, 2008). Therefore, our intervention will focus on two types of service quality: service-oriented task performance and empowering service. Service-oriented task performance, which finds its roots in task performance (Motowidlo and Van Scotter, 1994), is defined as 'the provision of high quality services to customers and clients in order to meet organizational and customer goals' (The authors, submitted). The construct highlights the importance of the quality of the relationship between client and service providing employee (Oliva and Sterman, 2001) through active listening, expectation management and emotional support. When applying serviceoriented task performance to the unemployment sector, it refers to the providing of high-quality services to unemployed candidates and potential employers to effectuate successful mediation between the unemployed candidate and his/her potential new employer.

Empowering service finds its roots in the concept of empowering leadership. Empowering leadership involves a replacement of power from management to employees who have the autonomy and the capacities to take initiative and make decisions about daily events (Amundsen and Martinsen, 2014). The leader-subordinate relationship is hierarchical, just as the relationship between service employee and unemployed customer. Service employees not only support their customer, they are also allowed to sanction them when they do not follow the rules regarding their unemployment benefits. Thus, as both the leader-subordinate and the service employee-customer relationship are hierarchical, empowering leadership may be applicable in the service context too. We labeled this type of service 'empowering service' and it refers to the replacement of power from service employee to unemployed customers who have the autonomy and capacities to take initiative and feel responsible to make decisions about their (daily) job seeking process.

We expect employees participating in the job crafting intervention to be able to maintain their levels of serviceoriented task performance and empowering service during times of organizational change. When crafting their job, employees can shape the conditions (resources and challenges) necessary to perform optimally. At the same time, job crafting can help diminish the effect of hindering or stressful work aspects that interfere with optimal performance (Tims and Bakker, 2010). Both aspects seem especially valuable during times of change, as top-down changes can cause cynicism and resistance, potentially undermining employee performance (Caldwell et al., 2004; Demerouti et al., 2017). If employees, undergoing organizational change, are able to mobilize their resources and diminish the effects of the hindering work aspects related to the organizational changes going on, they may be able to maintain their levels of performance (Van den Heuvel, 2013). When employees craft their job, they are able to create a more satisfying work context for themselves, enabling themselves to maintain to provide high quality services (i.e., service-oriented task performance and empowering service). Thus, as organizational changes are being implemented, we expect employees in the job crafting intervention to maintain their levels of service-oriented task performance and empowering service, while employees in the control group will show reduced levels of service-oriented task performance and empowering service.

H3: Employees participating in the job crafting intervention will be able to maintain their levels of (a) serviceoriented task performance and (b) empowering service while employees in the control group will show a decrease.

Finally, we aimed to examine whether the intervention has effects that are observable for others as well. Therefore, this study also takes customer-rated performance measures into account. We examine, 5 months and 1 year after the intervention, whether customers of employees in the intervention group rate the performance of their advisor more positively than customers of employees in the control group. The timeframe of 5 months is based on the work of Lally et al. (2010), who showed that it takes about 66 days for habits to form. As employees do not work 7 days a week, or even work full-time, we collected customer rated performance measures 5 months after the intervention, making sure all employees had at least 66 days to practice the newly learned job crafting techniques. Moreover, we collected customer rated performance measures after 1 year, as by then, the organizational changes were fully implemented. We examine whether the effects of the intervention were still noticeable for customers during 'quiet times.'

H4: (a) Five months and (b) one year after the intervention, customer-rated service quality (i.e., service-oriented task performance and empowering service) will be higher for 
employees participating in the intervention compared to employees in the control group.

For a full overview of the intervention and its timeline, please see Figure 1.

\section{MATERIALS AND METHODS}

\section{Study Design}

The intervention took place in a department of a Dutch unemployment agency. This department consisted out of three separate buildings. For the intervention two buildings were selected (based upon their size) as the intervention group. The other one served as the control group. People were recruited by posting small messages in the weekly newsletter and by giving more detailed presentations during work meetings. As the department shared the same newsletter, we could not prevent that people in the control group knew they were in the control group. However, the control group did not receive the more detailed presentations in their work meetings. As both groups worked in different buildings and had little contact with each other, the cross-over effects from the intervention to the control group were kept as limited as possible. Participation in both groups was voluntary and participants could drop out at any moment. Overall, nine workshops, with a maximum of 12 participants per group were given. Maximum group size was determined upon previous job crafting interventions (e.g., Van den Heuvel et al., 2015). The workshops were given at an external training facility. After the study was completed, people in the control group were offered to participate in the training as well, such that they could learn how to implement job crafting into their work routines too. All employees of the department of the Dutch unemployment agency in which the intervention took place were invited for a debriefing session in which the results of the intervention were discussed. Moreover, results were shared via the weekly newsletter.

The Dutch unemployment agency is a politically oriented organization, as their policies come from several Dutch ministries and depend upon the political landscape that regularly (mostly once every 4 years) changes. During the intervention, no political changes were affecting the organization, making it a 'quiet time' in the organization. However, local departments have some freedom to operationalize their work processes. Management in the departments participating in the intervention decided to double all targets. This meant that service employees had to have twice as many counseling sessions with their unemployed customers. Moreover, the workload of the supportive staff increased as the administrational tasks intensified. Thus, without getting additional capacity, employees had to work up to twice as efficient as before.

\section{Participants}

At T1 the intervention group consisted of 74 employees and the control group of 89 employees. The intervention group consisted of 49 women (66.2\%) and 25 men (33.8\%). The dropout at $\mathrm{T} 2$ was $13.2 \%$ in the intervention group and $31.5 \%$ in the control group, leaving $N=66$ for the intervention group and $N=61$ for the control group respectively (for an overview please see the CONSORT Flow Diagram, Figure 2). The dropout pattern was completely random $\left(M A R / M C A R ; \chi^{2}=128.3\right.$, $d f=133, p=0.60$ ) and participants who dropped out at T2 did not significantly differ from the other participants at T1 on the study variables (i.e., job crafting, work engagement, empowerment, empowering service and service-oriented task performance). Two weeks before the start of the intervention, both the intervention- and the control group were asked to fill out a pre-intervention questionnaire. Three months after the intervention, they were asked to fill out a post-intervention questionnaire. On average participants in the intervention group were 46.1 years old $(S D=10.2)$, worked 18.1 years $(S D=11.3)$ for the current organization, worked 5.3 years $(S D=6.0)$ in their current position and worked $32.6 \mathrm{~h}(S D=6.6)$ a week. The control group consisted of 60 women $(67.4 \%)$ and 29 men $(32.6 \%)$. On average participants were 46.3 years old $(S D=10.9)$, worked 18.23 years $(S D=11.2)$ for the current organization, worked 5.2 years $(S D=5.0)$ in their current position and worked $31.5 \mathrm{~h}(S D=7.2)$ a week. The control group matched the intervention group based on gender, age, tenure and position in the organization. Please see Table 2 for an overview of all biographical data, specified per time point.

\section{Customer Ratings}

Two weeks before the start of the intervention, 5 months afterward and 1 year after the intervention we collected customer ratings data to explore whether the effect of the intervention on stimulating the providing of high-quality services was also noticed by unemployed customers. Before the start of the intervention, 96 responses (34 intervention group; 62 control group) were collected. After 5 months 104 responses (34 intervention group; 69 control group) were collected. One case provided no details about the advisor. Therefore, this case was excluded from further analyses. After 1 year 201 responses (68 intervention, 131 control group) were collected. Again, one case lacked details about the advisor. Therefore, this case was excluded from further analyses. Recruitment of participants was done on site several days. The first author asked participants who happened to have an appointment with one of the advisors of the Dutch unemployment agency that day whether they were willing to fill out a short form after their appointment. The first author sat at the different departments for several days during each time point, to make sure that as many advisors as possible were included in the responses. If (at all three measurement points) there was more than one assessment of a specific advisor, the average of these assessments was used. This resulted in one (averaged) score per advisor per time point. There were some missing values for some of the customer assessments (as not all aspects of empowering service may occur during each appointment an advisor has). Therefore, we used expectation maximization (Moon, 1996) to deal with these missing values.

\section{The Workshop}

The design of the workshop was in line with recent job crafting interventions (e.g., Gordon et al., 2018; Dubbelt et al., 2019) and 


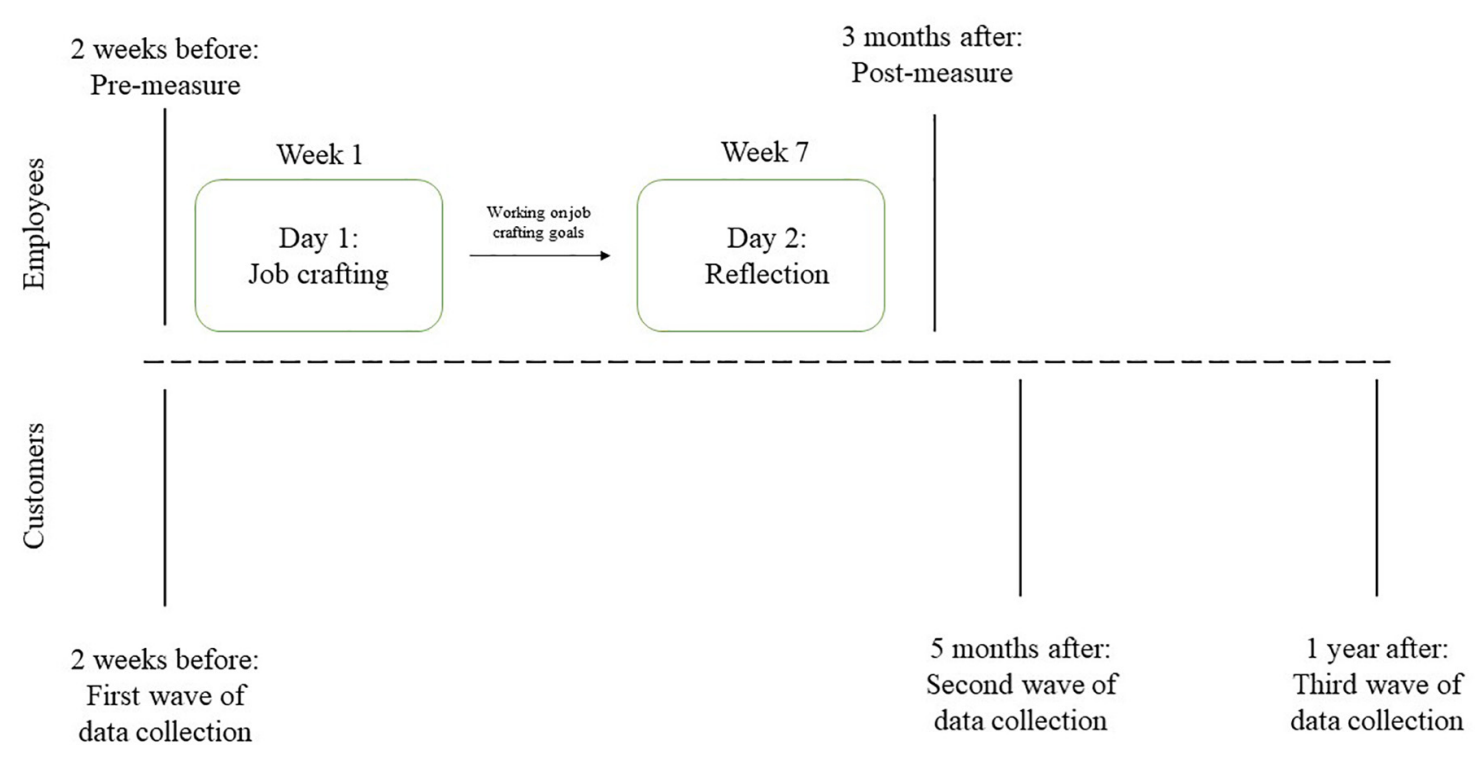

FIGURE 1 | Overview and timeline of the intervention.

was tailored to meet the needs of the unemployment agency. The focus of the unemployment agency is on providing high quality services to their unemployed customers. Therefore, we extended the workshop with $90 \mathrm{~min}$ (bringing the total to $5.5 \mathrm{~h}$ ) to train participants on how job crafting could help them to provide optimal services to their unemployed customers.

During the first day, the intervention focused on theory and practicing with job crafting (see Table 1A). Participants set four SMART goals (Doran, 1981) which they chose themselves and worked on them in the weeks between the first and second day. Participants received handouts of the presentation and a workbook in which they could take notes and formulate their job crafting goals. The first author, who is an experienced trainer, gave the workshops herself. Participants were told that the aims of the intervention were to increase job crafting behavior, work engagement and providing high quality services. Therefore, the workshop focused on employee's needs, past (success) experiences, the current work situation and the desired work situation. To make sure the intervention covered the needs of employees within the unemployment agency, we conducted interviews $(N=19)$ with employees from the various departments prior to the intervention. Overall, the interviews showed that people felt the need for a manageable workload, clear targets and more performance feedback. Additionally, they expressed the need for more role clarity and better communication with management and between the different departments. During the training, these results were used to set examples and to inspire employees to see potential ways in which they could implement job crafting into their work. Six weeks after the intervention, participants discussed their job crafting experiences during an evaluation session (see Table 1B). Participants reflected upon their experiences and thought about ways to implement job crafting in their work routines beyond the intervention. In the weeks between the first and second training day, people received a weekly reminder to help them work on their job crafting goals. A week before the second training day a reminder was sent to invite people to participate in the upcoming session. All training sessions and additional contact (via email) was standardized. Checklists were available for the trainer to check whether everything was discussed. Moreover, a timetable was maintained during each training session. This standardization process was conducted in order to actively maintain intervention fidelity (van Zyl et al., 2019).

\section{Measures \\ Job Crafting}

Job crafting was measured using the Job Crafting Scale (JCS) developed by Tims et al. (2012). The scale consists of 21 items, representing four sub dimensions: increasing structural job resources (5 items, e.g., I try to learn new things at work; $\alpha$ T1/T2 were, respectively, 0.79/0.83), increasing social job resources (5 items, e.g., I ask others for feedback on my performance; $\alpha$ T1/T2 were, respectively, 0.77/0.78), decreasing hindering job demands (6 items, e.g., I make sure my work is mentally less intense; $\alpha$ T1/T2 were, respectively, 0.76/0.77) and increasing challenging job demands (5 items, e.g., When an interesting projects comes along, I offer myself proactively as project co-worker; $\alpha$ T1/T2 were, respectively, 0.88/0.88). Items were measured on a 5-point Likert scale ranging from $1=$ never to 5 = always. Cronbach's alphas for the overall construct (T1/T2) were, respectively, 0.84/0.84.

\section{Work Engagement}

Work engagement was assessed using the short version of the Utrecht Work Engagement Scale (UWES) (Schaufeli et al., 2006). Nine items represent three sub dimensions: vigor (three items, e.g., At my work, I feel bursting with energy; $\alpha$ T1/T2 were, respectively, 0.84/0.85), dedication (3 items, e.g., I am 


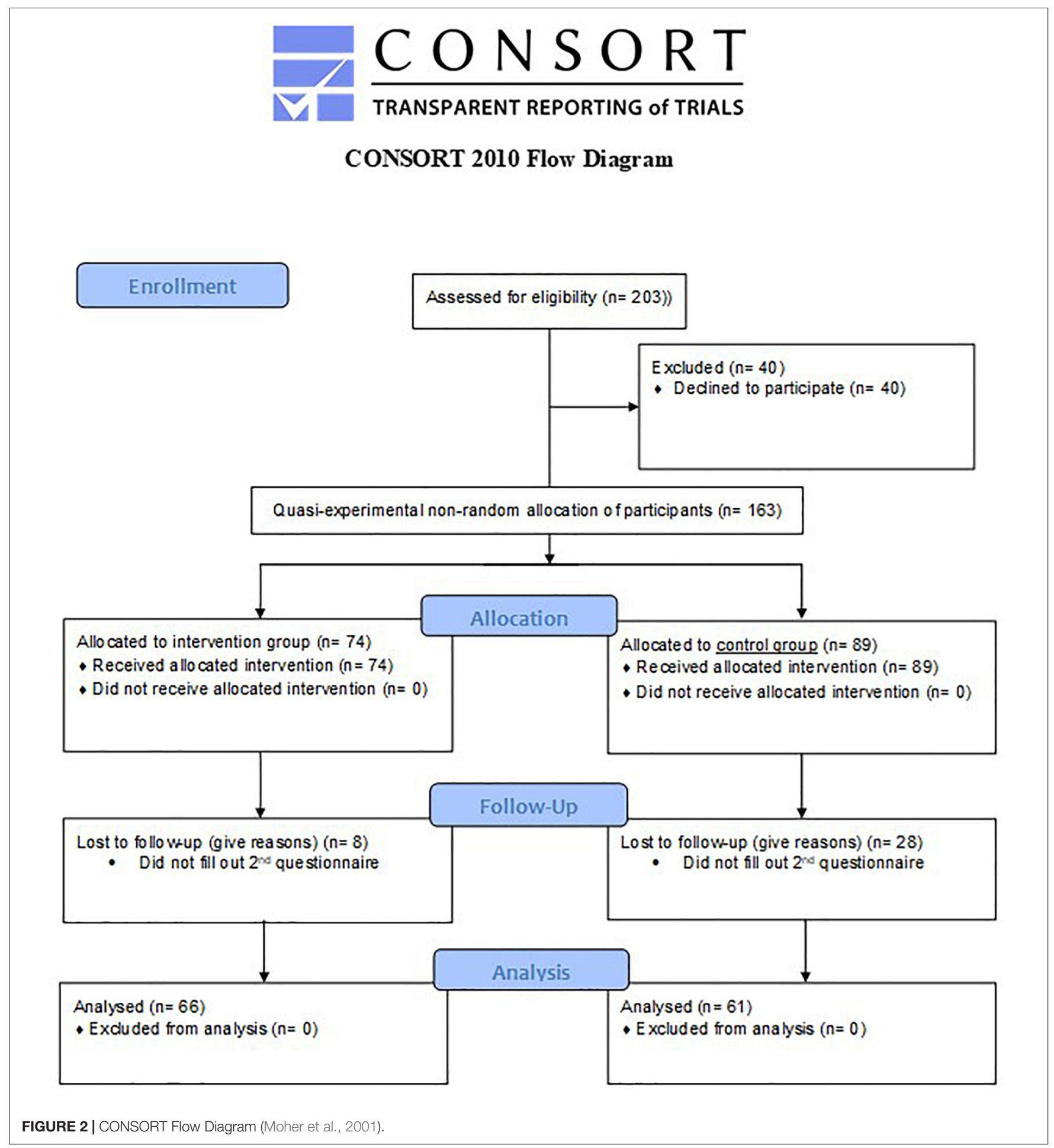

enthusiastic about my job; $\alpha$ T1/T2 were, respectively, 0.91/0.89) and absorption (3 items, e.g., I am immersed in my work; $\alpha$ T1/T2 were, respectively, 0.79/0.75). Items were measured on a 7 -point Likert scale, ranging from $0=$ never to $6=$ always. Cronbach's alphas for the overall construct (T1/T2) were, respectively, 0.92/0.91.

\section{Empowerment}

Empowerment was measured using the 12-item scale developed by Spreitzer (1995). This scale consists of four sub dimensions covering competence (three items e.g., I am confident about my ability to do my job; $\alpha$ T1/T2 were, respectively, 0.90/0.93), self-determination (three items, e.g., I can decide on my own 
TABLE 2 | Biographical information of all participants at T1 and T2.

\begin{tabular}{|c|c|c|c|c|}
\hline \multirow[t]{2}{*}{ Biographical information } & \multicolumn{2}{|c|}{ Intervention group } & \multicolumn{2}{|c|}{ Control group } \\
\hline & T1 $(N=74)$ & T2 $(N=66)$ & T1 $(N=89)$ & $\mathrm{T} 2(N=61)$ \\
\hline (1) Gender & $\begin{array}{l}\text { Male: } 25 \\
\text { Female: } 49\end{array}$ & $\begin{array}{l}\text { Male: } 24 \\
\text { Female: } 42\end{array}$ & $\begin{array}{l}\text { Male: } 29 \\
\text { Female: } 60\end{array}$ & $\begin{array}{l}\text { Male: } 22 \\
\text { Female: } 39\end{array}$ \\
\hline (2) Age & 46.1 & 45.9 & 46.3 & 46.5 \\
\hline (3) Tenure & 18.1 & 18.0 & 18.2 & 18.8 \\
\hline (4) Current position & 5.3 & 5.6 & 5.2 & 5.0 \\
\hline (5) Working hours per week & 32.6 & 32.8 & 31.5 & 32.1 \\
\hline (6) Dropout percentage & - & $13.2 \%$ & - & $31.5 \%$ \\
\hline
\end{tabular}

how to go about doing my job; $\alpha$ T1/T2 were, respectively, 0.92/0.88), impact (three items, e.g., My impact on what happens in my department is large; $\alpha$ T1/T2 were, respectively, 0.93/0.92) and meaning (three items, e.g., The work I do is meaningful to me; $\alpha$ T1/T2 were, respectively, 0.95/0.95). Items were measured on a 7 -point Likert scale ranging from $1=$ never to 7 = always. Cronbach's alphas for the overall construct (T1/T2) were, respectively, 0.89/0.89.

\section{Service-Oriented Task Performance ${ }^{1}$}

Service-oriented task performance was assessed using the scale developed by 'the authors', (submitted). This scale consisted of five items: 'I am meaningful for my customers,' 'I listen to the concerns my customers have,' 'I take the time to fulfill the emotional needs of my customers', 'I give clear explanations about the rules of the unemployment agency' and 'I support my customers in their search for a new job' ( $\alpha$ T1/T2 were, respectively, 0.89/0.89). Items were measured on a 5-point Likert scale ranging from $1=$ totally disagree to $5=$ totally agree.

\section{Empowering Service ${ }^{1}$}

Empowering service was measured using an adapted version of the Empowering Leadership Scale (ELS) developed by Amundsen and Martinsen (2014). This scale was originally developed for managers and leaders, but is also relevant for the unemployment sector since service employees and their unemployed customers have a hierarchical relationship too. We included 18 items which were adapted to match a service providing environment. Example items were 'I encourage my customers to take their own initiative when looking for a job' and 'I recognize the strong and weak sides of my customers' ( $\alpha$ T1/T2 were, respectively, 0.94/0.92). Items were measured on a 5-point Likert scale ranging from $1=$ never to $5=$ always.

\section{Customer Ratings}

Customer ratings were assessed using the 18 items from the empowering service scale, transcribed to the customer's perspective (e.g., 'My advisor encourages me to take personal initiative when looking for a job' and 'My advisor recognizes my strong and weak sides'). Customers rated the performance

\footnotetext{
${ }^{1}$ Not all participants in the intervention worked directly with customers. Therefore, these employees were excluded from the measure of service-oriented task performance and empowering service, resulting in $N_{\text {intervention group }}=44$; $N_{\text {control group }}=33$.
}

of their advisor ( $1=$ completely disagree; $5=$ completely agree). Cronbach's alphas (T1/T2) were, respectively, 0.98/0.98.

\section{Strategy of Analysis}

Data were analyzed using General Linear Modeling (GLM) repeated measures in SPSS to test the effects of the intervention over time. We conducted a two-way repeated measure analyses of variance with a time (T1 and $\mathrm{T} 2$ measure) by group (intervention and control) design. Time was used as the within-person factor and group as the between-person factor. Afterward, we conducted paired sample $t$-tests to explore differences within the groups. Customer satisfaction measures were analyzed using $t$-tests.

\section{RESULTS}

Table 3 shows the intercorrelations between the study variables on T1 and T2. Table 4 shows the means, standard deviations, results of the repeated measures ANOVAs and $t$-tests and the effect sizes for the study variables. Hypothesis $1 \mathrm{a}-\mathrm{d}$ examined whether employees in the intervention group showed higher levels of all types of job crafting behavior compared to the control group. Based on the repeated measures ANOVAs, $\mathrm{H} 1 \mathrm{a}-\mathrm{H} 1 \mathrm{~d}$ are rejected $\left(F_{\text {increasing structural resources }}=0.57\right.$, $p=$ n.s.; $F_{\text {increasing social resources }}=0.16, p=$ n.s.; $F_{\text {decreasing hindering demands }}=2.61, \quad p=$ n.s.; $\mathrm{F}_{\text {increasing challenging demands }}=0.90, p=\mathrm{n} . \mathrm{s}$.). However, when conducting t-tests to explore the growth patterns within both groups, results showed that employees in the intervention group experienced an increase in decreasing hindering demands $(t=-2.76, p<0.01)$ from $\mathrm{T} 1$ to $\mathrm{T} 2$, while employees in the control group did not $(t=-0.16, p=$ n.s.). Thus, even though $\mathrm{Hla}-\mathrm{d}$ are rejected based on the repeated measures ANOVAs, the $t$-test for decreasing hindering demands provides some support for hypothesis 1c. Given the Cohen's d of 0.26 (95\% CI $[0.12-0.39])$, this effect is small at best. Hypothesis $2 a-b$ examined whether employees in the control group experienced a decrease in work engagement and empowerment compared to the intervention group. Based on the repeated measures ANOVAs $\mathrm{H} 2 \mathrm{a}$ is rejected ( $F_{\text {work engagement }}=0.66, p=$ n.s. $)$. $\mathrm{H} 2 \mathrm{~b}$ is accepted $\left(F_{\text {empowerment }}=4.33, p=0.04\right)$, as empowerment in the control group is declining $(t=2.49, p=0.02)$ from T1 to T2, while in the experimental group it is not $(t=-0.56, p=n . s$. , see Figure 3. Given the Cohen's $d$ in the control group of -0.26 (95\% CI $[-0.42--0.12])$, the effect of the decreasing levels of empowerment is small. When conducting t-tests to compare growth patterns within each group for $\mathrm{H} 2 \mathrm{a}$, results showed that employees in the control group experienced a decrease in work engagement $(t=2.04, p=0.05)$ from T1 to T2, while employees in the intervention group $\operatorname{did}$ not $(t=1.18, p=$ n.s.). With a Cohen's $d$ of -0.20 (95\% CI $[-0.43--0.01])$ for the control group, the overall effect of loss of work engagement is small. Overall, $\mathrm{H} 2 \mathrm{~b}$ is accepted while $\mathrm{H} 2 \mathrm{a}$ is rejected, although the $t$-test provide some support for a buffering effect (i.e., no decrease) in work engagement for the intervention group. Hypothesis $3 \mathrm{a}-\mathrm{b}$ examined if employees participating in the 
TABLE 3 | Intercorrelations between the study variables for the pre- $(\mathrm{T} 1)$ and post- $(\mathrm{T} 2)$ measure $\left(N_{\mathrm{T} 1}=163 ; N_{\mathrm{T} 2}=127\right)$.

\begin{tabular}{|c|c|c|c|c|c|c|c|c|}
\hline Variable & 1 & 2 & 3 & 4 & 5 & 6 & 7 & 8 \\
\hline (1) Increasing structural resources & & -0.02 & $0.29^{\star \star}$ & $0.54^{\star *}$ & $0.55^{\star \star}$ & $0.50^{\star \star}$ & $0.28^{\star *}$ & $0.38^{\star \star}$ \\
\hline (2) Decreasing hindering demands & -0.04 & & $0.31^{\star \star}$ & 0.02 & 0.06 & $<0.01$ & -0.08 & $<-0.01$ \\
\hline (3) Increasing social resources & $0.41^{* *}$ & $0.22^{\star *}$ & & $0.30^{\star *}$ & $0.33^{\star *}$ & $0.18^{*}$ & -0.05 & 0.11 \\
\hline (4) Increasing challenging demands & $0.59^{\star \star}$ & -0.02 & $0.38^{\star \star}$ & & $0.42^{\star \star}$ & $0.35^{\star \star}$ & 0.17 & $0.31^{\star \star}$ \\
\hline (5) Work engagement & $0.53^{\star *}$ & 0.08 & $0.29^{\star \star}$ & $0.37^{\star \star}$ & & $0.66^{\star \star}$ & 0.14 & $0.38^{\star \star}$ \\
\hline (6) Empowerment & $0.35^{\star \star}$ & 0.03 & 0.06 & $0.17^{\star}$ & $0.56^{\star \star}$ & & $0.35^{\star \star}$ & $0.31^{* \star}$ \\
\hline (7) Service-oriented task performance & $0.36^{\star \star}$ & -0.06 & 0.06 & $0.23^{*}$ & $0.32^{\star \star}$ & $0.33^{\star \star}$ & & $0.45^{\star \star}$ \\
\hline (8) Empowering service & $0.32^{\star \star}$ & $-0.21^{*}$ & 0.12 & $0.25^{\star \star}$ & $0.30^{\star \star}$ & $0.21^{*}$ & $0.57^{\star \star}$ & \\
\hline
\end{tabular}

Correlations within the pre-(T1) measure are shown under the diagonal, correlations within the post-(T2) measure are shown above the diagonal. ${ }^{*} p<0.05$; ** $<0.01$.

job crafting intervention were able to maintain their levels of service-oriented task performance and empowering service, while employees in the control group could not. Based on the repeated measures ANOVAs and $t$-tests, both $\mathrm{H} 3 \mathrm{a}$ and $\mathrm{H} 3 \mathrm{~b}$ are rejected as both employees in the control group and the intervention group were able to maintain their (self-rated) levels of performance $\left(F_{\text {service-oriented task performance }}=1.50\right.$, $p=$ n.s., $t_{\text {sevice-oriented task performance }}=0.61, \quad p=$ n.s.; $F_{\text {empowering service }}=0.004, p=$ n.s., $t_{\text {empowering service }}=-0.41$, $p=$ n.s.). Hypothesis 4 examined whether customer ratings were higher for employees in the intervention group compared to employees in the control group before the start of the intervention, 5 months later and 1 year later. We used a $t$-test $t^{2}$ to explore the differences between the groups and found no differences between the intervention group and control group before the start of the intervention $(t=0.49, d f=94, p=$ n.s. $)$ and 5 months after the intervention $(t=-0.21, d f=101$, $p=$ n.s.). Therefore, hypothesis $4 \mathrm{a}$ is rejected. We did find an effect on customer ratings of empowering service 1 year after the intervention, as employees in the control group were rated more positively than their peers in the control group $(t=-2,51$, $d f=179, p=0.01)$. Therefore, hypothesis $4 \mathrm{~b}$ is accepted.

\section{DISCUSSION}

In this study, we examined the effects of a job crafting intervention, in which employees of a Dutch unemployment agency learned to implement job crafting behaviors in their work routines. The intervention aimed to prevent a decrease in empowerment, work engagement and employee performance (i.e., the provision of high-quality services) due to organizational changes. During a 1-day intervention, employees learned about job crafting and how to implement it into their work. Six weeks after the first day, they came back for a reflection session, in which they evaluated the effects of job crafting on their work. Both days were based on experiential learning theory (Kolb et al., 2000).

Our intervention increased one of the four job crafting behaviors (i.e., decreasing hindering demands). Furthermore,

\footnotetext{
${ }^{2}$ We were unable to conduct RM ANOVA's for the customer satisfaction measures because of organizational reasons. Data were collected at three fixed points in time and it appeared impossible to schedule all the customers from T1 for an appointment with their advisor at $\mathrm{T} 2$ and $\mathrm{T} 3$ for the follow up.
}

results showed that the intervention was successful to prevent a decrease in employee empowerment and work engagement. We did not find an effect for service-oriented task performance and empowering service as both the intervention group and the control group were able to maintain their performance levels. However, the effects of empowering service were noticeable for customers, as 1 year after the intervention customers were more positive about the service quality of employees in the intervention group compared to the control group. Overall, our results showed that the intervention may be a promising tool to maintain employee well-being during times of change. However, as will be discussed in more detail below, not all results were in line with our expectations.

First, we found support that the intervention had an effect on aspects of employee well-being. Using RM ANOVA's, our results showed that employees in the control group experienced a decrease in empowerment, whereas employees in the intervention group did not. Employee empowerment in the intervention group was stable over time, regardless of any changes going on in the organization. Furthermore, we found some preliminary support that the intervention had an effect on work engagement, as employees in the control group showed a decrease in work engagement, whereas employees in the intervention group did not. However, these effects were detected using $t$-tests (which considers pre- and postmeasures within the same group) but were not supported by the RM ANOVA (which considers both the intervention and control group simultaneously). Therefore, these results must be interpreted with caution. Nevertheless, they seem promising for the future. Based on our findings, we conclude that the job crafting intervention holds the potential to sustain employee well-being (i.e., empowerment and possibly work engagement). It provides employees with additional (personal) resources to adapt to increasing demands in an efficient way. When employees craft their job, they are suggested to enhance the fit between themselves and their work (Bakker et al., 2012). This is extremely valuable, especially during times of organizational change, as it provides employees with a sense of control and self-efficacy. Moreover, it helps to prevent feeling of powerlessness as a consequence of the organizational changes (Conger and Kanungo, 1988; Van Den Heuvel et al., 2013). Furthermore, through job crafting, employees can maintain their work engagement. This is not only valuable for the employee him-/herself, but also 
TABLE 4 | Mean, SD, $t$-test, effect size and repeated measures ANOVA's for the study variables.

\begin{tabular}{|c|c|c|c|c|c|c|c|c|c|c|c|c|c|c|c|}
\hline \multirow[b]{2}{*}{ Variable } & \multicolumn{4}{|c|}{ Experimental group $(N=66)$} & \multirow[b]{2}{*}{ Cohen's $d$} & \multirow[b]{2}{*}{$95 \% \mathrm{Cl}$} & \multicolumn{4}{|c|}{ Control group $(N=61)$} & \multirow[b]{2}{*}{ Cohen's $d$} & \multirow[b]{2}{*}{$95 \% \mathrm{Cl}$} & \multicolumn{2}{|c|}{ RM ANOVA } & \multirow[b]{2}{*}{ Cohen's $d$} \\
\hline & $M$ & $S D$ & $t$-Test $t$ & $p^{\mathrm{a}}$ & & & $M$ & $S D$ & $t$-Test $t$ & $p^{b}$ & & & $\boldsymbol{F}$ & $p^{c}$ & \\
\hline JC: ISTR (T1) & 3.99 & 0.52 & -0.12 & 0.90 & 0.02 & {$[-0.12-0.14]$} & 3.81 & 0.48 & -1.32 & 0.19 & 0.13 & {$[0.01-0.23]$} & 0.57 & 0.45 & 0.14 \\
\hline JC: ISTR (T2) & 4.00 & 0.55 & & & & & 3.87 & 0.47 & & & & & & & \\
\hline JC: DHD (T1) & 2.42 & 0.53 & -2.76 & $0.008^{* *}$ & 0.26 & {$[0.12-0.39]$} & 2.44 & 0.58 & -0.16 & 0.87 & 0.03 & {$[-0.11-0.15]$} & 2.61 & 0.11 & 0.29 \\
\hline JC: DHD (T2) & 2.57 & 0.61 & & & & & 2.46 & 0.59 & & & & & & & \\
\hline JC: ISOR (T1) & 2.70 & 0.49 & -0.44 & 0.66 & 0.04 & {$[-0.08-0.15]$} & 2.51 & 0.64 & -0.85 & 0.40 & 0.03 & {$[-0.12-0.17]$} & 0.16 & 0.69 & 0.07 \\
\hline JC: ISOR (T2) & 2.72 & 0.50 & & & & & 2.53 & 0.60 & & & & & & & \\
\hline JC: ICD (T1) & 3.51 & 0.75 & -0.44 & 0.66 & 0.03 & {$[-0.15-0.20]$} & 3.16 & 0.74 & 0.87 & 0.39 & -0.07 & {$[-0.26-0.06]$} & 0.90 & 0.35 & 0.17 \\
\hline JC: ICD (T2) & 3.53 & 0.73 & & & & & 3.11 & 0.72 & & & & & & & \\
\hline WE (T1) & 4.83 & 1.01 & 1.18 & 0.24 & -0.09 & {$[-0.32-0.14]$} & 4.92 & 0.91 & 2.04 & $0.05^{\star}$ & -0.20 & {$[-0.43--0.01]$} & 0.60 & 0.44 & 0.12 \\
\hline WE (T2) & 4.74 & 0.93 & & & & & 4.74 & 0.94 & & & & & & & \\
\hline $\mathrm{EMP}(\mathrm{T} 1)$ & 5.07 & 0.74 & -0.56 & 0.58 & 0.06 & {$[-0.12-0.22]$} & 5.23 & 0.67 & 2.49 & $0.02^{*}$ & -0.26 & {$[-0.42--0.12]$} & 4.33 & $0.04^{*}$ & 0.37 \\
\hline EMP (T2) & 5.11 & 0.71 & & & & & 5.06 & 0.66 & & & & & & & \\
\hline S-OTP $(T 1)^{d}$ & 4.55 & 0.36 & 0.61 & $0.55^{\mathrm{da}}$ & -0.08 & {$[-0.19-0.02]$} & 4.37 & 0.73 & -1.11 & $0.28^{\mathrm{db}}$ & 0.10 & {$[-0.14-0.35]$} & 1.50 & $0.22^{\mathrm{dc}}$ & 0.29 \\
\hline S-OTP (T2) ${ }^{d}$ & 4.52 & 0.38 & & & & & 4.44 & 0.69 & & & & & & & \\
\hline EMP SE (T1) ${ }^{d}$ & 4.33 & 0.40 & -0.41 & $0.69^{d a}$ & 0.05 & {$[-0.06-0.17]$} & 4.27 & 0.45 & -0.45 & $0.66^{\mathrm{db}}$ & 0.07 & {$[-0.06-0.23]$} & 0.004 & $0.95^{\mathrm{dc}}$ & 0.02 \\
\hline EMP SE (T2) ${ }^{d}$ & 4.35 & 0.37 & & & & & 4.30 & 0.39 & & & & & & & \\
\hline
\end{tabular}

JC, job crafting; ISTR, increasing structural resources; DHD, reducing hindering demands; ISOR, increasing social resources; ICD, increasing challenging demands; WE, work engagement; EMP, empowerment; S-OTP, Service-oriented task performance and EMP SE, empowering service. Repeated measures ANOVA: Time (within-person) $\times$ Group $\left(\right.$ between-person). ${ }^{a} d f=65 ;{ }^{b} d f=60 ;{ }^{c} d f=1,125 .{ }^{d} N{ }_{\text {experimental group }}=44$; $N_{\text {control group }}=33 .{ }^{d a} d f=43 ;{ }^{d b} d f=32 ;{ }^{d c} d f=1,75 .{ }^{*} p \leq 0.05 ;{ }^{* *} p<0.01$. 


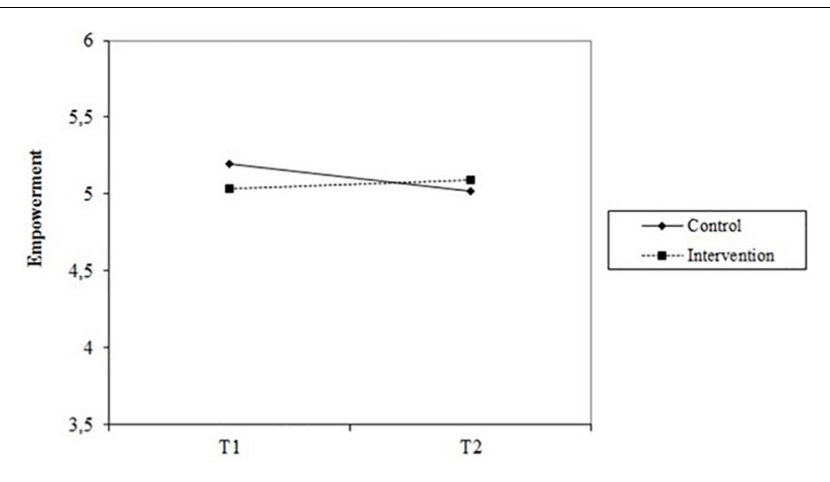

FIGURE 3 | Interaction effect of group (intervention and control) * time (T1 and T2) for employee empowerment.

for the organization. Engaged employees like their job, feel energized while working and have a lower risk of stress-related health issues like burn-out (Bakker et al., 2014). Moreover, as work engagement is contagious (Bakker and Demerouti, 2009) employees engaged in their job can act as a counterforce toward any possible cynicism regarding the organizational changes going on (Van den Heuvel et al., 2010). Moreover, such employees are more creative and willing to go the extra mile. This is important, as organizational change is hardly ever a smooth process (Cartwright and Holmes, 2006; Kompier, 2006). Thus, to protect employee well-being during times of change, the job crafting intervention is a valuable tool as it helps employees to adapt to the heightened demands.

The intervention had, unexpectedly, little effect on reported job crafting behavior. Results did show a significant increase in decreasing hindering demands for the intervention group, when conducting $t$-tests. Thus, employees in the intervention group showed an increase in decreasing hindering demands when comparing their pre- and post-measure. Although this result must be interpreted with caution, it is in line with the results of Oprea et al.'s (2019) meta-analysis which also showed that job crafting interventions have a stronger effect on the reducing demands dimension. One reason that the intervention seemed to have only little effect on reported job crafting behavior may be that employees specified very specific crafting goals to optimize their working conditions, which may not be captured by the (more generally formulated) items used to measure job crafting behavior (Van den Heuvel et al., 2015). For example, one participant worked in an open office space where it was hard to focus as people were making phone calls all day. Therefore, the participant decided to wear earplugs when carrying out tasks that needed full concentration. As researchers, we would classify this as reducing hindering demands. However, this specific behavior may not be captured by the items for reducing demands (e.g., 'I make sure my work is mentally less intense'). Although we used a more specific measure of job crafting in line with the suggestions of Van den Heuvel et al. (2015), it may be difficult for participants to see the link between their actual behavior and the job crafting items. One suggestion to improve the intervention is to gather and document the different job crafting goals set and check (at
T2) whether participants worked (successfully) on them. This way, it is possible to overcome the discrepancy between the job crafting items and the actual job crafting behaviors. Another reason that the intervention seemingly had little effect on job crafting behaviors, may be the organizational changes going on, especially when it comes to increasing challenging demands and seeking (structural and social) resources. Both structural and social resources may have been less available. Work load was increasing, as employees had to see twice as many clients. This may have inhibited them to provide resources to each other as they had other priorities. Furthermore, structural resources may have been harder to get as the organization required their employees to do more with less means. As for increasing challenging demands: the new targets asked a lot of extra effort form employees and they may be considered a (huge) challenge in itself. Therefore, as employees had to adjust to the changes, they may not have had sufficient time (or even motivation) to seek additional challenges.

The intervention had no effect on (self-reported) service quality. We found no differences between the intervention and the control group for both service-oriented task performance and empowering service, although we expected the control group to decline. One possible explanation that the control group did not show a decline may be that the timeframe between the two measurement points was too short. Employees experiencing high job demands over a prolonged period of time may become chronically exhausted, and this may negatively affect their performance (Bakker and Demerouti, 2017). We used a timeframe of 6 weeks and this may have been too short to be labeled as 'prolonged exposure.' Another reason that we did not find any differences in performance, might be that people tend to be more lenient toward their own performance (Holzbach, 1978). Therefore, we have also taken customer-rated measures of performance into account and found that 1 year after the intervention, employees in the intervention group were rated significantly more positive by their customers than employees in the control group. However, this effect was not found 5 months after the intervention. A possible explanation for finding differences in customer-rated measures of performance 1 year after the intervention, but not yet after 5 months, may be that behavioral change takes time. Lally et al. (2010) showed that on average it took 66 days to develop daily routines, but the range of habit formation was widespread, from 18 up to 254 days. In their study they examined the formation of simple (health-related) habits like drinking a bottle of water during lunch. However, the provision of high-quality services is much more complex and thus it may take longer for employees to change their behavior and form new habits. Moreover, Lally et al. (2010) state that habit formation is easier in a stable context. As organizational changes were implemented and as each client requires a different approach, the context was anything but stable, making it even harder for employees to change their behavior. Although we measured after 5 months, it may have been too early to notice any differences as the behavioral change was complex and the context was unstable. Nevertheless, our findings emphasize the importance of providing employees with sufficient tools (i.e., job crafting techniques) and resources to 
craft their work environment (Wrzesniewski and Dutton, 2001; Tims and Bakker, 2010).

Overall, our results are in line with and complementary to other studies regarding the job crafting intervention (e.g., Van den Heuvel et al., 2015; Demerouti et al., 2017; Gordon et al., 2018; Dubbelt et al., 2019) as it has shown to have an effect on employee well-being (i.e., empowerment and work engagement) as well as on service quality. Since the effects of the intervention on job crafting behavior were rather weak, the question that arises is how the intervention improved the outcomes. Demerouti et al.'s (2017) intervention that was conducted in an organizational change context showed that the effect of the intervention on openness to change and adaptive performance was explained by positive affect, instead of job crafting. Such an explanation could also be applicable in our study and is in line with the proposition of Oldham and Hackman (2010) that the benefits of job crafting may "derive from substantive changes in the work itself" (due to crafting) or "merely from having the opportunity to tailor one's own work responsibilities” (p. 471).

\section{Practical Implications}

This study is of practical relevance too. Many organizations are dealing with changes these days. They have to re-invent themselves to work more efficiently and they have to come up with innovative products and services to keep their customers satisfied (Chiang and Jang, 2008). As the pace in which changes are implemented is high (Kompier, 2006), employees have to adapt to these changes at a high pace too. Therefore, it is of vital importance for employees to have sufficient strategies to adapt to these changes. Moreover, to keep customers satisfied, it is important that employees provide optimal services and that these services are valued by their customers. Our study shows that through a job crafting intervention, employee well-being can be preserved during times of change, and that customer satisfaction can be enhanced, as 1 year after the job crafting intervention service employees in the intervention group are rated more positively by their customers than service employees in the control group. Therefore, as organizational changes are implemented, it is important for management to provide employees with sufficient tools (e.g., a job crafting intervention) to adequately adapt to and deal with the organizational changes going on. This way, employee well-being can be maintained, while customer satisfaction can even improve.

\section{Limitations and Future Research}

When interpreting the results of this study, some limitations should be kept in mind. First, almost all variables were measured using self-reports, which can result in common method bias (Podsakoff et al., 2003). We used self-reports in line with the recommendations of Conway and Lance (2010) who state that self-reports should be used when trying to capture private experiences (e.g., work engagement, empowerment). Although we included customer ratings of service quality, future studies could try to incorporate more other-rated measures. For example, one could include peer ratings of job crafting behaviors and service-oriented task performance as both are behavioral measures and thus, are visible for others.

Second, we did not have a completely randomized study design - a limitation ever-present in field studies as organizations cannot force employees to participate. We tried to encourage participation by giving presentations in work meetings and by posting small messages in the organization's weekly newsletter. However, we cannot rule out that only participants who were willing to change participated in the intervention. Nevertheless, employees in the intervention group did not differ from the control group on their pre-intervention scores, nor did they differ in age, tenure and years in their current position.

Third, although the intervention aimed to increase job crafting behavior, only one of the four job crafting dimensions significantly changed during the intervention period. As the intervention was delivered as intended, we cannot rule out that other factors, beside job crafting, influenced the results and being (at least partly) responsible for the effects found on work engagement, empowerment and performance.

Fourth, due to organizational constraints, it was impossible to collect customer satisfaction measures from the same customer over time. Therefore, we were forced to rely on t-test instead of RM-ANOVA's when examining customer ratings. Future research including customer ratings should try to incorporate a follow-up over time to explore whether there are improvements in service using more advanced methods of analysis.

Lastly, in this study we used a single pre-intervention measure. Multiple pre-intervention measures might have helped us to determine the baseline more accurately, as the mere presence of researchers and the completion of questionnaires might already affect participants. Therefore, we encourage future researchers to use multiple pre-intervention measures to overcome this limitation.

Future research should examine the effectiveness of job crafting interventions in other contexts as well. We were the first to explore the job crafting intervention in a service setting during times of change. However, our results are mixed and not always in line with expectations. This highlights the importance of tailormade interventions (Harden et al., 1999), designed to meet the requirements of different organizational phases (Swerissen and Crisp, 2004). For example, as increasing challenging demands might not be the most effective strategy during times of change, it may be beneficial for employees during more quiet times, as it can help to prevent boredom. More in-depth knowledge of the effects of job crafting interventions in various settings is extremely valuable, as only then interventions can effectively be tailored to adequately meet the specific needs of employees and the organization.

\section{CONCLUSION}

This is the first study to explore the effects of a job crafting intervention in a service setting during times of organizational change. Our results highlight the importance of a job crafting intervention as a means to sustain empowerment among service employees. Empowerment is a crucial 
asset during times of change as empowered employees feel more confident and in control when carrying out their (changing) work, optimizing their performance (Erstad, 1997). This is also supported by our results, as employee performance - as rated by customers - was more positive up to 1 year after the intervention. These findings emphasize the importance of tailormade job crafting interventions that provide employees with sufficient strategies to stay in control and preserve their level of performance during times of change.

\section{DATA AVAILABILITY STATEMENT}

The datasets generated for this study are available on request to the corresponding author.

\section{REFERENCES}

Amundsen, S., and Martinsen, ØL. (2014). Empowering leadership: construct clarification, conceptualization, and validation of a new scale. Leadersh. Q. 25, 487-511. doi: 10.1016/j.leaqua.2013.11.009

Ashforth, B. E. (1989). The experience of powerlessness in organizations. Organiz. Behav. Hum. Decis. Process. 43, 207-242. doi: 10.1016/0749-5978(89)90051-4

Bakker, A. B., and Demerouti, E. (2009). The crossover of work engagement between working couples: a closer look at the role of empathy. J. Manag. Psychol. 24, 220-236. doi: 10.1108/02683940910939313

Bakker, A. B., and Demerouti, E. (2017). Job demands-resources theory: taking stock and looking forward. J. Occup. Health Psychol. 22, 273-285. doi: 10.1037/ ocp0000056

Bakker, A. B., Demerouti, E., and Sanz-Vergel, A. I. (2014). Burnout and Work engagement: the JD-R approach. Annu. Rev. Organiz. Psychol. Organiz. Behav. 1, 389-411. doi: 10.1146/annurev-orgpsych-031413-091235

Bakker, A. B., Tims, M., and Derks, D. (2012). Proactive personality and job performance: the role of job crafting and work engagement. Hum. Relat. 65, 1359-1378. doi: 10.1177/0018726712453471

Bowden, J. L.-H. (2009). The process of customer engagement: a conceptual framework. J. Mark. Theory Pract. 17, 63-74. doi: 10.2753/MTP10696679170105

Caldwell, S. D., Herold, D. M., and Fedor, D. B. (2004). Toward an understanding of the relationships among organizational change, individual differences, and changes in person-environment fit: a cross-level study. J. Appl. Psychol. 89, 868-882. doi: 10.1037/0021-9010.89.5.868

Callan, V. J. (1993). Individual and organizational strategies for coping with organizational change. Work Stress 7, 63-75. doi: 10.1080/02678379308257050

Carbonell, J. G. (1983). "Learning by analogy: formulating and generalizing plans from past experience," in Machine Learning: An Artificial Intelligence Approach, eds R. S. Michalski, J. G. Carbonell, and T. M. Mitchell, (Berlin: Springer), 137-161. doi: 10.1016/b978-0-08-051054-5.50009-1

Cartwright, S., and Holmes, N. (2006). The meaning of work: the challenge of regaining employee engagement and reducing cynicism. Hum. Resour. Manag. Rev. 16, 199-208. doi: 10.1016/j.hrmr.2006.03.012

Cavanaugh, M. A., Boswell, W. R., Roehling, M. V., and Boudreau, J. W. (2000). An empirical examination of self-reported work stress among U.S. managers. J. Appl. Psychol. 85, 65-74. doi: 10.1037/0021-9010.85.1.65

Chen, G., Kirkman, B. L., Kanfer, R., Allen, D., and Rosen, B. (2007). A multilevel study of leadership, empowerment, and performance in teams. J. Appl. Psychol. 92, 331-346. doi: 10.1037/0021-9010.92.2.331

Chiang, C., and Jang, S. S. (2008). The antecedents and consequences of psychological empowerment: the case of Taiwan's hotel companies. J. Hosp. Tour. Res. 32, 40-61. doi: 10.1177/1096348007309568

Christian, M. S., Garza, A. S., and Slaughter, J. E. (2011). Work engagement: a quantitative review and test of its relations with task and contextual performance. Pers. Psychol. 64, 89-136. doi: 10.1111/j.1744-6570.2010. 01203.x

\section{ETHICS STATEMENT}

The studies involving human participants were reviewed and approved by the Onderzoekscommissie Industrial Engineering (OZC-IE). Written informed consent for participation was not required for this study in accordance with the national legislation and the institutional requirements.

\section{AUTHOR CONTRIBUTIONS}

All authors have made a substantial contribution to the conception of the manuscript, and the analysis and interpretation of the data. Moreover, all authors have been involved in the writing process.

Conger, J. A., and Kanungo, R. N. (1988). The empowerment process: integrating theory and practice. Acad. Manag. Rev. 13, 471-482. doi: 10.2307/258093

Conway, J. M., and Lance, C. E. (2010). What reviewers should expect from authors regarding common method bias in organizational research. J. Bus. Psychol. 25, 325-334. doi: 10.1007/s10869-010-9181-6

Crawford, E. R., Le Pine, J. A., and Rich, B. L. (2010). Linking job demands and resources to employee engagement and burnout: a theoretical extension and meta-analytic test. J. Appl. Psychol. 95, 834-848. doi: 10.1037/a0019364

Dall'erba, S., Percoco, M., and Piras, G. (2009). Service industry and cumulative growth in the regions of Europe. Entrepreneursh. Region. Dev. 21, 333-349. doi: 10.1080/08985620903019815

Davies, M. (2011). Concept mapping, mind mapping and argument mapping: what are the differences and do they matter? High. Educ. 62, 279-301. doi: 10.1007/s10734-010-9387-6

Demerouti, E., Bakker, A. B., and Gevers, J. M. P. (2015). Job crafting and extrarole behavior: the role of work engagement and flourishing. J. Vocat. Behav. 91, 87-96. doi: 10.1016/j.jvb.2015.09.001

Demerouti, E., Bakker, A. B., Nachreiner, F., and Schaufeli, W. B. (2001). The job demands-resources model of burnout. J. Appl. Psychol. 86, 499-512. doi: 10.1037//0021-9010.86.3.499

Demerouti, E., Peeters, M. C., and van den Heuvel, M. (2019). Job Crafting Interventions: Do They Work and Why?. In Positive Psychological Intervention Design and Protocols for Multi-Cultural Contexts (Cham: Springer), $103-125$.

Demerouti, E., Xanthopoulou, D., Petrou, P., and Karagkounis, C. (2017). Does job crafting assist dealing with organizational changes due to austerity measures? Two studies among Greek employees. Eur. J. Work Organiz. Psychol. 26, 574-589. doi: 10.1080/1359432x.2017.1325875

Doran, G. T. (1981). There's a S.M.A.R.T. way to write management's goals and objectives. Manag. Rev. 70, 35-36.

Dubbelt, L., Demerouti, E., and Rispens, S. (2019). The value of job crafting for work engagement, task performance, and career satisfaction: longitudinal and quasi-experimental evidence. Eur. J. Work Organiz. Psychol. 28, 300-314. doi: 10.1080/1359432x.2019.1576632

Erstad, M. (1997). Empowerment and organizational change. Int. J. Contemp. Hosp. Manag. 9, 325-333. doi: 10.1108/09596119710190976

Fry, J. P., and Neff, R. A. (2009). Periodic prompts and reminders in health promotion and health behavior interventions: systematic review. J. Med. Internet Res. 11:e16. doi: 10.2196/jmir.1138

Gilley, A., Gilley, J. W., and McMillan, H. S. (2009). Organizational change: motivation, communication and leadership effectiveness. Perform. Improv. Q. 21, 75-94. doi: 10.1002/piq20039

Gist, M. E. (1987). Self-efficacy: implications for organizational behavior and human resource management. Acad. Manag. Rev. 12, 472-485. doi: 10.5465/ amr.1987.4306562

Gordon, H. J., Demerouti, E., Le Blanc, P. M., Bakker, A. B., Bipp, T., and Verhagen, M. A. (2018). Individual job redesign: job crafting interventions in healthcare. J. Vocat. Behav. 104, 98-114. 
Harden, A., Peersman, G., Oliver, S., Mauthner, M., and Oakley, A. (1999). A systematic review of the effectiveness of health promotion interventions in the workplace. Occup. Med. 49, 540-548. doi: 10.1093/occmed/49. 8.540

Holzbach, R. L. (1978). Rater bias in performance ratings: superior, self-, and peer ratings. J. Appl. Psychol. 63, 579-588. doi: 10.1037/0021-9010.63.5.579

Hulshof, I. L., Demerouti, E., and Le Blanc, P. M. (2019). Meaning in work as an explanatory mechanism in the relationship between job crafting, work engagement and performance: a diary study. Career Dev. Int. (in press).

Kolb, A. Y., and Kolb, D. A. (2011). Experiental learning theory: a dynamic, holistic approach to management learning, education and development. Armstrong Manag. Learn. Educ. Dev. 3, 42-68. doi: 10.4135/9780857021038.n3

Kolb, D. A., Boyatzis, R. E., and Mainemelis, C. (2000). Experiental Learning Theory: Previous Research and New Directions in Perspectives on Cognitive, Learning, and Thinking Styles (Hillsdale, NJ: Erlbaum andLaurence), 227-247.

Kompier, M. A. J. (2006). New systems of work organization and workers' health. Scand. J. Work Environ. Health 32, 421-430. doi: 10.5271/sjweh. 1048

Lally, P., Van Jaarsveld, C. H. M., Potts, H. W. W., and Wardle, J. (2010). How are habits formed: modelling habit formation in the real world. Eur. J. Soc. Psychol. Eur. 40, 625-634.

Lamm, E., and Gordon, J. R. (2010). Empowerment, predisposition to resist change, and support for organizational change. J. Leadersh. Organiz. Stud. 17, 426-437. doi: $10.1177 / 1548051809355595$

McCelland, G. P., Leach, D. J., Clegg, C. W., and McGowan, I. (2014). Collaborative crafting in call centre teams. J. Occup. Organiz. Psychol. 87, 464-486. doi: 10.1111/joop. 12058

Miller, M. (2015). Relationships Between Job Design, Job Crafting, Idiosyncratic Deals and Psychological Empowerment. Minneapolis: Walden University.

Moher, D., Schulz, K. F., and Altman, D. (2001). The CONSORT statement: revised recommendations for improving the quality of reports of parallel-group randomized trials. JAMA 285, 1987-1991. doi: 10.1001/jama.285.15.1987

Moon, T. K. (1996). The expectation-maximization algorithm. IEEE Signal Process. Magaz. 13, 47-60.

Motowidlo, S. J., and Van Scotter, J. R. (1994). Evidence that task performance should be distinguished from contextual performance. J. Appl. Psychol. 79, 475-480. doi: 10.1037//0021-9010.79.4.475

Oldham, G. R., and Hackman, J. R. (2010). Not what it was and not what it will be: the future of job design research. J. Organiz. Behav. 31, 463-479. doi: 10.1002/job.678

Oliva, R., and Sterman, J. D. (2001). Cutting corners and working overtime: quality erosion in the service industry. Manag. Sci. 47, 894-914. doi: 10.1287/mnsc.47. 7.894.9807

Oprea, B. T., Barzin, L., Vîrgã, D., Iliescu, D., and Rusu, A. (2019). Effectiveness of job crafting interventions: a meta-analysis and utility analysis. Eur. J. Work Organiz. Psychol. 28, 723-741. doi: 10.1080/1359432x.2019.1646728

Petrou, P., Demerouti, E., Peeters, M. C. W., Schaufeli, W. B., and Hetland, J. (2012). Crafting a job on a daily basis: contextual correlates and the link to work engagement. J. Organiz. Behav. 33, 1120-1141.

Petrou, P., Demerouti, E., and Schaufeli, W. B. (2016). Crafting the change: the role of employee job crafting behaviors for successful organizational change. J. Manag. 44, 1766-1792. doi: 10.1177/0149206315624961

Petrou, P., Demerouti, E., and Schaufeli, W. B. (2018). Crafting the change: the role of employee job crafting behaviors for successful organizational change. J. Manag. 44, 1766-1792. doi: 10.1177/0149206315624961

Podsakoff, P. M., MacKenzie, S. B., Lee, J.-Y., and Podsakoff, N. P. (2003). Common method biases in behavioral research: a critical review of the literature and recommended remedies. J. Appl. Psychol. 88, 879-903. doi: 10.1037/0021-9010. 88.5.879

Pratt, M. G., and Ashforth, B. E. (2003). "Fostering meaningfulness in working and at work," in Positive Organizational Scholarship: Foundations of a New Discipline, eds K. Cameron, and J. Dutton, (San Francisco: Berrett-Koehler Publisher), 309-327.

Ryan, R. M., and Deci, E. L. (2000). Self-determination theory and the facilitation of intrinsic motivation. Soc. Dev. Well Being Am. Psychol. 55, 68-78. doi: 10. 1037/0003-066X.55.1.68
Sawyer, D. R., Brownson, C. A., and Toole, M. L. O. (2007). Patient-centered goal setting as a tool to improve diabetes self-management. Diabetes Educ. 33, 139-144. doi: 10.1177/0145721707304475

Schaufeli, W. B., Bakker, A. B., and Salanova, M. (2006). The measurement of work engagement with a short questionnaire: a cross-national study. Educ. Psychol. Meas. 66, 701-716. doi: 10.1177/0013164405282471

Schaufeli, W. B., Salanova, M., Bakker, A. B., and González-Romá, V. (2002). The measurement of engagement and burnout: a two sample confirmatory factor analytic approach. J. Happ. Stud. 3, 71-92.

Schunk, D. H. (1990). Goal setting and self-efficacy during self-regulated learning. Educ. Psychol. 25, 71-86. doi: 10.1017/CBO9781107415324.004

Seibert, S. E., Wang, G., and Courtright, S. H. (2011). Antecedents and consequences of psychological and team empowerment in organizations: a meta-analytic review. J. Appl. Psychol. 96, 981-1003. doi: 10.1037/a002 2676

Spreitzer, G. M. (1995). Psychological empowerment in the workplace: dimensions, measurement and validation. Acad. Manag. J. 38, 1442-1465. doi: 10.2307/ 256865

Swerissen, H., and Crisp, B. R. (2004). The sustainability of health promotion interventions for different levels of social organization. Health Promot. Int. 19, 123-130. doi: 10.1093/heapro/dah113

Taylor, D., and Pandza, K. (2003). "Networking capability: the competitive advantage of small firms," in Competitive Advantage in SMEs: Organising for Innovation and Change, eds O. Jones, and F. Tilley, (Hoboken, NJ: Wiley), 156-173.

Thomas, K. W., and Velthouse, B. A. (1990). Cognitive elements of empowerment: an "interpretive" model of intrinsic task motivation. Acad. Manag. Rev. 15, 666-681. doi: 10.5465/amr.1990.4310926

Tims, M., and Bakker, A. B. (2010). Job crafting: towards a new model of individual job redesign. SA J. Indust. Psychol. 36:841. doi: 10.4102/sajip.v36 i2.841

Tims, M., Bakker, A. B., and Derks, D. (2012). Development and validation of the job crafting scale. J. Vocat. Behav. 80, 173-186. doi: 10.1016/j.jvb.2011. 05.009

Van den Heuvel, M. (2013). Adaptation to Organizational Change: The Role of Meaning-Making and other Psychological Resources. Utrecht: University of Utrecht.

Van Den Heuvel, M., Demerouti, E., and Bakker, A. B. (2013). How psychological resources facilitate adaptation to organizational change. Eur. J. Work Organiz. Psychol. 23, 37-41. doi: 10.1080/1359432X.2013.817057

Van den Heuvel, M., Demerouti, E., Bakker, A. B., and Schaufeli, W. B. (2010) Personal resources and work engagement in the face of change. Contemp. Occupat. Health Psychol. Glob. Perspect. Res. Pract. 1, 124-150. doi: 10.1002/ 9780470661550.ch7

Van den Heuvel, M., Demerouti, E., and Peeters, M. C. W. (2015). The job crafting intervention: effects on job resources, self-efficacy, and affective well-being. J. Occup. Organiz. Psychol. 88, 511-532. doi: 10.1111/joop.12128

van Zyl, L. E., Efendic, E., Rothmann, S. Sr., and Shankland, R. (2019). "Bestpractice guidelines for positive psychological intervention research design," in Positive Psychological Intervention Design and Protocols for Multi-Cultural Contexts, eds L. E. van Zyl, and S. Rothmann, Sr. (Cham: Springer), 1-32. doi: 10.1007/978-3-030-20020-6_1

Wrzesniewski, A., and Dutton, J. E. (2001). Crafting a job: revisioning employees as active crafters of their work. Acad. Manag. Rev. 26, 179-201. doi: 10.5465/ amr.2001.4378011

Conflict of Interest: The authors declare that the research was conducted in the absence of any commercial or financial relationships that could be construed as a potential conflict of interest.

Copyright (C) 2020 Hulshof, Demerouti and Le Blanc. This is an open-access article distributed under the terms of the Creative Commons Attribution License (CC BY). The use, distribution or reproduction in other forums is permitted, provided the original author(s) and the copyright owner(s) are credited and that the original publication in this journal is cited, in accordance with accepted academic practice. No use, distribution or reproduction is permitted which does not comply with these terms. 


\title{
Coaching-Based Leadership Intervention Program: A Controlled Trial Study
}

\author{
María Josefina Peláez Zuberbuhler*, Marisa Salanova and Isabel M. Martínez \\ WANT Research Team, Universitat Jaume I, Castelló de La Plana, Spain
}

In spite of the potential benefits that coaching-based leadership interventions can bring to organizations, basic questions remain about their impact on developing coaching skills and increasing psychological capital (PsyCap), work engagement and in- and extra-role performance. In a controlled trial study, 41 executives and middle managers (25 in the experimental group and 16 in the waiting-list control group) from an automotive sector company in Spain received pre-assessment feedback, a coaching-based leadership group workshop, and three individual executive coaching sessions over a period of 3 months. The intervention program used a strengths-based approach and the RE-GROW model, and it was conducted by executive coaching psychologists external to the organization. Participants $(N=41)$ and their supervisors $(N=41)$ and employees $(N=180)$ took part in a pre-post-follow up 360-degree assessment during the research period. Quantitative data were analyzed using Analyses of Variance (ANOVA) with a $2 \times 2$ design, paired-samples $t$-tests, and univariate analyses between groups. Results indicated that the intervention program was successful in increasing the participants' coaching-based leadership skills, PsyCap, work engagement, and in- and extrarole performance. Qualitative measures were also applied, and results from individual responses provided additional support for the study hypotheses. Regarding practical implications, the results suggest that the Coaching-based Leadership Intervention Program can be valuable as an applied positive intervention to help leaders develop coaching skills and enhance well-being and optimal functioning in organizations.

Keywords: coaching leadership, psychological capital, work engagement, performance, control trial

\section{INTRODUCTION}

The rapid changes and advances in economic, political, technological, and social factors (Kirchner and Akdere, 2014) require managers in organizations to develop human capital in order to achieve strategic organizational goals (Kim, 2014). This complex and challenging context also creates the need to develop healthy and positive leaders who are able to maintain and optimize psychosocial wellbeing in organizations (Salanova et al., 2012).

Moreover, research increasingly shows that being an effective leader means being an effective coach (Goleman et al., 2012; Grant and Hartley, 2014). Thus, good coaching skills are becoming an

Abbreviations: ANOVA, analyses of variance; EX, experimental group; FUP, follow up time; JD-R, job demands-resources; POST, post-assessment time; PRE, pre-assessment time; PsyCap, psychological capital; WL, waiting-list control group. 
essential part of effective leadership and positive workplace cultures (Ellinger et al., 2011; Stehlik et al., 2014). In such cultures, coaching is the main style of managing and working with others, with a predominant commitment to employees' growth (Underhill et al., 2007; Wood and Gordon, 2009). Currently, organizations are starting to invest in training to develop coaching skills in their managers and leaders (Milner et al., 2018) in order to enhance wellbeing and performance and facilitate organizational and personal change (Ellinger et al., 2003; Wright, 2005; Grant and Cavanagh, 2007a).

Previous studies have highlighted coaching-based leadership (also known as leader-as-coach or managerial coaching) as a key indicator of effective managerial behavior to influence employees without relying on formal authority (Hamlin et al., 2006; Ellinger et al., 2008; Pousa et al., 2018). Specifically, leaders as coaches have been identified as crucial in developing and empowering employees due to the high cost of external coaching and the need to become learning organizations and innovate to stay competitive (Segers et al., 2011; Kim, 2014). For these reasons, organizations are transferring responsibilities of Human Resources Development practitioners, such as coaching, to their leaders (Liu and Batt, 2010; Kim, 2014). In this study, the term coaching-based leadership will be used to refer to the leader, manager, or supervisor in their roles as coaches or when using coaching skills in work settings.

Despite the growing popularity of coaching-based leadership interventions (Milner et al., 2018), the efficacy of these programs and their impact on the development of effective leaders have rarely been assessed (Ellinger et al., 2011; Grant and Hartley, 2014; Berg and Karlsen, 2016). Indeed, previous research has revealed that only one-third of these initiatives are evaluated (Ely et al., 2010). Although there are good initiatives and significant investments in leadership skill development programs, organizations still believe they have not effectively trained their leaders. In fact, they continue to report a lack of leadership skills among their employees (Lacerenza et al., 2017). Research has shown that leaders need at least 3 to 6 months to develop coaching skills and feel comfortable using them (Grant, 2010). So far, very little is known about the benefits of developing a coaching-based leadership style and its impact on work-related outcomes (Berg and Karlsen, 2016) such as psychological capital (PsyCap), work engagement and in-role and extrarole performance.

Moreover, effective methodologies for teaching and training coaching skills in organizations have to be further developed (Ellinger et al., 2003; Segers et al., 2011). There is also a need for empirical studies with strong designs and mixed methodologies (qualitative and quantitative) to investigate possible effects of these intervention programs over time (Grant and Hartley, 2013, 2014). Previous research has highlighted the value of qualitative approaches in the evaluation of the human process of coaching because they can lead to the discovery of novel themes and new insights about a topic under investigation (Coe, 2004; Gyllensten and Palmer, 2007). To address this research gap, we conducted a controlled trial Coaching-based Leadership Intervention Program and explored its impact on leaders' coaching skills, PsyCap, work engagement, and in- and extra-role performance over time, using a 360-degree assessment.

\section{THEORY AND HYPOTHESES}

\section{Defining Coaching-Based Leadership}

Coaching can be understood as a collaborative relationship between coach and coachee, oriented toward facilitating goal attainment and individual change (Spence and Grant, 2007). In the specific work context, coaching is generally provided by the leader as a way to enhance employees' goal achievement and performance through the use of a variety of emotional, cognitive, and behavioral techniques (Grant, 2010). Grounded theoretically in coaching leadership theory, this recently form of leadership has been defined as a day-to-day process of providing support, and helping employees identify opportunities to achieve individual development goals (Cox et al., 2010; Berg and Karlsen, 2016). Leaders who succeed with a coaching style enable employees to gain awareness and reflection, generate their own answers (Cox et al., 2010; Milner et al., 2018), require less control and directing, and have a desire to help them develop and flourish (Berg and Karlsen, 2016). Goleman et al. (2012) suggested that coaching is one of the leadership styles that achieves the best results, and that its main purpose is to develop employees' personal resources. Coaching leaders are oriented toward helping employees strengthen their talents by paying attention to their needs and building an effective alliance (Dello Russo et al., 2017). From a psychosocial perspective, coaching provided by leaders is suggested as an important job (social) resource that facilitate a motivational process that enhances the development of personal resources, leading to work engagement and better performance (Schaufeli and Bakker, 2004).

As noted by Ellinger et al. (2005), the coaching leadership style offers organizations a theoretical foundation for adopting a people-oriented approach in the relationship with employees. This recent theory on leadership has been developing away from other leadership approaches, such as transactional or transformational, toward a new paradigm that seeks to reduce the differentiation between the leader and the employee (Hagen and Aguilar, 2012). For instance, Bass and Avolio's (1994) transformational leadership style is essentially about motivating followers to look beyond their own self-interest toward the achievement of team-related goals (Bormann and Rowold, 2018). In contrast, leaders' coaching behaviors refer to one-on-one interactions between a leader and an employee aimed at stimulating individual growth (Anderson, 2013) and may therefore be more suitable for addressing personal and professional developmental goals (Kunst et al., 2018).

Given the little guidance that coaching-based leaders receive in their own growth and development, along with the limited number of frameworks to support this process, Kemp (2009) emphasized the need for leaders as coaches to be guided by a personal understanding of their expected responses in order to enhance change. This author proposed a coaching and leadership alliance framework to contextualize the coaching leadership process and clarify its role in helping employees to strengthen 
their potential. According to this theoretical proposal, leaders engage in a process similar to that of coaches by engaging in an alliance-building process with employees that leads to a deep sense of shared meaning. As a result of this alliance, the coaching leader facilitates work-related outcomes and fosters new ways to achieve performance.

The coaching leader displays a set of skills or beliefs that can support a coaching mentality that enables the execution of specific actions or behaviors toward their employees (David and Matu, 2013). In order to enhance optimal functioning, organizations increasingly ask their managers and leaders to develop specific skills such as effective communication, empathy, or trust, promote goal achievement, and enhance professional and personal change (Ellinger and Bostrom, 2002; Mai and Akerson, 2003; Grant, 2010; Grant and Hartley, 2013; Berg and Karlsen, 2016). According to the International Coach Federation (n.d.), the leading global coaching organization, essential coaching competencies consist of establishing trust and a working alliance, active listening, powerful questioning, direct communication, designing actions and goal setting, and managing progress. In using coaching skills, leaders enable employees to generate their own answers, thus enhancing development and performance (Grant and O'Connor, 2010; Milner et al., 2018). In the current study, we follow previous literature and research related to the professional coach's skills, the leader- as- coach, and managerial coaching, in order to identify eight core coaching-based leadership skills classified into four dimensions: (a) working alliance: developing a working alliance (1); (b) open communication: active, empathic, and compassionate listening (2), and powerful questioning (3); (c) learning and development: facilitating development (4), providing feedback (5), and strengths spotting and development (6); and (d) progress and results: planning and goal setting (7), and managing progress (8).

\section{Working Alliance}

Developing a working alliance refers to the ability to create a safe environment that contributes to the establishment of mutual respect, sincerity, trust, and transparency (Graham et al., 1994; Gyllensten and Palmer, 2007). Previous coaching and managerial coaching literature has highlighted the essential role of trust in the coaching relationship (Hunt and Weintraub, 2002; Ting and Riddle, 2006; Gregory and Levy, 2011). Effective coaching involves showing genuine interest in employees' wellbeing and future, continually demonstrating sincerity, establishing clear agreements, and keeping promises. This skill is essential for leaders because it allows them to develop partnerships and build warm, friendly relationships with employees (Graham et al., 1994). As a result, shared meaning, purpose and commitment emerges, allowing for high levels of mutual engagement to drive opportunities and achieve performance (Kemp, 2009).

\section{Open Communication}

Open communication is considered one of the key factors leading to effective coaching (Park et al., 2008). This dimension refers to the use of effective communication techniques to establish a good rapport with employees and facilitate personal and professional potential and performance (Gilley et al., 2010). Specifically, leaders as coaches engage in formal or informal conversations using techniques such as asking powerful questions, and active, empathic, and compassionate listening (Whitmore, 1992; Graham et al., 1994; Gilley et al., 2010). Question framing is considered an essential coaching-based leadership behavior that encourages employees to think through issues (Ellinger et al., 2003). Adequate questions are those that stimulate motivation and subsequently elicit deeper awareness and reflection (Kemp, 2009). Likewise, appropriate levels of empathy, understanding, compassion, and acceptance create an environment where employees can feel free to express their emotions and ideas (Graham et al., 1994; Grant and Cavanagh, 2007a; Kemp, 2009). With the leader's help, employees gain awareness, engage in reflection, and increase their ability to take responsibility for their own development (Gilley et al., 2010).

\section{Learning and Development}

Facilitating development refers to the ability to provide support and training to employees in order to encourage their progress and continuous learning and effectively lead them toward the desired results (Park et al., 2008; Berg and Karlsen, 2016). As Ellinger and Bostrom (2002) observed, a predominant behavior in coaching-based leadership involves creating and promoting a learning environment, for instance, by providing feedback and helping employees to identify, build and use personal strengths (Berg and Karlsen, 2016). In doing so, they encourage employees to better direct their talents and abilities toward meaningful and engaging behaviors (Peterson and Seligman, 2004). In essence, employees who use their strengths are more engaged at work (Harter et al., 2002) and more likely to achieve their goals (Linley et al., 2010b).

\section{Progress and Results}

Planning and goal setting refers to the ability to support employees in establishing individual development goals that are valued by them, and ensure that they complete the agreed-upon action steps (Grant and Cavanagh, 2007b). Previous research has indicated that leaders as coaches work collaboratively with each employee to set engaging, challenging goals that motivate performance (Dahling et al., 2016). Finally, managing progress requires leaders to monitor, re-define, and evaluate employee action plans and performance, and manage both responsibilities in the process (Grant, 2003; Grant and Cavanagh, 2007b).

\section{Coaching-Based Leadership Intervention and Its Efficacy}

In their meta-analysis on the impact of leadership, Avolio et al. (2009) defined leadership interventions as focusing on manipulating leadership as the independent variable through training, assignments, or other means. The authors indicated that the most common aim of these interventions is leadership training and development. Further research has suggested that leadership intervention programs should focus on knowledge and skills that can enhance leader effectiveness (Amagoh, 2009). These interventions have generally involved training in a workshop format, participation in executive coaching, or a 
combination of these two approaches (Kelloway and Barling, 2010; Lacerenza et al., 2017).

There has been some question about how leaders can be led to display a coaching-based leadership style. Specifically, leader-as-coach training programs aim to enhance leadership quality in organizations by providing training in coaching skills (Graham et al., 1994; Hagen, 2012; Grant and Hartley, 2014). The increased demand for leaders with coaching skills is generally attributed to the many recognized benefits, such as enhanced employee and organizational performance (Liu and Batt, 2010; Ellinger et al., 2011; Kim et al., 2013; Tanskanen et al., 2019). Additionally, previous studies have identified leaders as coaches as a powerful developmental intervention for motivating, developing, and retaining employees in organizations (Ellinger et al., 2011). Although leaders are often expected to apply coaching principles at work, and many of them express a desire for further training, these developmental programs do not always focus on specific coaching skills. In fact, to be operational, training needs to align these skills with personal and professional goals (Milner et al., 2018).

The second approach involved in leadership interventions, executive coaching, is an increasingly popular approach to help executives develop leadership skills or behaviors and improve their performance and, therefore, the performance of the organization as a whole (Feldman and Lankau, 2005; Gray, 2006). The number of organizations using executive coaching to develop leaders increases every year because it is considered one of the dominant methodologies for developing effective leaders (Grant, 2013). An effective way to support leadership development in organizations is the strengths-based leadership coaching approach (MacKie, 2014). This approach is based on positive psychology discipline, which focuses on developing positive qualities, rather than dealing with negative aspects such as weaknesses and pathologies (Seligman and Csikszentmihalyi, 2014). Strengths-based coaching is based on the identification, development, and use of personal strengths in order to foster positive outcomes such as goal attainment, optimal functioning, fulfillment, and well-being (Linley et al., 2010b). Specifically in leadership development, this approach provides a structure that includes strength awareness and balance, pairing strengths with leadership skills, and aligning them with personal or organizational goals (MacKie, 2014).

The use of coaching behaviors as a performance enhancement method has gained popularity in organizations (Boyatzis et al., 2013; Dimas et al., 2016). However, relatively few empirical studies have attempted to examine the efficacy of training and developing leaders as coaches (Grant, 2006). This is surprising because previous researchers reported that leadership interventions could be useful in developing and improving coaching skills (Styhre, 2008; Ellinger et al., 2010). In one of these studies, David and Matu (2013) found a positive impact of a managerial coaching program on increasing coaching abilities reported by the managers themselves and by external observers. Similarly, in the Cummings et al. (2014) quasi-experimental study, leaders' attitudes and intentions to be a coach increased significantly after participating in a workshop on how to coach their employees.
Although there has been an increase in the number of studies on this topic, there continues to be a call for more empirical investigation on the way leaders are being trained in coaching skills (Milner et al., 2018) and on the effectiveness of these intervention programs. Additionally, there is still a need to develop effective methodologies for training and assessing these interventions (Cavanagh and Grant, 2004; Grant and Hartley, 2013, 2014; Day et al., 2014). To fill this gap, in a controlled trial study, we tested the effects of a Coaching-based Leadership Intervention Program on essential coaching skills. A 360-degree format evaluation was applied that includes self-assessment along with employees' and supervisors' evaluations of the leader's coaching skills. Considering different insights is important in order to have diverse views of the training outcomes and efficacy (Milner et al., 2018).

Hypothesis 1 (H1): Participants' levels of coaching-based leadership skills will increase after the intervention (POST) compared to their baseline levels (PRE) and compared to the waiting-list control group (WL).

\section{Coaching-Based Leadership and PsyCap}

According to the Conservation of Resources theory (Hobfoll, 2002), individuals seek to obtain, retain, and protect personal resources to control and impact upon their environment successfully. Based on this theory, Luthans et al. (2007, 2015) refer to PsyCap as a positive personal resource and defined it as an individual's positive psychological state of development that is comprised of: (1) self-efficacy; having confidence to mobilize the motivation, cognitive resources or courses of action needed to successfully executive challenging tasks; (2) hope: persevering toward goals, and identifying alternative ways to reach goals in order to succeed; (3) resilience: the capacity to bounce back from adversity to attain success; and (4) optimism: making a positive attribution about succeeding in the present and in the future (Luthans et al., 2015). Although these four psychological resources are conceptually distinct, they combined into a higherorder construct in which they interact in a synergetic way. As a result of the investment of such set of psychological resources, individuals obtain experiential rewards from the present moment while also increasing the likelihood of future benefit (Kersting, 2003).

Based on the Job Demands-Resources (JD-R) model, Bakker and Demerouti (2007) claimed that job resources, such as supervisory coaching and opportunities for professional development, play an intrinsic motivational role fostering employees' growth, learning and development, thus suggesting that such job resources foster the development of personal resources. In line with this proposition, Goleman et al. (2012) argued that the main purpose of coaching leaders is to develop employee's personal resources. Leaders do so in daily interactions by paying attention to their employees needs, developing a trust environment, building an effective alliance, and providing personalized learning (Ellinger et al., 2011; Dello Russo et al., 2017). In other words, leaders can foster PsyCap through the use of specific coaching skills. Previous research has shown a positive direct link between job resources such as coaching provided 
by leaders and specific personal resources (i.e., self-efficacy, organizational-based self-esteem and optimism; Xanthopoulou et al., 2007). A recent study has examined and confirmed the positive direct relationship between managerial coaching and employees' PsyCap (Hsu et al., 2019). Furthermore, Pitichat et al. (2018) highlighted the significant relationship between the leaders self-development and their levels of PsyCap, thus resulting in enhanced chances of success at work. However, there is still a lack of studies that empirically examined the impact of a coaching-based leadership intervention on the leaders' PsyCap. This is important because there is growing evidence that PsyCap plays an important role in improving positive work attitudes and behaviors (Luthans et al., 2010).

Hypothesis 2 (H2): Participants' levels of PsyCap will increase after the intervention (POST), compared to PRE and compared to the WL.

\section{Coaching-Based Leadership and Work Engagement}

Research on leadership and coaching that analyses the relationship between coaching skills and well-being related outcomes, such as employees' job satisfaction, is on the rise (Ellinger et al., 2003, 2011; Kim et al., 2013). However, fewer studies have attempted to explore the impact of coaching-based leadership skill training and development on engagement in the work field. Work engagement is defined as a positive, fulfilling, work-related state of mind characterized by three dimensions: (1) vigor: which refers to high levels of energy and mental resilience while working, the willingness to invest effort in one's work, and persistence when facing difficulties; (2) dedication: which refers to strong involvement and psychological identification with one's work, characterized by a sense of significance, enthusiasm, pride, inspiration, and challenges; and (3) absorption: which refers to a state of full concentration and being engrossed in one's activities, where time passes quickly and it becomes difficult to separate oneself from work (Schaufeli et al., 2006). Based on the JD-R model (Bakker and Demerouti, 2007), work engagement arises from a motivational process that begins with the availability of job and personal resources that stimulate employees' motivation and, therefore, leads to desirable work outcomes such as organizational commitment and higher job performance (Llorens-Gumbau and Salanova-Soria, 2014).

Practitioner literature has highlighted the potential of leadership behavior as a key driver in enhancing engagement (Shuck and Herd, 2012). In line with MacLeod and Clarke's (2009) research, leaders promote engagement by providing employees with autonomy, empowerment, and developmental opportunities, offering them coaching and feedback, and ensuring that the work is effectively and efficiently designed. When the leader provides coaching, employees are more engaged with their work because they receive more guidance from their leader in achieving their goals (Kim, 2014). Although there are few studies on this link, research exploring the association between coaching-based leadership and employee work engagement is increasing. For instance, Ladyshewsky and Taplin $(2017,2018)$ found a significant positive relationship between these constructs. Further studies demonstrated a mediating role of work engagement in the relationship between the leader's coaching and performance-related outcomes (Lin et al., 2016; Ali et al., 2018; Lee et al., 2018; Tanskanen et al., 2019). Despite interesting findings, all these studies are crosssectional, and work engagement is evaluated as an employeerelated outcome.

With only one exception (Grant and Hartley, 2014), research exploring the impact of leader-as-coach development programs on increasing the leaders own work engagement is still missing. This is surprising because engagement is generally associated with core aspects of coaching, such as generating meaningful and positive feedback, goal clarity, and effective leader-employee communication (Bakker et al., 2008; Grant and Hartley, 2014). Moreover, previous research has highlighted the positive impact of training on individuals' self-efficacy (Holladay and Quiñones, 2003), which in turn generates the perception of challenging demands, positive job resources, and higher levels of engagement with work (Ventura et al., 2015). Accordingly, when leaders have high levels of energy, vitality, and engagement, they are likely to invest more effort in their activities and tasks and, therefore, in practicing their leadership skills at work (Kark, 2011). Thus, focusing on the leader's work engagement, we hypothesize the following:

Hypothesis 3 (H3): Participants' levels of work engagement will increase after the intervention (POST), compared to PRE and compared to the WL.

\section{Coaching-Based Leadership and In-Role and Extra-Role Performance}

Job performance generally includes two dimensions: in-role or task performance and extra-role or contextual performance. Although other types of job performance may be integrated into the concept, such as adaptive, innovate, or service performance, in this study we focus on in-role and extra-role performance which are considered as key healthy organizational outcomes from a psychosocial perspective (Salanova et al., 2012). In-role performance refers to activities that are related to the formal job and directly serve the goals of the organization (Goodman and Svyantek, 1999). According to the JD-R model, the extrinsic motivational potential of job resources, such as supervisor support, fosters employees to meet their goals, and become more committed to their job because they derive fulfillment from it (Bakker and Demerouti, 2007). Previous research has specified the role of managerial coaching in improving employee inrole performance by clarifying goals and providing resources to achieve them (Kim, 2014; Kim and Kuo, 2015). Leaders who act as role models, deliver instant feedback, and assist employees in the learning processes help to improve employees' task performance. Related to this assumption, previous research revealed a positive and direct link between supervisory coaching skills and employee in-role performance (Ellinger et al., 2003, 2005, 2011; Agarwal et al., 2009; Liu and Batt, 2010). Further studies also found an indirect effect of managerial coaching on task performance (Kim et al., 2013; Kim and Kuo, 2015). 
Whereas in-role performance describes technical core behaviors, extra-role performance denotes actions that exceed what the employee is supposed to do, such as helping others or voluntary overtime (Goodman and Svyantek, 1999). This contextual-related performance refers in part to citizenship behaviors that directly promote the effective functioning of an organization without necessarily directly influencing an employee's productivity (Podsakoff et al., 2000). Specific leader coaching skills, such as open communication with employees (Podsakoff et al., 2000; Bester et al., 2015) and one-on-one interactions, encourage employees to perform extra-role behaviors in the organization (Raza et al., 2017). From a social exchange perspective, the leader- as- coach is considered a form of organizational support (Kim, 2014; Kim and Kuo, 2015) that positively influences organizational citizenship behaviors (Ellinger and Cseh, 2007; Kim and Kuo, 2015).

Previous research has indicated that training to enhance the knowledge, skills, and abilities of individuals leads to an increase in performance in the work setting (Holladay and Quiñones, 2003). Although coaching can be perceived as time-consuming, the development of effective workplace coaching skills leads to increased performance at both managerial and supervisory levels (Graham et al., 1994; Grant, 2010). However, only a few studies have examined the impact of leader coaching skill interventions on job performance (Cummings et al., 2014; Grant and Hartley, 2014; Ratiu et al., 2017). Indeed, recent research has focused more on the effects of coaching-based leadership interventions on employees' performance, rather than examining the impact on the leader's own performance (Grant, 2010). Moreover, the few studies that have examined the impact of leader- as-coach interventions (Moen and Skaalvik, 2009; David and Matu, 2013; Grant and Hartley, 2014; Ratiu et al., 2017) have considered performance as a whole, without distinguishing between task and contextual dimensions. In the current study, we focus on leaders' in-role and extra-role performance as perceived by their supervisors and employees.

Hypothesis 4a (H4a): Participants' levels of in-role performance will increase after the intervention (POST), compared to PRE and compared to the WL.

Hypothesis 4b (H4b): Participants' levels of extra-role performance will increase after the intervention (POST), compared to PRE and compared to the WL.

\section{The Durability of the Effects}

In order to truly assess the effectiveness of an intervention, it is necessary to evaluate whether or not the reported effects are maintained over time (Grant and Hartley, 2013). Despite the significant investment in training programs in leadership skills, organizations continue to report a lack of leadership skills among their employees in the workplace (Lacerenza et al., 2017). Because leaders need time to develop and apply coaching skills in the workplace (Grant, 2010; Grant and Hartley, 2013), it is always a challenging task for facilitators and practitioners to ensure that the skills developed during training are actually transferred to the workplace (Burke and Baldwin, 1999; Grant and Hartley, 2013).
Therefore, previous researchers have highlighted the need to explore the long-term impact of leader-as-coach interventions (Kirchner and Akdere, 2014; Milner et al., 2018). Only a few scholars have demonstrated a long-term sustained influence of a leader-as-coach program on improvements in coaching skills and engagement (Grant and Hartley, 2014).

Not surprisingly, the development of effective methodologies for providing training in coaching-based leadership skills can facilitate positive organizational change, leading to higher levels of productivity and engaging workplace environments (Grant and Hartley, 2013). The majority of the quasi-experimental studies carried out to date have examined the effects of these interventions on performance-related outcomes immediately after participation (Moen and Skaalvik, 2009; Ratiu et al., 2017). However, none of these studies evaluated the long-term sustained impact after a certain number of months had passed (follow up) since the intervention. Thus, in the current study, we attempt to investigate the durability of the intervention program's effects on the outcome variables (coaching-based leadership skills, PsyCap, work engagement, and in- and extra-role performance) over time (FUP; Follow Up time; 4 months after finishing the program).

Hypothesis 5: Participants' levels of coaching-based leadership skills (H5a), PsyCap (H5b), work engagement $(\mathrm{H} 5 \mathrm{c})$, and in- and extra-role performance (H5d), will remain higher at FUP, compared to PRE intervention.

\section{MATERIALS AND METHODS}

\section{Participants and Procedure}

The study was conducted in a multinational automotive industry company in Spain. The plant had 42 managers and middle managers, all of whom were invited to participate in the program through informational meetings held by university researchers. During these meetings, participants were informed about the nature of the study and the aims of the intervention. There were no additional economic rewards or employee benefits in exchange for their involvement in the study. They were asked to take part voluntarily, with the confidentiality of their replies guaranteed, and 41 of them (97\%; 15 managers and 26 middle managers) initially agreed to participate. The study adhered to ethical standards and was approved by the University Research Ethics Committee.

Next, participants were distributed into the experimental group (EX; $N=25$ ) and the waiting-list control group (WL; $N=16$ ). Two simultaneous workshop groups were assigned to the EX, one for the managers $(N=15)$ and the other for the middle managers $(N=10)$, with one person dropping out in each group after the first individual coaching session. The groups were not randomly chosen because the managers have management responsibilities that affect middle managers; therefore, the company decided to separate the two groups. The WL served as an untreated comparison group during the study. After the EX had ended, 15 members of this WL also participated in the intervention program, with only one person dropping out after the workshop ended. Thus, the final sample consisted of 37 
participants $(\mathrm{EX}=23$; $\mathrm{WL}=14)$. For organizational reasons, the WL started the intervention immediately after the EX finished it, rather than waiting until the FUP assessment took place.

Participants $(N=41)$ and their supervisors $(N=41)$ and employees $(N=180)$ were asked to answer an online research questionnaire at different times (three times by the EX and four times by the WL) during the research period: (1) before starting the intervention, the EX (Time1: pre-assessment for the whole intervention group; participants: $N=41$; supervisors: $N=38$; employees: $N=180$ ); (2) immediately after finishing the intervention, the EX, and before the WL started (Time 2: post-assessment for EX and pre-assessment for WL; participants: $N=40$; supervisors: $N=38$; employees: $N=117$ ); (3) immediately after finishing the intervention, the WL (Time 3: post-assessment just for WL; participants: $N=14$; supervisors: $N=14$; employees: $N=53$ ); and 4 months after finishing the intervention each group (Time 4: follow up assessment for the whole intervention group; participants: $N=37$; supervisors: $N=33$; employees: $N=90$ ). All the study variables (coaching-based leadership skills, PsyCap, work engagement, in- and extra-role performance) were assessed at the four different times. Figure 1 outlines the research design of the study.

The participants' coaching-based leadership skills were both self- reported and evaluated by their supervisors and employees, in a 360-degree format. Additionally, only participants assessed their levels of work engagement. Furthermore, supervisors' and employees' ratings of the participants' performance were included in order to obtain an external performance assessment and avoid common method bias. Finally, during the last individual sessions, qualitative data were gathered through open questions.

Regarding the demographic breakdown of the subjects, $88 \%$ were men, with a mean age of 45 years $(S D=9.3$, ranging from 28 to 63$)$. Moreover, $100 \%$ had a tenured contract, and the average tenure in the company was 16.5 years $(\mathrm{SD}=10.8)$.

\section{Coaching-Based Leadership Intervention Program Description}

Participants took part in a "Coaching-based Leadership Intervention Program" over a period of 3 months. The main goal of the program was to support the development and improvement of the managers' and middle managers' coaching skills. The intervention was delivered in a group workshop format, followed by three individual executive coaching sessions.

The group workshop consisted of five 180-min weekly group sessions. In the first session, feedback about the PRE-assessment questionnaire results (coaching-based leadership skills, PsyCap, work engagement, and in- and extra-role performance variables) was given. Next, participants received academic input related to positive organizational psychology (Salanova et al., 2016) and emotional appraisal and regulation, given that every leader has to have the ability to manage his/her emotions and consider others' emotions when directing actions (Goleman et al., 2012). Previous research considered emotional regulation to be an important factor influencing general leadership effectiveness (Gooty et al., 2010). Next, participants received emotional regulation practice based on role-playing activities and mindfulness techniques (Tan, 2012; Kashdan and Ciarrochi, 2013; Hanson, 2017). By receiving training in this generic leadership skill, participants were then prepared to receive training in specific coaching skills. In addition, a booklet was provided that contained work slogans, relevant information for each week's instruction, and suggested reading materials.

The following four sessions combined academic input and practicing a coaching-based leadership skillset through role-playing among participants and with the use of the skills on-the-spot with their employees. Based on the pre-assessment results and the workshop contents, during session 2 participants established a goal related to the development or improvement of their coaching-based leadership skills. Additionally, they received theory and practice related to developing a working alliance (Gyllensten and Palmer, 2007; Acosta Antognoni et al., 2012) and open communication (Whitmore, 1992; Neff, 2003; Hoffman et al., 2008; Tan, 2012; Boyatzis et al., 2013; Gilbert, 2013) skills. During session 3, theory and practice related to facilitate development, providing feedback and strengths spotting and development skills was delivered (Park et al., 2008; Berg and Karlsen, 2016). During this session, participants worked on the identification, development and use of personal strengths, based on the VIA (Values In Action) inventory of strengths, the identification of strengths through answering open questions (e.g., "of what are you most proud?") in pairs, and the establishment of a strengths in action plan to be developed at work (Peterson and Seligman, 2004; Biswas-Diener, 2010;

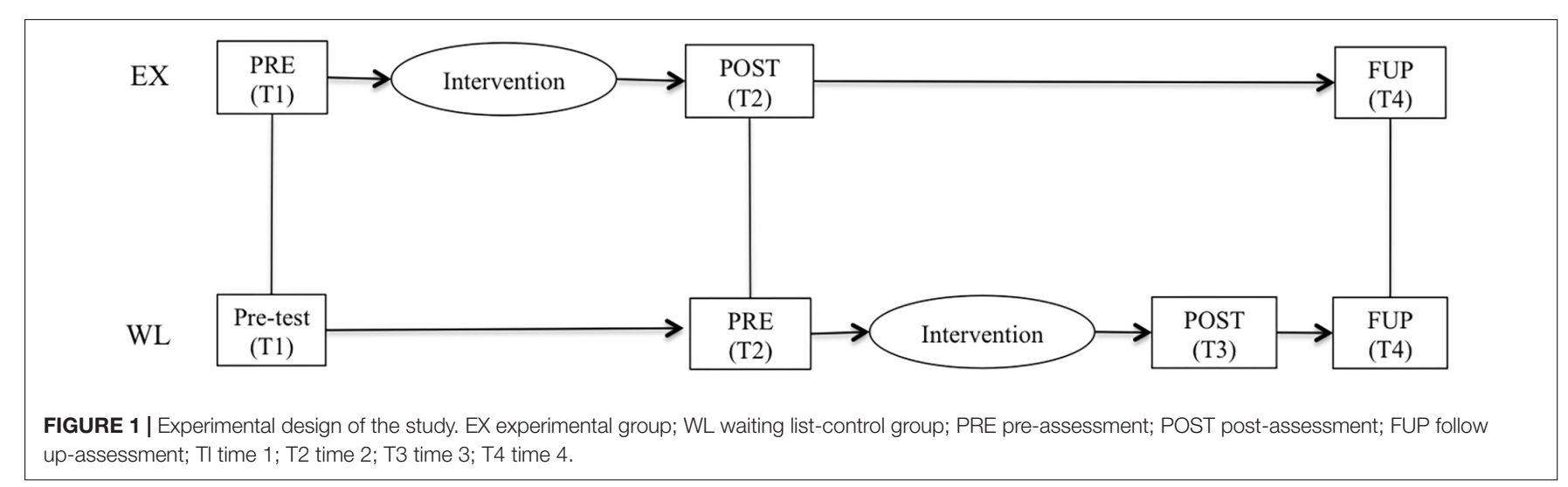


Meyers and van Woerkom, 2017). During session 4, the participants received academic inputs and practice related to planning goals and managing progress skills (Grant, 2003; Grant and Cavanagh, 2007b). Based on the Goal, Reality, Option, Wrap-up (GROW) model (Grant, 2011), the participants explored options in order to achieve the goal set during session 2, and established an action plan to be reviewed during the individual coaching process. Finally, a brief 2 -h closing session took place with the objective of savoring the positive experiences that occurred during the workshop. A future 'best possible self' (Peters et al., 2013) visualization exercise related to developing a coaching-based leadership style was delivered to strengthen the resulting improvements and foster the motivation to continue working on goal achievement during the coaching process. Participants also gave written qualitative feedback about their experiences in the workshop and the key learning points. The specific workshop contents and structure are presented in Table 1.

After the workshop, the participants went through an executive micro-coaching process based on a previous validated strengths-based micro-coaching intervention (see Peláez et al., 2019), which consisted of three biweekly 90-min individual sessions with a professional coaching psychologist external to the organization. Previous research has confirmed that coaching can be effective even when the number of coaching sessions is relatively low (Theeboom et al., 2014; Peláez et al., 2019). The individual coaching sessions aim to support participants during the development of an action plan related to the goal they set during the workshop, related to the improvement of their coaching skills. The coaching process followed a strengths-based leadership coaching approach, based on the identification, development, and use of personal strengths (Govindji and Linley, 2007; Linley et al., 2010b) and alignment with leadership skills (MacKie, 2014) to foster positive outcomes.

Based on the coaching literature (Spence and Grant, 2007), the strengths-based coaching approach (Govindji and Linley, 2007) and the Review, Evaluate, Goal, Reality, Option, Wrapup (RE-GROW) model (see Whitmore, 1992; Grant, 2011 for further review), the coaching process was structured in seven phases: (1) feedback and insight into PRE-assessment results; (2) establishing specific goals related to the development or improvement of coaching-based leadership skills; (3) awareness and development of personal strengths; (4) identifying options in order to achieve the goal; (5) formulating an action plan based on the use of personal resources and strengths for goal achievement; (6) reviewing and evaluating progress: each coaching session started with a process of monitoring and evaluating the learning and actions completed since the last session; and (7) modifying action plans based on the previous evaluation. Finally, between sessions, specific exercises were used to practice the skill set they were developing at work. The Coaching-based Leadership Intervention Program model is summarized in Figure 2.

\section{Measures}

\section{Coaching-Based Leadership Skills}

Based on the existing literature and research, a 12-item scale assessing eight essential coaching-based leadership skills

TABLE 1 | Specific workshop session contents.

\begin{tabular}{|c|c|c|}
\hline $\begin{array}{l}\text { Workshop } \\
\text { session no }\end{array}$ & Topics & Activities \\
\hline 1 & $\begin{array}{l}\text { Positive psychology and coaching-based leadership } \\
\text { skills } \\
\text { Workplace coaching } \\
\text { Emotion appraisal and regulation as a generic } \\
\text { leadership skill }\end{array}$ & $\begin{array}{l}\text { Welcome: presentation, objectives, structure and } \\
\text { internal rules of the program } \\
\text { Pre-assessment results: feedback and reflection } \\
\text { Role-playing and mindfulness practice } \\
\text { Booklet provided with work-session slogans, the } \\
\text { week's instruction, and suggested reading materials }\end{array}$ \\
\hline 2 & $\begin{array}{l}\text { GROW Model: phase 1: Goal setting (SMART+goals) } \\
\text { Skill no 1: Development of a working alliance } \\
\text { Skill no 2: Active, empathic, and compassionate } \\
\text { listening } \\
\text { Skill no 3: Powerful questioning }\end{array}$ & $\begin{array}{l}\text { Brief mindfulness practice } \\
\text { Role-playing in pairs: setting goal related to the } \\
\text { development and/or progress of coaching-based } \\
\text { leadership skills } \\
\text { Self-compassion test results and reflection } \\
\text { Role-playing in pairs: practicing effective listening and } \\
\text { questioning }\end{array}$ \\
\hline 3 & $\begin{array}{l}\text { Skill no 4: Facilitate development } \\
\text { Skills no 5: Providing feedback } \\
\text { Skill no 6: Strengths spotting and development } \\
\text { GROW Model: phase 2: Examine Reality: Personal } \\
\text { strengths, weaknesses, opportunities and threats (or } \\
\text { limitations) }\end{array}$ & $\begin{array}{l}\text { Brief mindfulness practice } \\
\text { VIA inventory of strengths results and reflection } \\
\text { Role-playing in pairs: detect and develop strengths } \\
\text { Choice of key personal strengths. Strengths in action } \\
\text { Role-playing: practicing structured feedback process }\end{array}$ \\
\hline 4 & $\begin{array}{l}\text { GROW Model: phase 3: Explore Options, and phase } \\
\text { 4: Establish the Will. } \\
\text { Skill no 7: Planning and goal setting } \\
\text { Skill no 8: Managing progress }\end{array}$ & $\begin{array}{l}\text { Table of alternatives: advantages and disadvantages } \\
\text { Action plan: establish and develop an action plan for } \\
\text { goal achievement }\end{array}$ \\
\hline 5 & Closing, review, and reflection & $\begin{array}{l}\text { Topics, booklet exercises and field weekly review } \\
\text { Follow-up of the action plan } \\
\text { Future BPS (Best Possible Self) exercise and } \\
\text { visualization }\end{array}$ \\
\hline
\end{tabular}

Homework

Self-compassion test (online) Field weekly to practice emotion appraisal and regulation

VIA Inventory of Strengths (online) Field weekly to practice skill no 1 and skill no 2

SWOT: analysis of Strengths, Weaknesses, Opportunities and Threats

Field weekly to practice skill no 3

Field weekly to practice skill no 4

Public image: ask co-workers and employees to complete files with strengths and improvement areas 


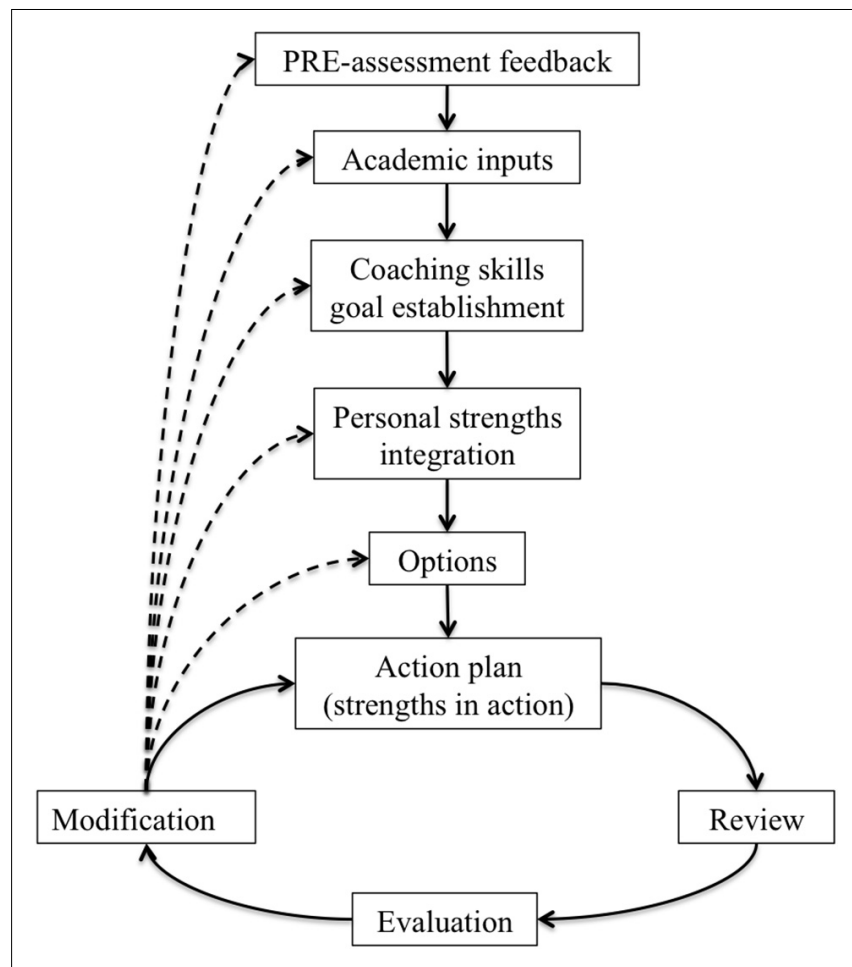

FIGURE 2 | Coaching-based leadership intervention program model.

classified into four dimensions was developed for the purpose of this particular study: (1) Working alliance, which consists of one skill (developing a working alliance) with two items based on the genuineness of the relationship subscale of the full Perceived Quality of the Employee Coaching Relationship scale (Gregory and Levy, 2010); (2) Open communication, which consists of two skills: active, empathic, and compassionate listening with three items based on the Compassionate Scale (Pommier, 2010) and powerful questioning with one item based on the communication dimension of the Coaching Skills Scale (Baron and Morin, 2009; (3) Learning and development, which consists of three skills: facilitate development and providing feedback with one item each based on the facilitate development subscale of the Managerial Coaching Skills Scale (Park et al., 2008), and strength spotting and development, with one item based on the ability and application subscales of The Strength Spotting Scale (Linley et al., 2010a); and (4) Progress and results, which consists of two skills: planning and goal setting and manage progress with one item each based on the Goal-Focused Coaching Skills Questionnaire (Grant and Cavanagh, 2007b). Sample items are listed in the Supplementary Appendix representing each dimension. Participants were asked to respond using a Likert scale ranging from 0 (strongly disagree) to 6 (strongly agree). The same measure was administrated to participants' employees and supervisors, but in this case, respondents were asked to think about their perception of the participants' skills. The scale was adapted and reworded, so that the referent was the leader who participated in the intervention (i.e., "He/she is able to...").
The revised scale was next tested using confirmatory factor analysis via Mplus and reliability tests using SPSS. Confirmatory factor analysis was constrained to a four-factor model and resulted in an acceptable fit to the data in almost all indicators (self-reported scores: $\chi^{2}=86.252$; d.f. $=48 ; p=0.00$; TLI $=0.87$; CFI $=0.90 ;$ RMSEA $=0.08 ;$ WRMR $=0.813 ;$ supervisors' scores: $\chi^{2}=88.702$; d.f. $=48 ; p=0.00$; TLI $=0.97$; CFI $=0.98$; RMSEA $=0.09$; WRMR $=0.734$; employees' scores: $\chi^{2}=104.150$; d.f. $=48 ; p=0.00$; TLI $=0.99 ;$ CFI $=0.99$; RMSEA $=0.08$; WRMR $=0.538$ ). Additionally, the coefficient alpha for the whole scale showed high levels of internal consistency: 0.85 for self-reported scores, 0.94 for supervisors' scores, and 0.97 for employees' scores. The values for each dimension analyzed separately also indicated acceptable consistency: developing a working alliance (self-reported scores $=0.64$; supervisors' scores $=0.91$; employees' scores $=0.91$ ); open communication (self-reported scores $=0.79$; supervisors' scores $=0.83$; employees' scores $=0.93$ ); facilitating learning and development (self-reported scores $=0.79$; supervisors' scores $=0.86$; employees' scores $=0.93)$; manage progress and results (self-reported scores $=0.81$; supervisors' scores $=0.93$; employees' scores $=0.93$ ).

\section{Work Engagement}

This variable was measured using the 9-item short version of the Utrecht Work Engagement Scale (Schaufeli et al., 2006). The scale consists of three dimensions (vigor, dedication, and absorption) with three items each (i.e., "At my work, I feel bursting with energy"; vigor). All the items were rated on a Likert scale ranging from 0 (almost never) to 6 (almost always).

\section{Psychological Capital}

This construct was assessed by the Psychological Capital Questionnaire (PCQ-12; Avey et al., 2011), adapted from the PCQ-24 scale (Luthans et al., 2007). The scale consists of 12 items with four dimensions (self-efficacy, measured with three items; hope, measured with four items; resilience, measured with three items; and optimism, assessed by two items (i.e., "I look on the bright side of things regarding this situation"; optimism). Participants were asked to rate each of the statements using a Likert scale ranging from 0 (strongly disagree) to 5 (strongly agree).

\section{In- and Extra-Role Performance}

This variable was assessed by six items included in the HERO (HEalthy and Resilient Organizations) questionnaire (Salanova et al., 2012), adapted from Goodman and Svyantek's (1999) scale. Two different dimensions (in-role performance and extra-role performance) were considered, with three items in each (i.e., "He/she helps other employees with their work when they have been absent"; extra-role performance). Participants' supervisors and employees were asked to rate each of the statements individually using a Likert scale ranging from 0 (strongly disagree/never) to 6 (strongly agree/always).

\section{Qualitative Measure}

In order to obtain data about their personal experiences with the program, participants were asked to respond to the 
following question during the last coaching session: "What specific positive outcomes (if any) did you gain from participating in this program?" The use of an open-question methodology is an important point in this study because it allows the participants to determine which issues they consider most beneficial (Grant and Hartley, 2014).

\section{Data Analyses}

Different data analyses were conducted. First, internal consistencies (Cronbach's alpha), descriptive analysis, and intercorrelations among the study variables were calculated. Then, one-factor Analyses of Variance (ANOVA) were performed, using SPSS, to discover whether there were significant differences between the executives and middle managers within the EX at the three evaluation times (PRE, POST, and FUP). Next, the same analyses were applied to examine whether there were significant differences in the study variables between the EX and WL prior to the intervention.

In order to test the effects of the intervention program, data were analyzed using $2 \times 2$ repeated-measures ANOVA, consisting of one between-subjects factor (group: EX, WL) and one within-subjects factor (time: Time 1; T1, and Time 2; T2). In this comparison, T1 refers to the first pre-intervention assessment for both EX and WL, whereas T2 refers to the post-intervention assessment for EX and the second pre-intervention assessment for WL, just before this group starts the program. The FUP time factor could not be considered when comparing the two groups. For organizational reasons, the WL had completed the intervention before the EX filled out the FUP assessment.

For supervisors' data, the same analyses were performed as in the self-reported data. However, for the employees' data, because responses were not identifiable, $2 \times 2$ repeatedmeasures could not be performed, and so univariate analysis was applied to employees' scores to examine interaction effects by comparing the whole means between T1-T2 for each group (EX and WL) separately.

Moreover, once the WL group had completed the intervention program, paired-sample $t$-tests were carried out for the whole intervention group ( $\mathrm{EX}$ and $\mathrm{WL} ; N=37$ ) to test for differences between PRE, POST, and FUP time factors. In this comparison, T1 referred to the PRE assessment for the EX, whereas T2 referred to the PRE assessment for the WL, that is, the evaluation applied just before this latter group started the intervention. For these analyses, both self-reported and supervisors' scores were used. Next, to test for differences in employees' scores across the three time factors, univariate analyses were performed.

Following Cohen (1988), eta squared in the repeated-measures ANOVA and Cohen's $d$ as a measure of effect sizes (small effect $=0.1-0.3$; moderate or intermediate effect $=0.3-0.5$; large effect $=>0.5$ ) in paired-sample $t$-tests were estimated, in addition to $t$-test comparisons between groups.

Finally, qualitative data on the outcomes of the intervention program were analyzed using the interpretive content analysis, proposed for coding texts into categories and counting the frequencies in each category (Ahuvia, 2001). This method is used to analyze categories and obtain conclusions based on a previous theoretical framework (Denecke and Nejdl, 2009). First, each leader's response was carefully analyzed and incorporated into a database. Next, responses were systematically classified and grouped according to thematic content. At this stage, a construction of themes emerged for the whole group of participants. Finally, the frequency of each emerging theme was estimated.

\section{RESULTS}

Means, standard deviations, internal consistencies (Cronbach's alpha), and correlations among the study variables for PRE, POST and FUP intervention scores are shown in Table 2 for selfreported scores, Table 3 for supervisors' scores, and Table 4 for employees' scores. Next, one-factor ANOVA results showed that there were no significant differences in self-reported variables between the executives and middle managers in the EX at the PRE intervention time [coaching-based leadership skills: $F(1,24)=0.31 ; p=0.58$, ns; PsyCap: $F(1,24)=1.92 ; p=0.18$, $n s$; work engagement: $F(1,24)=0.17 ; p=0.68, n s]$. Moreover, one-factor ANOVA results comparing the EX and WL revealed

TABLE 2 | PRE, POST, and FUP self-reported means, standard deviations, internal consistencies, and correlations of all variables for the whole intervention group.

\begin{tabular}{|c|c|c|c|c|c|c|c|c|c|c|c|c|}
\hline Variables & M & SD & $\alpha$ & 1 & 2 & 3 & 4 & 5 & 6 & 7 & 8 & 9 \\
\hline \multicolumn{13}{|l|}{ PRE intervention scores } \\
\hline 1. Coaching-based leadership skills & 4.80 & 0.48 & 0.85 & - & & & & & & & & \\
\hline 2. PsyCap & 4.15 & 0.44 & 0.82 & $0.57^{\star \star}$ & - & & & & & & & \\
\hline 3. Work engagement & 4.85 & 0.71 & 0.86 & $0.52^{\star \star}$ & $0.56^{\star \star}$ & - & & & & & & \\
\hline \multicolumn{13}{|l|}{ POST intervention scores } \\
\hline 4. Coaching-based leadership skills & 4.92 & 0.41 & 0.84 & $0.68^{\star \star}$ & $0.43^{\star *}$ & $0.26^{\star}$ & - & & & & & \\
\hline 5. PsyCap & 4.40 & 0.33 & 0.79 & $0.21^{*}$ & $0.45^{\star *}$ & $0.27^{*}$ & $0.35^{\star}$ & - & & & & \\
\hline 6. Work engagement & 5.12 & 0.55 & 0.93 & 0.13 & $0.33^{\star \star}$ & $0.73^{\star \star}$ & $0.31^{*}$ & $0.43^{\star \star}$ & - & & & \\
\hline \multicolumn{13}{|l|}{ FUP intervention scores } \\
\hline 7. Coaching-based leadership skills & 4.97 & 0.53 & 0.92 & $0.67^{\star \star}$ & $0.54^{\star *}$ & $0.33^{*}$ & $0.58^{\star \star}$ & $0.38^{*}$ & 0.12 & - & & \\
\hline 8. PsyCap & 4.27 & 0.47 & 0.87 & $0.28^{*}$ & $0.38^{\star *}$ & $0.22^{\star}$ & 0.15 & $0.52^{\star \star}$ & 0.27 & $0.56^{\star \star}$ & - & \\
\hline 9. Work engagement & 4.96 & 0.74 & 0.90 & 0.11 & $0.20^{\star}$ & $0.38^{*}$ & 0.13 & $0.23^{*}$ & $0.53^{\star \star}$ & $0.24^{\star}$ & $0.45^{\star \star}$ & - \\
\hline
\end{tabular}

Correlations; ** $p<0.01 ;{ }^{*} p<0.05$. 
TABLE 3 | PRE, POST, and FUP supervisor score means, standard deviations, internal consistencies, and correlations of all variables for the whole intervention group.

\begin{tabular}{|c|c|c|c|c|c|c|c|c|c|c|c|c|}
\hline Variables & $\mathbf{M}$ & SD & $\alpha$ & 1 & 2 & 3 & 4 & 5 & 6 & 7 & 8 & 9 \\
\hline \multicolumn{13}{|l|}{ PRE intervention scores } \\
\hline 1. Coaching-based leadership skills & 4.21 & 0.90 & 0.94 & - & & & & & & & & \\
\hline 2. In-role performance & 4.69 & 0.96 & 0.94 & $0.66^{\star \star}$ & - & & & & & & & \\
\hline 3. Extra-role performance & 5.00 & 0.96 & 0.90 & $0.62^{* \star}$ & $0.71^{\star \star}$ & - & & & & & & \\
\hline \multicolumn{13}{|l|}{ POST intervention scores } \\
\hline 4. Coaching-based leadership skills & 4.51 & 0.84 & 0.93 & $0.88^{* *}$ & $0.58^{\star \star}$ & $0.53^{\star \star}$ & - & & & & & \\
\hline 5. In-role performance & 4.90 & 0.75 & 0.87 & $0.65^{\star \star}$ & $0.82^{\star \star}$ & $0.67^{\star \star}$ & $0.65^{\star \star}$ & - & & & & \\
\hline 6. Extra-role performance & 5.22 & 0.69 & 0.83 & $0.39^{*}$ & $0.38^{*}$ & $0.66^{\star \star}$ & $0.49^{\star \star}$ & $0.55^{\star \star}$ & - & & & \\
\hline \multicolumn{13}{|l|}{ FUP intervention scores } \\
\hline 7. Coaching-based leadership skills & 4.6 & 0.86 & 0.94 & $0.78^{\star \star}$ & $0.72^{\star \star}$ & $0.46^{\star \star}$ & $0.79^{\star \star}$ & $0.65^{\star \star}$ & $0.33^{\star}$ & - & & \\
\hline 8. In-role performance & 5.00 & 0.94 & 0.93 & $0.39^{*}$ & $0.72^{\star \star}$ & $0.51^{\star \star}$ & $0.45^{\star \star}$ & $0.61^{\star \star}$ & $0.34^{*}$ & $0.73^{\star \star}$ & - & \\
\hline 9. Extra-role performance & 5.14 & 0.72 & 0.81 & $0.48^{\star \star}$ & $0.56^{\star \star}$ & $0.67^{\star \star}$ & $0.58^{\star \star}$ & $0.66^{\star \star}$ & $0.77^{\star *}$ & $0.55^{\star \star}$ & $0.61^{\star *}$ & - \\
\hline
\end{tabular}

Correlations; ${ }^{* *} p<0.01 ;{ }^{*} p<0.05$.

TABLE 4 | PRE, POST, and FUP employee score means, standard deviations, internal consistencies, and correlations of all variables for the whole intervention group.

\begin{tabular}{lcccccc}
\hline Variables & M & SD & $\alpha$ & $\mathbf{1}$ & $\mathbf{2}$ & $\mathbf{3}$ \\
\hline PRE intervention scores & & & & & & \\
1. Coaching-based leadership skills & 4.19 & 1.38 & 0.97 & - & & \\
2. In-role performance & 4.55 & 1.26 & 0.94 & $0.84^{\star \star}$ & - & \\
3. Extra-role performance & 4.32 & 1.35 & 0.87 & $0.82^{\star \star}$ & $0.83^{\star \star}$ & - \\
POST intervention scores & & & & & & \\
1. Coaching-based leadership skills & 4.76 & 0.95 & 0.96 & - & & \\
2. In-role performance & 4.94 & 1.03 & 0.94 & $0.79^{\star \star}$ & - & \\
3. Extra-role performance & 4.82 & 1.03 & 0.87 & $0.76^{\star}$ & $0.81^{\star \star}$ & - \\
FUP intervention scores & & & & & & \\
1. Coaching-based leadership skills & 4.98 & 0.66 & 0.92 & - & & \\
2. In-role performance & 5.23 & 0.81 & 0.86 & $0.66^{\star \star}$ & & - \\
3. Extra-role performance & 5.14 & 0.76 & 0.79 & $0.54^{\star \star}$ & $0.79^{\star \star}$ & -
\end{tabular}

Correlations; ${ }^{* *} p<0.01 ;{ }^{*} p<0.05$.

no significant differences between the two groups on the same variables at PRE intervention [coaching-based leadership skills: $F(1,40)=0.24 ; p=0.88, n s ;$ PsyCap: $F(1,40)=0.41 ; p=0.53$, ns; work engagement: $F(1,40)=0.86 ; p=0.36]$. With these results, we proceeded to carry out the study with both groups included in the same sample.

\section{Coaching-Based Leadership Skills}

A repeated-measures ANOVA for coaching-based leadership skills showed no significant time $(\mathrm{T} 1, \mathrm{~T} 2) \times \operatorname{group}(\mathrm{EX}, \mathrm{WL})$ interaction effects $[F(1,38)=2.11 ; p=0.15, n s]$ for self-reported scores, although the levels were higher at T2 than at T1. Paired sample $t$-tests results for EX separately indicated no significant differences from T1 to T2 $[t(23)=-1.883 ; n s]$ for self-reported scores. However, results showed significant differences from T1 to T4 (FUP) for this variable $[t(22)=-2.604, p<0.05, d=1.11)]$, demonstrating a large effect size. Moreover, paired sample $t$-test results for WL indicated no significant differences from T1 to T2 $[t(15)=-0.330 ; n s]$, as expected.
Results for supervisors' scores indicated a significant time $(\mathrm{T} 1, \mathrm{~T} 2) \times$ group $(\mathrm{EX}, \mathrm{WL})$ interaction effect $[F(1,33)=17.78$, $\left.p<0.001, \eta_{\mathrm{p}}{ }^{2}=0.054\right]$, indicating statistically higher levels at T2 compared to T1. This result had an intermediate effect size. Paired sample $t$-tests results for EX separately indicated significant differences from T1 to T2 $[t(19)=-5.233, p<0.001$, $d=2.40)]$ and from T1 to T4 (FUP) $[t(18)=-5.316, p<0.001$, $d=2.50)$ ], demonstrating large effect sizes. Whereas paired sample $t$-test results for WL indicated no significant differences from $\mathrm{T} 1$ to $\mathrm{T} 2[t(14)=-0.636 ; n s]$, as expected.

Additionally, univariate analysis of this variable was performed on employees' scores to compare time factors for each group separately. Results showed that the EX group had significantly higher scores at T2 compared to T1 $[t(195)=-2.31$, $p<0.05, d=0.33$ ], with a intermediate effect size, whereas the WL group did not differ significantly from $\mathrm{T} 1$ to $\mathrm{T} 2$ $[t(113)=-0.49 ; n s]$, as expected. Figure 3 shows plotted means for each time factor (T1, T2) across the groups (EX, WL) for self-reported, supervisors', and employees' scores.

Finally, paired-sample $t$-test results for the whole intervention group $(N=41)$ after the WL had completed the program indicated significant differences in the self-reported coachingbased leadership skills variable from PRE to POST $[t(37)=-2.07$, $p<0.05, d=0.68]$ and from PRE to FUP $[t(37)=-2.07, p<0.05$, $d=0.70]$. In both cases, levels were significantly higher at the endpoint compared to baseline, and the effect sizes reported were moderate. In the case of supervisors' scores, results also showed statistically significant higher levels at POST compared to PRE $[t(34)=-4.08, p<0.001, d=1.39]$, and at FUP compared to PRE $[t(32)=-3.51 p<0.001, d=1.24]$, with large effect sizes. Additionally, results from univariate analyses of employees' scores indicated that the whole intervention group had significantly higher scores at POST $[t(276)=-3.75$, $p<0.001, d=0.45]$ and FUP $[t(252)=-4.93, p<0.001, d=0.62]$, compared to PRE, with intermediate effect sizes.

\section{PsyCap}

A repeated-measures ANOVA of PsyCap showed a significant time $(\mathrm{T} 1, \mathrm{~T} 2) \mathrm{x}$ group $(\mathrm{EX}, \mathrm{WL})$ interaction effect for selfreported scores $\left[F(1,38)=6.78 p<0.05, \eta_{\mathrm{p}}^{2}=0.15\right]$, with a 

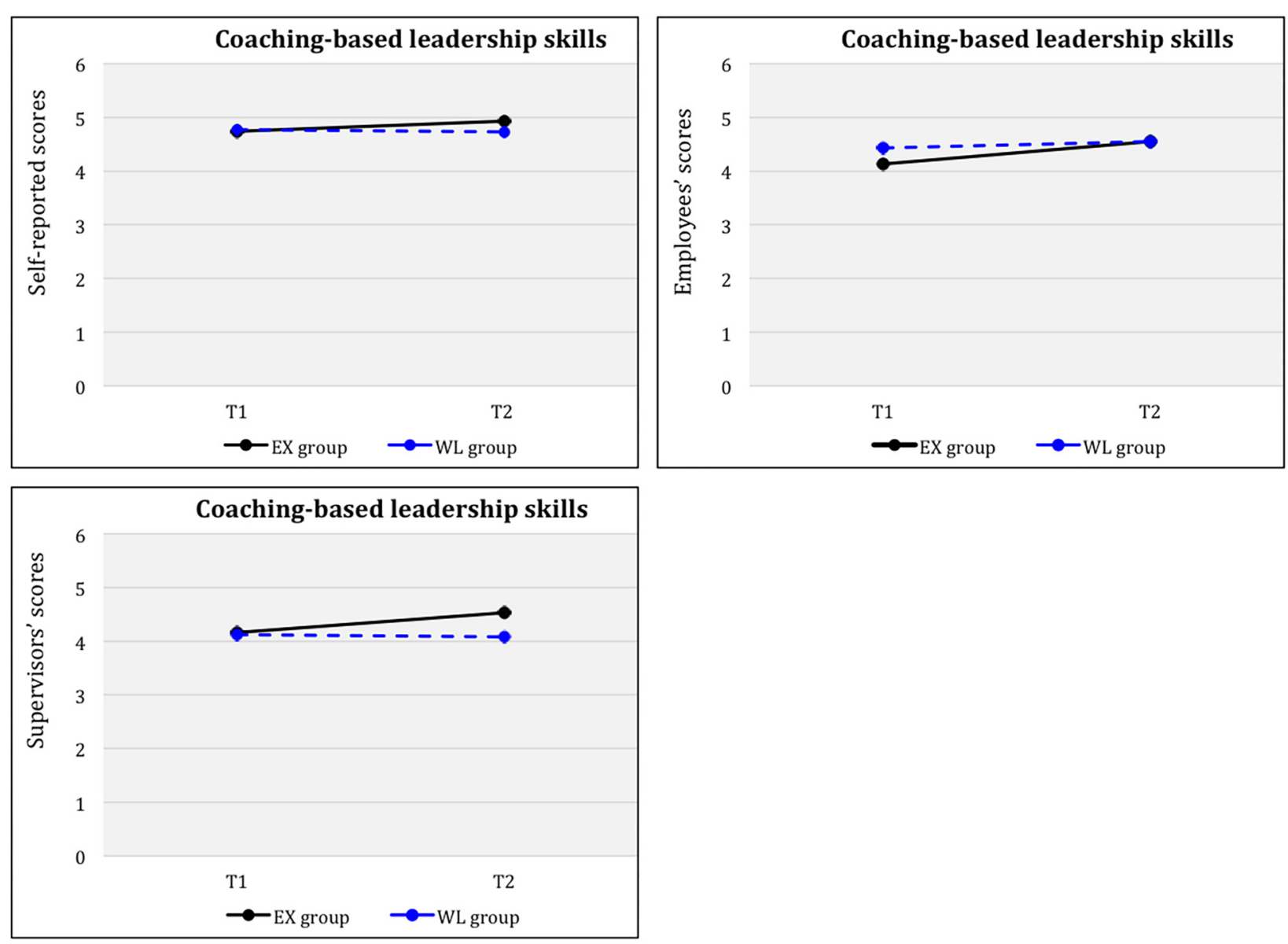

FIGURE 3 | Coaching-based leadership skills for groups (EX, WL) across time (TI, T2).

large effect size. Results indicated that the EX had statistically significant higher PsyCap scores than the WL at T2. Figure 4 shows plotted means for each time factor (T1, T2) across the groups (EX, WL) for self-reported scores. Paired sample $t$-tests results for EX separately indicated significant differences from $\mathrm{T} 1$ to $\mathrm{T} 2[t(23)=-3.699, p<0.001, d=1.54)]$ and from $\mathrm{T} 1$ to T4 (FUP) $[t(22)=-2.798, p<0.001, d=1.19)]$, demonstrating large effect sizes. Additionally, paired sample $t$-test results for WL indicated no significant differences from T1 to T2 $[t(15)=0.629$; $n s]$, as expected.

Furthermore, paired-sample $t$-test results for the whole intervention group $(N=41)$ after the WL had completed the program indicated significantly higher self-reported scores for PsyCap at POST compared to PRE $[t(37)=-3.65 p<0.001$, $d=1.20$ ], with a large effect size. However, results showed no significant differences between PRE and FUP $[t(34)=-0.94$ $p=0.35 ; n s]$, although the levels were higher at FUP.

\section{Work Engagement}

A repeated-measures ANOVA of work engagement showed a significant time $(\mathrm{T} 1, \mathrm{~T} 2) \mathrm{x}$ group $(\mathrm{EX}, \mathrm{WL})$ interaction effect for self-reported scores $\left[F(1,38)=10.9, p<0.005, \eta_{\mathrm{p}}{ }^{2}=0.19\right]$, with a large effect size. Results indicated that the EX had statistically significant higher work engagement scores than the WL at T2. Figure 4 shows plotted means for each time factor (T1, T2) across the groups (EX, WL) for self-reported scores. Moreover, paired sample $t$-tests results for EX separately indicated significant differences from T1 to T2 $[t(23)=-3.759, p<0.05, d=1.56)]$, demonstrating a large effect size. However, results showed no significant differences from T1 to T4 (FUP) for this variable $[t(23)=-1.024 ; n s]$. Additionally, paired sample $t$-test results for WL indicated no significant differences from $\mathrm{T} 1$ to $\mathrm{T} 2$ $[t(15)=1.374 ; n s]$, as expected.

Finally, paired-sample $t$-test results for the whole intervention group $(N=41)$ after the WL had completed the program indicated significantly higher self-reported scores for work engagement at POST compared to PRE $[t(37)=-3.42 p<0.05$, $d=1.12]$, with a large effect size. However, results showed no significant differences between PRE and FUP $[t(37)=-0.54 ; n s]$, although the levels were higher at FUP.

\section{In-Role and Extra-Role Performance}

A repeated-measures ANOVA for performance showed no significant time $(\mathrm{T} 1, \mathrm{~T} 2) \mathrm{x}$ group $(\mathrm{EX}, \mathrm{WL})$ interaction effects 

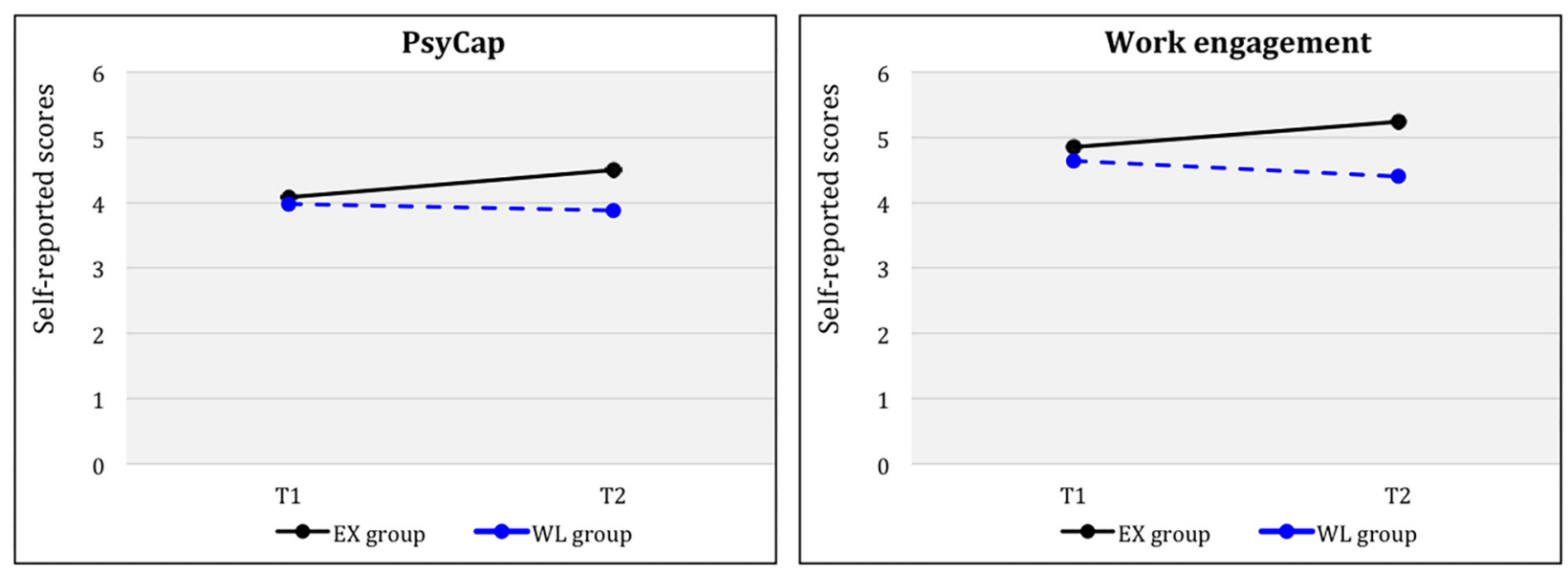

FIGURE 4 | PsyCap and work engagement for groups (EX, WL) across time (TI, T2).

for supervisors' scores [in-role performance: $F(1,33)=1.88$; $p=0.17, n s$; extra-role performance: $F(1,33)=1.7 ; p=0.2$, $n s]$, although the levels were higher at T2 compared with T1. Moreover, paired sample $t$-tests results for EX separately indicated no significant differences from T1 to $\mathrm{T} 2[t(19)=-1.831 ; n s)]$, and significant differences from T1 to T4 (FUP) $[t(18)=-2.394, p<0.01, d=1.13$ )], demonstrating a large effect size, for in-role performance. Additionally, results for extra-role performance for this group indicated significant differences from $\mathrm{T} 1$ to $\mathrm{T} 2$ $[t(19)=-1.945, p<0.05, d=0.89)]$ and from T1 to T4 (FUP) $[t(18)=-1.932, p<0.05, d=0.91)]$ demonstrating large effect sizes. Whereas paired sample $t$-test results for WL indicated no significant differences from T1 to T2 [in-role performance: $t(14)=-0.626 ; n s$; extra-role performance: $t(14)=0.118$; $n s]$, as expected.

Additionally, univariate analysis of this variable was performed on employees' scores to compare the time factors for each group separately. Results showed that the EX had significantly higher scores at T2 [in-role performance: $t(195)=-2.24, p<0.05, d=0.32$; extra-role performance: $t(195)=-2.24, p<0.05, d=0.32]$ compared to T1 (with an intermediate effect size), whereas the WL did not differ significantly from T1 to T2 [in-role performance: $t(90)=-0.69$; $n s$; extra-role performance: $t(90)=0.005 ; n s]$. Figure 5 shows plotted means for each time factor (T1, T2) across the groups (EX, WL) for supervisors' and employees' scores.

Finally, paired-sample $t$-tests were carried out for the whole intervention group $(N=41)$ after the WL had completed the program. Results for supervisors' scores showed significantly higher levels at POST compared to PRE [in-role performance: $t(33)=-2.20 p<0.05, d=0.77$; extra-role performance: $t(33)=-1.98 p<0.05, d=0.69]$, with intermediate effect sizes; and at FUP compared to PRE [in-role performance: $t(30)=-2.48$ $p<0.05, d=0.90$; extra-role performance: $t(30)=-1.84 p<0.05$, $d=0.67]$, with large and intermediate effect sizes, respectively. Additionally, results of univariate analyses of employees' scores indicated that the whole intervention group had significantly higher scores at POST compared to PRE [in-role performance: $t(277)=-2.65, p<0.05, d=0.32$; extra-role performance: $t(277)=-3.22, p<0.001, d=0.39$ ], with intermediate effect sizes; and at FUP compared to PRE [in-role performance: $t(253)=-4.54, p<0.001, d=0.57$; extra-role performance: $t(253)=-5.18, p<0.001, d=0.65]$, with moderate effect sizes. Moreover, results also showed significantly higher scores at FUP compared to POST [in-role performance: $t(196)=-2.20$, $p<0.05, d=0.31$; extra-role performance: $t(196)=-2.46$, $p<0.05, d=0.35]$, with an intermediate effect size.

Figure 6 shows the study variables' plotted means for the whole intervention group $(N=41)$ for self-reported, supervisors', and employees' scores. Means and standard deviations for each variable across both groups at different times (T1 and $\mathrm{T} 2$ ) are shown in Table 5.

\section{Qualitative Data}

All the participants $(N=37)$ answered a qualitative question ("What specific positive outcomes (if any) did you gain from participating in this program?") during the last individual coaching session. The following themes emerged and are listed below according to the frequency with which they were mentioned by the participants (note: some participants gave more than one response): (1) Awareness and professional insight (28 responses: 23.8\%; e.g., "Awareness of how I see myself as a leader and how others see me"); (2) Development/increases in coaching-based leadership skills (17 responses: 14.4\%; e.g., "Greater capacity to listen and ask employees powerful questions"); (3) Increased self and/or team performance (16 responses: 13.6\%; e.g., "The program has followed the plant's continuous improvement line, such as IDP; Indicators for Personal Development"); (4) Increased personal strengths/resources (14 responses: 11.9\%; e.g., "Being aware of how employees see me in the role of leader has increased my humility and open-mindedness"); and (5) Positive changes in the environment (10 responses: 8.5\%; e.g., "I am getting more signs of optimism from co-workers, and with better predisposition to help others"). 



FIGURE 5 | In-role and extra-role performance for groups (EX, WL) across time (TI, T2).

TABLE 5 | T1 and T2 means and standard deviations (SD) for the EX and the WL.

\begin{tabular}{|c|c|c|c|c|c|c|c|c|}
\hline & \multicolumn{4}{|c|}{$\operatorname{EX}(N=23)$} & \multicolumn{4}{|c|}{ WL $(N=15)$} \\
\hline & T1 & T2 & $t$-value & $p$-value & T1 & $\mathrm{T} 2$ & $t$-value & $p$-value \\
\hline \multicolumn{9}{|l|}{ Self-reported scores } \\
\hline Coaching-based leadership skills & $4.7(0.50)$ & $4.9(0.37)$ & -1.89 & 0.072 & $4.7(0.46)$ & $4.7(0.51)$ & 0.33 & 0.746 \\
\hline PsyCap & $4.0(0.50)$ & $4.5(0.34)$ & -3.69 & 0.001 & $4.0(0.53)$ & $3.9(0.73)$ & 0.63 & 0.54 \\
\hline Work engagement & $4.8(0.68)$ & $5.2(0.51)$ & -3.76 & 0.001 & $4.6(0.78)$ & $4.4(1.25)$ & 1.37 & 0.190 \\
\hline \multicolumn{9}{|l|}{ Supervisors' scores } \\
\hline Coaching-based leadership skills & $4.1(0.81)$ & $4.5(0.82)$ & -5.23 & 0.000 & $4.1(1.02)$ & $4.1(0.98)$ & 0.63 & 0.535 \\
\hline In-role performance & $4.8(0.77)$ & $4.9(0.73)$ & -1.83 & 0.083 & $4.6(1.05)$ & $4.5(1.13)$ & 0.63 & 0.540 \\
\hline Extra-role performance & $5.1(0.83)$ & $5.3(0.66)$ & -1.94 & 0.067 & $4.8(0.80)$ & $4.8(1.12)$ & 0.12 & 0.908 \\
\hline \multicolumn{9}{|l|}{ Employees' scores } \\
\hline Coaching-based leadership skills & $4.1(1.38)$ & $4.6(1.05)$ & -2.31 & 0.022 & $4.3(1.28)$ & $4.5(1.34)$ & -0.49 & 0.620 \\
\hline In-role performance & $4.4(1.29)$ & $4.8(0.99)$ & -2.24 & 0.026 & $4.9(1.00)$ & $5.1(0.82)$ & -0.70 & 0.483 \\
\hline Extra-role performance & $4.2(1.37)$ & $4.6(1.17)$ & -2.35 & 0.019 & $4.7(1.20)$ & $4.7(1.15)$ & 0.05 & 0.996 \\
\hline
\end{tabular}

\section{DISCUSSION}

This study examined the impact of participating in a Coachingbased Leadership Intervention Program on coaching-based leadership skills, PsyCap, work engagement, and in-role and extra-role performance. Overall, the results of the study revealed that the intervention program is a successful strategy for improving the participants' outcome variables (self-reported and 

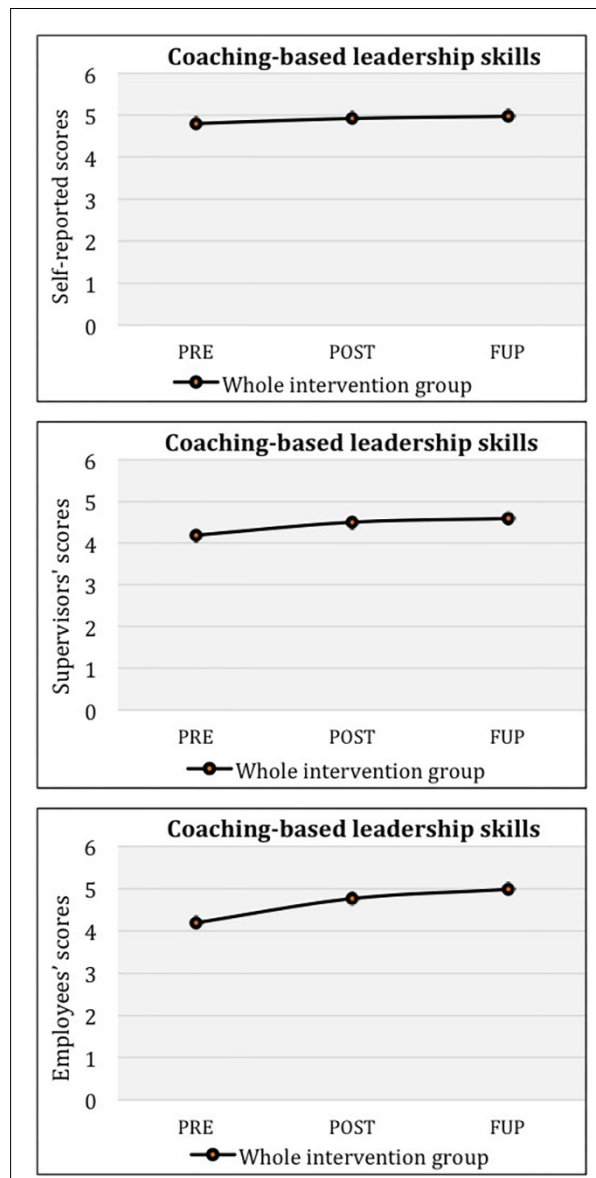


FIGURE 6 | Coaching-based leadership skills, PsyCap, work engagement, in-role and extra-role performance for the whole intervention group across time.

assessed by their employees and supervisors) after participating in the program and 4 months after finishing it. In other words, managers and middle managers that trained to develop a coaching-based leadership style, improved their coachingbased leadership skills (i.e., develop a working alliance, active, empathic, and compassionate listening, powerful questioning, facilitate development, provide feedback, strengths spotting and development, support in planning and goal setting, and manage progress), and increased their levels of positive PsyCap (i.e., self-efficacy, hope, resilience, and optimism), work engagement (vigor, dedication, and absorption), and in-role and extrarole performance.

This study makes several contributions to the coaching-based leadership development literature. First, this is the first empirical study to evaluate and confirm the positive effects of a coachingbased leadership intervention on increasing the levels of the leaders' coaching skills, PsyCap, work engagement, and in-role and extra-role performance. Since the coaching-based leadership term remains undertheorized (Berg and Karlsen, 2016), and its value and meaning within the organizational context have not been sufficiently captured (Dahling et al., 2016), findings of the current study can notable contribute to research on the benefits of this relatively new style of leadership. Additionally, identifying the attributes and outcomes that are most frequently associated with coaching-based leadership may allow for insight into the concept and further theory development (Cox et al., 2010).

Second, considering that previous research has focused on the impact of leadership development interventions on employees' variables (Grant, 2010), in this study we focused on the leaders' levels of the study variables (in a 360-degree assessment). Of the few studies that have examined the impact of a coaching leadership (Moen and Skaalvik, 2009; Grant and Hartley, 2014) or managerial coaching intervention (David and Matu, 2013; Ratiu et al., 2017) on the leaders' own performance, none of them considered task and contextual performance separately. An additional contribution of this study is the innovative approach implemented during the intervention program aim to support the development and improvement of the managers' coachingbased leadership skills. To achieve this goal and enhance positive outcomes, we followed a combination of workshop format, strengths-based leadership coaching, and practicing the skillset on-the-spot.

Fourth, this study extends the limited existing literature on empirical controlled trials with a 360-degree format using mixed 
methodologies to examine the efficacy of these intervention programs over time (longitudinal study; Grant, 2010). Given the importance of understanding the perceived benefits of participating in a leadership intervention and adopting coaching-based leadership skills in the workplace (Grant, 2010; Milner et al., 2018), a strength of this study is the exploration of the perceived outcomes of participating in the intervention using a qualitative methodology. Previous researchers have highlighted the potential usefulness of mixed methods for achieving a broader high-quality evaluation of interventions and providing a better understanding of research (Abildgaard et al., 2016). Lastly, considering the current lack of effectiveness (Lacerenza et al., 2017) and success in applying coaching-based leadership skills back in the workplace (Moen and Federici, 2012), in the current study we also analyzed the durability of the effects over time.

\section{Post-intervention Effects}

Results for coaching-based leadership skills partially supported $\mathrm{H} 1$ of the study. Findings indicated statistically significant higher supervisor scores after finishing the intervention, comparing the two groups (experimental and waiting-list control), and for the whole intervention group. Employee scores showed that, although there were no significant differences between the two groups at $\mathrm{T} 1$ and $\mathrm{T} 2$, the experimental group significantly increased their coaching-based leadership skills after the intervention program compared to their baseline levels. Additionally, employees' scores for the whole intervention group also increased significantly after finishing the intervention. Moreover, participants' self-reported levels for the whole intervention group increased significantly after finishing the program. However, self-reported increased levels of this variable were not statistically significant after finishing the program the experimental group compared to waiting-list. This result may be explained by the insight participants gained after receiving feedback from the pre-assessment about how they are seen by their employees. Additionally, this result is in line with prior research, which emphasized that leaders need at least 3 months to assimilate and feel really comfortable with using coaching skills in the workplace (Grant and Hartley, 2013). In line with this statement, we understand that, first, there might have been a process of self-discovery and consciousness-raising, followed by long-term assimilation of the coaching skills and application in their daily work. However, it is worth mentioning that results for the whole intervention group demonstrated a positive impact with significant differences in self-reported coachingbased leadership skills after finishing and 4 months after finishing the intervention compared to the baseline levels. Furthermore, the use of supervisor and employee ratings, which indicated a significant increase in leaders' coaching skills, help to support H1.

Overall, self-reported, employees', and supervisors' scores significantly increased after finishing the program in the whole intervention group, which helped to confirm H1. Additionally, participants' qualitative responses also supported $\mathrm{H} 1$ for one of the expected outcomes of the program (i.e., "development and increases in coaching-based leadership skills"). Participants reported a greater capacity to enhance the strengths of their employees, help them achieve goals, and make them grow. Some of them also reported more authenticity in their role as coach, greater closeness in the relationship, and an increased ability to communicate by using effective listening and questioning techniques. Both the quantitative and qualitative results suggest the importance of helping leaders to develop and increase coaching skills (i.e., developing a working alliance and trust environment, open communication, facilitating learning and development, managing progress and results) in the workplace. The results on the impact of the implemented intervention on coaching skills are aligned with past research specifying the effectiveness of these development programs for leaders (Ellinger et al., 2010, 2011; Grant, 2010; David and Matu, 2013; Cummings et al., 2014; Grant and Hartley, 2014). Overall, the Coachingbased Leadership Intervention Program can be recommended for implementation in organizational settings due to the set of tools it provides and its effective methodology for enhancing coaching skills that interact in the workplace.

Regarding the effects of the intervention on PsyCap and work engagement, the results fully supported $\mathrm{H} 2$ and H3, respectively; that is, participants' self-reported levels of PsyCap and work engagement increased significantly after participating in the program, both compared to the WL (from T1 to T2) and considering the whole intervention group (from PRE to POST). These findings suggest that training in core coaching skills, such as developing a warm and trusting environment among employees, generating effective communication, delivering meaningful and positive feedback, and helping them to discover and use strengths and achieve valuable goals and action plans, leads leaders to develop their personal resources (i.e., PsyCap), and increase their levels of energy, absorption, and dedication to the job. This is important because a resourceful work environment (i.e., coaching provided by the leader and opportunities for professional development) stimulate personal growth through the development of self-efficacy, hope, resilience, and optimism, which in turn lead to higher work engagement (Luthans et al., 2006; Xanthopoulou et al., 2007). Additionally, employees with high levels of engagement are likely to make more effort in their tasks and be more efficient (Kark, 2011; Llorens-Gumbau and Salanova-Soria, 2014).

Findings for the impact of the intervention program on PsyCap are consistent with previous research that found a positive direct relationship between job resources (i.e., coaching provided by the leader and opportunities for professional development) and personal resources (i.e., self-efficacy, organizational-based self-esteem and optimism; Xanthopoulou et al., 2007), and between managerial coaching and employees' PsyCap (Hsu et al., 2019). However, there are still no studies that examined or coaching leaders and their own levels of PsyCap in cross-sectional and quasi-experimental studies. Thus, the present study represents a step forward with respect to previous research in analyzing and confirming the effect of leaders developing a coaching-based leadership style on their levels of PsyCap after participating in a training intervention. Moreover, our findings for the impact of the intervention on work engagement are in line with previous research that found a positive link between this variable and the leader's coaching (Lin 
et al., 2016; Ladyshewsky and Taplin, 2017, 2018; Ali et al., 2018; Lee et al., 2018; Tanskanen et al., 2019). Despite the increasing number of studies exploring this link, work engagement has mostly been evaluated in non-experimental cross-sectional studies and as an employee-related outcome. Thus, our study provides an innovate approach by evaluating the effect of the intervention on the leaders' work engagement. Additionally, participants' qualitative responses helped to support $\mathrm{H} 2$ and $\mathrm{H} 3$ about two of the expected outcomes of the intervention (i.e., "increased personal strengths/resources" and "positive changes in the environment"). Specifically, the responses revealed that the program was a valuable tool in helping individuals to gain awareness and insight into personal resources and strengths, and produce positive changes in the work environment (i.e., quality of life, well-being, optimism, better communication).

Furthermore, the results for performance partially supported $\mathrm{H} 4 \mathrm{a}$ and H4b. Particularly, supervisors' perception of participants' in-role and extra-role performance was higher for the experimental group after finishing the program, compared to the waiting-list control group, although the differences were not significant. However, employees perception of both in- and extra-role performance was significantly higher after finishing the intervention, compared to the waiting-list control group. These results may be explained by the fluent interaction during the intervention between the participants and their employees while applying the coaching skills at work. Therefore, employees observed a short-term improvement in their leaders' performance after finishing the intervention, compared to the supervisors' assessment, which may have required more time to perceive any significant change in the leaders' performance. This last interpretation is confirmed by H5d. Precisely, supervisors perceived a significant increase in the participants' in-role and extra-role performance levels 4 months after finishing the program. Additionally, both supervisors' and employees' scores for the whole intervention group were significantly higher after finishing the program.

Findings for the impact of the intervention program on inrole and extra-role performance are consistent with previous research that found a positive link between leaders' as coaches skills and task-related performance (Ellinger et al., 2003, 2005, 2011; Gray, 2006; Grant and Cavanagh, 2007a; Agarwal et al., 2009; Grant et al., 2009; Liu and Batt, 2010; Kim, 2014; Kim and Kuo, 2015) and employees' contextual-related performance (Ellinger and Cseh, 2007; Kim and Kuo, 2015). However, there are still few empirical studies examining the impact of coachingbased leadership interventions on leaders' in-role and extra-role performance, and so our study contributes to and extends this aspect to the coaching-based leadership literature. Additionally, participants' qualitative responses helped to support $\mathrm{H} 3$ about one of the expected outcomes of the intervention (i.e., "increased performance levels"). Specifically, the intervention appears to be a valuable method for improving leaders' productivity and their teams' performance, as reported by the participants.

\section{The Durability of the Effects}

Taking into account the durability of the effects (FUP) in the whole intervention group, the findings fully confirmed
H5a; that is, self-reported, supervisors', and employees' scores given for coaching-based leadership skills significantly increased at FUP compared to PRE intervention time. These results are consistent with previous research confirming that leaders need at least 3 months to develop and feel comfortable with using coaching skills in the workplace (Grant and Hartley, 2013). However, H5b and H5c were not supported, indicating that although participants' levels of work engagement and PsyCap were higher 4 months after finishing the intervention, compared to the baseline levels, the differences were not significant, and so the effects were not sustained for these two variables. Finally, the study findings fully supported H5d. Specifically, supervisors' and employees' perceptions of leaders' in-role and extra-role performance levels increased significantly 4 months after finishing the program, compared to PRE intervention time. Additionally, employees also perceived a significant increase in participants' performance at FUP compared to POST time. Although this was not included in our hypotheses, it is worth mentioning because it demonstrates a strong trend toward improvement in leaders' performance over time, as perceived by their employees.

\section{Theoretical and Practical Implications}

This study has a number of theoretical implications. First, it contributes to the coaching and leadership framework alliance by exploring its conceptualization, structure, and the processes inherent in its development (Kemp, 2009). The study presents a rigorous and consistent empirical design that examines behaviors and skills of this relatively new form of leadership in the work environment (Batson and Yoder, 2012). Second, findings offer empirical support for the potential benefits of a coaching-based leadership style in organizations, advancing the theoretical understanding of its positive influence on workrelated outcomes (i.e., PsyCap, work engagement, and in-role and extra-role performance).

Third, results from the present study contribute to the JDR model (Bakker and Demerouti, 2007), confirming both the intrinsic motivational role of coaching-based leadership as a job resource that enhances personal resources (i.e., PsyCap), and work engagement, and its extrinsic motivational role fostering task performance. Additionally, the study findings extend this model by demonstrating the potential role of coaching-based leaders in fostering extra-role performance. In sum, leaders who train in developing a coaching-based leadership style (job resource), tend to increase their levels of positive PsyCap (personal resource), that is they expect good thing to happen at work, believe they can perform effectively, are more confident in accepting challenging tasks, are motivated to work hard when they encounter difficulties, proactively plan for alternative pathways for task accomplishment, and are able to rebound and start over when needed (Youssef and Luthans, 2012). Additionally, the development of a coachingbased leadership style and personal resources stimulate a motivational process that leads to higher levels of energy, absorption, and dedication to the job, and higher task and contextual performance. 
Fourth, the intervention presented in this study contributes to the positive psychology literature through the development of an effective intervention methodology based on a strengths-based coaching approach (Biswas-Diener and Dean, 2007; MacKie, 2014). It also extends this approach by pairing personal strengths with coaching-based leadership skills and aligning them with goal achievement. Finally, findings from this study also help to confirm that strengths-based coaching can be effective, even when the number of coaching sessions is relatively low (Theeboom et al., 2014; Peláez et al., 2019).

In terms of practical implications, given the little guidance that coaching leaders receive in their own growth and development (Kemp, 2009), this study addresses useful tools and techniques that can be used by practitioners or Human Resources professionals to teach and train the development of coachingbased leadership and, therefore, increase the effectiveness of leadership and work-related outcomes in organizations. Another practical implication is the potential for short-term coaching sessions to help improve coaching-based leadership skills, PsyCap, personal strengths, work engagement, well-being, and performance in work settings. In line with previous research that have indicated that $47 \%$ of line managers use coaching in their work, this study highlights the organizational need to build internal coaching capability in leaders (Hsu et al., 2019). This is important because as a result of the alliance-building process, both the leader and the employee collaborate to develop performance goals and new ways to achieve them (Kemp, 2009).

\section{Limitations and Directions for Future Research}

Although interesting results were obtained, the present study also has some limitations. First, the groups were not randomly chosen for the experimental condition because the middle managers in the study were line managers for whom the executives had management responsibilities. Thus, the company decided to separate the two groups. However, one-factor ANOVA results showed that there were no significant differences in any of the variables between the executives and middle managers in the experimental group on the PRE, POST, and FUP assessments. Moreover, previous studies highlighted the need to reinforce the link between research and professional practice, while considering the company or organization's characteristics, preferences, and requirements, in order to implement interventions (Tkachenko et al., 2017; OrtegaMaldonado, 2018).

Second, the sample size is not large enough to make assumptions about the general efficacy of the intervention. However, previous research stated that statistical significance can also be influenced by small sample sizes (Cumming, 2014). In line with this assumption, the majority of the effects obtained were significant, with moderate to large effect sizes, and the findings were novel. Moreover, this study aimed to be useful for both practitioners and researchers in terms of scientific accuracy, while approaching fieldwork activities as much as possible. Qualitative data were also obtained to reinforce and confirm the study conclusions. However, future research should extend and replicate this study in more diverse and larger samples to improve the generalizability of the results.

Third, due to an organizational decision, employees' answers to the questionnaires were anonymous, and responses were not identifiable over time. Additionally, some of the participants were supervisors or employees of other participants. This unbalanced sample may lead to non-independence in the study measures and experimental assignments. However, in the assessment, both supervisors and employees were asked to assess the leaders' skills and performance in their specific roles in the company, rather than the observed changes from the intervention.

A fifth limitation is that the research design had to be adapted to the organizational context and requirements, and so some adjustments were made. For instance, the waiting-list control group started the program immediately after the experimental group finished, and so comparisons of the two conditions at FUP could not be assessed. Although scores remained higher than baseline levels for the whole intervention group, the levels of some of the study outcomes (self-reported PsyCap and work engagement, and extra-role performance assessed by the supervisors) showed a decreasing pattern at FUP compared to POST-assessment. Therefore, future studies should include follow-up coaching sessions over time in order to maintain and optimize the outcome variables.

As a complementary approach, it would be interesting for future studies to include diary studies in order to obtain relevant information about the underlying psychological mechanisms throughout the program that can influence the outcome variables (i.e., PsyCap, work engagement). Future studies could also evaluate the impact of such programs on employees' variables of well-being and performance, in addition to objective organizational performance metrics. Finally, future controlledtrial studies should conduct research comparing coaching-based leadership interventions with other interventions, such as selfdevelopment tools from positive psychology, and with control groups, in order to explore and compare the effects on workrelated outcomes.

\section{DATA AVAILABILITY STATEMENT}

The datasets generated for this study are available on request to the corresponding author.

\section{ETHICS STATEMENT}

The studies involving human participants were reviewed and approved by the University Research Ethics Committee Universitat Jaume I. The patients/participants provided their written informed consent to participate in this study.

\section{AUTHOR CONTRIBUTIONS}

All the authors listed have made a substantial intellectual contribution to the research. MP and MS conceived the 
idea for the study and developed the study design. MP coordinated the entire intervention process, performed the data collection, conducted the analyses, and wrote the manuscript. MS contributed during the intervention program. MS and IM contributed to the interpretation of the results and revised the manuscript.

\section{FUNDING}

This work was supported by the Ministerio de Economía, Industria y Competitividad, Spain (Award Number PSI201564933-R) and Universitat Jaume I, Spain (Award Number UJI-B2017-81).

\section{REFERENCES}

Abildgaard, J. S., Saksvik, P. Ø., and Nielsen, K. (2016). How to measure the intervention process? An assessment of qualitative and quantitative approaches to data collection in the process evaluation of organizational interventions. Front. Psychol. 7:1380. doi: 10.3389/fpsyg.2016.01380

Acosta Antognoni, H., Salanova Soria, M., and Llorens Gumbau, S. (2012). How organizational practices predict team work engagement: the role of organizational trust. Cienc. Trab. 13, 7-15.

Agarwal, R., Angst, C. M., and Magni, M. (2009). The performance effects of coaching: a multilevel analysis using hierarchical linear modeling. Int. J. Hum. Resour. Manag. 20, 2110-2134. doi: 10.1080/09585190903178054

Ahuvia, A. (2001). Traditional, interpretive, and reception based content analyses: Improving the ability of content analysis to address issues of pragmatic and theoretical concern. Soc. Indic. Res. 54, 139-172.

Ali, M., Lodhi, S. A., Raza, B., and Ali, W. (2018). Examining the impact of managerial coaching on employee job performance: mediating role of work engagement, leader-member-exchange quality, job satisfaction, and turnover intentions. Pakistan J. Commer. Soc. Sci. 12, 253-282.

Amagoh, F. (2009). Leadership development and leadership effectiveness. Manag. Decision 47, 989-999. doi: 10.1108/00251740910966695

Anderson, V. (2013). A Trojan Horse? The implications of managerial coaching for leadership theory. Hum. Res. Dev. Int. 16, 251-266. doi: 10.1080/13678868. 2013.771868

Avey, J. B., Avolio, B. J., and Luthans, F. (2011). Experimentally analyzing the impact of leader positivity on follower positivity and performance. Leadersh. Q. 22, 282-294. doi: 10.1016/j.leaqua.2011.02.004

Avolio, B. J., Reichard, R. J., Hannah, S. T., Walumbwa, F. O., and Chan, A. (2009). A meta-analytic review of leadership impact research: experimental and quasi-experimental studies. Leadersh. Q. 20, 764-784. doi: 10.1016/j.leaqua.2009.06.006

Bakker, A. B., and Demerouti, E. (2007). The job demands-resources model: state of the art. J. Manag. Psychol. 22, 309-328. doi: 10.1108/0268394071073 3115

Bakker, A. B., Schaufeli, W. B., Leiter, M. P., and Taris, T. W. (2008). Work engagement: an emerging concept in occupational health psychology. Work Stress 22, 187-200. doi: 10.1080/02678370802393649

Baron, L., and Morin, L. (2009). The coach-coachee relationship in executive coaching: a field study. Hum. Resour. Dev. Q. 20, 85-106. doi: 10.1002/hrdq. 20009

Bass, B. M., and Avolio, B. J. (1994). Transformational leadership and organizational culture. Int. J. Public Admin. 17, 541-554. doi: 10.1080/ 01900699408524907

Batson, V. D., and Yoder, L. H. (2012). Managerial coaching: a concept analysis. J. Adv. Nurs. 68, 1658-1669. doi: 10.1111/j.1365-2648.2011.05840.x

Berg, M. E., and Karlsen, J. T. (2016). A study of coaching leadership style practice in projects. Manag. Res. Rev. 39, 1122-1142. doi: 10.1108/mrr-07-20150157

\section{ACKNOWLEDGMENTS}

The authors would like to thank Eduardo Guillamón (Manufacturing Engineering Manager at Ford Valencia Engine Plant), Pascual Chanzá Canut (Employee Suggestions Program Coordinator at Ford Valencia Engine Plant), and WANT Research Team members for their useful cooperation during the implementation of the intervention program.

\section{SUPPLEMENTARY MATERIAL}

The Supplementary Material for this article can be found online at: https://www.frontiersin.org/articles/10.3389/fpsyg. 2019.03066/full\#supplementary-material

Bester, J., Stander, M. W., and Van Zyl, L. E. (2015). Leadership empowering behaviour, psychological empowerment, organisational citizenship behaviours and turnover intention in a manufacturing division. SA J. Ind. Psychol. 41, 1-14. doi: 10.4102/sajip.v41i1.1215

Biswas-Diener, R. (2010). Practicing Positive Psychology Coaching: Assessment, Activities and Strategies for Success. Hoboken, NJ: John Wiley \& Sons.

Biswas-Diener, R., and Dean, B. (2007). Positive Psychology Coaching: Putting the Science of Happiness to Work for Your Clients. New York, NY: Wiley.

Bormann, K. C., and Rowold, J. (2018). Construct proliferation in leadership style research: reviewing pro and contra arguments. Organ. Psychol. Rev. 8, 149-173. doi: $10.1177 / 2041386618794821$

Boyatzis, R. E., Smith, M. L., and Beveridge, A. J. (2013). Coaching with compassion: inspiring health, well-being, and development in organizations. J. Appl. Behav. Sci. 49, 153-178. doi: 10.1177/0021886312462236

Burke, L. A., and Baldwin, T. T. (1999). Workforce training transfer: a study of the effect of relapse prevention training and transfer climate. Hum. Resour. Manag. 38, 227-241. doi: 10.1002/(sici)1099-050x(199923)

Cavanagh, M., and Grant, A. M. (2004). Executive coaching in organisations: the personal is the professional. Int. J. Coach. Organ. 2, 6-15.

Coe, S. (2004). Evaluating a personal experience of coaching-an insider's account. Int. J. Mentor. Coach. 2.

Cohen, J. (1988). Statistical Power Analysis for the Behavioral Sciences, 2nd Edn, Hillsdale, NJ: Lawrence Earlbaum Associates, doi: 10.2307/2290095

Cox, E., Bachkirova, T., and Clutterbuck, D. (2010). The Complete Handbook of Coaching. London: Sage.

Cumming, G. (2014). The new statistics: why and how. Psychol. Sci. 25, 7-29. doi: $10.1177 / 0956797613504966$

Cummings, G., Mallidou, A. A., Masaoud, E., Kumbamu, A., Schalm, C., Laschinger, H. K. S., et al. (2014). On becoming a coach: a pilot intervention study with managers in long-term care. Health Care Manag. Rev. 39, 198-209. doi: 10.1097/hmr.0b013e318294e586

Dahling, J. J., Taylor, S. R., Chau, S. L., and Dwight, S. A. (2016). Does coaching matter? A multilevel model linking managerial coaching skill and frequency to sales goal attainment. Pers. Psychol. 69, 863-894. doi: 10.1111/peps.12123

David, O. A., and Matu, S. A. (2013). How to tell if managers are good coaches and how to help them improve during adversity? The managerial coaching assessment system and the rational managerial coaching program. J. Cogn. Behav. Psychother. 13, 497-522.

Day, D. V., Fleenor, J. W., Atwater, L. E., Sturm, R. E., and McKee, R. A. (2014). Advances in leader and leadership development: a review of 25 years of research and theory. Leadersh. Q. 25, 63-82. doi: 10.1016/j.leaqua.2013.11.004

Dello Russo, S., Miraglia, M., and Borgogni, L. (2017). Reducing Organizational Politics in performance appraisal: the role of coaching leaders for agediverse employees. Hum. Resour. Manag. 56, 769-783. doi: 10.1002/hrm. 21799

Denecke, K., and Nejdl, W. (2009). How valuable is medical social media data? Content analysis of the medical web. Inform. Sci. 179, 1870-1880. doi: 10.1016/ j.ins.2009.01.025 
Dimas, I. D., Rebelo, T., and Lourenço, P. R. (2016). Team coaching: one more clue for fostering team effectiveness. Eur. Rev. Appl. Psychol. 66, 233-242. doi: 10.1016/j.erap.2016.05.003

Ellinger, A. D., and Bostrom, R. P. (2002). An examination of managers' beliefs about their roles as facilitators of learning. Manag. Learn. 33, 147-179. doi: $10.1177 / 1350507602332001$

Ellinger, A. D., and Cseh, M. (2007). Contextual factors influencing the facilitation of others' learning through everyday work experiences. J. Workplace Learn. 19, 435-452. doi: 10.1108/13665620710819384

Ellinger, A. D., Ellinger, A. E., Bachrach, D. G., Wang, Y. L., and Elmadağ Baş, A. B. (2011). Organizational investments in social capital, managerial coaching, and employee work-related performance. Manag. Learn. 42, 67-85. doi: 10.1177/ 1350507610384329

Ellinger, A. D., Ellinger, A. E., Hamlin, R. G., and Beattie, R. S. (2010). Achieving improved performance through managerial coaching. Handb. Improv. Perform. Workplace 1- 3, 275-298. doi: 10.1002/9780470592663.ch30

Ellinger, A. D., Ellinger, A. F., and Keller, S. B. (2003). Supervisory coaching behavior, employee satisfaction, and warehouse employee performance: a dyadic perspective in the distribution industry. Hum. Resour. Dev. Q. 14, 435-458. doi: 10.1002/hrdq. 1078

Ellinger, A. E., Ellinger, A. D., and Keller, S. B. (2005). Supervisory coaching in a logistics context. Int. J. Phys. Distrib. Logist. Manag. 35, 620-636. doi: 10.1108/ 09600030510634562

Ellinger, A. E., Ketchen, D. J., Jr., Hult, G. T. M., Elmadağ, A. B., and Richey, R. G., Jr. (2008). Market orientation, employee development practices, and performance in logistics service provider firms. Ind. Mark. Manag. 37, 353-366. doi: 10.1016/j.indmarman.2007.01.002

Ely, K., Boyce, L. A., Nelson, J. K., Zaccaro, S. J., Hernez-Broome, G., and Whyman, W. (2010). Evaluating leadership coaching: a review and integrated framework. Leadersh. Q. 21, 585-599. doi: 10.1016/j.leaqua.2010.06.003

Feldman, D. C., and Lankau, M. J. (2005). Executive coaching: a review and agenda for future research. J. Manag. 31, 829-848. doi: 10.1177/0149206305279599

Gilbert, P. (2013). Choden. Mindful Compassion. Using the Power of Mindfulness and Compassion to Transform our Lives. London: Robinson.

Gilley, A., Gilley, J. W., and Kouider, E. (2010). Characteristics of managerial coaching. Perform. Improv. Q. 23, 53-70. doi: 10.1002/piq.20075

Goleman, D., Welch, S., and Welch, J. (2012). What Makes A Leader?. Solon, OH: Findaway World, LLC.

Goodman, S. A., and Svyantek, D. J. (1999). Person-organization fit and contextual performance: do shared values matter. J. Vocat. Behav. 55, 254-275. doi: 10. 1006/jvbe.1998.1682

Gooty, J., Connelly, S., Griffith, J., and Gupta, A. (2010). Leadership, affect and emotions: a state of the science review. Leadersh. Q. 21, 979-1004. doi: 10.1016/ j.leaqua.2010.10.005

Govindji, R., and Linley, P. A. (2007). Strengths use, self-concordance and wellbeing: implications for strengths coaching and coaching psychologists. Int. Coach. Psychol. Rev. 2, 143-153.

Graham, S., Wedman, J. F., and Garvin-Kester, B. (1994). Manager coaching skills: what makes a good coach? Perform. Improv. Q. 7, 81-94. doi: 10.1111/j.19378327.1994.tb00626.x

Grant, A. M. (2003). The impact of life coaching on goal attainment, metacognition and mental health. Soc. Behav. Personal. 31, 253-263. doi: 10.2224/sbp.2003.31. 3.253

Grant, A. M. (2006). "Workplace and executive coaching: a bibliography from the scholarly business literature," in Evidence Based Coaching: Putting best practices to work for your clients, eds A. M. Grant, and D. R. Stober, (Hoboken, NJ: Wiley and Sons), 367-398.

Grant, A. M. (2010). It takes time: a stages of change perspective on the adoption of workplace coaching skills. J. Change Manag. 10, 61-77. doi: 10.1080/ 14697010903549440

Grant, A. M. (2011). Is it time to REGROW the GROW model? Issues related to teaching coaching session structures. Coach. Psychol. 7, 118-126.

Grant, A. M. (2013). The efficacy of coaching. Handb. Psychol. Coach. Mentor. 15-39. doi: 10.1002/9781118326459.ch2

Grant, A. M., and Cavanagh, M. J. (2007a). Evidence-based coaching: flourishing or languishing? Austr. Psychol. 42, 239-254. doi: 10.1080/0005006070164 8175
Grant, A. M., and Cavanagh, M. J. (2007b). The goal-focused coaching skills questionnaire: preliminary findings. Soc. Behav. Pers. Inter. J. 35, 751-760. doi: $10.2224 /$ sbp.2007.35.6.751

Grant, A. M., Curtayne, L., and Burton, G. (2009). Executive coaching enhances goal attainment, resilience and workplace well-being: a randomised controlled study. J. Posit. Psychol. 4, 396-407. doi: 10.1080/17439760902992456

Grant, A. M., and Hartley, M. (2013). Developing the leader as coach: insights, strategies and tips for embedding coaching skills in the workplace. Coach. Int. J. Theory Res. Pract. 6, 102-115. doi: 10.1080/17521882.2013.824015

Grant, A. M., and Hartley, M. (2014). Exploring the impact of participation in a leader as coach programme using the personal case study approach. Coach. Psychol. 10, 51-58.

Grant, A. M., and O'Connor, S. A. (2010). The differential effects of solution-focused and problem-focused coaching questions: a pilot study with implications for practice. Indust. Commer. Train. 42, 102-111. doi: 10.1108/ 00197851011026090

Gray, D. E. (2006). Executive coaching: towards a dynamic alliance of psychotherapy and transformative learning processes. Manag. Learn. 37, 475497. doi: 10.1177/1350507606070221

Gregory, J. B., and Levy, P. E. (2010). Employee coaching relationships: enhancing construct clarity and measurement. Coach. Int. J. Theory Res. Pract. 3, 109-123. doi: 10.1080/17521882.2010.502901

Gregory, J. B., and Levy, P. E. (2011). It's not me, it's you: a multilevel examination of variables that impact employee coaching relationships. Consult. Psychol. J. Pract. Res. 63:67. doi: 10.1037/a0024152

Gyllensten, K., and Palmer, S. (2007). The coaching relationship: an interpretative phenomenological analysis. Int. Coach. Psychol. Rev. 2, 168-177. doi: 10.1016/j. adolescence.2009.10.011

Hagen, M., and Aguilar, M. G. (2012). The impact of managerial coaching on learning outcomes within the team context: an analysis. Hum. Resour. Dev. Q. 23, 363-388. doi: 10.1002/hrdq. 21140

Hagen, M. S. (2012). Managerial coaching: a review of the literature. Perform. Improv. Q. 24, 17-39. doi: 10.1002/piq.20123

Hamlin, R. G., Ellinger, A. D., and Beattie, R. S. (2006). Coaching at the heart of managerial effectiveness: a cross-cultural study of managerial behaviours. Hum. Resource Dev. Int. 9, 305-331. doi: 10.1080/13678860600893524

Hanson, R. (2017). "Positive Neuroplasticity: The Neuroscience of Mindfulness," in Advances in Contemplative Psychotherapy, eds J. Loizzo, M. Neale, and E. Wolf, (New York, NY: Routledge), 48-60. doi: 10.4324/9781315630 045-5

Harter, J. K., Schmidt, F. L., and Hayes, T. L. (2002). Business-unit-level relationship between employee satisfaction, employee engagement, and business outcomes: a meta-analysis. J. Appl. Psychol. 87, 268-279. doi: 10.1037/ /0021-9010.87.2.268

Hobfoll, S. E. (2002). Social and psychological resources and adaptation. Rev. Gen. Psychol. 6, 307-324. doi: 10.1037//1089-2680.6.4.307

Hoffman, G. K., Monroe, C., Green, L., and Rivers, D. (2008). Compassionate Listening: An Exploratory Sourcebook About Conflict Transformation. Mulgrave: New Conversations net.

Holladay, C. L., and Quiñones, M. A. (2003). Practice variability and transfer of training: the role of self-efficacy generality. J. Appl. Psychol. 88, 1094-1103. doi: 10.1037/0021-9010.88.6.1094

Hsu, Y. P., Chun-Yang, P., Pi-Hui, T., and Ching-Wei, T. (2019). Managerial coaching, job performance, and team commitment: the meditating effect of psychological capital. Adv. Manag. Appl. Econ. 9, 101-125.

Hunt, J. M., and Weintraub, J. (2002). How coaching can enhance your brand as a manager. J. Organ. Excell. 21, 39-44. doi: 10.1002/npr.10018

International Coach Federation, (n.d.). ICF Core Competencies. Lexington, KY: International Coach Federation.

Kark, R. (2011). Games managers play: play as a form of leadership development. Acad. Manag. Learn. Educ. 10, 507-527. doi: 10.5465/amle.2010.0048

Kashdan, T. B., and Ciarrochi, J. V. (eds) (2013). Mindfulness, Acceptance, and Positive Psychology: The Seven Foundations of Well-Being. Oakland, CA: New Harbinger Publications.

Kelloway, E. K., and Barling, J. (2010). Leadership development as an intervention in occupational health psychology. Work Stress 24, 260-279. doi: 10.1080/ 02678373.2010 .518441 
Kemp, T. J. (2009). Is coaching an evolved form of leadership? Building a transdisciplinary framework for exploring the coaching alliance. Int. Coach. Psychol. Rev. 4, 105-110.

Kersting, K. (2003). Turning happiness into economic power. Monit. Psychol. 34:26.

Kim, S. (2014). Assessing the influence of managerial coaching on employee outcomes. Hum. Resour. Dev. Q. 25, 59-85. doi: 10.1002/hrdq.21175

Kim, S., Egan, T. M., Kim, W., and Kim, J. (2013). The impact of managerial coaching behavior on employee work-related reactions. J. Bus. Psychol. 28, 315-330. doi: 10.1007/s10869-013-9286-9

Kim, S., and Kuo, M. H. (2015). Examining the relationships among coaching, trustworthiness, and role behaviors: a social exchange perspective. J. Appl. Behav. Sci. 51, 152-176. doi: 10.1177/0021886315574884

Kirchner, M. J., and Akdere, M. (2014). Leadership development programs: an integrated review of literature. J. Knowl. Econ. Knowl. Manag. 9, 137-146.

Kunst, E. M., van Woerkom, M., van Kollenburg, G. H., and Poell, R. F. (2018). Stability and change in teachers' goal orientation profiles over time: managerial coaching behavior as a predictor of profile change. J. Vocat. Behav. 104, 115-127. doi: 10.1016/j.jvb.2017.10.003

Lacerenza, C. N., Reyes, D. L., Marlow, S. L., Joseph, D. L., and Salas, E. (2017). Leadership training design, delivery, and implementation: a meta-analysis. J. Appl. Psychol. 102, 1686-1718. doi: 10.1037/apl0000241

Ladyshewsky, R., and Taplin, R. (2017). Employee perceptions of managerial coaching and work engagement using the measurement model of coaching skills and the utrecht work engagement Scale. Int. J. Evid. Based Coach. Mentor. $15,25-42$.

Ladyshewsky, R. K., and Taplin, R. (2018). The interplay between organisational learning culture, the manager as coach, self-efficacy and workload on employee work engagement. Int. J. Evid. Based Coach. Mentor. 16, 3-19. doi: 10.1111/ medu. 12130

Lee, M. C. C., Idris, M. A., and Tuckey, M. (2018). Supervisory coaching and performance feedback as mediators of the relationships between leadership styles, work engagement, and turnover intention. Hum. Resour. Dev. Int. 22, 257-282. doi: 10.1080/13678868.2018.1530170

Lin, W., Wang, L., Bamberger, P. A., Zhang, Q., Wang, H., Guo, W., et al. (2016). Leading future orientations for current effectiveness: the role of engagement and supervisor coaching in linking future work self salience to job performance. J. Vocat. Behav. 92, 145-156. doi: 10.1016/j.jvb.2015.12.002

Linley, P. A., Garcea, N., Hill, J., Minhas, G., Trenier, E., and Willars, J. (2010a). Strengthspotting in coaching: conceptualisation and development of the strengthspotting scale. Int. Coach. Psychol. Rev. 5, 165-176. doi: 10.1037/ t44065-000

Linley, P. A., Nielsen, K. M., Gillett, R., and Biswas-Diener, R. (2010b). Using signature strengths in pursuit of goals: effects on goal progress, need satisfaction, and well-being, and implications for coaching psychologists. Int. Coach. Psychol. Rev. 5, 6-15.

Liu, X., and Batt, R. (2010). How supervisors influence performance: a multilevel study of coaching and group management in technologymediated services. Pers. Psychol. 63, 265-298. doi: 10.1111/j.1744-6570.2010. 01170.x

Llorens-Gumbau, S., and Salanova-Soria, M. (2014). Loss and gain cycles? A longitudinal study about burnout, engagement and self-efficacy. Burn. Res. 1, 3-11. doi: 10.1016/j.burn.2014.02.001

Luthans, F., Avey, J. B., Avolio, B. J., Norman, S. M., and Combs, G. M. (2006). Psychological capital development: toward a micro-intervention. J. Organ. Behav. 27, 387-393. doi: 10.1002/job.373

Luthans, F., Avey, J. B., Avolio, B. J., and Peterson, S. J. (2010). The development and resulting performance impact of positive psychological capital. Hum. Resour. Dev. Q. 21, 41-67. doi: 10.1002/hrdq.20034

Luthans, F., Avolio, B. J., Avey, J. B., and Norman, S. M. (2007). Positive psychological capital: measurement and relationship with performance and satisfaction. Pers. Psychol. 60, 541-572. doi: 10.1111/j.1744-6570.2007. 00083.x

Luthans, F., Youssef, C. M., and Avolio, B. J. (2015). Psychological capital and beyond. Oxford: Oxford University Press.

MacKie, D. (2014). The effectiveness of strength-based executive coaching in enhancing full range leadership development: a controlled study. Consult. Psychol. J. Pract. Res. 66, 118-137. doi: 10.1037/cpb0000005
MacLeod, D., and Clarke, N. (2009). Engaging for Success: Enhancing Performance Through Employee Engagement: A Report To Government. London: Department for Business, Innovation and Skills.

Mai, R., and Akerson, A. (2003). The Leader as Communicator: Strategies and Tactics to Build Loyalty, Focus Effort, and Spark Creativity. New York, NY: AMACOM.

Meyers, M. C., and van Woerkom, M. (2017). Effects of a strengths intervention on general and work-related well-being: the mediating role of positive affect. $J$. Happiness Stud. 18, 671-689. doi: 10.1007/s10902-016-9745-x

Milner, J., McCarthy, G., and Milner, T. (2018). Training for the coaching leader: how organizations can support managers. J. Manag. Dev. 37, 188-200. doi: 10.1108/jmd-04-2017-0135

Moen, F., and Federici, R. A. (2012). The effect from coaching based leadership. J. Educ. Learn. 1, 1-14. doi: 10.5539/jel.v1n2p1

Moen, F., and Skaalvik, E. (2009). The effect from executive coaching on performance psychology. Int. J. Evid. Based Coach. Mentor. 7, 31-49.

Neff, K. (2003). Self-compassion: an alternative conceptualization of a healthy attitude toward oneself. Self Identity 2, 85-101. doi: 10.1080/15298860309032

Ortega-Maldonado, A. (2018). It is Time to Act! Empirical Findings on How to Enhance Psychological Well-being and Performance through Positive Interventions. Doctoral thesis, Universitat Jaume I, Castellón.

Park, S., McLean, G. N., and Yang, B. (2008). "Revision and validation of an instrument measuring managerial coaching skills in organizations," in Proceedings of the Academy of Human Resource Development Conference, Panama City, FL.

Peláez, M. J., Coo, C., and Salanova, M. (2019). Facilitating work engagement and performance through strengths-based micro-coaching: a controlled trial study. J. Happ. Stud. 2019, 1-20. doi: 10.1007/s10902-019-00127-5

Peters, M. L., Meevissen, Y. M., and Hanssen, M. M. (2013). Specificity of the best possible self intervention for increasing optimism: comparison with a gratitude intervention. Ter. Psicol. 1, 93-100. doi: 10.4067/s0718-48082013000100009

Peterson, C., and Seligman, M. E. (2004). Character Strengths and Virtues: A Handbook and Classification, Vol. 1. Oxford: Oxford University Press.

Pitichat, T., Reichard, R. J., Kea-Edwards, A., Middleton, E., and Norman, S. M. (2018). Psychological capital for leader development. J. Leadersh. Organ. Stud. 25, 47-62. doi: 10.1177/1548051817719232

Podsakoff, P. M., MacKenzie, S. B., Paine, J. B., and Bachrach, D. G. (2000). Organizational citizenship behaviors: a critical review of the theoretical and empirical literature and suggestions for future research. J. Manag. 26, 513-563. doi: $10.1177 / 014920630002600307$

Pommier, E. A. (2010). The Compassion Scale. Austin, TX: The University of Texas.

Pousa, C., Richards, D. A., and Trépanier, C. (2018). Managerial coaching of frontline employees: the moderating role of gender. Hum. Resour. Dev. Q. 29, 219-241. doi: 10.1002/hrdq.21322

Ratiu, L., David, O. A., and Baban, A. (2017). Developing managerial skills through coaching: efficacy of a cognitive-behavioral coaching program. J. Ration. Emot. Cogn. Behav. Ther. 34, 244-266. doi: 10.1007/s10942-015-0225-8

Raza, B., Ali, M., Ahmed, S., and Moueed, A. (2017). Impact of managerial coaching on employee performance and organizational citizenship behavior: intervening role of thriving at work. Pakistan J. Commer. Soc. Sci. 11, 790-813. doi: 10. 33844/ijol.2018.60360

Salanova, M., Llorens, S., Cifre, E., and Martínez, I. M. (2012). We need a hero! Toward a validation of the healthy and resilient organization (HERO) model. Group Organ. Manag. 37, 785-822. doi: 10.1177/1059601112470405

Salanova, M., Llorens, S., and Martínez, I. M. (2016). Contributions from positive organizational psychology to develop healthy and resilient organizations. Pap. Psicól. 37, 177-184.

Schaufeli, W. B., and Bakker, A. B. (2004). Job demands, job resources, and their relationship with burnout and engagement: a multi-sample study. J. Organ. Behav. 25, 293-315. doi: 10.1002/job.248

Schaufeli, W. B., Bakker, A. B., and Salanova, M. (2006). The measurement of work engagement with a short questionnaire: a cross-national study. Educ. Psychol. Measur. 66, 701-716. doi: 10.1177/0013164405282471

Segers, J., Vloeberghs, D., Henderickx, E., and Inceoglu, I. (2011). Structuring and understanding the coaching industry: the coaching cube. Acad. Manag. Learn. Educ. 10, 204-221. doi: 10.5465/amle.10.2.zqr204

Seligman, M. E., and Csikszentmihalyi, M. (2014). Positive psychology: an introduction. Am. Psychol. 55, 5-14. doi: 10.1007/978-94-017-9088-8-18 
Shuck, B., and Herd, A. M. (2012). Employee engagement and leadership: exploring the convergence of two frameworks and implications for leadership development in HRD. Hum. Resour. Dev. Rev. 11, 156-181. doi: 10.1177/ 1534484312438211

Spence, G. B., and Grant, A. M. (2007). Professional and peer life coaching and the enhancement of goal striving and well-being: an exploratory study. J. Posit. Psychol. 2, 185-194. doi: 10.1080/17439760701228896

Stehlik, T., Short, T., and Piip, J. (2014). The Challenges of Leadership in the 21st Century Workforce Development. New York, NY: Springer.

Styhre, A. (2008). Coaching as second-order observations: learning from site managers in the construction industry. Leadersh. Organ. Dev. J. 29, 275-290. doi: 10.1108/01437730810861326

Tan, C. M. (2012). Search Inside Yourself: Increase Productivity, Creativity and Happiness. London: HarperCollins UK.

Tanskanen, J., Mäkelä, L., and Viitala, R. (2019). Linking managerial coaching and leader-member exchange on work engagement and performance. J. Happ. Stud. 20, 1217-1240. doi: 10.1007/s10902-018-9996-9

Theeboom, T., Beersma, B., and Van Vianen, A. E. (2014). Does coaching work? A meta-analysis on the effects of coaching on individual level outcomes in an organizational context. J. Posit. Psychol. 9, 1-18. doi: 10.1080/17439760.2013. 837499

Ting, S., and Riddle, D. (2006). "A framework for leadership development coaching," in The CCL Handbook of Coaching: A Guide for the Leader Coach, eds S. Ting, and P. Scisco, (San Francisco, CA: Jossey-Bass), 34-62.

Tkachenko, O., Hahn, H. J., and Peterson, S. L. (2017). Research-practice gap in applied fields: an integrative literature review. Hum. Resour. Dev. Rev. 16, 235-262. doi: 10.1177/1534484317707562
Underhill, B. O., McAnally, K., and Koriath, J. J. (2007). Executive Coaching for Results: The Definitive Guide to Developing Organizational Leaders. San Francisco: Berrett-Koehler.

Ventura, M., Salanova, M., and Llorens, S. (2015). Professional self-efficacy as a predictor of burnout and engagement: the role of challenge and hindrance demands. J. Psychol. 149, 277-302. doi: 10.1080/00223980.2013.876380

Whitmore, J. (1992). Coaching for Performance. London: Nicholas Brealey.

Wood, B., and Gordon, S. (2009). Linking MBA learning and leadership coaching. Int. Coach. Psychol. Rev. 4, 87-104.

Wright, J. (2005). Workplace coaching: what's it all about? Work J. Prevent. Assess. Rehabil. 24, 325-328.

Xanthopoulou, D., Bakker, A. B., Demerouti, E., and Schaufeli, W. B. (2007). The role of personal resources in the job demands-resources model. Int. J. Stress Manag. 14, 121-141. doi: 10.1037/1072-5245.14.2.121

Youssef, C. M., and Luthans, F. (2012). Positive global leadership. J. World Bus. 47, 539-547. doi: 10.1016/j.jwb.2012.01.007

Conflict of Interest: The authors declare that the research was conducted in the absence of any commercial or financial relationships that could be construed as a potential conflict of interest.

Copyright @ 2020 Peláez Zuberbuhler, Salanova and Martínez. This is an open-access article distributed under the terms of the Creative Commons Attribution License (CC BY). The use, distribution or reproduction in other forums is permitted, provided the original author(s) and the copyright owner(s) are credited and that the original publication in this journal is cited, in accordance with accepted academic practice. No use, distribution or reproduction is permitted which does not comply with these terms. 


\section{OPEN ACCESS}

Edited by:

Llewellyn Ellardus Van Zyl,

Eindhoven University of Technology,

Netherlands

Reviewed by: Ilaria Setti,

University of Pavia, Italy

Aleksandra Kroemeke,

SWPS University of Social Sciences

and Humanities, Poland

*Correspondence:

Maria C. W. Peeters m.peeters@uu.nl

Specialty section: This article was submitted to

Organizational Psychology, a section of the journal

Frontiers in Psychology

Received: 04 November 2019 Accepted: 05 February 2020

Published: 28 February 2020

Citation:

Peeters MCW,

van Steenbergen EF and Ybema JF

(2020) Positive Psychological

Micro-Interventions to Improve the Work-Family Interface: Use Your

Resources and Count Your Blessings.

Front. Psychol. 11:275

doi: 10.3389/fpsyg.2020.00275

\section{Positive Psychological} Micro-Interventions to Improve the Work-Family Interface: Use Your Resources and Count Your Blessings

\author{
Maria C. W. Peeters ${ }^{1,2 *}$, Elianne F. van Steenbergen ${ }^{1,3}$ and Jan Fekke Ybema ${ }^{1}$ \\ ${ }^{1}$ Department of Social, Health and Organizational Psychology, Utrecht University, Utrecht, Netherlands, ${ }^{2}$ Industrial \\ Engineering and Innovation Sciences, Eindhoven University of Technology, Eindhoven, Netherlands, ${ }^{3}$ Dutch Authority \\ for the Financial Markets (AFM), Amsterdam, Netherlands
}

The present study is designed to test the effectiveness of two positive psychological micro-interventions ("use your resources" and "count your blessings") aimed at improving the combination of work and family roles. Based on the Transactional Model of Stress (TMS), the Conservation of Resources (COR) Theory and the Work-Home Resources (WH-R) Model, it was expected that the interventions would result in a more positive cognitive appraisal of combining both roles as well as in less work-to-family and family-to-work conflict and more work-to-family and family-to-work enrichment. The hypotheses were tested in a field experiment with three conditions and three measurement waves. In total, 218 working mothers participated in the study. The "use your resources" intervention appeared effective in sorting positive effects on the workfamily outcome variables. Participating in the "count your blessing" micro-intervention did not result in a better (appraisal of the) combination of work and family roles. Moreover, for generating positive effects it was important that the participants performed the exercises on a regular basis: the more days women performed the exercise, the stronger the effects. The implications of our findings for future interventions to improve work-family role combining are discussed.

Keywords: cognitive appraisal, work-family conflict, work-family enrichment, positive psychology, microinterventions

\section{INTRODUCTION}

Over the past decades, the traditional gendered division of work and family roles has eroded and made place for dual-earner couples in which both partners combine paid work with family roles. Combining multiple roles is typically assumed to be difficult and stressful and a large body of research has shown that work can indeed negatively interfere with fulfilling family roles and vice versa (Allen et al., 2000; Van Steenbergen et al., 2008; Amstad et al., 2011).

However, on the positive side of role combining, work and family roles have also the potential to enrich one another (Greenhaus and Powell, 2006). Numerous studies have shown that the extent to which individuals experience role conflict and role enrichment has far reaching consequences for their health, performance and wellbeing both at work and at home (e.g., McNall et al., 2010; Reichl et al., 2014; Zhang et al., 2018) and for their relationships with partner and children 
(e.g., Van Steenbergen et al., 2014; Fellows et al., 2016). Therefore, scholars are increasingly trying to design interventions that help individuals to better combine their multiple roles, such as training supervisors to support the family domain (Hammer et al., 2011), offering new ways of working (Demerouti et al., 2014) or implementing mindfulness-based training at the workplace (Kiburz et al., 2017). Up till now, most interventions in this area are top down initiatives from for example the Human Resources Department and employees may or may not sign up for it. Less attention has been paid to the design of interventions that focus on actions that employees themselves can initiate on a daily basis to improve the combination of work and family roles. The present research tries to fill this gap by developing and testing two positive micro-interventions that are specifically designed to provide employees with techniques that are supposed to facilitate the combination of different roles. By designing micro-interventions that are easy to apply we expect employees to be more inclined to use them in their daily lives. The purpose of both interventions is to influence the cognitive appraisal of combining multiple roles. Based on the Transactional Model of Stress (TMS; Lazarus and Folkman, 1984), The Conservation of Resources (COR) Model (Hobfoll, 1989) and the Work-Home Resources (WH-R) Model (Ten Brummelhuis and Bakker, 2012) we assume that a more positive appraisal of the combination of roles will encourage employees to perceive less role conflict and more role enrichment.

\section{THEORETICAL BACKGROUND}

\section{The Cognitive Appraisal of Combining Work and Family Roles}

The TMS, developed by Lazarus and Folkman (1984), conceptualizes the occurrence of stress as "psychologically mediated." The central construct in this model is the individual's cognitive appraisal of a situation, which intervenes between the objective occurrence of a certain situation and the reaction of the individual to that specific situation. This cognitive appraisal consists of a primary and secondary appraisal. In primary appraisal the individual evaluates how stressful a certain situation is. If this situation is categorized as stressful, the appraisal can be characterized in three ways: (1) harm, which refers to the fact that harm is already experienced, (2) threat, which is harm that is anticipated, and (3) challenge, which is the potential for mastery or gain. A harm appraisal refers to harm in the past. Threat and challenge appraisals refer to ongoing or upcoming situations.

Secondary appraisal occurs almost at the same time, and the basic question here is "Can I cope?" When an individual assesses his/her available resources as sufficient to deal with the situation, the situation is likely to be perceived as challenging. This creates positive thoughts about the situation and more positive emotions, like enthusiasm, and motivation (Lazarus and Folkman, 1984). If one's resources seem insufficient to cope, the individual will perceive the situation as more threatening. He or she will feel anxious, emotionally overwhelmed, and will keep worrying about the situation (Van Steenbergen et al., 2008).
Primary and secondary appraisals converge to determine whether the combination of multiple roles is regarded as significant for well-being, and if so, whether it is primarily threatening or challenging (Folkman et al., 1986).

\section{The Influence of Positive Micro-Interventions on the Cognitive Appraisal of Role Combining}

The present study aims to investigate whether two positive microinterventions can influence how individuals cognitively appraise the combination of their work and family roles. The microinterventions are originally designed by Seligman et al. (2005) and are called "three good things in life" and "use signature resources in a new way." The interventions were designed from a positive psychological perspective to reduce the symptoms of depression by influencing thoughts positively. The interventions are called micro-interventions because they can be performed in a relatively short time period without intensive contact with a trainer or counselor. In "three good things in life" participants were asked to write down three good things that happened that day. The participants were also asked to explain each good thing that happened. "Use signature strengths in a new way" implied that participants had to find out their top five character strengths and use one of these in a new and different way every day for one week (Seligman et al., 2005). Both interventions reduced the symptoms of depression and increased happiness, even six months after the intervention. Because of these promising short and long-term effects we wanted to test the suitability of similar micro-interventions in the context of role combining. To this purpose we adapted both interventions slightly and applied them to the context of the present study. To distinguish our microinterventions from the ones by Seligman and colleagues we labeled them as "use your resources" (based on use signature strengths in a new way) and "count your blessings" (based on three good things in life).

In the "use your resources" intervention participants are encouraged to use their personal resources to improve their functioning at work, at home, or both. In line with the TMS, we argue that being aware of one's personal resources makes a stressor easier to handle and as a result people will appraise it more as a challenge and less as a treat. In addition, becoming more aware of one's personal resources and applying them, will also improve secondary appraisal (“can I cope?”) of role combination. This intervention would then lead to a more positive experience of the combination of work and family roles.

In the "count your blessings" intervention participants are encouraged to think about the positive things that happened on a particular day. We argue that this counting of blessings makes people more aware of their good things in life and makes them focus more on the positive side. This mindset will lead people to experience stressors less as a threat and more as a challenge. In turn this will lead to more positive thoughts, emotions and actions, and as a result a better combination of work and family life.

Van Steenbergen et al. (2008) already examined this phenomenon. In a field experiment, participants were provided 
with information that supported either a role expansion perspective or a scarcity perspective on the combination of work and family roles. Their findings showed that working mothers experienced their combination of work and family roles as more positive when they were provided with information that supported a role expansion perspective as compared to information that supported a scarcity perspective.

These insights indicate that, on a practical level, there are opportunities to develop intervention programs that can ameliorate the stress caused by the combination of both work and family roles. This means that potentially, interventions can be used to impact upon people's cognitive appraisals of combining work and family roles. Building on the TMS and previous research, we expect that:

H1: Compared to participants in the control condition, participants in the intervention conditions will appraise role combining (a) less as a threat and more as a challenge (primary appraisal) and (b) will have a more beneficial secondary appraisal, both directly after the intervention (T1) and three weeks later (T2).

\section{The Influence of Positive Micro-Interventions on Conflict and Enrichment}

By cognitively construing the task of combining work and family roles as a threat or as a challenge, over time, the extent to which individuals experience conflict and/or enrichment as a result of combining roles, will be affected. A conflict between work and family can be defined as: "a type of role conflict that arises when joint role pressures from the work and family domains are experienced as incompatible in some respect, as a result of which participation in one role is made more difficult by virtue of participation in the other role" (Greenhaus and Beutell, 1985, p. 77). These conflicts can arise in both the workto-family direction and the family-to-work direction (Byron, 2005). Research in this tradition is predominantly influenced by the scarcity perspective on the fulfillment of multiple roles and human energy (see Marks, 1977). The basic assumption here is that available time and energy resources are limited and that the fulfillment of multiple roles is likely to result in a depletion of these scarce resources. However, according to Marks' (1977) role-expansion approach individuals can also experience enrichment between roles. This approach posits that human energy is abundant and expendable, and that roles can also positively affect one another.

Work-family enrichment is defined as the individual's experience that participation in one role makes it easier to fulfill the requirements of another role (Greenhaus and Powell, 2006).

Work-family enrichment also occurs in two directions, namely work-to-family enrichment and family-to-work enrichment.

In line with research of Van Steenbergen et al. (2007), we argue that different types of conflict and enrichment need to be distinguished in order to better understand the different ways in which role-combining is experienced. In the present study we chose to focus on the energy/strain type as well as on the psychological type of conflict and enrichment. We omitted behavioral and time-based conflict and enrichment to keep the survey as short as possible, and because we expect that our interventions will tap more into the former two aspects of the work-family interface. Energy-based enrichment takes place when energy obtained in one role makes it easier to fulfill the requirements of another role. Strain-based conflict means that strain produced in one role can make it difficult to fulfill the requirements of another role (Carlson et al., 2000). Psychological conflict refers to the situation that psychological preoccupation with one role prevents one from becoming engaged in another role (Carlson and Frone, 2003). Finally, psychological enrichment occurs when an individual is able to put matters associated with one role into perspective by virtue of another role, which makes it easier to fulfill the requirements of the first role (Van Steenbergen et al., 2007).

An important aim of the present study is to investigate if the two positive psychological micro-interventions are powerful enough to achieve that - on the longer run - individuals will appraise the work-family combination less conflicting and more enriching. The COR theory (Hobfoll, 1989) as well as the WH-R model (Ten Brummelhuis and Bakker, 2012) provide arguments for an expected positive answer to this question. A basic tenet of the COR theory is that people strive to retain, protect and build resources that they value. COR theory describes two main processes: The first is a loss spiral, in which stress develops and resources further deplete, and the other is a gain spiral, in which resources accumulate. Those with greater resources are less vulnerable to perceive stress, and additionally they are more capable of future resource gain (Hobfoll, 1989, 2002). The W-HR model uses the loss and gain process of the COR theory to build a theoretical argument regarding the interface between work and home. Conflict between work and family occurs when stress in a particular domain depletes resources so that these resources are no longer available for functioning in the other domain. Enrichment occurs when resources from one domain lead to the development of resources in another domain which subsequently facilitates outcomes in the other domain. To summarize, as the names already imply, resources play a central role in both COR theory and W-HR model. Perceiving a loss of resources in either domain will result in perceiving the combination of roles as conflicting and perceiving resources gain in either domain will lead to a perception of role combining as enriching.

The preservation and use of resources is also at the core of the two micro-interventions that we are going to test in the present study. In the "use your resources" intervention participants are motivated to use the resources they already have at their disposal whereas in the "count your blessing intervention" participants are trained to value the resources they already have. We expect that both using as well as valuing resources will help employees to perceive the combination of work and family role after a few weeks (at T2) as less conflicting and more enriching. So, based on these theoretical insights we expect that:

Compared to the control condition, participants in the intervention conditions will experience at T2: 
H2a: lower WF conflict (strain-based, psychological)

H2b: higher WF enrichment (energy-based, psychological)

H2c: lower FW conflict (strain-based, psychological)

H2d: higher FW enrichment (energy-based, psychological)

\section{MATERIALS AND METHODS}

\section{Design and Procedure}

This study is a field experiment with three conditions and three measurement waves. Participants in the intervention conditions participated in an intervention week of seven days. Before the intervention, participants filled out the baseline questionnaire (T0), directly after the intervention week the first follow-up measurement (T1), and three weeks later the second follow-up measurement (T2) to examine the effects of the intervention in the somewhat longer run. Consistent with previous research (Van Steenbergen et al., 2008), we focus on working mothers of young children because the combination of work and family roles is a very salient issue for this group of employees. Criteria for inclusion were: (1) having at least one child aged five years or younger, (2) cohabiting with partner, and (3) both the participant and the partner had to work at least $24 \mathrm{~h}$ a week.

Participants were recruited by eight students who collaborated with the researchers. Students recruited in day-care centers, schools, and in shopping areas in and around the city of Utrecht in the Netherlands. In addition, both the students and the primary researchers recruited couples via email in their own networks and used a snowball technique to recruit more couples. The recruitment posters and emails stated the aim of the study, its voluntary nature, what was expected from participants, and that a voucher worth twenty euros (\$26) could be won when participating in the whole study. Participants could sign up via an email address that was created for the study. Upon signing up, they were informed about the dates before which the three surveys had to be completed.

Participants were randomly categorized into the three conditions: (1) "use your resources," (2) "count your blessings," and (3) control. To connect the data over time, participants were asked at each measurement moment to fill in the same unique personal code. Anonymity was ensured as this code was created by the participants themselves and was unknown to the researchers. Participants received all instructions and invitations to complete the surveys via email, and received reminder text messages for the surveys. After the first questionnaire (T0), participants were informed via email to which condition they were assigned.

The two interventions were designed in a highly similar fashion. Participants received a text (about 1.5 pages) that (a) gave information about the method (count your blessings or use your resources) and its theoretical roots in positive psychology. Then (b) a fictitious quote was given of a woman with two young children who described why she decided to participate in a training learning this method. Subsequently (c), instructions for the diary exercises were given, and participants were informed that they would receive an email with the URL to their diary every day at 7 p.m. Then (d) another fictitious quote was given by the same women describing how the method had helped her. Finally, (e) participants were instructed to perform the exercise as good as possible, and the importance was emphasized of performing the exercise every day. More specific information about the diary exercises is given below. The complete intervention texts are available upon request.

\section{Diary Exercise Use Your Resources}

The day before the diary exercises started, participants were instructed to reflect on their personal resources. We provided some examples of what this could be such as being assertive, energetic or optimistic, or having a good sense of humor, good organizational skills or financial resources. We then stated that it was step one to be aware of these resources, and step two to deploy them to manage their work, home life, or the combination of work and home more effectively or more pleasantly. Participants were instructed to write down their top 3 of personal resources. Each of the seven days, they had to deploy one of these resources in a conscious way to improve their work, their home life or the combination of these two. Each day, participants could choose in what area they wanted to implement the resource. As they could choose one of their three personal resources, some resources could be chosen more than once. Participants were instructed to apply the personal resource each day in a different way. Every day, participants were asked to write down on what personal resource they focused that day and in which area they deployed it. They also had to answer the question: "What effect did it have on you?"

\section{Diary Exercise Count Your Blessings}

The "count your blessings" diary exercise consisted of daily counting your blessings in one's work, home life or concerning the combination of work and home life. We provided some examples of what this could be such as having enjoyable or pleasant experiences or nice social encounters. Participants were instructed to, at least one time a day (preferably at a set time), think about the positive things that happened that day. Every day, participants were instructed to write down two blessings of the day in their diary. They could choose in which area (work, home, or the combination) they were counting their two blessings. For both blessings they had to answer the question: "Why was this experience positive?"

\section{Participants}

In total, 360 participants were recruited and randomly assigned to one of the three conditions. Of these participants, 240 completed all three surveys (overall response rate 67\%). The response rate for the "use your resources" condition was $67 \%$, for the "count your blessings" condition $73 \%$ and for the control condition $61 \%$. Out of the 240 participants, 14 participants were removed because they did not fit the inclusion criteria and eight because they did not answer the manipulation check correctly. This resulted in a sample of $N=218$ participants: $N=63$ in the "use your resources" condition, $N=79$ in the "count your blessings" condition, and $N=72$ in the control condition. Age of the participants ranged from 22 to 46 years $(M=35, \mathrm{SD}=4.1)$ and almost all participants were highly educated (92\%). There were no significant differences between the three conditions on the 
background variables, which were number of children, age of the participant, level of education, number of hours worked, and number of hours worked by the partner.

\section{Measures}

All measures were either existing Dutch measures or back translated from English.

Items were answered on 5-point rating scales ( $1=$ fully disagree, 5 = fully agree) unless stated otherwise.

Cognitive appraisals were assessed with measures developed by Kessler (1998), which we adapted to the situation of combining work and home roles. A 5-item scale assessed the extent to which participants appraised role-combining as a threat (e.g., "The combining of my work and home life is frightening to me," $\alpha \mathrm{T} 0=0.81, \alpha \mathrm{T} 1=0.87, \alpha \mathrm{T} 2=0.85)$. A six-item scale assessed the extent to which participants appraised role-combining as a challenge, e.g., "The combining of my work and home life enables me to learn more about myself," ( $\alpha \mathrm{T} 0=0.81, \alpha \mathrm{T} 1=0.84$, $\alpha \mathrm{T} 2=0.87)$. Secondary appraisal was assessed with a five-item scale e.g., "I have influence on the way in which I combine my work and home life." From this measure, we excluded one item ("I can change things in the way I combine my work and home life") because this resulted in more acceptable reliabilities, namely: $\alpha \mathrm{T} 0=0.67, \alpha \mathrm{T} 1=0.66, \alpha \mathrm{T} 2=0.67$ (instead of $\alpha \mathrm{T} 0=0.67$, $\alpha \mathrm{T} 1=0.62, \alpha \mathrm{T} 2=0.63)$. All items were answered on seven-point scales $(1=$ fully disagree, 7 = fully agree $)$.

\section{Work-Family Conflict (WFC)}

Strain-based WFC was assessed with the three-item scale developed by Carlson et al. (2000), e.g., "Due to all the pressures at work, sometimes when I get home I am too stressed to do the things I enjoy," $\alpha \mathrm{T} 0=0.74, \alpha \mathrm{T} 1=0.81, \alpha \mathrm{T} 2=0.84$.

Psychological WFC was also assessed with a 3 -item scale (Carlson and Frone, 2003), e.g., "When I am at home, I often think about things I need to accomplish at work" ( $\alpha \mathrm{T} 0=0.83$, $\alpha \mathrm{T} 1=0.85, \alpha \mathrm{T} 2=0.86)$.

\section{Work-Family Enrichment (WFE)}

Energy-based WFE and Psychological WFE were measured with two three-item scales (Van Steenbergen et al., 2007). Respectively, sample items and reliabilities were "When I get home from work I often feel emotionally recharged, enabling me to make a better contribution at home" $(\alpha \mathrm{T} 0=0.83, \alpha \mathrm{T} 1=0.89, \alpha \mathrm{T} 2=0.86)$ and "Because of my work, I am better able to put home-related matters into perspective" $(\alpha \mathrm{T} 0=0.80, \alpha \mathrm{T} 1=0.82, \alpha \mathrm{T} 2=0.86)$.

\section{Family-Work Conflict (FWC)}

Strain-based FWC was measured with a three-item scale developed by Carlson et al. (2000) and psychological FWC was measured with a three-item scale developed by Carlson and Frone (2003). Respectively, sample items and reliabilities were: "Tension and anxiety from my home life often weakens my ability to do my job" ( $\alpha \mathrm{T} 0=0.89, \alpha \mathrm{T} 1=0.91$, $\alpha \mathrm{T} 2=0.89)$ and "When I am at work, I often think about things I need to accomplish at home" $(\alpha \mathrm{T} 0=0.81, \alpha \mathrm{T} 1=0.84$, $\alpha \mathrm{T} 2=0.87)$.

\section{Family-Work Enrichment (FWE)}

Energy-based FWE and Psychological FWE were measured with the three-item scales developed by Van Steenbergen et al. (2007). Respectively, sample items and reliabilities were "Because I relax and regain my energy at home, I can better focus on performing my work" ( $\alpha \mathrm{T} 0=0.83, \alpha \mathrm{T} 1=0.83, \alpha \mathrm{T} 2=0.89)$, and "Because of my home life, I am more able to put work-related matters into perspective" $(\alpha \mathrm{T} 0=0.82, \alpha \mathrm{T} 1=0.87, \alpha \mathrm{T} 2=0.86)$.

\section{Manipulation Check and Level of Participation}

In the second questionnaire (T1), we included for the participants of the intervention conditions an item that served as a manipulation check, namely "What exercise did you perform during the previous week?" Participants could choose between "count your blessings" and "use your resources." As stated earlier, eight participants gave the wrong answer and we removed them from our sample. In addition, participants were asked: "How many days have you managed to actually perform the exercises seriously?" (0-7 days). Unfortunately, in the "count your blessings" condition, the average number of days $(M=5.3$, $\mathrm{SD}=1.7)$ was higher than in the "use your resources" condition $(M=4.2, \mathrm{SD}=2.0), F(1,144)=12.2 ; p<0.001$. To account for this difference in the implementation of the intervention, in all analyses not only the effects of the manipulation were examined, but also the additional effects of the number of days a participant performed the exercises.

\section{Statistical Analyses}

The data were analyzed using hierarchical linear regression (OLS) in SPSS 22 for Windows. To test the hypotheses, in the regression of the dependent variable at T1 (appraisal) or T2 (appraisal, conflict, enrichment), the dependent variable at baseline (T0) was entered in the first step. In the next step, two dummy variables concerning the manipulation were entered in the regression to test whether both interventions differed from the control condition. This step tested the main effects of the manipulation. In the third step, a variable indicating the number of days the participant had done the exercises in either of the intervention conditions was entered in the regression. In the final step the interaction between the type of intervention ("count your blessings" or "use your resources") and the number of participated days was entered in the regression. Participants in the control condition scored 0 on both dummy variables and on both number of days variables (main effect and interaction variable), and constitute the baseline for testing each effect in the regression. Participants in the "count your blessings" condition scored 1 on the "count your blessings" dummy and 0 to 7 on the number of days variable (main effect), and 0 on both other variables. Participants in the "use your resources" condition scored 1 on the "use your resources" dummy and 0 to 7 on both number of days variables (main effect and interaction effect), and 0 on the dummy variable for the other condition. The final regression gives full information on the influence of the manipulation and the number of days the participants did their exercises in both intervention conditions. It should be noted that predictors were not centered to the mean in order to keep the control condition as the baseline for testing each effect in 
the regression. To avoid faulty interpretations of the regression weights, we present the results of the regression hierarchically rather than the final regression equation.

\section{RESULTS}

\section{Descriptive Statistics and Correlations at Baseline}

Table 1 presents the descriptive statistics and correlations between appraisals, work-family conflict and enrichment, family-work conflict and enrichment at baseline.

Table 1 shows that threat appraisal correlated strongly negatively with challenge and secondary appraisal, whereas challenge and secondary appraisal were moderately positively related. Moreover, strain-based work-family conflict correlated strongly positively with threat appraisal, and strongly negatively with energy-based work-family enrichment. In general, the correlations between strain/energy-based and psychological conflict or enrichment were only moderate. A multivariate analysis of variance showed that there was neither an overall difference at baseline, $F(22,412)=0.87$, ns, nor significant differences between conditions for any of the individual variables at baseline, $F(2,215)<2.37$, ns. Thus, randomization worked as anticipated.

\section{Threat, Challenge, and Secondary Appraisals}

Hypothesis 1 stated that both interventions would contribute to lower threat and higher challenge appraisals of combining work and family in both the short term and the long term. Moreover, secondary appraisal - i.e., perceived coping opportunities was predicted to improve following both interventions. To test this, hierarchical regressions of threat, challenge, and secondary appraisals directly after the intervention (T1) and three weeks later (T2) were carried out to examine the effects of the interventions and the number of days the participants carried out the exercises. The results are presented in Table 2.

In the regression of threat appraisals, the first step showed that threat appraisal at baseline contributed strongly to the regression of threat appraisal at both $\mathrm{T} 1$ and $\mathrm{T} 2$. In step 2, the main effects of the intervention did not contribute significantly to the regression of threat appraisal at $\mathrm{T} 1[F(2,214)<1.0$; ns $]$ but - partly in line with the hypothesis - it did contribute significantly to the regression of threat appraisal at $\mathrm{T} 2[F(2,214)=4.4 ; p<0.05]$. As can be seen in Table 2, only the "use your resources" intervention reduced threat appraisals in the long run compared to the control condition. Neither the number of participated days nor the interaction between the type of intervention and the number of participated days contributed significantly to the regression of threat appraisals at $\mathrm{T} 1$ or $\mathrm{T} 2$.

The regressions of challenge appraisals showed that challenge appraisal at baseline contributed strongly to the regression of challenge appraisals at both $\mathrm{T} 1$ and $\mathrm{T} 2$. Contrary to hypothesis 1 , the main effects of the intervention did not contribute significantly to the regressions $[F(2,214)<1.2 ; \mathrm{ns}]$. Nevertheless, both the number of participated days and the interaction between the type of intervention and the number of participated days contributed significantly to the regression of challenge appraisal at T1 and at T2. Figure 1 depicts the regression lines for challenge appraisal at $\mathrm{T} 1$ on the number of participated days in both interventions groups. The graphic for challenge appraisal at $\mathrm{T} 2$ was almost identical.

It can be seen that for participants in the "use your resources" condition, the more days they did their exercises, the more they regarded combining work and family as a challenge. This was not true for participants in the "count your blessings" condition. The simple slope for the number of participated days was significant in the "use your resources" condition in both regressions of challenge appraisals at T1 and T2 $(p<0.001)$.

In the regressions of the secondary appraisal, secondary appraisal at baseline contributed strongly to the regression of secondary appraisals at both $\mathrm{T} 1$ and T2. Contrary to the hypothesis, the main effects of the intervention did not contribute significantly to the regressions $[F(2,214)<1.7 ; \mathrm{ns}]$. Nevertheless, the number of participated days contributed to the regression of secondary appraisal three weeks after the intervention (T2), and the interaction between the type of intervention and the number of participated days contributed significantly to both the regression of secondary appraisal directly after the intervention (T1) and three weeks later (T2). The graphics for secondary appraisals were highly similar to those presented in Figure 1 for challenge appraisals at T1. For participants in the "use your resources" condition, the more days they did their exercises, the more coping opportunities they experienced for combining work and family, both in the short and the long term. This was not true for participants in the "count your blessings" condition. The simple slope for the number of participated days was significant and positive in the "use your resources" condition in both regressions (T1, $p<0.05$; T2, $p<0.001$ ), but negative in the "count your blessings" condition directly after the intervention $(\mathrm{T} 1, p<0.05)$.

\section{Work-Family Conflict}

Hypothesis 2a stated that the interventions would reduce both strain-based and psychological work-family conflict in the long run. Hierarchical regressions of T2 WF conflict are presented in Table 3.

As can be seen, strain-based and psychological work-family conflict were highly stable: they were strongly predicted by these variables at baseline. No main effects of the interventions were found $[F(2,214)<1.7$; ns] but for psychological WF conflict, the number of participated days contributed significantly to the regression. This means that as participants did their exercises on more days, they experienced lower psychological WF conflict. However, the interaction between type of intervention and participated days was not significant in both regressions.

\section{Work-Family Enrichment}

Hypothesis 2b stated that the interventions would increase both energy-based and psychological work-family enrichment in the long run. Hierarchical regressions of T2 WF enrichment are presented in Table 3. 
TABLE 1 | Descriptive statistics and correlations of the dependent variables at baseline $(N=218)$.

\begin{tabular}{|c|c|c|c|c|c|c|c|c|c|c|c|c|c|c|c|}
\hline & & Range & $M$ & SD & 1 & 2 & 3 & 4 & 5 & 6 & 7 & 8 & 9 & 10 & 11 \\
\hline 1 & Threat appraisal & $1-7$ & 3.09 & 1.19 & 1.00 & & & & & & & & & & \\
\hline 2 & Challenge appraisal & $1-7$ & 5.23 & 0.88 & $-0.52^{\star}$ & 1.00 & & & & & & & & & \\
\hline 3 & Secondary appraisal & $1-7$ & 5.06 & 0.95 & $-0.44^{*}$ & $0.33^{*}$ & 1.00 & & & & & & & & \\
\hline 4 & Work-family conflict strain & $1-5$ & 2.57 & 0.90 & $0.53^{*}$ & $-0.46^{\star}$ & $-0.38^{\star}$ & 1.00 & & & & & & & \\
\hline 5 & Work-family conflict psychological & $1-5$ & 3.30 & 0.98 & $0.33^{\star}$ & $-0.20^{\star}$ & -0.04 & $0.24^{\star}$ & 1.00 & & & & & & \\
\hline 6 & Work-family enrichment energy & $1-5$ & 2.91 & 0.89 & $-0.27^{\star}$ & $0.33^{\star}$ & $0.21^{*}$ & $-0.56^{\star}$ & $-0.16^{*}$ & 1.00 & & & & & \\
\hline 7 & Work-family enrichment psychological & $1-5$ & 3.47 & 0.92 & -0.04 & $0.16^{\star}$ & 0.07 & $-0.15^{\star}$ & -0.00 & $0.37^{\star}$ & 1.00 & & & & \\
\hline 8 & Family-work conflict strain & $1-5$ & 1.85 & 0.85 & $0.35^{\star}$ & $-0.25^{\star}$ & $-0.34^{*}$ & $0.21^{*}$ & -0.02 & -0.06 & 0.01 & 1.00 & & & \\
\hline 9 & Family-work conflict psychological & $1-5$ & 2.47 & 0.92 & $0.26^{\star}$ & -0.12 & -0.13 & 0.05 & 0.02 & -0.02 & $0.18^{*}$ & $0.48^{\star}$ & 1.00 & & \\
\hline 10 & Family-work enrichment energy & $1-5$ & 3.70 & 0.81 & $-0.20^{\star}$ & $0.35^{\star}$ & 0.13 & $-0.17^{\star}$ & -0.02 & $0.20^{*}$ & $0.14^{*}$ & $-0.22^{*}$ & -0.08 & 1.00 & \\
\hline 11 & Family-work enrichment psychological & $1-5$ & 4.04 & 0.77 & -0.12 & $0.29^{*}$ & $0.17^{\star}$ & $-0.27^{\star}$ & -0.12 & $0.16^{*}$ & $0.25^{*}$ & -0.04 & 0.07 & $0.22^{*}$ & 1.00 \\
\hline
\end{tabular}

TABLE 2 | Regression of threat, challenge and secondary appraisals directly after the intervention (T1) and 3 weeks later (T2).

\begin{tabular}{|c|c|c|c|c|c|c|c|c|c|c|c|c|c|}
\hline \multirow[b]{2}{*}{ Step } & \multirow[b]{2}{*}{ Predictor } & \multicolumn{2}{|c|}{ Threat T1 } & \multicolumn{2}{|c|}{ Threat T2 } & \multicolumn{2}{|c|}{ Challenge T1 } & \multicolumn{2}{|c|}{ Challenge T2 } & \multicolumn{2}{|c|}{ Secondary appraisal T1 } & \multicolumn{2}{|c|}{ Secondary appraisal T2 } \\
\hline & & B & SE B & B & SE B & B & SE B & B & SE B & B & SE B & B & SE B \\
\hline \multirow[t]{4}{*}{1} & Constant & $0.73^{\star}$ & 0.17 & $0.85^{\star}$ & 0.16 & $2.61^{*}$ & 0.30 & $2.64^{*}$ & 0.31 & $2.08^{*}$ & 0.27 & $2.40^{*}$ & 0.27 \\
\hline & Threat T0 & $0.70^{\star}$ & 0.05 & $0.64^{*}$ & 0.05 & & & & & & & & \\
\hline & Challenge T0 & & & & & $0.51^{*}$ & 0.06 & $0.54^{*}$ & 0.06 & & & & \\
\hline & Secondary appraisal T0 & & & & & & & & & $0.61^{*}$ & 0.05 & $0.55^{\star}$ & 0.05 \\
\hline \multirow[t]{2}{*}{2} & Dummy count blessings & -0.03 & 0.15 & -0.03 & 0.14 & 0.14 & 0.12 & 0.13 & 0.12 & 0.04 & 0.12 & 0.09 & 0.12 \\
\hline & Dummy use resources & -0.18 & 0.15 & $-0.38^{\star}$ & 0.14 & 0.15 & 0.13 & 0.19 & 0.13 & 0.21 & 0.12 & 0.14 & 0.13 \\
\hline 3 & Days participated & -0.06 & 0.04 & -0.00 & 0.04 & $0.07^{*}$ & 0.03 & $0.08^{*}$ & 0.03 & 0.01 & 0.03 & $0.08^{*}$ & 0.03 \\
\hline \multirow[t]{2}{*}{4} & Interaction Intervention ${ }^{\star}$ Days & -0.09 & 0.08 & -0.04 & 0.08 & $0.21^{*}$ & 0.06 & $0.19^{\star}$ & 0.07 & $0.20^{*}$ & 0.06 & $0.16^{*}$ & 0.07 \\
\hline & $R^{2}$ & $0.46^{\star}$ & & $0.45^{\star}$ & & $0.33^{*}$ & & $0.34^{\star}$ & & $0.43^{*}$ & & $0.37^{*}$ & \\
\hline
\end{tabular}

$N=218 ;{ }^{*} p<0.05$.

As can be seen, energy-based work-family enrichment was more stable than psychological work-family enrichment. Again, no main effects of the interventions were found $[F(2,214)<1.0$;

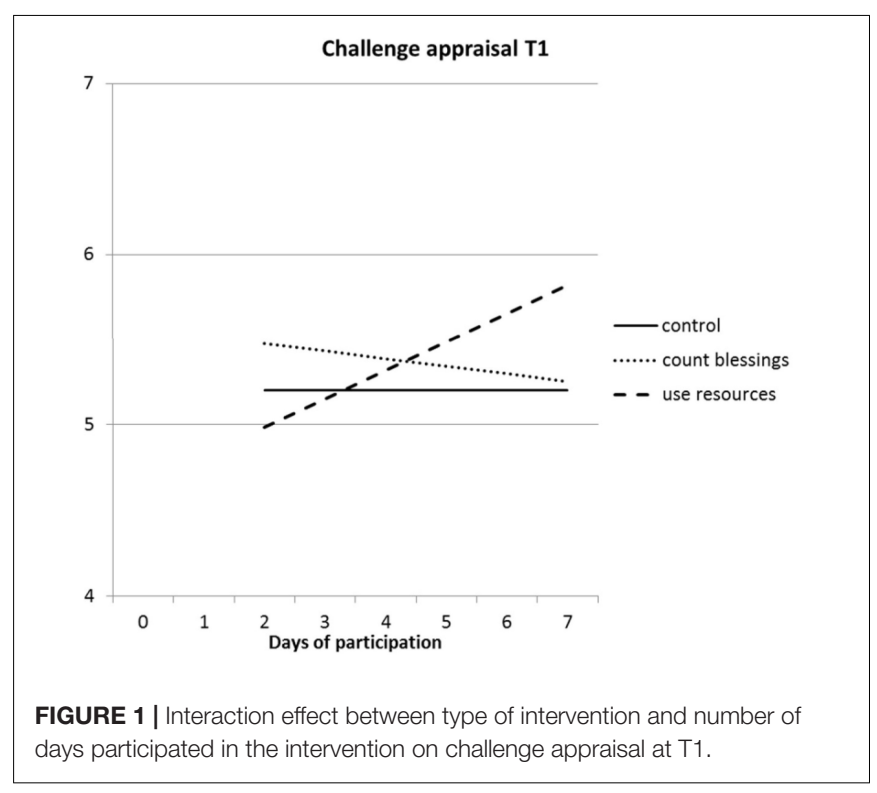

ns]. However, the interaction between type of intervention and participated days was significant in both regressions. Apparently, the relationship between the number of participated days and WF enrichment was different for participants in both conditions. Figure 2 shows the graphics for energy-based WF enrichment at T2. The graphics for psychological work-family enrichment was highly similar to those presented in Figure 2.

Both energy-based and psychological WF enrichment increased as participants in the "use your resources" condition did their exercises on more days, but not in the "count your blessings" condition. In both regressions, the simple slope for the number of participated days was significant for the "use your resources" intervention (energy-based, $p<0.001$; psychological, $p<0.05$ ), but not for the "count your blessings" intervention.

\section{Family-Work Conflict}

Hypothesis $2 \mathrm{c}$ stated that the interventions would reduce both strain-based and psychological family-work conflict in the long run. Hierarchical regressions of T2 FW conflict are presented in Table 4.

As can be seen, strain-based and psychological familywork conflict were highly stable: they were strongly predicted by these variables at baseline. No main effects of the interventions were found $[F(2,214)<1.9$; ns]. 
TABLE 3 | Regression of strain-based and psychological work-family conflict and energy-based and psychological work-family enrichment.

\begin{tabular}{|c|c|c|c|c|c|c|c|c|c|}
\hline \multirow[b]{2}{*}{ Step } & \multirow[b]{2}{*}{ Predictor } & \multicolumn{2}{|c|}{$\begin{array}{l}\text { WF conflict } \\
\text { strain T2 }\end{array}$} & \multicolumn{2}{|c|}{$\begin{array}{c}\text { WF conflict } \\
\text { psychological T2 }\end{array}$} & \multicolumn{2}{|c|}{$\begin{array}{c}\text { WF enrichment } \\
\text { energy T2 }\end{array}$} & \multicolumn{2}{|c|}{$\begin{array}{c}\text { WF enrichment } \\
\text { psychological T2 }\end{array}$} \\
\hline & & B & SE B & B & SE B & B & SE B & B & SE B \\
\hline \multirow[t]{5}{*}{1} & Constant & 0.50 & 0.14 & $0.75^{\star}$ & 0.16 & $1.29^{*}$ & 0.16 & $1.99^{*}$ & 0.20 \\
\hline & WF conflict strain TO & $0.73^{\star}$ & 0.05 & & & & & & \\
\hline & WF conflict psychological T0 & & & $0.71^{*}$ & 0.05 & & & & \\
\hline & WF enrichment energy T0 & & & & & $0.66^{*}$ & 0.05 & & \\
\hline & WF enrichment psychological T0 & & & & & & & $0.49^{*}$ & 0.06 \\
\hline \multirow[t]{2}{*}{2} & Dummy count blessings & -0.10 & 0.11 & 0.01 & 0.11 & 0.08 & 0.11 & -0.04 & 0.12 \\
\hline & Dummy use resources & -0.22 & 0.12 & -0.17 & 0.11 & 0.11 & 0.12 & 0.09 & 0.13 \\
\hline 3 & Days participated & -0.04 & 0.03 & $-0.08^{*}$ & 0.03 & 0.05 & 0.03 & 0.04 & 0.03 \\
\hline \multirow[t]{2}{*}{4} & Interaction Intervention`Days & -0.08 & 0.06 & -0.06 & 0.06 & $0.22^{\star}$ & 0.06 & $0.15^{\star}$ & 0.07 \\
\hline & $R^{2}$ & $0.49^{*}$ & & $0.55^{\star}$ & & $0.47^{*}$ & & $0.28^{*}$ & \\
\hline
\end{tabular}

$N=218 ; * p<0.05$.

The number of participated days nor the interaction with type of intervention contributed to either regressions of FW conflict.

\section{Family-Work Enrichment}

Hypothesis $2 \mathrm{~d}$ stated that the interventions would increase both energy-based and psychological family-work enrichment in the long run. Hierarchical regressions of T2 FW enrichment are presented in Table 4. Both energy-based and psychological family-work enrichment were moderately stable. There was a marginally significant effect of the interventions for energybased FW enrichment $[F(2,214)=2.6 ; p<0.10]$, but not for psychological FW enrichment $[F(2,214)=2.1 ; p>0.10]$. For both energy-based and psychological FW enrichment, the "use your resources" intervention seemed to increase FW enrichment compared to the control condition. The number of

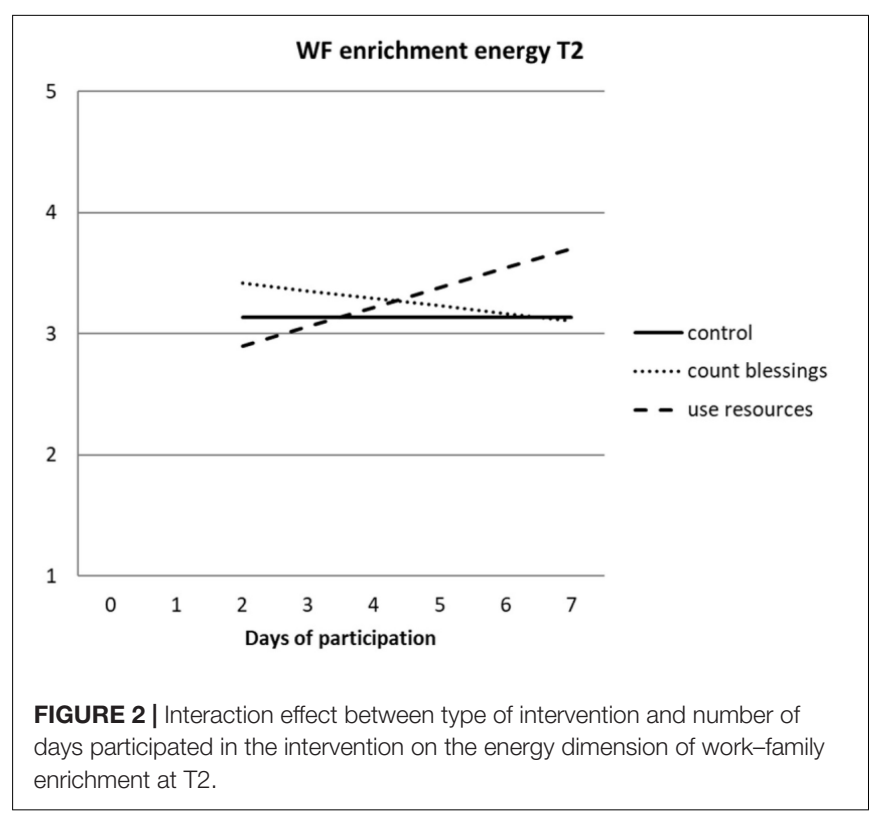

participated days did not contribute to the regression of energybased or psychological FW enrichment. The interaction between type of intervention and participated days was significant for psychological FW enrichment, but not for energy-based FW enrichment. The regression lines for psychological FW enrichment are presented in Figure 3.

It can be seen that psychological FW enrichment increases as participants in the "use your resources" condition did their exercises on more days, but not in the "count your blessings" condition. In this regression, the simple slope for the number of participated days was significant for the "use your resources" intervention $(p<0.001)$.

\section{DISCUSSION}

The goal of the present study was to develop and test two positive micro-interventions (i.e., "use your resources" and "count your blessings") which were based on the TMS (Lazarus and Folkman, 1984) and on insights derived from the positive psychology movement (Seligman et al., 2005) and aimed to influence the combining of work and family roles. In a field experiment among working mothers we examined whether participants of the micro-interventions showed an increase in challenge appraisal, a decrease in threat appraisal and an increase in perceived coping options after the intervention, compared to participants of the control group. In addition, we examined whether participants indicated to experience less work-family and family work-conflict, and more work-family and familywork enrichment.

In general, the results revealed that the daily exercise "use your resources" was successful in improving (the appraisal of) the combination of work and family roles. Participating in the "count your blessing" micro-intervention did not result in a better appraisal of combing work and family roles. Moreover, we also detected that for generating positive effects it was very important that the participants performed the exercises on a regular basis. 
TABLE 4 | Regression of family-work conflict, family-work enrichment.

\begin{tabular}{|c|c|c|c|c|c|c|c|c|c|}
\hline \multirow[b]{2}{*}{ Step } & \multirow[b]{2}{*}{ Predictor } & \multicolumn{2}{|c|}{$\begin{array}{c}\text { FW conflict } \\
\text { strain T2 }\end{array}$} & \multicolumn{2}{|c|}{$\begin{array}{c}\text { FW conflict } \\
\text { psychological T2 }\end{array}$} & \multicolumn{2}{|c|}{$\begin{array}{c}\text { FW enrichment } \\
\text { energy T2 }\end{array}$} & \multicolumn{2}{|c|}{$\begin{array}{c}\text { FW enrichment } \\
\text { psychological T2 }\end{array}$} \\
\hline & & B & SE B & B & SE B & B & SE B & B & SE B \\
\hline \multirow[t]{5}{*}{1} & Constant & $0.81^{*}$ & 0.11 & $0.74^{*}$ & 0.13 & $2.29^{*}$ & 0.20 & $2.37^{\star}$ & 0.23 \\
\hline & FW conflict strain TO & $0.57^{*}$ & 0.06 & & & & & & \\
\hline & FW conflict psychological TO & & & $0.69^{*}$ & 0.05 & & & & \\
\hline & FW enrichment energy T0 & & & & & $0.44^{*}$ & 0.05 & & \\
\hline & FW enrichment psychological TO & & & & & & & $0.42^{*}$ & 0.06 \\
\hline \multirow[t]{2}{*}{2} & Dummy count blessings & -0.21 & 0.11 & 0.06 & 0.11 & 0.12 & 0.10 & 0.14 & 0.10 \\
\hline & Dummy use resources & -0.10 & 0.12 & 0.08 & 0.12 & $0.24^{*}$ & 0.10 & $0.22^{\star}$ & 0.11 \\
\hline 3 & Days participated & -0.01 & 0.03 & -0.02 & 0.03 & -0.00 & 0.03 & 0.05 & 0.03 \\
\hline \multirow[t]{2}{*}{4} & Interaction Intervention`Days & -0.00 & 0.06 & 0.00 & 0.06 & 0.10 & 0.05 & $0.13^{*}$ & 0.05 \\
\hline & $R^{2}$ & $0.34^{*}$ & & $0.47^{*}$ & & $0.28^{*}$ & & $0.25^{\star}$ & \\
\hline
\end{tabular}

$N=218 ;{ }^{*} p<0.05$.

We found that the more days women performed the exercise, the stronger the effect. Below we discuss the study findings and implications in more detail.

\section{"Use Your Resources" Intervention and (the Cognitive Appraisal of) Role Combining}

Results showed that the more days women did this exercise, the more they appraised combining work and family as a challenge and the more coping opportunities (secondary appraisal) in dealing with role combination they experienced, both directly after the intervention and a few weeks later. Participating in this intervention also appeared to reduce threat appraisals, but only after a few weeks and it did not matter how many days one complied with the instructions. Apparently it takes longer before the "use your resources" micro-intervention generates its effects in terms of reduced threat appraisal. Generally, our findings support previous studies alluding that cognitive appraisal processes play an important role in combining work and family roles (Edwards and Rothbard, 2000; Green et al., 2011). More specifically, the results are in line with the study of Van Steenbergen et al. (2008) which also showed that it is possible to exert influence on the way in which individuals appraise their own combination of work and family roles. As such, our results substantiate the idea that the appraisal of the work-family interface can be influenced to some extent. Hence, the theoretical framework of the TMS appeared a good choice for demonstrating this.

Not only did the cognitive appraisal of the work-family interface change as a result of participating in this intervention, also the experience of the work-family interface itself changed in the expected direction. We examined several indicators of the work-family interface (conflict and enrichment in both directions and on an energy and psychological level) and found a rather straightforward pattern of results. Both energy-based and psychological WF enrichment increased as the participants in the "use your resources" condition did their exercises more frequently. With regard to energy-based FW enrichment the results also showed that this increased for participants in the "use your resources" conditions. For the psychological dimension of FW enrichment, this was dependent of the number of days they participated in the exercises: The more days they did the exercise, the stronger the effect. Participating in the "use your resources" intervention did not seem to be effective in reducing conflict. We distinguished between four types of role conflict (strain-based WF and FW conflict and psychological WF and FW conflict) and none of the types of role conflict showed significant differences between the participants in the three conditions. Apparently, the positive psychological "use your resources" intervention is effective in increasing positive states but less suitable for reducing negative states. This underlines the belief of many scholars in the area of positive psychology that positive psychology interventions are not explicitly designed to treat negative states: they are designed to build positive qualities.




Hence, if a positive intervention succeeds to reduce negative outcomes, this should be considered as an unexpected positive side effect (Sin and Lyubomirsky, 2009; Meyers et al., 2013). This in in line with a study by Ouweneel et al. (2014) who found that some positive psychological interventions seemed to foster positive emotions and academic engagement, but did not decrease negative emotions. One could also speculate that this has something to do with the nature of the sample. Since our sample was a non-clinical sample consisting of working women who were not on sick leave because of depression, burnout or otherwise, negative emotional states due to role combination may have been less prevalent than positive states, leading to a so-called "floor effect" for these negative states. In general, Sin and Lyubomirsky (2009) state that in clinical samples positive interventions are more likely to affect negative states, though in non-clinical samples this is probably not the case.

Our results can also be interpreted in line with a review of Gilbert et al. (2018) which shows promising evidence that personal resources can be built through simple interventions hereby contributing to many aspects of workers' performance and well-being. Although our intervention was not aimed at building resources but at using resources, it both refers to the same underlying premise that personal resources are beneficial for employee wellbeing and functioning and are as such worthwhile to invest in.

In general, the results of the "use your resources" intervention are in line with a review of 15 studies on the effects of positive psychological interventions in organizations (Meyers et al., 2013). The review showed that these type of interventions consistently enhanced employee well-being and, to a lesser degree, performance. However, as there were no studies included in the review that were specifically developed to test the added value of positive psychology interventions for the work-family interface, we should be a bit careful in drawing this conclusion. The results of the present study first need to be replicated. Surprisingly, to the best of our knowledge, ever since the promising results of the study of Van Steenbergen et al. (2008), no other researchers have taken up the challenge to apply positive psychology interventions to the work-family domain. We hope this study will stimulate new researchers to do so because we think that positive psychology (micro)-interventions have a lot to offer to the workfamily domain.

\section{"Count Your Blessings" Intervention and (the Cognitive Appraisal of) Role Combining}

Unexpectedly, participating in the "count your blessings" intervention did not change the appraisal of the combination of the work-family interface, nor did it influence the experience of the work-family interface itself, neither in the short run nor in the longer run. One possible explanation for this unexpected result could be that behavioral positive interventions (like using your resources) work better than cognitive interventions (like counting your blessings). A similar effect was found by Ouweneel et al. (2014). They found that the cognitive intervention "thoughts of gratitude" was less effective than the behavioral intervention "acts of kindness" in generating positive emotions and academic engagement. Behavioral interventions might evoke more immediate positive feedback than cognitive interventions because it is mostly about overt behavior that can be seen and rewarded by important others like the partner, children or colleagues. However, as other studies do report promising effects of the "three good things exercise" (on which our count your blessings exercise is based) (e.g., Bono et al. (2013) this explanation certainly warrants more research.

\section{Exercise Frequency as a Moderator}

It is well-known from the literature that a number of factors moderate the effects of positive psychology interventions. Voluntary participation seems to be the most crucial one. Two major meta-analyses (Sin and Lyubomirsky, 2009; Bolier et al., 2013) showed that self-selected volunteers derive greater well-being benefits (average $r=0.35$ ) than did participants who were assigned (average $r=0.20$ ). Our results add to this knowledge that the frequency of doing exercises also is an important factor for generating positive effects of the intervention. For the "use your resources" intervention we found stronger positive effects when the participants performed the exercise on more days. This aligns with results of a study of Lyubomirsky et al. (2011) who found that effort is associated with the magnitude of resource gains. Participants experienced larger gains when they expect the exercise to be useful and when they completed it repeatedly and attentively. Unfortunately attrition rates are often high, in studies of both online volunteers and workers (e.g., Page and Vella-Brodrick, 2013). So we can carefully conclude that employees who complete interventions as meant, tend to experience more resource gains (Meyers et al., 2013), but still little is known about those who drop out.

\section{Limitations and Implications for Future Research and Practice}

Our study is not without limitations. First, due to our sampling technique we have a selective sample which makes it difficult to generalize the results of his study to the total population of working mothers. More studies should try to replicate the present findings in order to more fully understand what works for whom. Second, we compared two intervention groups with a control group that did not receive an intervention. Future studies could include a second control group that receives another kind of intervention of which no effect is expected. This could probably address the potential influence of certain experimenter demands, like getting attention, on the dependent variables. Another limitation refers to the duration of the intervention. An intervention of seven days is a relatively short period for trying to structurally change appraisals and behaviors of individuals. Performing the exercises for a longer time period can possibly lead to more effectiveness of the interventions. Thus, future research could investigate 
whether a positive psychological intervention that entails a longer period of exercises is more effective. This would be in line with a study on habit formation, which showed that changes in lifestyle became automatic over a period ranging from 18 to 254 days, with a median of 66 days (Lally et al., 2010). As far as we know, no such study has yet been carried out for more psychological interventions such as using your strengths or counting your blessings, but it seems likely that for such psychological habits to form also a longer period of practice would be beneficial. As our results indicated at the same time, that the more frequently the exercises were performed during the seven days, the stronger the effect was on the outcome, it would also be worthwhile to examine the optimal frequency of exercises in future studies, in addition to examining the optimal duration of the intervention.

Also, in our study we focused on conflict and enrichment as outcome measures. Future research could examine if positive psychological micro-interventions also have implications for other outcomes, preferably more objective, behavioral outcomes such as positive organizational behavior or positive social behavior in the work and family domains (as rated by others). In a related vein, new research could also consider the working of certain moderator variables like self-regulatory strength. It can be expected that individuals with good self-regulatory capabilities are better able to adhere to the exercises and to adapt their behavior in accordance with the changing appraisal of the situation. Finally, future research could explore the possibilities to let participants perform both interventions simultaneously. Since the intervention "count your blessings" mainly tries to influence the primary appraisal and the intervention "use your resources" mainly tries to influence the secondary appraisal, letting participants perform both interventions could enhance the results. This aligns with the so-called shotgun approach (Sin and Lyubomirsky, 2009) in which individuals practice multiple positive psychological interventions. This may be more effective than engaging in only one activity (e.g., Seligman et al., 2005).

Regarding theoretical advancements, the present study shows that the TMS not only provides a promising framework to study some of the mechanisms through which individuals' cognitions about their combination of work and family roles influences their experiences in combining both roles, but also points to specific ways to intervene in this process. In addition, although positive psychological interventions have been used in general contexts to increase happiness (for an overview, see Lyubomirsky, 2007) as well as in work contexts to increase work engagement (for an overview, see Schaufeli and Salanova, 2010), the present study is to our knowledge, the first study that applies these insights in the context of combing multiple roles, hereby adding specifically to this literature. Moreover, the COR theory and W-HR model prove valuable in better understanding why the "use your strengths" intervention works. The COR theory posits that gain spirals occur when one's resources lead to the acquisition of even more resources. The $\mathrm{W}-\mathrm{HR}$ model explains more specifically how resources in one domain (e.g., work) can lead to the acquisition of resources in another domain (e.g., home), hence resulting in better outcomes in the "receiving domain." Take an employee who decides to use her strength "kindness to others" more at work. At work, she for example offers to help a co-workers out who is very busy. This act of kindness may be reciprocated by co-workers at times when she herself is very busy, which increases her perceived social support at work. Because of this positive experience, this worker also starts to offer help to other working parents, which is reciprocated in such a way that she is building a network of parents in the neighborhood who help each other out. This example illustrates how skills learned at work enrich the home domain.

Since our study showed that one micro-intervention (use your resources) is effective in improving employees' appraisal of their work-life balance, it has immediate and fairly easy to implement practical implications. This seems important because, preferably, interventions need to be integrated into the busy days of individuals for whom "time" is an important factor to reckon with (Meyers et al., 2013). Because the intervention is short, simple, and self-guided, there is also little in the way of costs or drawbacks for organizations. Thus, this intervention seems like a potentially useful component of workplace work-family initiatives. We recommend organizations to organize brief workshops in which the technique is explained and participants can practice under supervision of a qualified coach. After that, employees can use the strategy "use your resources" on their own initiative and on a daily basis in order to boost their work-family balance. So for employees who want to improve their work-family balance, the simplest advice we can give is: "Use your resources!"

\section{DATA AVAILABILITY STATEMENT}

The datasets generated for this study are available on request to the corresponding author.

\section{ETHICS STATEMENT}

Ethical review and approval was not required for the study on human participants in accordance with the local legislation and institutional requirements that were valid at the time of data collection. The patients/participants provided their written informed consent to participate in this study.

\section{AUTHOR CONTRIBUTIONS}

MP and ES were responsible for the conception and design of the study and organized the database. MP wrote the first draft of the manuscript. ES and JY wrote sections of the manuscript. JY performed the statistical analyses. All authors read and approved the final submitted version. 


\section{REFERENCES}

Allen, T. D., Herst, D. E., Bruck, C. S., and Sutton, M. (2000). Consequences associated with work-to-family conflict: a review and agenda for future research. J. Occup. Health Psychol. 5, 278-308. doi: 10.1037/1076-8998.5.2.278

Amstad, F. T., Meier, L. L., Fasel, U., Elfering, A., and Semmer, N. K. (2011). A meta-analysis of work-family conflict and various outcomes with a special emphasis on cross-domain versus matching-domain relations. J. Occup. Health Psychol. 16, 151-169. doi: 10.1037/a0022170

Bolier, L., Haverman, M., Westerhof, G. J., Riper, H., Smit, F., and Bohlmeijer, E. (2013). Positive psychology interventions: a meta-analysis of randomized controlled studies. BMC Public Health 13:119. doi: 10.1186/1471-2458-13-119

Bono, J. E., Glomb, T. M., Shen, W., Kim, E., and Koch, A. J. (2013). Building positive resources: Effects of positive events and positive reflection on work stress and health. Acad. Manag. J. 56, 1601-1627. doi: 10.5465/amj.2011.0272

Byron, K. (2005). A meta-analytic review of work-family conflict and its antecedents. J. Vocat. Behav. 62, 169-198. doi: 10.1016/j.jvb.2004.08.009

Carlson, D. S., and Frone, M. R. (2003). Relation of behavioral and psychological involvement to a new four-factor conceptualization of workfamily interference. J. Bus. Psychol. 17, 515-535.

Carlson, D. S., Kacmar, K. M., and Williams, L. J. (2000). Construction and initial validation of a multidimensional measure of work-family conflict. J. Vocat. Behav. 56, 249-276. doi: 10.1006/jvbe.1999.1713

Demerouti, E., Derks, D., Ten Brummelhuis, L., and Bakker, A. B. (2014). "New ways of working: Impact on working conditions, work-family balance, and well-being," in The impact of ICT on quality of working life, eds C. Korunka, and P. Hoonakker, (Netherlands: Springer), 123-141. doi: 10.1007/978-94-0178854-0_8

Edwards, J. R., and Rothbard, N. P. (2000). Mechanisms linking work and family: Clarifying the relationship between work and family constructs. Acad. Manag. Rev. 25, 178-199. doi: 10.5465/amr.2000.2791609

Fellows, K. J., Chiu, H. Y., Hill, E. J., and Hawkins, A. J. (2016). Work-family conflict and couple relationship quality: a meta-analytic study. J. Fam. Econ. Issues 37, 509-518. doi: 10.1007/s10834-015-9450-7

Folkman, S., Lazarus, R. S., Dunkel-Schetter, C., DeLongis, A., and Gruen, R. J. (1986). Dynamics of a stressful encounter: cognitive appraisal, coping, and encounter outcomes. J. Personal. Soc. Psychol. 50, 992-1003. doi: 10.1037/00223514.50.5.992

Gilbert, E., Foulk, T., and Bono, J. (2018). Building personal resources through interventions: An integrative review. J. Organ. Behav. 39, 214-228. doi: 10. 1002/job. 2198

Green, S. G., Bull Schaefer, R. A., MacDermid, S. M., and Weiss, H. M. (2011). Partner reactions to work-to-family conflict: cognitive appraisal and indirect crossover in couples. J Manag. 37, 744-769. doi: 10.1177/0149206309349307

Greenhaus, J. H., and Beutell, N. (1985). Sources of conflict between work and family roles. Acad. Manag. Rev. 10, 76-88. doi: 10.5465/amr.1985.4277352

Greenhaus, J. H., and Powell, G. N. (2006). When work and family are allies: a theory of work-family enrichment. Acad. Manag. Rev. 31, 72-92. doi: 10.5465/ amr.2006.19379625

Hammer, L. B., Kossek, E. E., Anger, W. K., Bodner, T., and Zimmerman Kristi, L. (2011). Clarifying work-family intervention processes: the roles of workfamily conflict and family-supportive supervisor behaviors. J. Appl. Psychol. 96, 134-150. doi: 10.1037/a0020927

Hobfoll, S. E. (1989). Conservation of resources: a new attempt at conceptualizing stress. Am. Psychol. 44, 513-524. doi: 10.1037/0003-066x.44.3.513

Hobfoll, S. E. (2002). Social and psychological resources and adaptation. Rev. General Psychol. 6, 307-324. doi: 10.1037/1089-2680.6.4.307

Kessler, T. A. (1998). The cognitive appraisal of health scale: development and psychometric evaluation. Res. Nur. Health 21, 73-82. doi: 10.1002/(sici)1098240x(199802)21:1<73::aid-nur8>3.0.co;2-q

Kiburz, K. M., Allen, T. D., and French, K. A. (2017). Work-family conflict and mindfulness: Investigating the effectiveness of a brief training intervention. J. Organ. Behav. 38, 1016-1037. doi: 10.1002/job.2181

Lally, P., Van Jaarsveld, C. H., Potts, H. W., and Wardle, J. (2010). How are habits formed: modelling habit formation in the real world. Eur. J. Soc. Psychol. 40, 998-1009. doi: 10.1002/ejsp.674

Lazarus, R. S., and Folkman, S. (1984). Stress, Appraisal, and Coping. New York, NY: Springer.
Lyubomirsky, S. (2007). The How of Happiness: A Scientific Approach to getting the Life you Want. New York, NY: Penguin.

Lyubomirsky, S., Dickerhoof, R., Boehm, J. K., and Sheldon, K. M. (2011). Becoming happier takes both a will and a proper way: an experimental longitudinal intervention to boost well-being. Emotion 11, 391-402. doi: 10. 1037/a0022575

Marks, S. P. (1977). Multiple roles and role strain: some notes on human energy, time and commitment. Am. Sociol. Rev. 42, 921-936.

McNall, L. A., Nicklin, J. M., and Masuda, A. D. (2010). A meta-analytic review of the consequences associated with work-family enrichment. J. Bus. Psychol. 25, 381-396. doi: 10.1007/s10869-009-9141-1

Meyers, M. C., Van Woerkom, M., and Bakker, A. B. (2013). The added value of the positive: a literature review of positive psychology interventions in organizations. Eur. J. Work Organ. Psychol. 22, 618-632. doi: 10.1080/ 1359432x.2012.694689

Ouweneel, E., Le Blanc, P. M., and Schaufeli, W. B. (2014). On being grateful and kind: Results of two randomized controlled trials on study-related emotions and academic engagement. J. Psychol. 148, 37-60. doi: 10.1080/00223980.2012. 742854

Page, K. M., and Vella-Brodrick, D. A. (2013). The working for wellness program: RCT of an employee well-being intervention. J. Happiness Stud. 14, 1007-1031. doi: 10.1007/s10902-012-9366-y

Reichl, C., Leiter, M. P., and Spinath, F. M. (2014). Work-nonwork conflict and burnout: A meta-analysis. Hum. Rel. 67, 979-1005. doi: 10.1177/ 0018726713509857

Schaufeli, W. B., and Salanova, M. (2010). “How to improve work engagement?, in The Handbook of Employee Engagement: Perspectives, Issues, Research and Practice, ed. S. Albrecht, (Northampton, MA: Edwin Elgar), 399-415.

Seligman, M. E. P., Steen, T. A., Park, N., and Peterson, C. (2005). Positive psychology progress: Empirical validation of interventions. Am. Psychol. 60, 410-421. doi: 10.1037/0003-066x.60.5.410

Sin, N. L., and Lyubomirsky, S. (2009). Enhancing well-being and alleviating depressive symptoms with positive psychology interventions: a practicefriendly meta-analysis. J. Clin. Psychol. 65, 467-487. doi: 10.1002/jclp. 20593

Ten Brummelhuis, L. L., and Bakker, A. B. (2012). A resource perspective on the work-home interface: the work-home resources model. Am. Psychol. 67, 545-556. doi: 10.1037/a0027974

Van Steenbergen, E. F., Ellemers, N., Haslam, S. A., and Urlings, F. (2008). There is nothing either good or bad but thinking makes it so: Informational support and cognitive appraisal of the work-family interface. J. Occup. Organ. Psychol. 81, 349-367. doi: 10.1348/096317908x3 12669

Van Steenbergen, E. F., Ellemers, N., and Mooijaart, A. (2007). How work and family can facilitate each other: distinct types of work-family facilitation and outcomes for women and men. J. Occup. Health Psychol. 12, 279-300. doi: 10.1037/1076-8998.12.3.279

Van Steenbergen, E. F., Kluwer, E. S., and Karney, B. (2014). Work-family enrichment, work-family conflict, and marital satisfaction: a dyadic analysis. J. Occup. Health Psychol. 19, 182-194. doi: 10.1037/a0036011

Zhang, Y., Xu, S., Jin, J., and Ford, M. T. (2018). The within and cross domain effects of work- family enrichment: a meta-analysis. J. Vocat. Behav. 104, 210-227. doi: 10.1016/j.jvb.2017.11.003

Conflict of Interest: The authors declare that the research was conducted in the absence of any commercial or financial relationships that could be construed as a potential conflict of interest.

The handling Editor declared a shared affiliation, though no other collaboration, with one of the authors MP at time of review.

Copyright (c) 2020 Peeters, van Steenbergen and Ybema. This is an open-access article distributed under the terms of the Creative Commons Attribution License (CC BY). The use, distribution or reproduction in other forums is permitted, provided the original author(s) and the copyright owner(s) are credited and that the original publication in this journal is cited, in accordance with accepted academic practice. No use, distribution or reproduction is permitted which does not comply with these terms. 


\section{OPEN ACCESS}

Edited by:

Llewellyn Ellardus Van Zyl,

Eindhoven University of Technology,

Netherlands

Reviewed by:

Stefania Fantinelli,

Università degli Studi “G. d'Annunzio"

Chieti-Pescara, Italy

Rudolf M. Oosthuizen,

University of South Africa,

South Africa

Ederick Stander

North-West University, South Africa

${ }^{*}$ Correspondence:

Lene llyna Graupner lene.graupner@nwu.ac.za

Specialty section: This article was submitted to Organizational Psychology, a section of the journal

Frontiers in Psychology

Received: 10 November 2019

Accepted: 05 March 2020

Published: 27 March 2020

Citation:

Jonker BE, Graupner LI and Rossouw L (2020) An Intervention Framework to Facilitate Psychological

Trauma Management in High-Risk Occupations. Front. Psychol. 11:530. doi: 10.3389/fpsyg.2020.00530

\section{An Intervention Framework to Facilitate Psychological Trauma Management in High-Risk Occupations}

\author{
Bouwer E. Jonker, Lene Ilyna Graupner* and Lizelle Rossouw
}

WorkWell Research Unit, Faculty of Economic and Management Sciences, School of Industrial Psychology and Human Resource Management, North-West University, Potchefstroom, South Africa

Various psychological trauma management programs (PTMPs) are offered to assist employees who have been exposed to a traumatic event in the workplace. There is, however, limited literature available on how employees in high-risk occupations experience these programs. This study qualitatively explored the experiences of PTMPs from the perspective of employees working in three high-risk occupations. The purpose of this study was to explore the experiences of the participants in order to compile a framework that could help support and improve the productivity and wellbeing of employees affected by work-related trauma. The study used a qualitative research design based on an approach informed by interpretivism and social constructivism. A multiple-case study was used as research strategy to incorporate three sectors in South Africa, namely mining, policing, and emergency medical services. Data were gathered through semi-structured interviews and focus groups, and analyzed using thematic analysis. The findings across the three sectors showed effective strategies considered by participants to manage psychological trauma. These strategies include multiple counseling sessions, face-to-face counseling, regaining control, and receiving support. Strategies that were viewed as ineffective include inability of counselors to relate to the participants' work environments, lack of involvement, lack of supervisor support, unavailability of counseling and specialized skills, premature resuming of duties, and a single-dimension approach. Based on the findings, an intervention framework is proposed to address psychological trauma in high-risk occupations.

Keywords: trauma management programs, high-risk occupations, trauma management framework, intervention framework, psychological trauma, workplace trauma

\section{INTRODUCTION}

There is major significance for organizations that implement effective psychological trauma management programs (PTMPs) to enhance employees' work performance and psychosocial functioning (Terblanche and Van Wyk, 2014). High-risk occupational settings considered globally as some of the most dangerous are the mining, policing and emergency medical services (EMS), which often result in traumatic incidents (Adriaenssens et al., 2012; Kowalski-Trakofler and Vaught, 2012; Ménard and Arter, 2013). In South Africa, these work environments are experienced as particularly hazardous and traumatic (Wilson, 2011; Steyn et al., 2013). Employees are left 
with psychological trauma that hinders their productivity and threatens their well-being (Ward et al., 2006; Zungu, 2013). Psychological trauma can be defined as an experience of psychological wounding caused by an event outside the usual range of human experience (Mitchell and Everly, 2001). Such events include unexpected, often life-threatening, situations that may inhibit employees' ability to respond in a normal way (Attridge and VandePol, 2010). Over recent years, various workplace-related incidents shook the world, such as terrorist attacks, civil wars, political violence, and state-supported oppression (Lemanski, 2004; Sorensen, 2012; Atvoli et al., 2013; North et al., 2013). These incidents warrant for employers to implement effective programs to manage workplace trauma.

\section{LITERATURE REVIEW}

For purposes of this article, a PTMP is viewed as a collection of crisis intervention models, protocols, procedures, strategies, techniques, and practices that help manage psychological trauma in the workplace (Mitchell, 2004). According to Georganta and Montgomery (2019), workplace interventions entail singleor multi-component programs that implement strategies on individual, environmental, organizational, and group level (Le Fevre et al., 2006). An effective program to manage trauma in the workplace should cover the crisis continuum from pre- to post-crisis (Everly et al., 2000; Forbes et al., 2011). It is important that organizations act proactively, thereby ensuring employees' wellbeing is promoted through effective interventions. Proactive programs to manage trauma in a workplace include a preparation phase for the organization and the employee (Mitchell, 2004). According to Forbes et al. (2011), a PTMP should be developed for a recipient organization in conjunction with the latter's policies and procedures. The PTMP should then be promoted throughout the organization and appropriate training should be provided in trauma management at the various levels (Forbes et al., 2011).

During the crisis level frontline interventions may commence during or shortly after a traumatic event (Litz, 2008).

Literature suggests the following elements for an effective frontline intervention (Ruzec et al., 2007; Van Wyk and Edwards, 2005):

1. Contact and engagement: The helper makes contact with the affected person(s) and becomes engaged in the helping process.

2. Safety and comfort (if applicable): Address affected employees' immediate concerns about safety. In this step, the various physical needs are provided for, such as medical care, food, or warm blankets.

3. Stabilization: The helper responds empathetically, in a safe and non-judgmental environment, to emotions the employee may experience.

4. Information gathering: Information on what happened is gathered in a sensitive manner.

5. Practical assistance: Practical solutions are provided to immediate challenges. Such assistance may include making contact with close family or friends and assisting with transport arrangements.

6. Connection with social supports: Employees who are vulnerable to isolation are identified. Non-judgmental social support from existing family and peer-group structures is encouraged.

7. Information on coping support: The affected employees are made aware of trauma-related symptoms that they may be experiencing, for example sleeplessness, nightmares, recurring thoughts, and difficulty with concentration. Such symptoms are normalized and the employees are provided with information that can help them cope after the traumatic event, such as avoiding being alone for long periods and talking to support networks about the trauma.

8. Linking to support services: A few days or up to 2 weeks after the event, follow-up takes place and affected individuals are reassessed. Employees who experience difficulty in the normal recovery process are offered trauma counseling or therapy.

Post-crisis or reactive interventions aimed at managing workplace trauma would traditionally include brief- and medium-term counseling, and long-term trauma therapy.

\section{Brief and Medium-Term Counseling}

According to Kaminer and Eagle (2010), such counseling should only start a few weeks after the traumatic incident. Only employees who experience acute stress and post-traumatic stress symptoms should receive such interventions (Kaminer and Eagle, 2010). The following elements are recommended for an effective brief and medium-term trauma intervention (Eagle, 1998):

1. Telling/retelling the story: Requests the employee to recount the story of the traumatic incident in as much detail as possible. The clients therefore narrate facts, thoughts, feelings, and sensations. The aim is to help clients express unexpressed feelings and fantasies about the event and reduce the anxiety associated with it.

2. Normalizing the symptoms: Employees must relay the symptoms they experienced since the incident. Psychoeducation on experienced trauma symptoms are provided and normalized. This is done to prevent the employee from forming irrational interpretations thereof.

3. Addressing self-blame and survivor guilt: These inner experiences are harmful to the employee's self-esteem and should be dealt with in appropriate steps.

4. Encouraging mastery: The employees are encouraged to utilize available support systems. The helper should also teach employees techniques to reduce anxiety and structure time effectively.

\section{Long-Term Trauma Therapy}

According to Kaminer and Eagle (2010), such interventions are associated with complex trauma involving post-traumatic stress disorder (PTSD). Long-term interventions can take months or years following a traumatic incident and may include the following elements to be effective (Kaminer and Eagle, 2010): 
1. Individual therapy: Intensive intervention to address not only the effects of a single traumatic incident, but also contributing factors such as previous events and depression.

2. Couples counseling: Employees in relationships are encouraged to engage in such counseling. Traumatic stress can be strenuous for personal relationships.

3. Group therapy: As recommended by a therapist, employees may also benefit by attending sessions with other individuals who have experienced similar circumstances.

When frontline trauma interventions are implemented correctly, the levels of acute distress should stabilize and decrease. Furthermore, affected individuals should have been provided continuous care (Everly and Lating, 2017). Relatedly, employees' immediate needs should be addressed (Schafer et al., 2016). According to McNally et al. (2003), and Rose et al. (2003), when frontline interventions are implemented incorrectly, they fail to prevent the onset of PTSD, and may even be harmful by re-traumatizing employees. After implementing brief and medium-term interventions, employees should reach a sense of closure, psychological stress should be alleviated, and a return to a level of pre-trauma functioning can be expected (Attridge and VandePol, 2010). In addition, anxiety levels should decrease, and the self-respect of employees restored (Eagle, 1998).

Since 2008, the International Society for Traumatic Stress Studies (ISTSS) withdrew its support for the use of psychological debriefing type of acute/frontline interventions (Litz, 2008; Foa, 2009). Critical incident stress debriefing is closely associated with psychological debriefing (Devilly and Cotton, 2003; Rose et al., 2003). In this regard, VandePol et al. (2006) point out that psychological first aid is favored by the World Health Organization [WHO] (2005) and the National Institute for Clinical Excellence (2005) above interventions that resemble debriefing. Psychological first aid is likewise recommended for use by the American Psychiatric Association (2004), the Australian Centre for Posttraumatic Mental Health (2007), and the Department of Veterans Affairs/Department of Defence (2004).

In contrast, the ISTSS recommends (Foa, 2009) that immediately after a traumatic incident, affected individuals should be offered practical support, information on possible stress reactions, and self-help guidelines. This should include information on accessing support from existing networks, as well as when and where to obtain further support if necessary. Frontline intervention should be based on existing and accurate assessment of needs. Furthermore, formal trauma intervention should not be mandatory for all employees exposed to trauma. The use of trauma support should be voluntary, except in instances where impairment is a threat to the safety of the individual or others. Foa (2009) adds that interventions should be developmentally appropriate, culturally sensitive, and contextually formulated by focusing on problems and coping strategies.

Therefore, managing trauma in high-risk occupational sectors with an effective intervention program should follow a holistic approach. The focus should be on offering a framework for understanding the complex and multi-dimensional concept of workplace health (Georganta and Montgomery, 2019).

In the present study, high-risk occupation sectors are viewed as jobs where employees are especially prone to exposure regarding traumatic experiences during the course of their work (Tehrani, 2004). These occupations, among others, include the mining, policing, and emergency medical sectors.

\section{Mining Sector}

Comprises dangerous occupations due to the life-threatening situations to which employees are exposed (Bao et al., 2017). These hazards include underground earthquakes/tremors and rock-fall incidents, which may trap employees underground (Maiden and Terblanche, 2006; Stevens et al., 2006).

Zungu (2013) identified mining as a high-risk environment for trauma in South Africa, citing earth-fall and transport accidents as the cause of serious injuries and fatalities. The Department Mineral Resources' 2017/2018 Annual Report recorded 88 mine fatalities in 2017. This figure signifies a $20.5 \%$ increase, year on year, as measured against the 73 mine-related deaths during 2016 (Department Mineral Resources: Republic of South Africa, 2018).

\section{Police Services}

Members often are exposed to traumatic incidents and risk experiencing critical incidents in their work environment (Ellrich and Baier, 2017). According to Mostert and Rothmann (2006), policing is identified as one of the most dangerous occupations in the world. Steyn et al. (2013) report that hyper-arousal, as a result from exposure to traumatic events is the main predictor of suicide ideation in the South African Police Service (SAPS).

South Africa can be regarded as a country of persistent conflict that is characterized by various divisions (van Riet, 2020). According to the SAPS 2018/2019 crime statistics report, the total number (national) of reported contact crimes (crimes against the person, for example, murder, assault to cause grievous bodily harm (GBH), and assault are 617,210 (SAPS Annual Crime Statistics 2018/2019, 2020).

\section{Emergency Medical Services}

These employees work in a high-risk environment (Roditi et al., 2019). EMS practitioners included in this study work as paramedics and EMS technicians who react to medical emergencies such as motor vehicle accidents and home responses; they are continuously exposed to witnessing severe injuries, death, suicide, and human suffering. As a result, they experience extreme and recurrent traumatic incidents that pose significant professional and emotional challenges (Adriaenssens et al., 2012). Relatedly, Bolm-Audorff et al. (2019) conclude that the risk of developing PTSD in EMS personnel is high.

Paramedics in South Africa are exposed to increased violent attacks, by criminal elements of the community (Mulaudzi, 2017). According to Evans (2018), nearly 30 cases were documented in the latter half of 2018 in the province of KwaZulu-Natal alone; similar incidents occurred in the Free State (Maphanga, 2019) and Gauteng (Chabalala, 2019). Monageng (2019) states that the high prevalence of attacks causes distress among EMS practitioners and disrupts service delivery to 
those who are most vulnerable. As a counter measure to this development, the South African Emergency Personnel Union (SAEPU) advised its 7,000 members to carry arms in preparation for the 2018 festive season (Evans, 2018).

The general objective of this article was to recommend an operational framework for psychological trauma management that may help improve trauma management in high-risk occupation sectors. This objective was attained by exploring the experiences involving PTMPs in high-risk occupations, namely the mining, policing, and medical emergency sectors, as viewed from the perspective of the employees.

\section{MATERIALS AND METHODS}

\section{Research Approach}

An explorative, descriptive qualitative research design was used. The philosophical paradigms that guided the design of the present study and interpretation of the data are anchored in constructivism and interpretivism. An ontological assumption of constructivism and interpretivism is that multiple realities exist (Denzin and Lincoln, 2013). Nieuwenhuis (2016) explains that human experience can only be understood from within; reality is constructed during human interaction and meaning is created in the human mind; behavior is affected by knowledge of the social world; therefore, the social world and human knowledge are intertwined (Nieuwenhuis, 2016). The present study also employed phenomenology as a research approach. Employees were asked to describe their experiences of PTMPs that are offered in the mining, policing and EMS sectors in South Africa. This approach therefore engages the subjective experiences and interpretations of those exposed to the phenomenon (Trochim et al., 2016).

\section{Research Strategy}

A multiple-case study strategy was used, which allowed the inquirers to explore employees within the mining, policing, and EMS sectors' lived experiences of the PTMPs. The unit of analysis was the individual employees who participated in the study (representing the mining, policing, and EMS sectors) and who had first-hand experience with PTMPs.

\section{Participants}

Three mining organizations selected from two provinces took part in this research. The mining companies were unrelated and chosen for their geographical positions. The research setting in the policing sector comprised three police stations from two provinces. The following crimes have a high incidence in these provinces: assault with intent to inflict GBH, murder, and sexual offences (South African Police Service [SAPS], 2020). Three police stations were selected where the murder and rape cases were the highest in the province, and also where the workforce was representative in terms of race, gender and age demographics. Two large EMS companies from one province and one medium-sized company from another province participated in the research. Purposive sampling was used to ensure employees from the mentioned three sectors, who were exposed to at least one traumatic incident in the line of duty, were included in the present study. Table 1 presents a summary of the participants.

\section{Data Collection}

In this study, a combination of semi-structured, face-to-face as well as focus group interviews was used as methods for data collection. The focus group interviews were conducted by the researcher and the interviews were conducted by the researchers and fieldworkers. The fieldworkers included three master's students in industrial psychology in their final year of study. The fieldworkers assisted with the interviews in the EMS sector. An interview guide for the fieldworkers was developed with questions directed at participants' experiences of the PTMP in their occupation sector.

Certain sectors in this study indicated that they could not avail the time for the participants for interviews since this was time consuming, and consequently the focus group method was chosen as data-gathering for those cases. At three police stations, the researcher was allowed to collect data from the shifts on duty. Therefore, conducting one focus group per police station was the best course of action to circumvent the issues of transport and poor service delivery. Forty police members participated in three focus groups conducted in the policing sector. At two mining operations, the work schedules of employees varied and scheduling individual interviews was the most practical procedure to follow; nine semi-structured interviews were conducted at the two mining operations. At one mining organization, the only way the researcher could collect data was to see one team as a collective before they

\begin{tabular}{|c|c|c|c|c|}
\hline \multirow[t]{2}{*}{ Item } & \multirow[t]{2}{*}{ Category } & \multicolumn{3}{|c|}{ Frequency } \\
\hline & & $\begin{array}{c}\text { Mining } \\
\text { sector } N\end{array}$ & $\begin{array}{l}\text { Policing } \\
\text { sector } N\end{array}$ & $\begin{array}{c}\text { EMS } \\
\text { sector } N\end{array}$ \\
\hline \multirow[t]{3}{*}{ Gender } & Male & 16 & 26 & 23 \\
\hline & Female & 4 & 13 & 11 \\
\hline & MV & 0 & 2 & 0 \\
\hline \multirow[t]{3}{*}{ Ethnicity } & African & 14 & 30 & 13 \\
\hline & Colored & 1 & 1 & 0 \\
\hline & White & 5 & 10 & 21 \\
\hline \multirow[t]{9}{*}{ Home language } & Afrikaans & 6 & 11 & 17 \\
\hline & English & 1 & 0 & 7 \\
\hline & isiXhosa & 3 & 4 & 0 \\
\hline & isiZulu & 3 & 2 & 2 \\
\hline & Sepedi & 0 & 2 & 2 \\
\hline & Sesotho & 5 & 9 & 2 \\
\hline & Setswana & 1 & 12 & 4 \\
\hline & siSwati & 1 & 0 & 0 \\
\hline & Xitsonga & 0 & 1 & 0 \\
\hline \multirow[t]{4}{*}{ Years of work experience } & $1-10$ & 12 & 8 & 29 \\
\hline & $11-20$ & 3 & 13 & 5 \\
\hline & $21-30$ & 3 & 14 & 0 \\
\hline & $31-40$ & 2 & 6 & 0 \\
\hline
\end{tabular}

MV, missing values. 
went underground into the mine. A focus group was the most appropriate procedure to follow in this case. Eleven underground mineworkers participated in this focus group. The operational managers at two EMS branches allowed the researcher to collect data only if it did not curtail the branches' ability to respond to emergencies. Individual interviews were therefore scheduled to ensure the availability of paramedics at all times. Thirty semistructured interviews were conducted at these two EMS branches. Apart from the individual interviews, one focus group with four EMS members was scheduled to allow all participants an opportunity to respond.

Participants gave written consent for the electronic recording of semi-structured face-to-face interviews or focus group sessions.

\section{Data Analysis}

The data in the present study were processed through thematic analysis. The researchers selected this method since it is compatible with the phenomenology paradigm and case study as research strategy (Botma et al., 2010). The six-step method of Creswell (2009) was applied to analyze the data of the present study: (1) the voice recordings of the semi-structured interviews and focus groups were transcribed verbatim into distinct Excel documents. (2) The researchers read through the data to obtain a general sense of the answers and an appropriate idea of how participants experienced the PTMPs in their respective workplaces as well as their recommendations to enhance psychological trauma management. (3) The researcher (BEJ) organized the data into sections of text before attaching meaning to the information. This process entails taking text data and dividing words, phrases, sentences, and paragraphs into categories. The supervisors helped identify the categories. (4) From the categories, the researcher and the supervisors created descriptions from the themes. Themes and subthemes were reported as principal findings of the study and conveyed multiple viewpoints of participants. The supervisors reviewed the themes and subthemes and therefore acted as appraisers of the findings. (5) The researcher reported the results of the study in a qualitative narrative. (6) The researchers interpreted the meaning of the data in accordance with findings from scientific literature. Based on the interpretation of the data, the main study leader developed a framework to address prevention interventions in high-risk occupations.

\section{Ethical Considerations}

The researcher and the supervisors obtained ethical clearance from the research institution, and participating organizations granted the researcher permission to collect data. Due to the sensitive nature of the study, participation was voluntary and participants could withdraw from the study at any time, without repercussions. Furthermore, all participants were ensured anonymity to guarantee their privacy. As a precautionary measure, trained psychological trauma counselors were placed on stand-by in the event participants became uncomfortable during the data collection phase. All participants were debriefed after data collection to ensure no contributor was left vulnerable or has experienced unresolved issues.

\section{FINDINGS}

This section outlines the collective results derived from the data analysis conducted for all three working environments. The results revealed two categories, from which themes and subthemes were extracted and corroborated with direct quotations from participants from all three sectors. Responses in African languages (mining sector) were translated into English by an accredited language practitioner. Frequencies (i.e., numbers) were not assigned to the extracted themes and sub-themes. In qualitative research the objective is not to quantify results as is done in quantitative studies, however, to rather report unique experiences of participants. Both the constructivism and interpretivism paradigm, as employed in this study is in support of this viewpoint. The objective of these two paradigms is to understand the unique and multiple realities and experiences of participants. Therefore, participants can be exposed to the same phenomenon (i.e., PTMP's), however, their experiences thereof may differ. The researchers therefore decided to rather report all the unique and multiple experiences of the participants.

\section{Category 1: Experiences Regarding Psychological Trauma Management Programs}

Results of this category were obtained by asking the participants about their experiences of the PTMPs in their respective workplaces. This question allowed a deeper understanding of how employees per sector experience the programs. In Category 1, the two main contrasting themes were identified as effectiveness of the PTMPs and ineffectiveness of these programs and are discussed next. Refer to Supplementary Tables A1, A2 for a more extensive overview of the responses of the participants for each theme.

\section{Theme 1: Effective PTMPs}

An interesting finding was that no participants from the policing sector could indicate positively how they experience the PTMP within their organization. Overall, it can be concluded that the participants in all three sectors generally had more negative than positive experiences of PTMTs. However, particularly in the policing sector, no participant felt that the management programs helped them manage trauma effectively. Figure 1 provides the common subthemes that emerged from the first theme in Category 1 for the two sectors involved:

From Figure 1, it can be seen that in both the mining and EMS sectors, the participants cited multiple counseling sessions and

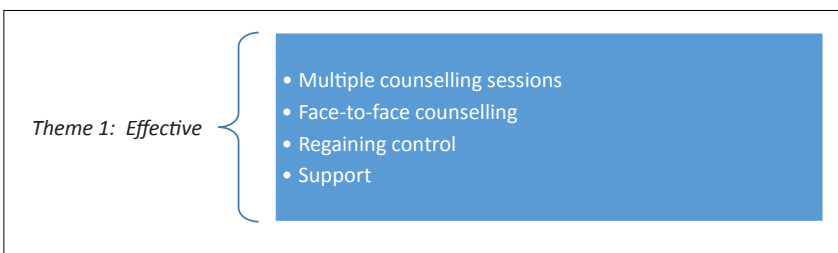

FIGURE 1| Psychological trauma management programs viewed as effective. 
referrals to a psychologist as effective means to manage traumatic experiences - as illustrated by the excerpts below.

"I had four or five sessions with them, but they didn't talk, no other funny things. Every time I walked away from there, it felt more and more that a weight is lifted off my shoulders." (Participant 9: Male. 36 years old. Mining sector)

The participants spoke highly of the PTMP's effectiveness, particularly when it took the form of face-to-face counseling. One participant mentioned that the counselor helped him verbalize his traumatic experience, as the following excerpt points out:

"In my initial contact with them, I went to five sessions with a clinical psychologist and we talked about the incident and she taught me coping mechanisms ... I still remember and I still use them." (Participant 28: Female. 32 years old. EMS sector)

Regaining control was an important benefit the paramedics described after utilizing the PTMP. One group member stated that he struggled previously to control his temper. After participating in the program, he found that he did not lose his temper that often anymore. Another paramedic explained that he did not suffer sleepless nights anymore, which often resulted from traumatic experiences at work.

The participants from the above-mentioned two sectors indicated further that they found support as efficient to manage their traumatic experiences. One participant explained that the support he received from the social worker had a harmonizing effect on them, after they were exposed to a traumatic incident. He indicated that the practitioner went out of her way to support them. Another participant attested that the social worker helped them understand and cope with the traumatic incident where one of their colleagues died in a mining-related accident. One respondent clarified that the social worker helped the crew become "normal" again.

Participants from the EMS sector indicated that they value colleague support as a way to manage psychological trauma. Turning to a colleague for support is known as the "buddy system" in the EMS sector. One participant explained that only paramedics can truly understand the nature of EMS work. Therefore, it is better to ask the opinion of someone who has had a similar experience. Another participant reported that she talks to more experienced colleagues after a difficult scene and this process makes it easier for her to cope, as seen in the response below:

"They have got more experience. I just talk to them. And then the more you talk, the easier it gets. The more it fades away... You can't even talk about it at home, because they don't understand what is happening or what happened." (Participant 33: Female. 35 years old. EMS sector)

\section{Theme 2: Ineffective PTMPs}

Several subthemes were captured from all three sectors in the second theme in the category: experiences of PTMPs as ineffective. The subthemes are shown in Figure 2.

Figure 2 shows that a common subtheme for all three sectors was that participants felt the counselors were unable to relate to them, which caused the trauma management program to be

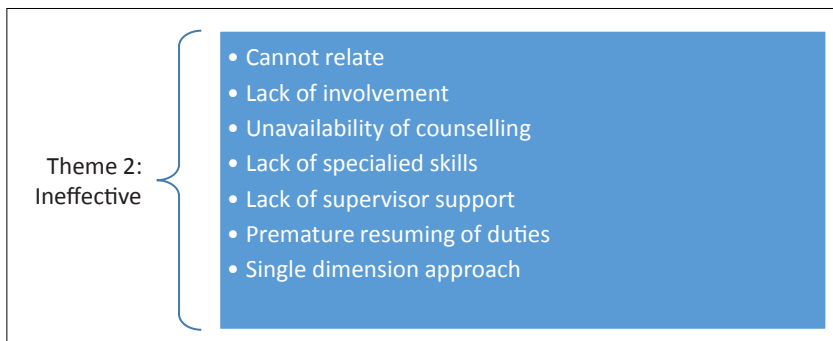

FIGURE 2 | Psychological trauma management programs viewed as ineffective.

ineffective. In the mining sector, one participant indicated that the counselor was not on site, and therefore could not relate to the mining environment. This participant experienced the counseling process as impersonal and felt he could not trust the counselor. In the policing sector, especially, the participants felt strongly that the counselors do not understand their experiences, and therefore are unable to provide an effective service, as the following response shows:

"The caseworker... has never had to pick up a body part on an
accident scene. He never had to pick up a child that has been cut in
half and place him on a trolley. He has never been shot at in his life.
He has never smelled how it smells when a, when a human being is
burning, and they want to come and debrief me. You cannot debrief
me if you do not know what is going on outside." (Participant 23:
Male. 42 years old. Policing sector)

Similarly, in the EMS sector, the participants indicated they felt the counselors could not relate to paramedics' experiences. One participant pointed out that counselors do not understand what EMS does, as is evident from the excerpt below:

"I don't think the guys from the counseling company understand what we are doing, they sit behind a desk ..." (Participant 20: Male. 33 years old. EMS sector)

Responses from participants in the EMS sector showed that they preferred to talk to one another after a particularly distressing incident. The participants indicated that they would rather talk to friends and family instead of making use of the PTMP. One participant mentioned that talking to friends about a bad incident they had experienced made them feel better. They also felt more appreciated and validated for the work they do almost like being a hero. Another group member stated that after a traumatic incident, he confides in family members, namely a wife who is a trained counselor. A different participant talks to her father who is also working in EMS.

In contrast, significantly, participants in the policing environment felt that counselors not being independent to the organization made the program ineffective. The participants indicated that counselors' objectivity is compromised since they work for the same organization, as the following excerpts clarify:

"You have people (counselors) that's working for the police; they are looking after the police problems, your problems start to be the second, or not prioritized." (Participant 35: Male. 32 years old. Police sector). 
Another common theme across the three sectors was that counseling services are available on request and when needed most. However, it is clear that the participants needed involvement from counselors as opposed to being off site and only available telephonically. In the mining sector, they indicated that mere telephonic counseling after an incident was ineffective. One participant explained that the process is impersonal since the counselor is not available on-site. Another participant reported that after an incident, she had to phone the counselor herself only to be told she needs to see a psychologist, who often was unavailable when she made contact by phone.

Similarly, in the policing sector, the participants indicated that they regarded the PTMPs as ineffective since no counseling was offered after a traumatic event. One participant related that she (as detective then) was denied access to counseling after a colleague (close friend) was shot because these interventions were offered only to uniformed police members. Other participants attested that the counselors were not involved at all; they have only heard about counseling after trauma, but were not offered it. In the EMS sector as well, a number of paramedics indicated the absence of PTMPs at their workplace - no counselor nor an emergency helpline to contact should they require counseling.

A further subtheme emerged from this category, especially in the policing and EMS sector. Participants revealed that counselors often lack proper skills, thereby rendering the trauma management program ineffective. In the policing sector, the participants indicated that counselors have insufficient knowledge and skills regarding psychological trauma management. One participant observed that the counselors refer police members to doctors and psychiatrists for medication without attempting to find the root of the problem themselves. In the EMS sector, the participants point out that counselors are not trained properly to provide clients a better perspective, as is illustrated by the following excerpt:

"Like the people that one talks to are not really trained to give you a better perspective." (Participant 11: Male. 25 years old. EMS sector)

In the mining sector, a specific subtheme that emerged was that participants viewed the PTMPs as ineffective since they lack support from their supervisors. Mineworkers indicated that the lack of physical presence (support) could be described as "a disgrace, poor and sad." According to participants, the way supervisors approach them, or talk to them after a traumatic incident, shows a lack of sensitivity and understanding about psychological trauma. One respondent mentioned that their supervisor did not even look in on them the day the accident occurred, he only came the following day. The excerpt below demonstrates the need of the respondents to have support from their supervisors:

"I used the word poor because sometimes, if we are working together and someone got sick. He's lying in hospital. The supervisors or anyone, they don't come and visit you or any employee of the company comes to see how you are doing." (Participant 17: Male.

37 years old. Mining sector)

Another subtheme captured across the three sectors indicated that the participants felt they are required to return to work prematurely to resume their duties after a traumatic incident. Underground mineworkers regarded the PTMPs as ineffective, because supervisors were allowed to send traumatized employees back to the same worksite where the incident took place, too soon after the incident. The response below illustrates participants' concern of being well enough to return to work:

\footnotetext{
"After the event, the way the counseling was done it was too quick. It wasn't done the way it's supposed to be done; and then you cannot say, 'Today there is a seismic event there was a fatal there, 'and the supervisor says, 'Go there tomorrow and fix one, two, and three.' You still think that person is in the right state of mind to perform any job underground?" (Participant 20: Male. 37 years old. Mining sector)
}

In the policing sector, the participants were critical of a singular approach to address traumatic experiences through formal debriefing offered to members after a traumatic incident. They found such debriefing insufficient to help them recover from psychological trauma, as illustrated by the excerpt below:

\begin{abstract}
"If an incident happens a group, a person is called for debriefing, they ask you questions and look into your eyes and then you go home. And that's the end of the story. That's where your trauma counseling in the police stops." (Participant 13: Male. 51 years old. Police sector)
\end{abstract}

\section{Category 2: Recommendations to Improve the Effectiveness of PTMPs}

The second category that emerged from the data showed that the participants from the mining, policing, and EMS sectors indicated their preferred type of PTMP, which they consider effective interventions to manage their trauma experiences. Table 2 presents the themes and subthemes, with verbatim responses on collective interventions the participants suggested across the three sectors.

From Table 2, it is clear that the three sectors share common themes on the PTMP they would prefer in their occupations. The data for the first theme centered on a preventative approach. This involves actions dealing proactively with psychological trauma before an incident occurs. Examples are: creating awareness through marketing material and sharing information to gain knowledge on psychological factors relating to trauma. The paramedics preferred physical activity and having a hobby as a way to deal with psychological trauma.

The respondents indicated various PTMP interventions they would prefer on a recuperative level, during the acute phase of the crisis. Participants across all three sectors indicated that they would prefer more regular psychological support as well as services available face to face and on site. One sector (policing) indicated that they would prefer an independent service provider. Medical support and evaluations were further mentioned as forms of preferred intervention. Specific reference was made to a medical aid division that provides psychological care.

On a post-crisis level, the participants in the mining and policing sectors indicated that they value management support, while the participants from the EMS sector highlighted the value of peer and family support. Further suggestions were 
TABLE 2 | Collective needs regarding PTMPs across the mining, policing, and EMS sectors.

Responses

\begin{tabular}{|c|c|c|}
\hline Theme & Subtheme & Mining sector \\
\hline \multirow[t]{3}{*}{$\begin{array}{l}\text { Prevention/pre- } \\
\text { crisis }\end{array}$} & Proactive & $\begin{array}{l}\text { "Psychologists must come and inform us and give } \\
\text { us more information on what we can do and what } \\
\text { process we can follow when we go through a } \\
\text { traumatic experience. We need to know who we } \\
\text { can consult. Errors are caused by a lack of } \\
\text { information." (Participant 15. Male. } 39 \text { years old) }\end{array}$ \\
\hline & Create awareness & $\begin{array}{l}\text { "There should definitely be more awareness about } \\
\text { it. A person knows about the program, but } \\
\text { someone does not always know what it is about, or } \\
\text { in what way it can help you... They must maybe } \\
\text { put up poster or such thing to create awareness. I } \\
\text { don't even know what the program's name is." } \\
\text { (Participant } 7 \text {. Male. } 48 \text { years) }\end{array}$ \\
\hline & Physical activity/hobby & - \\
\hline
\end{tabular}
approachable, or who has more time to see people at the mine ... you can arrange an appointment with him/her. Then you know you see the psychologist regularly." (Participant 4. Female. 36 years old)

Independent

psychological service

provider

\section{Policing sector}

"They should maybe just visit us, maybe twice a week, because now we don't see them at all. Maybe twice a week or once a week then they must just visit our parades and everything and ask if everything is still well and then if we need them the we should come to them." (Participant 4. Male. 31 years old)

"But most of us are not aware. We are not aware about this. You see on those psychological factors we are not aware of that." (Participant 7. Female. 26 years)

"Maybe twice a week or once a week then they must just visit our parades and ask if everything is still well and then if we need them then we should come to them." (Participant 4. Male. 31 years old)

\section{EMS sector}

"A program before on hand that prepare you for this and this and that. I just wish there could be some emotional training on that. The first time I saw a person died in my face I have never seen that." (Participant 33. Female. 35 years old)

"It is very important for one to just become knowledgeable and then make a thorough research to know what this is really." (Participant 8. Male.

41 years old)

"If I had a bad day at work, I get my load off by doing mixed martial arts." (Participant 2. Male. 27 years old)

"I always say you need to have a hobby. I have parrots that keep me busy and I also build up motorbikes at home and those types of things." (Participant 9. Male. 43 years old)

"I think it needs to be put in place. It is not normal what we see, so I think they need to get a traum counselor." (Participant 4. Male. 32 years old)

"When you have people that's working for the police they are looking after the police problems, your problems start to be the second, or not prioritized." (Participant 35. Male. 32 years old) 


\section{Responses}

\begin{tabular}{|c|c|c|c|c|}
\hline Theme & Subtheme & Mining sector & Policing sector & EMS sector \\
\hline & $\begin{array}{l}\text { Psychological support } \\
\text { on site }\end{array}$ & $\begin{array}{l}\text { "We need someone that can talk face-to-face with } \\
\text { us. That can see our pain, not over the phone." } \\
\text { (Participant } 8 . \text { Male. } 25 \text { years old) }\end{array}$ & $\begin{array}{l}\text { "I think they must be available at station level or } \\
\text { accounting station level on a } 24-h \text { basis, not } \\
\text { standby, they must be on a shift } 24 \text { h a day." } \\
\text { (Participant 1. Male. } 51 \text { years old) }\end{array}$ & $\begin{array}{l}\text { "We used to have that thing called debriefing after } \\
\text { everything that happened we sit at the table and } \\
\text { then we will discuss whatever happened, so that } \\
\text { was therapeutic for everyone there; it is accessible } \\
\text { at any time." (Participant } 3 . \text { Male. } 39 \text { years) }\end{array}$ \\
\hline & $\begin{array}{l}\text { Medical } \\
\text { support/evaluation }\end{array}$ & $\begin{array}{l}\text { "It takes long, because it goes from the Safety to } \\
\text { the manager. Then to the HR Department. So it has } \\
\text { to go through all the necessary steps before you } \\
\text { can qualify for psychological treatment. I do think } \\
\text { that the longer it takes, the deeper the trauma } \\
\text { becomes and the more difficult it will become for } \\
\text { someone to talk about the trauma." (Participant } 10 . \\
\text { Male. } 29 \text { years old) }\end{array}$ & $\begin{array}{l}\text { "My view is strengthen the psychological leg of the } \\
\text { medical aid and make it compulsory that every } \\
\text { member once a year must see a psychologist and } \\
\text { psychiatrist for an evaluation to make sure inside } \\
\text { the service." (Participant 13. Male. } 51 \text { years old) }\end{array}$ & - \\
\hline \multirow[t]{4}{*}{ Post-crisis } & Management support & $\begin{array}{l}\text { "We need our supervisors to be close to us, not too } \\
\text { close to us if it is something for the production only, } \\
\text { even if the event of the death of someone, the } \\
\text { event of bad things we need them to come close to } \\
\text { us, all the time." (Participant 19. Male. } 34 \text { years old) }\end{array}$ & $\begin{array}{l}\text { "Our commanders they read our dockets every day, } \\
\text { they know what we did, what we dealt with, I think } \\
\text { from them they can make an appointment with } \\
\text { EHW A police manager's job is and part of the } \\
\text { responsibility if you are a manager, is to look after } \\
\text { your members or the people that are serving and to } \\
\text { make sure that they can operate effective." } \\
\text { (Participant 1. Male. } 51 \text { years old) }\end{array}$ & - \\
\hline & $\begin{array}{l}\text { Peer support/family } \\
\text { support }\end{array}$ & - & - & $\begin{array}{l}\text { "I can add like if you are the crews, if we see } \\
\text { someone is not coping, we can talk. discuss things } \\
\text { and give her or him some advice how to deal with } \\
\text { it." (Participant } 17 \text {. Female. } 28 \text { years old) }\end{array}$ \\
\hline & & & & $\begin{array}{l}\text { "And sometimes I talk with friends and family," } \\
\text { Listen here, today I saw one two three.' Then it } \\
\text { becomes less of a bad thing because I have already } \\
\text { spoken about it." (Participant } 8 . \text { Male. } 41 \text { years old) }\end{array}$ \\
\hline & $\begin{array}{l}\text { Continuous } \\
\text { development and } \\
\text { training }\end{array}$ & $\begin{array}{l}\text { "Psychologists can do a workshop with case } \\
\text { studies to inform the employees how the process } \\
\text { works and that the process really helps." } \\
\text { (Participant 15. Male. } 39 \text { years old) }\end{array}$ & $\begin{array}{l}\text { "I think they need to be empowered. They don't } \\
\text { develop themselves, so they need to be } \\
\text { empowered, more experienced." (Participant } 34 . \\
\text { Male. } 58 \text { years old) }\end{array}$ & $\begin{array}{l}\text { "A program before on hand that prepare you for } \\
\text { this and this and that. I just wish there could be } \\
\text { some emotional training on that. The first time I saw } \\
\text { a person died in my face I have never seen that." } \\
\text { (Participant } 33 . \text { Female. } 35 \text { years old) }\end{array}$ \\
\hline
\end{tabular}


continuous development and training where employees could be empowered and informed.

\section{DISCUSSION}

The present study focused on the experience of employees in the three sectors of high-risk occupations regarding PTMPs. The findings indicated two categories in this regard, which are expounded below.

\section{Category 1}

The first category relates to participants' experience of the PTMPs in their various sectors. Two main themes were captured from this category: PTMPs viewed as effective and PTMPs viewed as ineffective in managing psychological trauma.

Across the three sectors, findings showed that the respondents considered multiple counseling sessions as effective to help manage psychological trauma. In their review and metaanalysis, Roberts et al. (2009) indicate that multiple counseling sessions, especially cognitive-behavioral therapy, seem more effective than supportive counseling. The respondents from all three sectors indicated that they prefer regular, face-toface and multiple counseling sessions to manage psychological trauma. This view corresponds with findings from Boshoff and Strydom (2017), who indicate that counseling services in the police sector consist mostly of a single-session intervention that lacks long-term therapeutic effectiveness. Mining companies in South Africa generally do not employ clinical psychologists on a full-time basis. Certain mining organizations contract clinical psychologists as part of an external network of service providers (Ntimbane, 2018, Personal communication). Traumatized mineworkers are referred to psychologists through doctors, wellness clinics or the human resource department of the mining company. A number of mining organization in South Africa, however, do employ social workers who render support and counseling services (Employee Assistance Program counselors) to mine employees (Maiden and Terblanche, 2006).

From the results, it is evident that the participants valued faceto-face counseling more than the telephonic mode. According to Stickley (2011), non-verbal communication is important to create a therapeutic space. Observing non-verbal communication is, however, impossible when counseling is done telephonically. The participants viewed support from social workers (mining sector), as well as colleague support (EMS sector) as a valuable part of a PTMP. According to Inbar and Ganor (2003), employees in the helping professions utilize self-made support systems from social networks and other professional colleagues. In the EMS sector, the buddy system is a peer-support structure where colleagues are encouraged to share their concerns and experiences mutually (Mishra et al., 2010). Alexander and Klein (2001) as well as Jonsson and Segesten (2004) point out that implementing the buddy system in the EMS sector has been effective by molding organizational culture, thereby preventing or mitigating the onset of burnout.

Paramedics found the PTMPs to be effective, since it helped them regain control after experiencing the negative effects of a traumatic event. Sanderson (2013) explains that EMS personnel use a degree of dissociation (screening out the environment) for improved functioning when they encounter risk, danger or chaos. This can be a highly adaptive strategy to strengthen concentration and contain emotions. A high degree of dissociation (i.e., clinically) can, however, cause a person to lose contact with reality, the body, or sense of self for a period of time. Clinical dissociation is often associated with a feeling that individuals have lost control over actions, feelings, memories, and thoughts (Sanderson, 2013). From the findings, it seems as if trauma counseling helps some paramedics regain a sense of control.

A significant and alarming finding from the policing sector was the lack of positive feedback on participants' experience of the PTMPs in the SAPS. Generally, the participants across the sectors indicated more negative than positive experiences of these programs. However, in the policing sector specifically, no participant felt the PTMPs help them manage trauma effectively. Cooper and Cartwright (1997) point out in their article that organizations should recognize counseling involves expert skills and requires extensive training. Particularly participants in the policing sector showed a reluctance to trust the counseling services. These participants found that the counselors do not always maintain confidentiality. The findings indicated further that the counselors cannot relate to police work, as they were not exposed to the same traumatic incidents such as life threatening situations and disturbing scenes. Macqueen (2019) states that principles such as confidentiality, integrity, and honesty require revision. The reason is that practitioners more often work in favor of the providers of psychotherapy than the clients and patients. Privacy and confidentiality are essential for counseling to be effective (Bond and Mitchels, 2014).

According to participants, a shared operational experience would be having a better understanding of a police official's work environment. It is therefore understandable why certain participants argued that psychologists with actual policing experience would be more effective as trauma counselors. However, exposing counselors to life-threatening situations and disturbing scenes may traumatize those who are supposed to render trauma services to their clients.

A major concern for the participants in both the mining and policing sector was supervisor support. Jansen and Brent (2005) explain that mineworkers are more likely to move beyond their job descriptions if they are satisfied with their jobs, perceive their supervisors to be supportive and understanding, and consider that they are treated fairly by the organization. Supervisors will therefore benefit from supporting employees during and after traumatic events. Employees will likely respond positively to such support. According to Stephens and Long (2007), in a sample of police officers $(n=517)$, supervisor support correlated strongly to lower PTSD symptoms. Bakker et al. (2003) found that employees who experience social support in the workplace seem more dedicated and committed to their organization.

From the results, it is clear that the participants valued a holistic multi-dimensional approach to psychological trauma management. However, police members from the present study perceived debriefing as insufficient. According to Everly et al. 
(2000) and Mitchell (2004), follow-up and referral are important aspects of critical incident stress management (CISD). Boshoff and Strydom (2017) point out that CISD in the SAPS consists mostly of a single-session intervention that is not therapeutically effective in the long term. Employees reported that they were referred too easily to doctors and psychiatrists for medication instead of being offered counseling to identify the root of the problem and addressing it accordingly.

The present study highlighted the importance of proper training and skills development for helping professionals. Participants pointed out that counselors lack proper skills, which cause PTMPs to be ineffective. In the policing sector, the participants indicated that the counselors had insufficient knowledge and skills to handle psychological trauma management, while interviewees from the EMS sector indicated that the practitioners they talked to were not properly trained to help improve their perspective on recovery from psychological trauma. This finding is in accordance with a recommendation made by the Society for Industrial and Organizational Psychology (2019), that employee counseling and individual rehabilitation are potential important process capabilities and skills that preferably need to be included in the training of industrial psychology practitioners. According to Forbes et al. (2011), employees at the various levels in an organization (including supervisors) should be educated about psychological trauma and their role in times of crisis. It could be advisable to train peer educators, especially in the policing sector, since the peers can relate to each other, a characteristic most participants indicated to be important in a PTMP. The paramedics also indicated that training is linked to improved management of their psychological trauma. This view can be explained by the volatile nature of emergencies where paramedics' actions and decisions make the difference between life and death. Findings from a sample of disaster workers showed that practical, procedural training in the job beforehand and group support during it, is more effective than psycho-education on stress management (Alexander, 2005).

Furthermore, participants highlighted adequate recovery time as crucial. They felt they have to resume their duties prematurely and do not have sufficient recovery time from psychological trauma. According to Cooper and Cartwright (1997), organizations should focus on workload and work pace. The organization should take care to allow recovery time from demanding tasks by allowing employees more control over the pace of work.

\section{Category 2}

The second category, emerging from the results, points to participants' needs about elements that should be included in a PTMP. From the results, it is clear that an effective PTMP should include three intervention levels, which could be compiled into a generic framework, but should also include personalized approaches. Table 3 indicates that participants from all three sectors recommended preventative interventions, also specific interventions during the crisis and recuperative interventions. The three levels that emerged from the participants can be illustrated as follows:

\section{Pre-crisis}

On preventative level, participants suggested certain proactive interventions before the crisis takes place. According to Everly et al. (2000) and Forbes et al. (2011), an effective workplace PTMP should include elements ranging from pre- to postcrisis interventions. Pre-crisis entails a preparation phase for both employees and the organization (Mitchell, 2004). This preparation includes elements such as developing a program aligned to the organization's policies and procedures; marketing the program; and training at the various organizational levels (Forbes et al., 2011). These elements were also found in the current study; the participants indicated that knowledge about trauma and emotional reactions would help them deal with psychological trauma more effectively. This view is in line with Everly et al. (2000), Forbes et al. (2011), and Mitchell (2004), who advocate pre-crisis preparation that includes psychological trauma education and training at the various levels in the organization.

The participants in the EMS sector specifically reflected on physical activity and hobbies that help them manage psychological trauma. Salmon (2001) argues that physical exercise reduces anxiety and depression and offers resistance to the physiological and psychological costs of stressors.

\section{Acute}

Regarding a recuperative level, such interventions should address the employees' needs during the crisis. The participants indicated that regular psychological support (across the three sectors) is necessary during the crisis phase. Only in the policing sector did participants indicate that they preferred an independent psychological service provider. Kaminer and Eagle (2010) point out that post-crisis interventions should include frontline as well as brief- and medium-term interventions, but also longterm trauma therapy. Roberts et al. (2009) report that multiple trauma counseling sessions were effective to address the negative impact of traumatic incidents on individuals. Mineworkers also recommended that the process of referring traumatized employees to psychologists should be accelerated during this phase. Badenhorst and Van Schalkwyk (1992) recommend that, within a South African context, trauma management should be implemented as soon as possible after a miningrelated accident.

Furthermore, participants in the EMS sector did not require any medical support or evaluation themselves. This is interesting, since they occupy a profession in the medical environment, as opposed to the other two sectors, policing and mining, who viewed medical support and evaluation as an important intervention to recover from psychological trauma. Mabunda and Idemudia (2012) recommend that the mental health of workers in South Africa should be evaluated regularly to detect, among others, signs of anxiety, stress, and depression. EMS employees suggested that continuous training should be provided to them since it is linked to the management of their psychological trauma during the acute phase. This view can be explained by the volatile nature of emergencies where paramedics' actions and decisions may imply life or death. Practical, procedural training in the job beforehand and group support during work were found to 
be more effective for disaster workers than psycho-education on stress management was (Alexander, 2005).

\section{Post-crisis}

On the third level, after a crisis took place, the organization's support clearly enhances employees' wellbeing when recovering from psychological trauma. Management support was found to be especially important for the mining and policing sectors. In contrast, participants from the EMS sector did not highlight supervisory support as a means to manage psychological trauma. However, the paramedics considered the valuable support those they received from their co-workers, friends, and family. Interestingly, the mining and policing sectors made no mention of co-worker or family support. Angelo and Chambel (2013) indicate that supervisory training is important in techniques to help strengthen peer support in the workplace. According to Gilbreath and Benson (2004), supervisors who are perceived to employ positive behaviors, and rarely negative conduct, contribute to the psychological health of subordinates. Furthermore, Inbar and Ganor (2003) point out that people in the helping professions make use of self-made support systems from social networks and other professional colleagues. This is also evident from the present study where EMS employees use the "buddy system."

From the aforementioned discussion, based on the findings of this study, a framework is conceptualized and presented in Figure 3. The aim is to address psychological trauma management in the workplace utilizing this framework on the three levels identified by Hurrell and Murphy (1996), namely primary, secondary, and tertiary prevention interventions. The conceptual framework, deliberated next, links the pre-crisis, acute, and post-crisis phases to the three levels of prevention interventions for high-risk occupations.

Hurrell and Murphy (1996) refer to the use of "primary prevention interventions to reduce risk factors or to change the nature of the job stressors" (p. 339). In the current study, primary prevention strategies that link to the participants' responses include a preparation phase such as induction to the organization, marketing and creating awareness of trauma-related symptoms and interventions, putting policies and procedures in place to address psychological trauma and employee wellness, supervisory training and a career management process for employees. During the acute phase of a crisis, the primary level interventions include having sufficient job-related resources, the availability of management support and addressing immediate needs, such as providing safety, food, and comfort. The post-crisis phase allowing job-redesign was a focus point in the study, also following up on employees who were involved in the incidents and providing continued support. An important aspect on primary intervention level is to have a return-to-work strategy in place to guide commencing with duties at a suitable stage. The participants indicated that having job control assisted them during the post-crisis phase and that a joint decision-making process with management was important.

Secondary interventions deal with the consequences rather than the causes of stress, which may be innate to the organization's culture, and focus on increasing awareness and improving employees' skills in stress management (Cooper and Cartwright, 1997). Strategies to improve stress management include activities that empower employees to identify symptoms of stress, thereby adding to the employee's physical and psychological resources. The intervention level of secondary prevention, however, assumes that the inherent nature of the organization may not change; for example, the nature of police work is likely to stay the same. Therefore, the inherent nature of the work will continue to be stressful and therefore employees have to increase their tolerance and resistance to stress. In this study, for the pre-crisis phase, the participants referred to psychoeducational training in topics such as EQ and trauma symptoms to empower them. Furthermore, having colleague and supervisor support was especially significant to the participants during this phase. During the acute phase of a crisis, having knowledge on coping support and following a team-based approach to cope with the crisis were effective psychological trauma management strategies. The participants also found family and colleague support especially helpful to cope during this phase. Colleague support was also effective in the post-crisis phase; however, support groups were mentioned to be of value to assist the employees with their recovery.

Tertiary prevention interventions are concerned mainly with the treatment, rehabilitation, and recovery of those individuals who have undergone or currently are suffering from serious ill health due to stressful events (Cooper and Cartwright, 1997). Typical interventions focus on counseling services, and procedures to facilitate and assist employees' recovery and return to work strategy (Cooper and Cartwright, 1997). In this study, during the pre-crisis phase, the participants indicated that it helped them to be physically active or to have a hobby to focus their attention on; having established rapport with significant others helped them during this phase as well as going for medical and psychological evaluations as a means to act proactively. During the acute phase of a crisis, having psychological support on site was especially helpful, also utilizing the frontline intervention model during counseling, identifying trauma symptoms and connecting employees with their social support were helpful during this phase. After the crisis took place, the tertiary interventions the participants found helpful to address ill health focused on brief and longterm therapy to address PTSD symptoms, going for medical assessments to evaluate their recovery, and having psychological follow-up sessions.

The framework is outlined in Figure 3.

\section{Limitations of the Study}

Firstly, the participants in the present study were mostly male. The mining, policing and EMS environments in South Africa are, however, male-dominated, which imply that females are underrepresented. One major challenge the authors were faced with was obtaining participation and approval from the sectors where females were mostly more representative, typically the officebased employee assistance support services. Unfortunately, these sectors declined participation. Despite the gender imbalance, this study still provides useful insights that can be applied more broadly in the field of psychological trauma management. 


\section{A Primary intervention B Secondary intervention C Tertiary intervention}

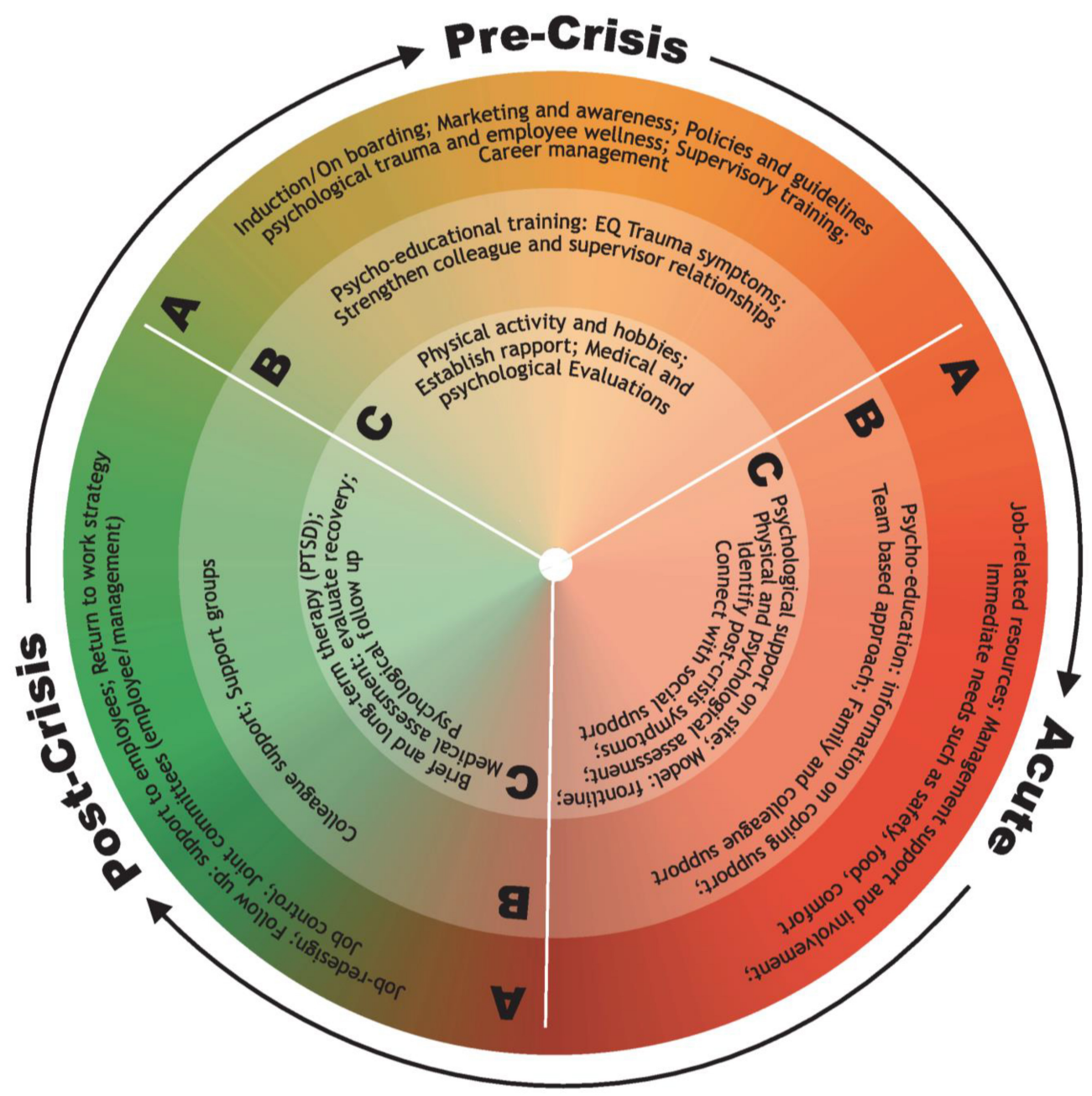

FIGURE 3 | A conceptual intervention framework to address psychological trauma in high-risk occupations.

Secondly, data were collected from only two of the nine provinces in South Africa. More provinces could have been included. This was done, however, since the study was exploratory in nature and sufficient cases were accessible to the researchers in the two provinces to investigate the phenomenon. Lastly, other sectors such as the fire-and-rescue services and the cash transportation industry could also have been included in the present study. These settings can also be regarded as high-risk occupational environments and should be eligible to trauma support services.

\section{Implications}

This study contributed to organizations in the mining, policing and EMS sectors by providing a contextualized understanding of the types of events their employees regard as traumatizing and how these events should be addressed and managed. For the mining sector, management should take note that management support was mainly a focus for employees when recovering from psychological trauma. Furthermore, it became clear that for participants, the management's involvement, especially with funerals and visits to staff members in hospitals after traumatic incidents, was deemed as having a positive effect. Implementing such requested support could make a significant difference to the way the employees experience workplaces. In the policing sector, the main focus was more on obtaining an independent confidential psychological service. Management in the policing sector could consider such a service and also address the stigmatization about receiving counseling.

Decision-making parties in the EMS sector should consider expanding on the perceived support from families and 
co-workers. The implication may be that signs and symptoms of psychological conditions such as acute stress disorder, PTSD and depression may not be recognized in time. Such support systems are helpful, but may not be trained adequately in diagnosing and treating the aforementioned conditions. An external service provider who can help a paramedic regain control of feelings, thoughts and behavior, would translate into an effective PTMP in this case.

Future studies should include other high-risk occupations such as fire and rescue services, also including more females, Indian and colored participants in its sampling. Another future research perspective could be to explore the employers' point of view. A practical implication and strength of the study is evidenced in the creation of a contextualized understanding of the participants' experiences regarding the current PTMPs and the recommendations to improve the effectiveness of such interventions. This leads the way toward a conceptual framework proposed for the management of PT in highrisk occupations in South Africa. Finally, a future research initiative could include to verify how the ad hoc framework could possibly support and improve productivity and wellbeing of employees affected by work-related trauma. In this way, they can establish a positive intervention framework for high risk occupations.

\section{CONCLUSION}

Organizations can benefit largely from implementing relevant PTMPs. Employees in high-risk occupations are often exposed to life-threatening and dangerous incidents, which may lead to psychological trauma. Managing these traumatic experiences should be facilitated by a program that incorporates multiple components ranging from pre- to post-crisis.

\section{DATA AVAILABILITY STATEMENT}

The datasets generated for this study are available on request to the corresponding author.

\section{REFERENCES}

Adriaenssens, J., De Gucht, V., and Maes, S. (2012). The impact of traumatic events on emergency room nurses: findings from a questionnaire survey. Int. J. Nurs. Stud. 49, 1411-1422. doi: 10.1016/j.ijnurstu.2012.07.003

Alexander, D. A. (2005). Early mental health intervention after disasters. $A d v$. Psychiatr. Treat. 11, 12-18. doi: 10.1192/apt.11.1.12

Alexander, D. A., and Klein, S. (2001). Ambulance personnel and critical incidents: Impact of accident and emergency work on mental health and emotional well-being. Br. J. Psychiatry 178, 78-81.

American Psychiatric Association (2004). Practice Guidelines for the Treatment of Patients with Acute Stress Disorder and Posttraumatic Stress Disorder. Arlington, VA: Author.

Angelo, R., and Chambel, M. (2013). An intervention with firefighters to promote psychological occupational health according to the Job Demands-Resources Model. Rev. Psicol. Soc. 28, 197-210. doi: 10.1174/021347413806196753

\section{ETHICS STATEMENT}

The studies involving human participants were reviewed and approved by the Ethics Committee: Economic and Management Sciences. The patients/participants provided their written informed consent to participate in this study.

\section{AUTHOR CONTRIBUTIONS}

All authors are registered industrial psychologists who share an interest in intervention research and qualitative research. BJ is a Ph.D. student who conducted this study as part of his doctoral thesis, responsible for the data collection, data interpretation, and writing of the thesis. LG is a professor and main supervisor of the Ph.D. study, helped to conceptualize the study, a part of the data collection and the writing up of the manuscript for publication purposes. LR is the co-supervisor and assisted with the conceptualizing of the study and data interpretation.

\section{FUNDING}

Recognition is hereby provided to the National Research Foundation (NRF) for funds provided to execute parts of this research (Nr 120255). Any opinions, findings and conclusions, and recommendations expressed in this material are those of the authors and therefore the NRF does not accept any liability therefore.

\section{ACKNOWLEDGMENTS}

The authors thank the participants for their contribution and sharing their experiences in this study.

\section{SUPPLEMENTARY MATERIAL}

The Supplementary Material for this article can be found online at: https://www.frontiersin.org/articles/10.3389/fpsyg. 2020.00530/full\#supplementary-material

Attridge, M. A., and VandePol, B. (2010). The business case for workplace critical incident response: a literature review and some employer examples. J. Workplace Behav. Health 25, 132-145. doi: 10.1080/15555241003761001

Atvoli, L., Stein, D. J., Williams, D. R., Mclaughlin, K. A., Petukhova, M., Kessler, R. C., et al. (2013). Trauma and posttraumatic stress disorder in South Africa: Analysis from the South African Stress and Health Study. BMC Psychiatry 13:182.

Australian Centre for Posttraumatic Mental Health (2007). Australian Guidelines for the Treatment of Adults with Acute Stress Disorder and Posttraumatic Stress Disorder. Melbourne VIC: Australian Centre for Posttraumatic Mental Health.

Badenhorst, J. C. C., and Van Schalkwyk, S. J. (1992). "Minimising posttraumatic stress in critical mining incidents," in Employee Assistance Programs in South Africa, ed. R. P. Maiden (New York, NY: Haworth Press).

Bakker, A. B., Demerouti, E., and Schaufeli, W. B. (2003). Dual processes at work in a call centre: an application of the job demands-resources model. Eur. J. Work Organ. Psychol. 12, 393-417. doi: 10.1080/13594320344000165 
Bao, J., Johansson, J., and Zhang, J. (2017). An occupational disease assessment of the mining industry's occupational health and safety management system based on FMEA and an improved AHP model. Sustainability 9, 94-103.

Bolm-Audorff, U., Petereit-Haack, G., and Seidler, A. (2019). Relationship between Occupational Trauma, Postraumatic Stress Disorder and Depression - An Assessment of Systematic Reviews. Available online at: https:/europepmc.org/ abstract/med/30641613 (accessed October 10, 2019).

Bond, T., and Mitchels, B. (2014). Confidentiality and Record Keeping in Counselling and Psychotherapy, 2nd Edn. Los Angeles, CA: SAGE.

Boshoff, P., and Strydom, H. (2017). A psycho-social therapeutic group work programme preventing the onset of post-traumatic stress disorder among police officials attached to the specialised units in the South African Police Service. Soc. Work 53, 445-469. doi: 10.15270/25-2-592

Botma, Y., Greeff, M., Mulaudzi, M., and Wright, S. (2010). Research in Health Sciences. Cape Town: Pearson.

Chabalala, J. (2019). Johannesburg Ambulance Crew Attacked in Cosmo City by Vigilante Mob. News24. Available online at: https://www.news24.com/ SouthAfrica/News/johannesburg-ambulance-crew-attacked-in-cosmo-cityby-vigilante-mob (accessed August 2, 2019).

Cooper, C. L., and Cartwright, S. (1997). An intervention strategy for workplace stress. J. Psychosom. Res. 43, 7-16. doi: 10.1016/s0022-3999(96)00392-3

Creswell, J. W. (2009). Research Design: Qualitative, Quantitative, and Mixed Methods Approaches, 2nd Edn. Thousand Oaks, CA: Sage.

Denzin, N. K., and Lincoln, Y. S. (2013). "The discipline and practice of qualitative research," in Strategies of Qualitative Inquiry, 4th Edn, eds N. K. Denzin and Y. S. Lincoln (Los Angeles, CA: Sage), 1-41.

Department of Mineral Resources: Republic of South Africa (2018). Department of Mineral Resources 2017/2018 Annual Report. Available online at: https://www.gov.za/sites/default/files/gcis_document/201810/mineralresources-annual-report-20172018.pdf (accessed March 19, 2019).

Department of Veterans Affairs/Department of Defence (2004). VA/DoD Clinical practice guideline for the management of post-traumatic stress, version 1.0. Washington DC: Veterans Health Administration, Department of Defence.

Devilly, G. J., and Cotton, P. (2003). Psychological debriefing and the workplace: Defining a concept, controversies and guidelines for intervention. Aust. Psychol. 38, 144-150. doi: 10.1080/00050060310001707147

Eagle, G. T. (1998). An integrative model for brief term intervention in the treatment of psychological trauma. Int. J. Psychother. 3, 135-146.

Ellrich, K., and Baier, D. (2017). Post-traumatic stress symptoms in police officers following violent assaults: a study on general and police-specific risk and protective factors. J. Interpers. Violence 32, 331-356. doi: 10.1177/ 0886260515586358

Evans, S. (2018). Another Paramedic Attacked on Duty Amid Calls to Arm Workers with Weapons. News24. Available online at: https: //www.news24.com/SouthAfrica/News/another-paramedic-attacked-onduty-amid-calls- to-arm-workers-with-weapons-graphic-warning-20181230 (accessed July 5, 2019).

Everly, G. S. Jr., Flannery, R. B. Jr., and Mitchell, J. T. (2000). Critical incident stress management (CISM): A review of the literature. Aggress. Violent Behav. $5,23-40$.

Everly, G. S. Jr., and Lating, J. M. (2017). The Johns Hopkins Guide to Psychological First Aid. Baltimore, MD: Johns Hopkins University Press.

Foa, E. (2009). Effective Treatments for PTSD, 2nd Edn. New York, NY: Guilford Press.

Forbes, D., Lewis, V., Varker, T., Phelps, A., O’Donnel, M., Wade, D. J., et al. (2011). Psychological first aid following trauma: implementation and evaluation framework for high-risk organizations. Psychiatry 74, 224-239. doi: 10.1521/ psych.2011.74.3.224

Georganta, K., and Montgomery, A. (2019). "Worksite interventions," in The Cambridge Handbook of Psychology, Health and Medicine, 3rd Edn, eds C. D. Llewellyn, S. Ayers, C. McManus, S. Newman, K. Petrie, T. Revenson, et al. (Cambridge: Cambridge University Press), 318-324.

Gilbreath, B., and Benson, P. G. (2004). The contribution of supervisor behaviour to employee psychological well-being. Work Stress 18, 255-266. doi: 10.1080/ 02678370412331317499

Hurrell, J. J., and Murphy, L. R. (1996). Occupational Stress Intervention. Am. J. Ind. Med. 29, 338-341.
Inbar, J., and Ganor, M. (2003). Trauma and compassion fatigue: Helping the helper. J. Jewish Communal Serv. 79, 109-111.

Jansen, J. C., and Brent, A. C. (2005). Reducing accidents in the mining industry an integrated approach. J. S. Afr. Inst. Min. Metall. 105, 719-725.

Jonsson, A., and Segesten, K. (2004). Guilt, shame and the need for a container: a study of post-traumatic stress among ambulance personnel. J. Accid. Emerg. Nurs. 12, 215-223. doi: 10.1016/j.aaen.2004.05.001

Kaminer, D., and Eagle, G. (2010). Traumatic Stress in South Africa. Johannesburg: Wits University Press.

Kowalski-Trakofler, K., and Vaught, C. (2012). Psycho-social issues in mine emergencies: the impact on the individual, the organization and the community. Minerals 2, 129-168. doi: 10.3390/min2020129

Le Fevre, M., Kolt, G. S., and Matheny, J. (2006). Eustress, distress and their interpretation in primary and secondary occupational stress management interventions: Which way first? J. Manag. Psychol. 21, 547-564.

Lemanski, C. (2004). A new apartheid? The special implications of fear of crime in Cape Town, South Africa. Environ. Urban. 16, 101-111. doi: 10.1177/ 095624780401600201

Litz, B. T. (2008). Early interventions for trauma: Where are we and where do we need to go? A commentary. J. Trauma. Stress 21, 503-506. doi: 10.1002/jts

Mabunda, M., and Idemudia, E. S. (2012). Cumulative adversities and mental health of employees in workplace settings in Gauteng Province, South Africa. J. Soc. Sci. 33, 189-199. doi: 10.1080/09718923.2012.11893098

Macqueen, D. (2019). Psychotherapist or secret police ... who do we really work for? Existent. Anal. 30, 353-361.

Maiden, R. P., and Terblanche, L. (2006). Managing the trauma of community violence and workplace accidents in South Africa. J. Workplace Behav. Health 21, 89-100. doi: 10.1300/j490v21n03_05

Maphanga, C. (2019). Free State Health MEC Condemns Violent Attacks on EMS. News24. Available online at: https:/www.news24.com/SouthAfrica/News/ free-state-health-mec-condemns-violent-attacks-on-ems-20190818 (accessed October 11, 2019).

McNally, R. J., Bryant, R. A., and Ehlers, A. (2003). Does early psychological intervention promote recovery from posttraumatic stress? Psychol. Sci. Public Interest 4, 45-79. doi: 10.1111/1529-1006.01421

Ménard, K. S., and Arter, M. L. (2013). Police officer alcohol use and trauma symptoms: associations with critical incidents, coping and social stressors. Int. J. Stress Manage. 20, 37-56. doi: 10.1037/a0031434

Mishra, S., Goebert, D., Char, E., Dukes, P., and Ahmed, I. (2010). Trauma exposure and symptoms of post-traumatic stress disorder in emergency medical services personnel in Hawaii. Emerg. Med. J. 27, 1-4. doi: 10.1136/emj.2009.080622

Mitchell, J. T. (2004). A response to the Devilly and Cotton article, "Psychological debriefing and the workplace ...". Aust. Psychol. 39, 24-28. doi: 10.1080/ 00050060410001660290

Mitchell, J. T., and Everly, G. S. Jr. (2001). Critical Incident Stress Debriefing: An Operations Manual for CISD, 3rd Edn. Ellicott City, MD: Chevron.

Monageng, R. (2019). Firefighters March on Johannesburg CBD Following Attacks on EMS Crews. News24. Available online at: https://www.news24. com/SouthAfrica/News/firefighters-march-in-johannesburg-cbd-followingattacks-on-ems-crews-20190726 (accessed September 2, 2019).

Mostert, K., and Rothmann, S. (2006). Work-related well-being in the South African Police Service. J. Crim. Justice 34, 479-491. doi: 10.1016/j. jcrimjus.2006.09.003

Mulaudzi, R. (2017). Paramedics Fear for their Lives. Daily Sun. Available online at: https://www.dailysun.co.za/News/National/paramedics-fear-for-their-lives20170925 (accessed October 11, 2019).

National Institute for Clinical Excellence (2005). Management of Post-Traumatic Stress Disorder in Adults in Primary, Secondary and Community Care. London: NICE.

Nieuwenhuis, J. (2016). "Qualitative research designs and data-gathering techniques," in First Steps in Research (2nd ed.), ed K. Maree (Pretoria: Van Schaik), 71-102.

North, C. S., Pfefferbaum, B., Hong, B. A., Gordon, M. R., Kim, Y., Lind, L., et al. (2013). Workplace response of companies exposed to the 9/11 World Trade Center attack: a focus-group study. Disasters 37, 101-118. doi: 10.1111/j.14677717.2012.01295.x

Roberts, N. P., Kitchener, N. J., Kenardy, J., and Bisson, J. I. (2009). Systematic review and meta-analysis of multiple-session early interventions following 
traumatic events. Am. J. Psychiatry 166, 293-301. doi: 10.1176/appi.ajp.2008. 08040590

Roditi, E., Bodas, M., Jaffe, E., Knobler, H. Y., and Adini, B. (2019). Impact of stressful events on motivations, self-efficacy, and development of posttraumatic symptoms among youth volunteers in emergency medical services. Int. J. Environ. Res. Public Health 16:E1613. doi: 10.3390/ijerph16091613

Rose, S., Bisson, J., and Wessely, S. (2003). A systematic review of singlesession psychological interventions ('debriefing') following trauma. Psychother. Psychosom. 72, 176-184. doi: 10.1159/000070781

Ruzec, J. I., Brymer, M. J., Jacobs, A. K., Layne, C. M., Fernberg, E. M., and Watson, P. J. (2007). Psychological first aid. J. Ment. Health Couns. 29, 17-49. doi: $10.17744 /$ mehc.29.1.5racqxjueafabgwp

Salmon, P. (2001). Effects of physical exercise on anxiety, depression and sensitivity to stress: a unifying theory. Clin. Psychol. Rev. 21, 33-61. doi: 10.1016/s02727358(99)00032-x

Sanderson, C. (2013). Counselling Skills for working with Trauma: Healing for Child Sexual Abuse, Sexual Violence and Domestic Abuse. London: Jessica Kingsley.

Schafer, A., Snider, L., and Sammour, R. (2016). A reflective learning report about the implementation and impacts of psychological first aid (PFA) in Gaza. Disaster Health 3, 1-10. doi: 10.1080/21665044.2015.111 0292

Society for Industrial and Organizational Psychology (2019). Guidelines for Education and Training in Industrial-Organizational Psychology. Available online at: https://www.siop.org/Portals/84/Educators/SIOP_ET_Guidelines_ 2017.pdf (accessed September 24, 2019).

Sorensen, P. (2012). The Marikana tragedy. Int. J. Environ. Stud. 69, 871-873. doi: 10.1080/00207233.2012.734046

South African Police Service [SAPS] (2020). SAPS Annual Crime Statistics 2018/2019. Available online at: https://www.saps.gov.za/services/crimestats.php

Stephens, C., and Long, N. (2007). Posttraumatic stress disorder in the New Zealand police: the moderating role of social support following traumatic stress. Anxiety Stress Coping 12, 247-264. doi: 10.1080/1061580990825 0477

Stevens, J. L., Calitz, F. J. W., Joubert, G., Gagiano, C. A., and Nel, M. (2006). Trauma-related risk factors in mineworkers with PTSD: a prospective follow-up study. S. Afr. J. Psychol. 36, 425-425.

Steyn, R., Vawda, N., Wyatt, G. E., Williams, J. K., and Madu, S. N. (2013). Posttraumatic stress disorder diagnostic criteria and suicidal ideation in a South African Police sample. Afr. J. Psychiatry 16, 19-22. doi: 10.4314/ajpsy. v16i1.3
Stickley, T. (2011). From SOLER to SURETY for effective non-verbal communication. Nurse Educ. Pract. 11, 395-398. doi: 10.1016/j.nepr.2011. 03.021

Tehrani, N. (2004). Bullying: a source of chronic post-traumatic stress? Br. J. Guid. Counc. 32, 357-366. doi: 10.1080/03069880410001727567

Terblanche, L., and Van Wyk, A. (2014). Critical incidents and critical incident stress management (CISM) - An employee assistance programme (EAP) perspective. Soc. Work 50, 19-37. doi: 10.15270/50-1-14

Trochim, W. M., Donnelly, J. P., and Arora, K. (2016). Research Methods: The Essential Knowledge Base. Boston, MA: Cengage Learning.

van Riet, G. (2020). Intermediating between conflict and security: private Security Companies as Infrastructures of Security in Post-apartheid South Africa. Politikon 47, 1-18.

Van Wyk, G., and Edwards, D. (2005). From trauma debriefing to trauma support: A South African experience of responding to individuals and communities in the aftermath of traumatising events. J. Psychol. Africa 15, 135-142.

VandePol, B., Labardee, L., and Gist, R. (2006). The evolution of psychological first aid. J. Employee Assist. 36, 18-20.

Ward, C. L., Lombard, C. J., and Gwebushe, N. (2006). Critical incident exposure in South African emergency services personnel: prevalence and associated mental health issues. Emerg. Med. J. 23, 226-231. doi: 10.1136/emj.2005.025908

Wilson, F. (2011). Labour in the South African Gold Mines 1911-1969, Vol. 6. Cambridge: Cambridge University Press.

World Health Organization [WHO] (2005). Single-Session Psychological Debriefing Not Recommended. Advisory Circular. Available online at: www.who.int/ mental_health/media/en/note_on_debriefing.pdf (accessed October 17, 2019).

Zungu, L. I. (2013). Prevalence of post-traumatic stress disorder in the South African mining industry and outcomes of liability claims submitted to Rand Mutual Assurance Company. Occup. Health South. Afr. 19, 22-26.

Conflict of Interest: The authors declare that the research was conducted in the absence of any commercial or financial relationships that could be construed as a potential conflict of interest.

Copyright (c) 2020 Jonker, Graupner and Rossouw. This is an open-access article distributed under the terms of the Creative Commons Attribution License (CC BY). The use, distribution or reproduction in other forums is permitted, provided the original author(s) and the copyright owner(s) are credited and that the original publication in this journal is cited, in accordance with accepted academic practice. No use, distribution or reproduction is permitted which does not comply with these terms. 
OPEN ACCESS

Edited by:

Mai P. Trinh,

Arizona State University, United States

Reviewed by:

Jean Côté

Queen's University, Canada

Anita Howard,

Case Western Reserve University,

United States

*Correspondence:

Llewellyn E. van Zy

Llewellyn101@gmail.com

tThese authors have contributed equally to this work

Specialty section:

This article was submitted to Organizational Psychology, a section of the journal Frontiers in Psychology

Received: 16 December 2019

Accepted: 31 March 2020 Published: 06 May 2020

Citation:

van Zyl LE, Roll LC, Stander MW and Richter S (2020) Positive Psychological Coaching Definitions and Models: A Systematic Literature

Review. Front. Psychol. 11:793 doi: 10.3389/fpsyg.2020.00793

\section{Positive Psychological Coaching Definitions and Models: A Systematic Literature Review}

\author{
Llewellyn E. van Zyl1,2,3,4*t, Lara C. Roll ${ }^{2,5 t}$, Marius W. Stander ${ }^{2 \dagger}$ and Stefanie Richter ${ }^{6 t}$ \\ ${ }^{1}$ Department of Industrial Engineering, University of Eindhoven, Eindhoven, Netherlands, ${ }^{2}$ Optentia Research Focus Area, \\ North-West University (VTC), Vanderbij/park, South Africa, ${ }^{3}$ Department of Human Resource Management, University of \\ Twente, Enschede, Netherlands, ${ }^{4}$ Institut für Psychologie, Goethe University, Frankfurt, Germany, ${ }^{5}$ Department of Applied \\ Psychology, Lingnan University, Tuen Mun, Hong Kong, ${ }^{6}$ Faculty of Psychology, Technische Universität Dresden, Dresden, \\ Germany
}

Despite the popularity of the term Positive Psychological Coaching within the literature, there is no consensus as to how it should be defined (framed) or what the components of a positive coaching "model" should include. The aim of this systematic review was to define positive psychological coaching and to construct a clear demarcated positive psychological coaching model based on the literature. A systematic literature review led to the extraction of 2,252 records. All records were screened using specific inclusion/exclusion criteria, which resulted in the exclusion of records based on duplicates $(n=1,232)$, titles $(n=895)$, abstracts $(n=78)$, and criteria violations $(n=23)$. Twenty-four academic, peer-reviewed publications on positive psychological coaching were included. Data relating to conceptual definitions and coaching models/phases/frameworks were extracted and processed through thematic content analysis. Our results indicate that positive psychological coaching can be defined as a short to medium term professional, collaborative relationship between a client and coach, aimed at the identification, utilization, optimization, and development of personal strengths and resources in order to enhance positive states, traits and behaviors. Utilizing Socratic goal setting and positive psychological evidence-based approaches to facilitate personal growth, optimal functioning, enhanced wellbeing, and the actualization of people's potential. Further, eight critical components of a positive psychological coaching model were identified and discussed. The definition and coaching process identified in this study will provide coaches with a fundamental positive psychological framework for optimizing people's potential.

Keywords: positive psychological coaching, coaching psychology, strengths-based coaching, positive psychological interventions, coaching model, positive organizational interventions, performance enhancement

\section{BACKGROUND}

Positive Psychological Coaching (also referred to as Strengths-Based Coaching, or Positive Coaching) has been positioned as a solution-focused "applied positive psychological approach" aimed at facilitating goal achievement, wellbeing and positive change in various life domains (Madden et al., 2011) and application areas (Castiello D'Antonio, 2018). This "positive" coaching approach is fuelled by recent developments in the strengths-literature, whereby an individual's 
signature strengths are used to facilitate the personal growth and development of a client ${ }^{1}$ (van Zyl and Stander, 2013). From this perspective, each individual's capacity for personal growth and goal achievement is a function of the identification, optimization and application of individual strengths (Linley and Joseph, 2004; Castiello D'Antonio, 2018). Focusing on the "positive" rather than fixing the "deficits" resonates with practitioners, as the focus is on development rather than deficit correction (Stander, 2016). Positive psychological coaching employs a comprehensive approach toward development, which aids clients to identify and actively deploy their character strengths as well as acknowledges the multiple contexts which influences their lives (Haberlin, 2019). Research showed that this novel approach to people development leads to various positive consequences for both the individual (e.g., improved performance, self-efficacy, life satisfaction, self-confidence etc.) and the organization (e.g., talent retention, employee engagement, customer satisfaction, financial growth etc.; Peláez et al., 2019). It is therefore not surprising that this positively framed approach has been popularized within practice and popular psychological press as an effective organizational or talent development intervention (Stander, 2016; Haberlin, 2019).

Despite the popularity of "strengths-based"- or "positive" coaching within the literature, there is still little consensus as to how it should be defined (framed) and what the components of a "positive coaching process" should involve (Peláez et al., 2019). Various definitions or conceptualizations of positive coaching approaches exist within the literature which differ significantly from one another. For example, Linley and Joseph (2004), (p. 4) argued that positive coaching is a process aimed at the promotion of optimal functioning across a full range of human capability. Where van Zyl and Stander (2013) defined it as a professional, client-centered relationship aimed at the identification, utilization, and optimization of individual strengths in order to facilitate the development of individuals and organizations. This definition is partially echoed by Grant et al. (2010) who postulated that positive coaching is a collaborative, solutions-orientated approach designed to facilitate the achievement of personal goals through capitalizing on individual strengths.

In contrast, Denison and Avner (2011) said that positive coaching concerns a set of behavioral guidelines which are easy to use, mechanistic and are formatted as best practice guidelines for what to do and what not to do within a given context. Orem et al. (2007) on the other hand argued that positive or "appreciative" coaching relates to the development of self-compassion through an appreciative relationship with a coach. Castiello D'Antonio (2018) further argued that positive psychological coaching is an approach which seeks to enhance the short-term hedonic- (life satisfaction) and sustainable longterm wellbeing (flourishing) of a client by using evidencebased positive psychological approaches. Although there is some overlap in how it is defined, significant differences in the conceptualization and approach toward positive psychological coaching exist within the literature. Moreover, these definitions

\footnotetext{
${ }^{1}$ The words "client" and "coachee" are used interchangeably in the paper.
}

are used by each of the respected authors as if agreement exists on the conceptualization of the construct, however these agreements are more often only shared between a specific set of authors rather than a matter of consensus. As such, the lack of a coherent theoretical conceptualization of the concept results in not only criticism of the paradigm, but also results in an inability to discern what constitutes positive coaching and what not (Wong and Roy, 2017).

The lack in consensus is not just confined to how positive psychological coaching is defined, but also as to how it is approached within practice. Specifically, there seems to be little consensus as to what constitutes a positive psychological coaching model, -framework or -approach. Anstiss and Passmore (2017) utilized the PERMA model of Seligman (2012) as a coaching framework indicating that coaches should aim to enhance positive emotional experiences, engagement, positive relationships, meaning and accomplishments of their clients. Freire (2013) on the other hand proposed that the "Authentic Happiness" framework of Seligman (2004) could act as a coaching model where clients are facilitated to enhance pleasure in the present/past/future, to increase engagement and to aid in finding meaning in life. However, Dyess et al. (2017) argued that these are merely outcomes of a coaching process and does not constitute a theoretically grounded coaching model or framework. Dyess et al. (2017) suggested that strengths-based coaching take the form of a 4-phased model starting off with (a) building trust, (b) naming the strengths of clients, (c) aiding clients to claim their strengths, and (d) aiming it at the right goals. This approach, however, fails to take the client's ideal or "best possible self" into consideration, which leads some authors to employ Appreciative Inquiry as an alternative coaching framework (Gordon and Gucciardi, 2011; Gordon, 2016). From this perspective, the focus is on identifying the best of what currently is or has been (Discovery), creating a clear vision of their ideal-selves (Dream), assisting the client to create possibilities to actualize their vision/goals (Design), and aiding clients to implement and track initiatives in order to achieve their dreams (Destiny) (Gordon and Gucciardi, 2011; Gordon, 2016).

Appreciative inquiry, however, only focuses on what currently works well, and negates opportunities to focus on the enhancement of developmental areas. As a result, Kauffman et al. (2015) as well as van Zyl and Stander (2013) argued for the adoption of solutions orientated approaches toward positive coaching. Both teams of authors argued for the identification of strengths/skills that could be used to not only achieve goals, but also to aid in closing the gaps between developmental areas and desired outcomes. van Zyl and Stander (2013) however presented a structured 10 phase model on how this could be achieved. They argued that clients need to be developed within the system in which they function, and therefore the organizational reality plays a major role in defining the coaching trajectory. In this strengths-based coaching model, the coach clarifies expectations with the client and his/her stakeholders, aids in the identification of signature strengths and developmental needs, which acts as the basis for deriving coaching themes (van Zyl et al., 2016b). Coaches aid in developing solutions-orientated goals, which stem from an ideal vision crafted by a client. Strengths and 
competencies are developed, and clients are empowered to reframe challenges/problems from a strengths-based perspective (Stander, 2016). Although these are just some examples of positive psychological coaching approaches/models, there are a magnitude of other approaches within the literature; yet no clear conceptual coaching framework exists.

The lack of both a clearly articulated definition and a process-orientated positive psychological coaching methodology/framework/model, leads some to believe that such is a product of pseudo-science, or that it is another victim of the jangle fallacy (i.e., the assumption that it may be an old concept in a proverbially new jacket; Wong and Roy, 2017; Compton and Hoffman, 2019; Yakushko, 2019). For positive psychological coaching to distinguish itself from other approaches to coaching and to develop its own identity within science, there need to be an objective, systematically developed and organized body of knowledge supporting such. This knowledge should be available for other researchers to utilize, implement, validate, evaluate, critique, and update in an objective and systematic manner. The bases of such a body of knowledge starts with a widely accepted and standardized definition of the concept (Creswell, 2013). The lack of a standardized definition and approach may also negatively affect the effectiveness of positive psychological coaching interventions as these are therefore not built on validated empirical models or evidence-based theoretical frameworks (Compton and Hoffman, 2019). This in turn may be harmful to the client as failures in the coaching process may lead to "confirmation" of his/her subjectively perceived personal deficiencies (Wong and Roy, 2017).

As such, the purpose of this systematic review is to clarify the theoretical conceptualization of positive coaching, as well as its underlying components. Specifically, the aim is to construct a commonly shared understanding or "definition" of the concept, and to construct a clear demarcated positive psychological coaching model/process to aid in the development of people.

\section{METHODS}

\section{Research Approach}

A systematic literature review was employed to determine how positive psychology coaching should be conceptualized, with the specific aim of constructing a definition, a coaching model and clarifying the components of such a coaching approach. A systematic literature review employs a systematic approach to identify, select and critically evaluate the available research on a given topic with the aim of synthesizing an answer to a clearly defined research question (Booth et al., 2016). For this systematic review, the "Preferred Reporting Items for Systematic Reviews and Meta-Analyses (PRISMA)" reporting guidelines were employed (Moher et al., 2009). The PRISMA guidelines provide a universally accepted evidence-based checklist of the components which need to be reported within a systematic literature review in order to enhance transparency, clarity and credibility. Derived from these guidelines, we developed and systematically applied a clear extraction and classification taxonomy aligned to the purpose of the study (Booth et al.,
2016). This taxonomy dictated the extent of the search, the inclusion/exclusion criteria, how data is to be coded/analyzed and how disagreement between researchers should be managed (Booth et al., 2016).

\section{Search Strategy}

We conducted a comprehensive systematic literature search between April and July 2019 in the bibliographic databases Scopus, Web of Science, ScienceDirect, PsycInfo, and ACM Digital Library. In those databases we used nine primary search terms: "positive psychology coaching," "strengths coaching," "strengths-based coaching," "positive coaching," "positive therapy at work," "positive personal development," "integrative positive coaching," "wellbeing coaching," and "happiness coaching." First, the primary search terms were applied, and second, in a subsequent search, the databases were queried with a combination of each primary term with the secondary terms "model OR process OR theory OR program" (e.g., "positive psychology coaching” AND "model OR process OR theory OR program”). Using these search terms, 2,252 titles were identified from $2000^{2}$ up until June 2019 (c.f. Figure 1 for the flow diagram of article selection).

\section{Eligibility Criteria}

For manuscripts to be eligible for inclusion into the paper, a number of inclusion and exclusion criteria was set before the start of the project. Included manuscripts needed to (a) be academic peer-reviewed, theoretical articles with a clear focus on model- or theory construction, (b) the focus of these publications needed to be centered around positive coaching psychology, (c) these papers needed to be specifically aligned with the theoretical tradition of positive psychology and could emanate from any application field (e.g., sports or business), (d) only academic peerreviewed scientific papers, books and book chapters published in English were eligible for inclusion, (e) manuscripts needed to be published in journals that were ISI, Web of Science and Scopus listed, and (f) the year of publication had to fall between 2000 and June 2019.

In contrast, we excluded: (1) Publications in non-English formats; (2) non-peer-reviewed books and articles (such as popular psychology- or management books and practitioner focused non-academic journals); (3) articles focusing on instrument development, empirical work or validations of a coaching intervention; (4) unpublished master and doctoral theses; (5) textbooks and conference proceedings; (6) any publications with a focus on non-psychological and/or nonbehavioral coaching (such as physical strengths conditioning in body building); and (7) articles which focused on the outcomes of positive coaching rather than the process itself.

\section{Study Selection}

After completing the search, the study selection process involved four distinct phases and was managed by all four authors. First, the titles of all the studies were tested against the eligibility criteria

${ }^{2} 2000$ marked the start of the positive psychology paradigm. Therefore, this starting point for the literature search seemed most appropriate. 


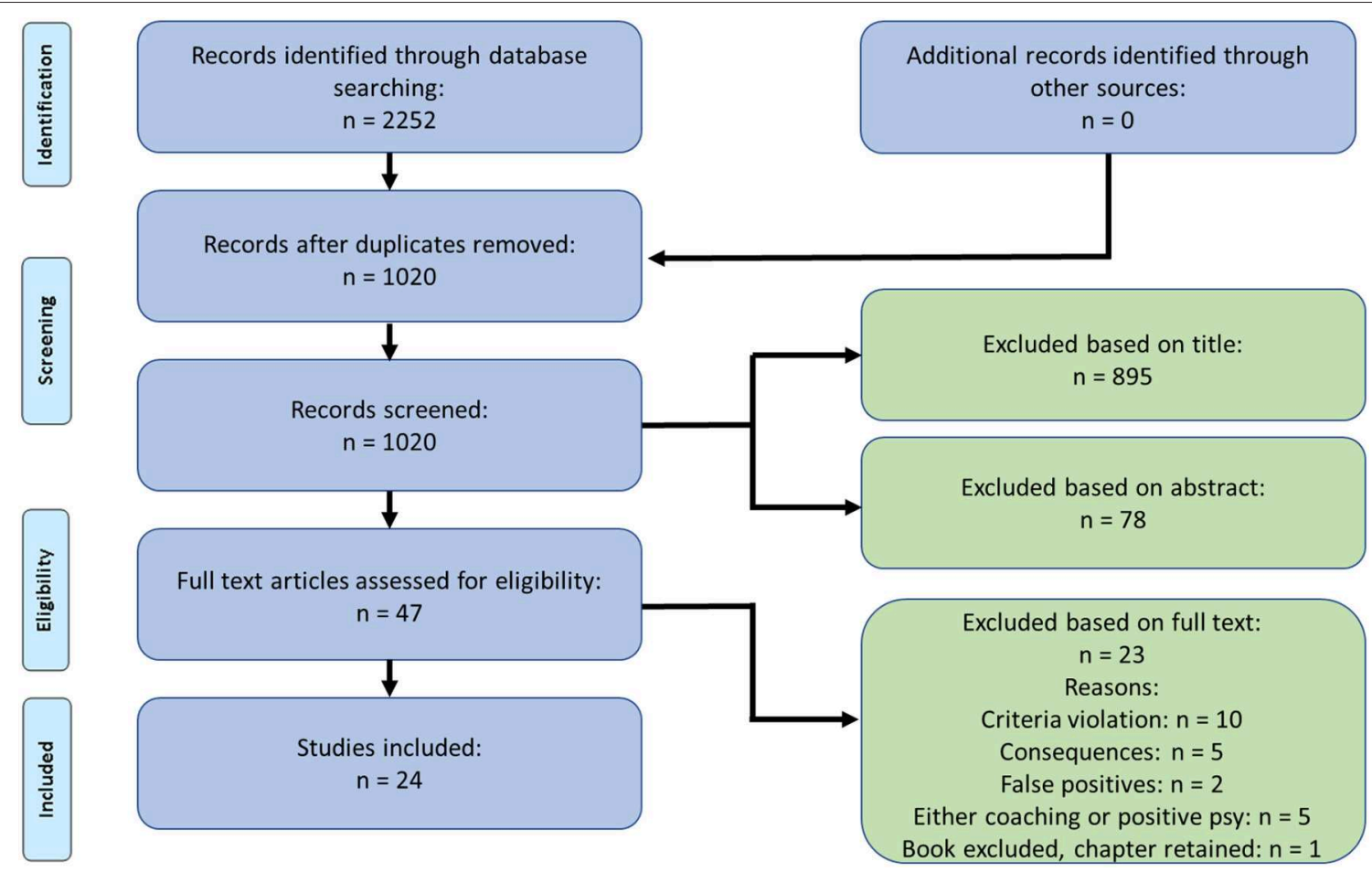

FIGURE 1 | Flow diagram of article selection.

and screened for inclusion by the co-ordinating author and the three co-authors. Second, the relevant abstracts of all papers included via the title screening process were then extracted and screened for inclusion by the authors. Third, the full papers were then extracted and screened for final inclusion. Lastly, the final list of included papers was collated and circulated to five prominent academics within the field of positive psychology and positive coaching psychology to identify additional records; no additional records were added.

Our search revealed 2,252 records. After removing duplicates, our systematic literature search yielded 1,020 unique titles, from which a total of 24 publications were included in the final selection (Figure 1). We excluded 895 publications based on titles, 78 publications after reading their abstracts, and 23 publications based on their full texts. Criteria violation, e.g., empirical or textbook papers, was the most common reason for publications to be excluded $(n=10)$, followed by 5 publications excluded because of their focus being on consequences of positive psychology coaching. A total of 5 papers had to be excluded because their focus was either on coaching or on positive psychology, but the two perspectives were not combined. In two cases the abstracts contained our key words, yet they were not discussed in the main text. These papers were classified as false positives and removed. One book was excluded with only the one relevant chapter thereof retained. Following this screening of titles, abstracts and full texts, we continued with the final selection of 24 articles for further analysis. A full overview of the included papers and their purpose can be seen in Appendix A.

\section{Selection Bias}

To manage selection bias and to enhance the credibility, conformability, and transparency of the systematic review, a number of strategies were employed. First, after the initial search by the co-ordinating author, one of the co-authors performed the literature search following the steps described in the study selection section above. This was done in order to ensure that no records were missed/excluded during the selection process (Moher et al., 2009). Secondly, each of the titles, abstracts and final papers were independently coded and scored by the coordinating author and one of the co-authors. At the completion of each phase, the co-authors would meet to debate the inclusion/exclusion of titles/abstracts/final papers. During these meetings, the reasons for exclusion of a record was discussed and noted. Here, Cohen's kappa coefficient was employed as a means to estimate the inter-rater reliability (McHugh, 2012). The following equation was used:

$$
k=\frac{\operatorname{Pr}(a)-\operatorname{Pr}(e)}{1-\operatorname{Pr}(e)}
$$

Cohen's kappa $(\kappa)$ is a function of the relative observed agreement between the raters $\left(\operatorname{Pr}_{\alpha}\right)$ minus the hypothetical probability of agreement by chance $\left(\mathrm{Pr}_{e}\right)$, divided by the standardized probability of chance (McHugh, 2012). Landis and Koch (1977) argued that a minimum kappa level of 0.61 would be considered acceptable. In order to calculate kappa, the Crosstabs function in SPSS was used. The results showed that that there was substantial 
agreement between raters $(k=0.87 ; p<0.01)$ which exceeded the suggested values of Landis and Koch (1977).

Third, to increase the trustworthiness of the thematic content analyses and the coding process, the data was independently analyzed by the co-ordinating author and one of the authors for each of the two separate sections (definition and model). Here open communication between the co-ordinating author and the three co-authors persisted throughout the analysis process (Coetzee and van Zyl, 2014). Disagreements in the coding process were discussed between the two coders until it was resolved. In the few cases where agreement could not have been found, a third member of the team's opinion was sought. After the initial coding process was completed, a meeting was held whereby all authors had the chance to work through the codes and to discuss agreements/disagreements. The average level of agreement between coders exceeded Miles and Huberman's (1994) suggested $70 \%$. All the raw and process data was retained for possible future scrutiny.

\section{Data Recording and Analyses}

Data from the selected studies were extracted and captured verbatim onto a Microsoft Excel Spreadsheet for further processing. Most authors included information relating to the definition and models of positive psychological coaching in their introduction and discussion sections, though each whole article/chapter was screened for all information related to both topics. Marginal cases were discussed among the authors of this article until consensus was reached whether to include the information for further analysis.

Subsequently, data was processed through thematic content analysis (Creswell, 2013). This procedure allows the quantification of large quantities of textual information. Important text properties were systematically identified through structured categorization according to its relevancy to definition, coaching model, and coaching tools (Creswell, 2013; van Zyl, 2013). The advantages of this procedure include that it is non-intrusive (Duriau et al., 2007), highly flexible (Creswell, 2013), and results can be replicated and quantified in terms of frequencies/percentages (van Zyl, 2013). However, this type of analysis is subjected to the same limitations as traditional nominal-oriented measurement techniques (Salkind, 2012).

Data analysis followed the best practice guidelines of Miles and Huberman (1994), which consisted of the following steps: First, the researchers read through all included articles to get an overview of the data; noting initial ideas. Second, initial codes were generated based on features of the data which became systematically apparent when working through the data set. Third, the various codes were clustered into potential themes based on similar characteristics. Fourth, the researchers then reviewed the themes in relation to the coded extracts in order to generate a thematic map based on the frequency of occurrence. Fifth, a process of on-going analyses and constant refinement was followed in order to specify the elements of each theme and to ensure that the overall analyses tell a coherent story with clear definitions, names and labels for each theme. Finally, the themes were collated based on frequency of occurrence, used as a means to develop the definition of positive coaching and to identify the most prominent components in a positive coaching process. Here all the codes were discussed and verified amongst the research team.

\section{FINDINGS}

The data obtained via the systematic literature review was processed using thematic content analyses. The most frequently occurring themes relating to positive psychological coaching definitions and -models were reported separately.

\section{Common Elements of Positive Psychological Coaching Definitions}

Table 1 summarizes and provides an overview of our findings related to the defining characteristics of positive psychological coaching. In our final selection of articles, we first extracted the information related to conceptual definitions provided by the various authors. Here the frequency of occurrence related to the amount of times a given component was mentioned within and between different records. Second, we identified the shared commonalities between those conceptualizations, which resulted in 20 commonly occurring themes.

In these papers, $20.21 \%$ mentioned that positive psychological coaching includes the "identification, utilization, optimization, and development of strengths and personal resources." For example, Kauffman (2006) described positive psychological coaching as follows: "It focuses on helping clients to use their existing strengths to identify vision of what they want and turn it into reality [through focusing on] strengths, vision, and dreams." A total of $14.89 \%$ described "facilitating personal growth, optimal functioning, and enhancing wellbeing" as core aspects of the positive psychological coaching process. Passmore and Oades (2014), for example, noted that these are "coaching approaches that seek to improve short term wellbeing (i.e., hedonic wellbeing) and sustainable wellbeing (i.e., eudaimonic wellbeing) using evidence-based approaches from positive psychology and the science of wellbeing and enable the person to do this in an on-going manner after coaching has completed."

Approximately $7.45 \%$ described positive psychological coaching as a "collaborative relationship between coach and client." Freire (2013) wrote that it is an "[...] action-orientated collaborative relationship in which the coach is the facilitator." This relationship, according to $12.77 \%$, is "directed toward enhancing positive states, traits, and behaviors," such as "[...] enhancing self-regulation, insight, resilience, self-efficacy and wellbeing by facilitating the establishment and pursuit of selfconcordant goals" (Grant and Spence, 2010). About 5.32\% of articles highlighted the need for positive psychological coaching to "utilize positive psychological evidence-based approaches." As Linley and Kauffman (2007) wrote, "coaches can learn from positive psychology about research and scientific rigor." Another part of positive psychological coaching, mentioned by $4.26 \%$, is "Socratic goal setting and achievement": "[It] is a Socratic, future- focused, collaborative conversation between a coach and the client, during which the coach uses open questions, affirmations, reflective listening, summaries, and information 
TABLE 1 | Common elements from positive psychological coaching definitions.

\begin{tabular}{cccc}
\hline Element & $\begin{array}{c}\text { Frequency } \\
(N=94)\end{array}$ & Percentage Quotation &
\end{tabular}

Identification, utilization,

optimization and development of strengths and personal

resources

Facilitating personal growth, optimal functioning and enhancing wellbeing

Directed toward enhancing positive states, traits and behaviors

Collaborative relationship between coach and client Actualizing client's potential

Utilizing positive psychological evidence-based approaches

Working with well-adjusted individuals

Socratic goal setting and achievement

Developing skills and capabilities

Focus on strengths not weaknesses

Active listening

Clients have the capacity to develop

Developing a personal vision (strategy)

Take ownership of growth

Having a balanced view of the

client's strengths and limitations

Enhance professional

development

Aids in coping with

work-demands

Continuous support

Holistic approach to development

Short- to medium term relationship

11.06
'It focuses on helping clients to use their existing strengths to identify vision of what they want and turn it into reality [through focusing on] strengths, vision and dreams.'

'Coaching approaches that seek to improve short term wellbeing (i.e. hedonic wellbeing) and sustainable wellbeing (i.e. eudaimonic wellbeing) using evidence-based approaches from positive psychology and the science of wellbeing and enable the person to do this in an on-going manner after coaching has completed.'

'[...] enhancing self-regulation, insight, resilience, self-efficacy and wellbeing by facilitating the establishment and pursuit of self-concordant goals.'

'[...] action-orientated collaborative relationship in which the coach is the facilitator.'

'[A process that...] encouraged [individuals] to seek positive things in life, harnessing the best in people and inspiring them to live out their potential.'

'Coaching can learn from positive psychology about research and scientific rigor.'

'The client is already "whole" and skilled.'

'[It] is a Socratic, future- focused, collaborative conversation between a coach and the client, during which the coach uses open questions, affirmations, reflective listening, summaries, and information exchange to stimulate and encourage self- awareness, personal responsibility, and behavioural change thought likely to lead to improved wellbeing outcomes over time.'

'Positive psychology applied to coaching [...] creates the conditions for skill and capability development beyond the usual professional activities, or beyond the prescribed area of organizational role [...]'

'They focus on strengths rather than on weaknesses and use a variety of assessment tools to explore character strengths, life satisfaction, and potentia routes to peak performance.'

'Positive psychology coaches listen for strengths and assets that a client may not be aware of, reflect back what is going right, ask questions that elicit images of better futures, and help clients define action steps supported by wellbeing theories.'

'Coach who believes in the client's ability to cope and change in positive ways, and who can identify, value, and develop the client's "muscles."'

'It focuses on helping clients to use their existing strengths to identify vision of what they want and turn it into reality [through focusing on] strengths, vision and dreams.'

'Taking charge of his own career development (ownership) and life-professional project.'

2.12 'A positive psychology theoretical base does not assume that clients are paragons of virtue or that everything goes smoothly.'

'It is a relationship formed between a coach and the client for the purpose of attaining professional or personal development outcomes.'

'Positive psychology-based leadership coaching also paradoxically assists leaders to grapple with the inevitable negative, toxic, or near-impossible demands of business life.'

'[The coaching process helps clients] develop and implement solutions to ongoing challenges faced during goal striving.'

'[lt] is a well being intervention approach in which clients are taught strategies and skills aimed at helping them to identify, pursue, and fulfill their most cherished needs, goals, and wishes in sixteen valued areas of life said to comprise human wellbeing or happiness.'

'Strengths-based coaching is a short to medium term strengths focused developmental process aimed at harnessing the inner potential of a client in order to optimise his/her performance and to actualise his/her potential.'
Kauffman, 2006

Passmore and

Oades, 2014

Grant and

Spence, 2010

Freire, 2013

Freire, 2013

Linley and

Kauffman, 2007

Kauffman and

Scoular, 2004

Anstiss and

Passmore, 2017

Castiello

D'Antonio, 2018

Tarragona, 2015

Yeager and

Britton, 2017

Noble et al., 2000

Kauffman, 2006

Castiello

D'Antonio, 2018

Kauffman et al., 2015

Grant and

Spence, 2010

Kauffman et al., 2015

Grant and

Spence, 2010

Frisch, 2013

van Zyl et al., $2016 b$ 
exchange to stimulate and encourage self- awareness, personal responsibility, and behavioral change thought likely to lead to improved wellbeing outcomes over time" (Anstiss and Passmore, 2017). This would help to "actualize clients' potential" as claimed by $6.38 \%$. Freire (2013) wrote in this regard that it is "[a process that...] encouraged [individuals] to seek positive things in life, harnessing the best in people and inspiring them to live out their potential."

According to $3.19 \%$ of the records, positive psychological coaches place the "focus on strengths not weaknesses": "They focus on strengths rather than on weaknesses and use a variety of assessment tools to explore character strengths, life satisfaction, and potential routes to peak performance" (Tarragona, 2015). Further, 2.13\% noted the importance of "active listening." Yeager and Britton (2017) wrote: "Positive psychology coaches listen for strengths and assets that a client may not be aware of, reflect back what is going right, ask questions that elicit images of better futures, and help clients define action steps supported by wellbeing theories."

The goals of positive psychological coaching, as mentioned in the identified papers, included (a) to create "a personal vision (strategy)," described by $2.13 \%$, and (b) to "develop skills and capabilities," according to $3.19 \%$. For example, Kauffman (2006) wrote that "it focuses on helping clients to use their existing strengths to identify vision of what they want and turn it into reality [through focusing on] strengths, vision and dreams." Castiello D'Antonio (2018) added that "positive psychology applied to coaching [...] creates the conditions for skill and capability development beyond the usual professional activities, or beyond the prescribed area of organizational role [...]."

In terms of client characteristics, $5.32 \%$ of articles described that positive psychological coaches "work with well-adjusted individuals" in the sense that "the client is already 'whole' and skilled" (Kauffman and Scoular, 2004). A further 2.13\% assumed that "clients have the capacity to develop," e.g., Noble et al. (2000) described a "coach who believes in the client's ability to cope and change in positive ways, and who can identify, value, and develop the client's 'muscles'."

Still, $2.13 \%$ of authors point out that coaches need to "have a balanced view of the client's strengths and limitations": "A positive psychology theoretical base does not assume that clients are paragons of virtue or that everything goes smoothly" (Kauffman et al., 2015). After all, it is the responsibility of clients to take "ownership of their growth," as reported by another $2.13 \%$. The client "taking charge of his own career development (ownership) and life-professional project" is mandatory, according to Castiello D’Antonio (2018).

Four individual articles, contributing $1.06 \%$ to the final estimate, added that positive psychological coaching takes a "holistic approach to development" and provides "continuous support" during the "short- to medium term relationship" to "enhance professional development" and "aid in coping with work-demands.” Regarding the holistic approach, Frisch (2013) recorded that it "is a wellbeing intervention approach in which clients are taught strategies and skills aimed at helping them to identify, pursue, and fulfill their most cherished needs, goals, and wishes in 16 valued areas of life said to comprise human wellbeing or happiness." The notion of continuous support is provided by Grant and Spence (2010), who said that the coaching process helps clients to "develop and implement solutions to ongoing challenges faced during goal striving." That it is a short- to medium-term relationship was contributed by van Zyl et al. (2016a): "Strengths-based coaching is a short to medium term strengths focused developmental process aimed at harnessing the inner potential of a client in order to optimize his/her performance and to actualize his/her potential." The emphasis on professional development was brought forward by Grant and Spence (2010), who wrote that "it is a relationship formed between a coach and the client for the purpose of attaining professional or personal development outcomes." Lastly, Kauffman et al. (2015) add that "positive psychologybased leadership coaching also paradoxically assists leaders to grapple with the inevitable negative, toxic, or near-impossible demands of business life."

\section{Common Elements of Positive Psychological Coaching Models}

Next, from the 24 included articles, several common elements relating to coaching models, approaches, or frameworks were extracted. Here, the frequency of occurrence related to the number of elements which was specifically mentioned as part of a a given phase. These common elements were used as indicators for eight overarching themes which we labeled as "Coaching Phases". These eight phases were: (1) Creating the relationship, (2) Strengths profiling and feedback, (3) Developing an ideal vision, (4) Realistic goal setting, strategizing, and execution centered around strengths, (5) Learning transfer, (6) Action tracking and evaluation, (7) Empowerment, and (8) Concluding the relationship and re-contracting. Table 2 provides a descriptive summary of the extracted themes, elements, frequencies, and supporting quotations from the papers.

The results show that the most frequently occurring theme derived from the records was "Strengths Profiling and Feedback" $(f=24)$. The coach plays an important role in determining what the client's strengths are, what helps them to overcome hurdles, and what gives them hope (Tarragona, 2015). From this perspective, coaches employ various techniques or tools to diagnose the strengths of clients as well as to assess wellness/wellbeing and to provide feedback on the findings. Given that the client knowingly or unknowingly filters the world through his/her strengths (Dyess et al., 2017), a stronger focus needs to be placed on the diagnosis of strengths as opposed to highlighting developmental areas (Linley and Kauffman, 2007). Therefore, the coach facilitates a process to enable clients to appreciate the power and opportunities of dominant strengths (Dyess et al., 2017). Here, coaches may employ various strengths based psychometric assessments (e.g., VIA Signature Strengths Inventory), strengths-based inquiry (e.g., Strengths Based Interviewing), and strengths-based identification initiatives (e.g., Strengths Spotting or Listening for Strengths) to aid in the diagnosis of strengths (van Zyl and Stander, 2013; van Zyl et al., 2016a).

Strengths profiling initiatives, such as guided self-reflections, may also be actioned in order to explore the presence of strengths 
TABLE 2 | Common elements from positive psychological coaching models.

\begin{tabular}{lll}
\hline $\begin{array}{l}\text { Coaching phase Elements } \\
\text { (theme) }\end{array}$ & Frequency Quotation References
\end{tabular}

\begin{tabular}{ll}
\hline Strengths profiling & Developing insight into \\
and feedback & strength use
\end{tabular}

$(f=24)$

Realistic goal setting, strategizing, and execution centered around strengths $(f=22)$

Empowerment (reframing, reinforcement) $(f=16)$

Clarifying expectations between all stakeholders

3

Strengths diagnosis and providing feedback to client

Strengths profiling based on present/past successes

Diagnosing quality of Life and wellbeing

Developing strengths and enhancing competencies

Establishing specific personal/work related goals and means to achieve such centered around the client's strengths

Identify available resources and formulate a utilization plan

Framing solutions and action plans to address problems

Strengthen affirmative capability

Reframing the victim- to a survivor mentality

Motivating client by highlighting strengths use to build self-efficacy

Empower clients

Building sustainable resilience

Creating the relationship $(f=16)$

Establishing rapport and creating a conducive environment

\begin{abstract}
'The coach helps the staff member to appreciate the power and opportunities that his or her dominant strengths give them. This often comes by the staff member reflecting on how their strengths have already helped them to be successful or in some cases have made certain jobs more difficult. We filter the world through our strengths either knowingly or unknowingly, so this is another aspect of strengths that coaches discuss.'
\end{abstract}

'It is therefore imperative in this phase to make the coachee aware of his/her strengths through either (a) strengths based psychometric assessments, (b) strengths-based inquiry and (c) strengths-based identification initiatives.'

'Exploring with the client the kind of activities he or she currently finds engaging, the things she or he used to find engaging but have stopped doing.'

'Quality of Life should be tested throughout planning and evaluating the [coaching] intervention.'

'The main function of this phase is to develop the coachee's competence through strengths enhancement, building and utilisation activities. The coachee is encouraged to [develop strengths] in the current work-related reality.'

7 'The last step in the coaching process is to help establish staff goals and determine how the staff member will invest in the development of their talents and strengths by using them more effectively in their work. Coaches help staff see how their strengths can be used to achieve their career goals by investing in activities that build on their strengths.'

'The coaching process facilitates goal attainment by helping individuals to [...] identify personal resources and formulate action plans.'

'This phase involves developing or framing solutions and action plans to current challenges and developmental areas. This is done through solution-building conversations.'

'Strengthen affirmative capability to build hope and sustain momentum for ongoing positive change and high performance.'

Grant and

Spence, 2010

van Zyl et al., 2016b

Gordon and Gucciardi, 2011

van Zyl and Stander, 2013 aids in altering the coachee's perspectives of the presented problem and establishes a sense that numerous possibilities exist to understanding the problem [...] which aids the coachee to shed the victim mentality.'

'Enhance motivation by identifying strengths and building self-efficacy.'

Grant and Spence, 2010

'Establishing a positive connection between coach and client. Leading the client to a more empowering perspective. Affirming a sense of the possible. Cultivating and supporting the cilent's belief in a positive future.'

'Build a level of resilience which will fortify the internal psychological barriers which buffer against reoccurrences in the future.'

'In order to establish rapport, the coach needs to attend to any physical barriers which might impact or interrupt the process. The coach should create a calm and trusting environment in order to establish the perception that the coach is providing his undivided attention to the coachee. The coach should [...] present genuine unconditional positive regard, free from judgement. This in turn establishes the perception that the coach is more attentive, empathic and caring. Further, a process of active listening needs to be invoked in order to show that the coach comprehends, retains and responds to what the coachee is presenting.'

'The purpose of this phase is to clarify the expectations between (a) the coach/coachee, (b) coach/senior management, (c) coach/direct manager and (d) coachee and his/her direct manager, in order to establish rapport, transparency of expectations and to include the organizational context (e.g. vision/mission/strategy) into the coaching process.'
Gordon, 2016

van Zyl et al., $2016 b$

van Zyl and Stander, 2013

van Zyl et al., $2016 b$ 
TABLE 2 | Continued

\begin{tabular}{|c|c|c|c|c|}
\hline $\begin{array}{l}\text { Coaching phase } \\
\text { (theme) }\end{array}$ & Elements & Frequency & Quotation & References \\
\hline & $\begin{array}{l}\text { Creating a positive } \\
\text { relationship }\end{array}$ & 1 & 'Strengthen and deepen the positive relationship with the client.' & $\begin{array}{l}\text { Anstiss and } \\
\text { Passmore, } \\
2017\end{array}$ \\
\hline \multirow[t]{3}{*}{$\begin{array}{l}\text { Developing an ideal } \\
\text { vision }(f=11)\end{array}$} & $\begin{array}{l}\text { Creating a vision of the } \\
\text { best possible self }\end{array}$ & 7 & $\begin{array}{l}\text { 'Help the client create a clear vision of a positive future that stretches beyond the } \\
\text { limits of their current comfort zone and level of performance.' }\end{array}$ & $\begin{array}{l}\text { White and } \\
\text { Barnett, } 2013\end{array}$ \\
\hline & $\begin{array}{l}\text { Identify future-orientated } \\
\text { desired outcomes }\end{array}$ & 1 & $\begin{array}{l}\text { 'The coaching process facilitates goal attainment by helping individuals to identify } \\
\text { [future-orientated] desired outcomes.' }\end{array}$ & $\begin{array}{l}\text { Grant and } \\
\text { Spence, } 2010\end{array}$ \\
\hline & Identify coaching themes & 3 & $\begin{array}{l}\text { 'The focus is to determine the coachee's areas of development through } \\
\text { understanding the current challenges in his/her current work-related reality (van Zyl } \\
\text { and Stander, 2013). As such, a deliberate attempt needs to be employed in order } \\
\text { to reveal the coachee's (a) perceptions associated with current } \\
\text { difficulties/challenges, (b) reasons why these exists, (c) the factors attributable to } \\
\text { the challenges, (d) the possible consequences if these are unresolved and (e) the } \\
\text { meaning derived from the given challenging context.' }\end{array}$ & Stander, 2016 \\
\hline \multirow{3}{*}{$\begin{array}{l}\text { Action tracking and } \\
\text { continuous } \\
\text { evaluation }(f=6)\end{array}$} & $\begin{array}{l}\text { Tracking the progress of } \\
\text { goal achievement }\end{array}$ & 2 & '[Continuously]... monitor and evaluate progression towards goal attainment.' & $\begin{array}{l}\text { Grant and } \\
\text { Spence, } 2010\end{array}$ \\
\hline & $\begin{array}{l}\text { Continuous assessment of } \\
\text { wellbeing }\end{array}$ & 3 & $\begin{array}{l}\text { 'Evaluation of the process should continue throughout the coaching intervention in } \\
\text { order to ensure that the developmental strategy is on track.' }\end{array}$ & $\begin{array}{l}\text { van Zyl and } \\
\text { Stander, } 2013\end{array}$ \\
\hline & $\begin{array}{l}\text { Revisiting or modifying } \\
\text { existing action plans }\end{array}$ & 1 & 'Modify action plans [when necessary].' & $\begin{array}{l}\text { Grant and } \\
\text { Spence, } 2010\end{array}$ \\
\hline \multirow[t]{3}{*}{$\begin{array}{l}\text { Learning transfer } \\
(f=5)\end{array}$} & $\begin{array}{l}\text { Provide client with } \\
\text { "Home-Work" to reinforce } \\
\text { learnings }\end{array}$ & 2 & $\begin{array}{l}\text { "'Instruct" our clients about topics that are relevant to their situation, comment on } \\
\text { evidence, share findings, or recommend a book or a video by an expert on the } \\
\text { topic we are discussing.' }\end{array}$ & $\begin{array}{l}\text { Tarragona, } \\
2015\end{array}$ \\
\hline & $\begin{array}{l}\text { Identify appropriate positive } \\
\text { psychological } \\
\text { self-administered } \\
\text { interventions }\end{array}$ & 2 & $\begin{array}{l}\text { 'Using evidence-based approaches from positive psychology and the science of } \\
\text { wellbeing- and enable the person to do this in an on-going manner after coaching } \\
\text { has completed.' }\end{array}$ & $\begin{array}{l}\text { Passmore and } \\
\text { Oades, } 2014\end{array}$ \\
\hline & $\begin{array}{l}\text { Look for opportunities for } \\
\text { active skill development }\end{array}$ & 1 & $\begin{array}{l}\text { 'Support coachees in handling essential but difficult emotions as well as continuing } \\
\text { to develop methods to increase their experiences of joy, contentment and hope } \\
\text { through active skill development.' }\end{array}$ & Sims, 2017 \\
\hline $\begin{array}{l}\text { Concluding or } \\
\text { re-contracting }(f=3)\end{array}$ & $\begin{array}{l}\text { Evaluating and } \\
\text { re-contracting the } \\
\text { relationship }\end{array}$ & 3 & $\begin{array}{l}\text { 'Evaluated against the initial objectives [at the onset of the coaching process], both } \\
\text { the coach and coachee needs to determine the success of the intervention. In the } \\
\text { scenarios where the expectations have not been met, or if the coachee presents a } \\
\text { need for further intervention, a re-contracting process could be initiated.' }\end{array}$ & $\begin{array}{l}\text { van Zyl et al., } \\
2016 b\end{array}$ \\
\hline
\end{tabular}

in past experiences or within the present. Clients may be asked to describe an event where they felt particularly good or at their best and reflect upon the factors (strengths) which contributed to or manifested in this experience (Anstiss and Passmore, 2017). Specifically, the client is facilitated to reflect on the function of strengths in their current realities (Linley and Kauffman, 2007). This is done in order to aid the client to develop insight into how/when their particular strengths manifest, and how to deploy such in the future (Dyess et al., 2017). Further, through becoming aware of one's strengths, clients could actively use such to develop job-related competencies (van Zyl and Stander, 2013). Finally, quality of life and wellbeing also needs to be assessed as such is an outcome of strengths use (Frisch, 2013). When individuals use their strengths, it has a direct, positive effect on their experience of overall life satisfaction/quality (Dyess et al., 2017). Therefore, tracking life satisfaction, wellbeing or quality of life would be a good indicator for the effectiveness of strength utilization (Frisch,
2013; van Zyl and Stander, 2013; Stander, 2016; van Zyl et al., 2016a).

The second most frequently occurring theme related to Realistic Goal setting, Strategizing, and Execution centered around Strengths $(f=22)$. Grant and Spence (2010) postulate that the purposeful pursuit of goals sits at the heart of coaching. Therefore, the focus is primarily on developing specific personal or work-related goals and determining a means to achieve such in a holistic and systematic fashion (Dyess et al., 2017). Clients are encouraged to set goals that are either aligned to their strengths or goals aimed at developing a given strength further (Spence and Grant, 2012; van Zyl and Stander, 2013). The coach must assist the client to access and develop unrecognized attributes, learn from other life experiences and set clear, specific, and tailor-made goals (Kauffman and Scoular, 2004). Here, the coach will actively clarify the purpose of the goals and aid in the development of a mutually agreed upon developmental strategy or plan (Dyess 
et al., 2017). This developmental plan is aimed at achieving the client's dream, affirming the client's reality, and supporting future actions (Frisch, 2013; White and Barnett, 2014). The function of the coach is to facilitate the motivation and commitment of the client to actively implement the designed developmental strategy (Frisch, 2013; Stander, 2016). Further, within this phase, clients are encouraged to identify their available and required personal resources needed in order to fast track goal achievement (Spence and Grant, 2012). Along with the developmental plan, the coach aids in constructing a personal resource map, which highlights the available/required physical, emotional, social, and fiscal resources needed to achieve their goals (van Zyl and Stander, 2013). This map is translated into a utilization plan which aligns goals, to resources (van Zyl et al., 2016b).

Another important part of establishing goals and action plans is to determine how the client will use his/her talents and strengths more effectively in their workplace (Dyess et al., 2017). Once a client realizes why competence in a particular activity is important, he/she can develop a strategy to spend more time on the activity (Linley and Kauffman, 2007). They further state that having clear goals, balancing challenges and skills, maintaining a high level of goal congruence, focusing on doing well and having immediate feedback is important in the setting of goals.

The third most frequently occurring theme or phase relates to Empowerment $(f=16)$. In this continuous phase clients are empowered to take ownership for their personal development (Gordon, 2016). This is not a once off phase but rather manifests in every interaction with the client and/or phase of the coaching process (van Zyl and Stander, 2013). The client's affirmation capability is strengthened in order to aid in the generation of perpetual motion needed to facilitate sustainable change and high performance (Gordon and Gucciardi, 2011). Clients need to be motivated by highlighting and reaffirming the strengths employed in given scenarios in order to build self-efficacy (Spence and Grant, 2012). The coach needs to cultivate and support clients' internal belief of a positive future and re-affirm their sense of that which is possible (Gordon, 2016). Further, clients also need to be encouraged to reframe the negative or challenging experiences of their work/private lives. Clients need to reframe these negative narratives as survivors, rather than victims, which in turn alters their perspective of the problem (van Zyl et al., 2016a). Through this process, the client is made aware that numerous possibilities exist in order to approach, interpret and experience a manifested problem (van Zyl and Stander, 2013; Stander, 2016). Through this reconditioning process, the client would systematically start shedding the victim mentality and would find it increasingly easier to look for the positive even in the most challenging environments (Stander, 2016).

The fourth most frequently occurring phase or theme was "Creating the Relationship" ( $f=16)$ which is a function of (a) establishing rapport and creating a conducive coaching environment, (b) clarifying expectations between all stakeholders in the coaching process and (c) creating a positive relationship with the client. Dyess et al. (2017) mentioned that effective coaching begins with building a solid, positive relationship. Creating the relationship is seen as a pre-coaching phase, in which the focus is on establishing a positive, open, trusting, supporting, non-judgemental, psychologically safe, and collaborative relationship with the client (Oades et al., 2009; Stander, 2016; Dyess et al., 2017; Yeager and Britton, 2017). Most records in the sample argued that creating and maintaining sound positive relationships between the client and coach is the most important precondition for both the experience of empowerment and the facilitation of personal development (Gordon, 2016). The coach therefore needs to ensure that he/she attends to both the physical as well as non-material barriers which may affect the coaching relationship (van Zyl and Stander, 2013). Tarragona (2015) mentions the role of curiosity to explore what works well in the client's life, what they enjoy and what values are most important to the client as a means to establish rapport.

During this phase, the coach needs to develop a thorough understanding of the client's working reality and ensure that there is alignment of expectations between stakeholders. van Zyl and Stander (2013) postulate that a psychological contract needs to be established between (a) the coach/client, (b) coach/senior management, (c) coach/direct manager, and (d) client and his/her direct manager, in order to establish rapport, transparency of expectations and to include the organizational context (e.g., vision/mission/strategy) into the coaching process.

Developing an ideal vision $(f=11)$ of the client's futureself came out as the fifth most frequently mentioned phases of positive psychological coaching processes. The coach is responsible to aid clients in creating a clear vision of a positive future where dreams are realized, all goals are attained, potential is actualized, and they are living in accordance with their best possible self. According to Gordon (2016), the client must be encouraged to create images of possibilities, engaging the client to give voice to her/his desired future and affirming the client's dream. The coach should assist the client in creating a clear vision of a positive future, beyond the limits of their current comfort zone and level of performance (White and Barnett, 2014). Here the focus is on expanding the capacity of the client, stretching his/her limits and then supporting the client to have faith when things get tough (Gordon, 2016). Gordon and Gucciardi (2011) mention that a dream of the ideal self must be aligned to clear, measurable results and to the discovered potential of the client. The coach must encourage clients to craft a vision that is aligned to their strengths, one where life and work has meaning, where the self-actualization tendency is active and where clients can optimize their inherent potential (van Zyl and Stander, 2013). Coaches can support clients in this process by posing questions that lead to a strategic narrative that is compelling and contributes to both meaning at work (Yeager and Britton, 2017) and in life (Stander, 2016).

As opposed to the other authors, Gordon (2016), Gordon and Gucciardi (2011), and Stander (2016) provide a framework based on the Appreciative Inquiry (AI) 4-D Cycle, which could be employed to aid the client to develop this ideal vision. Here, the authors argue that strength based coaching questions could be posed to aid the client in crafting their ideal future selves, which are categorized into four phases: Phase one is about Discovering strengths and the meaning of strengths from the perspective of the client. Then the client is encouraged to Dream about the ideal state and what it means to him/her on a practical level. In the 
Design phase the client must develop an action plan to achieve the ideal state while the focus of the last phase, Destiny, is to build hope and sustain momentum for ongoing positive change and high performance. From this ideal vision and analyzing the gap between the current and desired state, specific coaching themes can be derived, which can form the basis of the coaching relationship (Stander, 2016).

Action Tracking and Continuous Evaluation was mentioned as an important component of the coaching process by a number of authors $(f=6)$. The focus is on constantly evaluating the progress and effectiveness of the coaching intervention, the extent toward which goals are achieved and gains maintained, as well as a continued assessment of the wellness and wellbeing of the client (Gordon and Gucciardi, 2011; van Zyl and Stander, 2013). Linley and Kauffman (2007) highlighted the importance of continuous evaluation as changes in the aspirations, goals, and needs of clients may change throughout the coaching relationship. Therefore, goals and aspirations need to be continuously revisited and modified based on the current reality of the client (Grant and Spence, 2010).

The penultimate coaching phase/theme extracted from the records was Learning Transfer $(f=5)$. Some authors mentioned that personal growth and development is a continuing process, which stretches beyond the confines of the coaching session (Tarragona, 2015). Learnings from the coaching sessions need to be transferred to the work environment in order to aid the client to practice the skills learned during coaching and to take ownership of the learning process (Passmore and Oades, 2014; Sims, 2017). Providing clients with "homework" between sessions increases engagement with and adherence to the coaching process (Frisch, 2013), whilst it provides an active means (in a safe environment) to develop and grow (Tarragona, 2015). Tarragona (2015) argued that the role of the coach in this phase is to identify positive psychological topics that are relevant for the client, to share learnings and to recommend resources (such as books and videos) to facilitate self-development. These resources should reinforce or expand on what was facilitated in the coaching sessions. Further, the coach should identify appropriate positive psychological self-administered activities aligned to the strengths of the client, in order to ensure that significant gains in the client's positive state are facilitated (e.g., the gratitude visit; van Zyl et al., 2016a,b). These evidencebased positive psychological practices need to be aligned to the content of a given coaching session, they needs to be challenging (though not demanding), there should be an opportunity to actively practice such at work (van Zyl et al., 2016b) and they should be aimed at the active development of skills (Sims, 2017). The client should be requested to develop a portfolio of evidence while practicing these activities and developing their skills (Stander, 2016).

The final phase derived from the records was Concluding and Re-Contracting $(f=3)$ the coaching process. van Zyl and Stander (2013) believed that during this phase the client and the coach should formatively assess whether the coaching processes yielded the desired results and either prepare the client for the termination of the relationship or if there is a need for further development, a process of re-contracting could be initiated (van Zyl and Stander, 2013). Here, all stakeholders (clients, managers,
$\mathrm{HR}$, and the coach) should honor the progress made by the client and the coach is responsible to determine whether the changes that took place were a direct result of the positive psychological coaching process. Finally, Stander (2016) argued that at the end of the coaching process, the coach needs to calculate the return on investment of such for the company.

\section{DISCUSSION}

The purpose of this systematic review was to clarify the theoretical conceptualization of positive psychological coaching and determine the common components of positive psychological coaching models/frameworks. Specifically, the aim was to construct a commonly shared understanding or "definition" of the concept, and to construct a clear demarcated positive psychological coaching model/process. The initial literature search yielded 2,252 records, and through a systematic process of elimination, based on predefined inclusion/exclusion criteria, 24 academic peer-reviewed publications on positive coaching were included and coded for analyses. Data relating to definitions, and models were extracted and processed through thematic content analysis. The results highlighted 20 common elements of positive psychological coaching definitions which were used to construct an integrated definition. Further, eight commonly occurring critical components/phases of a positive psychological coaching model were found underpinning people development.

\section{Defining Positive Psychological Coaching}

The results showed that positive psychological coaching can be defined as:

'A short- to medium-term professional, collaborative relationship between a client and coach, aimed at the identification, utilization, optimisation and development of personal/psychological strengths and resources in order to enhance positive states, traits and behaviours. Utilizing Socratic goal setting and positive psychological evidence-based approaches facilitate personal/professional growth, optimal functioning, enhanced wellbeing, the actualization of people's potential and aid in coping with work-demands.'

Our definition of positive psychological coaching is in line with the definition by Linley and Joseph (2004) in the sense that they too argue that an aim of the positive coaching process is the promotion of optimal functioning. Furthermore, our definition echoes the one provided by van Zyl and Stander (2013) regarding the description of the coach-client relationship as professional and aimed at the identification, utilization and optimization of strengths to facilitate individual development. However, in contrast to van Zyl and Stander (2013), our definition does not specifically include positive outcomes for the organization. Our definition is further aligned with Grant et al. (2010) because they describe positive coaching as a collaborative approach applying personal goal setting and capitalizing on individual strengths. Similarly, in line with Castiello D’Antonio (2018), we highlight in our definition that positive psychological coaching is a short- to medium-term approach, aimed at enhancing positive states, such 
as life satisfaction and flourishing, by applying evidence-based positive psychological approaches.

In contrast, our definition deviates from Denison and Avner (2011), who described positive psychological coaching as a set of easy to use, behavioral guidelines according to best practice guidelines. While we also include in our definition that the positive psychological coaching approach should follow best practice guidelines in the form of employing evidencebased approaches, our definition focuses on the individual identification, utilization, and optimization of personal strength of the specific client. It is therefore a more personalized process rather than following mechanistic guidelines. Similarly, Orem et al. (2007) focused their definition on the development of selfcompassion through an appreciative relationship with a coach. While the positive relationship with the coach is also part of our definition, our definition takes a broader focus on positive states, traits and behaviors, of which self-compassion may be part. In sum, our definition is aligned with the majority of previous definitions, though takes a broader approach and combines elements from different definitions.

Further, the results highlight that the positive psychological coaching definition or process is underpinned by eight core principles. First, coaches employing a positive psychological coaching process work with relatively well-adjusted individuals, devoid of severe psychopathology. Green and Palmer (2018) argued that the coaching relationship is facilitative, and solutionfocused in nature, with the direct aim of enhancing personal fulfillment and growth. This in turn requires clients to be relatively devoid of severe psychopathology (van Zyl and Stander, 2013). Clients who present with psychopathological problems (e.g., depression or anxiety) would not gain much benefit from the coaching process and need to be referred to counseling or therapy (Seligman, 2012). Counseling or therapy is problem-focused and aimed at diagnosing psychopathological illnesses and restoring (as opposed to optimizing) psychological functioning (Green and Palmer, 2018).

Second, the focus is on the development and optimization of personal strengths and not "fixing" weaknesses. The positive psychological coaching process is focused on aiding clients to become aware of, utilize and develop their unique psychological strengths to reach personal goals (Kauffman, 2006; Linley and Kauffman, 2007; Seligman, 2012; Gordon, 2016) and not to focus on weaknesses (van Zyl and Stander, 2013). Positive psychological coaching is aimed at harnessing the best in people and to optimize their potential through strengthsbased initiatives (Freire, 2013). When focusing on "correcting" weaknesses, the process then reinforces low expectations, creates dependency on outside resources and discourages optimal development (Seligman, 2012; Stander and van Zyl, 2019).

Third, despite the focus being on strengths, the coach should have a balanced view of the client's strengths and developmental areas. Kauffman et al. (2015) cautions against assuming that clients are solely formed out of strengths and that the coach should adopt a balanced view of strengths and developmental areas. Positive psychological coaches should aid clients to determine their developmental areas but utilize their strengths in order to address such (Gordon, 2016). However, a one-to-one ratio of "strengths" and "developmental areas" could have a negative impact on the effectiveness of the coaching process. Fredrickson and Losada (2005) proposed that a balance be struck between positive and "negative" factors during such a process, suggesting a critical ratio of three positives (strengths) to one negative (developmental area).

Fourth, a holistic approach towards development is employed, where the client works on matters in all domains of his/her life; capitalizing on the resources within each of the systems in which he/she function. Clients function within an eco-system of inter-related sub-systems (e.g., work, family etc.) and developing skills and capabilities only in one domain would deter from full actualization of the client's potential (Hawkins and Turner, 2019). A holistic approach toward development needs to be employed covering all valued aspects of a client's life and capitalizing on all the internal (e.g., personal resource) and external resources (e.g., social support networks) in order to enhance their wellbeing and help deal with life's challenges (Frisch, 2013; Dyess et al., 2017).

Fifth, the approach assumes that clients have an inherent capacity to grow and develop. A fundamental principle to the positive psychological coaching process is the believe that clients have an expanding ability to develop and grow through deliberate or purposeful endeavors (Noble et al., 2000; Dweck, 2009). Clients have an inherent need and capacity to develop through active effort, dedication, deliberate practice and hard work (Gordon, 2016; Purdie, 2017). Adopting such a "growth mindset" leads to clients taking on more challenges, bounce back from setbacks at a faster pace and positively affects their level of workrelated performance (Palmer and Green, 2018). In effect, clients need to be made aware that they have direct control over both their development and their lives (Dweck, 2009).

Sixth, the client needs to be empowered to take ownership of their own growth process. Clients need to be facilitated in order to take responsibility for their own developmental journeys as they are not passive consumers of a product/service, but rather an active participant in the process (Noble et al., 2000). The coach should provide support and aid in discovering resources in order to aid the client to achieve their goals, but the process is fundamentally built around the extent toward which the client takes ownership of their growth process (Stander, 2016; Castiello D'Antonio, 2018).

Seventh, the developmental process is based on a personal vision of the ideal self, which is translated into specific goals and actions. The developmental process is based on a clearly defined vision of the "preferred future self" which is translated into specific, measurable, actionable, realistic, and time bound goals. Clients need to be encouraged to create clear images of possibilities, and to identify their preferred or "best possible self/future" (Gordon, 2016). The role of the coach in this process is to aid the client to develop a clear picture of the better future and to formalize such in a constructive manner (Yeager and Britton, 2017).

Eight, the coach's role is to listen actively and to provide continuous support throughout the developmental journey. Active listening is one of the core competencies of any type coaching process, but according to Yeager and Britton (2017), within the positive psychological coaching process, deeper level of listening is needed where the coach must listen for strengths that a client 



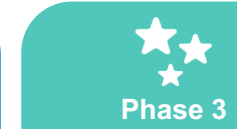

Developing an

Ideal Vision

Creating a Vision of the

"Perfect Version" of the

Client

Client
(Best Possible Self)
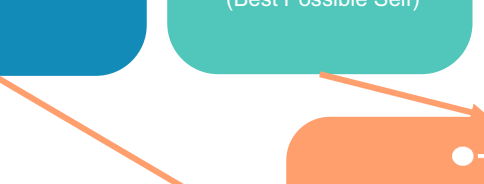

:

Learning Transfer

Evidence Based Self-

Administered Activities

Action Tracking and Continuous Evaluation

FIGURE 2 | The positive psychological coaching model.

is not yet aware of. The role of the coach is to actively encourage, empower and support the client throughout the developmental journey (Green and Palmer, 2018).

\section{A Positive Psychological Coaching Model}

The final goal of this paper was to determine the common elements of positive psychological coaching models/approaches/frameworks in an attempt to construct a clear demarcated positive psychological coaching model or process. From the final 24 articles retained, five common sequential positive psychological coaching phases were identified: (1) creating the relationship, (2) strengths profiling and feedback, (3) developing a personal vision of the ideal self, (4) setting-, strategizing-, and executing realistic goals based around one's strengths, and lastly (5) concluding the relationship and recontracting. These phases are supported by three continuous processes, namely (6) transferring learning to the workplace (homework), (7) empowering clients through reframing and positive reinforcement, and (8) setting clear evaluation criteria and continuously tracking actions and the developmental process. Based on these elements, a deductive approach was employed to construct a positive psychological coaching model (PPCM: c.f. Figure 2) and to arrange its phases in a logical-, chronological-, and sequential order ${ }^{3}$. Table 3 provides an

${ }^{3}$ No article within the sample specifically stipulated a proposed length or duration overview of the PPCM phases, coupled with a brief description of each phase.

Phase 1 of the PPCM relates to "creating the relationship." This is a pre-coaching phase where the focus is on building a positive, open, trusting, supportive, non-judgemental, and collaborative relationship between the coach and the client (van Zyl et al., 2016a; Dyess et al., 2017). This implies that rapport must be established, clear expectations are set between all stakeholders, that the coach has deep knowledge of the client's context/environment, and that an environment is created, which is conducive to the optimization of the client's potential (van Zyl et al., 2016a).

In this phase, the coach attempts to establish rapport through attending to the physical and psychological barriers which may influence the establishment of a positive relationship conducive to the developmental process (Jorgensen et al., 2016; Jorgensen-Graupner and van Zyl, 2019). The coach attempts to explore the reality of the client through a process of active listening (Jorgensen et al., 2016) and positively infused language (Linley et al., 2009). Through active, constructive and positive communication, the coach communicates empathy, positive regard and authenticity which in turn creates a psychologically

various components or phases associated with such. However, in a meta-analyses by Theeboom et al. (2014) they found that five or more coaching sessions of at least $45 \mathrm{~min}$ spread across 6 months are beneficial for developing coping strategies and for goal-directed self-regulation activities, four or less is required work/career attitudes, or enhancing performance/specific skills. 
TABLE 3 | Positive psychological coaching phases and brief description.

\begin{tabular}{|c|c|c|}
\hline Phase & Logical order & Brief description \\
\hline Phase 1 & Creating the relationship & $\begin{array}{l}\text { The purpose of this phase is to establish a positive, open, trusting, supportive, non-judgemental and collaborative } \\
\text { relationship with the client. This is done through establishing rapport and clarifying expectations between the client and } \\
\text { other stakeholders (direct line manager, and the coach). In this phase the coach needs to develop a thorough } \\
\text { understanding of the client's environment. }\end{array}$ \\
\hline Phase 2 & $\begin{array}{l}\text { Strengths profiling and } \\
\text { feedback }\end{array}$ & $\begin{array}{l}\text { The purpose of this phase is to aid the client to explicitly identify, develop insight into and facilitate the use/development of } \\
\text { his/her strengths. This is done through employing strengths diagnostic tools, -interviews or techniques to identify strengths } \\
\text { and to provide active, and constructive feedback. Wellness and Quality of Life needs to be assessed to track overall } \\
\text { effectiveness of the coaching intervention. }\end{array}$ \\
\hline Phase 3 & Developing ideal vision & $\begin{array}{l}\text { The client develops a clear picture of the perfect version of him/herself in the future. It can be described as an ideal future } \\
\text { state that will stretch the client in a process to optimize his/her potential. }\end{array}$ \\
\hline Phase 4 & $\begin{array}{l}\text { Realistic goal setting, } \\
\text { strategizing, and execution } \\
\text { centered around strengths }\end{array}$ & $\begin{array}{l}\text { Clients need to set specific, measurable, attainable, realistic, and time bound goals that are aligned to their strengths and } \\
\text { that builds up to their ideal vision. These goals need to be translated into a clear strategic-operational plan, which needs to } \\
\text { be easily implementable. }\end{array}$ \\
\hline Phase 5 & $\begin{array}{l}\text { Concluding or } \\
\text { re-contracting }\end{array}$ & $\begin{array}{l}\text { At the end of the coaching process, the effectiveness of the intervention needs to be assessed. Clients need to evaluate if } \\
\text { goals were achieved and if so, he/she needs to be prepared for terminations. If goals were not achieved, new goals can be } \\
\text { set, and the coaching relationship can be re-negotiated. }\end{array}$ \\
\hline $\begin{array}{l}\text { Continuous } \\
\text { process } 1\end{array}$ & Learning transfer & $\begin{array}{l}\text { Learning from the coaching process should be transferred to the work environment while the client takes ownership of the } \\
\text { learning process. The focus is on actively transferring or "practicing" learnings from the coaching process in real world } \\
\text { scenarios. Positive psychological evidence-based intervention strategies are selected that are aligned to the strengths of the } \\
\text { client in order to maximize the efficiency and benefits associated with deliberate practice. }\end{array}$ \\
\hline $\begin{array}{l}\text { Continuous } \\
\text { process } 2\end{array}$ & $\begin{array}{l}\text { Action tracking and } \\
\text { continuous evaluation }\end{array}$ & $\begin{array}{l}\text { The purpose is to determine how success of the coaching process will be measured and to develop a means to actively } \\
\text { track the effectiveness of the intervention. Both goal achievement and wellbeing are actively monitored and tracked. }\end{array}$ \\
\hline $\begin{array}{l}\text { Continuous } \\
\text { process } 3\end{array}$ & $\begin{array}{l}\text { Empowerment (reframing, } \\
\text { reinforcement) }\end{array}$ & $\begin{array}{l}\text { The purpose of this phase is to aid the client to feel connected to the proverbial bigger picture, reaffirm their confidence in } \\
\text { their abilities, to aid the client to experience a sense of control over initiating and regulating behavior and to make the client } \\
\text { feel like they are making a difference in their context. The focus is on reframing challenges as opportunities, and to find the } \\
\text { positive in negative experiences. The coach focuses on what went "right" rather than on what went "wrong" in order to } \\
\text { empower the client to take ownership for his/her personal development. }\end{array}$ \\
\hline
\end{tabular}

safe environment where clients can access their deepest thoughts, facilitate the development of self-insight and aids in creating an empowering environment conducive to change (Scheel et al., 2013). Both Rogers (1951) as well as Gallagher and Bennett (2018) argued that the success of a one-on-one developmental intervention largely depends on the strength of the relationship between the client and the coach, and therefore creating and maintaining a positive relationship should be a central focus during the coaching process.

Further, the coach needs to clarify expectations with the client's direct line manager as well as with senior management. This is done in order to determine (a) the potential (mis)alignment between the client's strengths and the organizational demands and (b) how the client fits into the proverbial dream/vision of the organization (van Zyl et al., 2016a). The coach also acts as a facilitator for the clarification of expectations between the client and his/her direct line manager (Stander, 2016). This is not only done in order to ensure complete alignment of the coaching process to the operational role of the client, but also to ensure that work-related expectations are clear from the onset of the process (Odendaal and le Roux, 2016). Thereafter, the coach needs to clarify expectations with the client (van Zyl and Stander, 2013). Here the focus should be on understanding the client's expectations of both the coach as well as the coaching process (van Zyl et al., 2016a). The coach also has an opportunity to clarify his/her expectations of the client/coaching process (Stander, 2016; Knotek et al., 2019). This process of expectation clarification culminates in a psychological contract, which defines the trajectory of the coaching relationship and demarcates the boundaries thereof (McComb, 2009; Hagen and Williams, 2019). This psychological contract is employed to define the beliefs, assumptions, obligations and expectations the client has about the coaching relationship and to clarify uncertainty (McComb, 2009).

Once this process has been completed, the coach needs to develop a thorough understanding of the client's environment (Knotek et al., 2019). The coach needs to explore the nature of the client's role within the organization, his primary function, the contextual challenges the client faces and the available resources at hand (Malinga et al., 2019). This is done in order to embed and align the coaching process to the organizational context (Fox, 2015). Upon completion of this phase, the coach and client can move on to the next.

Phase 2 in the PPCM aims to subject the client to a "strengths profiling and feedback" process. The focus here is to explicitly identify or diagnose the psychological strengths of the client through psychometric assessments (e.g., VIA Signature Strengths Inventory, Realise2, Strengths Finder 2.0), fit-for-purpose simulations (e.g., Talent Development Centres), strengths-based interviewing, strengths-spotting or other strengths-exploration 
exercises (Stander and van Zyl, 2019; van Zyl and Rothmann, 2019a). The client needs to become aware of his/her strengths and develop insight as to how these could be used to foster personal development and achieve goals (McQuaid et al., 2018). This is done through providing strengths-based feedback, focusing on which strengths are more likely to manifest in the day-to-day life of the client (Burke and Passmore, 2019). Specific focus needs to be placed on the development of strengths, and how such could be used to enhance competence in various applied domains (Stander, 2016). This is done to aid clients to overcome their preoccupation with developmental areas. Focusing and continually highlighting developmental areas reinforces low expectations, creates dependency on outside resources (such as the coach) and discourages optimal development (van Zyl and Rothmann, 2019b). Finally, the coach needs to also aid the client to identify the availability of potential personal resources and diagnose quality of life/wellbeing in order to identify potential coaching themes (Palmer and Green, 2018).

Phase 3, of the PPCM aims to aid clients in "developing an ideal vision" of themselves. During this phase, the coach engages in a collaborative strengths-based inquiry process in order to aid the client to (a) discover the best of his/her current situation, (b) imagine what his/her life could be, and (c) to develop a clear and compelling vision of the future where incentives, persuasion, or coercion is not needed (Whitney and Trosten-Bloom, 2010; White and Barnett, 2014). In effect, the client must develop a clear picture of the "perfect"- or best-possible version of him/herself in the future. It can be described as an ideal future state that will stretch the client's boundaries in a process to optimize his/her potential (Gordon and Gucciardi, 2011). Based on insights from the previous phase, the coach should facilitate clients to craft this vision around their desires and not around what they believe their lives "should" be like. This vision should be crafted around the best possible versions of themselves, where dreams are realized, all goals are attained, potential is actualized, and they are living in accordance with their best possible self (Palmer and Green, 2018). Compared to traditional coaching models, with a focus on addressing problems or development needs, the PPCM is focused on what is the best (ideal) state for the client and determining how this state could effectively be achieved through utilizing strengths. According to Gordon (2016) and Gordon and Gucciardi (2011), Appreciative Inquiry could be used as a framework for developing such an ideal vision. From this perspective, clients are facilitated to discover what is currently working well, to dream about a positive future, to align the dream to the practicalities of the current reality and to aid in the execution there of. From this, a clear action plan can be developed and implemented in order to aid the client to strive toward this ideal vision.

Phase 4, "goal setting, strategizing, and execution," is common to most coaching models or frameworks. In this phase, the

\footnotetext{
${ }^{4}$ It should be noted that although gaps between current and desired end-state are identified in this phase, and strategies developed to close such, gaps could also be identified consistently throughout the entire coaching relationship as a result of the continuous evaluation and action tracking process discussed below.
}

information of the previous phases is integrated into a solutionsbuilding conversation in order to (a) set goals, (b) develop an implementation strategy, and (c) facilitate the execution thereof. During goal setting, the client needs to perform a gap analysis through contrasting his/her current reality with the ideal vision crafted in the previous phase in order to determine the specific action step required to close these proverbial gaps (McQuaid et al., 2018; Stander and van Zyl, 2019). This can be done through various evidence-based techniques, such as using the Wheel of Life Brainstorming Framework (Byrne, 2005), or the Five Paths to Happiness or CASIO exercise (Frisch, 2013) to determine the discrepancy between the current and desired end state. This can then be translated into specific, measurable, attainable, relevant, time-bound, evaluated and rewarded (SMART) goals, which draw from the strengths and positive capacities of the client, in order to close the aforementioned gaps (Hyatt, 2018). Furthermore, there needs to be an active balance between the challenges the clients set for themselves, their current level of skill and their capacity to activate their strengths (Seligman, 2012). If the challenges far exceed the capabilities of the client, it would have negative consequences on the health, wellbeing, motivation, and performance of the client (Seligman, 2012). Therefore, careful consideration needs to be taken when setting goals. Cole and Stavros (2019) suggested that a positive strengthsbased approach should be used to manage such. They argued that clients use the SOAR framework to determine and translate the ideal vision into actionable goals through focusing on identifying the strengths they could use-, the opportunities available to aid in-, the aspirations they have from- and results associated with each goal they want to achieve.

Based on these goals, the client and coach need to develop an implementation strategy for how these goals could be achieved. Here, meta-goals should be broken down into smaller, more digestible actions with clear time frames and actions (Stander, 2016). The client needs to identify the resources and strengths needed in order to ensure that the strategy is realistic and easily implementable (Gordon, 2016). Further, clients should also be facilitated to look for their proverbial "blind spots" (factors which might influence the goal achievement process) (Tarragona, 2015). Once these goals have been translated into easily implementable strategies, the client needs to find supporters/mentors who could aid them in maintaining momentum once strategies are being actioned. Further, clear deadlines need to be set, and the client needs to commit to and be accountable for their achievement (van Zyl et al., 2016a). This strategy should be captured in an individual development plan, which highlights the goals, the developmental actions, the resources required and the timelines relating to its achievement.

Finally, the client needs to be empowered to execute the developed strategy. Here the client needs clear, immediate and developmental feedback on each stage of the process. Realtime updates on goal progress will facilitate more commitment and accountability (Stander and van Zyl, 2019). During execution, a high level of congruence between the goals, the strategy and strengths should exist.

The chronological phases of the PPCM culminates in Phase 5, "concluding the relationship and re-contracting." At the end of the 
coaching process, the effectiveness of the coaching intervention needs to be formally assessed and the client prepared for termination or re-contracting of the relationship (van Zyl and Stander, 2013). Clients need to evaluate if goals were achieved and if so, need to be prepared for termination of the relationship. Coaches could evaluate the client's progress through conducting psychometric assessments, positive 360-degree evaluations and the like, and through comparing such with the original results at the start of the coaching process (Stander, 2016). The changes over time would act as indicators of progress/development. Similarly, clients, managers, HR, and the coach should reflect upon the progress made by the client and the victories celebrated. If goals were not achieved, new goals can be set, and the coaching relationship can be re-negotiated. The focus here is on determining if the gaps identified at the start of the coaching process was closed (van Zyl and Stander, 2013).

Although the PPCM has a clear start and end date, the development process in itself is not linear. Given the fastchanging and ambiguous business environments in which clients function, short-term or unexpected changes in client's roles, or the demands of the business, could result in the reformulation of the client's goals or result in reprioritization thereof. As such the coaching model should be flexible to adapt to situational demands or needs as it may occur. The preceding sequential, chronological phases are supported by three dynamic or "continuous processes" that strengthens the interaction between the different phases. These three continuous processes apply to all the phases of the coaching model, but at the same time build on and are supported by each other.

First, Continuous Process 1 relates to "learning transfer." Learnings occurring from the coaching process should be transferred to the work environment in order to aid the client to both practice these skills in a real life setting and to also be empowered to take ownership of the learning process (van Zyl et al., 2019). The coach can provide "homework" to aid the client in developing new skills and capabilities or to ensure engagement with and adherence to the coaching process (Hayes and van $\mathrm{Zyl}, 2019)$. The client should engage in deliberate practices, focusing on using strengths in a constructive and developmental way (Passmore and Oades, 2015). The activities selected by the coach to support the developmental process need to be evidencebased and should strongly draw from the positive psychological intervention literature (Fox, 2015). Further, clients need to be empowered to introduce these evidence-based practices or skills in real world settings and be made aware that obstacles or failures to do so should be seen as a learning opportunity (Kauffman, 2006; Stander, 2016). This process is facilitated from Phase 2 of the coaching process, right through to the final session.

Continuous Process 2 relates to "action tracking and continuous evaluation." Here the focus is on the continuous evaluation of the coaching process, goal-achievement, and openness for changing aspirations of the client. Tracking the developmental process aids in ensuring that the developmental initiatives are in effect aiding the client to achieve his/her goals and to intervene if evidence suggests that the client is not on track with his/her goal achievement (van Zyl and Stander, 2013). At the onset of the coaching process, stakeholders need to develop clear, measurable criteria that constitutes "success" within the coaching process (van Zyl et al., 2016a,b). Based on these criteria, the coach and client need to develop a means through which to track actions and goal achievement. This could take the form of weekly updates, online coaching tracking software or quantitative assessments of wellbeing or performance (Linley et al., 2009; Stander and van Zyl, 2019). It is imperative that both goal achievement and wellbeing is assessed on a monthly basis in order to ensure that the developmental trajectory is on track (Noble et al., 2000; van Zyl et al., 2016a) and that it does not have any negative consequences for the wellbeing of the client (Gordon and Gucciardi, 2011; Frisch, 2013). Should changes in the developmental trajectory occur, the coach and client need to actively intervene or re-prioritize goals in order to ensure goal achievement is still on target (Stander, 2016). A further essential part of the evaluation process and action tracking is to determine to what extend learning is actively transferred between the coaching process and the workplace (van Zyl and Stander, 2016). To succeed in transferring learning, the client needs to be empowered to feel competent and in control of the development process. As such, the individual development plan should therefore be updated with all this information on a monthly basis.

Lastly, Continuous Process 3 relates to actions and behaviors exhibited by the coach relating to the "empowerment" of clients to take ownership for personal development and wellness. The purpose of this continuous process is to ensure that the client feels connected to the bigger picture and to reaffirm his/her confidence in his/her abilities. This is done to aid the client to experience a sense of control over initiating- and regulating behavior and to make the client feel like they are making a difference in their context (Kauffman et al., 2015). The coach frames questions in a positive and empowering manner in order to explore what is working well as opposed to an overemphasis on what is "wrong" (Whitney and Trosten-Bloom, 2010). Specifically, positive affirmations and positively infused questions should be used to affirm clients' faith in their own strengths and to positively reframe the world and its challenges (Grant and Spence, 2010; Yeager and Britton, 2017). The focus here is to aid the client to reframe challenges as opportunities, and to find the positive in negative experiences (Stander, 2016). Primarily, the coach should aid the client to tell stories from a survivor-, rather than from a victim-orientated position (van Zyl et al., 2016a). This aids in reframing the victim mentality and builds an internal locus of control. This empowers the client to take ownership for his/her personal development and reduces the dependency on external rewards/recognition systems (Yeager and Britton, 2017). This continuous process is a fundamental activating condition to facilitate change and is applicable to each of the five chronological phases and supports both learning transfer and the evaluating processes.

\section{LIMITATIONS AND RECOMMENDATIONS}

Despite thorough attempts to ensure the relevance and rigor of this systematic review, there are a number of limitations present. First, given the subjective nature of the development of the search protocol, bias could occur at any phase of the data extraction, analyses, and interpretation process. Although 
various processes were put into place to manage inherent biases (strict inclusion/exclusion criteria, multiple raters, calculating inter-rater reliability, conducting multiple searches with the same key words etc.), it is possible that such biases affected the process. Secondly, only academic peer-reviewed publications were included as part of the search protocol. Although this, in itself, would not be a problem within traditional systematic reviews, but within the field of positive psychology, many "popular psychology" books, practitioner-focused magazines, and the like get published daily. Although these manuscripts do not comply to the academic standards associated with the scientific method, most of these become highly cited within the academic literature due to their popularity (e.g., Biswas-Diener and Dean, 2007). In these types of manuscripts, authors have more freedom to explore and present ideas, and this is often where innovative ideas are born. Excluding popular psychology texts/books may present with a biased view. Thirdly, gray literature such as conference proceedings and those publications which were not in English were also excluded. As such, our review is limited by the potential for reporting bias. Fourthly, although thorough attempts have been made to ensure that all the appropriate literature was included, there is a possibility that a number of important publications may have been excluded either based on title, or abstracts or based on the selected keywords. Finally, the chronological ordering of the coaching phases was based on subjective and deductive reasoning processes (which were informed by the literature and the authors practical experience as coaches). This could imply that the sequentialor chronological order of the coaching phases could be in a different order.

These limitations do, however, provide an opportunity for future research. Future research should aim to contrast positive psychological coaching models and approaches presented within the popular literature with those found in this systematic review. Further, given the extensive discussion on the components of the model, and the techniques employed, future research could directly implement such and evaluate its effectiveness as a developmental framework. Interpretative phenomenological analyses could be used to deconstruct and reconstruct the coaching model in future studies in order to provide more systematic evidence for the chronological order of the coaching model.

Moreover, future endeavors in conducting research on and practicing PPC should take into account the advancements brought into the field by the "second wave positive psychology (PP2.0)" (Wong, 2011). This approach builds on the critique of positive psychology with regard to an overemphasis on the positive experiences and ideal visions, and more strongly endorses a holistic and integrative view on both the positive as well as the negative aspects of the human existence (Lomas

\section{REFERENCES}

*Anstiss, T., and Passmore, J. (2017). "Wellbeing coaching," in The Routledge Companion to Wellbeing at Work, eds C. Cooper and M. Leiter (London: Routledge), 237-248. doi: 10.4324/9781315665979-17 and Ivtzan, 2016). In this regard, our positive psychological coaching model highlights the positive reframing of negative experiences and changing a victim mentality as parts of a continuous "empowerment" process. However, our and other current positive psychological coaching models may benefit from a further elaboration of concrete techniques and tools to capture more comprehensively the complexity of human life.

\section{CONCLUSION}

This review provides a first attempt to systematically and scientifically consolidate the available literature on positive psychological coaching. Based on the literature, a clear and holistic definition could be derived as well as an integrative, multiphase positive psychological coaching model developed. For the academic, this article should contribute to the development of PPC as a science; for the practitioner it provides a practical framework from which to practically develop people. We are excited by the opportunities it will create for other researchers to explore, validate, critically debate, and build on this body of knowledge, enhancing the scientific image and identity of PPC. Academic institutions could structure their training programs according to the findings in this study, while for the practitioner it creates a practical and structured guide that facilitates and encourages the application of positive psychological principles in the development process of clients.

\section{DATA AVAILABILITY STATEMENT}

All records derived from the literature and employed for this study are available upon request from the corresponding author.

\section{AUTHOR CONTRIBUTIONS}

All authors listed have made a substantial, direct and intellectual contribution to the work, and approved it for publication.

\section{FUNDING}

This work was supported by the Optentia Research Programme of the North-West University as well as the National Research Foundation's Rated Researcher Incentive Fund (IFR170123217004). The funders had no role in study design, data collection and analysis, decision to publish, or preparation of the manuscript.

\section{SUPPLEMENTARY MATERIAL}

The Supplementary Material for this article can be found online at: https://www.frontiersin.org/articles/10.3389/fpsyg. 2020.00793/full\#supplementary-material

Biswas-Diener, R., and Dean, B. (2007). Positive Psychology Coaching: Putting the Science of Happiness to Work for your Clients. New Jersey, NY: John Wiley \& Sons.

Booth, A., Sutton, A., and Papaioannou, D. (2016). Systematic approaches to a successful literature review. London: Sage Publishers. 
Burke, J., and Passmore, J. (2019). "Strengths based coaching-a positive psychology intervention," in Theoretical Approaches to Multi-Cultural Positive Psychological Interventions, eds L. E. van Zyl and S. Rothmann (Cham: Springer), 463-475. doi: 10.1007/978-3-030-20583-6_21

Byrne, U. (2005). Wheel of life: effective steps for stress management. Bus. Inf. Rev. 22, 123-130. doi: $10.1177 / 0266382105054770$

*Castiello D'Antonio, A. (2018). Coaching psychology and positive psychology in work and organizational psychology. Psychol. Manag. J. 21, 130-150. doi: $10.1037 /$ mgr0000070

Coetzee, M., and van Zyl, L. E. (2014). A review of a decade's scholarly publications (2004-2013) in the South African Journal of Industrial Psychology. SA. J. Ind. Psychol. 40, 1-16. doi: 10.4102/sajip.v40i1.1227

Cole, M. L., and Stavros, J. M. (2019). "SOAR: a framework to build positive psychological capacity in strategic thinking, planning, and leading," in Theoretical Approaches to Multi-Cultural Positive Psychological Interventions, eds L. E. Van Zyl and S. Rothmann (Cham: Springer), 505-521. doi: 10.1007/978-3-030-20583-6_23

Compton, W. C., and Hoffman, E. L. (2019). Positive Psychology: The science of Happiness and Flourishing, 3rd Edn. Thousand Oaks, CA: Sage.

Creswell, J. W. (2013). Qualitative Inquiry \& Research Design: Choosing among the Five Approaches. Thousand Oaks, CA: Sage Publications, Inc.

Denison, J., and Avner, Z. (2011). Positive coaching: ethical practices for athlete development. Quest 63, 209-227. doi: 10.1080/00336297.2011.10483677

Duriau, V. J., Reger, R. K., and Pfarrer, M. D. (2007). A content analysis of the content analysis literature in organization studies: research themes, data sources, and methodological refinements. Organ. Res. Methods 10, 5-34. doi: $10.1177 / 1094428106289252$

Dweck, C. S. (2009). Mindsets: developing talent through a growth mindset. Olympic Coach 21, 4-7.

*Dyess, S. M., Sherman, R., Opalinski, A., and Eggenberger, T. (2017). Structured coaching programs to develop staff. J. Continuing Educ. Nurs. 48, 373-378. doi: 10.3928/00220124-20170712-10

Fox, V. (2015). Strength-based coaching: business. TAXtalk 2015, 76-77.

Fredrickson, B. L., and Losada, M. F. (2005). Positive affect and the complex dynamics of human flourishing. Am. Psychol. 60, 678-686. doi: 10.1037/0003-066X.60.7.678

*Freire, T. (2013). "Positive psychology approaches," in The Wiley-Blackwell Handbook of the Psychology of Coaching and Mentoring, eds J. Passmore, D. Peterson, and T. Freire (West Sussex: Wiley-Blackwell), 426-442. doi: $10.1002 / 9781118326459 . c h 22$

*Frisch, M. B. (2013). Evidence-based wellbeing/positive psychology assessment and intervention with quality of life therapy and coaching and the Quality of Life Inventory (QOLI). Soc. Indic. Res. 114, 193-227. doi: 10.1007/s11205-012-0140-7

Gallagher, T. L., and Bennett, S. M. (2018). The six "P" model: principles of coaching for inclusion coaches. Int. J. Mentor. Coach. Educ. 7, 19-34. doi: 10.1108/IJMCE-03-2017-0018

*Gordon, S. (2016). "Strengths-based coaching: case of mental toughness," in Sports and Athletics Preparation, Performance, and Psychology, The Psychology of Effective Coaching and Management, ed P. A. Davis (Hauppauge, NY: Nova Science Publishers), 267-283.

*Gordon, S., and Gucciardi, D. F. (2011). A strengths-based approach to coaching mental toughness. J. Sport Psychol. Action 2, 143-155. doi: 10.1080/21520704.2011.598222

*Grant, A. M., Passmore, J., Cavanagh, M. J., and Parker, H. M. (2010). The state of play in coaching today: a comprehensive review of the field. Int. Rev. Ind. Organ. Psychol. 25, 125-167. doi: 10.1002/97804706616 28.ch 4

Grant, A. M., and Spence, G. B. (2010). "Using coaching and positive psychology to promote a flourishing workforce: a model of goal-striving and mental health," in Oxford Library of Psychology. Oxford Handbook of Positive Psychology and Work, eds P. A. Linley, S. Harrington, and N. Garcea (London: Oxford University Press), 175-188. doi: 10.1093/oxfordhb/9780195335446. 013.0014

Green, S., and Palmer, S. (2018). Positive Psychology Coaching in Practice. London: Routledge. doi: 10.4324/9781315716169

Haberlin, S. (2019). Something always works: a self-study of strengths-based coaching in supervision. J. Educ. Supervision 2:38. doi: 10.31045/jes.2.1.3
Hagen, S. M., and Williams, D. E. (2019). The impact of loyalty and selfdetermination on managerial coaching outcomes. Perf. Improvement Q. 32, 207-236. doi: 10.1002/piq.21295

Hawkins, P., and Turner, E. (2019). Systemic Coaching: Delivering Value Beyond the Individual. London: Routledge. doi: 10.4324/9780429452031

Hayes, M., and van Zyl, L. E. (2019). "Positive journal writing across multi-cultural contexts: a protocol for practice," in Positive Psychological Intervention Design and Protocols for Multi-cultural Contexts, eds L. E. van Zyl and S. Rothmann (Cham: Springer), 415-433. doi: 10.1007/978-3-030-20020-6_19

Hyatt, M. (2018). Your Best Year Ever: A 5-step Plan for Achieving Your Most Important Goals. New York, NY: Baker Books.

Jorgensen, L. I., van Zyl, L. E., and Stander, M. W. (2016). "Training emerging psychologists as multi-cultural contextual coaches," in Coaching Psychology: Meta-Theoretical Perspectives and Applications in Multicultural Contexts, eds L. E. van Zyl, M. W. Stander, and A. Odendaal (Cham: Springer), 357-392. doi: 10.1007/978-3-319-31012-1_16

Jorgensen-Graupner, L. I., and van Zyl, L. E. (2019). "Inspiring growth: a counselling framework for industrial psychology practitioners," in Positive Psychological Intervention Design and Protocols for Multi-Cultural Contexts, eds L. E van Zyl and S. Rothmann (Cham: Springer), 381-404. doi: 10.1007/978-3-030-20020-6_17

*Kauffman, C. (2006). "Positive psychology: the science at the heart of coaching," in Evidence Based Coaching Handbook: Putting Best Practices to Work for your Clients, eds D. R. Stober and A. M. Grant (Hoboken, NJ: John Wiley \& Sons, Inc), 219-253.

*Kauffman, C., Joseph, S., and Scoular, A. (2015). "Leadership coaching and positive psychology," in Positive Psychology in Practice: Promoting Human Flourishing in Work, Health, Education, and Everyday Life, ed S. Josheph (Hoboken, NJ: John Wiley \& Sons, Inc.), 377-390. doi: $10.1002 / 9781118996874 . \operatorname{ch} 23$

* Kauffman, C., and Scoular, A. (2004). "Toward a positive psychology of executive coaching," in Positive Psychology in Practice, eds P. A. Linley and S. Joseph (John Wiley \& Sons Inc.), 287-302. doi: 10.1002/9780470939338.ch18

Knotek, S. E., Fleming, P., Wright Thompson, L., Fornaris Rouch, E., Senior, M., and Martinez, R. (2019). An implementation coaching framework to support a career and university readiness program for underserved first-year college students. J. Educ. Psychol. Consult. 29, 337-367. doi: 10.1080/10474412.2018.1544903

Landis, J. R., and Koch, G. G. (1977). The measurement of observer agreement for categorical data. Biometrics 33, 159-174. doi: 10.2307/2529310

Linley, P. A., and Joseph, S. (eds.). (2004). "Applied positive psychology: a new perspective for professional practice," in Positive Psychology in Practice (Hoboken, NJ: John Wiley \& Sons, Inc.), 3-12. doi: 10.1002/9780470939338

*Linley, P. A., and Kauffman, C. (2007). Positive coaching psychology: Integrating the science of positive psychology with the practice of coaching psychology. Int. Coach. Psychol. Rev. 2, 5-8.

*Linley, P. A., Woolston, L., and Biswas-Diener, R. (2009). Strengths coaching with leaders. Int. Coach. Psychol. Rev. 4, 37-48.

Lomas, T., and Ivtzan, I. (2016). Second wave positive psychology: exploring the positive-negative dialectics of wellbeing. J. Happiness Stud. 17, 1753-1768. doi: 10.1007/s10902-015-9668-y

Madden, W., Green, S., and Grant, A. M. (2011). A pilot study evaluating strengthsbased coaching for primary school students: enhancing engagement and hope. Int. Coach. Psychol. Rev. 6, 71-83.

Malinga, K. S., Stander, M., and Nell, W. (2019). Positive leadership: Moving towards an integrated definition and interventions. In Theoretical Approaches to Multi-Cultural Positive Psychological Interventions, eds L. E van Zyl and S. Rothmann (Cham: Springer) 201-228.

McComb, C. (2009). How does psychological contract explain the efficacy of coaching? New Z J. Employ. Relat. 34, 44-58.

McHugh, M. L. (2012). Interrater reliability: the kappa statistic. Biochem. Med. 22, 276-282. doi: 10.11613/BM.2012.031

McQuaid, M., Niemiec, R., and Doman, F. (2018). "A character strengths-based approach to positive psychology coaching," in Positive Psychology Coaching in Practice, eds S. Green and S. Palmer (New York, NY: Routledge), 71-79. doi: 10.4324/9781315716169-5

Miles, M. B., and Huberman, A. M. (1994). Qualitative Data Analysis. Thousand Oaks, CA: Sage. 
Moher, D., Liberati, A., Tetzlaff, J., and Altman, D. G. (2009). Preferred reporting items for systematic reviews and meta-analyses: the PRISMA statement. Ann. Int Med. 151, 264-269. doi: 10.7326/0003-4819-151-4-200908180-00135

*Noble, D. N., Perkins, K., and Fatout, M. (2000). On being a strength coach: child welfare and the strengths model. Child Adolescent Soc. Work J. 17, 141-153. doi: 10.1023/A:1007510407262

*Oades, L. G., Crowe, T. P., and Nguyen, M. (2009). Leadership coaching transforming mental health systems from the inside out: the collaborative recovery model as person-centred strengths based coaching psychology. Int. Coach. Psychol. Rev. 4, 25-36.

Odendaal, A., and le Roux, A. R. (2016). "Contextualising coaching psychology within multi-cultural contexts," in Coaching Psychology: Meta-Theoretical Perspectives and Applications in Multicultural Contexts (Cham: Springer), 3-25. doi: 10.1007/978-3-319-31012-1_1

Orem, S. L., Binkert, J., and Clancy, A. L. (2007). Appreciative Coaching: A Positive Process for Change. London: John Wiley \& Sons.

Palmer, S., and Green, S. (2018). "PERMA-powered coaching: building foundations for a flourishing life," in Positive Psychology Coaching in Practice, eds S. Green and S. Palmer (London: Routledge), 125-142.

* Passmore, J., and Oades, L. (2015). Positive psychology techniques: positive case conceptualisation. Coach. Psychol. 11, 43-45.

* Passmore, J., and Oades, L. G. (2014). Positive psychology coaching: a model for coaching practice. Coach. Psychol. 10, 68-70.

Peláez, M. J., Coo, C., and Salanova, M. (2019). Facilitating work engagement and performance through strengths-based micro-coaching: a controlled trial study. J. Happiness Stud. 1-20, doi: 10.1007/s10902-019-00127-5

Purdie, J. (2017). Growth Mindset for Athletes, Coaches and Trainers: Harness the Revolutionary New Psychology for Achieving Peak Performance. Berkeley, CA: Ulysses Press.

Rogers, C. R. (1951). Client-Centred Therapy. London, UK: Constable

Salkind, N. J. (2012). Exploring Research, 8th Edn. Salt River, NJ: Pearson Publications.

Scheel, M. J., Davis, C. K., and Henderson, J. D. (2013). Therapist use of client strengths: a qualitative study of positive processes. Counsel. Psychol. 41, 392-427. doi: 10.1177/0011000012439427

Seligman, M. E. (2004). Authentic Happiness: Using the New Positive Psychology to Realize your Potential for Lasting Fulfilment. New York, NY: Simon and Schuster.

Seligman, M. E. (2012). Flourish: A Visionary New Understanding of Happiness and Wellbeing. New York, NY: Simon and Schuster.

*Sims, C. M. (2017). Second wave positive psychology coaching difficult emotions: Introducing the mnemonic of 'TEARS HOPE'. Coach. Psychol. 13, 66-79.

Spence, G. B., and Grant, A. M. (2012). "Coaching and well-being: a brief review of existing evidence, relevant theory and implications for practitioners," in eds I. Boniwell and S. David (Oxford: Oxford Univeristy Press), 1009-1025.

*Stander, E., and van Zyl, L. E. (2019). "The Talent Development Centre (TDC) as an integrated positive psychological leadership development and talent analytics framework," in Positive Psychological Intervention Design and Protocols for Multi-cultural Contexts, eds L. E. van Zyl and S. Rothmann (Cham: Springer), 33-56. doi: 10.1007/978-3-030-20020-6_2

Stander, F. W. (2016). "Strength coaching as an enabler of positive athlete outcomes in a multi-cultural sport environment," in Coaching Psychology: Meta-Theoretical Perspectives and Applications in Multicultural Contexts, eds L. E. van Zyl, M. W. Stander, and A. Odendaal (Cham: Springer), 279-298. doi: 10.1007/978-3-319-31012-1_13

*Tarragona, M. (2015). "Positive psychology and life coaching," in Positive Psychology in Practice, ed S. Joseph (Hoboken, NJ: John Wiley \& Sons), 249-264. doi: 10.1002/9781118996874.ch15 *The Astrix is a standard way in Systematic Reviews to indicate which studies
was included in the review.
Theeboom, T., Beersma, B., and van Vianen, A. E. (2014). Does coaching work? A meta-analysis on the effects of coaching on individual level outcomes in an organizational context. J. Positive Psychol. 9, 1-18. doi: 10.1080/17439760.2013.837499

van Zyl, L.E., Efendic, E., Rothmann, S., and Shankland, R. (2019). "Best practice guidelines for positive psychological intervention experimental designs," in Theoretical Approaches to Multi-Cultural Positive Psychological Interventions, eds L. E. van Zyl and S. Rothmann (Cham: Springer).

van Zyl, L. E. (2013). Research Methodology for Economic and Management Sciences. Upper Saddle River, NJ: Pearson Education International.

*van Zyl, L. E., Motschnig-Pitrik, R., and Stander, M. W. (2016b). "Exploring positive psychology and person-centred psychology in multi-cultural coaching," in Coaching Psychology: Meta-Theoretical Perspectives and Applications in Multicultural Contexts, L. E. Van Zyl, M. W. Stander, and A. Odendaal (Cham: Springer), 315-355. doi: 10.1007/978-3-319-31012-1_15

van Zyl, L. E., and Rothmann, S. (2019a). Theoretical Approaches to Multi-Cultural Positive Psychological Interventions. Cham: Springer. doi: 10.1007/978-3-030-20583-6

van Zyl, L. E., and Rothmann, S. (2019b). Positive Psychological Intervention Design and Protocols for Multi-Cultural Contexts. Cham: Springer. doi: 10.1007/978-3-030-20020-6

*van Zyl, L. E., and Stander, M. W. (2013). "A strengths-based approach towards coaching in a multicultural environment," in Interdisciplinary Handbook of the Person-Centered Approach, eds J. H. D. Cornelius-White, R. Motschnig-Pitrik, and M. Lux (New York, NY: Springer), 245-257. doi: 10.1007/978-1-4614-7141-7_17

van Zyl, L. E., Stander, M. W., and Odendaal, A., (2016a). Coaching Psychology: Meta-Theoretical Perspectives and Applications in Multicultural Contexts. Cham: Springer. doi: 10.1007/978-3-319-31012-1

*White, M. K., and Barnett, P. (2014). A five step model of appreciative coaching: a positive process for remediation. in Remediation in Medical Education, eds A. Kalet and C. L.Chou (New York, NY: Springer), 265-281. doi: 10.1007/978-1-4614-9025-8_16

Whitney, D. D., and Trosten-Bloom, A. (2010). The Power of Appreciative Inquiry: A Practical Guide to Positive Change. San Francisco, CA: BerrettKoehler Publishers.

Wong, P. T. P. (2011). Positive psychology 2.0: towards a balanced interactive model of the good life. Can. Psychol. 52, 69-81. doi: 10.1037/a00 22511

Wong, P. T. P., and Roy, S. (2017). "Critique of positive psychology and positive interventions," in The Routledge International Handbook of Critical Positive Psychology, eds N. J. L. Brown, T. Lomas, and F. J. Eiroa-Orosa (London, England: Routledge), 142-160. doi: 10.4324/9781315659794-12

Yakushko, O. (2019). Scientific Pollyannaism: From Inquisition to Positive Psychology. Cham: Palgrave Macmillan. doi: 10.1007/978-3-030-15982-5

*Yeager, J. M., and Britton, K. H. (2017). "Positive psychology coaching for sports leaders," in Positive Psychology in Sport and Physical Activity, eds A. Brady and B. Grenville-Cleave (London: Routledge), 243-255. doi: 10.4324/9781315304397-20

Conflict of Interest: The authors declare that the research was conducted in the absence of any commercial or financial relationships that could be construed as a potential conflict of interest.

Copyright (C) 2020 van Zyl, Roll, Stander and Richter. This is an open-access article distributed under the terms of the Creative Commons Attribution License (CC BY). The use, distribution or reproduction in other forums is permitted, provided the original author(s) and the copyright owner(s) are credited and that the original publication in this journal is cited, in accordance with accepted academic practice. No use, distribution or reproduction is permitted which does not comply with these terms. 


\section{OPEN ACCESS}

Edited by:

Sebastiaan Rothmann

North-West University, South Africa

Reviewed by:

Jinqiang Zhu,

Minzu University of China, China

Eun Jin Jung,

Korea Research Institute

for Vocational Education and Training,

South Korea

*Correspondence:

Sajid Haider

sajidhaider@ciitvehari.edu.pk

Specialty section:

This article was submitted to

Organizational Psychology,

a section of the journal

Frontiers in Psychology

Received: 13 January 2020

Accepted: 31 March 2020

Published: 15 May 2020

Citation:

Haider S, De-Pablos-Heredero C and De-Pablos-Heredero M (2020) A

Three-Wave Longitudinal Study of Moderated Mediation Between

High-Performance Work Systems

and Employee Job Satisfaction:

The Role of Relational Coordination

and Peer Justice Climate.

Front. Psychol. 11:792.

doi: 10.3389/fpsyg.2020.00792

\section{A Three-Wave Longitudinal Study of Moderated Mediation Between High-Performance Work Systems and Employee Job Satisfaction: The Role of Relational Coordination and Peer Justice Climate}

\author{
Sajid Haider ${ }^{*}$, Carmen De-Pablos-Heredero ${ }^{2}$ and Monica De-Pablos-Heredero ${ }^{2,3}$ \\ ${ }^{1}$ Department of Management Sciences, COMSATS University Islamabad, Vehari Campus, Islamabad, Pakistan, ${ }^{2}$ ESIC \\ Business \& Marketing School and Universidad Rey Juan Carlos, Madrid, Spain, ${ }^{3}$ ESIC Business \& Marketing School, \\ Madrid, Spain
}

Existing literature lacks studies that examine the indirect effect of high-performance work systems (HPWSs) on employee job satisfaction through employee-employee relations. Moreover, less is known about the boundary conditions of this indirect effect. This study sought to longitudinally examine the mediating role of a specific form of employeeemployee relations - relational coordination - in the relationship between HPWS and job satisfaction. Data were collected in three waves from the employees of commercial banks ( $N=322$ ). Partial least squares structural equation modeling was used for data analysis. Results from multiple linear autoregressive longitudinal analysis indicate that HPWSs predict relational coordination, which in turn partially mediates the HPWS-job satisfaction relationship. Perceptions of peer justice climate provide boundary conditions for the aforementioned mediating effect. This study contributes to existing literature by explaining moderated-mediation mechanisms through which HPWSs predict employee job satisfaction. Managers can strengthen the effect of HPWS on employee-employee relations and subsequent effect on employee job satisfaction by promoting peer justice climate in organizations.

Keywords: high-performance work systems, job satisfaction, relational coordination, peer justice climate, longitudinal, moderated mediation

\section{INTRODUCTION}

High-performance work systems (HPWSs) have long been recognized as a means of firm performance (Fu et al., 2019). High-performance work systems refer to "a system of HR [human resource] practices designed to enhance employees" skills, commitment, and productivity in such a way that employees become a source of sustainable competitive advantage" (Datta et al., 2005, p. 136). This system of HR practices is generally induced by organizations to implement strategic human resource management. One remarkable progress in understanding the effect of strategic human resource management in the last two decades has been the rise of studies relating HPWS with employee outcomes (Agarwal and Farndale, 2017; Cooke et al., 2019; Martinaityte et al., 2019). Within 
employee level phenomena, job satisfaction has received greater attention as a consequence of HPWSs (Brinck et al., 2019) because it enhances employee productivity and performance (Argyle, 1989; Lucas and Diener, 2003). Job satisfaction can be defined as "a pleasurable or positive emotional state resulting from the appraisal of one's job or work experiences" (Locke, 1976, p. 1300). Based on motivational theories, it is presumed that HPWSs enhance employee well-being and satisfaction by providing them appropriate work conditions (Zhang et al., 2018; Brinck et al., 2019).

Given the importance of mediators as a "generative mechanism through which the focal independent variable is able to influence the dependent variable of interest" (Baron and Kenny, 1986, p. 1173), many good works appeared that examined the mechanisms through which HPWSs exert their effect on employee job satisfaction. For example, Liu et al. (2016) found partial mediation of organizational identification in this relationship. Perceived organizational support was found as a strong mediator between HPWS-job satisfaction relationship (García-Chas et al., 2016). Chen et al. (2016) reported psychological efficacy as a significant mediator of the relationship between HPWSs and job satisfaction. Similarly, procedural justice, interactional justice, and organizational role stress mediated the HPWS-job satisfaction relationship (Wu and Chaturvedi, 2009; Heffernan and Dundon, 2012; Garg, 2015).

However, these studies (and other similar work) remained mainly focused on examining the organizational- and individuallevel phenomena and largely ignored employee-employee level episodes that may explain the relationship between HPWSs and job satisfaction. More specifically, employeeemployee relations have been ignored as a mechanism between HPWSs and employee job satisfaction (Evans and Davis, 2005). Employees working under a same set of high-performance work practices are expected to have shared understanding of and attitude toward interpersonal exchange relationships in organization (Gong et al., 2010). This shared understanding strengthens organization's internal social structure, nourishes employment relationship, and, consequently, enhances employee job satisfaction (Requena, 2003; Evans and Davis, 2005; Chen et al., 2018). Given that HPWSs affect employees' interpersonal relationships in organizations, and these relationships increase employee job satisfaction, it can be stated that employee relations can mediate the relationship between HPWSs and employee job satisfaction (Evans and Davis, 2005; Haider et al., 2019a). Thus, employee-employee relationships constitute a mediating mechanism through which HPWSs affect organizational and employee outcomes (Gittell et al., 2010).

Existing literature has discussed employee-employee relationships in various forms such as social capital (Evans and Davis, 2005), coworker exchange (Sherony and Green, 2002), mindful interacting (Vogus, 2006), social networks (Collins and Clark, 2003), relational coordination (Gittell, 2000), and so on. Among the diverse forms of employee relations in organization, relational coordination provides a unique framework for understanding interpersonal relationships at work settings as it believes that employees' relational and communication ties interact with each other to achieve coordination during a work process (Gittell et al., 2010). According to Gittell (2002), "Relational coordination is a mutually reinforcing process of interaction between communication and relationships carried out for the purpose of task integration" (p. 301). Relational coordination is receiving the researchers' attention as it provides a unique perspective on high-quality employee-employee relations characterized by the interaction between employee communication and relational ties and focuses on microdynamics to develop collective identity among organizational members (Gittell, 2006; Carmeli and Gittell, 2009).

Relational coordination has been examined as a mediator of the relationship between HPWSs and quality and efficiency outcomes in healthcare settings (Gittell et al., 2010). In another study, employee job satisfaction was significantly predicted by relational coordination (Gittell et al., 2008). The results of these studies suggest that HPWSs predict relational coordination, and relational coordination predicts employee job satisfaction. Given that, a mediating effect of relational coordination can be expected between HPWSs and job satisfaction. To the researchers' knowledge, no previous study has examined the indirect effect of HPWSs on employee job satisfaction through relational coordination.

Furthermore, contemporary literature suggests that the contingent nature of indirect effect (or boundary conditions) needs to be examined for understanding "when that effect exists and when it does not" (Hayes, 2018, p. 4). Insights from organizational justice literature propound that employees' justice perceptions play a vital role in developing cooperation among coworkers (Li and Cropanzano, 2009; Li et al., 2013). Specifically, peer justice climate, "defined as team-level judgments of the fairness with which coworkers generally treat one another" (Li et al., 2013, p. 563), is positively associated with workplace cooperation and communication, which promote knowledge sharing, group coordination, and interpersonal relationships (Cropanzano et al., 2011; Li et al., 2013). This study proposes that our mediator, that is, relational coordination (characterized by communication and relationships), may be affected by the level of peer justice climate in organization. In other words, employees working in a peer justice climate are likely to develop positive interactions due to greater satisfaction with coworkers (Haider et al., 2018). Therefore, they are highly likely to exercise relational coordination among each other.

Findings of various empirical studies suggest that justice climate may interact with diverse organizational and individual phenomena to predict outcomes at employee and organizational level (Li et al., 2013). However, the moderating effect of peer justice climate on the relationship between HPWSs and relational coordination has not been found in existing literature. As peer justice climate affects communication and interpersonal relationships among coworkers (Li et al., 2013), this study posits that the effect of HPWSs on relational coordination may differ at different levels of peer justice climate in organization. Given that, it can be stated that the indirect effect of HPWSs on employee job satisfaction through relational coordination is moderated by peer justice climate. 
Moreover, previous studies have examined the mediating mechanisms between HPWSs and job satisfaction in crosssectional study designs, which are not well suited to test causal effects such as mediation (Cole and Maxwell, 2003; Maxwell and Cole, 2007). High-performance work systems exert their effect on employee outcomes over time (Birdi et al., 2008; Piening et al., 2013; Shin and Konrad, 2017). In other words, HPWSs affect employee job satisfaction by changing the nature of employeeemployee relations over time. Given the mediational nature of this relationship, there is need to "collect data in a fashion that allows time to elapse between the theoretical cause and its anticipated effect" (Cole and Maxwell, 2003, p. 561). So, we believe that longitudinal (rather than cross-sectional) study designs should be used for determining true causal relationships in a mediation model of HPWSs and employee job satisfaction.

The main objective of this study was to examine the mediating role of relational coordination between HPWS-job satisfaction relationship in a three-wave longitudinal study design. In addition, this study sought to examine the role of peer justice climate as a boundary condition for the aforementioned mediation process. Specifically, this study examined a moderated mediation model where peer justice climate increases employee job satisfaction by strengthening the effect of HPWSs on relational coordination among coworkers.

\section{THEORY AND HYPOTHESES}

Figure 1 shows this study's theoretical model where HPWSs predict job satisfaction through relational coordination. This indirect effect is moderated by peer justice climate. Specifically, peer justice climate moderates the effect of HPWSs on relational coordination. The variables and the nature of relationships depicted in this model are relevant to two major theoretical frameworks discussed in organizational studies: social exchange theory (SET) (Blau, 1964) and contingency theory of organizations (Drazin and Van de Ven, 1985). SET (Blau, 1964) has long been recognized as a framework for understanding social relationships in organizations. The generic model of social exchange suggests that any initiating action leads to a reciprocal response from the person/s for whom the action was initiated (Cropanzano et al., 2017). Based on this idea, the researchers in organizational psychology and human resource management have argued that the implementation of management practices positively affects social exchanges in an organization, which, subsequently, generate attitudinal and behavioral responses from employees (Takeuchi et al., 2007; Gong et al., 2010). These insights guide this study to suggest that HPWSs generate employees' attitudinal response (i.e., job satisfaction) by positively effecting employee relations in organization (i.e., relational coordination). The moderator's (peer justice climate) effect in Figure $\mathbf{1}$ is relevant to the contingency theory of organizations, which describes that the organization's contextual factors may affect the intensity of relationships among diverse organizational phenomena (Drazin and Van de Ven, 1985). This study argues that peer justice climate, as an important contextual factor, may affect the indirect



FIGURE 1 | Theoretical model.

relationship between HPWSs and employee job satisfaction through relational coordination.

\section{HPWSs and Relational Coordination}

While examining the processes underlying social exchange in work organization, Gittell (2002) described that relational coordination occurs through frequent, timely, accurate, and problem-solving communication, which is supported by shared knowledge, shared goals, and respect for each other. Gittell et al. (2008) and Gittell et al. (2010) argued that organizations' use of HPWSs supports relational coordination among employees and subsequently affects organizational and employee outcomes such as quality, efficiency, and job satisfaction. This provides the idea that relational coordination resulting from the use of HPWSs may be vital for deciding if any positive employee outcomes appear from the social exchange processes at workplace. We connote that a reason why HPWSs predict job satisfaction is that the employees may perceive that organization's use of HPWSs provides them an opportunity to develop workplace relationships. Consequently, this perception may provoke employee job satisfaction.

The relationship between relational coordination and employee job satisfaction has been supported in recent research (Gittell et al., 2008; Margalina et al., 2014). However, can relational coordination also explain why HPWSs predict job satisfaction? In order to support the assumption that relational coordination mediates the HPWS-job satisfaction relationship, we must support HPWSs as antecedents of relational coordination. Gittell et al. (2010) focused on six high-performance work practices: selection, conflict resolution, performance measurement, rewards, meetings, and boundary spanners. Gittell et al. (2010) explained that "boundary spanners are staff members whose primary task is to integrate the work of other people around a project, process, or customer" (p. 493). Gittell et al. (2010) developed theorydriven relationships between the aforementioned practices and relational coordination. They described that these practices "are expected to foster relational coordination, which is reflected in the frequency, timeliness, accuracy, and problem-solving nature of communication among employees and the degree to which their relationships are characterized by shared goals, shared knowledge, and mutual respect" (p. 494).

Consistent with Gittell et al. (2010), Riaz (2016) found a significant positive relationship between HPWSs and 
relational coordination. These thoughts are also consistent with Mossholder et al. (2011) and Vogus (2006), who described that high-performance HR practices promote employee relationships with their coworkers. Accordingly, it can be stated that employees could consider HPWSs as their organization's relationshipenhancing activity and obtain greater job satisfaction in this relational environment. From a social capital perspective, Jiang and Liu (2015) described that HPWSs promote shared cognitive systems and "enhance the relationships among members within an organization and improve interpersonal communication and coordination" (p. 130). This idea is consistent with Evans and Davis (2005), who noted that "HPWSs positively influence the internal social structure by facilitating bridging network ties, generalized norms of reciprocity, shared mental models role, making, and organizational citizenship behavior" (p. 758). It shows that organization's use of HPWSs, in fact, is the height of human resource management, which, according to Guest (1987), maximizes integration and collective relations in organizations. Based on above discussion, our first hypothesis is:

Hypothesis 1: High-performance work systems are positively associated with relational coordination.

\section{Mediating Role of Relational Coordination}

Social exchange theory (Blau, 1964) comes up with a valuable framework for explaining the dynamic relationships in our research model as it concentrates on the continuous reciprocal exchange between organizational inputs (i.e., HR practices) and employees' attitudinal and behavioral responses (Piening et al., 2013). The norm of reciprocity in SET suggests that organization's use of high-performance work practices may develop, over time, employees' shared understanding of exchange relationships, not only with their organization but also with their colleagues (Evans and Davis, 2005; Gittell et al., 2010; Gong et al., 2010; Chun et al., 2013). Based on Gittell et al.'s (2010) interpretation of the reciprocity emerging from organization's use of high-performance work practices, it can be stated that HPWSs predict employee-employee relationships (i.e., relational coordination) over time. In other words, employees' perceptions of HPWSs at one-point of time would lead relational coordination among coworkers at a future point of time. Subsequently, the dynamic nature of this relationship enhances employee job satisfaction over time.

In order to explain why HPWSs may affect employee job satisfaction, through relational coordination, we also used Gittell et al.'s (2010) model of HPWSs. Gittell et al.'s (2010) model includes following high-performance work practices: selection, conflict resolution, performance measurement, rewards, meetings, and use of boundary spanners. These authors proposed that employee selection, based on their ability to work in teams and person-organization fit, enhances mutual respect among coworkers. Organizations' use of "selection" tends to enhance employee job satisfaction by stimulating high-quality exchange relationships, which are characterized by mutual respect (Sherony and Green, 2002; Janssen and Van Yperen, 2004). Given the importance of mutual respect in enhancing employee job satisfaction (Gittell et al., 2008; Clarke and Mahadi, 2017), we can expect that HPWSs facilitate employee job satisfaction at least partially through their effect on mutual respect among coworkers.

The existence of "conflict resolution" mechanisms in organizations is likely to encourage knowledge sharing and mutual respect among fellow workers (Gittell et al., 2010). Conflict resolution is likely to increase employee job satisfaction by promoting those cultures that invigorate mutual respect and knowledge sharing (Trivellas et al., 2015). Recognizing the fact that mutual respect and knowledge sharing predict employee job satisfaction (Gittell et al., 2008; Trivellas et al., 2015; Kianto et al., 2016), it can be assumed that HPWSs predict employee job satisfaction through their effect on mutual respect and knowledge sharing among fellow workers.

Organizations' use of "performance measurement" practice is believed to "strengthen the shared goals and problem-solving communication dimensions of relational coordination" (Gittell et al., 2010, p. 493). Gittell et al. (2010) defined performance measurement as accountability for outcomes. Accountability is quite a suitable practice to augment employee job satisfaction because it encourages those behaviors (i.e., organizational citizenship behavior) that play a vital role in employees' goal sharing and problem-solving (Lee et al., 1991; Turnipseed and Rassuli, 2005; Hall et al., 2009). Once we acknowledge that goal sharing and problem-solving communication enhance job satisfaction (Gittell et al., 2008; Hall et al., 2009), it is easy to accept that HPWSs increase employee job satisfaction by affecting goal-sharing and problem-solving communication.

"Meetings", "rewards," and "boundary spanners" enhance goal sharing and knowledge sharing and encourage, overall, the communication dimensions of relational coordination (Gittell et al., 2010). These practices may increase employee job satisfaction by strengthening their effect on relational coordination. Insights from Carmeli and Gittell (2009) provide the same argument as they presumed that "high-quality relationships as manifested in shared goals, shared knowledge, and mutual respect create a positive social context in which people feel safe to perform and act" (p. 714). This positive social context emerges when organizations use HPWSs, as a result of which the relational coordination is promoted (Gittell et al., 2010). Accordingly, it can be stated that a reason why HPWSs predict employee job satisfaction is that HPWSs may affect employee's perceptions that they are working in a psychological safe environment characterized by high-quality relationships and communication (Carmeli and Gittell, 2009).

In order to ascertain whether relational coordination explains the relationship between HPWSs and employee job satisfaction, the following hypothesis was tested:

Hypothesis 2: Relational coordination mediates the relationship between HPWSs and employee job satisfaction.

\section{Moderating Role of Peer Justice Climate}

Peer justice climate provides strong foundations for establishing good communication, coordination, and interpersonal relationships among coworkers (Li et al., 2013). Previous research suggests that perceptions of peer justice promote 
organizationally desired behaviors such as organizational citizenship behavior and team satisfaction and performance by improving cooperative teamwork processes (i.e., communication, cooperation, coordination, cohesion, etc.) among coworkers (Cropanzano et al., 2011; Li et al., 2013). Peer justice also enhances group learning behavior when it is influenced by group ethical conduct (Walumbwa et al., 2017). These insights from existing literature suggest that relational coordination as an indicator of teamwork quality (Heredero et al., 2015) is greatly influenced by peer justice climate in organization. Literature also suggests that peer justice climate has the ability to change employee and organizational outcomes when it interacts with the antecedents of these outcomes (Li et al., 2013). Given that both HPWSs and peer justice influence relational coordination, and justice climate moderates various relationships in organizations, it can be expected that peer justice climate may change the effect of HPWSs on relational coordination when it interacts with HPWS.

Contingency theory of organizations (Lawrence and Lorsch, 1967; Drazin and Van de Ven, 1985) suggests that "boundary conditions specify the ranges over which a relationship is expected to hold" (Drazin and Van de Ven, 1985, p. 514). Peer justice climate, as a unique organizational context, may "affect the occurrence, meaning, and outcomes of certain behaviors" (Heslin, 2009, p. 133) and consequently may provide boundary conditions for the relationship between HPWSs and relational coordination. In other words, the effect of HPWSs on relational coordination will be stronger when employees strongly exhibit the dimensions of relational coordination (i.e., frequent, timely, accurate, and problem-solving communication and shared knowledge, shared goals, and mutual respect) as a result of peer justice climate.

Similarly, the notion of reciprocity in SET suggests that employees "tend to reciprocate beneficial treatment they receive with positive work-related behaviors" (Hekman et al., 2009). According to Li et al. (2013), "when individuals are treated fairly by their teammates (PJC)..., and when these feeling are shared among team members, they may consider the work environment as pleasant and satisfactory." As "social exchange tends to engender feelings of personal obligation, gratitude, and trust" (Blau, 1964, p.94), peer justice can make employees reciprocate in the form positive interpersonal relationships (mutual respect, knowledge sharing, and goal sharing) and fair communication (timely, accurate, frequent, and problem-solving communication). Given that peer justice climate enhances relational coordination, the effect of HPWSs on relational coordination will be stronger when employees' perceptions of peer justice are high, and this relationship will be weak when these perceptions are low. So, it can be argued that the benefits of HPWSs in improving relational coordination among coworkers increase when they interact with peer justice climate.

Considering peer justice climate as a moderator of the relationship between HPWSs and relational coordination, this study argues that peer justice climate increases employee job satisfaction by strengthening the effect of HPWSs on relational coordination. In other words, peer justice climate makes a difference in specifying the effect of HPWSs on employee job satisfaction through relational coordination. We contend that a positive peer justice climate extends the satisfactionenhancing benefits of HPWSs by strengthening relational coordination among coworkers. Although HPWSs enhance employee job satisfaction by influencing relational coordination among coworkers, the strength of this indirect effect depends on peer justice climate. This discussion leads us to formulate the following hypothesis:

Hypothesis 3: Peer justice climate moderates the indirect effect of HPWSs on employee job satisfaction through relational coordination.

\section{MATERIALS AND METHODS}

\section{Sample and Procedures}

Participants were employees from commercial banks in Southern Punjab (Pakistan). Randomly selected 920 employees were provided with printed questionnaires. Data were gathered in three waves, with 6-month lags. The reason for collecting data in three waves was that minimum three waves are necessary to test true causal effects in a mediation model (Collins et al., 1998; Cole and Maxwell, 2003). In order to match responses of all three waves, each individual employee was assigned a distinct code. The study survey was initiated after having a written informed consent from the participants and approval from the Ethical Committee for Scientific Research at COMSATS, Vehari.

All waves of survey obtained employees' self-ratings about relational coordination, job satisfaction, and the use of highperformance work practices. All study variables' ratings were obtained in three waves. However, the data were used according to the need of analytical procedures. The control variables (gender, education, and tenure) were surveyed only in the first wave. After looking for missing values, 717 responses were usable from first-wave survey (78\%).

In the second-wave survey, only those 717 employees were approached for whom we received usable responses in the first wave. However, two employees had left their jobs, and seven were on long-term leave. So, the second-wave questionnaires were distributed among 708 employees. After looking for missing values and matching the first- and second-wave responses, only 476 responses (67\%) were usable. In Time 3, one out of 476 had left his job, and two were on long-term leave. Questionnaires were distributed to 473 employees. After looking for missing values and matching responses for the second and first wave, 322 (68\%) usable responses were recorded. The response rate from initial sample to final usable data is $35 \%$. Of the final 322 respondents, 185 were male (57\%), and 137 (43\%) were female. The mean age of respondents was 28 years, and the mean experience was 6 years. Respondent's education was recorded as number of education years [ $\geq 18$ years: 40 (12\%); 16 years: $95(30 \%)$; 14 years: $46(14 \%)$; 12 years: $64(20 \%)$; 10 years: $77(24 \%)]$.

One may note a significant dropout of respondents from Wave 1 to Wave 3. Under such a situation, the issue of attrition bias may arise. However, attrition bias occurs "if participants who stay in a study differ from those who drop out" (Gustavson et al., 2012, p. 1). Following Brouer et al. (2011), we were able to ask 
branch managers to compare the characteristics of respondents and of those who did not respond in follow-up surveys. The managers informed that the respondents and non-respondents were alike in their characteristics (i.e., age, experience, education, gender). Moreover, in light of Miller and Wright (1995), we tested for attrition bias by applying independent-samples $t$-test to compare the characteristics of "those subjects who responded to all waves of the study with those who dropped out after only one wave" (p. 922). We performed an independent-samples $t$-test in the IBM (USA) Statistical Package for Social Sciences (SPSS) version 21.The results in Table 1 indicate that there was no significant difference in the characteristics of respondents and non-respondents with respect to gender, education, tenure, and age. So, attrition bias is less likely in our data.

\section{Measures}

Data were collected by using questionnaires already used in existing research. Relational coordination was measured by using employees' self-ratings on Gittell et al. (2000) seven-item instrument where communication dimensions were scaled as follows: 1 = never, 2 = rarely, 3 = occasionally, $4=$ often, 5 = always, and the relational dimensions were scaled as follows: for shared goals and mutual respect: $1=$ not at all, $2=$ a little, 3 = some, 4 = a lot, 5 = completely, and for shared knowledge; 1 = nothing, 2 = little, 3 = some, 4 = a lot, 5 = everything. High-performance work systems were measured by employees' perceptions about their organization's use of Gittell et al.'s (2010) six high-performance work practices: selection, conflict resolution, performance measurement, rewards, meetings, and use of boundary spanners. A five-point Likert scale was used ( $1=$ never, 2 = rarely, $3=$ occasionally, $4=$ often, $5=$ always $)$ to measure employees' self-ratings about using these practices. Peer justice climate was measured by using a five-item scale where four items were related to each of the justice dimensions, for example, distributive, procedural, interpersonal, and informational peer justice (Li et al., 2013; Molina et al., 2016), and one item was related to overall peer justice (Walumbwa et al., 2017). Job satisfaction was measured by using employees' self-ratings on a four-item scale used in Eisenberger et al. (1997). For both peer justice and job satisfaction questionnaires, employees specified their level of agreement with each item on a five-point Likert scale ( 1 = strongly disagree, $5=$ strongly agree).

Given that all study variables were measured by a single source (employees' self-ratings), the issue of common method variance (CMV) may arise (Podsakoff et al., 2003). Common method variance is defined as the "variance that is attributable to the measurement method rather than to the constructs the measures represent" (Podsakoff et al., 2003, p. 879). While explaining "techniques for controlling common method biases," Podsakoff et al. (2003) suggested that a potential remedy to control CMV "is to create a temporal separation by introducing a time lag between the measurement of the predictor and criterion variables" (p. 887). The issue of CMV is less likely in this study because we used time lags between the measurement of the predictor, mediator, and criterion variables. In addition, the variance inflation factor (VIF) generated in collinearity test also informs about the presence of CMV in data (Kock and Lynn,
2012; Kock, 2015). Moqbel and Kock (2018) suggested that VIF values lower than 3.3 indicate that CMV is not present in data. We performed a collinearity test before testing the hypothesized relationships in our model and found no VIF value higher than 3.3 (Table 4). So, it can be stated that CMV is not an issue in this study's data.

\section{Control Variables}

The effects of respondents' gender (1, "male," 2, "female”), age (in years), and tenure in the organization (in years) were controlled in direct and indirect effect models because these variables are likely to influence employee job satisfaction (Janssen and Van Yperen, 2004; Gittell et al., 2008).

\section{Analytical Approach}

Data were analyzed by applying partial least squares structural equation modeling (PLS-SEM) in the latest version of SmartPLS software. Partial least squares path modeling, in relation to other SEM techniques such as covariance based or CB-SEM, is more desirable in social sciences as it is effective in analyzing small samples and non-normal data (Hair et al., 2014). As a component-based estimation technique, PLS-SEM uses iterative algorithms of least squares regressions (Hair et al., 2014; Haider et al., 2020). It is an appropriate technique for the studies that aim to make prediction and develop theories (Hair et al., 2016). Partial least squares SEM is preferred to other SEM techniques such as CB-SEM (covariance based SEM) because it can efficiently handle small samples and the data that are not normally distributed. Partial least squares SEM validates data in measurement model and tests the significance and relevance of hypothesized relationships in structural model.

\section{RESULTS}

\section{Evaluation of Measurement Model}

Partial least squares measurement model has two types: reflective (principal factor) and formative (composite index) measurement models. The former type, where the "direction of causality is from construct to measure," is considered appropriate for studies measuring perceptions, attitudes, and so on (Jarvis et al., 2003, p. 201). The evaluation of measurement model is performed by estimating internal consistency reliability, convergent validity $(\mathrm{CV})$, and discriminant validity (DV) of survey instruments. Internal consistency reliability means that a construct's all items are equally reliable. The values of Cronbach $\alpha(>0.70)$ and CR (between 0.70 and 0.90 ) are two standards for establishing IC in a latent construct. Table 2 shows that Cronbach $\alpha$ for all latent constructs is greater than 0.70. The CR values for all latent constructs are between 0.70 and 0.90 , except for T1HPWS and T1-JS. However, the values of these construct are less than 0.95, which is acceptable under a lenient criterion (Hair et al., 2014).

Convergent validity "is the extent to which a measure correlates positively with alternative measures of the same construct" (Hair et al., 2014, p. 102). Indicator reliability (factor loading of each indicator $>0.70$ ) and average variance extracted 
TABLE 1 | Independent $t$-test to compare the characteristics of respondents and non-respondents.

\begin{tabular}{|c|c|c|c|c|c|c|c|}
\hline Group & & $N$ & Mean & Standard deviation & $t$-value & df & Significance (2-tailed) \\
\hline \multirow[t]{2}{*}{ Gender } & Non-respondents & 395 & 1.52 & 0.50 & -1.55 & 715 & 0.12 \\
\hline & Respondents & 322 & 1.57 & 0.50 & & & \\
\hline \multirow[t]{2}{*}{ Education } & Non-respondents & 395 & 2.87 & 1.35 & 0.07 & 715 & 0.95 \\
\hline & Respondents & 322 & 2.87 & 1.39 & & & \\
\hline \multirow[t]{2}{*}{ Tenure } & Non-respondents & 395 & 5.87 & 1.31 & -0.98 & 715 & 0.33 \\
\hline & Respondents & 322 & 5.96 & 1.32 & & & \\
\hline \multirow[t]{2}{*}{ Age } & Non-respondents & 395 & 28.11 & 7.01 & 0.29 & 715 & 0.77 \\
\hline & Respondents & 322 & 27.96 & 6.97 & & & \\
\hline
\end{tabular}

TABLE 2 | Assessment of measurement model (construct reliability).

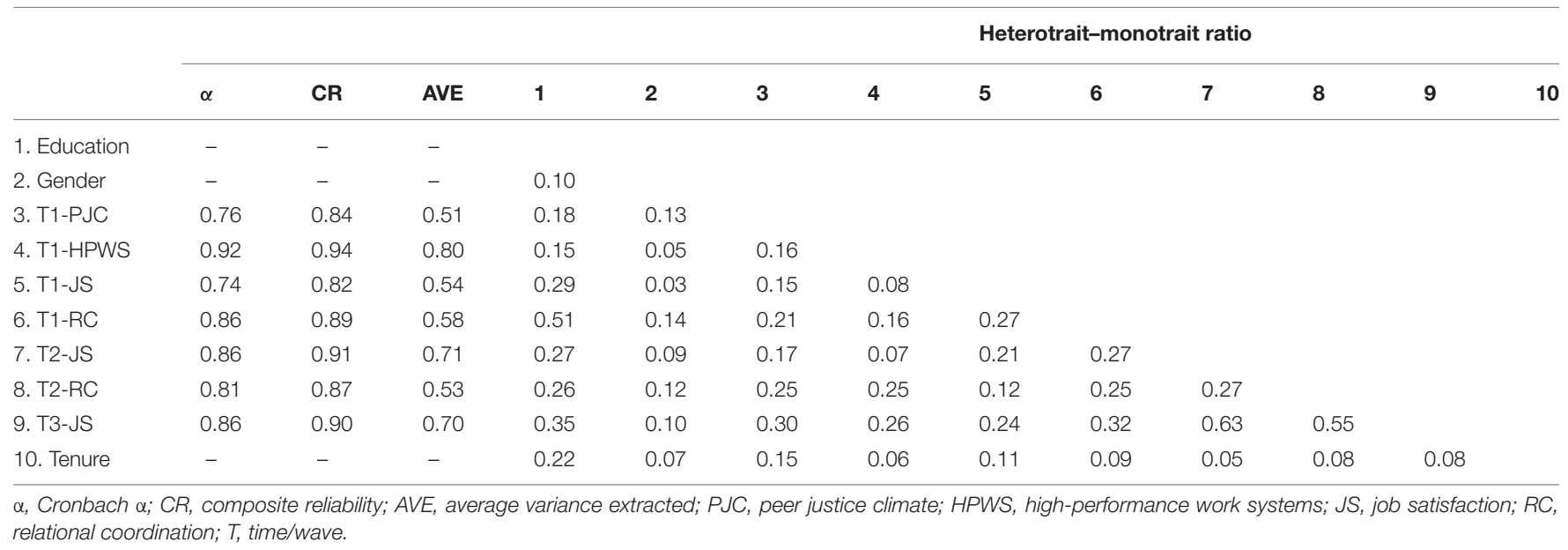

TABLE 3 | Factor loadings.

\begin{tabular}{|c|c|c|c|c|c|c|c|c|c|c|c|c|c|}
\hline \multicolumn{2}{|c|}{ PJC } & \multicolumn{2}{|c|}{ T1-HPWS } & \multicolumn{2}{|c|}{ T1-JS } & \multicolumn{2}{|c|}{ T1-RC } & \multicolumn{2}{|c|}{ T2-JS } & \multicolumn{2}{|c|}{ T2-RC } & \multicolumn{2}{|c|}{ T3-JS } \\
\hline ï & $\lambda$ & ï & $\lambda$ & ï & $\lambda$ & ï & $\lambda$ & ï & $\lambda$ & ï & $\lambda$ & ï & $\lambda$ \\
\hline T1-PJC1 & 0.74 & T1-HPWS2 & 0.92 & T1-JS1 & 0.63 & $\mathrm{~T} 1-\mathrm{RC} 1$ & 0.81 & T2-JS1 & 0.82 & $\mathrm{~T} 2-\mathrm{RC} 1$ & 0.60 & T3-JS1 & 0.74 \\
\hline T1-PJC2 & 0.76 & T1-HPWS3 & 0.93 & T1-JS2 & 0.73 & T1-RC2 & 0.84 & T2-JS2 & 0.86 & T2-RC2 & 0.78 & T3-JS2 & 0.83 \\
\hline T1-PJC3 & 0.65 & T1-HPWS4 & 0.94 & T1-JS3 & 0.77 & T1-RC3 & 0.80 & T2-JS3 & 0.86 & T2-RC3 & 0.88 & T3-JS3 & 0.92 \\
\hline T1-PJC4 & 0.70 & T1-HPWS5 & 0.78 & T1-JS4 & 0.80 & T1-RC4 & 0.56 & T2-JS4 & 0.82 & T2-RC4 & 0.85 & T3-JS4 & 0.86 \\
\hline \multirow[t]{2}{*}{ T1-PJC5 } & 0.70 & & & & & T1-RC5 & 0.80 & & & T2-RC5 & 0.60 & & \\
\hline & & & & & & T1-RC6 & 0.74 & & & T2-RC6 & 0.60 & & \\
\hline
\end{tabular}

I, indicators; $\lambda$, factor loadings; PJC, peer justice climate; HPWS, high-performance work systems; JS, job satisfaction; RC, relational coordination; T, time/wave.

$(\mathrm{AVE} \geq 0.50)$ are used for determining CV (Hair et al., 2014). The AVE values of all our latent constructs are greater than 0.50 (Table 2). The indicators T1-HPWS1, T1-HPWS6, T1$\mathrm{RC7}$, and T2-RC7 were deleted from their respective constructs because their factor loadings were less than 0.40 (Hair et al., 2014). Deletion, however, does not affect the meaning of a reflective construct (Jarvis et al., 2003). Factor loadings $(\lambda)$ of some indicators (T1-PJC3, T1-JS1, T1-RC4, T2-R1, T2-RC5, and T2-RC 6) are less than 0.70 (Table 3). Nevertheless, these items were kept with their corresponding latent constructs as the "indicators with outer loadings between 0.40 and 0.70 should be considered for removal only if the deletion leads to an increase in composite reliability and AVE above the suggested threshold value" (Hair et al., 2014, p. 107). The deletion process was performed by using insights from Hair et al. (2014), and there was no increase in composite reliability and AVE above the suggested threshold value.

Discriminant validity is established to evaluate that the measures of one construct do not correlate with other constructs (Ringle et al., 2010). As a tradition, DV was established by using cross-loadings and Fornell and Larcker's (1981) criterion. But these methods are insufficiently sensitive to detect DV. Henseler et al. (2015) introduced a more sensitive new criterion, heterotrait-monotrait ratio of correlations (HTMT), for measuring DV. We used this new criterion. Using a more conservative approach (considered as the strictest criterion), HTMT value between two constructs must be less than $0.85\left(\mathrm{HTMT}_{0} \cdot 85\right)$. Table 2 shows that all HTMT values 
between constructs are less than 0.85 . So, DV has been established in our model.

\section{Evaluation of Structural Model}

According to Hair et al. (2014), collinearity between each set of predictor variables must be checked before hypotheses testing. Partial least squares SEM also requires collinearity test at item level in formative measurement models. However, in case of reflective measurement model, collinearity test is not required at item level (see Hair et al., 2014). As we used reflective measurement model, the collinearity test was performed only at construct level. Variance inflation factor is a frequently used measure of collinearity. Its value should be 5 or lower. The SmartPls results in Table 4 indicate the absence of collinearity among the predictors because all VIF values are below 5 .

Figure 2 shows the estimated longitudinal path model for mediation and moderated mediation where dotted lines indicate the hypothesized relationships after controlling for the respondents' education, gender, and tenure and prior levels of study variables where applicable (solid lines). In this threewave autoregressive model, the direct and indirect effects of independent variable on dependent variable take two-unit time lags (Maxwell et al., 2011). Two-unit time lag models allow to avoid half longitudinal designs (where one part of the model becomes cross-sectional; either the effect of predictor on mediator or the effect of mediator on outcome variable is measured at same point of time) (Cole and Maxwell, 2003; Haider et al., 2019b). In a three-wave longitudinal model, half longitudinal design is avoided by testing the effect of Time 1 predictor on Time 2 mediator and subsequent effect on Time 3 outcome variable (controlling for Time 1 mediator, and Time 1 and Time 2 outcome variable). Therefore, this study's mediation hypothesis was examined by testing the effect of Time 1 HPWS (T1-HPWS) on Time 3 job satisfaction (T3-JS) through Time 2 relational coordination (T2-RC), controlling for the previous levels of relational coordination (T1-RC) and job satisfaction (T1-JS and T2-JS). Zhao et al.'s (2010) two-step process was followed to decide whether relational coordination mediated the HPWS-job satisfaction relationship.

TABLE 4 | Collinearity assessment (inner VIF values).

\begin{tabular}{|c|c|c|c|}
\hline & T2-JS & T2-RC & T3-JS \\
\hline Education & & & 1.19 \\
\hline Gender & & & 1.03 \\
\hline T1-PJC & & 1.04 & \\
\hline T1-HPWS & & 1.04 & 1.07 \\
\hline T1-JS & 1.05 & & \\
\hline $\mathrm{T} 1-\mathrm{RC}$ & 1.05 & 1.06 & \\
\hline T2-JS & & & 1.11 \\
\hline $\mathrm{T} 2-\mathrm{RC}$ & & & 1.13 \\
\hline \multicolumn{4}{|l|}{ T3-JS } \\
\hline Tenure & & & 1.08 \\
\hline
\end{tabular}

To test moderated mediation, Time 1 peer justice climate (T1PJC) and its interaction with Time 1 HPWS (T1-HPWS $\times$ T1PJC) were added in the mediation model. Specifically, moderated mediation was examined by extending Hayes' (2015) first stage moderation model to a three-wave longitudinal autoregressive mediation model. Based on Edwards and Lambert (2007) and Preacher et al. (2007), Hayes (2015) explained that first-stage model allows the effect of predictor on mediator in a mediation model to be moderated by another variable (moderator). This is the case in our research model.

\section{Mediation Results}

As already mentioned, this study used a two-step mediation procedure developed by Zhao et al. (2010) and explained in Hair et al. (2016). The first step suggests that the indirect effect of predictor on dependent variable, via mediator, must be significant. Preacher et al.'s (2007) product of coefficients approach was used to estimate the coefficient of indirect effect. The significance of this effect was tested by using bias-corrected bootstrap confidence interval method for 5,000 samples. The results indicate (Figure 2) that the effect of HPWSs on job satisfaction, through relational coordination, is significant $\left(\beta=0.17^{*} 0.30=0.05 ; P<0.05\right)$.

The second step requires testing the direct effect of predictor on the dependent variable. Figure 2 shows that the direct effect of HPWS (T1-HPWS) on employee job satisfaction (T3-JS) is insignificant $(\beta=0.07 ; P>0.05)$. Insights from existing literature (Cole and Maxwell, 2003; Rucker et al., 2011) suggest that the non-zero coefficient of direct effect indicates that relational coordination does not fully mediate the relationship between HPWSs and job satisfaction, and other possible mediators cannot be ignored. Given that the direct effect is non-zero and insignificant, and the indirect effect is significant, it can be stated that relational coordination mediates the relationship between HPWSs and job satisfaction (Zhao et al., 2010; Hair et al., 2016). It suggests that the mediator acquiesces well in our research model (supports Hypothesis 1).

\section{Moderated-Mediation Results}

As discussed earlier, the test of moderated mediation was based on Hayes (2015) first-stage model where the effect of HPWSs on relational coordination (in our mediation model) was moderated by peer justice climate. As a tradition among researchers, the significance of moderating effect on predictormediator relationship is examined in a moderated-mediation model (Muller et al., 2005; Preacher et al., 2007; Hair et al., 2016). However, the latest literature on moderated mediation suggests that "a formal test of moderated mediation based on a quantification of the relationship between the proposed moderator and the size of the indirect effect is required to determine whether the indirect effect depends on the moderator" (Hayes, 2015, p.9). In other words, it is recommended to test the moderator's effect on the indirect effect as a whole rather than testing an isolated moderating effect on independent variablemediator relationship (Hayes, 2015).

In a first-stage autoregressive moderated-mediation model, the indirect effect of Time 1 predictor (T1-HPWS) on Time 


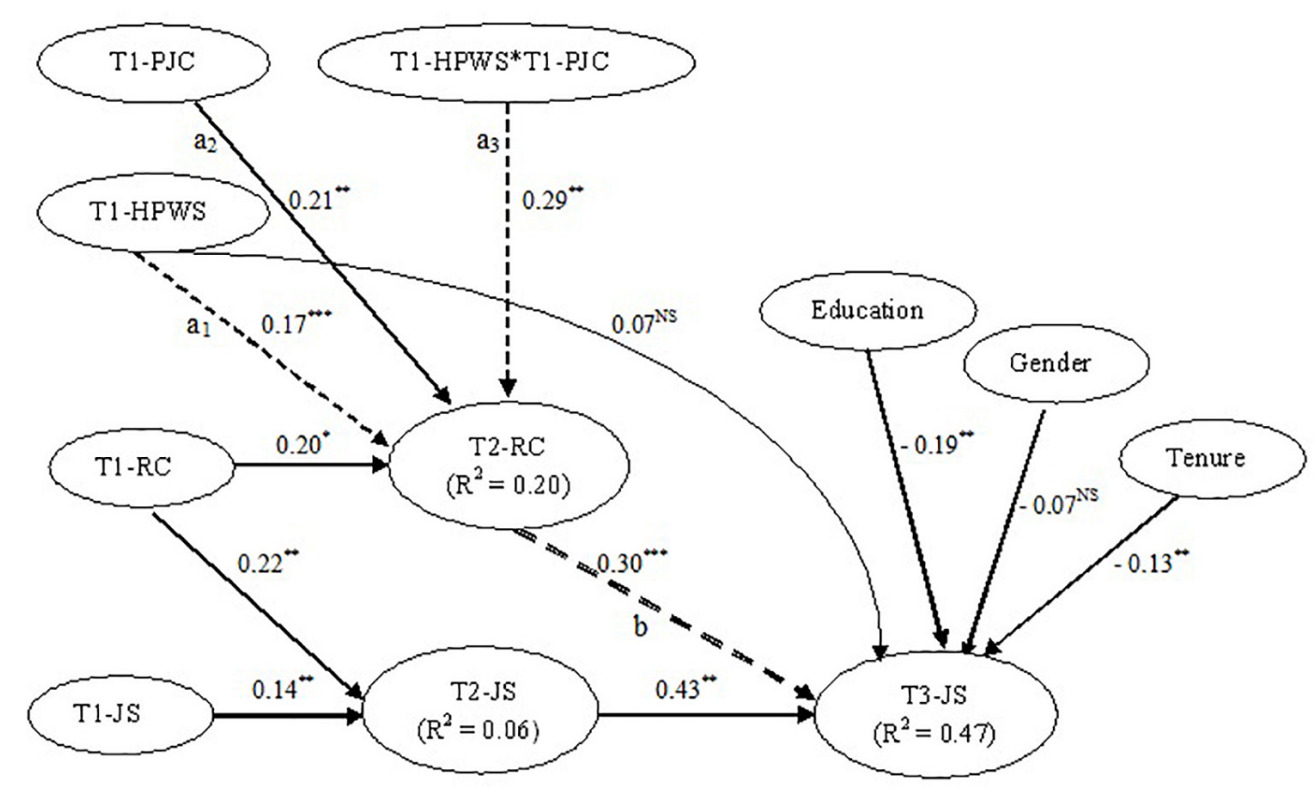

FIGURE 2 | Estimated PLS longitudinal moderated-mediation path models. T1, Time 1; T2, Time 2; T3, Time 3; HPWS, high-performance work systems; JS, job satisfaction; $\mathrm{RC}$, relational coordination; NS, non-significant. ${ }^{*} P<0.01 ;{ }^{*} P<0.05$.

3 outcome variable (job satisfaction: T3-JS) through Time 2 mediator (relational coordination: T2-RC) is the product of the conditional effect (i.e., T1-HPWS $\times$ T1-PJC) of Time 1 predictor (T1-HPWS) on Time 2 mediator (T2-RC), and the effect of Time 2 mediator (T2-RC) on Time 3 outcome variable (T3-JS). In other words, the product of path $\mathrm{a}_{3}$ and $\mathrm{b}$ in Figure 2 is the indirect effect in case of moderated mediation. This indirect effect (denoted as $\omega$ ) can be written as follows:

$$
\begin{aligned}
& \omega=\left(a_{1}+a_{3} \text { PJC }\right) b \\
& \omega=a_{1} b+a_{3} b \text { PJC }
\end{aligned}
$$

In the above equation, $a_{1} b$ is intercept, whereas $a_{3} b$ is slope. Based on Morgan-Lopez and MacKinnon (2006), Hayes (2015) calls $a_{3} b$ as "the index of moderated mediation," which "is a quantification of the effect of (moderator) on the indirect effect of (predictor) on (outcome variable) through (mediator)." This index is the product of two path coefficients ( $a_{3}$ and $b$ in Figure 2). Hayes (2015) states that a non-zero value of this index serves as a measure of moderated mediation and does not require "evidence of statistically significant interaction between any variable in the model and a putative moderator" (p. 3). In our model, the value of $a_{3} b(0.29 \times 0.30=0.09)$ is non-zero, which indicates that the indirect effect of HPWSs on employee job satisfaction, through relational coordination, is not independent of peer justice climate but, rather, depends on it.

A non-zero index of moderated mediation means that the indirect effect is systematically larger or smaller for some values of (moderator) than others (Hayes, 2015, p. 4). By using some arbitrary values for moderator (peer justice climate), one can obtain a visual representation of the linear function (shown in
Eq. 2). We used the arbitrary moderator values ranging from -5 to 5 (and the values of $\mathrm{a}_{1} \mathrm{~b}$ and $a_{3} b$ from Figure 2) in Eq. 2 and obtained the linear function relating peer justice climate to the indirect effect of HPWSs on employee job satisfaction, through relational coordination (Figure 3). The positive slope of this function shows that the indirect effect of HPWSs on employee job satisfaction, through relational coordination, seems to increase with increase in employees' perceptions of peer justice climate. The bootstrapping at 5,000 samples, in SmartPLS software, generated a biased corrected $95 \%$ bootstrap confidence interval (0.046-0.134) for the index of moderated mediation. This confidence interval has positive upper bound and does not include zero. Given that, it can be concluded that the indirect effect of HPWSs on employee job satisfaction, through relational coordination, is positively moderated by peer justice climate (supports Hypothesis 3).

\section{DISCUSSION}

The aim of this study was to provide an explanation for why HPWSs affect employee job satisfaction. We examined whether HPWSs influence job satisfaction by affecting the degree to which employees exhibit relational coordination and whether this coordination prompts job satisfaction. Consistent with existing research, the findings of this study provide support for the direct relationship between HPWSs and job satisfaction (Messersmith et al., 2011; García-Chas et al., 2016; Liu et al., 2016; Ogbonnaya and Valizade, 2018).

However, previous research on HPWS-job satisfaction relationship is dominated by the studies using cross-sectional design and informs little about the temporal effects of HPWSs 


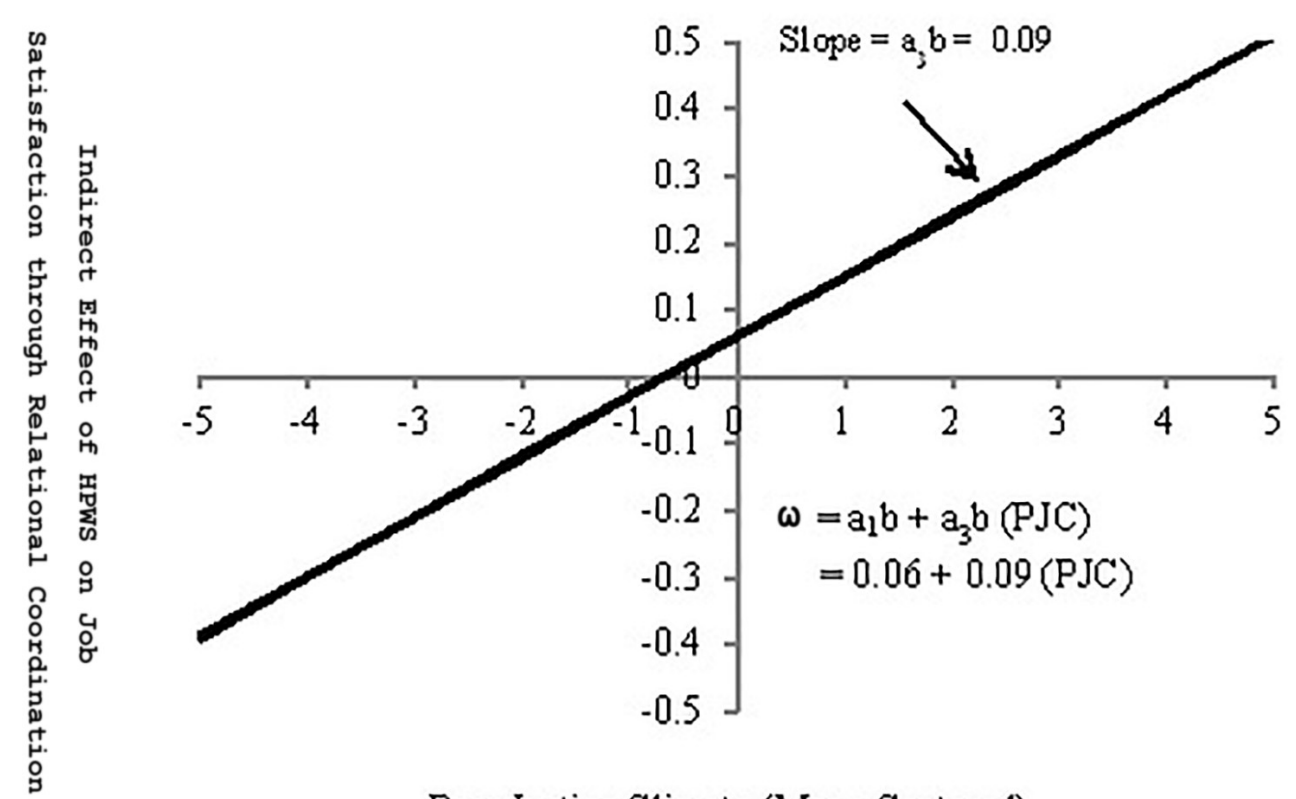

\section{Peer Justice Climate (Mean Centered)}

FIGURE 3 | Graphical representation of Eq. 2 at different values of peer justice climate.

on job satisfaction. Contrary to previous research, this study draws more accurate causal inferences by controlling for prior levels of job satisfaction and HPWSs in a longitudinal design. Given that, this study addresses the issue of scarce longitudinal research on the association between HPWSs and employee job satisfaction.

The results also provide support for the relationship between HPWSs and relational coordination. This finding is consistent with Gittell et al. (2010) and Riaz (2016), who found that high-performance work practices enhance relational coordination among employees. The longitudinal results also support the relationship between relational coordination and employee job satisfaction. This result is consistent with Gittell et al. (2008) and Margalina et al. (2014). Overall, the research on empirical examination of the aforementioned relationships is scarce. Moreover, previous research has used cross-sectional rather than longitudinal or experimental design and remains unable to draw true causal inferences. This study has addressed this issue.

An important aspect of this research is that it answered the question: Do HPWSs enhance relational coordination, and does increase in relational coordination lead to employee job satisfaction? By incorporating the mediating variable, we observed a strong support for a partially mediated model of the relationship between HPWSs and job satisfaction. Our research concludes that HPWSs themselves are less explicative in describing their effect on employee job satisfaction. Other mechanisms such as relational coordination can explain why HPWSs explain job satisfaction.

Previous research examined the mediating mechanisms between HPWS-job satisfaction relationship in cross-sectional study designs, which are not well suited to test mechanisms, that is, sets of causal effects (Cole and Maxwell, 2003; Maxwell and Cole, 2007). The use of longitudinal design has enabled us to determine true causal relationships in the mediation process. To our knowledge, this is the first longitudinal study examining the mediating effect of relational coordination in the relationship between HPWSs and employee job satisfaction.

The results of mediating hypothesis (Hypothesis 2) are in line with the Gittell et al.'s (2010) model of HPWSs and other theoretical insights provided while developing argument for this hypothesis. Empirical results confirm that HPWSs increase relational coordination among coworkers, and consequently, this increased relational coordination enhances their job satisfaction. By focusing on the mediating relationship, this study expands Gittell et al.'s (2008) and Gittell et al.'s (2010) work by confirming that HPWSs enhance relational coordination, and relational coordination enhances employee job satisfaction. However, our research is first in examining the effect of relational coordination as a mediating mechanism between HPWSs and job satisfaction.

Moreover, the results of Hypothesis 3 explain that the indirect effect of HPWSs on employee job satisfaction through relational coordination is moderated by peer justice climate. It suggests that the way coworkers treat each other affects how well they communicate and develop relationships in a work setting. Subsequently, it affects their job satisfaction. In other words, peer justice climate enhances fit between HPWSs and relational coordination as it provides a positive contingency in organizations. Although previous research has examined the moderating effect of justice climate on diverse relationships in organizations (Li et al., 2013), no previous study examined the 
moderating effect of peer justice climate on indirect effects. This study's examination of moderating effect on indirect relationship is important because the mediating mechanism such as relational coordination is likely to exert greater effect of employee job satisfaction as it receives greater effect of organizational policies (such as HPWSs) in the presence of peer justice climate.

There are some interesting findings about the effect of control variables on employee job satisfaction. We controlled for the level of education, gender, and tenure of the respondents and found negative effect of all these variables on job satisfaction. In existing literature, the relationship between education and job satisfaction is mix and inconclusive (González et al., 2016). In our research, the negative relationship between education and job satisfaction is consistent with existing research such as Clark et al. (1996); Gazioglu and Tansel (2006), Grund and Slivka (2001), Sloane and Williams (1996), Allen and Van der Velden (2001), while inconsistent with the findings of other research, which found a positive relationship between education and job satisfaction (Lydon and Chevalier, 2002; Nikolaou et al., 2005). As suggested by González et al. (2016), the negative effect in our study may be due to high expectations of highly qualified employees. We also found a negative (but insignificant) relationship between gender and job satisfaction. Consistent with existing research, this may be due to the fact that for an identical job men's expectation tends to be higher than women's (Clark, 1997). Regarding the effect of age on job satisfaction, previous research shows an increase in job satisfaction as age increases (Saleh and Otis, 1964). A recent study by Taiwo et al. (2017) shows that the level of job satisfaction decreases as respondents' age moves from 25 to 30 years. So, the negative relationship in our model is consistent with existing research because average age of our respondents is 28 years, which reflects a relatively young study sample.

\section{Theoretical Implications}

We believe that this study contributes to organizational behavior and human resource management literature in four ways. First, after a scholarly discussion on the effect of HPWSs on the dimensions of relational coordination and subsequent effect of these dimensions on employee job satisfaction, we provided theoretical reasoning as to why relational coordination mediates the relationship between HPWSs and job satisfaction. It is important because no previous research has developed such argument. Empirical examination of this mediating effect unfolds how HPWSs exert their effect of employee job satisfaction. In strategic HRM literature, one of the highly debated issues is to understand the mediating processes that explain why HPWSs affect employee and organizational outcomes (Buller and McEvoy, 2012; Agarwal and Farndale, 2017). Our analysis of mediating mechanism is a strong contribution in this debate. High-performance work systems are effective in enhancing employee job satisfaction because they provide employees with relational resources. This, in fact, draws researchers' attention toward the synergic effect of HPWSs on several mediators that, successively, affect employee and organizational outcomes (Delery and Doty, 1996; Agarwal and Farndale, 2017; BeltránMartín et al., 2017). Second, this study extends literature on the consequences of HPWSs by examining the boundary effect of peer justice climate on the aforementioned indirect relationship. Third, by testing the moderating effect of peer justice climate, this study has added in the scarce literature on the antecedents of relational coordination. Finally, this study has examined true causal relationships in a moderated-mediation model by using longitudinal rather than cross-sectional design.

\section{Practical Implications}

It is well recognized that human capital is a valuable source of competitive advantage. Besides human resource development, organizations need to retain these resources (Riaz, 2016). Satisfied employees are more likely to stay with the organization and perform better as they have greater organizational commitment (Whitener, 2001; Allen et al., 2003). This study's results suggest that organizations can achieve employee job satisfaction by implementing those practices that help foster relational coordination among coworkers. More specifically, managers' use of conflict resolution practice may hinder the situation of disrespect among coworkers. It is important because an environment of mutual respect promotes positive interactions among employees and, consequently, the job satisfaction (Trivellas et al., 2015). Overall, managers' use of meetings, rewards, and performance measurement can be effective in increasing communication, knowledge, and goal sharing among employees. Furthermore, the findings of this study suggest that managers should develop a climate of peer justice for achieving greater benefits from the application of high-performance work practices. In this regard, managers can help employees to improve peer justice climate by promoting dignity and respect and reducing biases among coworkers.

\section{Limitations and Future Research}

Despite its theoretical contribution and practical implications, our research does have some limitations. First, the issue of CMV may arise as the data were collected from a single source (Podsakoff et al., 2003). However, this bias can be controlled if longitudinal survey design is used (Malhotra et al., 2017). This study not only used a longitudinal design but also estimated the VIF to detect CMV. So, it is less likely that common method bias might have affected the results of this study. Future researchers can strengthen their findings by collecting data from multiple sources. Second, our sample was from the bank branches of Vehari district (Pakistan), and this context may be idiosyncratic enough to restrict the external viability of our results. Future studies can extend the findings of this research in other sectors and regions.

While theory and evidence support our research model, we cannot ignore other possible illustrations of our results. For instance, satisfied employees may be more likely to exhibit relational coordination and, consequently, may attain greater attention from management to participate in meetings and conflict resolution activities and receive rewards and positive performance appraisal. Because social exchanges are basic to relational coordination, we recognize that the process may be reciprocal. One recommendation for future scholars is to establish and examine a more comprehensive characterization 
of the viable antecedents of relational coordination and to also discover the level of mutual cause-effect relationship.

Despite these limitations, we surmise that we have reached the objective of this study. First, we provided an explication for why HPWSs may affect employee job satisfaction. The obvious process is that HPWSs influence the degree to which employees exhibit relational coordination, and this coordination prompts job satisfaction. Second, this study has also developed and supported the role of HPWSs and peer justice climate as antecedents of relational coordination. Although we did not test other predictors of relational coordination, it can be suggested that efforts to advance the use of HPWSs may be effective in conveying how an organization values and promotes employee relationships and job satisfaction.

\section{CONCLUSION}

This study concludes that HPWSs themselves are less explicative in describing their effect on employee job satisfaction. Other mechanisms such as relational coordination and peer justice climate can explain why and when HPWSs explain job satisfaction.

\section{REFERENCES}

Agarwal, P., and Farndale, E. (2017). High-performance work systems and creativity implementation: the role of psychological capital and psychological safety. Hum. Resour. Manag. J. 27, 440-458. doi: 10.1111/1748-8583. 12148

Allen, D. G., Shore, L. M., and Griffeth, R. W. (2003). The role of perceived organizational support and supportive human resource practices in the turnover process. J. Manag. 29, 99-118. doi: 10.1177/014920630302 900107

Allen, J., and Van der Velden, R. (2001). Educational mismatches versus skill mismatches: effects on wages, job satisfaction, and on-the-job search. Oxford Econ. Pap. 53, 434-452. doi: 10.1093/oep/53.3.434

Argyle, M. (1989). "Do happy workers work harder? The effect of job satisfaction on work performance," in How Harmful is Happiness?, ed. R. Veenhoven (The Netherlands: Universitaire Pers Rotterdam), 94-105.

Baron, R. M., and Kenny, D. A. (1986). The moderator-mediator variable distinction in social psychological research: conceptual, strategic, and statistical considerations. J. Pers. Soc. Psychol. 51, 1173-1182. doi: 10.1037/0022-3514.51. 6.1173

Beltrán-Martín, I., Bou-Llusar, J. C., Roca-Puig, V., and Escrig-Tena, A. B. (2017). The relationship between high performance work systems and employee proactive behaviour: role breadth self-efficacy and flexible role orientation as mediating mechanisms. Hum. Resour. Manag. J. 27, 403-422. doi: 10.1111/ 1748-8583.12145

Birdi, K., Clegg, C., Patterson, M., Robinson, A., Stride, C. B., Wall, T. D., et al. (2008). The impact of human resource and operational management practices on company productivity: a longitudinal study. Pers. Psychol. 61, 467-501. doi: $10.1111 / j .1744-6570.2008 .00136 . x$

Blau, P. M. (1964). Exchange and Power in Social Life. New York, NY: John Wiley and Sons.

Brinck, K., Otten, S., and Hauff, S. (2019). High-performance work practices and job satisfaction: gender's moderating role. Eur. Manag. Rev. 16, 333-345. doi: $10.1111 /$ emre. 12348

Brouer, R. L., Harris, K. J., and Kacmar, K. M. (2011). The moderating effects of political skill on the perceived politics-outcomes relationships. J. Organ. Behav. 32, 869-885. doi: 10.1002/job.718

\section{DATA AVAILABILITY STATEMENT}

The datasets used for this study are available on request to the corresponding author.

\section{ETHICS STATEMENT}

The study survey was initiated after having a written informed consent from the participants, and approval from the Ethical Committee for Scientific Research (ECSR) at COMSATS, Vehari.

\section{AUTHOR CONTRIBUTIONS}

$\mathrm{SH}$ initiated the basic idea and wrote the main part of the manuscript. CD-P-H built the article structure. MD-P-H improved the manuscript.

\section{ACKNOWLEDGMENTS}

The authors are thankful to the editor and the reviewers for their highly constructive feedback and exceptional service.

Buller, P. F., and McEvoy, G. M. (2012). Strategy, human resource management and performance: sharpening line of sight. Hum. Resour. Manag. R. 22, 43-56. doi: 10.1016/j.hrmr.2011.11.002

Carmeli, A., and Gittell, J. H. (2009). High-quality relationships, psychological safety, and learning from failures in work organizations. J. Organ. Behav. 30, 709-729. doi: 10.1002/job.565

Chen, T. J., Lin, C. C., and Wu, C. M. (2016). High performance work system, psychological efficacy, job satisfaction and task performance in the Hotel Workplace. Open J. Soc. Sci. 4, 76-81. doi: 10.4236/jss.2016.47012

Chen, X., Yu, B., Gong, J., Wang, P., and Elliott, A. L. (2018). Social capital associated with quality of life mediated by employment experiences: evidence from a random sample of rural-to-urban migrants in china. Soc. Indic. Res. 139, 327-346. doi: 10.1007/s11205-017-1617-1

Chun, J. S., Shin, Y., Choi, J. N., and Kim, M. S. (2013). How does corporate ethics contribute to firm financial performance? The mediating role of collective organizational commitment and organizational citizenship behavior. J. Manag. 39, 853-877. doi: $10.1177 / 0149206311419662$

Clark, A., Oswald, A., and Warr, P. (1996). Is job satisfaction U-shaped in age? J. Occup. Organ. Psych. 69, 57-81. doi: 10.1111/j.2044-8325.1996.tb00600.x

Clark, A. E. (1997). Job satisfaction and gender: why are women so happy at work? Lab. Econ. 4, 341-372.

Clarke, N., and Mahadi, N. (2017). The significance of mutual recognition respect in mediating the relationships between trait emotional intelligence, affective commitment and job satisfaction. Pers. Indiv. Differ. 105, 129-134. doi: 10.1016/ j.paid.2016.09.028

Cole, D. A., and Maxwell, S. E. (2003). Testing mediational models with longitudinal data: questions and tips in the use of structural equation modeling. J. Abnorm. Psychol. 112, 558-577. doi: 10.1037/0021-843X.112.4.558

Collins, C. J., and Clark, K. D. (2003). Strategic human resource practices, top management team social networks, and firm performance: the role of human resource practices in creating organizational competitive advantage. Acad. Manag. J. 46, 740-751. doi: 10.5465/30040665

Collins, L. M., Graham, J. J., and Flaherty, B. P. (1998). An alternative framework for defining mediation. Multivar. Behav. Res. 33, 295-312. doi: 10.1207/ s15327906mbr3302 5

Cooke, F. L., Cooper, B., Bartram, T., Wang, J., and Mei, H. (2019). Mapping the relationships between high-performance work systems, employee resilience and 
engagement: a study of the banking industry in China. Int. J. Hum. Resour. Man. 30, 1239-1260. doi: 10.1080/09585192.2015.1137618

Cropanzano, R., Anthony, E. L., Daniels, S. R., and Hall, A. V. (2017). Social exchange theory: a critical review with theoretical remedies. Acad. Manag. Ann. 11, 479-516. doi: 10.5465/annals.2015.0099

Cropanzano, R., Li, A., and Benson, I. I. I. L. (2011). Peer justice and teamwork process. Group Organ. Manag. 36, 567-596. doi: 10.1177/1059601111414561

Datta, D. K., Guthrie, J. P., and Wright, P. M. (2005). Human resource management and labor productivity: does industry matter? Acad. Manag. J. 48, 135-145. doi: 10.5465/amj.2005.15993158

Delery, J. E., and Doty, D. H. (1996). Modes of theorizing in strategic human resource management: tests of universalistic, contingency, and configurational performance predictions. Acad. Manag. J. 39, 802-835. doi: 10.2307/256713

Drazin, R., and Van de Ven, A. H. (1985). Alternative forms of fit in contingency theory. Admin. Sci. Quart. 1985, 514-539. doi: 10.2307/2392695

Edwards, J. R., and Lambert, L. S. (2007). Methods for integrating moderation and mediation: a general analytical framework using moderated path analysis. Psychol. Methods 12, 1-22. doi: 10.1037/1082-989X.12.1.1

Eisenberger, R., Cummings, J., Aemeli, S., and Lynch, P. (1997). Perceived organizational support, discretionary treatment, and job satisfaction. J. Appl. Psychol. 82, 812-820. doi: 10.1037/0021-9010.82.5.812

Evans, W. R., and Davis, W. D. (2005). High-performance work systems and organizational performance: the mediating role of internal social structure. J. Manag. 31, 758-775. doi: 10.1177/0149206305279370

Fornell, C., and Larcker, D. (1981). Evaluating structural equation models with unobservable variables and measurement error. J. Mark. Res. 18, 39-50. doi: $10.2307 / 3151312$

Fu, N., Bosak, J., Flood, P. C., and Ma, Q. (2019). Chinese and Irish professional service firms compared: linking HPWS, organizational coordination, and firm performance. J. Bus. Res. 95, 266-276. doi: 10.1016/j.jbusres.2018.08.021

García-Chas, R., Neira-Fontela, E., and Varela-Neira, C. (2016). High-performance work systems and job satisfaction: a multilevel model. J. Manag. Psychol. 31 , 451-466. doi: 10.1108/JMP-04-2013-0127

Garg, N. (2015). Organizational role stress in dual-career couples: mediating the relationship between HPWPs, employee engagement and job satisfaction. IUP J. Knowl. Manag. 13, 43-69.

Gazioglu, S., and Tansel, A. (2006). Job satisfaction in Britain: individual and job related factors. Appl. Econ. 38, 1163-1171. doi: 10.1080/00036840500392987

Gittell, J. H. (2000). Organizing work to support relational co-ordination. Int. J. Hum. Resour. Man. 11, 517-539. doi: 10.1080/095851900339747

Gittell, J. H. (2002). Relationships between service providers and their impact on customers. J. Serv. Res. US. 4, 299-311. doi: 10.1177/1094670502004004007

Gittell, J. H. (2006). "Relational coordination: coordinating work through relationships of shared goals, shared knowledge and mutual respect," in Relational Perspectives in Organizational Studies: A Research Companion, eds O. Kyriakidou and M. Ozbilgin (Cheltenham: Edward Elgar Publishers), 74-94. doi: 10.4337/9781781950548.00011

Gittell, J. H., Fairfield, K. M., Bierbaum, B., Head, W., Jackson, R., Kelly, M., et al. (2000). Impact of relational coordination on quality of care, postoperative pain and functioning, and length of stay: a nine-hospital study of surgical patients. Med. Care 38, 807-819. doi: 10.1097/00005650-200008000-00005

Gittell, J. H., Seidner, R., and Wimbush, J. (2010). A relational model of how highperformance work systems work. Organ. Sci. 21, 490-506. doi: 10.1287/orsc. 1090.0446

Gittell, J. H., Weinberg, D., Pfefferle, S., and Bishop, C. (2008). Impact of relational coordination on job satisfaction and quality outcomes: a study of nursing homes. Hum. Resour. Manag. J. 18, 154-170. doi: 10.1111/j.1748-8583.2007. 00063.x

Gong, Y., Chang, S., and Cheung, S. Y. (2010). High performance work system and collective OCB: a collective social exchange perspective. Hum. Resour. Manag. J. 20, 119-137. doi: 10.1111/j.1748-8583.2010.00123.x

González, F., Sánchez, S. M., and López-Guzmán, T. (2016). The effect of educational level on job satisfaction and organizational commitment: a case study in hospitality. Int. J. Hospital. Tour. Admin. 17, 243-259. doi: 10.1080/ 15256480.2016.1183547

Grund, C., and Slivka, D., (2001). The impact of wage increases on job satisfaction: Empirical evidence and theoretical implications. Bonn: IZA Discussion Papers, 387.
Guest, D. E. (1987). Human resource management and industrial relations. J. Manag. Stud. 24, 503-521. doi: 10.1111/j.1467-6486.1987.tb00460.x

Gustavson, K., Von Soest, T., Evalill Karevold, E., and Røysamb, E. (2012). Attrition and generalizability in longitudinal studies: findings from a 15-year populationbased study and a Monte Carlo simulation study. BMC Public Health 12:918. doi: 10.1186/1471-2458-12-918

Haider, S., Ahmed, M., Anwar, S., Aslam, M., and Asadullah, M. A. (2019a). Effect of relational coordination on employee turnover intentions through job satisfaction: the use of structural equation modeling and monte carlo simulation. ESIC Market 50, 19-42. doi: 10.7200/esicm.162.0501.1i

Haider, S., de Pablos Heredero, C., and Ahmed, M. (2019b). A three-wave time-lagged study of mediation between positive feedback and organizational citizenship behavior: the role of organization-based self-esteem. Psychol. Res. Behav. Manag. 12, 241-253. doi: 10.2147/PRBM.S192515

Haider, S., Fatima, N., and de Pablos-Heredero, C. (2020). A three-wave longitudinal study of moderated mediation between perceptions of politics and employee turnover intentions: the role of job anxiety and political skills. J. Work Organ. Psychol. doi: 10.5093/jwop2020a1 [Epub ahead of print]

Haider, S., Jabeen, S., and Ahmad, J. (2018). Moderated mediation between work life balance and employee job performance: the role of psychological wellbeing and satisfaction with coworkers. J. Work Organ. Psychol. 34, 29-37. doi: 10. 5093/jwop2018a4

Hair, J. F., Hult, G. T. M., Ringle, C. M., and Sarstedt, M. (2014). A Primer on Partial Least Squares Structural Equation Modeling (PLS-SEM). New York, NY: Sage publications.

Hair, J. F., Hult, G. T. M., Ringle, C. M., and Sarstedt, M. (2016). A Primer on Partial Least Squares Structural Equation Modeling (PLS-SEM). New York, NY: Sage publications.

Hall, A. T., Zinko, R., Perryman, A. A., and Ferris, G. R. (2009). Organizational citizenship behavior and reputation: mediators in the relationships between accountability and job performance and satisfaction. J. Leadersh. Org. Stud. 15, 381-392. doi: 10.1177/1548051809331504

Hayes, A. F. (2015). An index and test of linear moderated mediation. Multivar. Behav. Res. 50, 1-22. doi: 10.1080/00273171.2014.962683

Hayes, A. F. (2018). Partial, conditional, and moderated mediation: quantification, inference, and interpretation. Commun. Monogr. 85, 4-40. doi: 10.1080/ 03637751.2017.1352100

Heffernan, M., and Dundon, T. (2012). "Researching employee reactions to high performance work systems in the service sector: the role of organisational justice theory," in Proceedings of the 16th ILERA (IIRA) World Congress, Philadellphia, 1-24.

Hekman, D. R., Bigley, G. A., Steensma, H. K., and Hereford, J. F. (2009). Combined effects of organizational and professional identification on the reciprocity dynamic for professional employees. Acad. Manag. J. 52, 506-526. doi: 10.5465/amj.2009.41330897

Henseler, J., Ringle, C. M., and Sarstedt, M. (2015). A new criterion for assessing discriminant validity in variance-based structural equation modeling. J. Acad. Market. Sci. 43, 115-135. doi: 10.1007/s11747-014-0403-8

Heredero, C. D. P., Haider, S., and Martinez, A. G. (2015). Relational coordination as an indicator of teamwork quality: potential application to the success of e-learning at universities. Int. J. Emerg. Technol. Learn. 10, 4-8.

Heslin, P. A. (2009). Better than brainstorming? Potential contextual boundary conditions to brain writing for idea generation in organizations. J. Occup. Organ. Psychol. 82, 129-145. doi: 10.1348/096317908X285642

Jarvis, C. B., MacKenzie, S. B., and Podsakoff, P. M. (2003). A critical review of construct indicators and measurement model misspecification in marketing and consumer research. J. Consum. Res. 30, 199-218. doi: 10.1086/376806

Jiang, J. Y., and Liu, C. W. (2015). High performance work systems and organizational effectiveness: the mediating role of social capital. Hum. Resour. Manag. R. 25, 126-137. doi: 10.1016/j.hrmr.2014.09.001

Kianto, A., Vanhala, M., and Heilmann, P. (2016). The impact of knowledge management on job satisfaction. J. Knowl. Manag. 20, 621-636. doi: 10.1108/ JKM-10-2015-0398

Kock, N. (2015). Common method bias in PLS-SEM: a full collinearity assessment approach. Int. J. e Collabor. 11, 1-10. doi: 10.4018/ijec.2015100101

Kock, N., and Lynn, G. S. (2012). Lateral collinearity and misleading results in variance based SEM: an illustration and recommendations. J. Assoc. Inf. Syst. 13, 546-580. doi: 10.17705/1jais.00302 
Lawrence, P., and Chevalier, J. (1967). Organization and environment. Cambridge, MA: Harvard University Press.

Lee, C., Earley, P. C., Lituchy, T. R., and Wagner, M. (1991). Relation of goal setting and goal sharing to performance and conflict for interdependent tasks. Br. J. Manag. 2, 33-39. doi: 10.1111/j.1467-8551.1991.tb00013.x

Li, A., and Cropanzano, R. (2009). Fairness at the group level: justice climate and intraunit justice climate. J. Manag. 35, 564-599. doi: 10.1177/ 0149206308330557

Li, A., Cropanzano, R., and Bagger, J. (2013). Justice climate and peer justice climate: a closer look. Small Gr. Res. 44, 563-592. doi: 10.1177/ 1046496413498119

Liu, S., Ye, L., and Guo, M. (2016). "High-performance work systems and job satisfaction: mediation role of organizational identification," in Proceeding of the 2016 International Conference on Logistics, Informatics and Service Sciences (LISS), (Piscataway, NJ: IEEE), 1-5. doi: 10.1109/LISS.2016.7854378

Locke, E. A. (1976). "The nature and causes of job satisfaction," in Handbook of Industrial and Organizational Psychology (1st Ed.), M. D. Dunnette (Chicago, IL: Rand McNally), 1297-1349.

Lucas, R. E., and Diener, E. (2003). “The happy worker: hypotheses about the role of positive affect in worker productivity," in Personality and Work, eds M. Burrick and A. M. Ryan (San Francisco: JosseyBass), 30-59.

Lydon, R., and Chevalier, A. (2002). Estimates of the Effect of Wages on Job Satisfaction. London: London School of Economics and Political Science.

Malhotra, N. K., Schaller, T. K., and Patil, A. (2017). Common method variance in advertising research: when to be concerned and how to control for it. J. Advert. 46, 193-212. doi: 10.1080/00913367.2016.1252287

Margalina, V. M., de Pablos Heredero, C., Botella, J. L. M., and Martinez, A. R. G. (2014). The role of relational coordination in final teacher satisfaction in e-learning. Proc. Technol. 16, 365-375. doi: 10.1016/j.protcy.2014.10.102

Martinaityte, I., Sacramento, C., and Aryee, S. (2019). Delighting the customer: creativity-oriented high-performance work systems, frontline employee creative performance, and customer satisfaction. J. Manag. 45, 728-751. doi: $10.1177 / 0149206316672532$

Maxwell, S. E., and Cole, D. A. (2007). Bias in cross-sectional analyses of longitudinal mediation. Psychol. Methods 12, 23-44. doi: 10.1037/1082-989X. 12.1.23

Maxwell, S. E., Cole, D. A., and Mitchell, M. A. (2011). Bias in cross-sectional analyses of longitudinal mediation: partial and complete mediation under an autoregressive model. Multivar. Behav. Res. 46, 816-841. doi: 10.1080/ 00273171.2011 .606716

Messersmith, J. G., Patel, P. C., Lepak, D. P., and Gould-Williams, J. S. (2011). Unlocking the black box: exploring the link between high-performance work systems and performance. J. Appl. Psychol. 96, 1105-1118. doi: 10.1037/ a 0024710

Miller, R. B., and Wright, D. W. (1995). Detecting and correcting attrition bias in longitudinal family research. J. Marriage Fam. 57, 921-929. doi: 10.2307/ 353412

Molina, A., Moliner, C., Martínez-Tur, V., Cropanzano, R., and Peiró, J. M. (2016). Validating justice climate and peer justice in a real work setting. J. Work Organ. Psychol. 32, 191-205. doi: 10.1016/j.rpto.2016.09.002

Moqbel, M., and Kock, N. (2018). Unveiling the dark side of social networking sites: personal and work-related consequences of social networking site addiction. Inform. Manag. Amster 55, 109-119. doi: 10.1016/j.im.2017.05.001

Morgan-Lopez, A. A., and MacKinnon, D. P. (2006). Demonstration and evaluation of a method for assessing mediated moderation. Behav. Res. Methods 38, 77-87. doi: 10.3758/BF03192752

Mossholder, K. W., Richardson, H. A., and Settoon, R. P. (2011). Human resource systems and helping in organizations: a relational perspective. Acad. Manag. Rev. 36, 33-52. doi: 10.5465/amr.2009.0402

Muller, D., Judd, C. M., and Yzerbyt, V. Y. (2005). When moderation is mediated and mediation is moderated. J. Pers. Soc. Psychol. 89, 852-863. doi: 10.1037/ 0022-3514.89.6.852

Nikolaou, A., Theodossiou, I., and Vasileiou, E. G. (2005). "Does job security increase job satisfaction? A study of the European experience," in Proceedigs of the 2nd World Conference SOLE/EALE, European Association of Labour Economists, San Francisco.

Ogbonnaya, C., and Valizade, D. (2018). High performance work practices, employee outcomes and organizational performance: a 2-1-2 multilevel mediation analysis. Int. J. Hum. Resour. Manag. 29, 239-259. doi: 10.1080/ 09585192.2016.1146320

Piening, E. P., Baluch, A. M., and Salge, T. O. (2013). The relationship between employees' perceptions of human resource systems and organizational performance: examining mediating mechanisms and temporal dynamics. J. Appl. Psychol. 98, 926-947. doi: 10.1037/a0033925

Podsakoff, P. M., MacKenzie, S. B., Lee, J. Y., and Podsakoff, N. P. (2003). Common method biases in behavioral research: a critical review of the literature and recommended remedies. J. Appl. Psychol. 88, 879-903. doi: 10.1037/0021-9010. 88.5.879

Preacher, K. J., Rucker, D. D., and Hayes, A. F. (2007). Addressing moderated mediation hypotheses: theory, methods, and prescriptions. Multivar. Behav. Res. 42, 185-227. doi: 10.1080/00273170701341316

Requena, F. (2003). Social capital, satisfaction and quality of life in the workplace. Soc. Indic. Res. 61, 331-360. doi: 10.1023/A:1021923520951

Riaz, S. (2016). High performance work systems and organizational performance: an empirical study on manufacturing and service organizations in Pakistan. Public Organ. Rev. 16, 421-442. doi: 10.1007/s11115-015-0315-1

Ringle, C. M., Sarstedt, M., and Mooi, E. A. (2010). Response-Based Segmentation Using Finite Mixture Partial Least Squares. New York, NY: Springer US, 19-49. doi: 10.1007/978-1-4419-1280-0_2

Rucker, D. D., Preacher, K. J., Tormala, Z. L., and Petty, R. E. (2011). Mediation analysis in social psychology: current practices and new recommendations. Soc. Pers. Psychol. Compass. 5, 359-371. doi: 10.1111/j.1751-9004.2011. 00355.x

Saleh, S. D., and Otis, J. L. (1964). Age and level of job satisfaction. Person. Psychol. 17, 425-430. doi: 10.1111/j.1744-6570.1964.tb00077.x

Sherony, K. M., and Green, S. G. (2002). Coworker exchange: relationships between coworkers, leader-member exchange, and work attitudes. J. Appl. Psychol. 87, 542-548. doi: 10.1037/0021-9010.87.3.542

Shin, D., and Konrad, A. M. (2017). Causality between high-performance work systems and organizational performance. J Manag. 43, 973-997. doi: 10.1177/ 0149206314544746

Sloane, P. J., and Williams, H. (1996). Are "overpaid" workers really unhappy? a test of the theory of cognitive dissonance. Labour 10, 3-16. doi: 10.1111/labr. 1996.10.issue-1

Taiwo, S., Akin, O., Shola, O., and Akin, A. (2017). Modelling Job Satisfaction and Age Using a Composite Function of Gamma and Power Transformation Function. Int. J. Stat. Appl. 7, 107-112. doi: 10.5923/j.statistics.20170 702.05

Takeuchi, R., Lepak, D. P., Wang, H., and Takeuchi, K. (2007). An empirical examination of the mechanisms mediating between high-performance work systems and the performance of Japanese organizations. J. Appl. Psychol. 92, 1069-1083. doi: 10.1037/0021-9010.92.4.1069

Trivellas, P., Akrivouli, Z., Tsifora, E., and Tsoutsa, P. (2015). The impact of knowledge sharing culture on job satisfaction in accounting firms. The mediating effect of general competencies. Proc. Econ. Finan. 19, 238-247. doi: 10.1016/S2212-5671(15)00025-8

Turnipseed, D. L., and Rassuli, A. (2005). Performance perceptions of organizational citizenship behaviours at work: a bi-level study among managers and employees. Br. J. Manag. 16, 231-244. doi: 10.1111/j.1467-8551.2005. 00456.x

Janssen, O., and Van Yperen, N. W. (2004). Employees' goal orientations, the quality of leader-member exchange, and the outcomes of job performance and job satisfaction. Acad. Manag. J. 47, 368-384. doi: 10.2307/201 59587

Vogus, T. J. (2006). "What is it about relationships? A behavioral theory of social capital and performance," in Proceedings Of The Annual Meeting-Labor And Employment Relations Association, Vol. 58, (Illinois: Labor and Employment Relations Association), 164.

Walumbwa, F. O., Hartnell, C. A., and Misati, E. (2017). Does ethical leadership enhance group learning behavior? Examining the mediating influence of group ethical conduct, justice climate, and peer justice. J. Bus. Res. 72, 14-23. doi: 10.1016/j.jbusres.2016.11.013

Whitener, E. M. (2001). Do "high commitment" human resource practices affect employee commitment? A cross-level analysis using hierarchical linear modeling. J. Manag. 27, 515-535. doi: 10.1177/01492063010 2700502 
Wu, P. C., and Chaturvedi, S. (2009). The role of procedural justice and power distance in the relationship between high performance work systems and employee attitudes: a multilevel perspective. J. Manag. 35, 1228-1247. doi: $10.1177 / 0149206308331097$

Zhang, J., Akhtar, M. N., Bal, P. M., Zhang, Y., and Talat, U. (2018). How do high-performance work systems affect individual outcomes: a multilevel perspective. Front. Psychol. 9:586. doi: 10.3389/fpsyg.2018. 00586

Zhao, X., Lynch, J. G. Jr., and Chen, Q. (2010). Reconsidering Baron and Kenny: myths and truths about mediation analysis. J. Cons. Res. 37, 197-206. doi: $10.1086 / 651257$
Conflict of Interest: The authors declare that the research was conducted in the absence of any commercial or financial relationships that could be construed as a potential conflict of interest.

Copyright $\odot 2020$ Haider, De-Pablos-Heredero and De-Pablos-Heredero. This is an open-access article distributed under the terms of the Creative Commons Attribution License (CC BY). The use, distribution or reproduction in other forums is permitted, provided the original author(s) and the copyright owner(s) are credited and that the original publication in this journal is cited, in accordance with accepted academic practice. No use, distribution or reproduction is permitted which does not comply with these terms. 


\section{OPEN ACCESS}

Edited by:

Ana Jiménez-Zarco, Open University of Catalonia, Spain

Reviewed by:

Stefano Triberti,

University of Milan, Italy

Efrat Neter,

Ruppin Academic Center, Israel

${ }^{*}$ Correspondence:

Saskia M. Kelders

s.m.kelders@utwente.nl

Specialty section:

This article was submitted to

Organizational Psychology,

a section of the journal

Frontiers in Psychology

Received: 29 November 2019

Accepted: 14 April 2020

Published: 27 May 2020

Citation:

Kelders SM, van Zyl LE and Ludden GDS (2020) The Concept and Components of Engagement in Different Domains Applied to eHealth:

A Systematic Scoping Review.

Front. Psychol. 11:926

doi: 10.3389/fpsyg.2020.00926

\section{The Concept and Components of Engagement in Different Domains Applied to eHealth: A Systematic Scoping Review}

\author{
Saskia M. Kelders ${ }^{1,2 \star}$, Llewellyn Ellardus van $Z \mathrm{Zl}^{2,3,4,5}$ and Geke D. S. Ludden ${ }^{6}$ \\ ${ }^{1}$ Department of Psychology, Health and Technology, Centre for eHealth and Wellbeing Research, University of Twente, \\ Enschede, Netherlands, ${ }^{2}$ Optentia Research Focus Area, North-West University, Vanderbijlpark, South Africa, ${ }^{3}$ Department \\ of Industrial Engineering, University of Eindhoven, Eindhoven, Netherlands, ${ }^{4}$ Department of Human Resource Management, \\ University of Twente, Enschede, Netherlands, ${ }^{5}$ Institut für Psychologie, Goethe University, Frankfurt, Germany, ${ }^{6}$ Department \\ of Design, Production and Management, University of Twente, Enschede, Netherlands
}

Within the context of eHealth interventions, a shared understanding of what constitutes engagement in and with eHealth technologies is missing. A clearer understanding of engagement could provide a valuable starting point for guidelines relating to the design and development of eHealth technologies. Given the cross-disciplinary use of the term "engagement," investigating how engagement (and its components) is conceptualized in different domains could lead to determining common components that are deemed important for eHealth technological design. As such, the aim of this paper was 3-fold: (a) to investigate in which domains engagement features, (b) to determine what constitutes engagement in these different domains, and (c) to determine whether there are any common components that seem to be important. A comprehensive systematic scoping review of the existing literature was conducted in order to identify the domains in which engagement is used, to extract the associated definitions of engagement, and to identify the dimensionality or components thereof. A search of five bibliographic databases yielded 1,231 unique records. All titles, abstracts, and full texts were screened based on specific inclusion and exclusion criteria. This led to 69 articles being included for further analyses. The results showed that engagement is used in seven functional domains, categorized as follows: student $(n=18)$, customer $(n=12)$, health $(n=$ 11), society $(n=10)$, work $(n=9)$, digital $(n=8)$, and transdisciplinary $(n=1)$ domains. It seems that some domains are more mature regarding their conceptualization and theorizing on engagement than others. Further, engagement was found to be predominantly conceptualized as a multidimensional construct with three common components (behavior, cognition, and affective) shared between domains. Although engagement is prolifically used in different disciplines, it is evident that little shared consensus as to its conceptualization within and between domains exists. Despite this, engagement is foremost seen as a state of being engaged in/with something, which is part of, but should not be confused with, the process of engagement. Behavior, cognition, and affect are important components of engagement and should be specified for each new context.

Keywords: engagement, eHealth, mHealth, systematic scoping review, positive organizational e-interventions 


\section{INTRODUCTION}

Developing scalable, cost-effective, and efficient technological solutions to enhance the general health and well-being of individuals has become vital within today's digital economy (Stander and van Zyl, 2019). Positive organizational interventions that focus on harnessing and improving individuals' strengths to increase employees' well-being, and organizational outcomes are examples that have begun to gain more attention (Winslow et al., 2017; Salanova and Ortega-Maldonado, 2019). Designing these types of solutions requires designers to ensure that technological interventions (such as health apps and web-based platforms) not only are effective and usable but also have the potential to actively immerse consumers and users in its content (Couper et al., 2010). If individuals are able to actively engage with such technologically driven interventions, they could potentially reap all the associated physical and psychological health benefits that it may bring. However, it has been shown and argued that technologically driven interventions often do not fully engage people, thereby limiting the effectiveness thereof (Christensen et al., 2009; Donkin et al., 2011; Kelders et al., 2012; Perski et al., 2017). Designing engaging technological interventions is therefore a crucial success factor to consider. Although there is considerable agreement in the literature in support of this argument, as well as the benefits that engagement yields, little consensus exits with regard to what engagement is and how it should be conceptualized.

In eHealth, the use of technology to support health and wellbeing, a much-documented issue related to a lack of engagement, is non-adherence. Often, people who use an eHealth solution do not use the offered technology the way in which the developers intended; this is what researchers refer to as non-adherence (Christensen et al., 2009; Kelders et al., 2012). Examples are participants not completing all lessons within an eMental health intervention, or not using all of the functions within a diabetes management system. Research has shown that there is a doseresponse relationship: for people who use a technology more, the positive effects are greater (Donkin et al., 2011; Yeager et al., 2018). However, not all eHealth interventions show this relationship, and it has been argued that this has to do with the way adherence is conceptualized. The assumption that increased frequency of use equates to "better results" does not necessarily ring true (Sieverink et al., 2017; Kelders, 2019). Also, it seems that the reasons why people choose to use an intervention might be more important than the frequency or duration of its use. Research shows that when users feel involved in, or are able to identify with the intervention, the effects may be larger (Donkin and Glozier, 2012; Kelders, 2015). Similarly, a review on engagement in digital health interventions described engagement as the extent of usage and a subjective experience characterized by attention, interest, and affect (Perski et al., 2017). This definition clearly describes engagement to be more than only usage of a system. However, the majority of articles included in that review only viewed engagement in behavioral terms, that is, as usage. This call to see and measure engagement not (just) through usage data is shared by more researchers (Yardley et al., 2016; Short et al., 2018) not only within the field of eHealth technologies (O'Brien and Toms, 2008; Doherty and Doherty, 2018).

It is important to note here that both the content and the design (the way the content is delivered) of the intervention may influence users' level of engagement or adherence. The design of a technological solution, its aesthetics, functionality, and behavior, is an important precursor to individuals' engagement, because such actively influences their experience of - their emotional connection to-and the behavior directed toward the intervention (Desmet and Hekkert, 2007; Ludden et al., 2012; Niedderer et al., 2017). When controlling for intervention content, providing users with a highly immersive, personalized intervention experience seems to be more effective in enhancing outcomes than providing them with static, linear, and unengaging content (Couper et al., 2010; Kelders et al., 2018). In other words, the design of a technologically driven intervention strongly influences how it is perceived, how it is employed, and how effective it will eventually be (Ludden et al., 2015; Kelders, 2019). Given the importance that the design of a technological solution poses for both engagement and adherence, it is not surprising that it has become a centrally debated topic within the domains of Interaction Design and Human Computer Interaction in recent years (Doherty and Doherty, 2018). Researchers from these fields actively advocate for the design of highly engaging and immersive user experiences in order to enhance utilization and manage non-adherence. However, despite its relative importance, there is still no generally accepted model or theory on how design influences engagement. Overbeeke and colleagues (Overbeeke et al., 2004), for example, stated that engagement in interaction should be reinstated by a focus on the physicality of the product. In their line of reasoning, the aesthetics of interaction (the sensory pleasure that people experience through interaction) play an important role in engrossing individuals within the interaction. In contrast, Gulotta and colleagues (Gulotta et al., 2016) argued that the active use of a technologically driven intervention is a function of an alignment between an individual's desire for and ability to achieve a specific outcome with said system. Here, the alignment between the personal characteristics of the user and the nature of the design seems to be an important factor for engagement. These types of inconsistencies in the literature result in confusion as to how intervention platforms should be designed in order to enhance engagement.

It is therefore clear that despite the agreement among all disciplines from which eHealth intervention research draws as to the importance of engagement, a commonly shared conceptualization of such is lacking. As engagement is a broad concept that has been used in many domains, it seems useful to look at how other domains define and use engagement in order to capitalize on such within eHealth intervention design. Whereas in eHealth the discussion on what engagement constitutes is just emerging, other domains have a rich tradition in studying engagement [e.g., patient engagement (Carman et al., 2013) and work engagement (Bakker et al., 2008)]. Important discussions in these domains are, for example, whether engagement should be seen as a process (getting and remaining engaged and/or disengaged) or a state (of being engaged) (Sonnentag, 2017). 
In these domains, engagement is seen as a multidimensional construct consisting of multiple components (Graffigna, 2017), mirroring trends within eHealth research that engagement is more than just "usage." Insight in what these components are in other domains might be a particularly timely step forward to better understand engagement in eHealth technologies. A better understanding of engagement in and with eHealth technologies can provide a much necessary starting point for guidelines for the design and development of eHealth technology.

As such, the aim of this systematic scoping review is to gain a better understanding of in what domains the concept of engagement features and what constitutes engagement in these different domains and to determine whether there are any common components that seem to be important. This systematic scoping review will focus on all domains where engagement is used as a concept, providing that engagement means something more than only using or doing something (e.g., engaging in warfare). Focus will be on which components of engagement are commonly identified and how such can be translated into eHealth intervention research.

\section{METHODS}

\section{Research Approach}

In order to determine how engagement is conceptualized, and to determine the global factors underpinning such, a systematic scoping review was conducted in line with existing guidelines (Peters et al., 2015). A systematic scoping review was deemed the appropriate method because of its focus on mapping the concept of engagement (Arksey and O'Malley, 2005). This approach is particularly useful to synthesize and summarize knowledge about an objective in question that exhibits a high level of heterogeneity and complexity that spans disciplines (Horsley, 2019).

\section{Search Strategy}

A comprehensive, systematic literature search was conducted between August 2018 and January 2019 in the following bibliographic databases: Scopus, Web of Science, Science Direct, PsycINFO, and ACM Digital Library. The databases were queried with a combination of the terms "engagement" AND "concept OR theory OR definition" occurring in the title of published, peer-reviewed articles. The last run was conducted on 18 January 2019. With the use of this search string, 2,143 titles were identified from 1994 up until 2018 (see Figure 1 for the flow diagram of article selection).

\section{Eligibility Criteria}

This review aimed to identify peer-reviewed academic articles (seminal works) that aimed to provide a definition, conceptualization, or theory of engagement, within any discipline. Only academic peer-reviewed scientific papers and conference proceedings that were published in English were eligible for inclusion in this study. Exclusion criteria were as follows:

(1) Papers that only focused on antecedents or consequences of engagement and did not include a focus on the concept of engagement itself, for example, papers that solely aimed to explain or predict engagement (e.g., trust and usability) or focus on factors that resulted from engagement (e.g., enhanced performance), which did not specifically focus on conceptualizing engagement itself. This exclusion criterion was deemed relevant because of the large number of studies that focus solely on antecedents and consequences but do not provide any (new) information on the concept of engagement itself. Studies that state that they (also) focus on the concept of engagement were not excluded.

(2) Papers that solely used the concept of engagement as a metric or as part of a larger empirical model, for example, papers aimed at using engagement as a factor in a structural model. This exclusion criterion was deemed relevant because of the large number of studies that only used a measure of engagement as part of a larger empirical model, while not providing additional information on the concept of engagement itself.

(3) Papers that only employed engagement as a synonym for another term or to indicate action (e.g., interaction with the press and engagement in warfare).

(4) Unpublished masters or doctoral theses.

(5) Textbooks and book chapters were also excluded, because many textbooks and book chapters provide more of an overview of earlier work than new insights as original research papers do, and not all textbooks and book chapters are peer reviewed.

\section{Study Selection}

Study selection was done in two steps. First, after duplicates were removed, the titles and abstracts of all retrieved articles were screened for eligibility by two authors (SK and LvZ or GL). Next, the full text of all remaining publications was checked for inclusion by two authors (SK and LvZ or GL). Disagreements on the inclusion or exclusion of publications were discussed until agreement was reached. The average percentage of agreement between authors was approximately $90 \%$, which is higher than the suggested $70 \%$ overlap (Booth et al., 2012). To check whether seminal works had been overlooked during the initial search process, included papers were checked whether they referred to any important publications that were not yet included.

\section{Data Extraction}

The characteristics of all included studies were extracted by one author (SK). Data extraction of $20 \%$ of the included studies $(n=14)$ was validated by the other authors. Data items that were extracted from each included study were country of origin, year of publication, type and subtype of engagement, purpose of the study, used methods, and main findings. Furthermore, for each included paper, the definition of engagement used was extracted. Here, it is was indicated whether this was a process definition (i.e., a definition about the process of getting and remaining engaged and/or disengaged); whether the definition was newly developed or already existing; or if no specific definition was chosen or if the definition was unclear. Lastly, whether engagement was said to consist of multiple components, and what these components were, was extracted. 


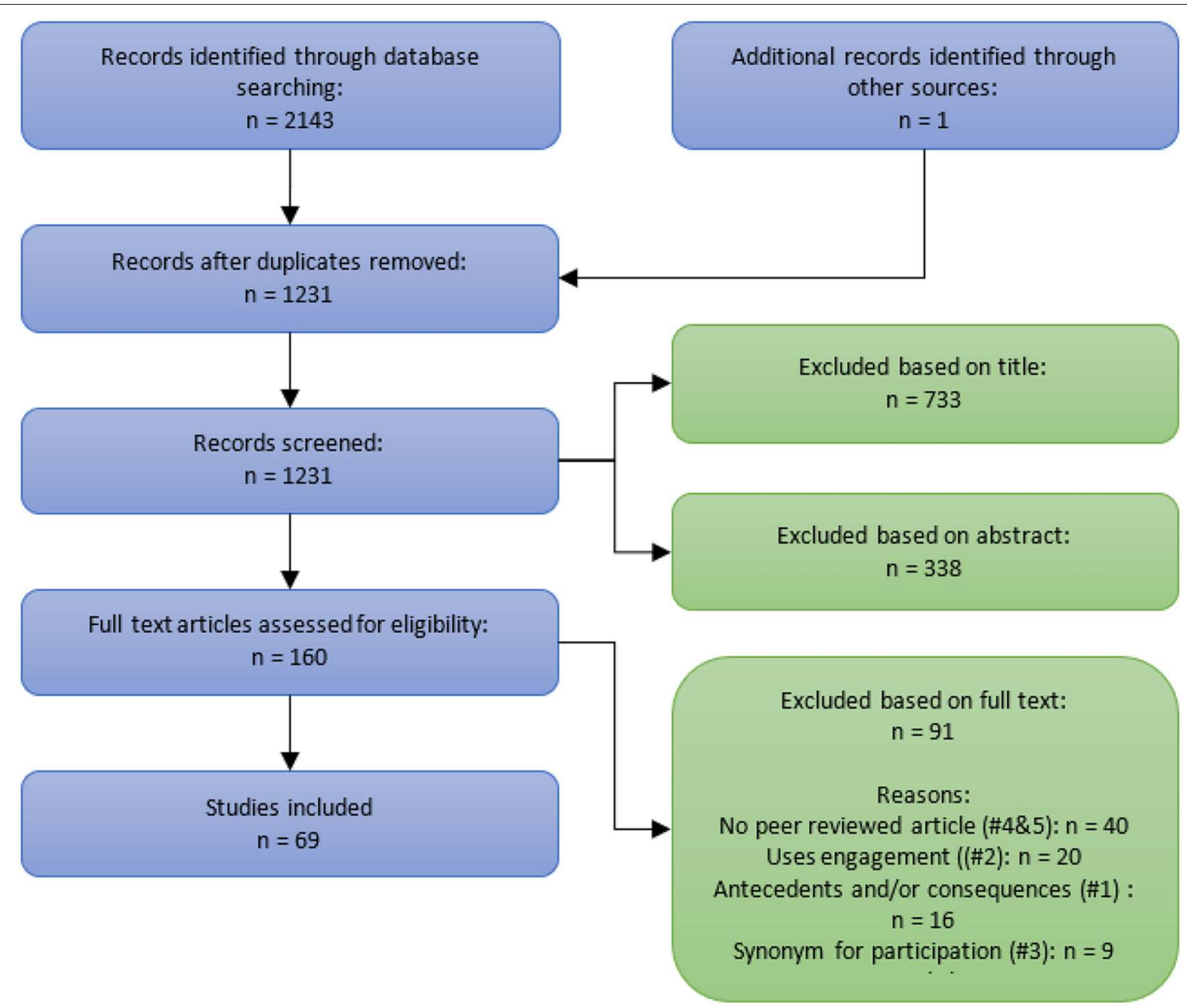

FIGURE 1 | Flowchart of article selection.

\section{RESULTS}

\section{Study Selection}

The search yielded 1,231 unique titles after duplicates were removed. After title, abstract, and full text screening, 69 articles were included (Figure 1). In total, 91 titles were excluded based on the full text. The most common reason for exclusion was that the titles were not peer-reviewed articles $(n=40)$. Of these, many were book chapters that are often not peer-reviewed and/or provide more of a summary of earlier work than new studies. Twenty titles were excluded because they included the concept of engagement in the title, but the study was not concerned with engagement itself and therefore did not provide any new insights on the concept or definition. Another 16 articles were excluded because they focused on antecedents or consequences of engagement, but not on the concept itself. Although these papers are interesting, they were excluded from this review because the focus is on what constitutes engagement and not on antecedents or consequences. Nine publications were excluded because in the full texts it became clear that engagement was not used as a concept in itself but only as a synonym for participation, involvement, or to action something specific. Lastly, six studies were excluded because the full texts were not in English.

\section{Characteristics of Included Studies}

In total, 69 papers published from 1990 up until 2018 were included. Publications were sparse from 1990 until 2007 (a total of $n=7$ ); however, it increased substantially afterwards, with a peak in $2017(n=14)$. Almost half of the publications emanated from the USA $(n=31), 21$ publications originated from Europe, 10 from Australia and New Zealand, and three from Canada and the others ranging from United Arab Emirates to Japan. We categorized the papers into seven domains of engagement: student $(n=18)$, customer $(n=12)$, health $(n=11)$, society $(n=10)$, work $(n=9)$, digital $(n=8)$, and transdisciplinary $(n=1)$. Each category is discussed below. For each category, the characteristics of the studies are provided in a separate table. All definitions used in the different studies are provided in Appendix 1. 
TABLE 1 | Characteristics and findings of student engagement studies.

\begin{tabular}{|c|c|c|c|c|}
\hline Study and subtype & Purpose & Method & Main findings & Definition and components \\
\hline $\begin{array}{l}\text { (Appleton et al., 2008); } \\
\text { student }\end{array}$ & Analyze concept & Discuss literature & Need for consensus and clarity & $\begin{array}{l}\text { None chosen; behavioral, } \\
\text { affective/emotional, psychological, } \\
\text { cognitive, academic }\end{array}$ \\
\hline $\begin{array}{l}\text { (Barkaoui et al., 2015); } \\
\text { student }\end{array}$ & $\begin{array}{l}\text { Stakeholder perspective of } \\
\text { concept }\end{array}$ & Qual. & $\begin{array}{l}\text { Need for contextualization, } \\
\text { antecedents explored }\end{array}$ & None chosen \\
\hline $\begin{array}{l}\text { (Bernard, 2015); } \\
\text { student }\end{array}$ & Analyze concept & Systematic review & Lack of clarity and consensus & $\begin{array}{l}\text { New (process); behavioral, cognitive, } \\
\text { emotional }\end{array}$ \\
\hline $\begin{array}{l}\text { (Burch et al., 2015); } \\
\text { student }\end{array}$ & $\begin{array}{l}\text { Propose concept }+ \text { test } \\
\text { scale }\end{array}$ & Quant. & Model of scale confirmed & $\begin{array}{l}\text { New; emotional, physical, cognitive in } \\
\text { class, cognitive out of class }\end{array}$ \\
\hline $\begin{array}{l}\text { (Ciric and Jovanovic, } \\
\text { 2016); student }\end{array}$ & Analyze concept & Discuss literature & $\begin{array}{l}\text { Concept is dynamic, malleable, } \\
\text { multidimensional, and interrelated }\end{array}$ & $\begin{array}{l}\text { Existing; emotional, cognitive, } \\
\text { behavioral }\end{array}$ \\
\hline $\begin{array}{l}\text { (Fredricks et al., 2004); } \\
\text { school }\end{array}$ & Analyze concept & Discuss literature & $\begin{array}{l}\text { Richer characterizations of } \\
\text { components are needed }\end{array}$ & $\begin{array}{l}\text { Existing; behavioral, emotional, } \\
\text { cognitive }\end{array}$ \\
\hline (Harris, 2008); student & $\begin{array}{l}\text { Stakeholder perspective of } \\
\text { concept }\end{array}$ & Qual. & $\begin{array}{l}\text { Six different ways of understanding } \\
\text { student engagement were found }\end{array}$ & $\begin{array}{l}\text { Unclear; behavioral, psychological, } \\
\text { cognitive }\end{array}$ \\
\hline (Harris, 2011); student & $\begin{array}{l}\text { Stakeholder perspective of } \\
\text { concept }\end{array}$ & Qual. & $\begin{array}{l}\text { Six different ways of understanding } \\
\text { student engagement were found }+ \\
\text { three ways of facilitating engagement }\end{array}$ & $\begin{array}{l}\text { Unclear; behavioral, psychological, } \\
\text { cognitive }\end{array}$ \\
\hline $\begin{array}{l}\text { (Hollingshead et al., } \\
\text { 2018); student }\end{array}$ & $\begin{array}{l}\text { Stakeholder perspective of } \\
\text { (components of) concept }\end{array}$ & Qual. & $\begin{array}{l}\text { Importance of and insight in } \\
\text { components for specific target group }\end{array}$ & Existing; behavior, cognition, affect \\
\hline $\begin{array}{l}\text { (Jimerson et al., 2003); } \\
\text { school }\end{array}$ & $\begin{array}{l}\text { Analyze concept + } \\
\text { measures }\end{array}$ & Systematic review & $\begin{array}{l}\text { Many terms and measurements used; } \\
\text { items classified in contexts }\end{array}$ & New; affective, behavioral, cognitive \\
\hline $\begin{array}{l}\text { (Lawson and Lawson, } \\
\text { 2013); student }\end{array}$ & Analyze concept & Discuss literature & $\begin{array}{l}\text { New definition as a system of } \\
\text { constructs and a process }\end{array}$ & New (process) \\
\hline $\begin{array}{l}\text { (Liem and Martin, } \\
\text { 2012); student }\end{array}$ & $\begin{array}{l}\text { Describe and discuss } \\
\text { concept }+ \text { measurement }\end{array}$ & Discuss literature & $\begin{array}{l}\text { Scale is a meaningful contribution to } \\
\text { research and practice }\end{array}$ & $\begin{array}{l}\text { Existing; adaptive cognition, adaptive } \\
\text { behavior, maladaptive cognition, } \\
\text { maladaptive behavior }\end{array}$ \\
\hline $\begin{array}{l}\text { (Montenegro, 2017); } \\
\text { agentic }\end{array}$ & Analyze concept & Discuss literature & $\begin{array}{l}\text { Agentic engagement is a consistent } \\
\text { researchable field }\end{array}$ & $\begin{array}{l}\text { Existing; agentic, (behavior, cognition, } \\
\text { emotion) }\end{array}$ \\
\hline (Reeve, 2013); agentic & $\begin{array}{l}\text { Introduce concept }+ \\
\text { measurement }\end{array}$ & Quant. & $\begin{array}{l}\text { Agentic engagement scale was } \\
\text { developed and tested }\end{array}$ & $\begin{array}{l}\text { Existing; agentic, (behavior, cognition, } \\
\text { emotion) }\end{array}$ \\
\hline $\begin{array}{l}\text { (Schuetz, 2008); } \\
\text { student }\end{array}$ & $\begin{array}{l}\text { Develop and test new } \\
\text { conceptual model }\end{array}$ & Qual. + quant. & Model and scale confirmed & $\begin{array}{l}\text { Existing; interest, mindfulness, } \\
\text { cognitive effort, deep processing of } \\
\text { new information }\end{array}$ \\
\hline $\begin{array}{l}\text { (Skinner et al., 2009); } \\
\text { academic }\end{array}$ & New conceptualization & $\begin{array}{l}\text { Discuss literature } \\
+ \text { quant. }\end{array}$ & Scale developed and tested & New; behavioral, emotional \\
\hline $\begin{array}{l}\text { (Unrau and Quirk, } \\
\text { 2014); reading }\end{array}$ & Analyze concept & Discuss literature & $\begin{array}{l}\text { Concept is often blurred; constructs } \\
\text { clarified }\end{array}$ & $\begin{array}{l}\text { New; affective, individual } \\
\text { participation, cognitive }\end{array}$ \\
\hline $\begin{array}{l}\text { (Wang et al., 2019); } \\
\text { school }\end{array}$ & $\begin{array}{l}\text { Analyze concept + develop } \\
\text { and validate scale }\end{array}$ & $\begin{array}{l}\text { Discuss literature } \\
+ \text { qual. + quant. }\end{array}$ & $\begin{array}{l}\text { Scale developed and tested; aspects } \\
\text { confirmed }\end{array}$ & New; behavioral, emotional, cognitive \\
\hline
\end{tabular}

\section{Student Engagement}

Table 1 shows the characteristics of the 18 studies classified as student engagement. Of these studies, 11 used the term student engagement, and three focused on school engagement, two on agentic engagement (as a component of student engagement), one on reading engagement, and one on academic engagement. Eleven studies analyzed the concept of engagement by discussing or reviewing literature. Four studies focused on developing and testing a scale to measure engagement, using both qualitative and quantitative methods. Three studies used qualitative methods to investigate a stakeholder perspective of the concept and its components. Eight studies used one or more existing definitions of engagement for their study and aimed to get more insight in this definition, whereas seven studies resulted in a new definition. In three studies,

it was unclear what definition of engagement the authors have used.

Looking at the components of engagement in this category, there seems to be some consensus: 11 studies mentioned behavior (or physical), affect (or emotion), and cognition as components of engagement. However, within these studies, there is much discussion on what exactly these components entail. Another five studies mention two of these components, or suggest other components besides behavior, affect and cognition, for example, agentic engagement. The last study also identifies cognition (cognitive effort) and adds other components as interest and mindfulness. Furthermore, two studies explicitly mention that the opposite of engagement (termed disengagement or disaffection) is also a construct that needs to be conceptualized (Skinner et al., 2009; Wang et al., 2019). Lastly, multiple 
TABLE 2 | Characteristics and findings of customer engagement studies.

\begin{tabular}{|c|c|c|c|c|}
\hline Study and subtype & Purpose & Method & Main findings & Definition and components \\
\hline $\begin{array}{l}\text { (Abdul-Ghani et al., } \\
\text { 2018); consumer }\end{array}$ & $\begin{array}{l}\text { Apply to specific area }+ \\
\text { stakeholder perspective }\end{array}$ & Qual. & $\begin{array}{l}\text { Conceptual framework with } \\
\text { engagement cycle in } \mathrm{C} 2 \mathrm{C} \text { contexts }\end{array}$ & $\begin{array}{l}\text { New; cognitive, affective, self-image, } \\
\text { motivation }\end{array}$ \\
\hline $\begin{array}{l}\text { (Bowden, 2014); } \\
\text { customer }\end{array}$ & Analyze concept & Discuss literature & $\begin{array}{l}\text { Conceptual framework with } \\
\text { antecedents and consequences }\end{array}$ & New (process) \\
\hline $\begin{array}{l}\text { (Brodie et al., 2011); } \\
\text { customer }\end{array}$ & Analyze concept & $\begin{array}{l}\text { Discuss literature } \\
+ \text { qual. }\end{array}$ & $\begin{array}{l}\text { New conceptualization and } \\
\text { fundamental propositions }\end{array}$ & New; cognitive, emotional, behavioral \\
\hline $\begin{array}{l}\text { (Dhanesh, 2017); } \\
\text { customer }\end{array}$ & Analyze concept & Discuss literature & $\begin{array}{l}\text { Need for broader definition; } \\
\text { importance of certain (new) aspects }\end{array}$ & New; affective, cognitive, behavioral \\
\hline $\begin{array}{l}\text { (Graffigna and } \\
\text { Gambetti, 2015); } \\
\text { consumer brand }\end{array}$ & Analyze concept & Qual. & $\begin{array}{l}\text { Identify concepts and process as } \\
\text { experienced by customers }\end{array}$ & $\begin{array}{l}\text { New (process); cognitive, affective, } \\
\text { behavioral }\end{array}$ \\
\hline $\begin{array}{l}\text { (Hollebeek, 2011); } \\
\text { customer brand }\end{array}$ & $\begin{array}{l}\text { Analyze concept + new } \\
\text { conceptualization }\end{array}$ & $\begin{array}{l}\text { Discuss literature } \\
+ \text { qual. }\end{array}$ & $\begin{array}{l}\text { New definition and key themes } \\
\text { (immersion, passion and activation) }\end{array}$ & New; cognitive, emotional, behavioral \\
\hline $\begin{array}{l}\text { (Hollebeek et al., 2014); } \\
\text { consumer brand }\end{array}$ & $\begin{array}{l}\text { Evaluate concept }+ \text { develop } \\
\text { and validate scale }\end{array}$ & Qual. + quant. & $\begin{array}{l}\text { Confirm concept; antecedents and } \\
\text { consequences; scale validation }\end{array}$ & $\begin{array}{l}\text { Existing; cognitive processing, } \\
\text { affection, activation }\end{array}$ \\
\hline $\begin{array}{l}\text { (Kulta and Karjaluoto, } \\
\text { 2016); mobile customer }\end{array}$ & $\begin{array}{l}\text { Analyze concept in specific } \\
\text { area }\end{array}$ & Systematic review & $\begin{array}{l}\text { Two different conceptualizations } \\
\text { (behavioral activity or holistic) }\end{array}$ & New; behavior, cognition, emotion \\
\hline $\begin{array}{l}\text { (Mittler et al., 2013); } \\
\text { consumer }\end{array}$ & $\begin{array}{l}\text { Apply to specific area }+ \\
\text { propose framework }\end{array}$ & $\begin{array}{l}\text { Systematic review } \\
+ \text { case }\end{array}$ & $\begin{array}{l}\text { Conceptual framework to classify } \\
\text { engagement programs }\end{array}$ & New; activation, engaged behaviors \\
\hline $\begin{array}{l}\text { (Solem and Pedersen, } \\
\text { 2016); Customer brand }\end{array}$ & $\begin{array}{l}\text { Analyze concept + develop } \\
\text { and test scale }\end{array}$ & $\begin{array}{l}\text { Discuss literature } \\
+ \text { quant. }\end{array}$ & $\begin{array}{l}\text { Components confirmed; antecedents } \\
\text { and consequences }\end{array}$ & New; physical, emotional, cognitive \\
\hline $\begin{array}{l}\text { (Tan and Apisit-Isariyah, } \\
\text { 2018); brand } \\
\text { community }\end{array}$ & $\begin{array}{l}\text { Analyze concept }+ \text { develop } \\
\text { model }\end{array}$ & $\begin{array}{l}\text { Discuss literature } \\
+ \text { qual. }\end{array}$ & $\begin{array}{l}\text { Typology and model with } \\
\text { characteristics, antecedents and } \\
\text { consequences }\end{array}$ & $\begin{array}{l}\text { Unclear; cognitive, affective, } \\
\text { behavioral, agentic/emphatic, } \\
\text { para-social }\end{array}$ \\
\hline $\begin{array}{l}\text { (Yoshida et al., 2014); } \\
\text { fan }\end{array}$ & $\begin{array}{l}\text { Analyze concept in specific } \\
\text { area + validate new scale }\end{array}$ & Quant. & $\begin{array}{l}\text { Components confirmed; antecedents } \\
\text { and consequences }\end{array}$ & $\begin{array}{l}\text { New; management cooperation, } \\
\text { individual participation, performance } \\
\text { tolerance }\end{array}$ \\
\hline
\end{tabular}

authors stress the need for each study to be clear about what conceptualization of engagement is used (Jimerson et al., 2003; Appleton et al., 2008; Unrau and Quirk, 2014; Bernard, 2015).

\section{Customer Engagement}

Table 2 shows the 12 studies classified as customer engagement. These studies used variations of the term for their specific form of engagement (customer or consumer; with or without "brand") but often did not differentiate between the terms. Interestingly, almost all studies yielded a new definition of engagement. Of the two that did not, one was a follow-up from an earlier study of the same author to evaluate the conceptualization of the previous study, and the other developed a new typology and model but was unclear about the specific definition. Four studies analyzed and applied the concept of consumer engagement to a new area, for example, sports fans, mobile technology, and health care. Eight studies included qualitative or quantitative data and the same number of studies reviewed literature.

When looking at the components, the same components (cognition, affect, and behavior) are found in eight studies, seemingly contradicting the need for a new definition in every study. When looking at these definitions (Appendix 1), it seems that many definitions convey a similar meaning (engagement as a multidimensional construct) but vary in what the different components entail, especially when applying the broad definition to a specific area. Interestingly, two studies explicitly see engagement more as a process than a state where the different components have a dynamic interplay that is more meaningful than the components in isolation (Bowden, 2014; Graffigna and Gambetti, 2015).

\section{Health Engagement}

Table 3 shows the 11 studies classified within the health engagement category. Within this category, there are numerous subtypes of which some (e.g., patient engagement, $n=3$ ) seem to be broader than others (e.g., engagement in persons with dementia, $n=2$; engagement in genetic testing, $n=1$ ). The main purpose of seven studies is to analyze the concept of engagement, but there is also attention toward discussing and testing measures of engagement $(n=5)$. Most studies discuss or review literature $(n=8)$, and some use empirical data (qualitative, $n=3$ and quantitative, $n=2$ ) to gain more insight into the concept. There is an equal number of studies that formulate a new definition as studies that use an existing definition $(n=5)$, showing the breadth of the health engagement category.

This breadth is further illustrated in the components used to describe engagement, as these vary widely. A behavioral component is seen most $(n=8)$, with participation used most frequently $(n=5)$. Five studies include more than one behavioral component. Next to the behavioral component, attitude is mentioned most often $(n=4)$. Lastly, there are four studies that see engagement as a process of which two do not identify any components. 
TABLE 3 | Characteristics and findings of health engagement studies.

\begin{tabular}{|c|c|c|c|c|}
\hline Study and subtype & Purpose & Method & Main findings & Definition and components \\
\hline $\begin{array}{l}\text { (Bright et al., 2015); } \\
\text { patient }\end{array}$ & Analyze concept & Systematic review & $\begin{array}{l}\text { Conceptualization of } \\
\text { engagement as a process and } \\
\text { state }\end{array}$ & $\begin{array}{l}\text { New (process and state); collaboration, } \\
\text { contribution, active participation, } \\
\text { emotional investment }\end{array}$ \\
\hline $\begin{array}{l}\text { (Cohen-Mansfield et al., } \\
\text { 2009); persons with } \\
\text { dementia }\end{array}$ & $\begin{array}{l}\text { Analyze concept }+ \text { new } \\
\text { theoretical framework }+ \text { test } \\
\text { measure }\end{array}$ & $\begin{array}{l}\text { Discuss literature } \\
+ \text { Quant. }\end{array}$ & $\begin{array}{l}\text { Most important dimensions of } \\
\text { engagement found }\end{array}$ & $\begin{array}{l}\text { Unclear; refusal, attention, time, attitude, } \\
\text { manipulating, holding }\end{array}$ \\
\hline $\begin{array}{l}\text { (Cohen-Mansfield et al., } \\
\text { 2017); persons with } \\
\text { dementia }\end{array}$ & $\begin{array}{l}\text { Analyze concept }+ \text { new } \\
\text { theoretical framework }+ \text { test } \\
\text { measure }\end{array}$ & $\begin{array}{l}\text { Discuss literature } \\
+ \text { Quant }\end{array}$ & $\begin{array}{l}\text { Good psychometric properties of } \\
\text { scale }\end{array}$ & $\begin{array}{l}\text { Existing; attendance, attitude, active } \\
\text { participation, asleep, group size, positive } \\
\text { and negative interactions among group } \\
\text { members }\end{array}$ \\
\hline $\begin{array}{l}\text { (Graffigna and Barello, } \\
\text { 2018); patient }\end{array}$ & $\begin{array}{l}\text { Discuss Patient Health } \\
\text { Engagement (PHE) model } \\
\text { and scale }\end{array}$ & Discuss literature & Process model seems valuable & Existing (process) \\
\hline $\begin{array}{l}\text { (Higgins et al., 2017); } \\
\text { patient }\end{array}$ & Analyze and define concept & Systematic review & Four defining attributes & $\begin{array}{l}\text { New (process); personalization, access, } \\
\text { commitment, therapeutic alliance }\end{array}$ \\
\hline $\begin{array}{l}\text { (Macgowan, 2006); } \\
\text { group }\end{array}$ & $\begin{array}{l}\text { Discuss Group Engagement } \\
\text { Measure (GEM) }\end{array}$ & Discuss literature & $\begin{array}{l}\text { Multidimensional construct; } \\
\text { good psychometric properties }\end{array}$ & $\begin{array}{l}\text { Existing; attendance, individual } \\
\text { participation, relating to worker and other } \\
\text { members, contracting, working on own } \\
\text { and other group members' problems }\end{array}$ \\
\hline $\begin{array}{l}\text { (McAllister, 2002); } \\
\text { genetic testing }\end{array}$ & $\begin{array}{l}\text { Explain behavior around } \\
\text { predictive genetic testing } \\
\text { (PGT) }\end{array}$ & Qual. & $\begin{array}{l}\text { Engagement can explain } \\
\text { variations in approaches and } \\
\text { reactions to PGT }\end{array}$ & New; cognitive, individual participation \\
\hline $\begin{array}{l}\text { (Norris et al., 2017); } \\
\text { stakeholder }\end{array}$ & $\begin{array}{l}\text { Stakeholder perspective of } \\
\text { concept }\end{array}$ & Qual. & Three main themes/attributes & $\begin{array}{l}\text { New; individual participation, connecting } \\
\text { around a purpose, meaningful interaction } \\
\text { and dialog }\end{array}$ \\
\hline $\begin{array}{l}\text { (Pullmann et al., 2013); } \\
\text { treatment }\end{array}$ & Analyze concept & Qual. & New definition & $\begin{array}{l}\text { New; conduct, attitudes, relationships, } \\
\text { empowerment, social context }\end{array}$ \\
\hline $\begin{array}{l}\text { (Staudt, 2007); } \\
\text { treatment }\end{array}$ & $\begin{array}{l}\text { Analyze concept and } \\
\text { consequences }\end{array}$ & Discuss literature & $\begin{array}{l}\text { More insight in the behavioral } \\
\text { and attitudinal aspects }\end{array}$ & Existing; behavioral, attitudinal \\
\hline $\begin{array}{l}\text { (Yasui et al., 2017); } \\
\text { mental health services }\end{array}$ & $\begin{array}{l}\text { Analyze the role of culture in } \\
\text { concept and measures }\end{array}$ & Systematic review & $\begin{array}{l}\text { Limitations of current tools for } \\
\text { minorities }+ \text { new culturally } \\
\text { infused model }\end{array}$ & Existing (process) \\
\hline
\end{tabular}

\section{Societal Engagement}

Table 4 shows the characteristics of the ten studies classified as societal engagement. Within societal engagement, multiple subtypes are identified. These vary in whose engagement they define and measure, that is, the engagement of citizens $(n=$ 6) (Nicotera et al., 2010; Kemp, 2015; Nguyen et al., 2016; Arvanitidis, 2017; Cortés-Cediel et al., 2018; Pontes et al., 2018) in, for example, their community, politics, or art; the engagement of organizations with citizens $(n=3)$ (Taylor and Kent, 2014; Sallnow and Paul, 2015; Eder et al., 2018), for example, engagement of research organizations with citizens, or of an end-of-life care service with the community surrounding it; or the engagement of interest groups in policy $(n=1)$ (Halpin and Fraussen, 2017). Four studies' main aim is to analyze the concept, but an equal number of studies apply the concept to a new area or seek a stakeholder perspective. Almost all studies discuss literature to achieve their aims $(n=$ 8 ), but four use quantitative data and one includes qualitative data. Interestingly, only one study used an existing definition, whereas seven studies developed a new definition, often based on earlier definitions. Three studies mainly see engagement as a process, but all but one study identify multiple components of engagement.
Looking at these components, it is difficult to find commonalities, which might be due to the different target groups of these forms of engagement. However, there seem to be quite a few components of engagement that relate to behavior (e.g., civic or online activities). Furthermore, not all components seem to really reflect what engagement is but are motivations to be engaged (e.g., intrinsic motivations to the subject and system), goals of engagement (e.g., to inform or consult), or preconditions to be able to be engaged (e.g., access and prominence).

\section{Work Engagement}

Table 5 shows the nine studies categorized as work engagement. Most studies discuss or review literature to analyze the concept and related issues, whereas one uses qualitative data. Within this field, we found three different concepts: work engagement, personal engagement, and employee engagement (in one paper further specified as organization engagement). It seems that in literature, these concepts are sometimes used interchangeably, but a firm need is expressed to use the appropriate concept in the appropriate context (Shuck et al., 2017; Gupta and Sharma, 2018).

For work engagement, there is one dominant (operational) definition, based on the Utrecht Work Engagement Scale 
TABLE 4 | Characteristics and findings of societal engagement studies.

\begin{tabular}{|c|c|c|c|c|}
\hline Study and subtype & Purpose & Method & Main findings & Definition and components \\
\hline (Arvanitidis, 2017); civic & $\begin{array}{l}\text { Analyze concept and } \\
\text { antecedents }\end{array}$ & $\begin{array}{l}\text { Discuss literature } \\
+ \text { quant. }\end{array}$ & Antecedents found & $\begin{array}{l}\text { Existing; civic activities, electoral } \\
\text { activities, political voice }\end{array}$ \\
\hline $\begin{array}{l}\text { (Cortés-Cediel et al., } \\
\text { 2018); citizen }\end{array}$ & Present a process model & Discuss literature & $\begin{array}{l}\text { Life cycle model different phases of } \\
\text { engagement }\end{array}$ & $\begin{array}{l}\text { New (process); intrinsic to the } \\
\text { subject, intrinsic to the system, } \\
\text { subjects' extrinsic motivations }\end{array}$ \\
\hline $\begin{array}{l}\text { (Eder et al., 2018); } \\
\text { community }\end{array}$ & $\begin{array}{l}\text { Stakeholder perspective of } \\
\text { concept }\end{array}$ & Quant. & $\begin{array}{l}\text { Different definitions used, but similar } \\
\text { indicators and measures }\end{array}$ & None chosen (process) \\
\hline $\begin{array}{l}\text { (Halpin and Fraussen, } \\
\text { 2017); policy }\end{array}$ & Analyze concept & Discuss literature & Identified forms of engagement & $\begin{array}{l}\text { Unclear; involvement, access, } \\
\text { prominence }\end{array}$ \\
\hline (Kemp, 2015); arts & $\begin{array}{l}\text { Analyze concept }+ \text { develop } \\
\text { measure }\end{array}$ & $\begin{array}{l}\text { Discuss literature } \\
+ \text { quant. }\end{array}$ & $\begin{array}{l}\text { Scale validated; antecedents and } \\
\text { consequences }\end{array}$ & $\begin{array}{l}\text { New; affective, cognitive, behavioral, } \\
\text { social, connection }\end{array}$ \\
\hline $\begin{array}{l}\text { (Nguyen et al., 2016); } \\
\text { community } \\
\text { crowdsourcing }\end{array}$ & $\begin{array}{l}\text { Propose behavioral } \\
\text { perspective on definition } \\
\text { and measurement }\end{array}$ & Discuss literature & $\begin{array}{l}\text { Illustrate utility of the Participant } \\
\text { Engagement Index }\end{array}$ & $\begin{array}{l}\text { New; Activity, intensity, diversity, } \\
\text { recency }\end{array}$ \\
\hline $\begin{array}{l}\text { (Nicotera et al., 2010); } \\
\text { civic }\end{array}$ & $\begin{array}{l}\text { Develop and validate scale } \\
\text { for new target group } \\
\text { (preadolescents) }\end{array}$ & Quant. & Components confirmed and specified & $\begin{array}{l}\text { New; foundation for civic ethics, } \\
\text { community connection }\end{array}$ \\
\hline $\begin{array}{l}\text { (Pontes et al., 2018); } \\
\text { political }\end{array}$ & $\begin{array}{l}\text { Stakeholder perspective of } \\
\text { concept }\end{array}$ & $\begin{array}{l}\text { Discuss literature } \\
+ \text { qual. }\end{array}$ & $\begin{array}{l}\text { New definition; example actions and } \\
\text { behaviors }\end{array}$ & New; cognitive, emotional \\
\hline $\begin{array}{l}\text { (Sallnow and Paul, } \\
\text { 2015); community }\end{array}$ & $\begin{array}{l}\text { Apply concept to specific } \\
\text { topic; present model and } \\
\text { definition }\end{array}$ & Discuss literature & New model with types of engagement & $\begin{array}{l}\text { New (process): inform, consult, } \\
\text { co-production, collaborate, empower }\end{array}$ \\
\hline $\begin{array}{l}\text { (Taylor and Kent, 2014); } \\
\text { dialogic }\end{array}$ & $\begin{array}{l}\text { Analyze concept within } \\
\text { dialogue theory }\end{array}$ & Discuss literature & $\begin{array}{l}\text { New definition and conceptualization, } \\
\text { fitting in dialogue theory }\end{array}$ & $\begin{array}{l}\text { New; individual participation, } \\
\text { relational purpose, advice, contribute }\end{array}$ \\
\hline
\end{tabular}

(UWES) (Bakker et al., 2008). This definition, with the concepts vigor, dedication, and absorption, is used in four of five studies on work engagement. The components have also been categorized as energy, behavior, or physical engagement (vigor); emotion (dedication); and cognition (absorption). The discussion within this concept is mainly on specific issues (e.g., whether work engagement is the opposite of burnout) and less on the definition of the concept itself. For employee engagement, different new definitions have been proposed. The used components mirror the components of work engagement (e.g., cognitive, emotional, and behavioral energy), but other components have also been identified (e.g., social behavior). Interestingly, all studies within this category see engagement as a state and none as a process.

\section{Digital Engagement}

Table 6 shows the characteristics of the eight papers categorized as digital engagement. Four papers focus on (general) user engagement, three specifically on digital gaming (of which two on learning games), and one on engagement to digital behavior change interventions. Seven papers discussed or reviewed literature to analyze the concept, whereas three papers (also) used empirical data for this goal. In five studies, a new definition of engagement was constructed, based on the results of the study. Only one paper used an existing definition from literature, one study reviewed definitions but did not choose or construct one itself, and in one study, it was unclear what the chosen definition was based upon. In two papers, engagement is (also) seen as a process.
Seven papers consider engagement to exist of one or more components. Affect or emotion is mentioned in five papers, as well as cognition or related concepts (thought, interest, and attention). Behavior or participation is mentioned in four papers. Looking at the various definitions (Appendix 1), engagement seems to be a much-debated concept in this field, and there seems to be no accepted definition. The two most recent studies both strive to tackle this issue using a systematic review but arriving a two seemingly different conclusions: whereas Perski et al. created a new definition for their specific target area (digital behavior change interventions) (Perski et al., 2017), Doherty and Doherty stated that the field needs to move away from identifying one definition of engagement and that it is more important to select the most useful interpretation and measurement of engagement, based on the context (Doherty and Doherty, 2018).

\section{Transdisciplinary Engagement}

One study was classified as covering transdisciplinary engagement as it employs a systematic review to integrate literature on employee, consumer, and patient engagement to find overlap between the concepts (c.f. Table 7). The study concludes that there are similarities between the fields of engagement, for example, in that the concept is seen as consisting of multiple components of which emotional, cognitive, and behavioral are most apparent.

\section{DISCUSSION}

The purpose of this systematic scoping review was to investigate in what domains the concept of engagement features and 
TABLE 5 | Characteristics and findings of work engagement studies.

\begin{tabular}{|c|c|c|c|c|}
\hline Study and subtype & Purpose & Method & Main findings & Definition and components \\
\hline $\begin{array}{l}\text { (Bakker et al., 2008); } \\
\text { work }\end{array}$ & $\begin{array}{l}\text { Introduce concept of work } \\
\text { engagement }\end{array}$ & Discuss literature & $\begin{array}{l}\text { Components, antecedents and } \\
\text { consequences }\end{array}$ & Existing: vigor, dedication, absorption \\
\hline $\begin{array}{l}\text { (Bargagliotti, 2012); } \\
\text { work }\end{array}$ & Apply concept to new context & Systematic review & Antecedents and consequences & Existing: vigor, dedication, absorption \\
\hline $\begin{array}{l}\text { (Green et al., 2017); } \\
\text { work }\end{array}$ & $\begin{array}{l}\text { Analysis of the concept }+ \text { new } \\
\text { theory }\end{array}$ & Discuss literature & $\begin{array}{l}\text { Components; framework with } \\
\text { antecedents }\end{array}$ & $\begin{array}{l}\text { New: energy, positive experience, } \\
\text { behavior }\end{array}$ \\
\hline $\begin{array}{l}\text { (Gupta and Sharma, } \\
\text { 2018); employee }\end{array}$ & $\begin{array}{l}\text { Analysis of the concept }+ \\
\text { measures }\end{array}$ & Systematic review & $\begin{array}{l}\text { Differences in concepts, predictive } \\
\text { validity and utility between scales }\end{array}$ & $\begin{array}{l}\text { None chosen: cognitive, affective, } \\
\text { physical strength, social, behavioral }\end{array}$ \\
\hline (Kahn, 1990); personal & Theory construction & Qual. & $\begin{array}{l}\text { Defined the concept, its components, } \\
\text { antecedents and consequences }\end{array}$ & $\begin{array}{l}\text { New: physical, cognitive, and } \\
\text { emotional connection }\end{array}$ \\
\hline $\begin{array}{l}\text { (Schaufeli and } \\
\text { Salanova, 2011); work }\end{array}$ & $\begin{array}{l}\text { Analyze specific issues of } \\
\text { concept }\end{array}$ & Discuss literature & $\begin{array}{l}\text { More conceptual clarity on specific } \\
\text { issues }\end{array}$ & Existing: vigor, dedication, absorption \\
\hline $\begin{array}{l}\text { (Shuck et al., 2017); } \\
\text { employee }\end{array}$ & $\begin{array}{l}\text { Analyze concept and compare to } \\
\text { existing frameworks }\end{array}$ & Systematic review & $\begin{array}{l}\text { New framework, need to differ } \\
\text { between forms of engagement }\end{array}$ & $\begin{array}{l}\text { New: cognitive, emotional, and } \\
\text { behavioral energy }\end{array}$ \\
\hline $\begin{array}{l}\text { (Sonnentag, 2017); } \\
\text { work }\end{array}$ & $\begin{array}{l}\text { Analyze concept from task-level } \\
\text { perspective }\end{array}$ & Discuss literature & $\begin{array}{l}\text { Engagement varies between tasks } \\
\text { and is not the opposite of from } \\
\text { burnout }\end{array}$ & Existing: vigor, dedication, absorption \\
\hline $\begin{array}{l}\text { (Welch, 2011); } \\
\text { employee, organization }\end{array}$ & $\begin{array}{l}\text { Analyze concept and } \\
\text { communication as antecedent }\end{array}$ & Discuss literature & New model with antecedents & New: emotional, cognitive, physical \\
\hline
\end{tabular}

TABLE 6 | Characteristics and findings of user engagement studies.

\begin{tabular}{|c|c|c|c|c|}
\hline Study and subtype & Purpose & Method & Main findings & Definition and components \\
\hline $\begin{array}{l}\text { (Bouvier et al., 2014); } \\
\text { digital gaming }\end{array}$ & $\begin{array}{l}\text { Analyze concept }+ \\
\text { characterize behavior }\end{array}$ & Discuss literature & $\begin{array}{l}\text { Define related concepts }+ \\
\text { characterize engaged behaviors }\end{array}$ & New; emotion, affect, thought \\
\hline $\begin{array}{l}\text { (Doherty and Doherty, } \\
\text { 2018); user }\end{array}$ & $\begin{array}{l}\text { Analyze concept }+ \\
\text { antecedents, consequences } \\
\text { and measurements }\end{array}$ & Systematic review & $\begin{array}{l}\text { Interpretation and measurement } \\
\text { of engagement should be based } \\
\text { on the context }\end{array}$ & None chosen \\
\hline $\begin{array}{l}\text { (Drejing et al., 2015); } \\
\text { user }\end{array}$ & $\begin{array}{l}\text { Propose definition and } \\
\text { framework }\end{array}$ & Discuss literature & $\begin{array}{l}\text { New framework and definition }+ \\
\text { propose way to measure it }\end{array}$ & New; behavior \\
\hline $\begin{array}{l}\text { (Kappelman and } \\
\text { McLean, 1994); user }\end{array}$ & Analyze concept & Discuss literature & $\begin{array}{l}\text { Identify four types of } \\
\text { engagement }\end{array}$ & Unclear; participation, involvement \\
\hline $\begin{array}{l}\text { (Ke et al., 2016); } \\
\text { game-based learning }\end{array}$ & $\begin{array}{l}\text { Analyze concept }+ \text { its } \\
\text { development }\end{array}$ & $\begin{array}{l}\text { Discuss literature } \\
+ \text { Qual. }\end{array}$ & New definition & $\begin{array}{l}\text { New (process); affect, cognition, content, } \\
\text { gameplay relevance }\end{array}$ \\
\hline $\begin{array}{l}\text { (O'Brien and Toms, } \\
\text { 2008); user }\end{array}$ & $\begin{array}{l}\text { Analyze concept }+ \text { propose } \\
\text { definition and } \\
\text { operationalization }\end{array}$ & $\begin{array}{l}\text { Discuss literature } \\
+ \text { qual. }\end{array}$ & $\begin{array}{l}\text { New process and attributes of } \\
\text { engagement }\end{array}$ & $\begin{array}{l}\text { New (process and state); interest, } \\
\text { motivation, affect, attention, challenge, } \\
\text { feedback, aesthetics and sensory appeal, } \\
\text { awareness, novelty, perceived control, } \\
\text { perceived time, interactivity }\end{array}$ \\
\hline $\begin{array}{l}\text { (Perski et al., 2017); } \\
\text { digital behavior change } \\
\text { interventions }\end{array}$ & $\begin{array}{l}\text { Analyze concept }+ \text { develop } \\
\text { framework }\end{array}$ & Systematic review & $\begin{array}{l}\text { New definition }+ \text { antecedents } \\
\text { and consequences }\end{array}$ & New; behavior, attention, interest, affect \\
\hline $\begin{array}{l}\text { (Phillips et al., 2014); } \\
\text { game-based learning }\end{array}$ & $\begin{array}{l}\text { Expand definition and } \\
\text { measurement of concept }\end{array}$ & Qual. + quant. & $\begin{array}{l}\text { Highlight the importance of } \\
\text { components }\end{array}$ & Existing; behavior, cognition, affect \\
\hline
\end{tabular}

what constitutes engagement in these different domains and to determine whether there are any common components that seem to be important. With the 69 papers we identified on the conceptualization of engagement, we have identified seven different domains of engagement: student, customer, health, societal, work, digital, and transdisciplinary engagement. The results showed that engagement is a maturing concept that stretches across disciplinary boundaries. However, it seems as though some disciplines (e.g., organizational psychology) have a more crystalized view of such than others (e.g., within political sciences and sociology). Despite the level of maturity within a given discipline, our results showed that engagement is predominantly seen as a multidimensional construct, which is composed of a cognitive, behavioral, and affective component.

\section{Engagement Across Domains}

A first observation is that engagement is viewed as an important concept across different domains but is also much disputed as seen by the many papers that analyze this concept. This resonates with the discussion on engagement in the field of eHealth 
TABLE 7 | Characteristics and findings of transdisciplinary engagement study.

\begin{tabular}{|c|c|c|c|c|}
\hline Study and subtype & Purpose & Method & Main findings & Definition and components \\
\hline $\begin{array}{l}\text { (Graffigna, 2017); } \\
\text { trans-disciplinary }\end{array}$ & $\begin{array}{l}\text { Analyze the concept in different } \\
\text { fields }\end{array}$ & Systematic review & $\begin{array}{l}\text { Five propositions that show overlap } \\
\text { between employee, consumer and } \\
\text { patient engagement }\end{array}$ & $\begin{array}{l}\text { Unclear; emotional, cognitive, } \\
\text { behavioral }\end{array}$ \\
\hline
\end{tabular}

technologies, or digital interventions (e.g., Yardley et al., 2016; Perski et al., 2017; Short et al., 2018). It seems that some fields are more mature regarding their conceptualization and theorizing on engagement than others. In particular, the field of work engagement seems to have a widely accepted definition (Bakker et al., 2008), but even in that area, there are numerous discussions surrounding the concept, for example, what the antipode is, what the attributing conditions are, and what the relationship is with employee/personal engagement. One of the aspects that seemed to have matured the domain of work engagement is the use of a commonly accepted measurement scale (UWES; Schaufeli et al., 2006), which is something that is not found in other fields. Other fields, for example, customer and societal engagement, seem to be somewhat less mature, in that they are in the phase of defining engagement as evidenced by the many new definitions that have been proposed in literature.

In all domains, engagement is mainly seen as a state of being engaged with something, but almost all domains also refer to engagement as a process. This process of getting engaged, staying engaged, disengaging, and re-engaging is sometimes viewed as more important that defining what the state of engagement really is (e.g., Bowden, 2014; Graffigna and Gambetti, 2015). However, it seems that by not separating the process of engagement from the state of engagement, antecedents for engagement can be confused for being part of engagement itself. Examples are digital engagement, where aesthetics have been proposed to be part of engagement (O'Brien and Toms, 2008), but recognized as antecedent or predictor of engagement in other studies (Short et al., 2018), and also societal engagement where motivations, goals, and preconditions are sometimes viewed as being part of engagement (Sallnow and Paul, 2015; Halpin and Fraussen, 2017; Cortés-Cediel et al., 2018).

\section{Engagement as a Multidimensional Construct}

The results further show that across different domains, engagement is predominantly seen as a multidimensional construct comprising behavioral, cognitive, and affective components. There seems to be consensus on the combination of these three components in the domains of student and work engagement. Moreover, in customer and digital engagement, this combination is also seen quite often, although there does not seem to be consensus on the simultaneous manifestation or combination of these components (yet). In contrast, conceptualizations within health engagement seem to place more emphasis on the behavioral component (e.g., participation), but there is an ongoing discussion that engagement should be more than just doing something (Bright et al., 2015; Graffigna and Barello, 2018), which is similar to the discussion seen in engagement with eHealth technologies (Perski et al., 2017; Short et al., 2018). Similarly, societal engagement places emphasis on the behavioral component of engagement (e.g., various activities; Arvanitidis, 2017); however, recent discussions within the literature seem to point to engagement being more than just involvement or participation in societal activities (Pontes et al., 2018).

Although there is congruence between different domains as to the presence of behavioral, cognitive, and emotional components of engagement, the content of such differs significantly. Even within mature domains, such as work engagement, there are still debates into the psychological conditions or activities that categorize each of these components. For example, Kahn (1990) indicated that the physical/behavioral component of engagement refers to the extent toward which an individual can express himself or herself physically in a work role, whereas Bakker et al. (2008) argued that vigor (the physical/behavioral component in his model) refers to physical energy derived from work. The content of such differs even more between domains such as student engagement vs. work engagement. It is therefore understandable that different conceptualizations and definitions of engagement exist within and between different domains. Various studies aim to clarify what is meant by the behavioral, emotional, and cognitive components of engagement within a given context. This is done by either (a) constructing an operational or context-specific definition or approach of engagement or (b) employing a general meta-level model for engagement. The former results in a proliferation of definitions of engagement, which is difficult to keep track of or to maintain, and the latter results in a meta-level construct that ignores the context-specific challenges, experiences, or attributing factors. Arguably, an approach that lies between both options holds most merit for conceptualizing engagement in a new domain as eHealth interventions.

\section{Implications for Engagement With eHealth Technologies}

Interest in understanding engagement within different disciplines has been increasing during the past three decades. Despite agreement between domains as to its importance, it is clear that theoretical discussions as to its conceptualization is ongoing within the literature. Controlling for context and discipline, it would seem as though engagement is predominantly seen as a state of being involved in or occupied with an object, activity, or artifact, which usually results in a positive outcome. This is part of the larger process of engagement. 
Second, to go beyond the meta-construct of engagement, which ignores the context-specific challenges, experiences, or attributing factors and at the same time avoid a proliferation of definitions of engagement, which is difficult to keep track of or to maintain, it seems that the field needs a clear, tailored, and domain specific definition of the construct, which captures the associated emotional, behavioral, and cognitive components present within the given context. Questions that may need to be answered to arrive at this domain specific definition are, for example, whether behavioral engagement includes just the amount of usage or whether it should also include the quality of usage, for example, using as intended (Sieverink et al., 2017); whether interest and attention are the relevant cognitive aspects (Perski et al., 2017) or should other concepts be considered as, for example, involvement (Kelders et al., 2018) or "macro-engagement" (Yardley et al., 2016); and whether only positive emotions such as enjoyment should be seen as affective engagement or might negative affect also play a role, for example, when experiencing through eHealth technology that you have not reached your health-related goals (Triberti et al., 2018). In particular, when investigating the role of affect, a complicating factor is whether we should distinguish between experiences that are brought about by the content of the intervention and those that are triggered by the design of the intervention, for example, the sensory pleasure that people might derive from interacting with the intervention or the meaning they attribute to a particular feature in the design and that influences their affect. This is an area that has not received much attention but may give us more insight in the interplay between the design and content of interventions.

Ultimately, this may lead to a context-specific definition of engagement on a lower abstraction level, with an appropriate measurement method. However, it stands to reason that the more detailed the specification of the components will become, the more it will be aimed at one specific form of eHealth technologies. As the eHealth domain is very broad (e.g., encompassing interventions with or without care professionals; various devices and technologies; and various contexts), it is still an open question whether it is possible to gain a sufficiently detailed specification of the behaviors, cognitions, and affect that constitute engagement that is still broad enough to encompass the breath of the eHealth domain or whether there should be multiple specifications (and definitions) for subdomains. Therefore, it remains important for each individual study to be clear about what they mean by engagement.

Having a more commonly accepted understanding of the different components of engagement for eHealth technologies could allow a more structured investigation of how different technologies and forms of eHealth impact engagement; for example, in what way does blended care, or new forms of technology such as wearables, interactive devices, and virtual and augmented reality impact (the different components of) engagement? Also, new questions may then be addressed; for example, do people have different styles of being engaged; are some more inclined to be behaviorally engaged and others more affectively engaged (Kelders and Kip, 2019)? This might shed more light on why certain strategies, as, for example, gamification, work for some but not for others.

\section{STRENGTHS AND LIMITATIONS}

This review set out to give an overview of how engagement is conceptualized in different fields. This is both the major strength and limitation of the review. By encompassing many different fields, a comprehensive overview of conceptualizations is given, which can inspire researchers in the field of eHealth technologies and beyond to use the concept of engagement in a substantiated way. However, owing to the large scope of the review, we needed to limit the search to papers that indicate in the title their focus on the concept of engagement. This may have caused us to miss papers that provide interesting insights on engagement but whose main focus was other than that. However, we feel that we have overcome this limitation by including many overview and review papers that do take these primary studies into account.

\section{DATA AVAILABILITY STATEMENT}

All datasets generated for this study are included in the article/ Supplementary Material.

\section{AUTHOR CONTRIBUTIONS}

SK, LZ, and GL contributed to the conception and design of the study. SK performed the search, analysis, and wrote the first draft of the manuscript. LZ and GL contributed to the search and analysis. LZ and GL wrote sections of the manuscript. All authors contributed to manuscript revision, read and approved the submitted version.

\section{FUNDING}

The work was supported by the Netherlands Organization for Scientific Research (NWO) through the Innovational Research Incentives Scheme-VENI-project of the first author (The Personalization Approach: Using engagement as a mediator for the effectiveness of eMental Health interventions; grant number 451-17-031). The funders had no role in study design, data collection and analysis, decision to publish, or preparation of the manuscript.

\section{SUPPLEMENTARY MATERIAL}

The Supplementary Material for this article can be found online at: https://www.frontiersin.org/articles/10.3389/fpsyg. 2020.00926/full\#supplementary-material 


\section{REFERENCES}

Abdul-Ghani, E., Hyde, K. F., and Marshall, R. (2018). Conceptualising engagement in a consumer-to-consumer context. Australas. Market. J. 27, 2-13. doi: 10.1016/j.ausmj.2018.06.004

Appleton, J. J., Christenson, S. L., and Furlong, M. J. (2008). Student engagement with school: critical conceptual and methodological issues of the construct. Psychol. Sch. 45, 369-386. doi: 10.1002/pits.20303

Arksey, H., and O'Malley, L. (2005). Scoping studies: towards a methodological framework. Int. J. Soc. Res. Methodol. 8, 19-32. doi: 10.1080/1364557032000119616

Arvanitidis, P. A. (2017). The concept and determinants of civic engagement. Hum. Aff. 27, 252-272. doi: 10.1515/humaff-2017-0022

Bakker, A. B., Schaufeli, W. B., Leiter, M. P., and Taris, T. W. (2008). Work engagement: an emerging concept in occupational health psychology. Work Stress 22, 187-200. doi: 10.1080/02678370802393649

Bargagliotti, A. L. (2012). Work engagement in nursing: a concept analysis. J. Adv. Nurs. 68, 1414-1428. doi: 10.1111/j.1365-2648.2011.05859.x

Barkaoui, K., Barrett, S. E., Samaroo, J., Dahya, N., Alidina, S., and James, C. E. (2015). Teachers' conceptions of student engagement in learning: the case of three Urban schools. Alberta J. Educ. Res. 61, 80-99.

Bernard, J. S. (2015). Student engagement: a principle-based concept analysis. Int. J. Nurs. Educ. Scholarsh. 12:58. doi: 10.1515/ijnes-2014-0058

Booth, A., Papaioannou, D., and Sutton, A. (2012). The literature review: its role within research. Syst. Approach. Successful Literature Rev. 1, 1-16.

Bouvier, P., Lavoué, E., and Sehaba, K. (2014). Defining engagement and characterizing engaged-behaviors in digital gaming. Simulation Gaming 45, 491-507. doi: 10.1177/1046878114553571

Bowden, J. L.-H. (2014). The process of customer engagement: a conceptual framework. J. Market. Theor. Pract. 17, 63-74. doi: 10.2753/MTP1069-6679170105

Bright, F. A., Kayes, N. M., Worrall, L., and McPherson, K. M. (2015). A conceptual review of engagement in healthcare and rehabilitation. Disabil. Rehabil. 37, 643-654. doi: 10.3109/09638288.2014.933899

Brodie, R. J., Hollebeek, L. D., Jurić, B., and Ilić, A. (2011). Customer engagement. J. Serv. Res. 14, 252-271. doi: 10.1177/1094670511411703

Burch, G. F., Heller, N. A., Burch, J. J., Freed, R., and Steed, S. A. (2015). Student engagement: developing a conceptual framework and survey instrument. $J$. Educ. Business 90, 224-229. doi: 10.1080/08832323.2015.1019821

Carman, K. L., Dardess, P., Maurer, M., Sofaer, S., Adams, K., Bechtel, C., et al. (2013). Patient and family engagement: a framework for understanding the elements and developing interventions and policies. Health Aff. 32, 223-231. doi: 10.1377/hlthaff.2012.1133

Christensen, H., Griffiths, K. M., and Farrer, L. (2009). Adherence in internet interventions for anxiety and depression: systematic review. J. Med. Int. Res. 11:e13. doi: 10.2196/jmir.1194

Ciric, M., and Jovanovic, D. (2016). "Student engagement as a multidimensional concept," in Multidimensional Concept. WLC 2016: World LUMEN Congress. Logos Universality Mentality Education Novelty 2016. LUMEN 15th Anniversary Edition, 187-194. doi: 10.15405/epsbs.2016.09.24

Cohen-Mansfield, J., Dakheel-Ali, M., and Marx, M. S. (2009). Engagement in persons with dementia: the concept and its measurement. Am. J. Geriatr. Psychiatr. 17, 299-307. doi: 10.1097/JGP.0b013e31818f3a52

Cohen-Mansfield, J., Hai, T., and Comishen, M. (2017). Group engagement in persons with dementia: the concept and its measurement. Psychiatr. Res. 251, 237-243. doi: 10.1016/j.psychres.2017.02.013

Cortés-Cediel, M. E., Gil, O., and Cantador, I. (2018). "Defining the engagement life cycle in e-participation," in Proceedings of the 19th Annual International Conference on Digital Government Research: Governance in the Data Age, 1-2.

Couper, M. P., Alexander, G. L., Zhang, N., Little, R. J. A., Maddy, N., Nowak, M. A., et al. (2010). Engagement and retention: measuring breadth and depth of participant use of an online intervention. J. Med. Int. Res.12:e52. doi: 10.2196/jmir.1430

Desmet, P. M., and Hekkert, P. (2007). Framework of product experience. Int. J. Design 1, 57-66.

Dhanesh, G. S. (2017). Putting engagement in its PRoper place: state of the field, definition and model of engagement in public relations. Public Relat. Rev. 43, 925-933. doi: 10.1016/j.pubrev.2017.04.001
Doherty, K., and Doherty, G. (2018). Engagement in HCI: conception, theory and measurement. ACM Comput. Surveys 51, 1-39. doi: 10.1145/3234149

Donkin, L., Christensen, H., Naismith, S. L., Neal, B., Hickie, I. B., and Glozier, N. (2011). A systematic review of the impact of adherence on the effectiveness of e-therapies. J. Med. Internet Res. 13:e52. doi: 10.2196/jmir.1772

Donkin, L., and Glozier, N. (2012). Motivators and motivations to persist with online psychological interventions: a qualitative study of treatment completers. J. Med. Internet. Res. 14:e91. doi: 10.2196/jmir.2100

Drejing, K., Thill, S., and Hemeren, P. (2015). Engagement: a traceable motivational concept in human-robot interaction. IEEE 4, 956-961. doi: 10.1109/ACII.2015.7344690

Eder, M. M., Evans, E., Funes, M., Hong, H., Reuter, K., Ahmed, S., et al. (2018). Defining and measuring community engagement and communityengaged research: clinical and translational science institutional practices. Prog. Commun. Health Partnersh. 12, 145-156. doi: 10.1353/cpr.2018.0034

Fredricks, J. A., Blumenfeld, P. C., and Paris, A. H. (2004). School engagement: potential of the concept, state of the evidence. Rev. Educ. Res. 74, 59-109. doi: $10.3102 / 00346543074001059$

Graffigna, G. (2017). Is a transdisciplinary theory of engagement in organized settings possible? A concept analysis of the literature on employee engagement, consumer engagement and patient engagement. Front. Psychol. 8, 872. doi: 10.3389/fpsyg.2017.00872

Graffigna, G., and Barello, S. (2018). Spotlight on the Patient Health Engagement model (PHE model): a psychosocial theory to understand people's meaningful engagement in their own health care. Patient Prefer Adherence 12, 1261-1271. doi: 10.2147/PPA.S145646

Graffigna, G., and Gambetti, R. C. (2015). Grounding consumer-brand engagement: a field-driven conceptualisation. Int. J. Market Res. 57, 605-630. doi: 10.2501/IJMR-2015-049

Green, P. I., Finkel, E. J., Fitzsimons, G. M., and Gino, F. (2017). The energizing nature of work engagement: toward a new need-based theory of work motivation. Res. Organ. Behav. 37, 1-18. doi: 10.1016/j.riob.2017.10.007

Gulotta, R., Forlizzi, J., Yang, R., and Newman, M. W. (2016). "Fostering engagement with personal informatics systems," in Proceedings of the 2016 ACM Conference on Designing Interactive Systems (New York, NY: ACM), 286-300. doi: $10.1145 / 2901790.2901803$

Gupta, N., and Sharma, V. (2018). The comparative analysis of employee engagement measures: a theoretical perspective. Int. J. Manage. Pract. 11, 42-68. doi: 10.1504/IJMP.2018.10008647

Halpin, D. R., and Fraussen, B. (2017). Conceptualising the policy engagement of interest groups: involvement, access and prominence. Eur. J. Political Res. 56, 723-732. doi: $10.1111 / 1475-6765.12194$

Harris, L. (2011). Secondary teachers' conceptions of student engagement engagement in learning or in schooling? Teach. Teach. Educ. 27, 376-386. doi: 10.1016/j.tate.2010.09.006

Harris, L. R. (2008). A phenomenographic investigation of teacher conceptions of student engagement in learning. Aust. Educ. Res. 35, 57-79. doi: 10.1007/BF03216875

Higgins, T., Larson, E., and Schnall, R. (2017). Unraveling the meaning of patient engagement: a concept analysis. Patient Educ. Couns. 100, 30-36. doi: $10.1016 /$ j.pec.2016.09.002

Hollebeek, L. (2011). Exploring customer brand engagement: definition and themes. J. Strategic Market. 19, 555-573. doi: 10.1080/0965254X.2011.599493

Hollebeek, L. D., Glynn, M. S., and Brodie, R. J. (2014). Consumer brand engagement in social media: conceptualization, scale development and validation. J. Interactive Market. 28, 149-165. doi: 10.1016/j.intmar.2013.12.002

Hollingshead, A., Williamson, P., and Carnahan, C. (2018). Cognitive and emotional engagement for students with severe intellectual disability defined by the scholars with expertise in the field. Res. Pract. Persons Severe Disabil. 43, 269-284. doi: $10.1177 / 1540796918812803$

Horsley, T. (2019). Tips for improving the writing and reporting quality of systematic, scoping, and narrative reviews. J. Contin. Educ. Health Prof. 39, 54-57. doi: 10.1097/CEH.0000000000000241

Jimerson, S. R., Campos, E., and Greif, J. L. (2003). Toward an understanding of definitions and measures of school engagement and related terms. Calif. Sch. Psychol. 8, 7-27. doi: 10.1007/BF03340893

Kahn, W. A. (1990). Psychological conditions of personal engagement and disengagement at work. Acad. Manage. J. 33, 692-724. doi: 10.2307/256287 
Kappelman, L. A., and McLean, E. R. (1994). User engagement in information system development, implementation, and use: toward conceptual clarity. Proc. Twenty-Seventh Hawaii Int. Conf. 4 199-214. doi: 10.1109/HICSS.1994.323467

Ke, F., Xie, K., and Xie, Y. (2016). Game-based learning engagement: a theory- and data-driven exploration. Br. J. Educ. Technol. 47, 1183-1201. doi: $10.1111 /$ bjet.12314

Kelders, S. M. (2015). Involvement as a Working Mechanism for Persuasive Technology. Cham: Springer International Publishing.

Kelders, S. M. (2019). "Design for engagement of online positive psychology interventions," in Positive Psychological Intervention Design and Protocols for Multi-cultural Contexts, eds L. E. van Zyl and I. Rothmann (New York, NY: Springer), 297-313. doi: 10.1007/978-3-030-20020-6_13

Kelders, S. M., and Kip, H. (2019). "Development and Initial Validation of a Scale to Measure Engagement with eHealth Technologies," in CHI Conference on Human Factors in Computing Systems Extended Abstracts (CHI'19 Extended Abstracts) (Glasgow: ACM; New York, NY, USA), 1-6. doi: $10.1145 / 3290607.3312917$

Kelders, S. M., Kok, R. N., Ossebaard, H. C., and van Gemert-Pijnen, J. E. W. C. (2012). Persuasive system design does matter: a systematic review of adherence to web-based interventions. J. Med. Internet Res. 14, 17-40. doi: 10.2196/jmir.2104

Kelders, S. M., Sommers-Spijkerman, M., and Goldberg, J. (2018). Investigating the direct impact of a gamified versus nongamified well-being intervention: an exploratory experiment. J. Med. Internet Res. 20:e247. doi: 10.2196/jmir.9923

Kemp, E. (2015). Engaging consumers in esthetic offerings: conceptualizing and developing a measure for arts engagement. Int. J. Nonprofit Voluntary Sector Market. 20, 137-148. doi: 10.1002/nvsm.1525

Kulta, H.-P., and Karjaluoto, H. (2016). "Conceptualizing engagement in the mobile context," in AcademicMindtrek '16: Proceedings of the 20th International Academic Mindtrek Conference (Tampere), 169-176. doi: $10.1145 / 2994310.2994324$

Lawson, M. A., and Lawson, H. A. (2013). New conceptual frameworks for student engagement research, policy, and practice. Rev. Educ. Res. 83, 432-479. doi: $10.3102 / 0034654313480891$

Liem, G. A. D., and Martin, A. J. (2012). The motivation and engagement scale: theoretical framework, psychometric properties, and applied yields. Aust. Psychol. 47, 3-13. doi: 10.1111/j.1742-9544.2011.00049.x

Ludden, G. D., Schifferstein, H. N., and Hekkert, P. (2012). Beyond surprise: a longitudinal study on the experience of visual-tactual incongruities in products. Int. J. Design 6, 1-16.

Ludden, G. D., van Rompay, T. J., Kelders, S. M., and van Gemert-Pijnen, J. E. (2015). How to increase reach and adherence of web-based interventions: a design research viewpoint. J. Med. Internet Res. 17:e172. doi: 10.2196/jmir.4201

Macgowan, M. (2006). The group engagement measure: a review of its conceptual and empirical properties. J. Groups Addict. Rec. 1, 33-52. doi: 10.1300/J384v01n02_04

McAllister, M. (2002). Predictive genetic testing and beyond: a theory of engagement. J. Health Psychol. 7, 491-508. doi: 10.1177/1359105302007005628

Mittler, J. N., Martsolf, G. R., Telenko, S. J., and Scanlon, D. P. (2013). Making sense of 'consumer engagement' initiatives to improve health and health care: a conceptual framework to guide policy and practice. Milbank Q. 91, 37-77. doi: $10.1111 /$ milq.12002

Montenegro, A. (2017). Understanding the concept of agentic engagement. Colombian Appl. Linguistics J. 19:117. doi: 10.14483/calj.v19n1.10472

Nguyen, C., Tahmasbi, N., de Vreede, T., de Vreede, G.-J., Oh, O., and ReiterPalmon, R. (2016). "A definition of community crowdsourcing engagement and application," in Blurring the Boundaries Through Digital Innovation, Vol. 19, (Basel: Springer Heidelberg) 283-296. doi: 10.1007/978-3-319-38974-5_22

Nicotera, N., Altschul, I., Schneider-Munoz, A., and Webman, B. (2010). Conceptual and Analytic Development of a Civic Engagement Scale for Preadolescents. Charlotte, NC, US: IAP Information Age Publishing.

Niedderer, K., Clune, S., and Ludden, G. (2017). Design for Behaviour Change: Theories and Practices of Designing for Change. Routledge. doi: $10.4324 / 9781315576602$

Norris, J. M., White, D. E., Nowell, L., Mrklas, K., and Stelfox, H. T. (2017). How do stakeholders from multiple hierarchical levels of a large provincial health system define engagement? A qualitative study. Implement. Sci. 12:98. doi: $10.1186 / \mathrm{s} 13012-017-0625-5$
O'Brien, H. L., and Toms, E. G. (2008). What is user engagement? A conceptual framework for defining user engagement with technology. J. Am. Soc. Inform. Sci. Technol. 59, 938-955. doi: 10.1002/asi.20801

Overbeeke, K., Djajadiningrat, T., Hummels, C., Wensvveen, S., and Frens, J. (2004). "Let's make things engaging," in Funology: From Usability to Enjoyment, eds M. A. Blythe, A. F. Monk, K. Overbeeke, and P. C. Wright (New York, NY: Springer; Kluwer, Academic Press), 7-17.

Perski, O., Blandford, A., West, R., and Michie, S. (2017). Conceptualising engagement with digital behaviour change interventions: a systematic review using principles from critical interpretive synthesis. Transl. Behav. Med. 7 , 254-267. doi: 10.1007/s13142-016-0453-1

Peters, M. D., Godfrey, C. M., Khalil, H., McInerney, P., Parker, D., and Soares, C. B. (2015). Guidance for conducting systematic scoping reviews. Int. J. Evid. Based Healthc.13, 141-146. doi: 10.1097/XEB.0000000000000050

Phillips, R. S., Horstman, T., Vye, N., and Bransford, J. (2014). Engagement and games for learning: expanding definitions and methodologies. Simulation Gaming 45, 548-568. doi: 10.1177/1046878114553576

Pontes, A., Henn, M., and Griffiths, M. D. (2018). Towards a conceptualization of young people's political engagement: a qualitative focus group study. Societies 8:17. doi: 10.3390/soc 8010017

Pullmann, M. D., Ague, S., Johnson, T., Lane, S., Beaver, K., Jetton, E., et al. (2013). Defining engagement in adolescent substance abuse treatment. Am. J. Commun. Psychol. 52, 347-358. doi: 10.1007/s10464-013-9600-8

Reeve, J. (2013). How students create motivationally supportive learning environments for themselves: the concept of agentic engagement. J. Educ. Psychol. 105, 579-595. doi: 10.1037/a0032690

Salanova, M., and Ortega-Maldonado, A. (2019). "Psychological capital development in organizations: an integrative review of evidencebased intervention programs," in Positive Psychological Intervention Design and Protocols for Multi-Cultural Contexts (Springer), 81-102. doi: 10.1007/978-3-030-20020-6_4

Sallnow, L., and Paul, S. (2015). Understanding community engagement in endof-life care: developing conceptual clarity. Critical Public Health 25, 231-238. doi: $10.1080 / 09581596.2014 .909582$

Schaufeli, W., and Salanova, M. (2011). Work engagement: on how to better catch a slippery concept. Eur. J. Work Organ. Psychol. 20, 39-46. doi: 10.1080/1359432X.2010.515981

Schaufeli, W. B., Bakker, A. B., and Salanova, M. (2006). The measurement of work engagement with a short questionnaire: a cross-national study. Educ. Psychol. Measure. 66, 701-716. doi: 10.1177/0013164405282471

Schuetz, P. (2008). A theory-driven model of community college student engagement. Commun. Coll. J. Res. Pract. 32, 305-324. doi: $10.1080 / 10668920701884349$

Short, C. E., DeSmet, A., Woods, C., Williams, S. L., Maher, C., Middelweerd, A., et al. (2018). Measuring engagement in eHealth and mHealth behavior change interventions: viewpoint of methodologies. J. Med. Internet Res. 20:e292. doi: 10.2196/jmir.9397

Shuck, B., Osam, K., Zigarmi, D., and Nimon, K. (2017). Definitional and conceptual muddling: identifying the positionality of employee engagement and defining the construct. Hum. Resour. Dev. Rev. 16, 263-293. doi: $10.1177 / 1534484317720622$

Sieverink, F., Kelders, S. M., and van Gemert-Pijnen, J. E. (2017). Clarifying the concept of adherence to eHealth technology: systematic review on when usage becomes adherence. J. Med. Internet Res. 19:e402. doi: 10.2196/jmir.8578

Skinner, E. A., Kindermann, T. A., and Furrer, C. J. (2009). A motivational perspective on engagement and disaffection: conceptualization and assessment of children's behavioral and emotional participation in academic activities in the classroom. Educ. Psychol. Measure. 69, 493-525. doi: $10.1177 / 0013164408323233$

Solem, B. A. A., and Pedersen, P. E. (2016). The role of customer brand engagement in social media: conceptualisation, measurement, antecedents and outcomes. Int. J. Int. Market. Advert. 10, 223-254. doi: 10.1504/IJIMA.2016.081344

Sonnentag, S. (2017). A task-level perspective on work engagement: a new approach that helps to differentiate the concepts of engagement and burnout. Burnout Res. 5, 12-20. doi: 10.1016/j.burn.2017.04.001

Stander, F. W., and van Zyl, L. E. (2019). "The talent development centre as an integrated positive psychological leadership development and talent analytics framework," in Positive Psychological Intervention Design and Protocols for 
Multi-Cultural Contexts, eds L. E. van Zyl and S. Rothmann (Cham: Springer), 33-56. doi: 10.1007/978-3-030-20020-6_2

Staudt, M. (2007). Treatment engagement with caregivers of at-risk children: gaps in research and conceptualization. J. Child Family Stud. 16, 183-196. doi: 10.1007/s10826-006-9077-2

Tan, C. C., and Apisit-Isariyah, P. (2018). Towards a community-based theory of brand community engagement. Adv. Sci. Lett. 24, 5167-5170. doi: 10.1166/asl.2018.11296

Taylor, M., and Kent, M. L. (2014). Dialogic engagement: clarifying foundational concepts. J. Public Relat. Res. 26, 384-398. doi: 10.1080/1062726X.2014. 956106

Triberti, S., Kelders, S. M., and Gaggioli, A. (2018). "User engagement," in eHealth Research, Theory and Development, eds L. van Gemert-Pijnen, S. M. Kelders, H. Kip, and R. Sanderman (London, UK: Routledge), 271-289. doi: 10.4324/9781315385907-13

Unrau, N. J., and Quirk, M. (2014). Reading motivation and reading engagement: clarifying commingled conceptions. Read. Psychol. 35, 260-284. doi: 10.1080/02702711.2012.6 84426

Wang, M. T., Fredricks, J., Ye, F., Hofkens, T., and Linn, J. S. (2019). Conceptualization and assessment of adolescents engagement and disengagement in school: a multidimensional school engagement scale. Euro. J. Psychol. Assess. 35:592. doi: 10.1027/1015-5759/a0 00431

Welch, M. (2011). The evolution of the employee engagement concept: communication implications. Corp. Commun. 16, 328-346. doi: 10.1108/13563281111186968

Winslow, C. J., Kaplan, S. A., Bradley-Geist, J. C., Lindsey, A. P., Ahmad, A. S., and Hargrove, A. K. (2017). An examination of two positive organizational interventions: for whom do these interventions work? J. Occup. Health Psychol. 22, 129-137. doi: 10.1037/ocp0000035

Yardley, L., Spring, B. J., Riper, H., Morrison, L. G., Crane, D. H., Curtis, K., et al. (2016). Understanding and promoting effective engagement with digital behavior change interventions. Am. J. Prev. Med. 51, 833-842. doi: 10.1016/j.amepre.2016.06.015

Yasui, M., Pottick, K. J., and Chen, Y. (2017). Conceptualizing culturally infused engagement and its measurement for ethnic minority and immigrant children and families. Clin. Child Family Psychol. Rev. 20, 250-332. doi: 10.1007/s10567-017-0229-2

Yeager, C. M., Shoji, K., Luszczynska, A., and Benight, C. C. (2018). Engagement with a trauma recovery internet intervention explained with the health action process approach (HAPA): longitudinal study. JMIR Ment. Health 5:e29. doi: $10.2196 /$ mental.9449

Yoshida, M., Gordon, B., Nakazawa, M., and Biscaia, R. (2014). Conceptualization and measurement of fan engagement: empirical evidence from a professional sport context. J. Sport Manage. 28, 399-417. doi: 10.1123/jsm.2013-0199

Conflict of Interest: The authors declare that the research was conducted in the absence of any commercial or financial relationships that could be construed as a potential conflict of interest.

Copyright (c) 2020 Kelders, van Zyl and Ludden. This is an open-access article distributed under the terms of the Creative Commons Attribution License (CC BY). The use, distribution or reproduction in other forums is permitted, provided the original author(s) and the copyright owner(s) are credited and that the original publication in this journal is cited, in accordance with accepted academic practice. No use, distribution or reproduction is permitted which does not comply with these terms. 
OPEN ACCESS

Edited by:

Sebastiaan Rothmann,

North-West University, South Africa

Reviewed by:

Maria Elisa Maiolo,

Università degli Studi “G. d'Annunzio"

Chieti - Pescara, Italy

Rachele Paver,

North-West University, South Africa

${ }^{*}$ Correspondence:

Loes M. Kreemers

I.m.kreemers@hva.nl

Edwin A. J. van Hooft

e.a.j.vanhooft@uva.n

Specialty section: This article was submitted to

Organizational Psychology, a section of the journal

Frontiers in Psychology

Received: 06 November 2019

Accepted: 22 May 2020

Published: 02 July 2020

Citation:

Kreemers $L M$, van Hooft EAJ, van Vianen AEM and Sisouw de

Zilwa SCM (2020) Testing a Self-Compassion Intervention

Among Job Seekers:

Self-Compassion Beneficially Impacts

Affect Through Reduced

Self-Criticism

Front. Psychol. 11:1371

doi: 10.3389/fpsyg.2020.01371

\section{Testing a Self-Compassion} Intervention Among Job Seekers: Self-Compassion Beneficially Impacts Affect Through Reduced Self-Criticism

\author{
Loes M. Kreemers ${ }^{1 *}$, Edwin A. J. van Hooft ${ }^{2 *}$, Annelies E. M. van Vianen ${ }^{2}$ and \\ Sophie C. M. Sisouw de Zilwa ${ }^{3}$
}

${ }^{1}$ Research Group Psychology for Sustainable Cities, Amsterdam Research Institute for Societal Innovation, Amsterdam University of Applied Sciences, Amsterdam, Netherlands, ${ }^{2}$ Work and Organizational Psychology, University of Amsterdam, Amsterdam, Netherlands, ${ }^{3}$ Erasmus Happiness Economics Research Organization, Erasmus University Rotterdam,

Rotterdam, Netherlands

Job search is associated with various obstacles and difficulties that can elicit negative emotions and undermine positive emotions. Having self-compassion may benefit job seekers' well-being by stimulating more balanced emotional responses to negative job search experiences. In an intervention study we examined whether state selfcompassion can be increased among job seekers through writing exercises in which job seekers are instructed to reflect with self-compassion on their negative job search experiences. We further examined whether the self-compassion intervention benefited job seekers' affective responses, through reducing self-criticism. We designed a between-participants field experiment with two conditions (i.e., self-compassion vs. control) and three measurement times 1 week apart: a baseline questionnaire, the intervention with a second questionnaire, and a follow-up questionnaire ( $N=180$ ). Results show that the self-compassion writing exercise increased job seekers' state selfcompassion, which in turn related to their affective responses to job search. Specifically, their negative deactivating affect (e.g., sadness) was lower and their positive deactivating affect (e.g., calmness) was higher immediately after the self-compassion writing exercise than after reflecting freely (i.e., the control condition). The effects on job seekers' affect were partially mediated by reduced self-criticism.

Keywords: intervention, job search, negative affect, positive affect, self-compassion, self-criticism

\section{INTRODUCTION}

Most people search for a job at some stage in their career, for example when entering the labor market after finishing school, when a temporary contract ends, after being laid off, or when desiring to make a career move. The chance of finding employment increases to the extent that job seekers put effort in their search and search intensively (Kanfer et al., 2001; 
Van Hooft et al., in press). However, job search can be difficult and stressful, and is associated with various negative experiences such as rejections or failing to find job leads (Song et al., 2009), making job seekers prone to feelings of self-doubt, anxiety, self-criticism, and rumination (e.g., Wanberg et al., 2012). This makes job search an emotional experience that may harm job seekers' well-being (McKee-Ryan et al., 2005). Understandably, job seekers can become discouraged during their search and postpone or hold off searching for a job, which lengthens the duration of their unemployment, leading to adverse consequences for themselves, their families, and society as a whole (Klehe and Van Hooft, 2018).

Several scholars have called for research that investigates ways in which job seekers can deal with negative job search experiences to reduce their negative emotional impact (e.g., Song et al., 2009; Turban et al., 2013). This is important because while negative affect during job search frequently occurs, it is positive affectivity that enhances job search success (Turban et al., 2013). Self-compassion may be a promising coping mechanism for job seekers when experiencing negative job search events because self-compassioned cognitions make individuals respond to failure with kindness to the self, make them aware that failure is human, and let them acknowledge their emotions with a healthy distance (Neff, 2003a). A recent correlational study has indeed shown that job seekers higher on trait self-compassion were less affected by negative job search experiences, such that they felt more positively and less negatively while searching for a job (Kreemers et al., 2018).

Although it is promising that naturally occurring variation in self-compassion is related to job seeker affect, an important remaining question is if and how job seekers' self-compassion can be increased, and whether this results in more emotionally balanced responses during job search. In the current study, we therefore build on previous research (e.g., Leary et al., 2007; Shapira and Mongrain, 2010; Breines and Chen, 2012; Zhang and Chen, 2016) to develop an intervention composed of online writing exercises that facilitate taking a self-compassioned perspective toward job search difficulties. In an experimental field study we tested whether this online intervention indeed increases job seekers' state self-compassion and subsequently makes them feel better, as compared to a control condition composed of online writing exercises in which job seekers reflect freely on their difficulties.

The current study aims to contribute to job search interventions research, by showing that self-compassion has the potential to aid job seekers in effectively dealing with stress that occurs as a consequence of negative job search experiences. This is important as research thus far could not identify stress management interventions as effective components of job search interventions (Liu et al., 2014). Further, we extend prior research by Kreemers et al. (2018), who showed a relationship between trait self-compassion and job seekers' affect. Because their design was correlational, we cannot rule out the possibility that this relationship is spurious (e.g., affected by omitted third variables). Our experimental design allows for drawing causal conclusions regarding the impact of self-compassion on job seekers' affective responses to their job search experiences. This is important for theory, as it provides a stringent test of selfcompassion theory in the context of job search, but also for practice. Practical recommendations often rely on the notion of causality (e.g., Aguinis and Edwards, 2014; Eden, 2017). Hence, this study provides tools that can be implemented in practice, such as writing exercises to facilitate taking a selfcompassioned perspective on job search difficulties to benefit job seekers' emotions.

In addition to testing whether writing exercises promote job seekers' state self-compassion and consequently positively influence their affect, we aim to increase our understanding of the process through which self-compassion influences affect. Based on theorizing and prior research, we propose reduced self-criticism as underlying mechanism that drives the effects of the self-compassion intervention. Although previous research has shown a negative relation between self-compassion and self-criticism (Gilbert and Procter, 2006), self-criticism has not been tested as mediator between self-compassion and affect. As such, we aim to contribute to the self-compassion literature by uncovering an important underlying mechanism that explains the effects of self-compassion. Understanding how self-compassion makes job seekers feel better is also important for practice to target sensitive groups (e.g., those who suffer more from self-criticism; Shapira and Mongrain, 2010) who could benefit from a self-compassion intervention.

\section{Job Search and Mental Well-Being}

Job search requests cyclical self-regulatory behavior that is purposive and self-organized (Kanfer et al., 2001). It includes a range of activities such as searching for vacancies, having network conversations, contacting employment agencies, and submitting applications. The amount of time and effort that job seekers spend on job search activities is positively related to job search success (Kanfer et al., 2001; Van Hooft et al., in press). However, during job search there is hardly a clear pathway toward reaching the desired employment outcome. People oftentimes receive little feedback on the steps they take along the way other than rejections, which makes it hard to perceive progress. Results of a daily diary study show that a lack of job search progress adversely relates to how job seekers feel (Wanberg et al., 2010). Furthermore, the more time job seekers spend on their job search, the more negative job search experiences they have and the higher their distress (Song et al., 2009). Qualitative research has indicated that job seekers are especially prone to feelings of self-doubt, anxiety, self-criticism, and rumination (Wanberg et al., 2012). Job search difficulties such as failure to find suitable leads, lack of job search progress, and rejections elicit negative thoughts and feelings, which in turn harm job seekers' mental well-being. In addition to eliciting negative emotions, job search difficulties also undermine positive emotions (Kreemers et al., 2018), which has consequences for job search outcomes, as especially positive feelings are related to job search success (Turban et al., 2013). Therefore, it is important to identify how negative affective responses during 
job search can be reduced and positive affective responses can be increased.

\section{Self-Compassion}

A healthy way to respond to negative experiences such as setbacks, humiliation, and failure is reflecting on them with self-compassion. Self-compassion emanated from Buddhist philosophy and is an emotion-focused coping strategy. It is different from traditional emotion regulation strategies in that it does not aim to alter people's emotional state, but rather allows for emotions to exist in kind awareness (Neff, 2003a). Self-compassion entails three basic components: selfkindness, common humanity, and mindfulness. People who are self-compassioned respond to their failures with self-kindness and understanding (self-kindness) rather than with harsh selfjudgment, they are understanding of the shared nature of their experiences (common humanity) rather than feeling isolated, and they acknowledge their emotions with mindful acceptance (mindfulness) rather than ignoring or exaggerating them (Neff, 2003b). While these components are conceptually distinct, they also interact so as to mutually enhance and engender one another (Neff, 2003a). Self-compassion should not be confused with selfpity because people who pity themselves feel isolated in their misery and fail to recognize the shared nature of their experience (Neff, 2003a). Self-compassion also differs from self-esteem, in that it constitutes more stable feelings of self-worth enabling people to see themselves and their flaws with more clarity than self-esteem, which is more contingent on positive ego-focused outcomes (Neff and Vonk, 2009).

Self-compassionate individuals are better at withstanding experiences of pain and failure, because these experiences are not met with harsh self-condemnation, feelings of isolation, or over-identification with thoughts and emotions. Therefore, there are lower incidences of anxiety and depression among selfcompassionate individuals and better mental health outcomes such as more connectedness and subjective well-being (Neff, 2003a,b; Neff et al., 2005, 2007). Previous research shows that people who are able to reflect on their experiences with self-compassion generally feel better and have more moderate responses to unpleasant and self-relevant experiences than people who are not able to reflect on their experiences with selfcompassion (e.g., Neff et al., 2005, 2007; Leary et al., 2007). For example, research showed that students who were instructed to be more self-compassioned experienced less negative affect in response to unfavorable feedback (Leary et al., 2007). Other research showed that students dealt more adaptively with academic failure when they had more self-compassion (Neff et al., 2005). The beneficial role of self-compassion is also apparent in studies with clinical samples with participants suffering from shame or trauma (e.g., Thompson and Waltz, 2008; Raes, 2010).

We propose that self-compassion can be helpful during the job search process, which is usually full of self-relevant negative experiences. A recent correlational study indeed showed that job seekers higher on trait self-compassion experienced more positive and fewer negative emotions during their job search than job seekers lower on trait self-compassion (Kreemers et al., 2018). Given the aforementioned theorizing and empirical support for the beneficial psychological effect of self-compassion in times of perceived failure and setback, we expect that stimulating job seekers to reflect on their job search experiences with self-compassion will decrease negative affect and increase positive affect in comparison to job seekers who reflect on their experiences freely.

\section{Enhancing State Self-Compassion}

Given that state self-compassion relates to an array of beneficial psychological outcomes, there have been various attempts to develop methods aimed at stimulating self-compassion (e.g., Gilbert and Procter, 2006; Adams and Leary, 2007; Leary et al., 2007; Shapiro et al., 2007; Shapira and Mongrain, 2010; Neff, 2011; Breines and Chen, 2012; Smeets et al., 2014; Zhang and Chen, 2016; Au et al., 2017). The most simple example is letting participants know that they were not alone in their experience and encouraging them to not be hard on themselves (cf. Adams and Leary, 2007; Breines and Chen, 2012, Experiment 3). More elaborate forms of stimulating self-compassion are continuous practice with a multitude of exercises intended to move toward a kinder, more mindful mindset that acknowledges the shared nature of negative experiences (see Neff, 2011; Smeets et al., 2014). There are also various therapy forms that have incorporated self-compassion (e.g., Compassion-Based Therapy, Gilbert and Procter, 2006; Mindfulness-Based Stress Reduction, Kabat-Zinn, 1982) and have been shown to successfully increase self-compassion (e.g., Shapiro et al., 2007; Au et al., 2017). A thorough but more accessible option than weekly meetings and therapy is having participants engage in self-compassion writing exercises (Leary et al., 2007; Breines and Chen, 2012, Experiment 5; Shapira and Mongrain, 2010; Zhang and Chen, 2016). Participants who were instructed to reflect on a personal weakness and take a self-compassioned and understanding perspective have been shown to have more state self-compassion than participants who were instructed to contrast their weakness with things they were proud of or describe their hobby after reflecting on a weakness (Breines and Chen, 2012).

Based on these positive effects in previous studies (e.g., Leary et al., 2007; Breines and Chen, 2012, Experiment 5; Zhang and Chen, 2016), in the current study we adopted the self-compassion writing exercise method and adapted it to the job search setting. Specifically, we instructed job seekers online to reflect on their worst job search experience and then asked them to reflect on this experience with self-compassion (i.e., self-compassion condition) or freely (i.e., control condition). Based on previous research using a comparable design (Leary et al., 2007, Experiment 5), we expect that after the writing exercise job seekers in the self-compassion condition will have more state self-compassion than job seekers in the control condition, which in turn will result in less negative affect and more positive affect. Previous research by Shapira and Mongrain (2010), who also made use of writing exercises, has shown that the effects of self-compassion interventions can have lasting effects. Therefore, we measured job seekers' affect immediately after the exercises and we measured affect in a follow-up measurement 1 week later. As such, we extend previous research by Leary et al. (2007), who measured 
affect only directly after the exercises, by exploring whether the effects of the self-compassion exercise last over time.

\section{The Mediating Role of Self-Criticism}

Furthermore, we expect that the beneficial influence of state self-compassion on affect can be attributed to reduced selfcriticism. Negative experiences in personally relevant areas of life, such as job search, can make people more self-critical (Wanberg et al., 2012; Pinto-Gouveia et al., 2013). When people perceive personal failure or inadequacies (e.g., during job search), they tend to have an exaggerated focus on the implications of this experience for their self-worth, leading to feelings of isolation and overly severe judgments and criticism of the self (Neff, 2003a). Indeed negative job search experiences such as rejections or lack of progress have been shown to make job seekers prone to feelings of self-criticism (Wanberg et al., 2012). Neff (2003a) emphasizes that self-compassion is most relevant in situations that elicit feelings of shame and self-criticism, because self-compassion counteracts these feelings by means of its three mutually enhancing components. Selfkindness softens the self-consciousness that is strengthened though harsh self-judgment. Common humanity, that is, realizing that failure and personal suffering is shared, lessens the blame placed on oneself, further reducing self-criticism (Neff, 2003a). Finally, mindfulness contributes to reducing self-criticism by increasing the other two components of self-compassion. The non-judgmental, detached stance of mindfulness increases self-understanding and self-kindness (Jopling, 2000), whereas the balanced perspective-taking of mindfulness directly counters the egocentrism that causes feelings of isolation and separateness from the rest of humanity and thus increases feelings of interconnectedness (Elkind, 1967).

Empirical evidence further supports the notion that selfcompassion is negatively related to self-criticism (Neff, 2003b; Gilbert and Procter, 2006; Neff et al., 2007), and that selfcriticism is related to maladaptive outcomes such as depression (Blatt et al., 1982; Dunkley and Blankstein, 2000; Dunkley et al., 2003) and higher negative affect and lower positive affect (Zuroff et al., 1999). Therefore, we expect that reducing job seekers' self-critical thoughts through self-compassioned cognitions when reflecting on a negative job search experience will promote their positive affect and reduce their negative affect. In other words, we expect that job seekers in the self-compassion condition report lower negative affect and higher positive affect than job seekers in the control condition as mediated by state self-compassion and self-criticism.

\section{MATERIALS AND METHODS}

\section{Participants and Design}

We designed a between-participants experimental field study with two conditions and three measurement times. More specifically, we administered a baseline questionnaire before the intervention at Time 0 , conducted the intervention (i.e., a self-compassion or control writing exercise) 6 days $^{1}$ later, immediately followed by the Time 1 questionnaire, and a Time 2 questionnaire 5-7 days later.

Job search occurs in several stages of people's lives, as reflected by job seeking research that has typically sampled students seeking for employment upon graduation, unemployed individuals looking for reemployment, and employed individuals seeking for a job change (e.g., Boswell et al., 2012; Van Hooft et al., in press). Rather than restricting to a particular group, in the present study we included job seekers from all these groups. Specifically, we recruited job seekers who were searching for a paid job (of at least $20 \mathrm{~h}$ ) via the alumni department of a Dutch university, employment agencies, and social media, to participate in a study about job search. To be eligible for the study, participants had to be currently searching for a job and had to have searched in the last month. This ensured that participants had job search experiences to reflect on during the selfcompassion/control writing exercise. Participants received $€ 10$ for completing all three questionnaires and the writing exercise.

A total of 354 participants started the Time 0 questionnaire. Of these, 288 participants met the eligibility criteria (currently searching for a job and having searched in the last month) and 205 finished the self-compassion/control writing exercise and subsequent Time 1 questionnaire. We excluded 18 participants from the analyses because they indicated to have found a job at Time 1. We further read all responses to the writing exercises, which led to the exclusion of seven participants from the analyses because their responses were absent or unrelated to job search. The final sample consisted of 180 participants, with complete data on both Time 0 and Time 1. Of these, 173 participants also completed the Time 2 questionnaire.

The average age in the final sample of 180 participants was 29 years $(S D=9.17)$ and $75.60 \%$ were women $(n=136)$. Most participants (59.40\%) had a paid (student) job $(n=107)$, in which they worked an average of $26.08 \mathrm{~h}$ a week $(S D=11.78)$, and $9.40 \%$ had an unpaid job $(n=17)$, with an average of $11.53 \mathrm{~h} \mathrm{a}$ week $(S D=8.64)$. Of the employed participants $32.20 \%$ worked under temporary employment, $13.90 \%$ had a permanent position, $11.10 \%$ was volunteer or intern, and $4.40 \%$ worked as freelancer. The sample was generally highly educated $(74.40 \%$ university degree, $9.40 \%$ higher vocational education). Some participants $(16.70 \%)$ were still studying but would graduate within 6 months (within 3.37 months on average). Mean job search duration at Time 0 was 5.71 months $(S D=6.06)$.

\section{Procedure}

At Time 0 participants received an e-mail with a link to the baseline questionnaire. After having filled out the informed consent, participants had 14 days to finish the baseline questionnaire. Participants received reminders 3,5 , and 7 days after receiving a questionnaire if they had not finished the questionnaire. The Time 0 questionnaire contained questions

${ }^{1}$ Due to logistic reasons the time between the baseline questionnaire and the intervention varied. The average time was 6.81 days $(S D=2.71)$. These varying times are not problematic as the average time between Time 0 and Time 1 did not differ between conditions, $t(178)=1.22, p=0.225$, and our research questions focus on differences between the conditions. 
about $^{2}$ job search history, demographics, trait self-compassion, self-criticism, and affect.

One day after finishing Time 0, participants received a link to the writing exercise and Time 1 questionnaire. Participants were first asked to describe their worst job search experience in the past period. ${ }^{3}$ After having provided a description of the event, participants were randomly assigned to the selfcompassion condition or the control condition. In the selfcompassion condition participants were asked to reflect on their negative job search experience with self-compassion and to report these reflections in writing. In the control condition participants were asked to reflect on their negative job search experience by freely describing their naturally occurring thoughts and feelings. The writing exercise was followed by the Time 1 questionnaire, which included measures of state self-compassion, self-criticism, and affect. Five days after filling out the Time 1 questionnaire participants received the link to the Time 2 questionnaire, which included the same measures as at Time 1. Participants had 3 days to finish the Time 2 questionnaire and received reminders at days 2 and 3 if they had not finished the questionnaire.

\section{Self-Compassion and Control Assignments}

The self-compassion intervention was based on the laboratory experiment of Leary et al. (2007) with psychology students, showing that self-compassion can be manipulated with a writing exercise using three questions tapping into the three selfcompassion dimensions. Original materials were translated into Dutch and adjusted to the job search context and pilot tested to ensure that the instructions were clear. ${ }^{4}$ First, participants in both conditions were asked to describe a negative job search event in detail, how many weeks ago it occurred, what happened, who was present, and what had led to the event. Then, participants in the self-compassion condition answered

\footnotetext{
${ }^{2}$ In addition to the variables mentioned in the Section "Materials and Methods," the Time 0 questionnaire also contained various other personality traits (i.e., perfectionism, self-esteem, learning goal orientation, openness to change, incremental beliefs regarding emotions, and neuroticism), potential mediators (i.e., fear of failure, job search self-efficacy, and rumination), and dependent variables (i.e., exhaustion, vitality, job search intention, and job search time). At Time 1 participants were first asked whether they had negative job search experiences and to what extent they perceived job search progress in the last month before proceeding with the writing task. After the intervention the same mediator and dependent variables were measured as in the Time 0 questionnaire and these were also measured at Time 2 .

${ }^{3}$ The negative job search experiences that participants described, included experiences related to forethought and exploration (e.g., realization that one's educational or work profile does not fit the qualifications necessary for the type of job people are interested in), preparatory job search behavior (e.g., not meeting advertised job requirements due to lack of work experience; negative networking experiences), active job search behavior (e.g., self-doubt in how to present oneself; not being taken seriously or negative interactions in the job interview), selection result (e.g., unfair or unexpected rejections; poor communication of the rejection), and the entire job search process (e.g., insecurity of finding a job; dissatisfaction with progress and feeling stuck; indifference of hiring organizations). For more information, see Kreemers (2020).

${ }^{4}$ For the pilot test we asked seven individuals to complete the writing exercise in presence of a researcher, using a think-aloud instruction. Based on the pilot we slightly rephrased the third question by adding a more specific instruction (i.e., "Imagine your emotions as clouds drifting by. Which emotions are drifting by? Please describe them.")
}

three questions regarding the negative event tailored to the three dimensions of self-compassion (cf. Neff, 2003a; Leary et al., 2007). Specifically, they were asked to (a) indicate in what ways other people experience similar events (common humanity), (b) write a paragraph directed to themselves in a tone they would use for a friend (self-kindness), and (c) picture the emotions that they associated with the event as temporary states and describe them objectively and with mindfulness (mindful acceptance).

In the control condition, participants were asked to freely reflect on the negative job search event and describe their naturally occurring thoughts and feelings. We deliberately chose an active writing control condition as opposed to a passive control condition in which no task was assigned to the participants to ensure that we could attribute any effect of the self-compassion condition to self-compassion rather than to the mere process of reflecting on and writing about a certain event (cf. Leary et al., 2007). This is because writing about an emotional event is an intervention by itself, which has been shown to positively influence people's affective state (Pennebaker et al., 1990).

\section{Measures Trait Self-Compassion}

Trait self-compassion was measured at Time 0 with the SelfCompassion Scale (Neff, 2003b; Neff and Vonk, 2009), which consists of 26 statements (e.g., "I'm tolerant to my own flaws and inadequacies" and "I try to see my failings as part of the human condition"). Participants indicated the extent to which they agreed with these statements on a 5-point scale ranging from strongly disagree (1) to strongly agree (5). Cronbach's alpha was 0.94 .

\section{State Self-Compassion}

At Time 1 after the intervention, participants were asked to indicate on a 7-point scale to what extent they agreed with three statements regarding their current self-compassion regarding their job search. We selected three ${ }^{5}$ statements from the SelfCompassion Scale of Neff (2003b) that each reflected one component of self-compassion (cf. Breines and Chen, 2012; Experiment 4) and adjusted the items to make them specific to job search (i.e., "When I look back at my job search experiences of the past month: I now treat myself kindly with respect of my job search experiences; I now try to have a balanced stance toward my job search experiences; I see my weaknesses in search for a job now as part of being human"; $\alpha=0.71$ ).

\section{Self-Criticism}

Self-criticism was measured at Time 0 and 1 with 10 items of the Self-Criticism Questionnaire (Brewin et al., 1992), adapted to the current job search context. Specifically, we adjusted

\footnotetext{
${ }^{5} \mathrm{We}$ originally selected the same four items as Breines and Chen (2012). In adjusting the items to the job search context one item became conceptually illogical as part of a state self-compassion measure right after the writing exercise, because it addressed job seekers' self-compassioned attitudes during job search, while there had been no time to search since the exercise. Therefore, we decided to run the analyses with the remaining three items which each represented one of the three components of self-compassion.
} 
the formulation such that the items apply to how self-critical participants feel considering their job search at the moment of measurement rather than generally (e.g., "I am very critical of myself in searching for a job"; "I blame myself for things that go wrong during job search"; "I find that I don't live up to my own standards or ideals in my job search). Participants were asked to indicate their agreement with the statements on a 5-point scale ranging from totally disagree (1) to totally agree (5). Cronbach's alpha was 0.87 at both measurement times.

\section{Affect}

Affective responses can be classified along hedonic tone (i.e., positive vs. negative) and activation level (i.e., activating vs. deactivating) (Feldman Barrett and Russell, 1998; Russell, 2003; Yik et al., 2011). This results in four types of affect: activating negative affect (e.g., nervous), activating positive affect (e.g., enthusiastic), deactivating negative affect (e.g., disappointed), and deactivating positive affect (e.g., at ease). Accordingly, we measured affect at Time 0,1 , and 2 with a selection of 16 emotions from the PANAS (Crawford and Henry, 2004) that clearly fell into the four affect categories of the emotion circumplex (Yik et al., 2011). Each affect category was measured with four emotions, that is, negative activating affect with nervous, stressed, frustrated, and jittery ( $\alpha=0.84-0.87)$, negative deactivating affect with sad, disappointed, down, and downcast ( $\alpha=0.89-0.91)$, positive activating affect with enthusiastic, cheerful, lively, and energetic ( $\alpha=0.94-0.96$ ), and positive deactivating with at ease, calm, relaxed, and laid back ( $\alpha=0.94$ at all times). Participants indicated the extent to which they felt the emotions when they considered their job search experiences of the last month on a 5point scale ranging from strongly disagree (1) to strongly agree (5).

\section{Demographics}

Demographics were measured at Time 0. Specifically, age, gender, education (primary school, high school level 1, 2, or 3, intermediate vocational education, higher vocational education, or university degree), employment position (employed or unemployed), and job search duration (in months) were measured as control variables, as meta-analyses has shown their importance to the job search process (Kanfer et al., 2001).

With confirmatory factor analyses in Mplus 7.11 we tested a 6factor model with all Time 1 variables (i.e., state self-compassion, self-criticism, and the four affect variables) against theoretical plausible alternative models (i.e., collapsing state self-compassion and self-criticism, collapsing the two negative and the two positive affect variables, collapsing all affect variables). The 6factor model fit the data significantly better than all alternative models (all $\Delta \chi^{2}$ larger than 101.39; all $p$-values $<0.05$; all $\Delta \mathrm{CFI}>0.03)$.

\section{RESULTS}

\section{Preliminary Analyses}

To assess whether the participants in the self-compassion $(n=82)$ and control condition $(n=98)$ differed before the intervention, we compared participants' demographics, employment status, job search duration, trait self-compassion, self-criticism, and affect at Time 0 between both conditions. Supporting the successfulness of the random assignment, there were no significant differences between conditions for age, $t(174.38)=1.70, p=0.09$, gender, $\chi^{2}(1)=1.32, p=0.72$, education, $\chi^{2}(1)=0.53, p=0.47$, employment status, $\chi^{2}(1)=1.68, p=0.20$, job search duration, $t(178)=0.65, p=0.52$, trait self-compassion, $t(178)=-1.57$, $p=0.12$, self-criticism, $t(156.50)=0.67, p=0.51$, negative activating affect, $t(178)=-0.54, p=0.59$, negative deactivating affect, $t(178)=-0.38, p=0.70$, positive activating affect, $t(178)=-0.66, p=0.51$, and positive deactivating affect, $t(178)=-0.08, p=0.94$. Given the absence of significant $a$ priori differences between the conditions there is no need to control for these Time 0 variables when testing the effectiveness of the intervention. Table 1 shows the correlations between all study variables.

\section{Effects of the Intervention}

First, we tested the effects of the intervention on state selfcompassion, measured directly after the writing exercises (Time $1)$. An independent $t$-test showed that participants in the selfcompassion condition $(M=5.09, S D=1.00)$ scored significantly higher on Time 1 state self-compassion than participants in the control condition $(M=4.78, S D=0.99), t(178)=2.11$, $p=0.036, d=0.32$. In other words, the self-compassion writing exercises had a small to medium-sized positive effect on selfcompassion toward job search experiences as compared to the control writing exercises.

Second, we tested the effects of the intervention on job seekers' affect, as mediated by state self-compassion and selfcriticism. We examined these indirect effects using the PROCESS bootstrapping method Model 6 (Hayes, 2012) in SPSS with the variables measured at Time 1 . In line with affect theory, we ran an analysis for each of the four types of affect as dependent variable. In each analysis we entered condition as independent variable and state self-compassion and self-criticism as mediators. The pattern of results was roughly similar across different types of affect and is shown in Figure 1. For each type of affect there was no direct relation between condition and affect, $b$ ranged from -0.24 to $0.28, t(176)$ ranged from -1.36 to 1.59 , all $p$ values $>0.05$, and no direct relation between condition and self-criticism, $b=0.03, p=0.79$. However, for each type of affect results did show two significant indirect effects: from condition through state self-compassion to affect (indirect effect A), and from condition to state self-compassion to self-criticism to affect (indirect effect B). This means that the effects of condition on affect run fully through state self-compassion, and partially also through self-criticism. As shown in Figure 1, the indirect effects are composed of the following relations. Regarding effect A, there was a positive relation between condition and state self-compassion. Further, state self-compassion had a negative relation with both types of negative affect and a positive relation with both types of positive affect. Regarding effect B, there was a negative relation between state self-compassion and selfcriticism. Further, self-criticism had a positive relation with both types of negative affect and a negative relation with both types of positive affect. 
TABLE 1 | Means, standard deviations, and correlations among the study variables.

\begin{tabular}{|c|c|c|c|c|c|c|c|c|c|c|c|c|c|c|c|c|c|c|c|c|c|c|c|}
\hline & $M$ & $S D$ & 1 & 2 & 3 & 4 & 5 & 6 & 7 & 8 & 9 & 10 & 11 & 12 & 13 & 14 & 15 & 16 & 17 & 18 & 19 & 20 & 21 \\
\hline \multicolumn{24}{|l|}{ Time 0} \\
\hline (1) Age & 29.13 & 9.17 & & & & & & & & & & & & & & & & & & & & & \\
\hline (2) Gender ${ }^{a}$ & 1.76 & 0.43 & -0.03 & & & & & & & & & & & & & & & & & & & & \\
\hline (3) Education ${ }^{b}$ & 0.84 & 0.37 & $-0.31^{\star \star}$ & -0.04 & & & & & & & & & & & & & & & & & & & \\
\hline $\begin{array}{l}\text { (4) Employment } \\
\text { status }^{c}\end{array}$ & 0.59 & 0.49 & $-0.24^{\star \star}$ & 0.11 & 0.07 & & & & & & & & & & & & & & & & & & \\
\hline $\begin{array}{l}\text { (5) Job search } \\
\text { duration }^{\text {d }}\end{array}$ & 5.71 & 6.06 & $0.63^{* \star}$ & -0.03 & $-0.19^{\star}$ & 0.01 & & & & & & & & & & & & & & & & & \\
\hline $\begin{array}{l}\text { (6) Trait } \\
\text { self-compassion }\end{array}$ & 3.08 & 0.64 & $0.20^{\star \star}$ & $-0.20^{\star \star}$ & -0.04 & -0.13 & 0.07 & & & & & & & & & & & & & & & & \\
\hline (7) Self-criticism & 2.81 & 0.86 & $-0.23^{\star *}$ & 0.01 & $0.21^{\star *}$ & 0.07 & 0.00 & $-0.58^{\star *}$ & & & & & & & & & & & & & & & \\
\hline $\begin{array}{l}\text { (8) Negative } \\
\text { activating affect }\end{array}$ & 4.38 & 1.41 & $-0.29^{\star \star}$ & $0.18^{\star}$ & $0.20^{\star *}$ & -0.02 & -0.10 & $-0.38^{\star \star}$ & $0.45^{\star \star}$ & & & & & & & & & & & & & & \\
\hline $\begin{array}{l}\text { (9) Negative } \\
\text { deactivating affect }\end{array}$ & 3.79 & 1.57 & $-0.17^{\star}$ & $0.18^{\star}$ & 0.05 & -0.10 & -0.04 & $-0.47^{\star \star}$ & $0.50^{\star \star}$ & $0.69^{* *}$ & & & & & & & & & & & & & \\
\hline $\begin{array}{l}\text { (10) Positive } \\
\text { activating affect }\end{array}$ & 3.89 & 1.49 & -0.08 & -0.10 & 0.03 & 0.05 & $-0.20^{\star \star}$ & $0.31^{* \star}$ & $-0.32^{\star *}$ & $-0.32^{\star \star}$ & $-0.43^{\star \star}$ & & & & & & & & & & & & \\
\hline $\begin{array}{l}\text { (11) Positive } \\
\text { deactivating affect }\end{array}$ & 3.63 & 1.41 & 0.08 & $-0.21^{\star \star}$ & -0.11 & -0.04 & -0.11 & $0.47^{\star \star}$ & $-0.46^{\star \star}$ & $-0.53^{\star \star}$ & $-0.47^{\star \star}$ & $0.67^{* \star}$ & & & & & & & & & & & \\
\hline \multicolumn{24}{|l|}{ Time 1} \\
\hline (12) Conditione & 0.46 & 0.50 & -0.12 & 0.03 & -0.05 & 0.10 & -0.05 & 0.12 & -0.05 & 0.04 & 0.03 & 0.05 & 0.01 & & & & & & & & & & \\
\hline $\begin{array}{l}\text { (13) State } \\
\text { self-compassion }\end{array}$ & 4.92 & 1.00 & 0.03 & -0.01 & 0.02 & 0.00 & 0.05 & $0.37^{\star \star}$ & $-0.34^{\star \star}$ & $-0.29^{\star \star}$ & $-0.30^{\star \star}$ & $0.33^{* *}$ & $0.36^{\star \star}$ & $0.16^{\star}$ & & & & & & & & & \\
\hline (14) Self-criticism & 2.87 & 0.85 & $-0.30^{\star \star}$ & 0.09 & $0.17^{\star}$ & 0.08 & -0.06 & $-0.56^{\star \star}$ & $0.78^{* *}$ & $0.52^{* \star}$ & $0.55^{\star \star}$ & $-0.26^{\star \star}$ & $-0.44^{\star \star}$ & -0.05 & $-0.44^{\star *}$ & & & & & & & & \\
\hline $\begin{array}{l}\text { (15) Negative } \\
\text { activating affect }\end{array}$ & 4.03 & 1.47 & $-0.26^{\star \star}$ & 0.10 & $0.25^{* \star}$ & 0.02 & -0.14 & $-0.35^{\star \star}$ & $0.48^{* *}$ & $0.71^{\star \star}$ & $0.53^{* \star}$ & $-0.36^{\star \star}$ & $-0.51^{\star \star}$ & -0.14 & $-0.44^{\star *}$ & $0.58^{\star \star}$ & & & & & & & \\
\hline $\begin{array}{l}\text { (16) Negative } \\
\text { deactivating affect }\end{array}$ & 3.81 & 1.47 & -0.10 & $0.18^{\star}$ & 0.07 & -0.02 & -0.06 & $-0.39^{\star \star}$ & $0.45^{\star \star}$ & $0.47^{\star \star}$ & $0.64^{* *}$ & $-0.44^{\star \star}$ & $-0.44^{\star \star}$ & -0.15 & $-0.52^{\star \star}$ & $0.60^{\star *}$ & $0.73^{\star *}$ & & & & & & \\
\hline $\begin{array}{l}\text { (17) Positive } \\
\text { activating affect }\end{array}$ & 3.96 & 1.39 & 0.05 & -0.10 & -0.08 & -0.05 & -0.06 & $0.33^{\star \star}$ & $-0.35^{\star \star}$ & $-0.34^{\star \star}$ & $-0.42^{\star \star}$ & $0.57^{\star *}$ & $0.48^{\star \star}$ & 0.09 & $0.48^{* \star}$ & $-0.35^{\star \star}$ & $-0.47^{\star *}$ & $-0.59^{\star *}$ & & & & & \\
\hline $\begin{array}{l}\text { (18) Positive } \\
\text { deactivating affect }\end{array}$ & 4.06 & 1.37 & 0.08 & $-0.18^{\star}$ & $-0.15^{\star}$ & -0.04 & 0.04 & $0.38^{* \star}$ & $-0.40^{* *}$ & $-0.52^{\star \star}$ & $-0.48^{\star \star}$ & $0.42^{* *}$ & $0.57^{\star \star}$ & $0.17^{*}$ & $0.48^{* \star}$ & $-0.45^{\star \star}$ & $-0.69^{* \star}$ & $-0.64^{\star *}$ & $0.66^{\star \star}$ & & & & \\
\hline \multicolumn{24}{|l|}{ Time 2} \\
\hline $\begin{array}{l}\text { (19) Negative } \\
\text { activating affect }\end{array}$ & 3.64 & 1.39 & $-0.27^{\star \star}$ & 0.13 & $0.16^{*}$ & 0.00 & -0.10 & $-0.37^{\star \star}$ & $0.50^{* *}$ & $0.70^{\star *}$ & $0.56^{* *}$ & $-0.41^{* *}$ & $-0.48^{\star \star}$ & -0.09 & $-0.39^{* \star}$ & $0.53^{\star \star}$ & $0.78^{\star \star}$ & $0.61^{* *}$ & $-0.50^{\star \star}$ & $-0.64^{\star \star}$ & & & \\
\hline $\begin{array}{l}\text { (20) Negative } \\
\text { deactivating affect }\end{array}$ & 3.18 & 1.46 & -0.07 & 0.09 & 0.08 & -0.05 & 0.06 & $-0.37^{\star \star}$ & $0.40^{* *}$ & $0.52^{\star \star}$ & $0.61^{\star *}$ & $-0.40^{* *}$ & $-0.43^{\star \star}$ & -0.09 & $-0.44^{\star *}$ & $0.44^{\star \star}$ & $0.57^{\star \star}$ & $0.66^{\star \star}$ & $-0.50^{\star \star}$ & $-0.50^{\star \star}$ & $0.73^{\star \star}$ & & \\
\hline $\begin{array}{l}\text { (21) Positive } \\
\text { activating affect }\end{array}$ & 4.22 & 1.44 & 0.08 & -0.08 & -0.04 & -0.08 & -0.08 & $0.23^{\star \star}$ & $-0.30^{* *}$ & $-0.27^{\star \star}$ & $-0.27^{\star \star}$ & $0.60^{* *}$ & $0.45^{\star \star}$ & 0.01 & $0.34^{* *}$ & $-0.28^{\star \star}$ & $-0.38^{\star \star}$ & $-0.41^{\star \star}$ & $0.68^{\star \star}$ & $0.43^{\star \star}$ & $-0.51^{\star \star}$ & $-0.48^{\star \star}$ & \\
\hline $\begin{array}{l}\text { (22) Positive } \\
\text { deactivating affect }\end{array}$ & 4.29 & 1.40 & $0.24^{\star *}$ & $-0.17^{\star}$ & -0.12 & 0.00 & 0.09 & $0.39^{* \star}$ & $-0.47^{\star \star}$ & $-0.48^{\star \star}$ & $-0.43^{\star \star}$ & $0.51^{* \star}$ & $0.55^{\star *}$ & 0.06 & $0.37^{\star \star}$ & $-0.44^{* *}$ & $-0.62^{* *}$ & $-0.53^{\star \star}$ & $0.54^{* *}$ & $0.65^{* \star}$ & $-0.72^{\star \star}$ & $-0.52^{\star \star}$ & $0.64^{*}$ \\
\hline
\end{tabular}

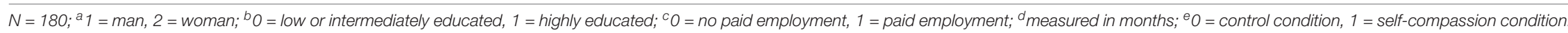
${ }^{*} p<0.05,{ }^{* *} p<0.01$. 




Indirect effect B: $b=-0.10,95 \%$ CI [-0.225, -0.007$]$

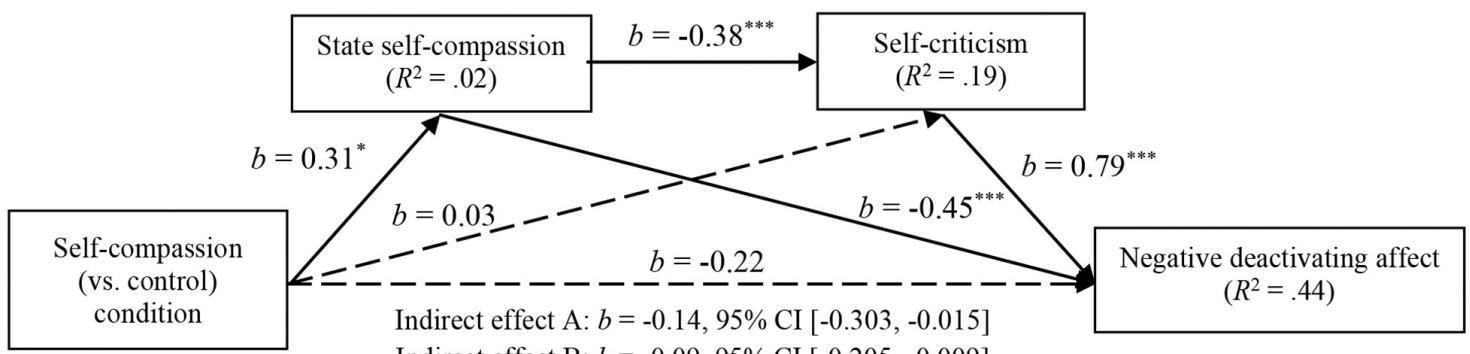

Indirect effect B: $b=-0.09,95 \%$ CI [-0.205, -0.009]


FIGURE 1 | Results of the effects of condition on the four affect variables, as mediated by state self-compassion and self-criticism. Indirect effect A: condition through state self-compassion to affect. Indirect effect B: condition through state self-compassion and self-criticism to affect. The dashed lines are not significant. ${ }^{*} p<0.05,{ }^{* *} p<0.01,{ }^{* * *} p<0.001$.

Third, we examined the extent to which the effects of the intervention on job seeker affect hold over time from Time 1 to Time 2. Table 2 presents the raw means over time for the two conditions. We conducted four repeated measures analyses of variance (ANOVA) with the different types of affect at each measurement point (Times 0,1 , and 2) as withinparticipant variables and condition as between-participant variable. The repeated measures ANOVA assumptions of normality and homogeneity of variance were met. However, Mauchly's test indicated that the assumption of sphericity had been violated for positive activating affect. Therefore, we corrected the degrees of freedom for positive activating affect using Huynh-Feldt estimates of sphericity $(\varepsilon=0.97)$. With contrast analyses we examined the changes in affect in the two conditions in more detail.

Results for negative activating affect showed a significant main effect of time, $F(2,346)=42.73, p<0.001, \eta_{\mathrm{p}}^{2}=0.20$, and a significant interaction between time and condition, $F(2,346)=5.68, p=0.004, \eta_{\mathrm{p}}^{2}=0.03$ (see Figure 2A). Contrast analyses showed a significant decrease in negative activating affect 
TABLE 2 | Descriptives of the four affect variables at the Time 0, Time 1, and Time 2 measurement for the control and the self-compassion condition.

\begin{tabular}{|c|c|c|c|c|c|c|c|}
\hline \multirow[t]{2}{*}{ Affect } & \multirow[t]{2}{*}{ Condition } & \multicolumn{2}{|c|}{ Baseline (T0) } & \multicolumn{2}{|c|}{ Post intervention (T1) } & \multicolumn{2}{|c|}{ Follow-up (T2) } \\
\hline & & $M$ & $S D$ & $M$ & $S D$ & $M$ & $S D$ \\
\hline \multirow[t]{2}{*}{ Negative activating affect } & Control & 4.31 & 1.40 & 4.19 & 1.42 & 3.75 & 1.33 \\
\hline & Self-compassion & 4.40 & 1.44 & 3.76 & 1.50 & 3.51 & 1.44 \\
\hline \multirow[t]{2}{*}{ Negative deactivating affect } & Control & 3.78 & 1.56 & 4.02 & 1.46 & 3.30 & 1.44 \\
\hline & Self-compassion & 3.80 & 1.60 & 3.55 & 1.48 & 3.03 & 1.47 \\
\hline \multirow[t]{2}{*}{ Positive activating affect } & Control & 3.82 & 1.48 & 3.85 & 1.39 & 4.21 & 1.40 \\
\hline & Self-compassion & 4.00 & 1.51 & 4.13 & 1.35 & 4.23 & 1.51 \\
\hline \multirow[t]{2}{*}{ Positive deactivating affect } & Control & 3.63 & 1.44 & 3.84 & 1.32 & 4.21 & 1.35 \\
\hline & Self-compassion & 3.68 & 1.37 & 4.36 & 1.33 & 4.38 & 1.45 \\
\hline
\end{tabular}

$N_{\text {control }}=95 ; N_{\text {self-compassion }}=80$.

between Time 0 and Time 1 in the self-compassion condition $\left(M_{\text {diff }}=-0.64, p<0.001\right)$, but not in the control condition. At Time 1, participants' mean negative activating affect was lower in the self-compassion condition than in the control condition, but this difference was only approaching significance $\left(M_{\text {diff }}=-0.43, p=0.055\right)$. Negative activating affect significantly decreased between Time 1 and Time 2 in both the selfcompassion $\left(M_{\text {diff }}=-0.25, p=0.018\right)$ and the control condition $\left(M_{\text {diff }}=-0.44, p<0.001\right)$. There was no significant difference in negative activating affect between conditions at Time 2 .

Similarly, for negative deactivating affect we found a significant main effect of time, $F(2,346)=27.28, p<0.001$, $\eta_{\mathrm{p}}^{2}=0.14$, and a significant interaction between time and condition, $F(2,346)=3.24, p=0.040, \eta_{p}^{2}=0.02$ (see Figure 2B). Contrast analyses showed a decrease in negative deactivating affect between Time 0 and Time 1 in the self-compassion condition that approached significance $\left(M_{\text {diff }}=-0.25, p=0.082\right)$, and an increase in the control condition that approached significance $\left(M_{\text {diff }}=0.24, p=0.069\right)$. At Time 1 , participants' mean negative deactivating was significantly lower in the self-compassion condition than in the control condition $\left(M_{\text {diff }}=-0.47, p=0.036\right)$. There was a significant decrease in negative deactivating affect between Time 1 and Time 2 for both control and self-compassion conditions $\left(M_{\text {diff }}=-0.72\right.$, $p<0.001 ; M_{\text {diff }}=-0.52, p<0.001$, respectively). There was no significant difference in negative deactivating affect between conditions at Time 2 .

Results for positive activating affect showed a significant main effect of time, $F(1.94,335.70)=5.60, p=0.004, \eta_{p}^{2}=0.03$, whereas the interaction between time and condition was not significant, $F(1.94,335.70)=0.90, p=0.41, \eta_{\mathrm{p}}^{2}=0.01$ (see Figure 2C). Positive activating affect did not increase between Time 0 and Time 1 in both conditions. At Time 1, participants' mean positive activating in the self-compassion condition was higher than in the control condition but not significantly $\left(M_{\text {diff }}=0.28, p=0.18\right)$. In the control condition there was a significant increase between Time 0 and Time $2\left(M_{\text {diff }}=0.39, p=0.005\right)$ and between Time 1 and Time $2\left(M_{\text {diff }}=0.36, p=0.002\right)$. There was no significant difference in positive activating affect between conditions at Time 2 .

For positive deactivating affect we found a significant main effect of time, $F(2,346)=23.73, p<0.001, \eta_{p}^{2}=0.12$, and a significant interaction between time and condition, $F(2,346)=3.33, p=0.037, \eta_{\mathrm{p}}^{2}=0.02$ (see Figure 2D). Contract analyses show that there was a significant increase between the Time 0 and Time 1 measure in the self-compassion condition $\left(M_{\text {diff }}=0.68, p<0.001\right)$, but not in the control condition. At Time 1 participants mean positive deactivating affect was higher in the self-compassion condition than in the control condition $\left(M_{\text {diff }}=0.52, p=0.011\right)$. Subsequently, positive deactivating affect increased significantly between Time 1 and Time 2 in the control condition $\left(M_{\text {diff }}=0.37, p=0.002\right)$, but not in the self-compassion condition. Therefore, the difference in positive deactivating affect between the conditions was no longer significant at Time 2 .

\section{DISCUSSION}

Job search is necessary to find a job but also negatively impacts job seekers' feelings due to an abundance of negative job search experiences, leading to reduced well-being. In the current study we tested whether reflecting on negative job search experiences with self-compassion through a writing exercise can alter job seekers' state self-compassion, and subsequently reduce their negative affect and increase their positive affect in comparison to reflecting on negative job search experiences freely.

Our results extend previous experimental research on selfcompassion (Leary et al., 2007; Breines and Chen, 2012). We found that the online self-compassion writing exercise had a small to medium-sized positive impact on job seekers' state self-compassion in comparison to reflecting freely. Since there were no significant differences between conditions in trait self-compassion before the intervention this finding shows that online writing exercises can effectively induce job seekers' state self-compassion with regard to their negative job search experiences, suggesting that people's self-compassion is malleable. Furthermore, we found that state self-compassion related positively to positive affect and negatively to negative affect. As we found no significant direct effects of the intervention on affect, but only through increased state self-compassion, our findings indicate that an increase in self-compassion is the explaining mechanism for our findings on job seekers' positive and negative affect. 


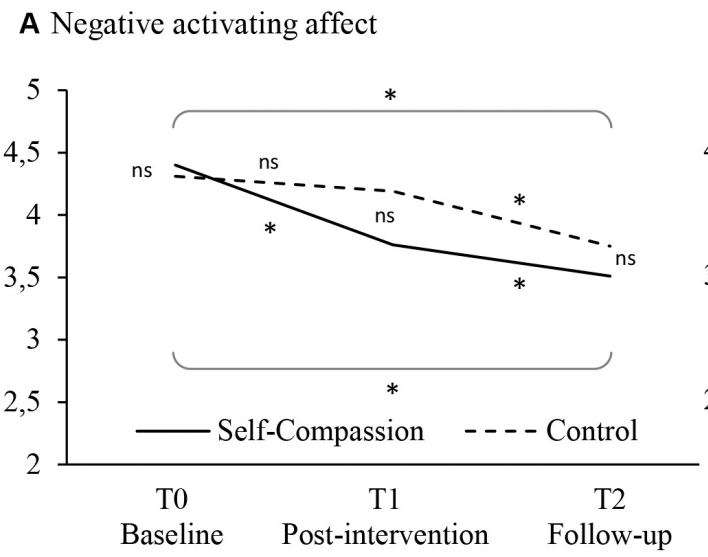

C Positive activating affect

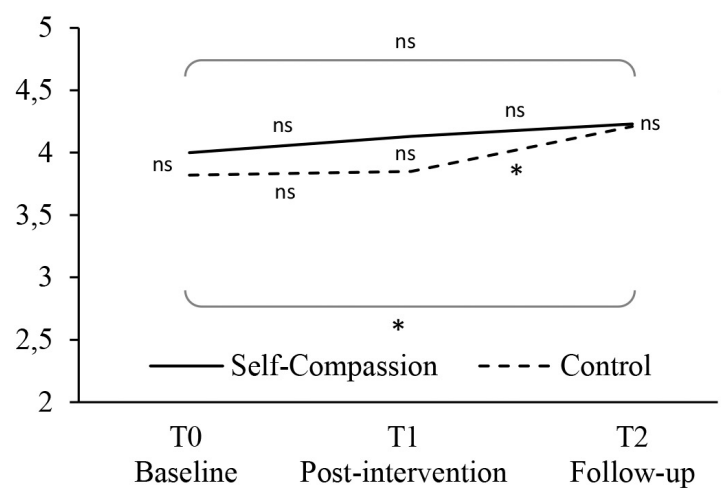

B Negative deactivating affect

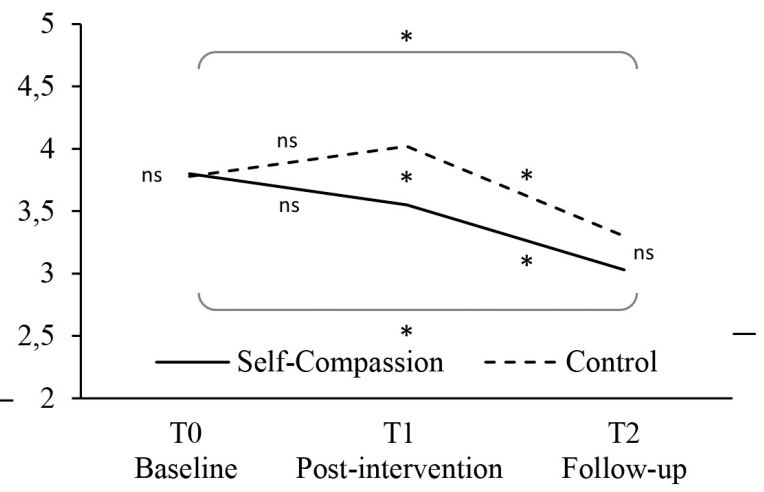

D Positive deactivating affect

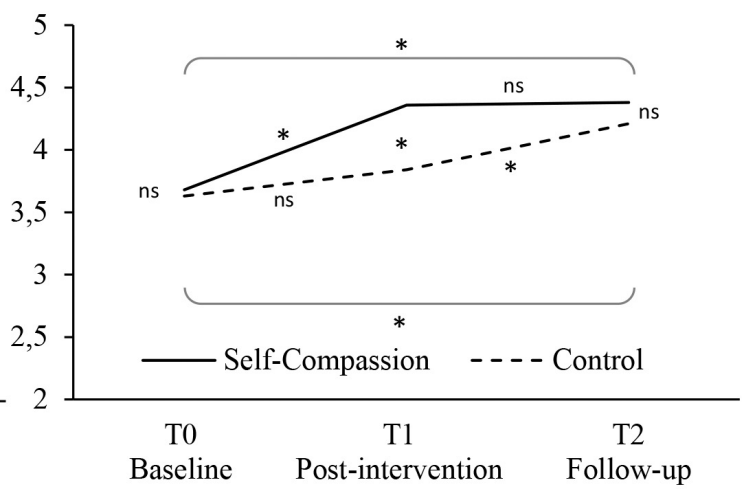

FIGURE 2 | Graphical representation of the means of the four affect variables at the baseline, post-intervention, and follow-up measurements for the self-compassion and control condition. (A) Negative activating affect. (B) Negative deactivating affect. (C) Positive activating affect. (D) Positive deactivating affect. Significant difference in affect between times and conditions is indicated with an asterisk; non-significant differences is indicated with ns.

Our findings further show that the effect of the selfcompassing writing exercise on affect is partly explained by reduced self-criticism. Specifically, through increasing job seekers' state self-compassion the intervention negatively influenced their self-criticism, which related positively to negative affect and negatively to positive affect. These findings can be explained by self-compassion theory, which states that self-compassioned individuals are better able to withstand negative experiences as these are not amplified by harsh selfjudgment (Neff, 2003a). Previous research has shown a negative relation between self-compassion and self-criticism (Gilbert and Procter, 2006). Our study extends these findings by showing that reduced self-criticism in part mediates the relation between self-compassion and affect.

Even though the indirect effects of the intervention on each of the four types of affect were significant, the repeated measures analyses showed somewhat more support for the intervention effects for deactivating affect than for activating affect. Specifically, after the intervention (Time 1) job seekers reported significantly less negative deactivating affect (e.g., sadness) and more positive deactivating affect (e.g., calmness) as compared to the control condition, while there were no significant differences between the two conditions in positive activating affect (e.g., cheerfulness) and those for negative activating affect (e.g., frustration) only approached significance. We might therefore tentatively conclude that deactivating emotions are somewhat more affected by the self-compassion intervention than activating emotions. This finding supports the theoretical importance of distinguishing between types of affect based on not only the hedonic tone but also their activation level (cf. Feldman Barrett and Russell, 1998; Russell, 2003).

Previous self-compassion intervention studies have looked at various outcomes, such as depressive symptoms and happiness (Shapira and Mongrain, 2010), general negative affect (Leary et al., 2007), improvement motivation (Breines and Chen, 2012), and psychopathological outcomes in clinical setting such as trauma recovery (Zeller et al., 2015) or chronic self-loathing (Krawitz, 2012), but did not include all four types of affect as outcome variables. This study therefore contributes to selfcompassion research by generating insight into the impact of selfcompassion interventions on affect of different activation levels, that is, by showing differential effects for different types of affect. 
Our results are thus partly in line with previous research, in that existing research suggests that self-compassion is beneficial for both deactivating and activating affect. For example, Kreemers et al. (2018) showed that trait self-compassion related similarly to affect with different activation levels: negatively to negative (de)activating affect and positively to positive (de)activating affect. This pattern of findings is also apparent in our study between trait self-compassion and affect as measured at Time 0 (see Table 1) and between state self-compassion measured at Time 1 and Time 2 (see Table $\mathbf{1}$ ). The fact that we do not seem to find the same effects of the intervention on affect may be attributed to the modesty of the intervention. A relatively short writing exercise filled out once can be expected to have less impact on state self-compassion than a week of daily exercises such as in the study of Shapira and Mongrain (2010). They conducted an intervention study with Canadian adults (Shapira and Mongrain, 2010) with seven daily repeated self-compassion writing exercises. Their intervention reduced depressive symptoms and increased participants' experience of happiness. The decrease in depressive symptoms after a selfcompassion intervention is in line with our results as these symptoms could be categorized as negative deactivating affect. The increase in happiness, however, is not in line with our results, as happiness is a form of positive activating affect and we did not find an increase in positive activating affect after our intervention.

The differences between the intervention and control condition in our study were no longer apparent in the followup measurement 1 week after the exercise. In both conditions job seekers felt better: they reported less negative affect and more positive deactivating affect in the Time 2 follow-up in comparison to the baseline. A potential explanation for finding immediate but no long-lasting effects may be the small scope of our self-compassion intervention. Another explanation might be that the experience of writing on one's worst job search experience aroused negative affect and lowered positive affect, which then was mitigated by the selfcompassion intervention. In the control group time seemed to mitigate this negative emotional impact. Nevertheless, job seekers in the self-compassion condition felt better sooner (i.e., immediately after the intervention), while job seekers in the control condition caught up feeling equally well 1 week later. This is an important finding, since job search requires continuous effort over time.

Our findings seem to contrast with those of Shapira and Mongrain (2010), who found that the beneficial effects of a self-compassion intervention only became apparent 3 months after the exercises, even though their intervention was stronger, consisting of seven daily repeated self-compassion writing exercises. However, their outcome measures may be harder to influence as they focused on happiness and depressive symptoms rather than more momentary affect. Combining our results with those of Shapira and Mongrain (2010) we conclude that the effect of a self-compassion intervention on how people feel depends on the frequency with which people are stimulated to be selfcompassioned and the malleability of the targeted outcomes. To have a lasting effect on people's general sense of happiness or dejection, self-compassion likely needs some time to be learned and routinized. These results emphasize the importance of taking time into account when researching the dynamics of emotion regulation through self-compassion by having multiple followup measurements.

\section{Implications}

Our findings have implications for both research and practice in the context of job search. Although previous correlational research (Kreemers et al., 2018) demonstrated that trait-selfcompassion beneficially relates to job seekers' affect, it could not ascertain causal relationships. In the current study, we address the call that various scholars (e.g., Aguinis and Edwards, 2014; Eden, 2017) made to adopt experimental field designs to provide more rigorous tests of our theories. By adopting an experimental design our results support the causal effects of self-compassion on job seekers' emotional responses, which provides evidence for selfcompassion theory in the context of job seeking. In addition, we contribute to our understanding of how self-compassion makes job seekers feel better by identifying self-criticism as mediator in the relation between self-compassion and affect. Hereby we add weight to the notion that self-compassion may help to reduce self-criticism and that interventions could be tailored to specific sensitive groups (e.g., those who suffer more from self-criticism; Shapira and Mongrain, 2010).

Furthermore, by showing that self-compassion has the potential to aid job seekers in effectively dealing with negative job search experiences, we gained insights that can be implemented in practice (e.g., unemployment counseling; career counseling; and job search interventions). The writing exercises can function as a starting point to further develop or extend interventions aimed at job seekers taking a self-compassioned perspective toward experienced difficulties, which can help them to retain or increase the positive emotions that benefit their job search. Thus far, stress management interventions have not been found effective in the context of job search (see Liu et al., 2014 for a meta-analysis). Self-compassion may not only benefit job seekers' emotional well-being but may also improve their motivation, as was shown in prior research on people's responses to negative feedback (Breines and Chen, 2012). Considering that job seekers have to continue to search for a job also after negative feedback, self-compassion could encourage them to do so. In future research job search success should therefore also be taken into account as an outcome of a selfcompassion intervention.

Our results add to the growing body of literature that distinguishes different activation levels of affect (e.g., Watson and Tellegen, 1985; Taylor, 1991; Feldman Barrett and Russell, 1998; Russell, 2003; Carver, 2004; Baas et al., 2008; Yik et al., 2011; Wrzus et al., 2015) by showing that our self-compassion intervention was effective for positive and negative deactivating affect but less so for activating affect. In other words, reflecting on negative job search experiences generally made job seekers calmer and less sad but not more cheerful or less frustrated than reflecting freely. These outcomes are perhaps explainable by self-compassion's self-soothing properties. According to the social mentality theory (Gilbert, 1989), which draws on principles 
of evolutionary biology, neurobiology, and attachment theory, self-compassion deactivates the threat system (associated with feelings of insecurity, defensiveness and the limbic system) and activates the self-soothing system (associated with feelings of secure attachment, safeness, and the oxytocin-opiate system). This self-soothing system speaks more to deactivating affect and might therefore explain why a self-compassion intervention influences these emotions more strongly.

\section{Limitations and Future Research}

To put our results into perspective, we have to take the limitations of our research into account. First, our intervention was small and its effects were modest. Our results show that a selfcompassion exercise has a small beneficial impact on state selfcompassion, self-criticism, and affective responses to negative job search experiences immediately after the intervention. Our results also show that the impact of the exercises on affect were matched by the control condition after a week. Given that our intervention was small and performed in a field setting, which carries more noise than a laboratory setting, having a modest effect is understandable and even promising (Prentice and Miller, 1992). In recent years there has been a development toward briefer and more precise psychological interventions, called wise interventions (Walton, 2014). These interventions aim to "alter a specific way in which people think or feel in the normal course of their lives to help them flourish" (Walton, 2014, p. 73) and they are furthermore characterized by lasting effects over time. Inducing self-compassion fits that description of a wise intervention. However, wise interventions will affect long-term outcomes only if they alter critical recursive processes. Future research could therefore focus on ways to make a self-compassion intervention more recursive.

Second, several issues should be taken into account regarding the generalizability of our findings. Our sample was rather small, relatively highly educated, and included mostly women. Future research is needed to develop and test a self-compassion intervention targeted to lower-educated job seekers. Also, because women generally have somewhat lower levels of selfcompassion (Yarnell et al., 2015), a self-compassion intervention may be more useful for women than for men. Our sample size was too small for detecting such interaction effects, but future research should examine to what extent a self-compassion intervention has differential effects for men and women. Further, we tested the effectiveness of our self-compassion intervention in a mixed sample of job seekers, including new entrants, employed, and unemployed job seekers. Although job search is relevant in all these groups (e.g., Kanfer et al., 2001; Boswell et al., 2012; Van Hooft et al., in press), future research is needed to examine to what extent our findings generalize to especially vulnerable populations such as long-term unemployed individuals. Possibly, stronger interventions are needed in such groups to obtain lasting effects.

Third, this study presents a first step to testing the effectiveness of a self-compassion intervention for job seekers. Although we showed that the intervention impacted job seekers' affective responses beneficially, we need additional data to test whether the improved affective responses can translate to better job search cognitions, behaviors, and outcomes. Future research should therefore examine whether self-compassion affects relevant job search cognitions and behaviors such as job search strategies (Crossley and Highhouse, 2005), metacognitive activities (Turban et al., 2009), job search intensity (Blau, 1994), job search quality (Van Hooft et al., 2013), and job search success (e.g., interview invitations and job offers).

Fourth, our mediators and outcomes were assessed using self-report measures. Although it can be argued that our focal constructs such as state self-compassion and self-criticism can best be measured through self-reports, future research may examine whether a self-compassion intervention has visible effects on affect as perceived by others and on more objective outcomes such as job attainment. Further, similar to previous research (e.g., Breines and Chen, 2012), we measured state selfcompassion with a relatively brief scale. Therefore, we could not examine which self-compassion dimension(s) carried the effects of the intervention. Future research should develop multiple-item state self-compassion scales for each of the three self-compassion dimensions and test the effects for the dimensions separately.

Last, all participants were asked to reflect on their worse negative job search experience. This reflection constitutes a wide range of experiences that happened to the job seekers longer or less long ago. We did not control for the intensity of the experience or the time that had been passed since the event had happened, as we were mostly interested in the difference between the conditions. Moreover, job seekers were randomly divided over the conditions. Still, future research could explore how different experiences can contribute to different emotional responses.

\section{CONCLUSION}

Our results show that a self-compassion intervention consisting of a writing exercise promotes state self-compassion and has a beneficial short-term effect on job seekers' deactivating emotions. Moreover, state self-compassion reduces self-criticism among job seekers, which is beneficial for their affective responses to negative job search experiences. These results can inspire the development of self-compassion interventions and can be implemented in practice (e.g., unemployment counseling, career counseling, and job search interventions).

\section{DATA AVAILABILITY STATEMENT}

The datasets generated for this study are available on request to the corresponding author.

\section{ETHICS STATEMENT}

The studies involving human participants were reviewed and approved by Faculty Ethics Review Board (ERB) 
of the Faculty of Social and Behavioural Sciences of the University of Amsterdam. The patients/participants provided their online informed consent to participate in this study.

\section{AUTHOR CONTRIBUTIONS}

LK, EH, AV, and SS contributed to the conception and design of the study. LK and SS organized the data collection. LK, EH, and SS performed the statistical analysis. $\mathrm{LK}, \mathrm{EH}$, and AV contributed to writing the manuscript. All authors contributed to the article and approved the submitted version.

\section{REFERENCES}

Adams, C. E., and Leary, M. R. (2007). Promoting self-compassionate attitudes toward eating among restrictive and guilty eaters. J. Soc. Clin. Psychol. 26, 1120-1144. doi: 10.1521/jscp.2007.26.10.1120

Aguinis, H., and Edwards, J. R. (2014). Methodological wishes for the next decade and how to make wishes come true. J. Manag. Stud. 51, 143-174. doi: 10.1111/ joms. 12058

Au, T. M., Sauer-zavala, S., King, M. W., Petrocchi, N., Barlow, D. H., and Litz, B. T. (2017). Compassion-based therapy for trauma-related shame and posttraumatic stress: initial evaluation using a multiple baseline design. Behav. Ther. 48, 207-221. doi: 10.1016/j.beth.2016.11.012

Baas, M., De Dreu, C. K. W., and Nijstad, B. A. (2008). A meta-analysis of 25 years of mood-creativity research: hedonic tone, activation, or regulatory focus? Psychol. Bull. 134, 779-806. doi: 10.1037/a0012815

Blatt, S. J., Quinlan, D. M., Chevron, E. S., McDonald, C., and Zuroff, D. (1982). Dependency and self-criticism: psychological dimensions of depression. J. Consult. Clin. Psychol. 50, 113-124. doi: 10.1037/0022-006x.50.1.113

Blau, G. (1994). Testing a two-dimensional measure of job-search behavior. Organ. Behav. Hum. Decis. Process. 59, 288-312. doi: 10.1006/obhd.1994.1061

Boswell, W. R., Zimmerman, R. D., and Swider, B. D. (2012). Employee job search: toward an understanding of search context and search objectives. J. Manag. 38, 129-163. doi: 10.1177/0149206311421829

Breines, J. G., and Chen, S. (2012). Self-compassion increases self-improvement motivation. Personal. Soc. Psychol. Bull. 38, 1133-1143. doi: 10.1177/ 0146167212445599

Brewin, C. R., Firth-Cozens, J., Furnham, A., and McManus, C. (1992). Selfcriticism in adulthood and recalled childhood experience. J. Abnorm. Psychol. 101, 561-566. doi: 10.1037/0021-843x.101.3.561

Carver, C. S. (2004). Negative affects deriving from the behavioral approach system. Emotion 4, 3-22. doi: 10.1037/1528-3542.4.1.3

Crawford, J. R., and Henry, J. D. (2004). The positive and negative affect schedule (PANAS): construct validity, measurement properties and normative data in a large non-clinical sample. Br. J. Clin. Psychol. 43, 245-265. doi: 10.1348/ 0144665031752934

Crossley, C. D., and Highhouse, S. (2005). Relation of job search and choice process with subsequent satisfaction. J. Econ. Psychol. 26, 255-268. doi: 10.1016/j.joep. 2004.04.001

Dunkley, D. M., and Blankstein, K. R. (2000). Self-critical perfectionism, coping, hassles, and current distress : a structural equation modeling approach. Cogn. Ther. Res. 24, 713-730.

Dunkley, D. M., Zuroff, D. C., and Blankstein, K. R. (2003). Self-critical perfectionism and daily affect: dispositional and situational influences on stress and coping. J. Personal. Soc. Psychol. 84, 234-252. doi: 10.1037/0022-3514.84. 1.234

Eden, D. (2017). Field experiments in organizations. Annu. Rev. Organ. Psychol. Organ. Behav. 4, 91-122.

Elkind, D. (1967). Egocentrism in adolescence. Child Dev. 38, 1025-1034.

Feldman Barrett, L., and Russell, J. A. (1998). Independence and bipolarity in the structure of current affect. J. Personal. Soc. Psychol. 74, 967-984. doi: 10.1037/ 0022-3514.74.4.967

Gilbert, P. (1989). Human Nature and Suffering. Hove: Lawrence Erlbaum.

\section{FUNDING}

This study was supported by an Open Research Area (ORA) grant (Nr. 464-13-046) from the Netherlands Organisation for Scientific Research (NWO).

\section{ACKNOWLEDGMENTS}

A previous version of this manuscript was presented at the 19th Congress of the European Association of Work and Organizational Psychology, Turin, Italy.

Gilbert, P., and Procter, S. (2006). Compassionate mind training for people with high shame and self-criticism: overview and pilot study of a group therapy approach. Clin. Psychol. Psychother. 379, 353-379. doi: 10.1002/cpp.507

Hayes, A. F. (2012). PROCESS: A versatile computational tool for observed variable mediation, moderation, and conditional process modeling [White paper]. Available online at: http://www.afhayes.com/public/process2012.pdf

Jopling, D. A. (2000). Self-Knowledge and the Self. New York, NY: Routledge.

Kabat-Zinn, J. (1982). An outpatient program in behavioral medicine for chronic pain patients based on the practice of mindfulness meditation. Gen. Hosp. Psychiatry 4, 33-47. doi: 10.1016/0163-8343(82)90026-3

Kanfer, R., Wanberg, C. R., and Kantrowitz, T. M. (2001). Job search and emloyment: a personality - motivational analysis and meta-analytic review. J. Appl. Psychol. 86, 837-855. doi: 10.1037/0021-9010.86.5.837

Klehe, U. C., and Van Hooft, E. A. J. (2018). The Oxford Handbook of Job Loss and Job Search. New York, NY: Oxford University Press.

Krawitz, R. (2012). Behavioural treatment of severe chronic self-loathing in people with borderline personality disorder. Part 2: self-compassion and other interventions. Australas. Psychiatry 20, 501-506. doi: 10.1177/ 1039856212459586

Kreemers, L. M. (2020). Searching for a Job: Problem-and Emotion-Focused Coping. Unpublished doctoral dissertation, University of Amsterdam, Amsterdam.

Kreemers, L. M., Van Hooft, E. A. J., and Van Vianen, A. E. M. (2018). Dealing with negative job search experiences: the beneficial role of self-compassion for job seekers' affective responses. J. Vocat. Behav. 106, 165-179. doi: 10.1016/j.jvb. 2018.02.001

Leary, M. R., Tate, E. B., Adams, C. E., Allen, A. B., and Hancock, J. (2007). Selfcompassion and reactions to unpleasant self-relevant events: the implications of treating oneself kindly. J. Personal. Soc. Psychol. 92, 887-904. doi: 10.1037/ 0022-3514.92.5.887

Liu, S., Huang, J. L., and Wang, M. (2014). Effectiveness of job search interventions: a meta-analytic review. Psychol. Bull. 140, 1009-1041. doi: 10.1037/a00 35923

McKee-Ryan, F., Song, Z., Wanberg, C. R., and Kinicki, A. J. (2005). Psychological and physical well-being during unemployment: a meta-analytic study. J. Appl. Psychol. 90, 53-76. doi: 10.1037/0021-9010.90.1.53

Neff, K. D. (2003a). Self-compassion: an alternative conceptualization of a healthy attitude toward oneself. Self Identity 2, 85-101. doi: 10.1080/15298860 309032

Neff, K. D. (2003b). The development and validation of a scale to measure self-compassion. Self Identity 2, 223-250. doi: 10.1080/15298860309027

Neff, K. D. (2011). Self-Compassion. New York, NY: WilliamMorrow.

Neff, K. D., Hsieh, Y.-P., and Dejitterat, K. (2005). Self-compassion, achievement goals, and coping with academic failure. Self Identity 4, 263-287. doi: 10.1080/ 13576500444000317

Neff, K. D., Kirkpatrick, K. L., and Rude, S. S. (2007). Self-compassion and adaptive psychological functioning. J. Res. Personal. 41, 139-154. doi: 10.1016/j.jrp.2006. 03.004

Neff, K. D., and Vonk, R. (2009). Self-compassion versus global self-esteem: two different ways of relating to oneself. J. Personal. 77, 23-50. doi: 10.1111/j.14676494.2008.00537.x

Pennebaker, J. W., Colder, M., and Sharp, L. K. (1990). Accelerating the coping process. J. Personal. Soc. Psychol. 58, 528-537. doi: 10.1037/0022-3514.58.3.528 
Pinto-Gouveia, J., Castilho, P., Matos, M., and Xavier, A. (2013). Centrality of shame memories and psychopathology: the mediator effect of self-criticism. Clin. Psychol. 20, 323-334. doi: 10.1111/cpsp.12044

Prentice, D. A., and Miller, D. T. (1992). When small effects are impressive. Psychol. Bull. 112, 160-164. doi: 10.1037/0033-2909.112.1.160

Raes, F. (2010). Rumination and worry as mediators of the relationship between self-compassion and depression and anxiety. Personal. Individ. Differ. 48, 757761. doi: $10.1016 /$ j.paid.2010.01.023

Russell, J. A. (2003). Core affect and the psychological construction of emotion. Psychol. Rev. 110, 145-172. doi: 10.1037/0033-295x.110.1.145

Shapira, L. B., and Mongrain, M. (2010). The benefits of self-compassion and optimism exercises for individuals vulnerable to depression. J. Posit. Psychol. 5, 377-389. doi: 10.1080/17439760.2010.516763

Shapiro, S. L., Brown, K. W., and Biegel, G. M. (2007). Teaching self-care to caregivers: effects of mindfulness-based stress reduction on the mental health of therapists in training. Train. Educ. Prof. Psychol. 1, 105-115. doi: 10.1037/ 1931-3918.1.2.105

Smeets, E., Neff, K. D., Alberts, H., and Peters, M. (2014). Meeting suffering with kindness: effects of a brief self-compassion intervention for female college students. J. Clin. Psychol. 70, 794-807. doi: 10.1002/jclp.22076

Song, Z., Uy, M. A., Zhang, S., and Shi, K. (2009). Daily job search and psychological distress: evidence from China. Hum. Relations 62, 1171-1197. doi: $10.1177 / 0018726709334883$

Taylor, S. E. (1991). Asymmetrical effects of positive and negative events: the mobilization-minimization hypothesis. Psychol. Bull. 110, 67-85. doi: 10.1037/ 0033-2909.110.1.67

Thompson, B. L., and Waltz, J. (2008). Self-compassion and PTSD symptom severity. J. Trauma. Stress 21, 556-558. doi: 10.1002/jts.20374

Turban, D. B., Lee, F. K., Da Motta Veiga, S. P., Haggard, D. L., and Wu, S. Y. (2013). Be happy, don't wait: the role of trait affect in job search. Pers. Psychol. 66, 483-514. doi: 10.1111/peps.12027

Turban, D. B., Stevens, C. K., and Lee, F. K. (2009). Effects of conscientiousness and extraversion on new labor market entrants' job search: the mediating role of metacognitive activities and positive emotions. Pers. Psychol. 62, 553-573. doi: 10.1111/j.1744-6570.2009.01148.x

Van Hooft, E. A. J., Kammeyer-Mueller, J., Wanberg, C., Kanfer, R., and Basbug, G. (in press). Job search and employment success: a quantitative review and future research agenda. J. Appl. Psychol. doi: 10.1037/apl0000675

Van Hooft, E. A. J., Wanberg, C. R., and Van Hoye, G. (2013). Moving beyond job search quantity: towards a conceptualization and self-regulatory framework of job search quality. Organ. Psychol. Rev. 3, 3-40. doi: 10.1177/ 2041386612456033
Walton, G. M. (2014). The new science of wise psychological interventions. Curr. Dir. Psychol. Sci. 23, 73-82. doi: 10.1177/0963721413512856

Wanberg, C. R., Basbug, G., Van Hooft, E. A. J., and Samtani, A. (2012). Navigating the black hole: explicating layers of job search context and adaptational responses. Pers. Psychol. 65, 887-926. doi: 10.1111/peps.12005

Wanberg, C. R., Zhu, J., and Van Hooft, E. A. J. (2010). The job search grind: perceived progress, self-reactions, and self-regulation of search effort. Acad. Manag. J. 53, 788-807. doi: 10.5465/amj.2010.52814599

Watson, D., and Tellegen, A. (1985). Toward a consensual structure of mood. Psychol. Bull. 98, 219-235. doi: 10.1037/0033-2909.98.2.219

Wrzus, C., Luong, G., Wagner, G. G., and Riediger, M. (2015). Can't get it out of my head: age differences in affective responsiveness vary with preoccupation and elapsed time after daily hassles. Emotion 15, 257-269. doi: 10.1037/emo00 00019

Yarnell, L. M., Stafford, R. E., Neff, K. D., Reilly, E. D., Knox, M. C., and Mullarkey, M. (2015). Meta-analysis of gender differences in self-compassion. Self Identity 14, 499-520. doi: 10.1080/15298868.2015.1029966

Yik, M., Russell, J. A., and Steiger, J. H. (2011). A 12-point circumplex structure of core affect. Emotion 11, 705-731. doi: 10.1037/a0023980

Zeller, M., Yuval, K., Nitzan-Assayag, Y., and Bernstein, A. (2015). Self-compassion in recovery following potentially traumatic stress: longitudinal study of atrisk youth. J. Abnorm. Child Psychol. 43, 645-653. doi: 10.1007/s10802-014-9 937-y

Zhang, J. W., and Chen, S. (2016). Self-compassion promotes personal improvement from regret experiences via acceptance. Personal. Soc. Psychol. Bull. 42, 244-258. doi: 10.1177/0146167215623271

Zuroff, D. C., Moskowitz, D. S., and Cote, S. (1999). Dependency, self-criticism, interpersonal behaviour and affect: evolutionary perspectives. J. Br. Clin. Psychol. 38, 231-250. doi: 10.1348/0144665991 62827

Conflict of Interest: The authors declare that the research was conducted in the absence of any commercial or financial relationships that could be construed as a potential conflict of interest.

Copyright (c) 2020 Kreemers, van Hooft, van Vianen and Sisouw de Zilwa. This is an open-access article distributed under the terms of the Creative Commons Attribution License (CC BY). The use, distribution or reproduction in other forums is permitted, provided the original author(s) and the copyright owner(s) are credited and that the original publication in this journal is cited, in accordance with accepted academic practice. No use, distribution or reproduction is permitted which does not comply with these terms. 


\section{OPEN ACCESS}

Edited by:

Llewellyn Ellardus Van Zyl, Eindhoven University of Technology, Netherlands

Reviewed by:

Claude Houssemand,

University of Luxembourg,

Luxembourg

Edwin A. J. Van Hooft,

University of Amsterdam, Netherlands

Pascale Le Blanc,

Eindhoven University of Technology,

Netherlands

*Correspondence: Rachele Paver

rachele.paver@nwu.ac.za

TORCID:

Rachele Paver

orcid.org/0000-0002-3824-3038

Hans De Witte

orcid.org/0000-0002-6691-517X

Sebastiaan Rothmann orcid.org/0000-0001-6065-4338

Anja Van den Broeck

orcid.org/0000-0002-5896-9506

Roland Willem Bart Blonk

orcid.org/0000-0001-8699-2511

Specialty section:

This article was submitted to

Organizational Psychology, a section of the journal

Frontiers in Psychology

Received: 18 January 2020 Accepted: 27 May 2020

Published: 14 July 2020

Citation:

Paver R, De Witte $H$,

Rothmann S, Van den Broeck $A$ and Blonk RWB (2020) The Implementation and Evaluation of the South African Adaptation of the JOBS

Program. Front. Psychol. 11:1418. doi: 10.3389/fpsyg.2020.01418

\section{The Implementation and Evaluation of the South African Adaptation of the JOBS Program}

\author{
Rachele Paver, $12 *+$, Hans De Witte ${ }^{1,2+}$, Sebastiaan Rothmann ${ }^{1 \dagger}$, Anja Van den Broeck ${ }^{1,3 t}$ \\ and Roland Willem Bart Blonk ${ }^{1,4,5 t}$ \\ ${ }^{1}$ Optentia Research Focus Area, North-West University Vaal Triangle Campus, Vanderbij/park, South Africa, ${ }^{2}$ Research \\ Group Work, Organizational and Personnel Psychology, KU Leuven, Leuven, Belgium, ${ }^{3}$ Department of Work \\ and Organization Studies, KU Leuven, Brussels, Belgium, ${ }^{4}$ Healthy Living, Netherlands Organisation for Applied Scientific \\ Research, Leiden, Netherlands, ${ }^{5}$ Department of Human Resource Studies, Tilburg University, Tilburg, Netherlands
}

No validated intervention that specifically addresses the psychosocial needs of unemployed people exists in the South African context. This study intends to evaluate an evidence-based job-search program, called the JOBS intervention, that is aimed at the self-efficacy, amotivation, and self-esteem related to participants searching for jobs. A quasi-experimental research design was used. Convenient samples were taken of unemployed individuals from two low-income communities $(N=130$; experimental group = 69; control group =61). The Qhubekela Phambili program, which is based on the JOBS program, was adapted for the South African context and was implemented over six 4-h sessions. Data collection took place pre- and post-intervention. One-way repeated measures multivariate analysis of variance was used to analyze the data. Those who had undergone the intervention showed statistically significantly higher levels of job-search self-efficacy and self-esteem. This study makes a novel contribution to the literature on the JOBS program, particularly regarding developing countries. This study showed that in a context characterized by poverty and a lack of support for the unemployed, the program also delivered promising results. It confirms previous findings that the JOBS program is suitable in a variety of labor market and economic conditions.

\footnotetext{
Keywords: job-search self-efficacy, amotivation, self-esteem, job-search intervention, JOBS program, Qhubekela Phambili career-enhancement program, unemployed, South Africa
}

\section{INTRODUCTION}

Unemployment has various adverse consequences for people, such as decreased self-esteem, a loss of personal control, and patterns of reduced (or no) job-search efforts, when unemployed for prolonged periods (Schaufeli and VanYperen, 1993; Kanfer et al., 2001; Paul and Moser, 2009; Preuss and Hennecke, 2018; Wanberg et al., 2020). Considering the undesirable effects of unemployment, the limited solutions sought from a psychosocial perspective is concerning, particularly so within the South African context (Cobb-Clark, 2015).

Labor market interventions generally focus on job creation, subsidized employment opportunities, and providing the unemployed with resources and services, such as vocational training and employment services (Kluve et al., 2017). While these programs undoubtedly assist in removing some constraints to obtain employment, a somewhat underemphasized approach 
to solving the employment challenge may be resource-based interventions (Malmberg-Heimonen et al., 2019) driven from a psychosocial perspective, that support the emotional and psychological needs of the participants (Price and Vinokur, 2014; Van den Hof, 2015; Paver et al., 2019a). In a metaanalysis evaluating job-search interventions, Liu et al. (2014) found that programs aimed at strengthening participants' selfefficacy, encouraging proactive and goal-orientated behavior, teaching job search skills, and providing them with social support were more effective than interventions that did not include such components. Also, interventions that combined skills development with a motivational component were most successful in facilitating job-search success (Liu et al., 2014; Wanberg et al., 2020).

Previously conducted research agrees on the fact that unemployment should be seen within a social, more humane context and not solely as an economic burden (Donaldson and Weiss, 1998). The latent deprivation model (Jahoda, 1982) suggests that a job fulfills both manifest (remuneration) and latent functions (time structure, social contact, common goals, status or identity, and enforced activity). Likewise, Donaldson and Weiss (1998) state that employment increases people's self-esteem and provides them with a sense of identity. Consequently, when people lose their jobs, they experience not only a loss of income but also a loss of these essential latent functions, which may negatively impact one's psychological wellbeing (Jahoda, 1982). Therefore, based on these views of the importance of work, it should be considered that economic and psychological deprivation are so closely intertwined that one aspect cannot be affected without impacting the other (Møller, 1991). By applying labor market programs that solely focus on easing financial hardship (which is the status quo in the African context), psychological aspects, which may contribute to making unemployment (un)bearable, are deliberately left out of the equation.

Even though South Africa has one of the highest unemployment rates in the world (World Bank, 2018) programs implemented to assist the unemployed lack the psychosocial aspects required to have a sustainable impact (Paver et al., 2019a). An intervention designed specifically for this purpose is the JOBS program (Caplan et al., 1989; City of Johannesburg, 2018). This empirically robust preventive intervention has obtained positive results in various studies (Caplan et al., 1989; Vinokur et al., 1995; Malmberg-Heimonen et al., 2019). The purpose of this study is to implement the JOBS program, with the aim of studying whether results, similar to previous versions of the program, can be achieved, within the South African context.

\section{THE JOBS PROGRAM}

In general, the aim of JOBS program is to prevent deterioration of mental health and promotion of (re)employment (Vinokur and Van Ryn, 1993). These instilled outcomes, however, operate as a vehicle to build participants' competence and confidence, making the real underlying goal of the program to empower them by focusing on their emotional and motivational needs and helping them to cope with their circumstances (Curran et al., 1999). This is accomplished through the trainers' abilities to facilitate the process in which the participants acquire the intended skills while applying the underlying principles of the program. The JOBS program comprises the following underlying five principles:

Guiding behavior. Facilitators have the responsibility to demonstrate effective and positive behavior to participants. They provide participants with specific positive feedback and steer them away from any ineffective or negative actions or feedback.

Social support. Fragile participants are put at ease by creating a supportive environment that encourages unconditional acceptance by facilitators and other participants (Michigan Prevention Research Center, 2013). This entails building trust and reducing the social distance by treating participants with respect and offering positive feedback. Generating such a safe environment creates an opportunity to destigmatise unemployment and remove other associated negative connotations (Vinokur and Price, 2015). Trainers model and reinforce supportive behaviors for participants. Group exercises are designed in such a way that they provide opportunities for participants to be supportive of one another.

Trainer referent power. The influence trainers have on participants is based on the participants' experience of trainers as reliable self-esteem enhancers and as referent persons whom they admire. This requires trainers to build trust and reduce social distance by providing participants with unconditional positive regard, specific positive feedback, moderate self-disclosure, and encouragement of participant self-disclosure. Facilitators also create opportunities in which they help participants to realize that their accomplishments are entirely a result of their hard work and talents (Curran et al., 1999).

Inoculation against setbacks. Inoculation training is a coping and group problem-solving process. It involves specific problem identification and analysis, generation of possible behavioral or cognitive responses, evaluation of responses, skill acquisition, and behavioral rehearsal, and re-evaluation. The program emphasizes an extension of this process, where the group anticipates possible barriers and, once challenges and obstacles have been identified, problem-solving skills are required to generate and evaluate potential solutions to overcome these setbacks (Curran et al., 1999).

Active teaching/learning methods. The program relies strongly on active learning techniques (e.g., brainstorming sessions, group discussions, problem-solving, and roleplaying exercises), as opposed to didactic passive methods (Caplan et al., 1997). Facilitators refrain from providing solutions and rather foster an environment where the participants are encouraged to apply their knowledge and experience as part of the learning process (Caplan et al., 1997). The learning process is elicited through 
group discussions, brainstorming, and other activities. Participants spend much of their time rehearsing new skills and providing support to one another. This process seeks to maximize the effectiveness of the learning environment and to promote self-esteem and self-efficacy.

The principles mentioned above are the essence of the JOBS program. Because participants actively participate and rely on their knowledge and experience throughout the program, they tend to take ownership of their situation. Likewise, by asking the participants to suggest solutions, they are actively involved in the problem-solving process. The more it is repeated, the more natural the process becomes. The unconditional positive regard and support provided by the facilitators and the other participants also contribute to a space where participants can share experiences for others to relate to (Curran et al., 1999). Finally, the facilitators play a crucial role in the example they portray to participants.

\section{THE CURRENT STUDY}

The earliest version of the JOBS program is referred to as the JOBS I intervention. Findings from the original JOBS intervention demonstrated that some components of the program contributed more prominently to the positive outcomes achieved (Vinokur et al., 1995). This led to the development of the JOBS II intervention. One of the components that inspired the changes made in the revised program was a stronger focus on participants' sense of mastery - comprising job-search selfefficacy, locus of control, and self-esteem (Vinokur et al., 2000). Because a sense of mastery played such a prominent role in the JOBS intervention, the current paper aims to determine the effectiveness and the role of the various components, job-search self-efficacy, locus of control, and self-esteem.

Unemployment is often accompanied by humiliation and feelings of inferiority and incompetence (Curran et al., 1999). Studies showed that providing jobseekers with coping resources, such as the confidence and ability to effectively seek for employment, overcoming feelings of helplessness, and building their self-esteem can be vital in their search for employment (Van Ryn and Vinokur, 1992; Vinokur et al., 1995, 2000; Price and Vinokur, 2014). Successfully obtaining a new job largely depends on an individual's ability to apply job-search strategies effectively (Price et al., 2002a) hence the emphasis placed on job-search self-efficacy within the JOBS program.

Bandura describes self-efficacy as a person's belief that they can be successful (Bandura, 1986). Because self-efficacy is context-specific, job-search self-efficacy refers to individuals' confidence in their ability to perform job-seeking activities (Vinokur and Caplan, 1987; Saks and Ashforth, 1999). The JOBS program likely enhances the perceptions of job search selfefficacy because it teaches new skills, and it tries to embed the newly taught behaviors into people's skill set through consistent positive reinforcement from the facilitators. The acquisition of these resources is accomplished through the empowerment of participants to confidently and persistently engage in job-seeking undertakings (Vinokur et al., 2000). The JOBS intervention is specifically designed to maximize the job-search skills of the job seekers and to enhance and maintain their motivation (Price and Vinokur, 2014) building their confidence to seek employment. Therefore, the following hypothesis is formulated:

Hypothesis 1. After taking part in the JOBS program, participants from the experimental group will report higher levels of jobsearch self-efficacy, compared to their control group counterparts.

The contexts in which the JOBS program has been implemented consist mainly of Western countries and differ quite significantly from the South African context. One significant difference may be the prolonged periods of unemployment experienced by job seekers. Unemployment, but perhaps even more so, long-term unemployment, may contribute to people feeling discouraged about re-entering the labor market (Van der Vaart et al., 2018). This discouragement intensifies feelings of helplessness and loss of personal control (Curran et al., 1999). A loss of control (or perceptions that chance is a controlling factor in finding employment) among unemployed is associated with longer periods of unemployment (Houssemand et al., 2019). While, a loss of personal control may be common among unemployed persons, perhaps more uncommon is the fact that $32 \%$ of the unemployed in South Africa have been identified as being amotivated (Van der Vaart et al., 2019) implying that they are neither intrinsically nor extrinsically motivated and may experience the relative absence of motivation (Rotter, 1966; Ryan and Deci, 2000). A fundamental component of the JOBS program is inoculating participants against setbacks. This entails that participants anticipate potential challenges or difficulties, generate possible solutions to overcome these obstacles or barriers, and acquire the necessary skills to deal with the setbacks (Hobfoll, 1989; Vinokur and Schul, 1997). What is essential is that these are the participants' own solutions. Thus, they are cultivating control that empowers them to take ownership of their situation (Deci and Ryan, 1985; Curran et al., 1999). It seems reasonable to ascertain that these unemployed individuals, who are particularly prone to be amotivated, may benefit from an intervention such as the JOBS program. Therefore, the second hypothesis is as follows:

Hypothesis 2. After taking part in the JOBS program, participants from the experimental group will report lower levels of amotivation, compared to their control group counterparts.

Again, drawing on Jahoda's work, a loss of self-esteem is one of the deprivations experienced when losing one's job (Jahoda, 1982). To successfully find employment, self-esteem is considered essential to remaining motivated and to persevere in job search behavior (Caplan et al., 1989). Rosenberg describes self-esteem as the extent to which one's attitude is favorable or unfavorable toward him- or herself (Rosenberg, 1965). It is understandable that such a perception may be influenced by one's employment status, perhaps even more so for individuals who have never held a job before. The JOBS intervention protocol relies heavily on confidence-boosting techniques and empowering participants by giving them opportunities to become aware of, display, and build their personal resources (Price et al., 2002b). Activities 
were designed to have participants experience success through trainers providing participants with sincere and specific praising comments on the behavior. The purpose of the support provided by the facilitators and other participants is to establish a sense of belongingness and to enhance participants' self-esteem (Caplan et al., 1989). Finally, the third hypothesis derives as follows:

Hypothesis 3. After taking part in the JOBS program, participants from the experimental group will report higher levels of selfesteem, compared to their control group counterparts.

\section{MATERIALS AND METHODS}

\section{Research Design}

To evaluate the impact of the JOBS intervention, a quasiexperimental research design was used (see Figure 1). Participants were randomly assigned to an experimental or control group. Both groups were tested at two intervals (Time 0 and Time 1), with the experimental group undergoing the intervention between the two measurements. The outcomes of the experimental group were compared with the outcomes of the control group, to determine the impact of the intervention.

\section{Intervention}

\section{Qhubekela Phambili Career-Enhancement Program}

To better understand the mechanisms of the JOBS program and its effects, Paver et al. (2019b) conducted a literature review of the JOBS program and variations thereof. The current study is executed based on suggestions made to effectively implement and evaluate the JOBS program (see Supplementary Material; Paver et al., 2018). The name of the South African version of the JOBS program is Qhubekela Phambili, which means "moving forward" in IsiZulu.

\section{Content}

Striking a balance between maintaining fidelity to evidence-based practices and adapting the program to suit local circumstances can be problematic (Price and Vinokur, 2014). Although some content-related changes were made, none of the changes influenced the theoretical foundation of the program. Due to slow economic growth and limited job opportunities in the labor market, paid employment is not always a feasible option (Price and Vinokur, 1995). Also, the lack of means to travel



FIGURE 1 | The quasi-experimental research design. from their communities to a job that unemployed people experience makes it challenging. Therefore, a critical element that was incorporated into the Qhubekela Phambili program was a self-employment/entrepreneurial component. The main content-related difference is that the original JOBS program aims to link participants' strengths, passions, values, network, action plans, and job-search strategies to a job within the formal sector. Participants are encouraged to develop action plans to which they commit themselves, such as developing a strong network of people and identifying job leads. The Qhubekela Phambili program draws participants' attention to the needs and opportunities within their community and to accordingly align their identified strengths, passions, values, network, and opportunity-seeking strategies to create and utilize opportunities. Their action plan and what they commit to is, therefore, not limited to seeking job leads and opportunities within the formal sector, but is also expanded to identify and commit to selfemployment opportunities. An outline of the program content is presented in Table 1.

\section{Training of Facilitators}

The first author who led and coordinated the project was trained in the JOBS program in the Netherlands. This was done to ensure that the program will be delivered at an acceptable standard and to ensure the reliability and validity of the JOBS intervention. Additionally, an international trainer with vast experience in conducting the JOBS program was invited to present a train-thetrainer workshop to selected facilitators in South Africa.

Six facilitators were trained in the program. These candidates were selected on the premise that they have a background in psychology, social work, industrial psychology, or a related field. Facilitators also had to be experienced in working with people in similar conditions, possess good facilitation skills, such as speaking and listening skills, giving feedback, facilitating, understand group processes and dynamics, and able to deal with conflict constructively (Price and Vinokur, 1995). The train-the-trainer program was conducted over five 8 -h sessions. Practical exercises were integrated into these sessions so that where trainees had the opportunity to practice the relevant skills. These sessions aimed to ensure that the facilitators were comfortable with the content and the underlying processes of the program. During the Qhubekela Phambili program, facilitators met daily to share their experiences and to deal with topics and possible issues that may have surfaced during the sessions (Price and Vinokur, 1995).

\section{Participants and Data Collection Procedures}

Unemployed individuals from townships in two geographical areas in Gauteng, namely Orange Farm and Boipatong, were approached to participate in the study. Several inclusion criteria were used to select participants. Participants had to be unemployed South African citizens, aged between 18 and 55. They had to reside in either Boipatong or Orange Farm. They also had to show an adequate understanding of English. Participants from the same regions, who previously participated in an unemployment research conducte by Du Toit et al. (2018) 
TABLE 1 | An outline of the Qhubekela Phambili career-enhancement program.

\begin{tabular}{|c|c|}
\hline Topics & Duration \\
\hline \multicolumn{2}{|l|}{ Session 1: Who am I, and what am I good at? } \\
\hline Introduction (includes time for questionnaire) & $140 \mathrm{~min}$ \\
\hline What do I stand for? & $50 \min$ \\
\hline What am I good at? & $40 \mathrm{~min}$ \\
\hline Conclusion & $15 \min$ \\
\hline \multicolumn{2}{|l|}{ Session 2: Exploring my passions, my values, and my future } \\
\hline Welcome & $15 \min$ \\
\hline What are my passions? & $30 \min$ \\
\hline What are my values? & $75 \min$ \\
\hline Distinguishing between employment and entrepreneurship & $40 \mathrm{~min}$ \\
\hline Linking my attributes to my career & $35 \min$ \\
\hline Conclusion & $15 \min$ \\
\hline $\begin{array}{l}\text { Session 3: Exploring opportunities and finding ways to } \\
\text { realize them }\end{array}$ & $15 \min$ \\
\hline Welcome & $45 \min$ \\
\hline Identifying possibilities applicable to me & $50 \mathrm{~min}$ \\
\hline My future & $90 \min$ \\
\hline Developing my career & $15 \min$ \\
\hline \multicolumn{2}{|l|}{ Conclusion } \\
\hline Session 4: What resources do I have? & $15 \min$ \\
\hline Welcome & $125 \min$ \\
\hline My network plan & $30 \min$ \\
\hline Resources in my community & $15 \min$ \\
\hline \multicolumn{2}{|l|}{ Conclusion } \\
\hline Session 5: Resources within myself & $15 \min$ \\
\hline Welcome & $40 \min$ \\
\hline Communication skills and professional conduct & $50 \mathrm{~min}$ \\
\hline My goals & $20 \min$ \\
\hline What is holding me back? & $105 \min$ \\
\hline Conclusion (includes time for questionnaire) & $15 \min$ \\
\hline \multicolumn{2}{|l|}{ Closing ceremony } \\
\hline Session 6: Return day & $35 \min$ \\
\hline Welcome and looking back & $60 \mathrm{~min}$ \\
\hline My goals/commitments & $105 \mathrm{~min}$ \\
\hline Conclusion (includes time for questionnaire) & \\
\hline
\end{tabular}

and Van der Vaart et al. (2018) were contacted to participate. From the 867 participants previously involved one of the studies (Van der Vaart et al., 2019) only 354 met our inclusion criteria. An additional 60 people, who were previously involved in the study conducted by $\mathrm{Du}$ Toit et al. (2018) were approached to participate. The identified people were contacted, via telephone. During each call the purpose of the program, as well as basic information such as the dates, time, duration, and location of the program. Based on the potential participants' adherence to the inclusion criteria and their willingness to participate they were divided into two groups randomly - an experimental and a control group.

Initially, 414 people, selected from previous studies, were invited to participate in the workshop. However, among both groups some participants who had agreed to participate failed to show up. Attrition of participants in social interventions is also unavoidable (Vinokur et al., 1991a). In some cases, the percentage of "no shows" was up to $75 \%$ of the group. In these cases, community leaders who work with the unemployed were asked for assistance to recruit additional participants. Although the inclusion criteria were communicated to leaders, non-compliant participants were still invited. The requirement the majority did not meet was the completion of Grade 12. It did not seem to have any impact on the process. There were two cases where participants were not able speak to English fluently. Although facilitators could communicate with them in other languages, completing the questionnaires seemed to be a barrier. They were therefore omitted from the study.

The Qhubekela Phambili program consisted of five 4-h sessions in 1 week with a return day 4 weeks after the program. Two experimental groups attended the workshop per week (morning and afternoon group). At the same time, two control groups were asked to complete the research questionnaire. The intervention program was executed over 2 weeks and included four experimental groups and four control groups. Both groups (intervention and control) were asked to complete a pre-test survey on the first day of the program and a post-test survey on the last day of the program (although the control group did not receive the intervention). The attendance and dropout of participants are reported in Table 2.

The characteristics of the participants are displayed in Table 3.

\section{Measuring Instruments Biographical Information}

A questionnaire to determine the biographical characteristics of the participants was used. Characteristics such as gender, age, race, level of education, and duration of unemployment were asked in this questionnaire.

\section{Job-Search Self-Efficacy}

The job-search self-efficacy measure was developed in earlier investigations of the JOBS program (Vinokur et al., 1991b; Vinokur and Schul, 2002; Lefcourt, 2014). It consists of six items. Participants were asked how confident they felt executing tasks related to finding a job (i.e., "How confident do you feel about completing a good job application and CV?"). Items were rated on a five-point frequency scale ranging from not at all confident (l) to a very confident (5). The Cronbach's alpha coefficient for this index was $\alpha=0.79$ (Time 0 ) and $\alpha=0.74$ (Time 1).

\section{Amotivation}

The self-regulation questionnaire job-searching scale (Vansteenkiste et al., 2004) was used to measure amotivation (Vansteenkiste et al., 2005). This scale consists of 10 items and intends to measure individuals' motives not to search for employment (i.e., "I do not look for a job because I am tired of looking for a job"). Items were measured on a five-point Likert scale, ranging from strongly disagree (1) to strongly agree (5). The scale showed acceptable internal consistency $(\alpha=0.82$, Time $0 ; 0.85$, Time 1$)$.

\section{Self-Esteem}

The Rosenberg self-esteem scale (Rosenberg et al., 1995) was utilized to measure respondents' positive and negative feelings 
TABLE 2 | Attendance and dropout of participants ( $N=130)$.

\begin{tabular}{|c|c|c|}
\hline & Morning session & Afternoon session \\
\hline & $(08: 00-12: 00)$ & $(13: 00-17: 00)$ \\
\hline \multirow[t]{8}{*}{ Week 1} & Experimental group 1 (attended the program) & Experimental group 2 (attended the program) \\
\hline & Invited to participate $n=25$ & Invited to participate $n=25$ \\
\hline & Arrived for program $n=19$ & Arrived for program $n=5$ \\
\hline & Final number participated $n=19$ & Additional participants recruited $n=19$ \\
\hline & & Final number participated $n=14$ \\
\hline & Control group 1 (completed the survey) & Control group 2 (completed the survey) \\
\hline & Invited to pre-test $n=25$ & Invited to pre-test $n=25$ \\
\hline & Arrived for pre-test $n=25$ & Arrived for pre-test $n=16$ \\
\hline \multirow[t]{8}{*}{ Week 2} & Experimental group 3 (attended the program) & Experimental group 4 (attended the program) \\
\hline & Invited to participate $n=20$ & Invited to participate $n=20$ \\
\hline & Arrived for program $n=19$ & Arrived for program $n=3$ \\
\hline & Final number participated $n=19$ & Additional participants recruited $n=15$ \\
\hline & & Final number participated $n=18$ \\
\hline & Control group 3 (completed the survey) & Control group 4 (completed the survey) \\
\hline & Invited to pre-test $n=20$ & Invited to pre-test $n=20$ \\
\hline & Arrived for pre-test $n=18$ & Arrived for pre-test $n=17$ \\
\hline
\end{tabular}

about themselves (i.e., "On the whole, I am satisfied with myself"). This scale consisted of 10 items and was measured on a five-point Likert scale, ranging from strongly disagree (1) to strongly agree (5). After analyzing the reliability coefficient of the scales, some problematic items were identified. The loading of item 8 ("I wish I could have more respect for myself") in the self-esteem scale was not significant and was therefore deemed not suitable for inclusion in further analyses. Cronbach's alpha coefficient for this scale was 0.67 (Time 0), and 0.71 (Time 1).

\section{Intervention Indices}

Participants' experience and perception of the program were measured to indicate the intervention's integrity and strength. The measure consisted of six multi-item indices, rated on a five-point scale. The following aspects of the intervention were included: Trainer support was measured with five items and group support with five items. The facilitators and other group participants were rated on their warmth, expertise, and helpfulness ( $1=$ most negative rating; $5=$ most positive rating). Both active learning and job-search skills were answered on a frequency scale that varied from $1=$ not at all to $5=$ a great deal and were measured with five items. Example items are "During the workshop, to what extent do you feel that you could share your experiences?" (active learning) and "During the workshop, to what extent do you feel that the trainers and other group members helped you to identify possible job opportunities?" (jobsearch skills). An example item of inoculation against setbacks is "Do you anticipate difficulties and setbacks during your jobsearch?" which was answered from $1=$ very few to $5=$ very much and measured with three items. Learning experience ranged from 1 (improved to a very small extent) to 5 (improved to a very great extent). It was measured with seven items (i.e., "To what extent do you feel that the workshop has prepared you to conduct interviews?"). The reliability of these scales ranged from 0.66 to 0.91 .

\section{Statistical Analysis}

SPSS version 25.0 was used to analyze the data (IBM Corp, 2017). The validity and reliability of the program was established by (i) using multivariate analysis of variance (MANOVA) to report on participant randomization; and (ii) examining mean scores of the program's indices to determine the integrity and strength of the intervention. Secondly, Cronbach alpha coefficients were computed to establish the internal consistency of the constructs (Clark and Watson, 1995). Correlation coefficients were used to determine the relationship between the measured variables, the confidence interval level was set at $95 \%$, to indicate statistical significance. Practical significance of the correlation coefficients was set at a cut-off point of 0.30 (medium effect) and 0.50 (large effect, Cohen, 1988). A one-way repeated measures multivariate analysis of variance (MANOVA) was used to study whether the pre- (T0) and post-test (T1) means differ between the experimental and control groups. If the oneway repeated measures MANOVA were statistically significant, we analyzed which of the groups differed in terms of the combined dependent variables and which of the variables were statistically significant. Listwise deletion were used to deal with missing data.

\section{Ethical Considerations}

Ethical clearance was obtained from the Humanities and Health Research Ethics Committee (HHREC; NWU-HS-2018-0006). Based on these ethical considerations, much attention and effort were paid to ensure a program that is as accessible and resourceful as possible for the participants. The program was presented at a venue at the university. Participants were transported by bus from townships to the university and back. The Flemish Interuniversity Board, the funding agency for the project, paid the costs of the transport. The venue provided for a conducive atmosphere that promotes capacity building. 
TABLE 3 | Characteristics of the experimental $(N=69)$ and control groups $(N=61)$.

\begin{tabular}{|c|c|c|c|c|}
\hline \multirow[b]{2}{*}{ Characteristics } & \multicolumn{2}{|c|}{ Experimental group } & \multicolumn{2}{|c|}{ Control group } \\
\hline & Total & $\%$ & Total & $\%$ \\
\hline \multicolumn{5}{|l|}{ Gender } \\
\hline Male & 27 & $39 \%$ & 23 & $40 \%$ \\
\hline Female & 42 & $61 \%$ & 35 & $60 \%$ \\
\hline \multicolumn{5}{|l|}{ Age } \\
\hline Below 20 & 1 & $1 \%$ & 3 & $7 \%$ \\
\hline $20-29$ & 36 & $52 \%$ & 27 & $47 \%$ \\
\hline 30-39 & 23 & $33 \%$ & 16 & $28 \%$ \\
\hline $40-49$ & 6 & $9 \%$ & 9 & $22 \%$ \\
\hline $50-59$ & 2 & $3 \%$ & 3 & $5 \%$ \\
\hline \multicolumn{5}{|l|}{ Race } \\
\hline Black & 69 & $100 \%$ & 41 & $100 \%$ \\
\hline White & 0 & $0 \%$ & 0 & $0 \%$ \\
\hline Indian & 0 & $0 \%$ & 0 & $0 \%$ \\
\hline Colored & 0 & $0 \%$ & 0 & $0 \%$ \\
\hline \multicolumn{5}{|l|}{ Education level } \\
\hline Less than Grade 12 & 21 & $30 \%$ & 23 & $40 \%$ \\
\hline Grade 12 & 37 & $54 \%$ & 25 & $43 \%$ \\
\hline National Certificate & 10 & $14 \%$ & 4 & $7 \%$ \\
\hline National Diploma/Degree & 1 & $1 \%$ & 6 & $10 \%$ \\
\hline \multicolumn{5}{|c|}{ Duration of unemployment } \\
\hline Less than 3 months & 9 & $13 \%$ & 3 & $7 \%$ \\
\hline 3-5 months & 5 & $7 \%$ & 7 & $12 \%$ \\
\hline 6-11 months & 5 & $7 \%$ & 4 & $6 \%$ \\
\hline $1-2$ years & 8 & $12 \%$ & 16 & $28 \%$ \\
\hline $2-5$ years & 27 & $39 \%$ & 12 & $21 \%$ \\
\hline More than 5 years & 15 & $22 \%$ & 16 & $28 \%$ \\
\hline
\end{tabular}

Data was collected using self-administered questionnaires on two occasions. Questionnaires were completed with pen and paper and took $\sim 40 \mathrm{~min}$. In cases where participants had difficulty understanding the survey questions, the facilitators explained them, without changing the meaning of the questions. A participation number was allocated to participants to identify them in the subsequent data collection rounds. Therefore, participation was not completely anonymous, but questionnaires did not contain any confidential information. Furthermore, facilitators were asked to take note of their experiences and the observed behaviors of the participants after each session. All notes and observations were used as qualitative information to be referred to in the explanation of the findings.

Furthermore, participants received food parcels on each day of the workshop, a gift voucher, and an attendance certificate. An Unemployment Research Advisory Board (URAB) was established to advise the researchers on the development and implementation of the program in the two townships. Lastly, participants from the control groups $(n=61)$ were also invited to undergo the training to ensure that all participants benefit equally. This training took place 1 week after the experimental groups had undergone their training.

\section{RESULTS}

\section{Preliminary Analyses}

To ensure acceptable validity and reliability of the program, previous JOBS studies used two types of measures, namely testing the integrity of randomization, and the strength of the program (Vinokur et al., 1995). The first check to determine the validity of the program is to determine whether the statistical analyses were conducted on a randomized (true) experimental design. This is determined by comparing the demographic and other tested variables of the experimental and control conditions at baseline to identify possible differences. If no significant differences are found, the integrity of randomization can be confirmed. Multivariate analysis of variance (MANOVA) were used to assess whether the participants in the condition groups (experimental and control groups; $n=130$ ), at baseline, differed from participants who randomly dropped out of the program $(n=17)$. A significant difference between the level of amotivation of the two conditions and the dropout group was found $[F(1,147)=4.98 ; p<0.01 ; \eta=0.06]$. Those in the condition groups scored lower levels of amotivation $(M=2.47 ; S D=0.76)$, compared to those who dropped out $(M=3.04 ; S D=0.78)$. There were no significant differences between conditions for gender $[F(1,144]=0.89 ; p<0.36$; partial $\left.\eta^{2}=0.01\right)$, age $[F(1,144)=0.27 ; p<0.60$; partial $\left.\eta^{2}<0.01\right]$, race $\left[F(1,144)=0.89 ; p<0.36\right.$; partial $\eta^{2}<$ $0.01]$, education $\left[F(1,144)=0.30 ; p<0.58\right.$; partial $\eta^{2}<$ $0.01]$, or duration of unemployment $[F(1,144)=0.03 ; p<$ 0.86; partial $\left.\eta^{2}<0.01\right]$. Participants who dropped out of the program were excluded from further the analyses due to the lack of data at Time 1 .

To test for random sampling between the experimental and control groups, MANOVA was conducted. Baseline scores of the condition groups' demographic variables, job-search selfefficacy, amotivation and self-esteem were compared. Supporting the successfulness of the random assignment, there were no significant differences between conditions for gender $[F(1$, $130)=0.11 ; p<0.74$; partial $\left.\eta^{2}<0.01\right]$, age $[F(1,130)=1.18$; $p<0.28$; partial $\left.\eta^{2}<0.01\right]$, race $[F(1,130)=2.27 ; p<0.13$; partial $\left.\eta^{2}=0.02\right]$, education $[F(1,130)=0.12 ; p<0.73$; partial $\left.\eta^{2}<0.01\right]$, or, duration of unemployment $[F(1,130)=0.89$; $p<0.36$; partial $\left.\eta^{2}=0.01\right]$. Given the absence of significant a priori differences between the two conditions there is no need to control for any variables at baseline (Time 0 ), when testing the effectiveness of the intervention.

The second check is to test the strength and integrity of the intervention. Participants were asked to evaluate their experience of facilitators and the program. These evaluations are used to determine whether various intervention elements (trainer support, group support, active learning methods, job-search skills, inoculation against setbacks, and learning experiences) had been implemented and had operated as designed (Vinokur et al., 1996). Participants experienced the program as psychologically and socially positive, based on the mean scores of the intervention indices.

According to Field (2013) there are several assumptions need to be assessed prior to the analyses of inferential statistics. Some of the most common assumptions include independent random sampling, normality, linearity, equality of variance, and homogeneity of variance-covariance. Firstly, integrity of randomization has already been confirmed. Secondly, to test if the data was normally distribution an inspection of the 
Q-Q plots and histograms of the post-test scores on the three dependent variables showed some deviations of normality. Therefore, the results should be interpreted with caution (Field, 2013). Since, MANOVA is sensitive to outliers, Q-Q plots were used to determine whether the sample included outliers, no was outliers were detected. Thirdly, to test the linear relationship between the independent and dependent variables correlation coefficients were used. Table 4 shows the correlations between all study variables. Some relationships are worth mentioning. Several statistically significant relationships are worth mentioning: Self-esteem Time 1 showed a positive statistically significant negative effect (with medium effect) with the condition variable; participants' age were significantly related to their duration of unemployment; job-search self-efficacy at Time 0 is significantly related to job-search self-efficacy Time 1 (with medium effect); likewise, amotivation at Time 0 is significantly related to amotivation Time 1 (with medium effect), and lastly, self-esteem Time 1 is significantly correlated with jobsearch self-efficacy Time 1 (with medium effect) and amotivation Time 1 (with medium effect). No signs of multicollinearity are evident, as measured variables were moderately correlated with each other.

Fourthly, to test whether the variances of the differences between conditions are equal repeated measures MANOVA was used. Repeated measures MANOVA requires sphericity and Mauchly's test evaluates if this holds. The sphericity assumption was met by our data because the repeated measure variables had only two levels. Finally, homogeneity of variance-covariance was tested with Box's $M$ test of equality of covariance homogeneity of variance. Box's M (13.17) was not significant $(p>0.05)$, therefore, the assumption is not violated, and Wilk's Lambda is an appropriate test to use. The results show that there are no are significant differences among the experimental and control groups on a linear combination of the three dependent variables at baseline [Wilks' Lambda $(\Lambda)=0.99, F(3,122)=0.46, p=0.71$, $\eta=0.14]$. Equality of variance was assessed with utilizing Levene's test, which uses the F-test, none of the variables' were significant [job-search self-efficacy: $F(1,130)=2.31, p=0.13$; amotivation $F(1,130)=1.45, p=0.24$; self-esteem: $F(1$,
130) $=0.40, p=0.85]$; therefore the assumption of equality of variance is met.

\section{Effects of the Intervention}

To examine for statistical differences between the included dependable variables (job-search self-efficacy, amotivation and self-esteem), by an independent grouping variable (experimental and control conditions), a one-way repeated measures MANOVA was conducted.

The results showed a statistically significant interaction effect between the experimental condition (experimental group vs. control group) and the combined dependent variables (job-search self-efficacy, amotivation and self-esteem): $[F(3$, $124)=8.16, p<0.001$, Wilk's $\Lambda=0.84$, partial $\left.\eta^{2}=0.17\right]$. This was a medium effect (Cohen, 1988) where $17 \%$ of the variance is explained. Univariate analyses showed that the effects of two dependent variables (job-search self-efficacy and self-esteem) were statistically significant: job-search self-efficacy $(F=11.50, p$ $<0.001$, partial $\left.\eta^{2}=0.08\right)$ and self-esteem $(F=18.08, p<0.001$, partial $\left.\eta^{2}=0.13\right)$. The F-test of amotivation was not statistically significant: $F=0.06, p>0.05$. The plots in Figures $2-4$ confirm that the effect for the combined dependent variable is clearly different for the experimental and control groups.

Next, we tested the effects of combined dependent variables (job-search self-efficacy, amotivation and self-esteem) for the experimental group (EG) and control group (CG) separately. The following results were obtained: $F_{E G}(3,64)=13.56, p<0.001$, Wilk's $\Lambda=0.61$, partial $\left.\eta^{2}=0.39\right) ; F_{C G}(3,58)=0.95, p>0.5$, Wilk's $\Lambda=0.95)$.

Univariate analyses in the experimental group showed that the effects of two dependent variables (job-search self-efficacy and self-esteem) were statistically significant: job-search self-efficacy $\left(F=18.62, p<0.001\right.$, partial $\left.\eta^{2}=0.22\right)$ and self-esteem $(F=31.91$, $p<0.001$, partial $\left.\eta^{2}=0.33\right)$. The F-test of amotivation was not statistically significant: $F=0.44, p>0.05$. The pairwise comparisons (of T0 and T1 scores) for the experimental and control groups are reported in Table 5. Univariate analyses in the control group showed that the effects of all three dependent variables were statistically insignificant: job-search self-efficacy

TABLE 4 | Correlations matrix of biographic and dependent variables $(N=130)$.

\begin{tabular}{|c|c|c|c|c|c|c|c|c|c|c|c|c|c|}
\hline Construct & Mean & $S D$ & 1 & 2 & 3 & 4 & 5 & 6 & 7 & 8 & 9 & 10 & 11 \\
\hline 1. Condition & 1.47 & 0.50 & & & & & & & & & & & \\
\hline 2. Gender & 1.60 & 0.49 & -0.03 & & & & & & & & & & \\
\hline 3. Race & 1.05 & 0.37 & 0.13 & -0.15 & & & & & & & & & \\
\hline 4. Education & 1.87 & 0.82 & 0.01 & -0.02 & -0.06 & & & & & & & & \\
\hline 5. Age & 31.15 & 8.50 & 0.10 & -0.15 & 0.08 & $-0.23^{\star \star}$ & & & & & & & \\
\hline 6. Duration of unemployment & 4.28 & 1.58 & 0.04 & 0.11 & 0.02 & -0.14 & $0.31^{\star \star}$ & & & & & & \\
\hline 7. Job-search self-efficacy T0 & 3.92 & 0.76 & 0.07 & -0.13 & -0.03 & -0.03 & 0.09 & $-0.24^{\star \star}$ & & & & & \\
\hline 8. Amotivation TO & 2.46 & 0.75 & -0.07 & -0.02 & -0.01 & -0.17 & 0.13 & 0.16 & -0.09 & & & & \\
\hline 9. Self-esteem T0 & 3.91 & 0.60 & 0.04 & -0.03 & 0.09 & 0.11 & -0.08 & -0.14 & $0.28^{\star \star}$ & $-0.24^{\star \star}$ & & & \\
\hline 10. Job-search self-efficacy T1 & 4.10 & 0.72 & $-0.21^{\star}$ & -0.12 & 0.07 & -0.10 & -0.08 & -0.16 & $0.47^{\star \star}$ & 0.05 & 0.10 & & \\
\hline 11. Amotivation $\mathrm{T} 1$ & 2.41 & 0.80 & -0.02 & 0.01 & 0.03 & $-0.23^{\star \star}$ & 0.15 & 0.15 & -0.13 & $0.44^{\star *}$ & $-0.28^{\star \star}$ & -0.07 & \\
\hline 12. Self-esteem T1 & 4.02 & 0.61 & $-0.40^{\star \star}$ & 0.06 & -0.09 & 0.12 & $-0.22^{\star}$ & -0.13 & 0.14 & 0.01 & $0.24^{\star \star}$ & $0.35^{\star \star}$ & $-0.33^{\star \star}$ \\
\hline
\end{tabular}

${ }^{* *} p<0.01$ statistically significant; ${ }^{*} p<0.05$ statistically significant. $r<0.30$ is practically significant (medium effect); $r<0.50$ is practically significant (large effect). 
$(F=0.08, p>0.05)$, amotivation $(F=0.05, p>0.05)$, and SE $(F=2.27, p>0.05)$.

Therefore hypothesis 1 , namely that after taking part in the JOBS program, participants from the experimental group will report higher levels of job-search self-efficacy compared to their control group counterparts, is supported.

The second hypothesis of this study was that after taking part in the JOBS program, participants from the experimental group would report lower levels of amotivation, compared to their control group counterparts. The results of the MANOVA showed that the mean amotivation score was not statistically significantly higher in the experimental group, when compared to their counterparts. As a result, hypothesis 2 is not supported.

The third hypothesis of this study was that after taking part in the JOBS program, participants from the experimental group will report higher levels of self-esteem, compared to their control group counterparts. The results of the MANOVA showed the experimental group showed statistically significantly higher mean scores for self-esteem (compared to the control group). Consequently, hypothesis 3 was supported.

\section{DISCUSSION}

To date, much research has been conducted on the psychological consequences of being unemployed. Yet, when it comes to practice, employability interventions seldom include crucial psychosocial aspects to assist the unemployed, particularly so in South Africa. One program addressing the gap in literature and practice is the JOBS intervention. Due to the encouraging results, several JOBS derivatives have been implemented globally (Price and Fang, 2002; Vuori et al., 2002; Barry et al., 2006; Shirom et al., 2008; Brenninkmeijer and Blonk, 2011), however, mainly in developed countries. The lack of similar interventions in South Africa, together with the successful replication of the JOBS program, created an opportunity to explore whether such an intervention will be effective in the South African context. This paper intended to apply a South African version of the JOBS program, called the Qhubekela Phambili career-enhancement program. Suggestions pertaining to the implementation and evaluation of the JOBS program made in Paver et al. (2019b) were adhered to.

Preliminary analyses were conducted to determine whether the Qhubekela Phambili program was valid and reliable. Two aspects, randomization of intervention conditions and strength and integrity of the program, were considered. Given that no significant differences were found between the experimental and control group at baseline, the integrity of randomization of the experimental and control groups was fully preserved. Also, the strength and integrity of the program was fully preserved, as the Qhubekela Phambili program adhered to the researchbased principles of the JOBS program. An analysis of the working elements of the JOBS program revealed that a sense of mastery, comprising job-search self-efficacy, amotivation, and self-esteem, is one of the most predictive elements of positive outcomes in the JOBS program (Vinokur and Schul, 1997; Vinokur and Price, 2015). Therefore, the general aim of
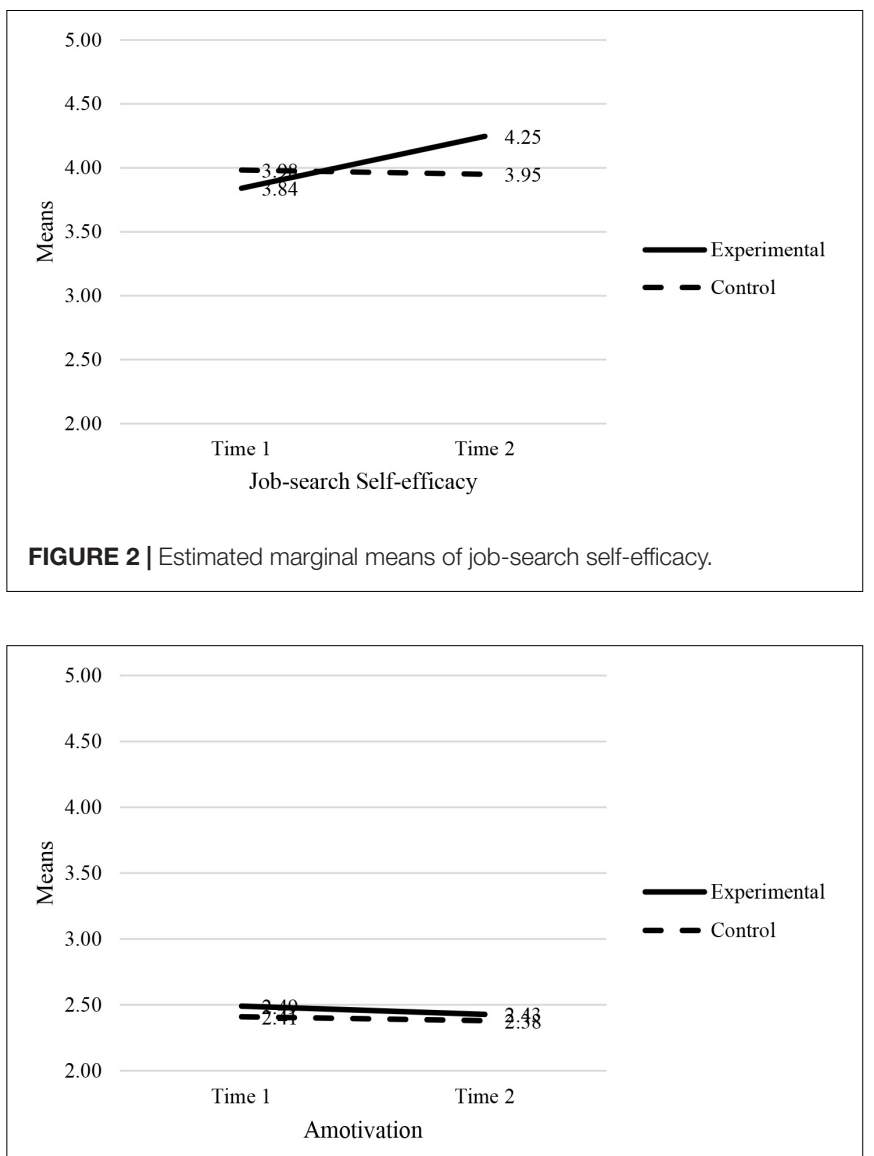

FIGURE 3 | Estimated marginal means of amotivation.

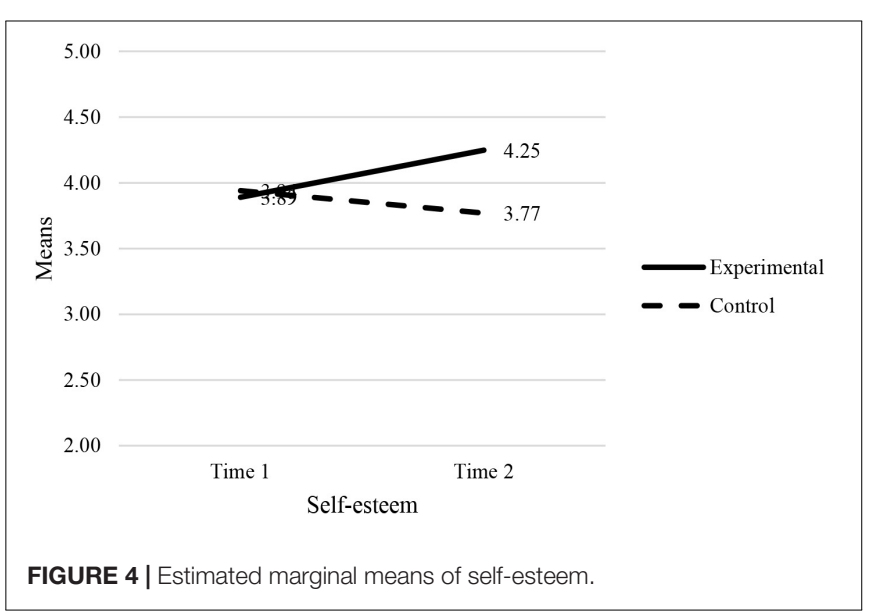

the paper was to establish whether the Qhubekela Phambili intervention affected participants' levels of job-search selfefficacy, amotivation, and self-esteem.

The first hypothesis, and also one of the most significant findings to emerge from this study, was that the Qhubekela Phambili intervention succeeded in increasing participants' jobsearch self-efficacy levels. Experimental group participants scored significantly higher in job-search self-efficacy, compared to their 
TABLE 5 | Means, standard errors and pairwise comparisons for the experimental and control conditions.

\begin{tabular}{|c|c|c|c|c|c|c|}
\hline \multirow{2}{*}{$\begin{array}{l}\text { Variable } \\
\text { Experimental group }\end{array}$} & \multicolumn{2}{|c|}{ Mean (SE) } & \multirow[t]{2}{*}{ Difference } & \multirow[t]{2}{*}{ SE } & \multirow[t]{2}{*}{$p$} & \multirow[t]{2}{*}{$95 \% \mathrm{Cl}$} \\
\hline & TO & T1 & & & & \\
\hline Job search self-efficacy & $3.84(0.07)$ & $4.25(0.10)$ & $-0.41^{*}$ & 0.10 & $0.00^{*}$ & {$[-0.66,-0.22]$} \\
\hline Amotivation & $2.49(0.09)$ & $2.43(0.10)$ & 0.06 & 0.09 & 0.51 & {$[-0.12,0.25]$} \\
\hline Self-efficacy & $3.89(0.07)$ & $4.25(0.05)$ & $-0.36^{\star}$ & 0.06 & $0.00^{*}$ & {$[-0.49,-0.24]$} \\
\hline Control group & TO & T1 & & & & \\
\hline Job search self-efficacy & $3.98(0.09)$ & $3.95(0.11)$ & 0.03 & 0.09 & 0.77 & {$[-0.15,0.19]$} \\
\hline Amotivation & $2.41(0.11)$ & $2.38(0.11)$ & 0.03 & 0.12 & 0.83 & {$[-0.21,0.26]$} \\
\hline Self-efficacy & 3.94 (0.08) & 3.77 (0.09) & 0.17 & 0.11 & 0.14 & {$[-0.05,0.39]$} \\
\hline
\end{tabular}

${ }^{*} p<0.001$.

control group counterparts. This finding is consistent with previous empirical studies reporting that the JOBS program can enhance participants' job-search self-efficacy. Increases in job-search self-efficacy is a crucial finding, as it has previously been related to sustained job-search efforts, despite repeated disappointments (Van Ryn and Vinokur, 1992; Choi et al., 2003).

The second aim of the study was to determine whether participants would show lower levels of amotivation after the Qhubekela Phambili workshop. No significant changes in participants' levels of amotivation were found. This finding may be somewhat concerning, as the only variable to differ significantly differ between the condition and dropout groups was amotivation. Possible explanations for this finding may be found in the literature. It has previously been noted that the adverse effects of unemployment on mental health are larger among the long-term unemployed than the short-term unemployed (McKee-Ryan et al., 2005). Bearing in mind that $75 \%$ (18\% longer than a year, 31\% between 2 and 5 years, and $26 \%$ longer than 5 years) of the current study's sample have been unemployed for longer than 12 months, severe feelings of discouragement, hopelessness, and a lack of personal control may occur. A qualitative study conducted among the unemployed in South Africa testified that due to abundant unsuccessful jobsearch efforts, the unemployed often develop a passive attitude and a sense of learned helplessness (Du Toit et al., 2018).

Earlier literature found that amotivation is negatively related to job-search efforts due to the jobseekers' lack of motivation to persist (Vansteenkiste et al., 2004). Considering that feelings of helplessness may be so deeply embedded, perhaps a need exists to foster an intrinsically inclined motivation among participants. While much attention is given to inoculating participants against possible setbacks, to truly change such behavior, using the same principles to emphasize the importance of taking ownership of one's reality may deliver promising results. This is an important finding considering the fact that it was previously reported that, in a sample of unemployed individuals, $32 \%$ reported to be amotivated (Van der Vaart et al., 2018).

The third hypothesis of this study was that participants would show higher levels of self-esteem after attending the program. Indeed, the program demonstrated the capability to increase participants' self-esteem. As hypothesized, after taking part in the JOBS program, participants from the experimental group reported higher levels of self-esteem, compared to their control group. This finding is in line with previous research that suggests that the intervention provided the participants with the intended support to raise their self-esteem (Caplan et al., 1989; Vinokur et al., 1995; Vuori and Silvonen, 2005).

\section{Limitations and Recommendations}

Several limitations of this study need to be acknowledged. First, only self-report measures were used. While self-report measures are considered the most appropriate for assessing perceived behavioral constructs, efforts to study such constructs more objectively may yield significant findings. Second, it was not possible to investigate the measurement invariance of the measures of the three dependent variables in this study because of the small sample sizes (Cheung et al., 2011). Future research should focus on the measurement invariance of longitudinal variables.

In social interventions, non-participation is a reality (Vinokur et al., 1991a). In previous studies on the JOBS program to preserve the integrity of a randomized experimental design, dropout participants were kept in the experimental group - it is believed to allow for stronger conclusions. Yet, it is reported that such a design yields conservative estimates of the achieved effects (Caplan et al., 1989). Since follow-up data from dropout participants in the current study was not available, the integrity of randomization was not fully preserved.

Another potential weakness in this investigation may be the number of no-show (54\%) and dropout (14\%) participants. Those who participated in the first round of surveys and then did not return, reported significantly higher levels of amotivation, compared to participants in the experimental conditions. Though previous research has shown that the people who need the intervention the most were indeed the ones who participated (Price et al., 1992) this is perhaps not the case in the current study. It begs the question of what the program could have achieved if targeted at this possibly more vulnerable group. Therefore, a need exists to explore improved recruitment strategies in future endeavors.

To be able to compare the findings of the current study with previous studies conducted on the JOBS program, 
similar dependent variables (job-search self-efficacy, amotivation, and self-esteem) were measured. However, given that the program was adjusted to also focus on entrepreneurship, an additional measure or an adapted version of the job-search selfefficacy questionnaire, not limited to job-search self-efficacy, but also determining a broader self-efficacy concept may have been valuable.

According to Price et al. (1992) participants with a higher risk of depression were more likely to benefit from the intervention. Consequently, a prospective screening mechanism was used to identify potential participants. Because $69 \%$ of the unemployed have been unemployed for longer than a year (Statistics South Africa, 2018) and that $\sim 70 \%$ have reported to experience unemployment as feeling desperate or discouraged (Van der Vaart et al., 2018) for ethical reasons it was difficult to discriminate on the grounds of psychological aspects. Therefore, lastly, but perhaps most noteworthy, the limitation is that mental health and depressive symptoms were not studied in the current paper and could be considered in future research.

A final limitation, particularly relevant to intervention studies in behavioral research, may be that much time has been spent with the experimental group, therefore, the results of this study can be attributed to the attention they received during the program. A comparative framework should be considered to provide an opportunity for the control group to receive equal attention (Aycock et al., 2018).

\section{CONCLUSION}

Unemployment is considered one of the South African government's top priorities (Ramaphosa, 2019). Although unemployment is a much-researched and timely topic, programs aimed at assisting the unemployed in South Africa often neglects important psychosocial aspects. Considering the severe repercussions of unemployment, an urgent need exists to intervene on a psychological level. Likewise, while derivatives of JOBS program have been successfully implemented in many countries, its exposure to circumstances and economic conditions similar to that of South Africa is limited. This is the first study to undertake a longitudinal analysis of the JOBS program within the South African context. The primary purpose of this paper was to implement the JOBS program in two lowincome communities in South Africa.

The present study contributed to existing literature to support the effectiveness of the JOBS program in a variety of contexts. Overall, the Qhubekela Phambili program provided evidence to demonstrate the programs' ability to enhance the job-search self-efficacy and the self-esteem of participants. Contrary to expectations, the program did not succeed in decreasing the levels

\section{REFERENCES}

Aycock, D. M., Hayat, M. J., Helvig, A., Dunbar, S. B., and Clark, P. C. (2018). Essential considerations in developing attention control groups in behavioral research. Res. Nurs. Health 41, 320-328. doi: 10.1002/nur.21870 of amotivation experienced by participants, which may reveal another valuable finding. Since the amotivated believe that their actions will not yield desired outcomes (Vansteenkiste et al., 2004) emphasis should be on helping the unemployed overcome such perceptions. Fostering beliefs of personal control may contribute significantly to coping with and overcoming unemployment.

\section{AUTHOR'S NOTE}

This manuscript has been released in a repository at https:// repository.nwu.ac.za/handle/10394/33069, Paver (2019).

\section{DATA AVAILABILITY STATEMENT}

The datasets generated for this study are available on request to the corresponding author.

\section{ETHICS STATEMENT}

The studies involving human participants were reviewed and approved by the North-West University - Humanities and Health Research Ethics Committee (HHREC; NWU-HS-20180006). The participants provided their written informed consent to participate in this study.

\section{AUTHOR CONTRIBUTIONS}

This publication was based on the Ph.D. thesis of RP. HD, SR, and AV were co-authors as well as supervisors of the project. $\mathrm{RB}$ made conceptual contributions to the manuscript. All authors contributed to the article and approved the submitted version.

\section{FUNDING}

This work was supported by the Experiences of Unemployment Research Project funded by the Flemish Interuniversity Council University Development Cooperation (VLIR-UOS). We were truly grateful for this opportunity.

\section{SUPPLEMENTARY MATERIAL}

The Supplementary Material for this article can be found online at: https://www.frontiersin.org/articles/10.3389/fpsyg. 2020.01418/full\#supplementary-material

Bandura, A. (1986). The explanatory and predictive scope of self-efficacy theory. J. Soc. Clin. Psychol. 4, 359-373. doi: 10.1521/jscp.1986.4.3.359

Barry, M., Reynolds, C., Sheridan, A., and Egenton, R. (2006). Implementation of the JOBS program in Ireland. J. Public Mental Health 5, 10-25. doi: 10.1108/ 17465729200600028 
Brenninkmeijer, V., and Blonk, R. W. (2011). The effectiveness of the JOBS program among the long-term unemployed: a randomized experiment in the Netherlands. Health Promot. Int. 27, 220-229. doi: 10.1177/1069072716657534

Caplan, R. D., Vinokur, A. D., and Price, R. H. (1997). "From job loss to reemployment: field experiments in prevention-focused coping," in Primary Prevention Works: Issues in Children's and Families' Lives, eds G. W. Albee and T. P. Gullotta (Thousand Oaks, CA: Sage), 341-379.

Caplan, R. D., Vinokur, A. D., Price, R. H., and Van Ryn, M. (1989). Job seeking, reemployment, and mental health: a randomized field experiment in coping with job loss. J. Appl. Psychol. 74, 759-769. doi: 10.1037/0021-9010.74. 5.759

Cheung, F. M., Van de Vijver, F. J. R., and Leong, F. T. L. (2011). Toward a new approach to the study of personality in culture. Am. Psychol. 66, 593-603. doi: $10.1037 / \mathrm{a} 0022389$

Choi, J. N., Price, R. H., and Vinokur, A. D. (2003). Self-efficacy changes in groups: effects of diversity, leadership, and group climate. J. Organ. Behav. 24, 357-372. doi: $10.1002 /$ job.195

City of Johannesburg (2018). Integrated Development Plan: 2018/19 Review. Johannesburg: City of Johannesburg Metropolitan Municipality.

Clark, L. A., and Watson, D. (1995). Constructing validity: basic issues in objective scale development. Psychol. Assess. 7, 309-319.

Cobb-Clark, D. A. (2015). Locus of control and the labor market. IZA J. Lab. Econ. 4, 1-19. doi: 10.1186/s40172-014-0017-x

Cohen, J. (1988). Statistical Power Analysis for the Behavioral Sciences, 2nd Edn. Hillsdale, NJ: Erlbaum.

Curran, J., Wishart, P., and Gingrich, J. (1999). JOBS: A Manual for Teaching People Successful Job Search Strategies. Michigan: University of Michigan.

Deci, E. L., and Ryan, R. M. (1985). Intrinsic Motivation and Self-Determination in Human Behavior. New York, NY: Plenum.

Donaldson, S. I., and Weiss, R. (1998). "Health, well-being, and organizational effectiveness in the virtual workplace," in The Virtual Workplace, eds M. Igbaria and M. Tan (Hershey, PA: Idea Group Publishing), 24-44.

Du Toit, M., De Witte, H., Rothmann, S., and Van den Broeck, A. (2018). Unemployment experiences in context: a phenomenological study in two townships in South Africa. J. Psychol. Africa 28, 122-127. doi: 10.1080/ 14330237.2018.1454575

Field, A. (2013). Discovering Statistics Using SPSS. Thousand Oaks, CA: SAGE Publications.

Hobfoll, S. E. (1989). Conservation of resources: a new attempt at conceptualizing stress. Am. Psychol. 44, 513-524.

Houssemand, C., Meyers, R., and Pignault, A. (2019). Adaptation and validation of the perceived control in unemployment scale. Front. Psychol. 10:383. doi: 10.3389/fpsyg.2019.00383

IBM Corp (2017). IBM SPSS Statistics for Windows, Version 25.0. Armonk, NY: IBM Corp.

Jahoda, M. (1982). Employment and Unemployment: A Social-Psychological Analysis. London: Cambridge University Press.

Kanfer, R., Wanberg, C. R., and Kantrowitz, T. M. (2001). Job search and employment: a personality-motivational analysis and meta-analytic review. J. Appl. Psychol. 86, 837-855. doi: 10.1037/0021-9010.86.5.837

Kluve, J., Puerto, S., Robalino, D., Romero, J. M., Rother, F., Stöterau, J., et al. (2017). Interventions to improve the labour market outcomes of youth: a systematic review of training, entrepreneurship promotion, employment services, and subsidized employment interventions. Campbell Syst. Rev. 12, 1-288. doi: 10.4073/csr.2017.12

Lefcourt, H. M. (2014). Locus of Control: Current Trends in Theory and Research. New York, NY: Psychology Press.

Liu, S., Huang, J. L., and Wang, M. (2014). Effectiveness of job search interventions: a meta-analytic review. Psychol. Bull. 140, 1009-1041. doi: 10.1037/a0035923

Malmberg-Heimonen, I. E., West, B. T., and Vuori, J. (2019). Long-term effects of research-based and practice-based job search interventions: an RCT reevaluation. Res. Soc. Work Pract. 29, 36-48. doi: 10.1177/10497315177 48424

McKee-Ryan, F. M., Song, Z., Wanberg, R., and Kinicki, A. J. (2005). Psychological and physical well-being during unemployment: a meta-analytic study. J. Appl. Psychol. 90, 53-74. doi: 10.1037/0021-9010.90.1.53

Michigan Prevention Research Center (2013). The JOBS Project for the Unemployed: Update. Michigan: Michigan Prevention Research Center.
Møller, V. (1991). The Unemployment Blues: Psychological Effects of Unemployment on the Individual. (Working Paper No. 6). Durban: University of Natal.

Paul, K. I., and Moser, K. (2009). Unemployment impairs mental health: metaanalyses. J. Vocat. Behav. 74, 264-282. doi: 10.1016/j.jvb.2009.01.001

Paver, R. (2019). Vocational Interventions for the Unemployed. Doctoral dissertation, North-West University, Vanderbijlpark.

Paver, R., Blonk, R. W. B., Rothmann, S., De Witte, W., and Van den Broeck, A. (2018). Qhubekela Phambili Career-enhancement Programme: AJobseeker's Guide to Employment. Vanderbijlpark, South Africa: North-West University.

Paver, R., De Witte, W., Rothmann, S., Van den Broeck, A., and Blonk, R. W. B. (2019a). A systematic literature review of the implementation and evaluation of the JOBS program: a suggested framework for South Africa. South Afr. J Econ. Manag. Sci. 23:a3049.

Paver, R., Rothmann, S., Van den Broeck, A., and De Witte, W. (2019b). A review of labour market interventions to assist the unemployed in two townships in South Africa. South Afr. J. Econ. Manag. Sci. 45:a1596. doi: 10.4102/sajip.v45i0. 1596

Preuss, M., and Hennecke, J. (2018). Biased by success and failure: how unemployment shapes locus of control. Lab. Econ. 53, 63-74.

Price, R. H., Choi, J., and Vinokur, A. D. (2002a). Links in the chain of adversity following job loss: how economic hardship and loss of personal control lead to depression, impaired functioning and poor health. J. Occupat. Health Psychol. 7, 302-312.

Price, R. H., Vinokur, A. D., and Friedland, D. S. (2002b). “The job seeker role as resource in achieving reemployment and enhancing mental health new directions," in Socioeconomic Conditions, Stress and Mental Health Disorders: Toward a New Synthesis of Research and Public Policy, eds A. Maney and J. Ramos (Washington, DC: National Institute of Mental Health).

Price, R. H., and Fang, L. (2002). Unemployed Chinese workers: the survivors, the worried young and the discouraged old. Int. J. Hum. Resour. Manag. 13, 416-430. doi: 10.1080/09585190110111459

Price, R. H., Van Ryn, M., and Vinokur, A. D. (1992). Impact of a preventive job search intervention on the likelihood of depression among the unemployed. J. Health Soc. Behav. 33, 158-167. doi: 10.2307/2137253

Price, R. H., and Vinokur, A. D. (1995). "Supporting career transitions in a time of organizational downsizing: the Michigan JOBS program," in Employees, Careers and Jobs Creation: Developing Growth-Orientated Human Resource Strategies and Programs, ed. M. London (San Francisco, CA: JosseyBass Publishers).

Price, R. H., and Vinokur, A. D. (2014). "The JOBS program: impact on job seeker motivation reemployment, and mental health," in Oxford Handbook of Job Loss and Job Search, eds U. Klehe and E. A. J. van Hooft (Oxford: Oxford University Press).

Ramaphosa, C. (2019). State of the Nation Address of the President of South Africa, Cyril Ramaphosa. Cape Town: Houses of Parliament.

Rosenberg, M. (1965). Society and the Adolescent Self-Image. Princeton, NJ: Princeton University Press.

Rosenberg, M., Schooler, C., Schoenbach, C., and Rosenberg, F. (1995). Global self-esteem and specific self-esteem: different concepts, different outcomes. Am. Sociol. Rev. 60, 141-156. doi: 10.2307/2096350

Rotter, J. B. (1966). Generalized expectancies for internal versus external control of reinforcement. Psychol. Monogr. 80, 1-28. doi: 10.1037/h0092976

Ryan, R. M., and Deci, E. L. (2000). Intrinsic and extrinsic motivations: classic definitions and new directions. Contemp. Educ. Psychol. 25, 54-67. doi: 10.1006/ ceps. 1999.1020

Saks, A. M., and Ashforth, B. E. (1999). Effects of individual differences and job search behaviors on the employment status of recent university graduates. J. Vocat. Behav. 54, 335-349. doi: 10.1006/jvbe.1998.1665

Schaufeli, W. B., and VanYperen, N. W. (1993). Success and failure in the labour market. J. Organ. Behav. 14, 559-572.

Shirom, A., Vinokur, A., and Price, R. (2008). Self-efficacy as a moderator of the effects of job-search workshops on re-employment: a field experiment. J. Appl. Soc. Psychol. 38, 1778-1804. doi: 10.1111/j.1559-1816.2008.00369.x

Statistics South Africa (2018). Quarterly labour force survey: Quarter 3, 2018. Pretoria: Statistics South Africa.

Van den Hof, R. A. (2015). Self-esteem, self-efficacy and employability among disadvantaged youth in Orange Farm, Johannesburg. Unpublished master's thesis, University of Johannesburg, Johannesburg. 
Van der Vaart, L., De Witte, H., Van den Broeck, A., and Rothmann, S. (2018). A psychosocial typology of the unemployed in South Africa. South Afr. J. Psychol. 48, 179-192. doi: 10.1177/0081246317721600

Van der Vaart, L., Van den Broeck, A., Rothmann, S., and Witte, H. D. (2019). Experiences, attitudes, and behaviors of the unemployed: the role of motivation and psychological needs. Psychol. Rep. doi: 10.1177/0033294119849020 [Epub ahead of print].

Van Ryn, M., and Vinokur, A. D. (1992). How did it work? An examination of the mechanisms through which an intervention for the unemployed promoted job-search behavior. Am. J. Community Psychol. 20, 577-597. doi: 10.1007/ BF00941773

Vansteenkiste, M., Lens, W., De Witte, H., and Feather, N. T. (2005). Understanding unemployed people's job search behaviour, unemployment experience and well-being: a comparison of expectancy-value theory and self-determination theory. Br. J. Soc. Psychol. 44, 268-287. doi: 10.1348/ $014466604 \mathrm{X} 17641$

Vansteenkiste, M., Lens, W., De Witte, S., De Witte, H., and Deci, E. L. (2004). The 'why' and 'why not' of job search behaviour: their relation to searching, unemployment experience, and well-being. Eur. J. Soc. Psychol. 34, 345-363. doi: 10.1002/ejsp.202

Vinokur, A., and Caplan, R. D. (1987). Attitudes and social support: determinants of job-seeking behavior and well-being among the unemployed. J. Appl. Soc. Psychol. 17, 1007-1024. doi: 10.1111/j.1559-1816.1987.tb02345.x

Vinokur, A. D., and Price, R. H. (2015). "Promoting reemployment and mental health among the unemployed," in Sustainable Working Lives. Aligning Perspectives on Health, Safety and Well-Being, eds J. Vuori, R. Blonk, and R. Price (Dordrecht: Springer), 171-186. doi: 10.1007/978-94-017-9798-6_10

Vinokur, A. D., Price, R. H., and Caplan, R. D. (1991a). From field experiments to program implementation: assessing the potential outcomes of an experimental intervention program for unemployed persons. Am. J. Community Psychol. 19, 543-562. doi: 10.1007/978-1-4615-0565-5_3

Vinokur, A. D., Van Ryn, M., Gramlich, E. M., and Price, R. H. (1991b). Longterm follow-up and benefit-cost analysis of the Jobs program: a preventive intervention for the unemployed. J. Appl. Psychol. 76, 213-219.

Vinokur, A. D., Price, R. H., and Caplan, R. D. (1996). Hard times and hurtful partners: how financial strain affects depression and relationship satisfaction of unemployed persons and their spouses. J. Pers. Soc. Psychol. 71, 166-179. doi: 10.1037/0022-3514.71.1.166

Vinokur, A. D., Price, R. H., Caplan, R. D., Van Ryn, M., and Curran, J. (1995). “The Jobs I preventive intervention for unemployed individuals: short-and long-term effects on reemployment and mental health," in Job Stress Interventions, eds L. R. Murphy, J. J. Hurrell Jr., S. L. Sauter, and G. P. Keita (Washington, DC: American Psychological Association), 125-138. doi: 10.1037/10183-009

Vinokur, A. D., and Schul, Y. (1997). Mastery and inoculation against setbacks as active ingredients in the JOBS intervention for the unemployed. J. Consult. Clin. Psychol. 65, 867-877. doi: 10.1037/0022-006X.65.5.867

Vinokur, A. D., and Schul, Y. (2002). The web of coping resources and pathways to reemployment following a job loss. J. Occup. Health Psychol. 7, 68-83. doi: 10.1037/1076-8998.7.1.68

Vinokur, A. D., Schul, Y., Vuori, J., and Price, R. H. (2000). Two years after a job loss: long term impact of the JOBS program on reemployment and mental health. J. Occup. Health Psychol. 5, 32-47. doi: 10.1037/1076-8998.5.1.32

Vinokur, A. D., and Van Ryn, M. (1993). Social support and undermining in close relationships: their independent effects on the mental health of unemployed persons. J. Pers. Soc. Psychol. 65, 350-359.

Vuori, J., and Silvonen, J. (2005). The benefits of a preventive job search program on re-employment and mental health at 2-year followup. J. Occup. Organ. Psychol. 78, 43-52. doi: 10.1348/096317904X2 3790

Vuori, J., Silvonen, J., Vinokur, A. D., and Price, R. H. (2002). The Työhön Job Search Program in Finland: benefits for the unemployed with risk of depression or discouragement. J. Occup. Health Psychol. 7, 5-19. doi: 10.1037/1076-8998.7. 1.5

Wanberg, C. R., Ali, A. A., and Csillag, B. (2020). Job seeking: the process and experience of looking for a job. Ann. Rev. Organ. Psychol. Organ. Behav. 7, 315-337.

World Bank (2018). Overcoming Poverty and Inequality in South Africa: An Assessment of Drivers. Washington, DC: World Bank.

Conflict of Interest: The authors declare that the research was conducted in the absence of any commercial or financial relationships that could be construed as a potential conflict of interest.

Copyright (c) 2020 Paver, De Witte, Rothmann, Van den Broeck and Blonk. This is an open-access article distributed under the terms of the Creative Commons Attribution License (CC BY). The use, distribution or reproduction in other forums is permitted, provided the original author(s) and the copyright owner(s) are credited and that the original publication in this journal is cited, in accordance with accepted academic practice. No use, distribution or reproduction is permitted which does not comply with these terms. 


\section{OPEN ACCESS}

Edited by:

Sebastiaan Rothmann,

North-West University, South Africa

Reviewed by:

Annika Luisa Meinecke,

University of Hamburg, Germany

Shaun Pichler.

California State University, Fullerton,

United States

*Correspondence:

Marianne van Woerkom

m.vanwoerkom@uvt.nl

Specialty section:

This article was submitted to

Organizational Psychology,

a section of the journal

Frontiers in Psychology

Received: 08 November 2019 Accepted: 07 July 2020

Published: 31 July 2020

Citation:

van Woerkom M and Kroon B (2020)

The Effect of Strengths-Based

Performance Appraisal on Perceived

Supervisor Support and the

Motivation to Improve Performance.

Front. Psychol. 11:1883.

doi: 10.3389/fpsyg.2020.01883
The Effect of Strengths-Based Performance Appraisal on Perceived Supervisor Support and the Motivation to Improve Performance

\author{
Marianne van Woerkom ${ }^{1,2 *}$ and Brigitte Kroon ${ }^{1}$ \\ ${ }^{1}$ Department of Human Resource Studies, Tilburg University, Tilburg, Netherlands, ${ }^{2}$ Center of Excellence for Positive \\ Organizational Psychology, Erasmus University Rotterdam, Rotterdam, Netherlands
}

Strengths-based performance appraisal focuses on identifying, appreciating, and developing employee's qualities in line with the company goals. Based on selfdetermination theory (SDT), we hypothesized that strengths-based performance appraisals will bring about a stronger motivation to improve (MTI) performance, by making subordinates feel supported by their supervisor and thereby fulfill their need for relatedness. Moreover, we hypothesized that strengths-based performance appraisal will reduce the threat to the relationship between supervisor and subordinate when the performance rating is relatively low. To investigate our hypotheses, we distributed a questionnaire to employees working for a large Dutch consultancy firm right after their yearly appraisal $(N=422)$ and linked the questionnaire data to their official performance ratings. Conditional process analysis indicated that strengths-based performance appraisal had a positive effect on perceived supervisor support (PSS), and in turn on MTI performance. Furthermore, the effect of strengths-based performance appraisal was particularly strong, when the performance rating was relatively low. Our findings may inspire future research into strengths-based performance appraisal as a relational approach to employee development.

Keywords: performance appraisal, perceived supervisor support, strengths, performance rating, motivation

\section{INTRODUCTION}

One of the main goals of performance appraisal is to motivate employees toward higher levels of performance (Kuvaas, 2007). However, for many workers, performance appraisal is not a source of motivation (Adler et al., 2016; Murphy, 2019). Some even argue that performance appraisal may undermine the relationship between the supervisor and the employee (Culbert, 2010; Kluger and Nir, 2010) and may have a negative impact on employee motivation (Neville and Roulin, 2016). Traditional performance appraisal tends to focus on employees' deficiencies in their job performance, knowledge, and skills, and how to remediate these deficiencies (Aguinis et al., 2012). As an alternative, strengths-based performance 
appraisal focuses on identifying, appreciating, and promoting the future use and development of employee strengths (Aguinis et al., 2012) and can therefore be seen as a powerful positive organizational intervention.

Based on self-determination theory (SDT; Deci and Ryan, 2008), we propose that strengths-based performance appraisals will make subordinates feel supported by their supervisor and thereby fulfill their psychological need for relatedness. In turn, the satisfaction of their need for relatedness will bring about a stronger motivation to learn and improve. SDT research often examines need-satisfaction constructs as mediators that connect particular social contexts to the outcomes that result from those contexts (Sheldon et al., 2011). A strengths-based performance appraisal may serve as a social context in which an authority (the supervisor) supports the need satisfaction of a subordinate. Although SDT posits three basic psychological needs, i.e., the need for autonomy, competence, and relatedness, in this study, we focused in particular on the need for relatedness, given the strongly interpersonal nature of the performance appraisal (Reinke, 2003). Strengths-based performance appraisals foster the need for relatedness by encouraging subordinates to express their authentic self (Roberts et al., 2005; Cable et al., 2013), thereby making them more identified and socially integrated (Swann et al., 2000; Polzer et al., 2002; Cable et al., 2015). This increases the chance that their supervisor will see them as they see themselves, leading to positive relationships and higher levels of perceived supervisor support (PSS; Cable et al., 2013). In turn, the fulfillment of the need for relatedness in the form of PSS may provide a safe and secure environment that stimulates subordinates toward higher levels of intrinsic motivation, thereby making them more inclined to seek challenges, extend their capacities, explore, and learn (Ryan and Deci, 2000).

Even though supervisors may focus on strengths in the performance appraisal, they may still need to comply with the performance management system that has been implemented in the organization. These systems often include performance ratings to compare the performance of employees relative to each other and to a predetermined set of criteria, and to make decisions regarding promotions and salary increases (Adler et al., 2016). Even when the performance management system is perceived as fair, ratings that are relatively low compared to ratings given to other employees may harm the relationship between the subordinate and the supervisor, because most employees consider their work performance to be above average (Pearce and Porter, 1986).

The aim of this study is to investigate the effect of strengthsbased performance appraisal in the context of traditional performance ratings. We expect the effect of strengths-based performance appraisal on PSS is particularly strong when the relationship between a supervisor and subordinate is threatened by a relatively low performance rating. By emphasizing mastery experiences, supervisors may enhance employees' self-efficacy regarding improving this rating in the future (Luthans et al., 2008), thereby leading to higher levels of PSS. This may be especially important when the relationship between the supervisor and subordinate is under pressure because the supervisor has given a relatively low performance rating.

This study contributes to the literature in two ways. First, by investigating the impact of strengths-based performance appraisal on employee outcomes, we answer to the call of Asplund and Blacksmith (2012) for research that explores the ways in which specific applications of strength-based interventions boost positive outcomes for employees. Even though the evidence for the effectiveness of strengths-based approaches in organizations is growing (Ghielen et al., 2018; Miglianico et al., 2020), there is still limited research into the effectiveness of strengths-based performance appraisals. Whereas, a qualitative case-study by Bouskila-Yam and Kluger (2011) concludes that strengths-based performance appraisals improved the relationship and the communication with the supervisor and increased the level of motivation and performance, these findings have not yet been replicated by quantitative studies. Only one recent study by Budworth et al. (2015) showed that employees who engaged in a feedforward interview with their manager performed significantly better than employees who received the company's traditional performance appraisal. However, this study does not uncover the mechanisms that were responsible for this improved performance.

Second, this study contributes to SDT by investigating the performance appraisal as a social context that may have implications for the need satisfaction and motivation to improve (MTI) of subordinates, and by exploring the performance rating as a boundary condition. Even though several SDT studies have explored the role of feedback in the satisfaction of basic needs (e.g., Deci, 1971; Deci et al., 2017), very few studies have focused on the performance appraisal interview as a context which may facilitate or thwart the support of basic psychological needs. This is relevant, especially since most organizations still use competency-, task-, or behavior-based rating scales to rate the performance of employees (Hall, 2004; Adler et al., 2016), even though they might also be experimenting with strengths-based performance appraisals. This means that the employee will receive two different signals (Haggerty and Wright, 2009): one signal about how their performance is rated against a fixed set of criteria (Hall, 2004; van Woerkom and de Bruijn, 2016), and one signal about who they are at their best. We contribute to SDT by investigating the interplay between these different signals.

\section{Strengths-Based Performance Appraisal}

Most performance feedback in organizations is based on a deficit approach in which person's weaknesses are seen as their greatest opportunity for development (van Woerkom et al., 2016). However, developments in the field of positive psychology (Seligman and Csikszentmihalyi, 2000) have inspired practitioners and scholars to promote the benefits of detecting and using individual strengths as a pathway to performance improvement. Individual strengths refer to trait-like characteristics that are energizing to the user and allow people to perform at their 
personal best (Wood et al., 2011). If individual strengths are recognized by oneself and by others, they can be refined through practice and by developing related knowledge and skills, so that they can ultimately be productively applied. Recent studies have indicated that it is the use of strengths, no matter what these strengths are, that leads to valuable outcomes, such as job satisfaction, work engagement, wellbeing, personal growth, and higher levels of work performance (see reviews by Ghielen et al., 2018; Miglianico et al., 2020).

Even though every person has strengths, many people have trouble identifying their strong points (Buckingham and Clifton, 2001) and tend to pay more attention to their weaknesses than to their strengths (Rozin and Royzman, 2001; Roberts et al., 2005). Individual strengths might come so naturally to a person that they are used unconsciously or might be seen as "normal" or something that "everyone does" (van Woerkom and de Bruijn, 2016). Strengths-based performance appraisal helps workers in raising awareness of their own strengths by paying attention to and expressing appreciation for their unique qualities. Research has indicated that particularly feedback from others regarding ones strengths at the times when one is at his or her best is effective in raising strengths awareness (Cable et al., 2015). This may be partly so because this feedback produces strong positive emotions, thereby inducing changes in self-knowledge (McAdams, 1988; Poole et al., 1989).

Strengths-based performance appraisal also supports future strengths use by discussing how strengths could be developed even further and how these strengths could be applied more effectively in the work context. A strengths-based performance appraisal does not imply that performance problems performance can no longer be discussed or that supervisors can only be positive (van Woerkom and de Bruijn, 2016). It does however mean that the supervisor makes an effort to discover the unique qualities of employees and to maximize the opportunity for employees to carry out work activities in a manner that plays to their strengths.

\section{The Relationship Between Strengths-Based Performance Appraisals and Motivation to Improve}

We expect that a performance appraisal interview that supports employees in detecting, developing, and using the characteristics that allow them to perform at their personal best, will have a positive effect on their MTI their performance. Because employee development has become an important aim of the performance appraisal (Kuvaas, 2007), the MTI one's performance can be considered as an important performance appraisal reaction, next to satisfaction, fairness, perceived utility, and perceived accuracy (Keeping and Levy, 2000; Jawahar, 2010; Pichler, 2012; Pichler et al., 2018). Unfortunately, the motivational effect of performance appraisal is still an under-researched outcome variable for performance appraisals (DeNisi and Pritchard, 2006; Roberson and Stewart, 2006; Selvarajan and Cloninger, 2012).

Helping employees to pinpoint their individual strengths and making them tell stories about occurrences where they felt "at their best," had a positive impact on others, and tapped their full potential, is likely to boost feelings of mastery and competence (Peterson and Seligman, 2004; van Woerkom and Meyers, 2019). By discussing aspects of the self that have been successfully developed in the past, employees will feel reassured that future development endeavors will be equally successful (Thoen and Robitschek, 2013) and will help them understand which steps are necessary for future growth processes (Borowa et al., 2016). Furthermore, discussing how employees can make better use of their strengths in the future, for instance by crafting their job in line with their strengths (Kooij et al., 2017) is likely to strengthen feelings of ownership and autonomy (Peterson and Seligman, 2004; Linley et al., 2010; Quinlan et al., 2012). In turn, based on SDT it can be argued that these feelings of competence and autonomy will lead to intrinsic motivation, making people work on tasks because they find them enjoyable and interesting (Deci, 1989) and making them inclined to seek challenges, extend their capacities, explore, and learn (Ryan and Deci, 2000). The positive effect of strengths-based approaches on personal growth and professional development has been shown by several studies (Hiemstra and Van Yperen, 2015; Meyers et al., 2015; van Woerkom and Meyers, 2019). Therefore, we hypothesize the following:

Hypothesis 1: Strengths-based performance appraisal is positively related to the MTI.

\section{The Mediating Role of Perceived Supervisor Support}

Given the strong relational nature of performance appraisals, we propose that the fulfillment of the need for relatedness, referring to the fundamental desire for close ties with others (Graves and Luciano, 2013), functions as a mediating mechanism in the relationship between strengths-based performance appraisals and the MTI. For employees, feeling supported by a supervisor, and being able to share one's joys and problems facilitates satisfaction of relatedness needs (Graves and Luciano, 2013). According to Asplund and Blacksmith (2012), the strengths-based approach to management is the best way to enhance PSS. By engaging in a discussion with their supervisor about how their strengths may be leveraged, employees will feel more supported by them in their future development because discussing the situations where they used their strengths will bring about feelings of competence, efficacy, and mastery (Peterson and Seligman, 2004). Encouraging subordinates to express their strengths that are an integral part of their authentic self, also makes them feel more identified and socially integrated (Swann et al., 2000; Polzer et al., 2002; Cable et al., 2015), leading to positive relationships (Cable et al., 2013). Moreover, highlighting employees' strengths beyond the immediate job description signals a less transactional relationship thereby strengthening the bond between both parties (Robinson, 1996; Cable et al., 2015). When the supervisor and the subordinate know each other well, the positive character of the interview might help to enhance and deepen their relationship, whereas when the supervisor and the 
subordinate do not know each other well, it offers an opportunity to get to know each other (Kluger and Nir, 2010).

Several studies have shown that interventions that help people to identify their strengths and make better use of them in the future are associated with higher levels of relatedness. Quinlan et al. (2015) found that a strengths intervention in the context of education, in which pupils and teachers were taught how to identify strengths in them and in others, led to a stronger fulfillment of the need for relatedness. In two lab experiments and a field experiment in a consultancy organization, Cable et al. (2015) show that best-self activations, that affirm the strengths of participants lead to more relatedness with their employer. In a field experiment, at a call center Cable et al. (2013) show that when new employees are affirmed in their positive qualities, they are more inclined to stay with their current employer. Lee et al. (2016) show that when team members are stimulated to reflect on their positive traits, they feel more socially accepted by the other team members.

In turn, the fulfillment of the need for relatedness is highly salient for producing variability in intrinsic motivation (Ryan and Deci, 2000). This can already be observed in infancy, when intrinsic motivation in the form of exploratory behavior is more evident when the infant is securely attached to a parent (Frodi et al., 1985). SDT proposes that a similar dynamic occurs in interpersonal settings over the life span, with intrinsic motivation more likely to flourish in contexts that are characterized by a sense of security and relatedness (Ryan and Deci, 2000). Satisfaction of the need to be related to others and to be effective in the social world supports people's tendency to internalize the values and regulatory processes that are ambient in their world (Gagné and Deci, 2005). Therefore, based on SDT it can be expected that perceived supervisory support is a mediating variable in the relationship between strengths-based performance appraisal and the MTI.

The mediating role of PSS in the relationship between strengths-based performance appraisal and the MTI is also supported by literature about communication dynamics during appraisal interviews. By making an effort to spot strengths in a subordinate and to find applications of these strengths in the work context, managers express empathy and the willingness to see the world from the perspective of the subordinate, thereby supporting the process of building rapport (Meinecke and Kauffeld, 2019). Based on the work on clientcentered counseling (Rogers, 1975), it can be argued that expressed empathy is one of the most important factors in bringing about change and learning. By empathetic communication, leaders inquire more deeply into the views and needs of their subordinate, and thereby develop a better understanding of topics that need more attention during the appraisal interview.

Based on the reasoning above, we hypothesize:

Hypothesis 2: The positive relationship between strengths-based performance appraisal and MTI is mediated by PSS.

\section{The Performance Rating as a Moderator}

Even though many organizations are inspired by positive psychology approaches and are currently in the process of revising their performance management systems, most companies continue to use competency-, task-, or behaviorbased rating scales to rate the performance of employees against a fixed set of criteria (Hall, 2004; Adler et al., 2016). These ratings have been severely criticized. Research indicates that employees have an aversion to receiving performance appraisal feedback (Cleveland et al., 2007) and the appraisal feedback they receive is often unreliable (Murphy et al., 2001). Moreover, due to a fundamental attribution error (Ross, 1977), people tend to attribute their own successes to internal factors and their own failures to external factors, but to make the opposite attributions when others succeed or fail. This attribution error causes peoples' self-ratings of performance to be consistently higher than the ratings that they get from their supervisors (Heneman, 1974; Harris and Schaubroeck, 1988). Especially when performance ratings that are given by the supervisor are relatively low, employees may dismiss this feedback as inaccurate, harsh, and unfair (Adler et al., 2016), thereby harming the relationship with their supervisor. Performance ratings provide comparative information regarding the ranking of the employee in relation other employees. Since people generally think that they are above average (Meyer, 1980), and want to be perceived as a good employee, even average performance ratings may be perceived as low performance ratings compared to "good" ratings, and may therefore threaten self-identity (Greenberg et al., 2007).

When the performance rating is relatively high, this rating by itself already gives a powerful signal to the employee that he or she is valued and appreciated. However when the rating is relatively low, this might challenge ones positive self-view, leading to self-protective psychological processes such as withdrawing from the relationship with the rater by disqualifying the relationship with this person (Green et al., 2017). We expect that especially under this condition, a strengths-based performance appraisal will be important to safeguard the perception of being supported by the supervisor. A discussion on employees' talents and strengths is based on a within-person analysis regarding the situations when this person is at his or her best, rather than on a normative approach of looking across people to see who is the best among groups (Roberts et al., 2005). This enables supervisors to empower employees in coping with the setback of a disappointing performance rating and successfully address and manage their negative emotions. This is supported by a study by Kluger and Nir (2010), who found that a focus on strengths prior to a traditional $\mathrm{PA}$, reduced employee defensiveness to the review and to 360-degree feedback. Based on the reasoning above we hypothesize the following:

Hypothesis 3: The indirect positive effect of a strengthsbased performance appraisal on MTI via PSS is stronger for employees who received a relatively low performance rating.

Figure 1 visualizes our conceptual model. 


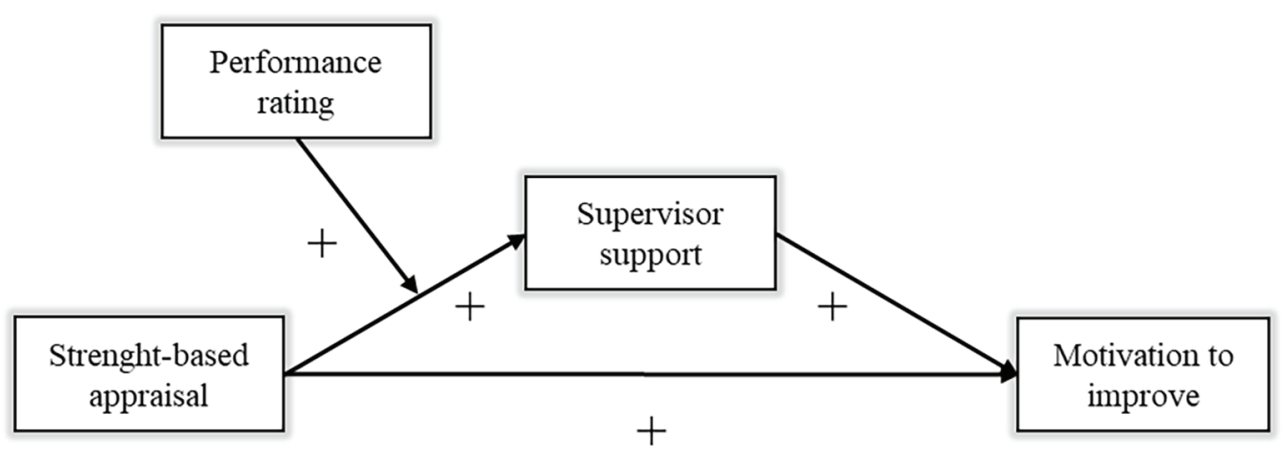

FIGURE 1 | Conceptual model.

\section{MATERIALS AND METHODS}

\section{Procedure and Sample}

This study was conducted among consultants of a strategic business unit of a Dutch IT consultancy firm. After the study was approved by the works council, the HR director of the strategic business unit sent an e-mail to all consultants to inform them about the purpose of the study. The same day, the researchers sent an e-mail to the employees with a link to the questionnaire and an accompanying introduction letter. In the introduction letter, the objectives of the study were briefly outlined, and it was stressed that participation was completely voluntary, and the anonymity of the participants was guaranteed. Furthermore, employees were asked to fill out the questionnaire as soon as possible after their yearly performance appraisal. The data that we collected for this study are unique and have not been used in another paper.

In total, 422 of the 1,675 consultants responded (response rate of $25.2 \%)$. The sample included 355 men (84.1\%) and 67 women $(15.9 \%)$. The average age was 42.7 years old $(S D=12.13)$. Most of the respondents had either a master's (43.8\%) or a bachelor's degree (47.9\%). On average, respondents had an organizational tenure of 11.11 years $(S D=9.62)$. In total, 422 of the 1,675 employees filled out the questionnaire. A comparison of the performance ratings between respondents and non-respondents revealed that the performance ratings of respondents $(M=3.34, S D=0.746)$ were significantly higher than the ratings of the non-respondents $[(M=3.18, S D=0.73)$; $t(711.918)=3.3834, p=0.000]$.

\section{Measures}

Strengths-based performance appraisal was measured with four items that were based on a scale to measure strength-based psychological climate as developed by van Woerkom and Meyers (2015). The following items were used: (In the performance appraisal interview...) "appreciation was expressed for my unique qualities," "attention was paid to discovering my unique qualities in relation to my work," "attention was paid to how I can further my talents," "attention was paid to how I can make better use of my strengths in my work." Responses were made on a five-point scale $(1=$ to a small extent to $5=$ to a large extent). Cronbach's alpha was 0.84 .

Performance ratings were obtained from the organizational records. The performance score was rated on a five-point scale ranging from: 1 = far below expectations, 2 = below expectations, 3 = meets expectations, 4 = above/exceeding expectations, and 5 = far above (greatly exceeding) expectations. The performance ratings were matched with the survey data based on e-mail address. As soon as this match was made, the e-mail addresses were removed from the data-set.

PSS was measured with four items from a scale developed by Rhoades et al. (2001). "My supervisor cares about my opinions," "My supervisor cares about my well-being," "My supervisor strongly considers my goals and values," "My supervisor shows very little concern for me." The scale had a seven point response format ranging from 1 (strongly disagree) to 7 (strongly agree). Cronbach's alpha was 0.87 .

Confirmatory factor analysis (CFA) analyses showed that a two-factor model with strengths-based performance appraisal and PSS loading on two separate factors $\left(\chi^{2}=63.200, d f=19\right.$; CFI $=0.98$, TLI $=0.97$, RMSEA $=0.07)$ fits significantly better to the data than a one-factor model with strengthsbased performance appraisal and PSS loading on one $\left(\Delta \chi^{2}=371.207, d f=1, p<0.001 ; \mathrm{CFI}=0.81\right.$, TLI $=0.73$, RMSEA $=0.22$ ).

MTI performance. The employee's MTI his/her performance was measured with a scale by Roberson and Stewart (2006). To match the purpose of our study, we slightly adapted this scale by replacing the word feedback by the term performance appraisal. The following items were used: (The performance appraisal interview...) "made me want to do better," "encouraged me to improve my performance," "increased my commitment to do well." Since the scale consisted of only three items we added the following item: "The performance appraisal inspired me to develop myself more in my work." The items were rated on a seven-point scale ( 1 = strongly disagree, $7=$ strongly agree $)$. Cronbach's alpha was 0.94 .

CFA analyses also indicated that a three-factor model with strengths-based performance appraisal, PSS, and MTI loading on three separate factors $\left(\chi^{2}=119.779, d f=51\right.$; CFI $=0.98$, 
TLI $=0.98$, RMSEA $=0.06)$ fitted significantly better to the data than a one-factor model with all three constructs loading on one factor $\left(\Delta \chi^{2}=1375.445, d f=3, p<0.001\right.$; CFI $=0.63$, TLI $=0.55$, RMSEA $=0.25$ ) and a two-factor model with supervisory support as a separate factor $\left(\Delta \chi^{2}=470.576, d f=2\right.$, $p<0.001$; CFI $=0.86$, TLI $=0.83$, RMSEA $=0.16$ ), MTI as a separate factor $\left(\Delta \chi^{2}=417.367, d f=2, p<0.001\right.$; CFI $=0.88$, $\mathrm{TLI}=0.85, \mathrm{RMSEA}=0.15)$ or strengths-based performance appraisal as a separate factor $\left(\Delta \chi^{2}=1009.409, d f=2, p<0.001\right.$; CFI $=0.72$, TLI $=0.66$, RMSEA $=0.22)$.

\section{Analyses}

To assess the relation between strengths-based performance appraisal and MTI (Hypothesis 1), mediated by PSS (Hypothesis 2), we utilized bootstrapping (Model 4) within PROCESS (Hayes, 2013). Furthermore, to test the potential moderation effect of the performance rating in the indirect relationship between strengths-based performance appraisal and MTI via PSS, we again used bootstrapping within PROCESS (Model 7). In both cases, we constructed a 95\% bootstrap CI with 5,000 bootstrap samples (Shrout and Bolger, 2002). Conditional process analysis is based on techniques to assess mediation effects as proposed by MacKinnon et al. (2007), in combination with procedures for investigating interaction effects as suggested by Muller et al. (2005). It calculates the relationship between an indirect effect and a moderator and produces an index of moderated mediation that computes whether the mediated buffer effect is significant (see Hayes, 2015). In all analyses, we controlled for the age, and gender of the participants. Age stereotypes are negatively related to performance ratings of older workers (Posthuma and Campion, 2009), and gender stereotypes are negatively related to performance evaluations of women (Heilman, 2001).

\section{RESULTS}

\section{Descriptives and Correlations}

Means, standard deviations, and correlations among the study variables are presented in Table 1 . The average and standard deviation of the performance ratings $(M=3.337, S D=0.746)$ indicated a slightly skewed distribution of this variable, with the majority of ratings being 3 (meets expectations) or 4 (above/ exceeding expectations). The correlations show that strengthsbased performance appraisal, performance rating, and PSS were all associated with MTI (respectively, $r=0.567, p<0.01$, $r=0.257, p<0.01$, and $r=0.478, p<0.01$ ). Table 1 also indicates that strengths-based performance appraisal and performance rating were positively related to PSS (respectively, $r=0.572, p<0.01$, and $r=0.257, p<0.01)$. Also, strengthsbased performance appraisal was associated with the performance rating $(r=0.342, p<0.01)$. Moreover, age was negatively associated with strengths-based performance appraisal, the performance rating, PSS, and the MTI (respectively, $r=-0.123$, $p<0.05, r=-0.468, p<0.01, r=-0.106, p<0.05$, and $r=-0.217, p<0.01)$.

\section{Hypotheses Testing}

The results of the PROCESS mediation analyses are displayed in Table 2. Model $1[F(3,418)=68.35, p<0.001]$ shows the main effects of strengths-based performance appraisal on PSS (the mediator variable). Model $2[F(4,417)=63.50$, $p<0.001$ ] shows the main effects of strengths-based performance appraisal, and perceived supervisor on MTI [the dependent variable (DV)]. As can be seen in Table 2, strengths-based performance appraisal was significantly related to MTI ( $B=0.68, p<0.001)$, thereby supporting our first hypothesis. Furthermore, strengths-based performance appraisal was significantly related to PSS $(B=0.77, p<0.001)$ and, in turn, PSS was significantly related to MTI $(B=0.26, p<0.001)$. The bootstrap results for the indirect effect of strength-based performance appraisals on motivation to perform, mediated by PSS, indicated that this effect was significant with a CI excluding zero (respectively, $0.10-0.30$, at a $95 \% \mathrm{CI}$ ). This supports our second hypothesis.

Table 3 shows the results of the PROCESS moderated mediation analyses. Model $1[F(5,416)=44.57, p<0.001]$ shows the main effects of strengths-based performance appraisals, performance rating, and the interaction between these variables on PSS (the mediator variable). Model $2[F(4,417)=63.50$, $p<0.001$ ] shows the main effects of strengths-based performance appraisal, and PSS on MTI (the DV).

TABLE 1 | Means, standard deviations, and pearson correlations between the study variables.

\begin{tabular}{|c|c|c|c|c|c|c|c|}
\hline & $M$ & $S D$ & 1 & 2 & 3 & 4 & 5 \\
\hline 1. Gender ${ }^{a}$ & 0.16 & 0.366 & & & & & \\
\hline 2. Age & 42.70 & 12.132 & $-0.119^{\star}$ & & & & \\
\hline 4. Performance rating ${ }^{c}$ & 3.337 & 0.746 & $0.100^{*}$ & $-0.468^{\star \star}$ & $0.342^{\star \star}$ & & \\
\hline 5. Perc. supervisor support & 5.449 & 1.217 & 0.076 & $-0.106^{*}$ & $0.572^{\star \star}$ & $0.257^{\star \star}$ & \\
\hline 6. Motivation to improve & 3.933 & 1.421 & 0.021 & $-0.217^{\star \star}$ & $0.567^{\star \star}$ & $0.257^{\star \star}$ & $0.478^{\star \star}$ \\
\hline
\end{tabular}

${ }^{*}$ Correlation is significant at 0.05 level (2-tailed).

${ }^{* *}$ Correlation is significant at 0.01 level (2-tailed).

${ }^{a} 0=$ male, 1 = female.

bStrengths-based performance appraisal.

${ }^{\circ} 1$ = far below expectations, 2 = below expectations, 3 = meets expectations, 4 = above/exceeding expectations, and 5 = far above (greatly exceeding) expectations. 
TABLE 2 | Results of mediation analysis of strengths-based performance appraisal on motivation to improve (MTI), mediated by perceived supervisor support (PSS).

\begin{tabular}{|c|c|c|c|c|c|}
\hline & $B$ & SE & $t$ & $p$ & $R^{2}$ \\
\hline Model 1, DV: PSS & & & & & 0.33 \\
\hline \multicolumn{6}{|l|}{$F(3,418)=68.35^{\star \star \star}$} \\
\hline Constant & 3.10 & 0.27 & 11.58 & 0.00 & \\
\hline $\mathrm{SBPA}^{a}$ & 0.77 & 0.06 & 13.99 & 0.00 & \\
\hline Age & -0.00 & 0.00 & -0.80 & 0.42 & \\
\hline Gender $^{b}$ & 0.10 & 0.13 & 0.75 & 0.46 & \\
\hline Model 2, DV: MTI & & & & & 0.38 \\
\hline \multicolumn{6}{|l|}{$F(4,417)=63.50^{\star \star \star}$} \\
\hline Constant & 1.10 & 0.35 & 3.18 & 0.00 & \\
\hline SBPA & 0.68 & 0.08 & 9.01 & 0.00 & \\
\hline PSS & 0.26 & 0.06 & 4.73 & 0.00 & \\
\hline Age & -0.02 & 0.01 & -3.73 & 0.00 & \\
\hline \multirow[t]{2}{*}{ Gender } & -0.17 & 0.15 & -1.15 & 0.25 & \\
\hline & Effect & $S E$ & LL 95\% & UL 95\% & \\
\hline $\begin{array}{l}\text { Direct effect of } \\
\text { SBPA on MTI }\end{array}$ & 0.68 & 0.08 & 0.56 & 0.82 & \\
\hline $\begin{array}{l}\text { Indirect effect of } \\
\text { SBPA on MTI }\end{array}$ & 0.20 & 0.06 & 0.10 & 0.30 & \\
\hline
\end{tabular}

$N=422 .{ }^{* *}$ Significant at 0.001 level. Bootstrap sample size $=5,000$.

DV, dependent variable.

a Strengths-based performance appraisal.

${ }^{b} \mathrm{O}=$ male, 1 = female. Results of analyses without the control variables age and gender were not substantially different.

TABLE 3 | Results of moderated mediation analysis on PSS and MTI.

\begin{tabular}{|c|c|c|c|c|c|}
\hline & $B$ & SE & $t$ & $p$ & $R^{2}$ \\
\hline Model 1, DV: PSS & & & & & 0.35 \\
\hline \multicolumn{6}{|l|}{$F(5,416)=44.57^{\star \star \star}$} \\
\hline Constant & -0.05 & 0.93 & -0.06 & 0.95 & \\
\hline SBPA $^{a}$ & 1.58 & 0.26 & 6.03 & 0.00 & \\
\hline Perf. rating & 0.98 & 0.28 & 3.52 & 0.00 & \\
\hline SBPA * perf. rating & -0.26 & 0.08 & -3.27 & 0.00 & \\
\hline Age & -0.00 & 0.00 & -0.17 & 0.87 & \\
\hline Gender $^{\mathrm{b}}$ & 0.08 & 0.13 & 0.60 & 0.55 & \\
\hline Educational level & -0.03 & 0.08 & -0.35 & 0.73 & \\
\hline Model 2, DV: MTI & & & & & 0.38 \\
\hline \multicolumn{6}{|l|}{$F(4,417)=63.50^{\star \star \star}$} \\
\hline Constant & 1.10 & 0.35 & 3.18 & 0.00 & \\
\hline SBPA & 0.68 & 0.08 & 9.01 & 0.00 & \\
\hline PSS & 0.26 & 0.06 & 4.73 & 00 & \\
\hline Age & -0.02 & 0.01 & -3.73 & 00 & \\
\hline Gender & -0.17 & 0.15 & -1.15 & 0.25 & \\
\hline \multicolumn{6}{|c|}{$\begin{array}{l}\text { Bootstrap results for conditional indirect effect of SBPA on PSS by } \\
\text { perf. rating }\end{array}$} \\
\hline & Effect & SE & LL 95\% Cl & UL 95\% Cl & \\
\hline Rating $=3$ & 0.21 & 0.06 & 0.11 & 0.33 & \\
\hline Rating $=4$ & 0.14 & 0.04 & 0.07 & 0.23 & \\
\hline \multirow{2}{*}{$\begin{array}{l}\text { Index of moderated } \\
\text { mediation }\end{array}$} & Index & $S E$ & LL 95\% Cl & UL 95\% Cl & \\
\hline & -0.07 & 0.03 & -0.14 & -0.01 & \\
\hline
\end{tabular}

$N=422 .{ }^{* * *}$ Significant at 0.001 level. Bootstrap sample size $=5,000$.

DV, dependent variable.

aStrengths-based performance appraisal.

${ }^{b} \mathrm{O}=$ male, 1 = female. Results of analyses without the control variables age and gender were not substantially different.
As can be seen in Table 3, the interaction between strengthsbased performance appraisal and the performance rating was significantly related to PSS $(B=-0.26, p<0.001)$. Furthermore, the bootstrap results for the conditional indirect effect of strength-based performance appraisals on motivation to perform, mediated by PSS, indicated that this effect was significant at both moderator values with CIs excluding zero (respectively, $0.11-0.33$ for when the rating is 3 , and $0.07-0.23$ when the rating is 4 , at a $95 \% \mathrm{CI}$ ). The index of moderated mediation indicated that the product term of strengths-based performance appraisal and performance ratings was significantly related to PSS ( $B=-0.07, p<0.01$ ), with confidence levels excluding zero $(-0.14$ to -0.01 at the $95 \% \mathrm{CI})$. This confirms our third hypothesis. Figure 2 displays the interaction plot for the association between strengths-based performance appraisal and PSS under the condition of relatively low $(3=$ meets expectations) and relatively high $(4=$ exceeding expectations $)$ performance ratings. The gradient slope for ratings at score 3 is 0.806 $(t=3.406, p=0.001)$, which is steeper than the gradient slope for ratings at score 4 (gradient slope $0.546, t=1.820$, $p=0.071$ ). As can be seen from Figure 2 and the simple slope analysis, the association between strengths-based performance appraisal and PSS is stronger when performance ratings are relatively low.

\section{DISCUSSION}

This study is an answer to the call of Asplund and Blacksmith (2012) for research that explores the ways in which specific applications of strength-based interventions boost positive outcomes for employees. Based on SDT (Deci and Ryan, 2008), we investigated whether supervisors who focus on subordinates' strengths in the yearly performance appraisal are perceived as more supportive, and if this perception of supervisor support is in turn associated with a stronger MTI performance. We found that strengths-based performance appraisal contributes to employees' MTI, partly because it is associated with higher levels of PSS. This is in line with the results of a qualitative study (Bouskila-Yam and Kluger, 2011) and a field experiment (Budworth et al., 2015) that investigated the effectiveness of strengths-based performance appraisal. Our results are also in line with previous research that suggests that social aspects of the performance appraisal sessions have an impact on the evaluation that employees make of their supervisor (Levy and Williams, 2004). By discussing employee's unique qualities, and how these can be furthered, the employee is invited to participate actively in the conversation, thereby stressing the developmental purpose (versus the evaluative purpose) of the review, leading to more positive evaluations of the supervisor (Cawley et al., 1998).

Moreover, we found that the effect of strengths-based performance appraisal on MTI, mediated by PSS, was even stronger for employees who received a relatively low performance rating. Employees, as receivers of performance evaluations, use the performance appraisal procedure to understand what their supervisor is signaling to them (Connelly et al., 2011). 


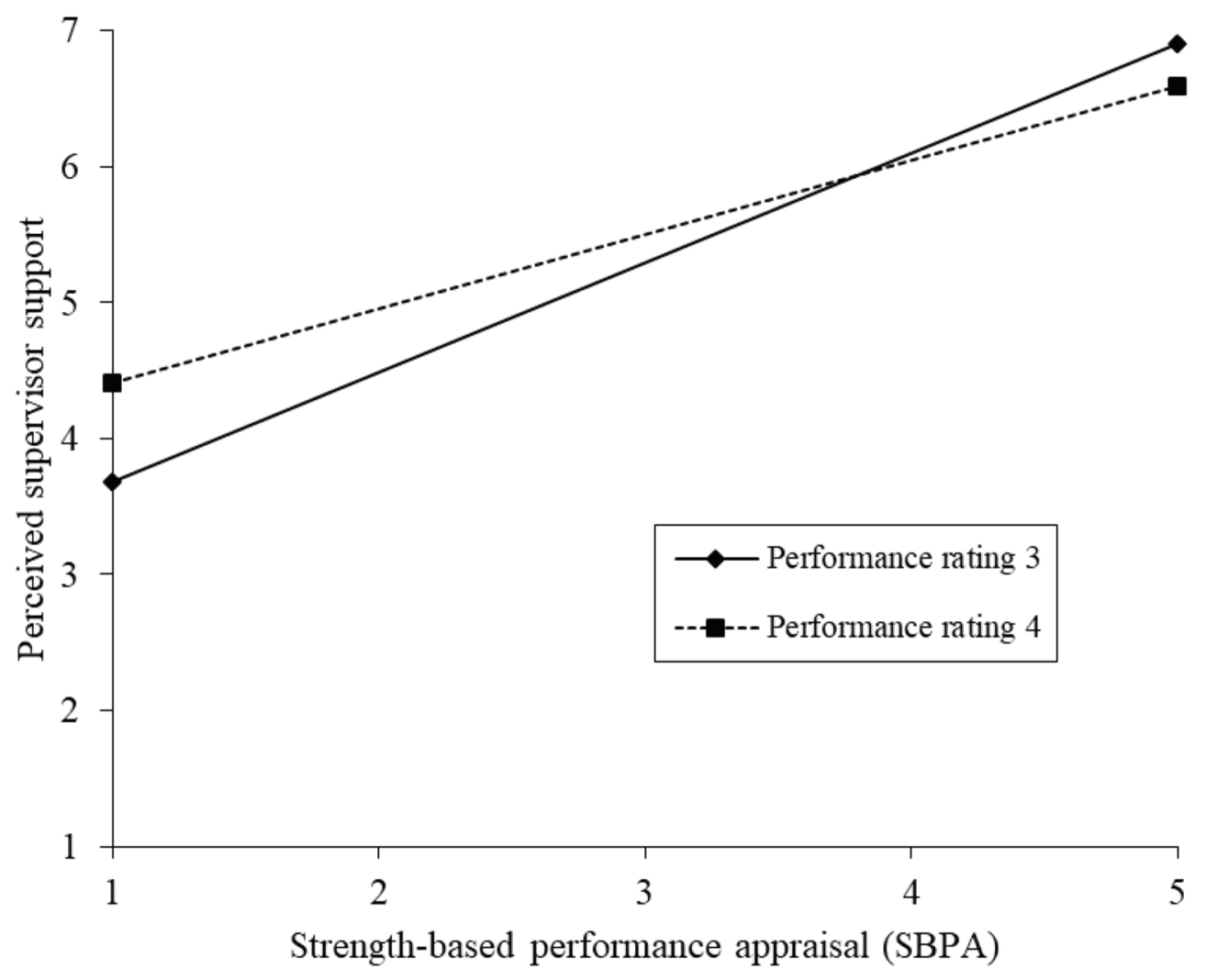

FIGURE 2 | Interaction plot for the relation between strengths-based performance appraisal and perceived supervisor support (PSS) at performance rating levels 3 (meets expectations) and 4 (above/exceeding expectations).

The performance rating usually signals the value of an employee relative to the organization's standards and other employees (Adler et al., 2016). When the performance rating is relatively high, this gives a powerful signal to the employee that he or she is valued and appreciated. When the performance rating is relatively low, employees are signaled that they are of limited value to the organization, leading to self-protective psychological processes (Green et al., 2017) such as disqualifying the relationship with the supervisor, who is seen as a representative of the organization (Eisenberger et al., 1986). By focusing the appraisal interview on a within-person analysis regarding the situations when this person is at his or her best (Roberts et al., 2005), supervisors can convey positive competence information that may empower employees in coping with a disappointing performance rating, and may be able to successfully address and manage their negative emotions. As a result, employees may give less weight to their relative organizational value, and give more weight to the support offered by their supervisor to build on their personal strengths (Connelly et al., 2011). Also, previous research has indicated that performance feedback is most likely to lead to performance improvement when feedback recipients perceive a need to change their behavior, believe that change is feasible, and have a positive reaction to the feedback (Smither et al., 2005). Whereas a relatively low rating might signal the need for behavior change, strengthsbased performance appraisal might contribute to a positive feedback orientation, and the belief that change is possible by formulating an action plan that is based on the unique qualities of employees (Hiemstra and Van Yperen, 2015).

This study contributes to SDT by investigating the performance appraisal as a social context that may have implications for the need satisfaction of subordinates. Even though research on the job characteristics, types of justice, managerial styles, and types of leadership that support the basic psychological needs has burgeoned (Deci et al., 2017), only very few studies have focused on the performance appraisal interview as a context, which may facilitate or thwart the support of basic psychological needs. Of course, the performance appraisal can be seen as a form of feedback, and several SDT studies have investigated the impact of feedback on need satisfaction. For example, a previous study pointed out that in general positive feedback satisfies the recipient's basic psychological need for competence and enhances intrinsic motivation by conveying positive competence information (Deci, 1971; Deci et al., 2017). Another study showed that managers who give behavior specific and positive feedback are perceived as more autonomy supportive (Deci, 1989). However, the effect of the interplay between different types of feedback as part of the performance appraisal, 
which is a very realistic scenario in today's organizations, has to the best of our knowledge never been investigated.

Our study also contributes to the knowledge about the effectiveness of positive organizational interventions. Based on a systematic review of the literature, Meyers et al. (2013) conclude that these interventions are promising for enhancing employee well-being and performance, and diminishing job stress and burnout. However, they call for more research on the operating mechanisms that link positive psychology interventions to specific outcomes. Moreover, they also conclude that there is a predominance of interventions that focus on the enhancement of positive subjective experiences, and that more research is needed to test the effects of interventions that are focused on leveraging positive resources such as employee talents and strengths. By providing insight in the mechanisms and conditions that make strengths-based performance appraisals effective, we answer to this call.

One unexpected finding in our study was that age was negatively associated with the performance rating and the MTI performance. This finding is in line with a meta-analysis by Gordon and Arvey (2004), who revealed a significant overall effect of age on performance evaluations, with younger workers being evaluated more positively than older applicants and workers. However, research also indicates that the association between age and performance may be based on stereotypical beliefs about older workers and does not correspond with their actual performance ( $\mathrm{Ng}$ and Feldman, 2012). The fact that this study was conducted within an IT company may also be relevant here. Even though, some mental capacities that are based on experience and creativity such as general knowledge, vocabulary, verbal comprehension, and arithmetic (crystalized intelligence) improve with age, mental capacities such as information processing speed, working memory, abstract reasoning, and processing new information (fluid intelligence) are known to decline with age (Kanfer and Ackerman, 2004). Given the fast developments in the IT sector, especially capacities that are based on fluid intelligence may be seen as essential for a good job performance. The fact that age was also negatively related to perceptions of strengths-based performance appraisal and PSS however signals that there is probably room for improvement in the support of older workers. This was also shown by a study by Kooij et al. (2017), that indicated that especially older workers benefited from an intervention that was aimed at crafting the job toward the strengths of the worker.

\section{Limitations and Future Research}

Our study is subject to four main limitations. A first limitation is that even though we extracted the performance ratings from the company records, our study relies for a large part on cross-sectional employee data. However, whereas employees may not always perceive the objective existence of human resource practices as the organization intends (Whitener, 2001); individual differences among appraisers affect how those who are appraised experience performance appraisal (Kuvaas, 2007). Therefore, the best criterion to use in investigating performance appraisal systems is the reactions of the appraises (Keeping and Levy, 2000; Wright, 2004; Kuvaas, 2007). Of course, our use of self-report data entails the risk that our results are subject to common-source bias. However, because CFA showed our measures to be distinct and we found a moderation effect (Siemsen et al., 2010), it can be assumed that common-source bias is not a major problem in this study. Since our cross-sectional research design does not allow for causal interpretations, future research should try to replicate our results based on longitudinal field experiments, in which the type of performance appraisal (traditional vs. strengths-based) is manipulated and in which the measurement of PSS and the MTI over time is measured over time. Another option for future research would be to study the real-time communication dynamics that are at the heart of performance appraisals by investigating how performance feedback is actually communicated by supervisors and how the employees react to that feedback, based on recordings or observations. For instance, Asmuß (2013) shows that in the performance appraisal interview, interactional symmetries, and asymmetries can emerge that impede the ideals of these interviews as being dialogs between equal partners. Greater acknowledgement of the interactional nature of the performance appraisal interview might improve our understanding of the conditions that strengthen the impact of strengths-based performance appraisals.

A second limitation concerns our use of the performance ratings that were given by the supervisor. Performance appraisal is a social process and despite the objective connotation, performance ratings risk subjectivity, and may reflect the quality of an employees' relationship with their supervisor (Duarte et al., 1994; Levy and Williams, 2004). Research on employeesupervisor dyads indicates that interpersonal justice, affect and similarity all influence performance ratings (e.g., Duarte et al., 1994). Furthermore, the variation in the performance rating was limited, with $59.5 \%$ scoring a 3 (meets expectations) and $25 \%$ scoring a 4 (above/exceeding expectations). However, restriction of range is not uncommon for performance ratings (Boswell and Boudreau, 2000). Also, since our main intention was to investigate employee reactions to their performance rating, irrespective of how biased or unreliable these performance ratings may be, we do not consider these issues as highly problematic for our study.

The third limitation of this study is that we focused on one of the three basic psychological needs that are proposed by SDT, i.e., the need for relatedness, given the strongly interpersonal nature of the performance appraisal (Reinke, 2003). However, it can also be expected that strengths-based performance appraisals support the needs for competence and autonomy, and therefore have an effect on the MTI performance. Future research should therefore aim to include the mediating role that the fulfillment of the needs for competence and autonomy may play in the effect of strengths-based appraisals on the MTI.

The fourth limitation is that our sample is exclusively based on the employees of one particular IT company, which limits generalizability to other occupations and sectors. Furthermore, the generalizability of our sample to the entire company population is also limited because employees with relatively high performance ratings were overrepresented in our sample. 
Future research is therefore needed to replicate our findings in other contexts and to investigate whether the results are the same when employees with relatively low performance ratings are equally represented in the sample.

\section{Practical Implications}

Despite the fact that most organizations have moved away from a narrow focus on psychometric and evaluation issues to the more developmental and motivational aspects of performance management (Kuvaas, 2007), many managers, HR professionals, and employees are still dissatisfied with their performance management systems (Adler et al., 2016; Murphy, 2019). Even though the performance review, and in particular the performance rating, is the most dreaded component of performance management, many companies are reluctant to abolish this rating. Performance ratings help companies to invest greater resources in the employees who provide the most value, take proper action when employees are underperforming, and comply with government regulations regarding the skill certifications that are required to hold specific jobs (Hunt, 2016). However, given its focus on what has already occurred, instead of the infinite possibilities for the future (Budworth et al., 2019); the performance rating is not particularly helpful in stimulating the growth and development of workers. Our study shows that besides the performance rating, also a focus on strengths in the performance interview influences employees' perception of supervisor support and their MTI their performance. Because people in general - and supervisors are no exception to this - are predisposed toward noticing and remembering negative information more than positive information (Baumeister et al., 2001; Rozin and Royzman, 2001) organizations may want to train supervisors in spotting strengths in their subordinates, and helping them to put these strengths to better use. To this end supervisors may be trained to use instruments like the Strengthsfinder (Rath, 2007), the values in action inventory of strengths (VIA-IS; Peterson and Seligman, 2004), feedforward interviews (Bouskila-Yam and Kluger, 2011), reflected best self-exercises (Roberts et al., 2005), and in applying a 3:1 ratio between positive and negative feedback (Fredrickson and Losada, 2005) in the context of performance appraisal interview.

Focusing the conversation on what works helps employees understand their unique patterns of strengths and how to

\section{REFERENCES}

Adler, S., Campion, M., Colquitt, A., Grubb, A., Murphy, K., Ollander-Krane, R., et al. (2016). Getting rid of performance ratings: genius or folly? A debate. Ind. Organ. Psychol. 9, 219-252. doi: 10.1017/iop.2015.106

Aguinis, H., Gottfredson, R. K., and Joo, H. (2012). Delivering effective performance feedback: the strengths-based approach. Bus. Horiz. 55, 105-111. doi: 10.1016/j.bushor.2011.10.004

Asmuß, B. (2013). The emergence of symmetries and asymmetries in performance appraisal interviews: an interactional perspective. Econ. Ind. Democr. 34, 553-570. doi: 10.1177/0143831X13489045

Asplund, J., and Blacksmith, N. (2012). "Leveraging strengths" in The oxford handbook of positive organizational scholarship. eds. K. S. Cameron and G. M. Spreitzer (New York, NY: Oxford University Press), 353-365. broaden and expand these strengths and talents in the future (Roberts et al., 2005; Kluger and Nir, 2010). Focusing on positive performance also helps in preventing the Pavlovian reflex to translate deficits into development goals. In some cases, it may indeed be essential to remediate deficits to the level of acceptable performance. However, in other cases, it may be better to accept that an employee may never be an excellent performer in one particular aspect of his or her job and manage around those deficits, for instance by letting him or her join forces with a colleague with complementary strengths (van Woerkom and de Bruijn, 2016). Our results also indicate that strengths-based performance appraisal is particularly helpful when performance ratings are relatively low. Focusing on what works, how to extend that in the future, and how to use strengths in overcoming deficits, may prevent harm to the supervisor-subordinate relationship and provide employees with tools to deal in a constructive way with a disappointing performance rating. Therefore, particularly organizations that do not want to let go of performance ratings, may be wise to train supervisors in employing a more strengths-based approach to the performance interview.

\section{DATA AVAILABILITY STATEMENT}

The datasets generated for this study are available on request to the corresponding author.

\section{ETHICS STATEMENT}

Ethical review and approval was not required for the study on human participants in accordance with the local legislation and institutional requirements. The patients/participants provided their written informed consent to participate in this study.

\section{AUTHOR CONTRIBUTIONS}

The author sequence matches with the contribution to the paper, with the first author taking the largest share in drafting the manuscript and running the analyses. All authors contributed to the article and approved the submitted version.

Baumeister, R. F., Bratslavsky, E., Finkenauer, C., and Vohs, K. D. (2001). Bad is stronger than good. Rev. Gen. Psychol. 5, 323-370. doi: 10.1037/1089-2680.5.4.323 Borowa, D., Robitschek, C., Harmon, K. A., and Shigemoto, Y. (2016). Posttraumatic stress and growth in student service members and veterans: the role of personal growth initiative. J. Am. Coll. Heal. 64, 527-534. doi: 10.1080/ 07448481.2016.1188395

Boswell, W. R., and Boudreau, J. W. (2000). Employee satisfaction with performance appraisals and appraisers: the role of perceived appraisal use. Hum. Resour. Dev. Q. 11, 283-299. doi: 10.1002/1532-1096

Bouskila-Yam, O., and Kluger, A. N. (2011). Strength-based performance appraisal and goal setting. Hum. Resour. Manag. Rev. 21, 137-147. doi: 10.1016/ j.hrmr.2010.09.001

Buckingham, M., and Clifton, D. O. (2001). Now, discover your strengths. New York, NY: Free Press. 
Budworth, M. H., Harrison, J. A., and Chummar, S. (2019). Beyond feedback: understanding how feedforward can support employee development. J. Manag. Dev. 38, 46-57. doi: 10.1108/JMD-12-2017-0402

Budworth, M. H., Latham, G. P., and Manroop, L. (2015). Looking forward to performance improvement: a field test of the feedforward interview for performance management. Hum. Resour. Manag. 54, 45-54. doi: 10.1002/ hrm. 21618

Cable, D. M., Gino, F., and Staats, B. R. (2013). Breaking them in or eliciting their best? Reframing socialization around newcomers' authentic self-expression. Adm. Sci. Q. 58, 1-36. doi: 10.1177/0001839213477098

Cable, D., Lee, J. L., Gino, F., and Staats, B. R. (2015). How best-self activation ifluences emotions, physiology and employment relationships. Harvard Business School NOM Unit Working Paper (16-029).

Cawley, B. D., Keeping, L. M., and Levy, P. E. (1998). Participation in the performance appraisal process and employee reactions: a meta-analytic review of field investigations. J. Appl. Psychol. 83, 615-633. doi: 10.1037/0021-9010. 83.4.615

Cleveland, J. N., Lim, A. S., and Murphy, K. R. (2007). "Feedback phobia? Why employees do not want to give or receive performance feedback" in Research companion to the dysfunctional workplace. Management challenges and symptoms. eds. J. Langan-Fox, C. L. Cooper and R. J. Klimoski (Cheltenham, UK: Edward Elgar), 168-186.

Connelly, B. L., Certo, S. T., Ireland, R. D., and Reutzel, C. R. (2011). Signaling theory: a review and assessment. J. Manag. 37, 39-67. doi: 10.1177/ 0149206310388419

Culbert, S. A. (2010). Get rid of the performance review!: How companies can stop intimidating, start managing-and focus on what really matters. New York: Business Plus.

Deci, E. L. (1971). Effects of externally mediated rewards on intrinsic motivation. J. Pers. Soc. Psychol. 18, 105-115. doi: 10.1037/h0030644

Deci, E. L. (1989). Self-determination in a work organization. J. Appl. Psychol. 74, 580-590. doi: 10.1037/0021-9010.74.4.580

Deci, E. L., Olafsen, A. H., and Ryan, R. M. (2017). Self-determination theory in work organizations: the state of a science. Annu. Rev. Organ. Psych. Organ. Behav. 4, 19-43. doi: 10.1146/annurev-orgpsych032516-113108

Deci, E. L., and Ryan, R. M. (2008). Self-determination theory: a macrotheory of human motivation, development, and health. Can. Psychol. 49, 182-185. doi: $10.1037 / \mathrm{a} 0012801$

DeNisi, A. S., and Pritchard, R. D. (2006). Performance appraisal, performance management and improving individual performance: a motivational framework. Manag. Organ. Rev. 2, 253-277. doi: 10.1111/j.17408784.2006.00042.x

Duarte, N. T., Goodson, J. R., and Klich, N. R. (1994). Effects of dyadic quality and duration on performance appraisal. Acad. Manag. J. 37, 499-521. doi: $10.5465 / 256698$

Eisenberger, R., Huntington, R., Hutchison, S., and Sowa, D. (1986). Perceived organizational support. J. Appl. Psychol. 71, 500-507. doi: 10.1037/ 0021-9010.71.3.500

Fredrickson, B. L., and Losada, M. F. (2005). Positive affect and the complex dynamics of human flourishing. Am. Psychol. 60, 678-686. doi: 10.1037/ 0003-066X.60.7.678

Frodi, A., Bridges, L., and Grolnick, W. (1985). Correlates of mastery-related behavior: a short-term longitudinal study of infants in their second year. Child Dev. 56, 1291-1298. doi: 10.1111/j.1467-8624.1985.tb00197.x

Gagné, M., and Deci, E. L. (2005). Self-determination theory and work motivation. J. Organ. Behav. 26, 331-362. doi: 10.1002/job.322

Ghielen, S. T. S., van Woerkom, M., and Meyers, M. C. (2018). Promoting positive outcomes through strengths interventions: a literature review. J. Posit. Psychol. 13, 573-585. doi: 10.1080/17439760.2017.1365164

Gordon, R. A., and Arvey, R. D. (2004). Age bias in laboratory and field settings: a meta-analytic investigation. J. Appl. Soc. Psychol. 34, 468-492. doi: $10.1111 /$ j.1559-1816.2004.tb02557.x

Graves, L. M., and Luciano, M. M. (2013). Self-determination at work: understanding the role of leader-member exchange. Motiv. Emot. 37, 518-536. doi: $10.1007 /$ s11031-012-9336-z

Green, P., Gino, F., and Staats, B. R. (2017). Shopping for confirmation: How disconfirming feedback shapes social networks. Boston, Massachusetts: Harvard Business School.
Greenberg, J., Ashton-James, C. E., and Ashkanasy, N. M. (2007). Social comparison processes in organizations. Organ. Behav. Hum. Decis. Process. 102, 22-41. doi: 10.1016/j.obhdp.2006.09.006

Haggerty, J., and Wright, P. (2009). "Strong situations and firm performance: a proposed re-conceptualization of the role of the HR function" in The sage handbook of human resource management. eds. A. Wilkinson, N. Bacon, T. Redman and S. Snell (London: Sage), 100-114.

Hall, D. T. (2004). The protean career: a quarter-century journey. J. Vocat. Behav. 65, 1-13. doi: 10.1016/j.jvb.2003.10.006

Harris, M. M., and Schaubroeck, J. (1988). A meta-analysis of self-supervisory, self-peer, and peer-subordinate ratings. Pers. Psychol. 41, 43-62. doi: 10.1111/ j.1744-6570.1988.tb00631.x

Hayes, A. F. (2013). Introduction to mediation, moderation, and conditional process analysis: A regression-based approach. New York: Guilford Press.

Hayes, A. F. (2015). An index and test of linear moderated mediation. Multivar. Behav. Res. 50, 1-22. doi: 10.1080/00273171.2014.962683

Heilman, M. E. (2001). Description and prescription: how gender stereotypes prevent women's ascent up the organizational ladder. J. Soc. Issues 57, 657-674. doi: 10.1111/0022-4537.00234

Heneman, H. G. (1974). Comparisons of self- and superior ratings of managerial performance. J. Appl. Psychol. 59, 638-642. doi: 10.1037/h0037341

Hiemstra, D., and Van Yperen, N. W. (2015). The effects of strength-based versus deficit-based self-regulated learning strategies on students' effort intentions. Motiv. Emot. 39, 656-668. doi: 10.1007/s11031-015-9488-8

Hunt, S. T. (2016). Rating performance may be difficult, but it is also necessary. Ind. Organ. Psychol. 9, 296-304. doi: 10.1017/iop.2016.14

Jawahar, I. M. (2010). The mediating role of appraisal feedback reactions on the relationship between rater feedback-related behaviors and ratee performance. Group Org. Manag. 35, 494-526. doi: 10.1177/1059601110378294

Kanfer, R., and Ackerman, P. L. (2004). Aging, adult development, and work motivation. Acad. Manag. Rev. 29, 440-458. doi: 10.5465/amr.2004.13670969

Keeping, L. M., and Levy, P. E. (2000). Performance appraisal reactions: measurement, modeling, and method bias. J. Appl. Psychol. 85, 708-723. doi: 10.1037/0021-9010.85.5.708

Kluger, A. N., and Nir, D. (2010). The feedforward interview. Hum. Resour. Manag. Rev. 20, 235-246. doi: 10.1016/j.hrmr.2009.08.002

Kooij, D. T. A. M., van Woerkom, M., Wilkenloh, J., Dorenbosch, L., and Denissen, J. A. (2017). Job crafting towards strengths and interests: the effects of a job crafting intervention on person-job fit and the role of age. J. Appl. Psychol. 102, 971-981. doi: 10.1037/apl0000194

Kuvaas, B. (2007). Different relationships between perceptions of developmental performance appraisal and work performance. Pers. Rev. 36, 378-397. doi: 10.1108/00483480710731338

Lee, J. J., Gino, F., Cable, D. M., and Staats, B. R. (2016). Preparing the self for team entry: how relational affirmation improves team performance. Harvard Business School working paper series. 16-111, 2-48.

Levy, P. E., and Williams, J. R. (2004). The social context of performance appraisal: a review and framework for the future. J. Manag. 30, 881-905. doi: 10.1016/j.jm.2004.06.005

Linley, P. A., Nielsen, K. M., Wood, A. M., Gillett, R., and Biswas-Diener, R. (2010). Using signature strengths in pursuit of goals: effects on goal progress, need satisfaction, and well-being, and implications for coaching psychologists. Int. Coach. Psychol. Rev. 5, 6-15.

Luthans, F., Avey, J. B., and Patera, J. L. (2008). Experimental analysis of a web-based training intervention to develop positive psychological capital. Acad. Manag. Learn. Educ. 7, 209-221. doi: 10.5465/amle.2008.32712618

MacKinnon, D. P., Fairchild, A. J., and Fritz, M. S. (2007). Mediation analysis. Annu. Rev. Psychol. 58, 593-614. doi: 10.1146/annurev.psych.58.110405.085542

McAdams, D. P. (1988). Biography, narrative, and lives: an introduction. J. Pers. 56, 1-18. doi: 10.1111/j.1467-6494.1988.tb00460.x

Meinecke, A. L., and Kauffeld, S. (2019). Engaging the hearts and minds of followers: leader empathy and language style matching during appraisal interviews. J. Bus. Psychol. 34, 485-501. doi: 10.1007/s10869-018-9554-9

Meyer, H. H. (1980). Self-appraisal of job performance. Pers. Psychol. 33, 291-295. doi: 10.1111/j.1744-6570.1980.tb02351.x

Meyers, M. C., van Woerkom, M., and Bakker, A. B. (2013). The added value of the positive: a literature review of positive psychology interventions in organizations. Eur. J. Work Organ. Psychol. 22, 618-632. doi: 10.1080/ 1359432X.2012.694689 
Meyers, M. C., van Woerkom, M., de Reuver, R., Bakk, Z., and Oberski, D. L. (2015). Enhancing psychological capital and personal growth initiative: working on strengths or deficiencies? J. Couns. Psychol. 62, 50-62. doi: 10.1037/cou0000050

Miglianico, M., Dubreuil, P., Miquelon, P., Bakker, A. B., and Martin-Krumm, C. (2020). Strength use in the workplace: a literature review. J. Happiness Stud. 21, 737-764. doi: 10.1007/s10902-019-00095-w

Muller, D., Judd, C. M., and Yzerbyt, V. Y. (2005). When moderation is mediated and mediation is moderated. J. Pers. Soc. Psychol. 89, 852-863. doi: 10.1037/0022-3514.89.6.852

Murphy, K. R. (2019). Performance evaluation will not die, but it should. Hum. Resour. Manag. J. 30, 13-31. doi: 10.1111/1748-8583.12259

Murphy, K. R., Cleveland, J. N., and Mohler, C. (2001). "Reliability, validity, and meaningfulness ofmultisource ratings" in Handbook of multisource feedback. eds. D. Bracken, C. Timmreck and A. Church (San Francisco, CA: Jossey-Bass), 130-148.

Neville, L., and Roulin, N. (2016). Genius or folly? It depends on whether performance ratings survive the psychological immune system. Ind. Organ. Psychol. 9, 281-288. doi: 10.1017/iop.2016.12

Ng, T. W. H., and Feldman, D. C. (2012). Evaluating six common stereotypes about older workers with meta-analytical data. Pers. Psychol. 65, 821-858. doi: 10.1111/peps.12003

Pearce, J. L., and Porter, L. W. (1986). Employee responses to formal performance appraisal feedback. J. Appl. Psychol. 71, 211-218. doi: 10.1037/0021-9010.71.2.211

Peterson, C., and Seligman, M. E. P. (2004). Character strengths and virtues: A handbook and classification. New York, NY: Oxford University Press.

Pichler, S. (2012). The social context of performance appraisal and appraisal reactions: a meta-analysis. Hum. Resour. Manag. 51, 709-732. doi: 10.1002/ hrm. 21499

Pichler, S., Beenen, G., and Wood, S. (2018). Feedback frequency and appraisal reactions: a meta-analytic test of moderators. Int. J. Hum. Resour. Manag. doi: 10.1080/09585192.2018.1443961 [Epub ahead of print]

Polzer, J. T., Milton, L. P., and Swarm, W. B. (2002). Capitalizing on diversity: interpersonal congruence in small work groups. Adm. Sci. Q. 47, 296-324. doi: $10.2307 / 3094807$

Poole, P. P., Gioia, D. A., and Gray, B. (1989). Influence modes, schema change, and organizational transformation. J. Appl. Behav. Sci. 25, 271-289. doi: $10.1177 / 0021886389253004$

Posthuma, R. A., and Campion, M. A. (2009). Age stereotypes in the workplace: common stereotypes, moderators, and future research directions. J. Manag. 35, 158-188. doi: 10.1177/0149206308318617

Quinlan, D. M., Swain, N., Cameron, C., and Vella-Brodrick, D. A. (2015). How "other people matter" in a classroom-based strengths intervention: exploring interpersonal strategies and classroom outcomes. J. Posit. Psychol. 10, 77-89. doi: 10.1080/17439760.2014.920407

Quinlan, D., Swain, N., and Vella-Brodrick, D. A. (2012). Character strengths interventions: building on what we know for improved outcomes. J. Happiness Stud. 13, 1145-1163. doi: 10.1007/s10902-011-9311-5

Rath, T. (2007). Strengthsfinder 2.0. Washington: Gallup Press.

Reinke, S. J. (2003). Does the form really matter? Leadership, trust, and acceptance of the performance appraisal process. Rev. Public Pers. Adm. 23, 23-37. doi: $10.1177 / 0734371 \times 02250109$

Rhoades, L., Eisenberger, R., and Armali, S. (2001). Affective commitment to the organization: the contribution of perceived organizational support. J. Appl. Psychol. 86, 825-836. doi: 10.1037/0021-9010.86.5.825

Roberson, Q. M., and Stewart, M. M. (2006). Understanding the motivational effects of procedural and informational justice in feedback processes. $\mathrm{Br}$. J. Psychol. 97, 281-298. doi: 10.1348/000712605X80146

Roberts, L. M., Dutton, J. E., Spreitzer, G. M., Heaphy, E. D., and Quinn, R. E. (2005). Composing the reflected best-self portrait: building pathways for becoming extraordinary in work organizations. Acad. Manag. Rev. 30, 712-736. doi: $10.5465 / a m r .2005 .18378874$

Robinson, S. L. (1996). Trust and breach of the psychological contract. Adm. Sci. Q. 41, 574-599. doi: 10.2307/2393868

Rogers, C. R. (1975). Empathic: an unappreciated way of being. Couns. Psychol. 5, 2-10. doi: 10.1177/001100007500500202

Ross, L. (1977). "The intuitive psychologist and his shortcomings: distortions in the attribution process" in Advances in experimental social psychology. ed. L. Berkowitz (New York, NY: Academic Press), 173-220.
Rozin, P., and Royzman, E. B. (2001). Negativity bias, negativity dominance, and contagion. Personal. Soc. Psychol. Rev. 5, 296-320. doi: 10.1207/ s15327957pspr0504_2

Ryan, R. M., and Deci, E. L. (2000). Self-determination theory and the facilitation of intrinsic motivation, social development, and well-being. Am. Psychol. 55, 68-78. doi: 10.1037/0003-066X.55.1.68

Seligman, M. E. P., and Csikszentmihalyi, M. (2000). Positive psychology: an introduction. Am. Psychol. 55, 5-14. doi: 10.1037/0003-066X.55.1.5

Selvarajan, T. T., and Cloninger, P. A. (2012). Can performance appraisals motivate employees to improve performance? A Mexican study. Int. J. Hum. Resour. Manag. 23, 3063-3084. doi: 10.1080/09585192.2011.637069

Sheldon, K. M., Abad, N., and Hinsch, C. (2011). A two-process view of Facebook use and relatedness need-satisfaction: disconnection drives use, and connection rewards it. J. Pers. Soc. Psychol. 100, 766-775. doi: 10.1037/ a0022407

Shrout, P. E., and Bolger, N. (2002). Mediation in experimental and nonexperimental studies: new procedures and recommendations. Psychol. Methods 7, 422-445. doi: 10.1037/1082-989X.7.4.422

Siemsen, E., Roth, A., and Oliveira, P. (2010). Common method bias in regression models with linear, quadratic, and interaction effects. Organ. Res. Methods 13, 456-476. doi: 10.1177/1094428109351241

Smither, J. W., London, M., and Reilly, R. R. (2005). Does performance improve following multisource feedback? A theoretical model, meta-analysis, and review of empirical findings. Pers. Psychol. 58, 33-66. doi: 10.1111/ j.1744-6570.2005.514_1.x

Swann, W. B. Jr., Milton, L. P., and Polzer, J. T. (2000). Should we create a niche or fall in line? Identity negotiation and small group effectiveness. J. Pers. Soc. Psychol. 79, 238-250. doi: 10.1037/0022-3514.79.2.238

Thoen, M. A., and Robitschek, C. (2013). Intentional growth training: developing an intervention to increase personal growth initiative. Appl. Psychol. Health Well Being. 5, 149-170. doi: 10.1111/aphw.12001

van Woerkom, M., and de Bruijn, M. (2016). Why performance appraisal does not lead to performance improvement: excellent performance as a function of uniqueness instead of uniformity. Ind. Organ. Psychol. 9, 275-281. doi: 10.1017/iop.2016.11

van Woerkom, M., and Meyers, M. C. (2015). My strengths count! Effects of a strengths-based psychological climate on positive affect and job performance. Hum. Resour. Manag. 54, 81-103. doi: 10.1002/hrm.21623

van Woerkom, M., and Meyers, M. C. (2019). Strengthening personal growth initiative; the effects of a strengths intervention on personal growth initiative with general self-efficacy as moderator and mediator. J. Occup. Organ. Psychol. 92, 98-121. doi: 10.1111/joop.12240

van Woerkom, M., Mostert, K., Els, C., Bakker, A. B., de Beer, L., and Rothmann, S. Jr. (2016). Strengths use and deficit correction in organizations: development and validation of a questionnaire. Eur. J. Work Organ. Psychol. 25, 960-975. doi: 10.1080/1359432X.2016.1193010

Whitener, E. M. (2001). Do high commitment human resource practices affect employee commitment? A cross-level analysis using hierarchical linear modeling. J. Manag. 27, 515-535. doi: 10.1177/014920630102700502

Wood, A. M., Linley, P. A., Maltby, J., Kashdan, T. B., and Hurling, R. (2011). Using personal and psychological strengths leads to increases in well-being over time: a longitudinal study and the development of the strengths use questionnaire. Pers. Individ. Differ. 50, 15-19. doi: 10.1016/ j.paid.2010.08.004

Wright, R. P. (2004). Mapping cognitions to better understand attitudinal and behavioral responses in appraisal research. J. Organ. Behav. 25, 339-374. doi: $10.1002 /$ job. 245

Conflict of Interest: The authors declare that the research was conducted in the absence of any commercial or financial relationships that could be construed as a potential conflict of interest.

Copyright $\odot 2020$ van Woerkom and Kroon. This is an open-access article distributed under the terms of the Creative Commons Attribution License (CC BY). The use, distribution or reproduction in other forums is permitted, provided the original author(s) and the copyright owner(s) are credited and that the original publication in this journal is cited, in accordance with accepted academic practice. No use, distribution or reproduction is permitted which does not comply with these terms. 


\section{OPEN ACCESS}

Edited by:

Sebastiaan Rothmann, North-West University, South Africa

Reviewed by: Rita Chiesa

University of Bologna, Italy Suzanne McDonough Ulster University, United Kingdom

${ }^{*}$ Correspondence: Merilyn Lock merilyn.lock@mymail.unisa.edu.au merilyn.lock@yahoo.com.au

Specialty section: This article was submitted to Organizational Psychology, a section of the journal Frontiers in Psychology

Received: 08 December 2019 Accepted: 18 August 2020 Published: 30 September 2020

Citation:

Lock M, Post D, Dollman J and Parfitt G (2020) Feasibility

and Process Evaluation of a Need-Supportive Physical Activity Program in Aged Care Workers: The Activity for Well-Being Project.

Front. Psychol. 11:518413. doi: 10.3389/fpsyg.2020.518413

\section{Feasibility and Process Evaluation of a Need-Supportive Physical Activity Program in Aged Care Workers: The Activity for Well-Being Project}

\author{
Merilyn Lock*, Dannielle Post, James Dollman and Gaynor Parfitt \\ UniSA Allied Health and Human Performance, University of South Australia, Adelaide, SA, Australia
}

The need to undertake pilot testing and evaluation of novel health promotion programs has become increasingly apparent for the purpose of understanding the true effects of complex interventions and for testing and refining behavioral theories that these interventions are informed by. A mixed-methods process evaluation and feasibility study was undertaken for a need-supportive physical activity program that was piloted in a single-group pre-post study. The piloted program was designed to support participant needs of autonomy, competence, and relatedness through evidence-based and theory-informed behavior change strategies including a motivational interviewing style appointment, education on self-management tools (i.e., pedometers, goal setting, action and coping planning, a customized website for goal setting and self-monitoring), and self-determined methods of regulating physical activity intensity [affect, rating of perceived exertion (RPE), and self-pacing]. The program aimed to positively impact physical activity behavior, psychological well-being, and associated motivational processes. Reach, adoption, fidelity, context, change and performance objectives, and feasibility of the program were evaluated using information from survey respondents from the target population $(n=118)$ and implementing staff $(n=6)$; questionnaires from pilot study participants ( $n=21$ ); and individual semi-structured interviews with a combination of pilot study participants, non-participants, and implementing staff $(n=19)$. Process evaluation of the Activity for Well-Being program found that the reach of the program was moderate but adoption was low. The use of self-management tools and self-determined methods of regulating physical activity intensity appeared to be feasible. The website had mixed responses and low engagement. The element of having a support person elicited a strong positive response in the program participant interviews. Involving local implementing staff more directly into the delivery of the intervention could have potentially improved reach, adoption, and feasibility of the program.

Keywords: physical activity, need support, self-determination theory, affective valence, rating of perceived exertion, process evaluation, aged care workers 


\section{INTRODUCTION}

A large body of research has been devoted to investigating the effects of physical activity interventions in the workplace over the past four decades, many of these being complex behavior change interventions (Dugdill et al., 2008; Abraham and GrahamRowe, 2009; Malik et al., 2013). Complex interventions have been described as interventions that contain several interacting components (Craig et al., 2008; Moore et al., 2015). The relationships between the mechanisms of behavior change, the implementation of the intervention, and the context within which it is being implemented are critically important to the impact and outcomes of the intervention (Moore et al., 2015). Many factors may influence outcomes that would make it difficult to determine what elements are at play when testing the effectiveness of an intervention in a real-world context (Shepperd et al., 2009; O'Brien et al., 2015). These factors may include the variability of the population or outcomes, the number of groups or organizational levels targeted by the intervention, and the degree of flexibility or tailoring of the intervention (Craig et al., 2008); traditionally, these factors have not been accounted for in program evaluation. Quested et al. (2017) noted that intervention implementation was not a significant focus for the majority of identified physical activity interventions informed by motivational theory, while Wierenga et al. (2013) reported only $7.2 \%$ of studies investigating the effects of workplace health promotion programs also published a process evaluation. Similarly, in their systematic review of reviews, Greaves et al. (2011) noted that of 30 included literature reviews, none accounted for fidelity. These reviews emphasize the need for better evaluation of the implementation process, fidelity, and other contextual factors. The Medical Research Council (London, United Kingdom), as an organization that provides funding for preventative health research, has developed and refined guidance to account for these elements through process evaluation (Moore et al., 2015). The use of process evaluations is being increasingly recognized as important for ensuring scientific rigor (Glasgow et al., 1999; Issel and Wells, 2017; Glasgow et al., 2019) and also for clearly testing and refining behavioral theory (Brug et al., 2005; Dombrowski et al., 2007).

In addition to evaluation, Hoddinott (2015) outlined the importance of having systematic and transparent development of interventions that can then be tested in pilot studies and then refined before full efficacy testing in the form of a randomized controlled trial. Many behavior change interventions that have been tested in full randomized controlled trials have reported a basis in behavioral theory; however, the true extent to which theory was actually used to inform these interventions is often unknown. Past reviews of behavioral interventions have identified that, although studies may claim to be informed by behavioral theory, often the application of the theory within the development of the interventions is not methodical or thorough (Painter et al., 2008; Prestwich et al., 2014). This knowledge has led to an increased emphasis on the systematic development and evaluation of behavioral interventions, including the methodical application of behavioral theory within the development process.
Intervention mapping provides a systematic, six-step process for ensuring better quality and more explicit integration of health psychology theory into intervention design (Bartholomew et al., 1998; Kok et al., 2004; Bartholomew et al., 2011). The steps for the development and evaluation of behavioral interventions include (i) the implementation of a needs assessment; (ii) the preparation of matrices of change and performance objectives; (iii) the selection of theory-informed intervention methods and practical applications; (iv) the production of program components and materials; v) the planning of program adoption, implementation, and sustainability; and (vi) the planning for evaluation (Bartholomew et al., 2011). It is thought that more explicit use of theory within the development of the behavioral interventions ensures a higher quality of testing theoretical constructs and may also have the potential to improve the efficacy of the targeted interventions (Taylor et al., 2012). As such, frameworks like intervention mapping may prove valuable for ensuring systematic and transparent development of theoryinformed interventions and subsequently the progression of the field of behavior change theory.

The Activity for Well-Being program was developed taking guidance from the intervention mapping framework, and the behavior change strategies used were based on selfdetermination theory (Deci and Ryan, 2000; Ryan and Deci, 2000). The application of self-determination theory within behavior change interventions tends to focus on psychological need support (i.e., Levy and Cardinal, 2004; Edmunds et al., 2006; Friederichs et al., 2016). As a theory, it has shown promise for effective physical activity behavior change, with a growing number of studies demonstrating positive relationships between need satisfaction and physical activity behavior, through the use of a need-supportive approach (Fortier et al., 2007; Weman-Josefsson et al., 2015).

Need support has also been seen to be positively related to psychological well-being (Edmunds et al., 2008; $\mathrm{Ng}$ et al., 2013) and exercise-related affect (Edmunds et al., 2008), another important predictor of physical activity behavior. Affect measured during exercise has been shown to predict future physical activity behavior (Williams et al., 2008; Rhodes and Kates, 2015), but only a limited number of studies have applied affect as a method of regulating activity intensity (Rose and Parfitt, 2008; Hamlyn-Williams et al., 2015). Strong arguments can be posed for the use of approaches such as self-pacing or preferred intensity (Parfitt et al., 2006; Williams, 2008; VazouEkkekakis and Ekkekakis, 2009); however, little is known about the true impact of these approaches on motivation and behavior in a real-world context. In theory, strategies such as selfpacing or the use of affect or rating of perceived exertion (RPE) may provide a method of regulating physical activity intensity that align well with self-determination theory and are inherently supportive of the participant's autonomy (Williams, 2008; Rhodes and Kates, 2015).

Acknowledging all of these factors, the Activity for WellBeing project extended the work of previous need-supportive interventions by ensuring the explicit application of theory within the development of the intervention, including an emphasis on the use of more self-determined methods of 
regulating activity intensity and evaluating fidelity and feasibility of the project. This paper presents the findings of the mixedmethods process and feasibility evaluation of the project.

The objectives of the current study were as follows:

(1) To evaluate the reach, adoption, fidelity, and context related to the implementation of the Activity for WellBeing program in the form of a pilot intervention trial.

(2) To investigate the feasibility and limitations of the program for the target population of frontline aged care workers and to provide recommendations and guidance regarding the future directions for the program.

\section{MATERIALS AND METHODS}

The Activity for Well-Being program was run as a singlegroup pre-post pilot trial with follow-up measures at 9 months. Methods of evaluation drew from multiple well-established guidelines and frameworks (Glasgow et al., 1999; Bartholomew et al., 2011; Moore et al., 2015; Issel and Wells, 2017). Data collection for the process evaluation occurred concurrently with the pilot testing of the program and continued until after the 9-month follow-up period was completed. The process evaluation and feasibility study for the Activity for Well-Being program used a mixed-methods approach including quantitative questionnaire and survey data, and qualitative semi-structured individual interviews. Reach and Implementer Surveys were sent out to all frontline employees and implementing staff, respectively, after the completion of the Activity for WellBeing program. Reach Surveys were distributed to communitybased workers via an online survey and via a paper survey for residential employees who had limited access to emails at work. A detailed description of the methods for the development and evaluation of the program, including the intervention mapping approach and findings of the needs assessment, has been outlined previously (Lock et al., 2018). Figure 1 provides a schematic of the structure of the project and process evaluation. Ethical approval for this study was obtained from the University of South Australia Human Ethics Research Committee, and the trial was preregistered with the Australian and New Zealand Clinical Trials Registry (registration number: ACTRN12617001395325).

\section{Participants and Recruitment}

All participants in the pilot program, process evaluation, and feasibly study were employees of a large not-for-profit, aged care organization in the metropolitan and surrounding regional areas of Adelaide, South Australia. The process evaluation and feasibility study outlined here included survey and interview data from program participants, non-program participants, and implementing staff.

Program participants included community- and residentialbased aged care workers who chose to participate in the pilot study of the Activity for Well-Being program during the period of November 2017-April 2019. Frontline aged care workers were identified as the target population during the initial needs assessment and consultation with the funding organization.

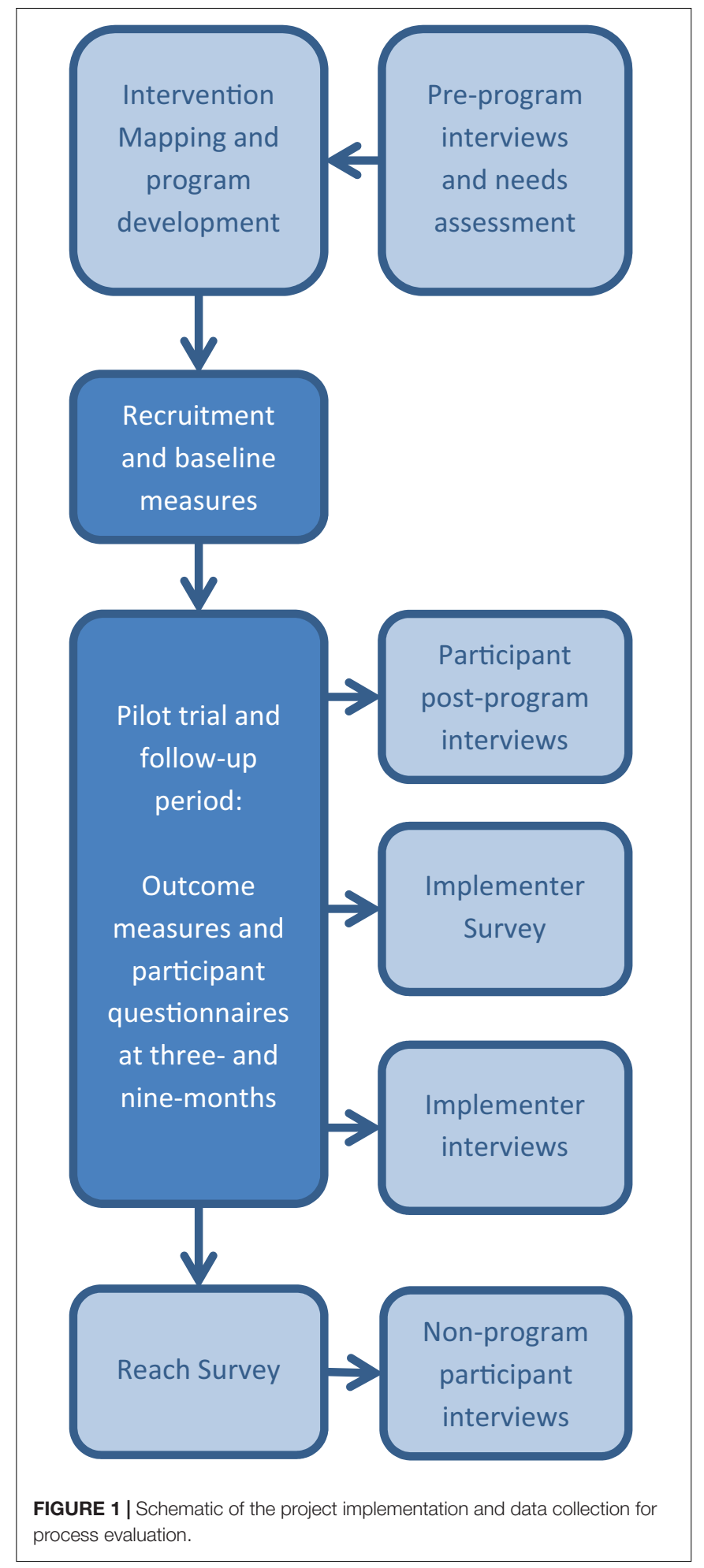

Program participants were recruited from all community-based areas and three residential sites using a combination of emails, posters, flyers, staff newsletter entries, and face-to-face introductions at staff meetings (undertaken by the primary researcher or local implementing staff). Community-based 
employees were primarily recruited through emails and team meetings, since they had limited time in an office or physical space and received most communications on work phones or devices. Residential employees were primarily recruited through the use of posters/flyers or newsletter entries, as well as staff meetings, since these employees worked in a regular location but had limited access to work emails. All program participants provided informed, written consent for the program and the interviews at baseline, at which point they indicated whether they would like to be contacted regarding an interview. Program participants were invited to participate in an interview during the period between the 3- and 9-months measures but were under no obligation to accept the invitation.

Non-program participants consisted of members of the target population (frontline aged care workers) who did not participate in the pilot study of the program. Non-program participants were recruited via an online survey (the Reach Survey) that was sent out after the conclusion of the pilot study. Consent for this survey was implied by the respondent completion of the survey, while all participants gave recorded verbal informed consent at the start of the interview. All survey respondents had access to an online version of the participant information for interviews and were given the chance to opt-in to an interview during the Reach Survey process. Interviews were offered to survey respondents who had "opted-in" until data saturation was reached. Purposive sampling was used to include participants with a range of responses to survey questions in interviews.

Implementing staff consisted of any employee involved with the implementation or promotion of the program within the local site or location. These staff may have included managers or assistant managers, team leaders, staff involved with healthy aging and health promotion (i.e., gym staff or therapy assistants), administration staff, or others. All implementing staff members were emailed directly with a copy of the participant information and an invitation to participate in the interviews.

For all invitations to participate in interviews (to program participants, non-program participants, and implementing staff), the researchers made it clear that invited staff were under no obligation to accept the invitation. For all interviews, points of consent were read, and clarified where necessary, and written (for face-to-face interviews) or verbal (for telephone interviews) consent was obtained prior to initiating any interviews. All Reach Survey respondents went into a draw to win a \$50 AUD gift card (with one in 10 chance of winning), and all interview participants received a gift card honorarium of $\$ 30$ AUD in appreciation of their participation.

\section{Overview}

The Activity for Well-Being program was developed using a participatory approach guided by the intervention mapping framework (Bartholomew et al., 1998, 2011) and was based on self-determination theory (Deci and Ryan, 2000; Ryan and Deci, 2000). As a part of the development process, a needs assessment was undertaken that included pre-program interviews with members of the target population (frontline aged care workers, $n=10$, all community based) (Lock et al., 2018). In brief, the program was based on self-determination theory and used a number of evidence-based strategies including: a motivational interviewing style initial appointment delivered by an accredited exercise physiologist (AEP) with masters-level training in motivational interviewing (a common strategy used within AEP practice in Australia). Program participants also received education on goal setting, action and coping planning, self-monitoring via a pedometer or own wearable device, and education on the use of self-determined methods of activity intensity regulation (affect, RPE, and self-pacing). To facilitate the use of these methods of regulating physical activity intensity, participants were given a business size card with Hardy and Rajeski's Feeling Scale (Hardy and Rejeski, 1989) and Borg's RPE scale (Borg, 1982) to keep, were given the opportunity to use the scales during the initial appointment, and were provided instructions as to how to use the scales and self-pacing for regulating physical activity intensity.

Participants were also provided with ongoing physical activity support by the AEP, including need-supportive follow-ups, exercise prescription for home- or gym-based programs, faceto-face assistance with initiating exercise programs, and sign posting to community activities depending on the goals and preferences of the participant. Support was actively offered for the 3 months of the active program period, initiated via two need-supportive follow-up communications (at around weeks 2 and 8 , unless initiated by the participant prior). For the followup period of 6 months, support was no longer actively offered by the AEP, but participants were able to contact the AEP for support until the end of the follow-up period (the 9-month time point). This approach was taken in order to promote autonomy in activity management within the program participants without withdrawing all need support. Participants also received access to a website, previously piloted (Frensham et al., 2014) and modified for the target population, and monthly informational newsletters for the entire 9-month period. The website had a function for tracking step counts, setting tiered goals (three different weekly step goals based on whether the participant was feeling "good," "okay," or "bad"), and links to health information and local community activities.

The process evaluation of the program included assessments of reach, adoption, fidelity, and context. Outcome, performance, and change objectives that were created through the intervention mapping process were evaluated for program participants through a questionnaire at 3 months. The feasibility of the program was evaluated through qualitative and quantitative research methods and included elements of attrition, adherence, subjective outcomes, program components, and sustainability. The theoretical mechanisms of behavior change were evaluated as process measures, along with the outcomes, and are not within the scope of this paper.

\section{Process Evaluation \\ Reach and Adoption}

After the completion of the program, the online Reach Survey was sent to all frontline workers from all sites and areas that were originally invited to participate. Reach was calculated as the 
percentage of the population aware of the program. Additional information gathered from the survey included the following: would the Activity for Wellbeing program have been something you would have been interested in participating in, had you known about it; what do you feel would have been the best way to promote the program; and why did you choose to/not to participate in the program? Adoption was calculated as the percentage of the population who chose to participate in the program. Demographic data for the program participant sample were compared with the whole population data and data for individual sites and areas, where available. An Implementer Survey that was sent to all implementing staff at the same time as the Reach Survey was distributed. This survey assessed the level of knowledge about the nature of the program by allowing the respondent to select different components of the program according to their understanding. Other questions included in this survey were as follows: do you feel that the program had value for improving the health and wellbeing of your employees; during the course of the program, did you feel that the program was something that you promoted to your employees or encouraged participation in; did you notice any impact of the program; what do you feel may have been the greatest barrier(s) to participation; what do you feel were the main incentives to participate; do you feel that it would be valuable to maintain the use of a program such as this in the future; and do you feel that it would be valuable to use a different type of program in the future? Information gathered from this survey was used to compare differences between community and residential locations.

\section{Fidelity}

Fidelity of the implementation of the initial appointments was evaluated through consented recordings of four randomly selected initial appointments (16\% of total). These recordings were evaluated by a member of the research team who was highly proficient in motivational interviewing but not directly involved in the implementation of the program or delivery of the interviews. The interviews were assessed using a preprepared fidelity checklist that scored 15 components as achieved, not achieved, or not applicable. These components included education around six program components (goal setting, action and coping planning, and the use of the pedometer, website, and self-determined forms of regulating activity intensity); four elements relating to the collaborative development of the program (the use of participant preferred activities, whether the participant perceived the activity plan as achievable as measured on a confidence scale of 1-10, whether the plan was adapted and confidence re-measured when necessary, and if activities were not imparted on the participant without participant engagement or consent); and five fundamentals of the initial appointments (use of empathy, supporting and developing discrepancy, rolling with resistance, supporting self-efficacy, and supporting autonomy), emphasizing autonomy support and principles of motivational interviewing (Miller, 1983; Rollnick and Allison, 2004). The support of autonomy, as a fundamental element of a needsupportive approach, was additionally measured with the Health Care Climate Questionnaire (HCCQ) (Williams et al., 1996).

\section{Intervention Mapping Evaluation}

Evaluation of the intervention mapping components included outcome objectives (behavioral, well-being, and interpersonal environmental), performance objectives, and change objectives. The results of the behavioral, well-being, and interpersonal environmental outcomes, along with additional process and performance measures, will be reported elsewhere.

Specific performance objectives and change objectives were developed during the program development using guidance from the intervention mapping framework. Performance objectives were three "sub-behaviors" of the target behavior (physical activity participation) that were identified as important for this population during the pre-program needs assessment. These performance objectives were as follows: find time to undertake physical activity, find motivation to undertake physical activity, and identify opportunities to undertake physical activity. Twelve change objectives were developed as composites of these sub-behaviors and four targeted determinants of behavior (perceived autonomy, perceived competence and perceived relatedness in exercise, and positive exercise affect). The matrices of performance and change objectives can be seen in Supplementary Material 1.

Each of the performance and change objectives was assessed through a questionnaire that was completed at the 3-month data collection point. The achievement of performance objectives was assessed using questions that specifically related to the objectives, e.g., for the performance objective "find time to undertake physical activity," the evaluating question was "do you generally feel you are better able to find time to be active?" Change objectives were assessed using a small cluster of questions developed within the domains of the targeted personal determinants (support for autonomy, competence, and relatedness). Participants rated each objective-related question on a five-point Likert scale, where $1=$ not at all and 5 = very much so. Since " 3 " could be considered a "neutral" score between " 1 " and " 5 ," scores of " 1 " or " 2 " could be considered negative changes, and scores of " 4 " or " 5 " could be considered positive changes. Mean scores for the whole participant sample were calculated for each of the singleitem performance objectives and composite change objectives. Groupings of questions for the change objectives were assessed for internal consistency using Cronbach's alpha $(\alpha)$ in SPSS (version 25.0; IBM Corp., Armonk, NY). In the cases where the questions were deemed to contain elements of more than one domain, groupings were refined based on best fit. Questions that demonstrated a poor fit within all groups were excluded from the final groupings.

\section{Feasibility, Context, and Qualitative Methods}

Qualitative research methods were used to gather information to support the quantitative data outlined for each of the different components of the process evaluation. In addition to this, qualitative methods were used to assess the overall feasibility of the program for the target population as well as the context in which the program was implemented. Individual telephone or face-to-face interviews were undertaken with program participants, non-program participants, and 
implementing staff. Interviews used a semi-structured, emergentsystematic approach. Interviews with program participants investigated elements of the program that the participant felt did or did not work, as well as the perceived impact of the program from the perspective of the individual program participant. The following open-ended facilitating questions were used (and adapted where necessary) to initiate discussion and address the objectives of the study: What aspects of the program were helpful for increasing/maintaining physical activity levels? What aspects of the program were not helpful? Do you think you have you maintained physical activity levels since the end of the three-month program? What has helped you/stopped you from doing this?

Interviews with implementing staff explored feasibility and perceived impact of the program from their perspective. The primary facilitating questions for the implementing staff were as follows: What aspects of the recruitment for the program were effective? What aspects of the recruitment were not effective? How could the recruitment for the program be improved? What aspects of the implementation of the program were effective? What aspects of the implementation were not effective? How could the implementation of the program be improved? Do you have any other feedback about the program?

Interviews with non-participants focused on the reasons for choosing not to participate in the program or other well-being programs offered by the organization. The primary facilitating question for non-participant interviews was as follows: what are your reasons for choosing not to participate in the program? Information on the level of awareness of the program, the recruitment methods, and the work context within which the program was being implemented was drawn from emergent conversation that developed across all (program participant, implementer, and non-participant) interviews. All interviews were undertaken during the period of April 2018-May 2019.

\section{Data Processing and Analysis}

For the purposes of the process evaluation, the data from all surveys and questionnaires were analyzed using descriptive statistics. Audio recordings of interviews were transcribed and imported into NVivo qualitative analysis software, version 12.0 (QSR International). All interviews were analyzed using a structured thematic approach (Braun and Clarke, 2013). Interview transcripts were coded thoroughly by two members of the research team. The coding was undertaken by allocating sections of speech from within the transcripts to nodes developed within the NVivo software. Most sections of speech were coded to multiple nodes that were then refined as themes and sub-themes. During the refinement process, some similar codes were merged and some codes were separated. Overarching themes were developed for sorting codes into factors that influenced program adherence, different elements of the process evaluation (reach, adoption, sustainability, and context), and information relating to specific program components (i.e., self-management tools or activity intensity regulation). Within the overarching themes of reach, adoption, and adherence, codes were separated into factors that had a positive influence (facilitators) and those that had a negative influence (barriers). Codes within the other overarching themes were sorted into themes and sub-themes based upon the content. Information pertaining to adherence, program components, subjective outcomes of the program, and sustainability was used to inform the feasibility component of the evaluation.

\section{RESULTS}

\section{Process Evaluation}

\section{Participants and Recruitment}

A total of 118 employees responded to the Reach Survey including 99 community-based workers and 19 residential workers. The Implementer Survey was completed by six of the 12 implementing staff directly involved with the program, including three residential-based workers, two community-based workers, and one staff member involved with implementation across both residential and community settings. Interview participants included 10 pilot program participants (nine community based and one residential based), six non-program participants (four community based and two residential based), and three implementing staff (one community based and two residential based).

The pilot trial of the Activity for Well-being Program was finalized with 25 participants. One participant withdrew from the program at 3 months, and two participants withdrew at 9 months. No participants who withdrew from the program gave consent to an interview; however, the reasons that were given for the withdrawal from the program included pregnancy $(n=1)$ and time constraints $(n=2)$. The results of the mixed-methods process evaluation and feasibility study are outlined here. Themes, sub-themes, and selected quotes from the interviews can be found in Supplementary Material 2.

\section{Reach and Adoption}

The primary findings of the Reach Survey and recruitment, including levels of awareness, preferred modes of promotion, and reasons for participating or not participating in the pilot program, can be seen in Table 1.

Survey responses indicated that the preferred methods of recruitment were consistent with those methods that were used; however, recruitment could have benefited from more promotion over a longer period of time with additional notifications through staff memos and newsletters (where applicable). Recruitment of community-based workers may have benefited from SMS notifications. Some responses to the Reach Survey and nonparticipant interviews indicated a level of confusion around the program, with responses referring to other well-being initiatives that were implemented by the organization. Four residential survey respondents made reference to a different (unrelated nutritional) well-being initiative that had been implemented in residential sites when describing their reasons for choosing not to participate. This was supported by some level of confusion and uncertainty around the program that was seemingly present within the non-program participant interviews, where some 
TABLE 1 | Elements of reach and adoption informed by survey responses and recruitment.

\begin{tabular}{|c|c|c|c|}
\hline & Total & Community & Residential \\
\hline Employees invited to participate in the program and to complete the Reach Survey & 493 & 287 & 206 \\
\hline Responded to Reach Survey & 118 & 99 & 19 \\
\hline (\% of total population) & $(23.94)$ & $(34.49)$ & $(9.22)$ \\
\hline Primarily voluntary employee & 4 & 2 & 2 \\
\hline Not aware of program, unsure, or no response & 48 & 42 & 6 \\
\hline (\% of respondents) & $(40.68)$ & $(42.42)$ & $(31.58)$ \\
\hline Would have been interested had they known about it & 22 & 18 & 4 \\
\hline \multicolumn{4}{|l|}{ Preferred mode of promotion } \\
\hline Email & 26 & 23 & 3 \\
\hline SMS & 7 & 6 & 1 \\
\hline "Same as was done" & 5 & 3 & 2 \\
\hline Compulsory training & 4 & 4 & 0 \\
\hline Other & 21 & 15 & 6 \\
\hline \multicolumn{4}{|l|}{ Adoption } \\
\hline \multicolumn{4}{|l|}{ Reasons for participating, indicated in the Reach Survey } \\
\hline Improve health & 12 & 11 & 1 \\
\hline Education/desire for knowledge & 2 & 2 & 0 \\
\hline \multicolumn{4}{|l|}{ Reasons for not participating, indicated in the Reach Survey } \\
\hline Time constraints & 24 & 20 & 4 \\
\hline (\% of total population) & $(5.07)$ & $(8.36)$ & $(0.49)$ \\
\hline Did not enroll in the pilot program & 16 & 12 & 4 \\
\hline (\% of total population) & $(3.25)$ & $(4.18)$ & $(1.94)$ \\
\hline \multicolumn{4}{|l|}{ Reasons for not entering program, indicated through recruitment efforts } \\
\hline Lost to follow-up (no reason specified) & 6 & 4 & 2 \\
\hline Time constraints & 3 & 3 & 0 \\
\hline Acute or chronic injury & 2 & 1 & 1 \\
\hline Personal reasons & 1 & 1 & 0 \\
\hline Retired & 1 & 1 & 0 \\
\hline Refused to obtain medical clearance for a previous health condition & 1 & 1 & 0 \\
\hline Didn't want to focus on physical activity & 1 & 0 & 1 \\
\hline Felt they could do it alone & 1 & 1 & 0 \\
\hline
\end{tabular}

interview participants were not sure if they were thinking of the correct program.

Sometimes I get a bit mixed up with other programs. We get a lot of information through work, and I just read things through in the moment.

Non-participant 02 , community support worker
Through thematic analysis of qualitative interviews, all barriers to reach seemed to be related to issues of communicating the program information to potential participants. Barriers included workers missing or not reading information due to having a relatively large number of email communications and the automatic deletion of emails. Promotion of the program using a face-to-face approach (i.e., at team meetings) and promotion via 
team leaders or line managers were identified as factors that did facilitate, or could have improved, the reach of the program.

\begin{abstract}
I don't know whether it's practical for someone like yourself, or your team, or - I'm not quite sure how the project is run - to be at every one of those team meetings. But one of our team leaders is definitely at one of those meetings. So that's definitely a much better way to get the message across. We're in a small group. We take it in better, and they're really mandatory. We have to be there.
\end{abstract}

Non-participant 01, community-based worker

Recruitment for the pilot program took place over a 6month period (October 2017-May 2018). The final number of participants adopted into the pilot program included 5.07\% of the invited population. The median age of the program sample was 57 years, which was slightly older but relatively comparable with the median age of the whole communitybased employee population ( 52 years). The sample was $88 \%$ female compared with $85 \%$ of the total community-based population. Demographic information for the total residential worker population was not available for comparison.

The interviews explored factors impacting adoption into the program. Barriers to adoption included competing priorities, cognitive factors, and current physical activity levels. Consistent with the pre-intervention interviews and Reach Survey responses, competing priorities that acted as barriers to adoption to the program consisted of home and family commitments, and associated work-life balance and lack of time.

And again, I don't have time - I just wish I had time for me. The only time I have off, when the kids go to bed and I watch my shows, and then I have to go to sleep. So I just - I do try and focus on the weekends catching up with friends at night-time with them coming over, in between the sports during the day, et cetera. And that's my "me time" to say, "okay, I'm seeing the girls," or, "the family's coming over," or we're visiting somebody else or going to a birthday party. So yeah, that's it.

Non-participant 03, community-based worker

Other participants reported to be maintaining regular physical activity, either through work or in leisure time, as a reason for not participating in the program. Cognitive factors included wanting to keep their work and private lives separate and a reluctance to enter into the program if they felt that they would not be able to commit to it entirely.

If I can't make a commitment to something, I can't - I'm not going to do it because I won't be able to put in $100 \%$, but I didn't want to waste your time doing that when I'm not going to do it, you know? Non-participant 03, community-based worker

Potential facilitators of adoption from the interviews included factors relating to the nature of the program; nature of the promotion; and having site level input, involvement, and support. Factors relating to the nature of the program included having the choice to engage without pressure, keeping the program/information relevant to the workers, and offering initiatives at set or suitable times. Having the choice to engage without pressure mainly encompassed positive feedback around having other well-being services, or potential services such as the
Activity for Well-Being program, as something that staff have the option to access if they want to but were not obligated to do so.

I've never actually - I've worked in lots of different industries in my life and I'd probably say this is the first industry that I've worked in that offers like all sorts of different supports, networks, to their employees. So even if you -whether you choose to use them or to access them or not, that's to your discretion. But at least we're always made aware that they are there if we need them.

Non-participant 04 , community support worker

The qualitative information from the interview data was consistent with the findings of the Reach and Implementer Surveys. Interviews indicated that using a face-to-face approach and having clearer communication about the nature of the program were potential facilitators relating to adoption of the program. Other potential facilitators were selling the program better and including multiple prompts (nature of the promotion). Having site level input, involvement, and support was also identified as a strong theme throughout the interviews. In accord with factors influencing the reach of the study, strategies such as making team leaders a part of the process, having better input at the local/site level, and having support from those around the workers (such as line managers and work peers) were thought to be factors that could improve participation in the program at the individual level.

We would've been a good resource for you because in a lot of cases, we've known these people for a long time and there's that trust element. So, often, if I have to read through a lot of information myself or do something, but if someone who I really trust says to me, "this is a great thing, you should just try it," you just go, okay, I'll give that a try.

Implementer staff 01 , community

But we just think yeah...not realizing how much it could actually benefit us as individuals. Because, even I'm sort of thinking now, well I'm learning more talking to you now than I knew before, so yeah, I don't know how else you'd sort of bring things to people's fore. Unless you try and got somebody like [us] that could bring things, a little bit more information to staff and then be a bit more of an encourager.

Implementer staff 02, residential

Findings of the Implementer Survey highlighted a notably better understanding of the program by the community-based implementers compared with those in residential sites. The most frequently stated perceived barriers to adoption from the perspective of the implementing staff were reported as time constraints, a lack of confidence in individuals' ability to be active, and a perceived lack of support from those around them (i.e., friends/family/work peers). A potential lack of interest in the program itself was also highlighted by two of the residentialbased implementers. Despite this, five out of the six implementing staff felt that it would be valuable to maintain the use of a program such as this in the future, with the remaining staff member suggesting the use of a well-being initiative, which becomes part of the training agenda and is partially funded. 


\section{Fidelity}

Assessment of the fidelity recordings demonstrated high fidelity for all aspects of education around the program components and for the collaborative development of the program for all recorded interviews. The fundamental principles of motivational interviewing were assessed as having high fidelity for the use of an empathetic approach, rolling with resistance, supporting selfefficacy, and supporting autonomy; the support and development of discrepancy by the AEP could have been improved in the recorded interviews. In addition to the assessment of the fidelity recordings, the results of the HCCQ demonstrated high levels of autonomy support. From 25 program participants, the HCCQ had 16 respondents and achieved a mean score of 6.61 out of 7 $( \pm 0.54)$. Good fidelity of the implementation of the autonomysupportive approach through the initial appointments and across the course of the intervention and follow-up was also supported by the qualitative data from the interviews (see Program Components and table of selected quotes in Supplementary Material - program components).

\section{Context}

Themes from the interview data that related to context included work culture, work population (individual factors within the work context), and work structure (nature of the work). Some differences in work culture appeared to be present in the community settings compared with residential contexts. Positive relationships and trust between community-based workers and their team leaders were outlined by communitybased implementers, program participants, and non-program participants. Particularly important for this seemed to be a team leader understanding and experience of the role of the frontline workers as well as close communications between the two.

What also is really good about our team leaders is our team leaders used to do our job, and previously the rostering staff used to do our job, and the advisors used to do our job. And anyone that used to do the job of the people that they're now in charge of is so much better at their job. Non-participant 01 , community support worker

Short and long-term changes within the structure of the work also impacted work stress and culture. Substantial changes to work structure in the short-term that were occurring around the time of the 9-month measures appeared to have a large impact on work stress within the community-based population. Longerterm changes included community-based employees moving from a physical space and face-to-face interaction with work peers and line managers to an almost exclusive interaction via mobile devices due to changes in technology. This latter change seemed to have some impact on social support within a workplace context.

We all used to work out of this office... and it was a lovely time because you'd always be popping in there to get out your rosters and things and you'd run into people. You'd run into the office staff and it was a really lovely atmosphere and that's all gone now.

Program participant 10, community support worker

Within residential settings, work stresses were focused more around staffing and residents (i.e., the stress of dealing with residents passing away or behavioral problems). As outlined in the barriers to adoption, there also appeared to be a preference to keeping work and personal lives separate, or a general hesitancy toward engaging with activities that were not directly a part of their work. In addition to these issues, physical workload as an element of work structure was identified as a source of fatigue and a barrier to participation for residential staff. This was consistent with the findings of the pre-program needs assessment undertaken with community-based workers.

We work all day, and it's a physically demanding day. We just don't want to do any more physically demanding things...but there's some days that we just come home exhausted from work, and to actually think about doing more physical work - it would be a drain to even think about it.

Non-participant 05, residential care worker

\section{Intervention Mapping Evaluation Performance and Change Objectives}

Twenty-two program participants completed the 3-month questionnaire for the assessment of performance and change objectives. The mean participant-rated scores for each of the performance and change objectives are outlined in Supplementary Material 3. Most performance and change objectives achieved a positive change score $(\geq 3.0)$. The performance objective to achieve the strongest mean change score was that for identify opportunities to undertake physical activity ( $4.05 \pm 1.13)$. The remaining two performance objectives (find time to undertake physical activity and find motivation to undertake physical activity) received change scores of 3.73 $( \pm 1.24)$ and $3.93( \pm 1.13)$, respectively.

The final groupings of questions relating to the change objectives included three questions each in the autonomy and competence clusters and two questions in the relatedness cluster. One question (do you feel that you are now more confident in your ability to control activity intensity?) was initially considered to include elements of both autonomy and competence; however, the question had a poor fit with both clusters and was subsequently excluded from both of these clusters and presented as a stand-alone item. The composite scores for the autonomy, competence, and relatedness clusters were $4.16( \pm 0.88 ; \alpha=0.87)$, $3.75( \pm 1.24 ; \alpha=0.94)$, and $3.64( \pm 1.25 ; \alpha=0.84)$, respectively. The change score for the stand-alone item of do you feel that you are now more confident in your ability to control activity intensity was $3.90( \pm 1.26)$.

\section{Feasibility}

Elements of the qualitative interviews relating to adherence, program components, subjective outcomes, and sustainability were used to inform the feasibility part of the study.

\section{Adherence and Subjective Outcomes}

Barriers to adherence as outlined within the post-program interviews were similar to those for adoption and those outlined within the pre-program interviews. These included competing priorities (i.e., home and family commitments, and time constraints); environmental and accessibility issues (i.e., poor weather and accessibility of exercise facilities, including location and available times); and individual factors (i.e., fatigue and 
energy levels; injury and illness; and amotivation and resistance to change). One notable individual factor that was identified as a barrier to adherence, but was not noted within the pre-program interviews, was "not wanting to inconvenience people." This barrier related to participants within the program not wanting to ask too much of the supporting AEP. One specific example of this was a change of gyms for one participant (due to convenience of location). The program AEP supported the participant with adapting her initial program and using the equipment in the new gym; however, the participant was initially reluctant ask for this support since the AEP had also assisted the participant with the previous gym.

Because I'd gotten used to the [first gym], and then I thought "oh, this [second gym]," there's no-one there; can't get anyone to help you. And I think I'd joined up on the "I'm going to do it" because I didn't want to lose that continuity of I'm going to stop again. And the whole thought, went in there and gone "oh, how am I going to do all this again, is it going to be the same equipment?" or whatever, and I'd sort of temporarily lost the mojo for a while of going "yeah, I don't know." And so then you sort of offered to do that and I'm like "oh". . "am I asking too much for that to happen?"

Program participant 25, community support worker

Facilitators of adherence included having accessible and comfortable environments, overcoming barriers to physical activity, personal motivators, social factors and support, and taking charge (independence) with behavior. The closely related sub-themes of taking charge (independence) with behavior and overcoming barriers to activity indicated a level of resilience in some of the program participants who appeared to facilitate adherence to regular physical activity participation.

I might have adapted something differently at different times.

When I've stopped going to [the gym], so I've tried to sort of compensate and do things.

Program participant 20, community support worker

Subjective outcomes of the program described within the interviews with program participants were varied but generally positive. These included subjective improvements in mental and physical health, improved motivation and mindset, positive emotion (i.e., pride, sense of achievement, and feeling of value), and positive changes in perceptions around physical activity and health behavior. Many of these subjective outcomes appeared to be somewhat interrelated with participants expressing concurrent improvements in different subjective outcomes (i.e., improvements in physical and mental health; and improvements in mental health and motivation).

But what happened was doing this program, is this program actually. . helped me reach my - it was my mental senses, you know my state of mental health and my sense of - it motivated me. So it motivated me to be more active about everything and one of the problems that I've had with this depression and anxiety thing, is pursuing the things that I love.

Program participant 01, community support worker

I can see the benefits of what it's done for me improving my mental health and physical health. I sleep better and I'm enjoying life a lot better. It's definitely a plus. I can see the relationship between the exercise and mental health; helping to improve it.

Program participant 09, voluntary community worker
Positive changes in perceptions around physical activity and health behavior included changes such as increased awareness of habits and decreased negative emotions around relapse.

I think I generally do quite well but every now and then I fall off the wagon, as I have with my eating. That's the thing that starts it and I've just come to terms with it, "Well, we all do that. It's not the end of the world." I've learnt not to be so hard on myself. I think that's it. I get very hard on myself.

Program participant 10, community support worker

Similarly, positive emotions included the expression of positive emotions such as pride, a sense of achievement, and a feeling of value.

But I guess it's just mainly the satisfaction of knowing that I have done this myself - I mean with your help - and I am going to stick to it. Yeah. I am going to stick to it, and there will be times that I will probably lapse, and there's probably times that I will do more but I know that it's all there and it's available to me.

Program participant 15, community support worker

\section{Program Components}

The use of self-monitoring of step counts or other health behaviors (via a pedometer or other wearable device, diary, or activity calendar) was strongly endorsed by participants throughout the interviews as a way of managing their own behavior. Setting or using goals, exercise programming, and technical support from the AEP were also strongly identified as components of the program that assisted participants to manage their activity levels and develop independence with behavior management.

Well I'm setting myself goals. I'm doing that and it's just got me thinking. It's always in the back of my head now. Always in there and yeah, it's hard to get out what I'm trying to say. Definitely it has; it's given me the motivation, and I have started thinking outside the square too and it's got me thinking about more ways that I can try and do things and make it fun.

Program participant 04, community support worker

Yeah, a lot of structure to my exercise routine, like the gym and that sort of thing. Going in there and being shown machines to use for what I was trying to achieve and that sort of thing. So yeah, it's given a lot of structure to that, and encouragement to continue and go for it.

Program participant 09, voluntary community worker

In addition to the self-management tools, the need support from the AEP was strongly referenced as a program component that was positively viewed by program participants. Of the subtheme need support and affect, having someone that was nonjudgmental and the participants felt comfortable contacting was viewed particularly positively.

Well, the program has helped me tremendously and having you helped because I know I can ring you up at any time. That's been great. And yeah, just the whole aspect of it. I feel as if someone is prepared to listen to me and cares.

Program participant 15, community support worker

You haven't judged us, whether we've done it or not, you haven't said "oh, you're a rotten person, you should be up to doing five days 
a week by now, at least $5 \mathrm{~km}$ every time you go out." You haven't done that to us, and I think that's important as well. Program participant 13, community support worker

Other program components had mixed responses. Newsletters were generally well accepted, and positive feedback centered around the newsletters offering small amounts of information without extensive reading. The website had only a small number of regular users (12\% of program participants regularly using the website for tracking step counts and $12 \%$ using the website for a short time before ceasing to log in), with a large number of participants who never used the website (76\% of program participants). The two primary reasons for this were forgetting about the website and not being "tech savvy."

\section{Sustainability}

Although sustainability was not formally addressed within the pilot trial or evaluation of the Activity for Well-Being project, naturally emerging discussion within the interviews addressed some aspects of sustainability. Across the postprogram interviews, several of the interview participants spoke positively about a number of ongoing well-being services that the organization had in place (i.e., skin checks, influenza vaccinations, confidential counseling, and early intervention physiotherapy). Conversely, some other short-term initiatives seemed to be met with criticism and a lack of engagement. Responses from program participants, non-participants, and implementing staff indicated a good level of support for incorporating a similar program into the organization on a longterm basis.

The primary reasons for program participants in the current study not utilizing organizational gym facilities (despite 20\% of program participants choosing to utilize the university gyms during the course of the program) were all related to the accessibility of the facilities. Most organizational gyms were only available for a very limited number of hours per day (those where the site was accessible but the gym was not being used for customer services), which generally overlapped with participant working hours.

Yeah and I did ask about that [the gym] but unless it's during working hours, and now they've been promoting more they're getting, the gym it's quite full. . And I mean they opened up the great big new gym complex down, that's [in one area], which isn't feasible for me distance wise because I live [in another]. But once again for us to use the equipment after hours - that's not, it's a no go.

Program participant 20, community support worker

In some areas, organizational gyms not being available in the local area or difficulties finding time to be inducted into the gym were also barriers to utilizing these facilities.

One of the nurses has been trying to do an induction for I don't know how long, they keep saying, "I will. .. do it", but she wants to do it in five minutes... so, that's sort of put her off.

Implementing staff 02 , residential

\section{DISCUSSION}

Process evaluation of the pilot trial of the Activity for WellBeing program indicated moderate reach, with just over half of the community-based workers and a slightly higher proportion of the residential workers who completed the Reach Survey reporting that they were aware of the program. Despite this, there was poor adoption into the pilot trial, with only $5 \%$ of the whole population choosing to participate. This is compared with the $27-84 \%$ reported by a previous review of participation in workplace exercise/fitness programs (Glasgow et al., 1993) and previous trials with aged care employees that have ranged between 49 and 61\% (Gerdle et al., 1995; Brox and Frøystein, 2005; Christensen et al., 2012). The most common reasons for participating in the pilot of the Activity for Well-Being program were related to a desire to improve health, while the most common reason for not participating was related to time constraints. These findings are consistent with previous studies such as the Step It Up Challenge, a workplace physical activity intervention in New Zealand, that reported the most prevalent reasons for participating in the program were associated with a desire to improve health and fitness (Davey et al., 2009); and the Healthy@Work program, a Tasmanian study that found timeand health-related factors were associated with lower levels of participation (Kilpatrick et al., 2017).

Qualitative and survey data from the current project indicated that the actual modes of recruitment used (i.e., emails, flyers, and presentations at team meetings) were appropriate; however, there was a need for more promotion through multiple sources, including promotion over a longer period of time and better education around the nature of the program, particularly in residential settings. Qualitative findings of the Activity for Well-Being project also indicated that incorporating local implementing staff (such as team leaders, line managers, or healthy aging staff) more actively into the project, as well as improving education about the program, may have improved employee engagement with the pilot program. More specifically, findings indicated the greater use of a face-to-face approach, directly or through line management, may have improved reach and adoption for the program across both community and residential settings and could have improved local knowledge around the program. An Austrian study by Nöhammer et al. (2010) noted that having easy and regular access to information and being personally notified may increase employee participation in workplace health promotion. Other studies have shown that perceived management support for such programs contributes to employee participation (Sloan and Gruman, 1988; Kilpatrick et al., 2017). Similarly, management support has previously been identified as impacting the implementation process for worksite health promotion programs (Wierenga et al., 2013). Within $36 \%$ of the primary studies included in a systematic review by Wierenga et al. (2013), poor management support was found to be a barrier to implementation, while strong management support was described as a facilitator of the implementation process. In the case of the Activity for WellBeing program, better understanding of the program by line management and more direct involvement could have improved 
managerial support and better facilitated the implementation process. In addition to these implementation issues, contextual factors could have played a role in the low adoption rates for the Activity for Well-Being project. One Danish study showed that low social support, fatiguing work, high physical demands/low job control, and high emotional demands/low job control were associated with low participation rates in workplace health promotion activities (Jørgensen et al., 2016). Factors such as these may be common for frontline aged care workers (Rao Hill and Clarke, 2010; Miranda et al., 2015) and potentially could have contributed to low levels of participation in the program.

Despite the low levels of adoption, positive feedback was received from those who participated in the program. Interview data from program participants indicated that the fundamental approach of the Activity for Well-Being program may be feasible for community-based frontline aged care workers. The fidelity of the autonomy-supportive approach of the program was confirmed by multiple datasets, including the fidelity recordings, the HCCQ scores, and the change scores for the autonomy cluster of the change objective questions.

Relatively high retention of participants within the Activity for Well-Being program and the positive subjective outcomes (health related, motivational, and behavioral) that were outlined in the interviews indicate good feasibility of the program for those who did choose to participate. Various components of the program were commented on during the interviews. Monitoring of step counts using a pedometer or other wearable device along with setting or using goals, exercise programming and technical support from the AEP, and having a support person who could be contacted (even if they did not need to be) were all program components that seemed to elicit the strong positive feedback from program participants. A large proportion of program participants self-reported frequent use of the Feeling Scale, RPE, or self-pacing for regulating activity intensity at 3 and 9 months. Coupling this with positive qualitative feedback around these self-determined methods of regulating physical activity intensity indicated that these could be a feasible and need-supportive strategy for exercise prescription within this population. Conversely, the website had mixed responses, and only a small number of program participants opted to use the website for the whole 9-month period. Improving the accessibility of organizational fitness facilities for the workers would also improve the feasibility of that aspect of the Activity for Well-Being program. Previous investigations into the preferences of different populations around the use of web-based health promotion have indicated some characteristic differences regarding preferences for mode of delivery. A study by Short et al. (2014) indicated that females and people with higher levels of physical activity tended to prefer face to face rather than print or online mediated interventions. Balk-Møller et al. (2017) had high levels of attrition and low numbers of active users in a web-based health promotion intervention in social welfare and health care sector employees, including some with very limited skills with smartphone technology. Conversely a study by Cook et al. (2015) showed good retention rates for a web-based program in a group of older office-based employees. One systematic review by Hobbs et al. (2013) suggested that mode of delivery does not appear to be important for effectiveness of behavioral interventions in adults aged 55-70 years; however, the review was not workplace specific and did not account for differences in population characteristics in regard to efficacy or participant preferences. While it is not entirely clear why some participants may prefer certain modes of delivery over others, the web-based component of the Activity for Well-Being program did not appear to be feasible (or preferable) for this particular cohort.

Barriers to adherence for program participants were found to be similar to those identified in the pre-program interviews (Lock et al., 2018), with the most prominent barrier being time constraints. Time constraints have long been established as one of the most prevalent barriers to regular physical activity participation in adults in both by cross-sectional and experimental studies (Booth et al., 1997; Trost et al., 2002; Mailey et al., 2014; Kilpatrick et al., 2017). One barrier that was specific to the Activity for Well-Being program was the issue of participants not wanting to inconvenience the supporting AEP, despite the scheduled follow-ups from the AEP during the active intervention period and the emphasis that participants could approach the AEP for any support at any stage throughout the intervention and follow-up. Strategies to address this more formally may be needed to decrease this as a barrier within future versions of the program. Considering this as a barrier to adherence, and acknowledging a need for workers to be able to access well-being services on their terms without pressure (considering the sub-theme of nature of the program), the Activity for Well-Being program may become more feasible if it was to be built into the organization at a broader level like an early intervention service, but incorporating local implementers, and could be accessed by staff without pressure or excessive perceived commitment. It is likely that the cost-effectiveness of this approach would be low unless the organization utilized resources (i.e., wellness staff and organizational gyms/facilities) that were already in place. Building wellbeing education into paid staff training was another potential strategy highlighted by program participants, non-program participants, and implementing staff and could address some of these issues.

The process evaluation highlighted that certain factors associated with the current delivery of the program would need to be addressed prior to implementing the intervention on a broader scale. These include implementation and contextual factors contributing to low adoption of the program, and thereby the cost-effectiveness of any adaptions of the program that may be developed in the future. Despite the inclusion of participatory, pre-program interviews, the findings of the process evaluation indicated a greater need for input and support at the local and site levels across all stages of the project. Input and support from line managers and team leaders in the early stages of the implementation were lacking in the current pilot of the program and may have improved both reach and adoption. This may be particularly important since the program was implemented in a large and geographically disperse organization and having more direct involvement of local staff and line management could potentially have facilitated a better understanding of the program and greater advocacy within trusted networks. Despite this, feedback from both community- and residential-based implementing staff indicated a good level of perceived value in 
continuing a program such as this on a broader scale within the organization.

It should also be noted that despite the positive feedback from those program participants who consented to an interview, there are several limitations of the current study. Firstly, the low levels of adoption into the pilot program may limit the ability to generalize the results to the whole target population and may have increased the risk of selection bias in the sample. Additionally, feedback could not be obtained from the few program participants who withdrew from the program. There was an under-representation of residential staff within the pilot program, which makes it all the more difficult to draw any conclusions regarding the feasibility of this type of program for residential workers.

\section{CONCLUSION}

Process evaluation of the Activity for Well-Being program found that the reach of the program was moderate but adoption was low. The process evaluation of the Activity for Well-Being project also demonstrated clear differences between community and residential employee populations in regard to reach, adoption, and context. Recruitment for the pilot trial of the program initially encountered challenges resulting in a low adoption level into the program. This number was sufficient for the pilot trial; however, barriers to adoption would need to be addressed prior to implementing a full trial. General feedback from those that did participate in the program was positive, and retention of participants was high. The use of self-management tools and self-determined methods of regulating physical activity intensity appeared to be feasible, while other components of the program, such as the website, had mixed responses and low engagement. The simple element of having someone that participants could contact if they needed (even if they did not) elicited a strong positive response in the program participant interviews. Qualitative information also indicated that involving local implementing staff, such as team leaders or line managers, more directly into the intervention could have potentially improved reach, adoption, and feasibility of the program.

\section{DATA AVAILABILITY STATEMENT}

The data that support the conclusions of this article will be made available on request by the corresponding author. The data are not publicly available due to content that could compromise the privacy of research participants.

\section{REFERENCES}

Abraham, C., and Graham-Rowe, E. (2009). Are worksite interventions effective in increasing physical activity? A systematic review and meta-analysis. Health Psychol. Rev. 3, 108-144. doi: 10.1080/17437190903151096

Balk-Møller, N. C., Larsen, T. M., and Holm, L. (2017). Experiences from a weband app-based workplace health promotion intervention among employees in the social and health care sector based on use-data and qualitative interviews. J. Med. Internet Res. 19:e350. doi: 10.2196/jmir.7278

\section{ETHICS STATEMENT}

All parts of this study involving human participants were reviewed and approved by the Human Research Ethics Committee, University of South Australia. All participants provided their written and/or verbal informed consent to participate in the pilot study and process evaluation.

\section{AUTHOR CONTRIBUTIONS}

ML undertook initial development of this manuscript with all authors having contributed the final drafts of the manuscript. ML and DP collaborated on the development of the evaluation plan, the change and performance objectives matrices, and qualitative analyses. JD and GP have overseen the entire project from initiation to present and have contributed to the research design and implementation of all aspects of the plan outlined within this manuscript. All authors contributed to the article and approved the submitted version.

\section{FUNDING}

This project was funded by the Activity for Well-being doctoral scholarship (ACH Group). ML was funded under this scholarship in conjunction with an Australian Government fee-offset scholarship.

\section{ACKNOWLEDGMENTS}

We would like to sincerely thank the funding organization and all of the staff and participants who have contributed to the implementation and evaluation of the Activity for Well-Being program. We would like to give an extra special thank you to program participants for all of their time and commitment.

\section{SUPPLEMENTARY MATERIAL}

The Supplementary Material for this article can be found online at: https://www.frontiersin.org/articles/10.3389/fpsyg. 2020.518413/full\#supplementary-material

Bartholomew, L. K., Parcel, G. S., and Kok, G. (1998). Intervention mapping: a process for developing theory- and evidence-based health education programs. Health Educ. Behav. 25, 545-563. doi: 10.1177/109019819802 500502

Bartholomew, L. K., Parcel, G. S., Kok, G., Gottlieb, N. H., and Fernández, M. E. (2011). Planning health Promotion Programs: an Intervention Mapping approach, 3rd Edn, Hoboken, NJ: John Wiley \& Sons.

Booth, M. L., Bauman, A. E., Owen, N., and Gore, C. J. (1997). Physical activity preferences, preferred sources of assistance, and perceived barriers to increased 
activity among physically inactive Australians. Prevent. Med. 26, 131-137. doi: 10.1006/pmed.1996.9982

Borg, G. A. V. (1982). Psychophysical bases of perceived exertion. Med. Sci. Sports Exerc. 14, 377-381.

Braun, V., and Clarke, V. (2013). Successful Qualitative Research: A Practical Guide for Beginners. London: Sage Publications.

Brox, J. I., and Frøystein, O. (2005). Health-related quality of life and sickness absence in community nursing home employees: randomized controlled trial of physical exercise. Occup. Med. 55, 558-563. doi: 10.1093/occmed/kqi153

Brug, J., Oenema, A., and Ferreira, I. (2005). Theory, evidence and Intervention Mapping to improve behavior nutrition and physical activity interventions. Intern. J. Behav. Nutr. Phys. Activ. 2, 1-7.

Christensen, J. R., Overgaard, K., Carneiro, I. G., Holtermann, A., and Søgaard, K. (2012). Weight loss among female health care workers- a 1-year workplace based randomized controlled trial in the FINALE-health study. BMC Public Health 12:625. doi: 10.1186/1471-2458-12-625

Cook, R. F., Hersch, R. K., Schlossberg, D., and Leaf, S. L. (2015). A web-based health promotion program for older workers: randomized controlled trial. J. Med. Internet Res. 17:e82. doi: 10.2196/jmir.3399

Craig, P., Dieppe, P., Macintyre, S., Michie, S., Nazareth, I., and Petticrew, M. (2008). developing and evaluating complex interventions: the new medical research council guidance. Br. Med. J. 337:1655.

Davey, J., Fitzpatrick, M., Garland, R., and Kilgour, M. (2009). Adult participation motives: empirical evidence from a workplace exercise program. Eur. Sport Manag. Q. 9, 141-162. doi: 10.1080/16184740802571427

Deci, E. L., and Ryan, R. M. (2000). The 'what' and 'why' of goal pursuits: human needs and the self-determination of behavior. Psychol. Inq. 11, 227-268. doi: 10.1207/s15327965pli1104_01

Dombrowski, S. U., Sniehotta, F. F., and Avenell, A. (2007). Current issues and future directions in psychology and health : towards a cumulative science of behaviour change: do current conduct and reporting of behavioural interventions fall short of best practice? Psychol. Health 22, 869-874. doi: 10.1080/08870440701520973

Dugdill, L., Brettle, A., Hulme, C., McCluskey, S., and Long, A. (2008). Workplace physical activity interventions: a systematic review. Intern. J. Workplace Health Manag. 1, 20-40. doi: 10.1108/17538350810 865578

Edmunds, J., Ntoumanis, N., and Duda, J. L. (2006). A test of self-determination theory in the exercise domain. J. Appl. Soc. Psychol. 36, 2240-2265. doi: 10. 1111/j.0021-9029.2006.00102.x

Edmunds, J., Ntoumanis, N., and Duda, J. L. (2008). Testing a self-determination theory-based teaching style intervention in the exercise domain. Eur. J. Soc. Psychol. 38, 375-388. doi: 10.1002/ejsp.463

Fortier, M. S., Sweet, S. N., O’Sullivan, T. L., and Williams, G. C. (2007). A selfdetermination process model of physical activity adoption in the context of a randomized controlled trial. Psychol. Sport Exerc. 8, 741-757. doi: 10.1016/j. psychsport.2006.10.006

Frensham, L. J., Zarnowiecki, D. M., Parfitt, G., King, S., and Dollman, J. (2014). The experiences of participants in an innovative online resource designed to increase regular walking among rural cancer survivors: a qualitative pilot feasibility study. Support. Care Cancer 22, 1923-1929. doi: 10.1007/s00520014-2177-4

Friederichs, S. A. H., Oenema, A., Bolman, C., and Lechner, L. (2016). Motivational Interviewing and self-determination theory in a web-based computer tailored physical activity intervention: a randomized controlled trial. Psychol. Health 31, 1-24.

Gerdle, B., Brulin, C., Elert, J., Eliasson, P., and Granlund, B. (1995). Effect of a general fitness program on musculoskeletal symptoms, clinical status, physiological capacity, and perceived work environment among home care service personnel. J. Occup. Rehabil. 5, 1-16. doi: 10.1007/bf02 117816

Glasgow, R. E., Harden, S. M., Gaglio, B., Rabin, B., Smith, M. L., Porter, G. C., et al. (2019). RE-AIM planning and evaluation framework: adapting to new science and practice with a 20-year review. Front. Public Health 7:64. doi: 10.3389/fpubh.2018.00064

Glasgow, R. E., McCaul, K. D., and Fisher, K. J. (1993). Participation in worksite health promotion: a critique of the literature and recommendations for future practice. Health Educ. Q. 20, 391-408. doi: 10.1177/109019819302000309
Glasgow, R. E., Vogt, T. M., and Boles, S. M. (1999). Evaluating the public health impact of health promotion interventions: the RE-AIM framework. Am. J. Public Health 89, 1322-1327. doi: 10.2105/ajph.89.9.1322

Greaves, C. J., Sheppard, K. E., Abraham, C., Hardeman, W., Roden, M., Evans, P. H., et al. (2011). Systematic review of reviews of intervention components associated with increased effectiveness in dietary and physical activity interventions. BMC Public Health 11:119. doi: 10.1186/1471-245811-119

Hamlyn-Williams, C. C., Tempest, G., Coombs, S., and Parfitt, G. (2015). Can previously sedentary females use the feeling scale to regulate exercise intensity in a gym environment? an observational study. BMC Sports Sci. Med. Rehabil. 7:30. doi: 10.1186/1471-2458-13-30

Hardy, C. J., and Rejeski, W. J. (1989). Not what, but how one feels: the measurement of affect during exercise. J. Sport Exerc. Psychol. 11, 304-317. doi: 10.1123/jsep.11.3.304

Hobbs, N., Godfrey, A., Lara, J., Errington, L., Meyer, T. D., Rochester, L., et al. (2013). Are behavioral interventions effective in increasing physical activity at 12 to 36 months in adults aged 55 to 70 years? a systematic review and meta-analysis. BMC Med. 11:75. doi: 10.1186/1471-2458-13-75

Hoddinott, P. (2015). A new era for intervention development studies. Pilot Feasibil. Stud. 1:36.

Issel, L. M., and Wells, R. (2017). Health Program Planning and Evaluation: A Practical, Systematic Approach for Community Health, 4th Edn, Burlington, MA: Jones \& Bartlett Learning LLC.

Jørgensen, M. B., Villadsen, E., Burr, H., Punnett, L., and Holtermann, A. (2016). Does employee participation in workplace health promotion depend on the working environment? A cross-sectional study of Danish workers. BMJ Open 6:e010516. doi: 10.1136/bmjopen-2015-010516

Kilpatrick, M., Blizzard, L., Sanderson, K., Teale, B., Jose, K., and Venn, A. (2017). Barriers and facilitators to participation in workplace health promotion (WHP) activities: results from a cross-sectional survey of public-sector employees in Tasmania, Australia. Health Promot. J. Austr. 28, 225-232. doi: 10.1071/ he16052

Kok, G., Schaalma, H., Ruiter, R. A. C., Van Empelen, P., and Brug, J. (2004). Intervention Mapping: Protocol for applying health psychology theory to prevention programmes. J. Health Psychol. 9, 85-98. doi: 10.1177/ 1359105304038379

Levy, S. S., and Cardinal, B. J. (2004). Effects of a self-determination theory-based mail-mediated intervention on adults' exercise behavior. Am. J. Health Promot. 18, 345-349. doi: 10.4278/0890-1171-18.5.345

Lock, M., Post, D., Dollman, J., and Parfitt, G. (2018). Development of a self-determination theory-based physical activity intervention for aged care workers: protocol for the activity for well-being program. Front. Public Health 6:341. doi: 10.3389/fpubh.2018.00341

Mailey, E. L., Huberty, J., Dinkel, D., and McAuley, E. (2014). Physical activity barriers and facilitators among working mothers and fathers. BMC Public Health 14:657. doi: 10.1186/1471-2458-13-657

Malik, S. H., Blake, H., and Suggs, L. S. (2013). A systematic review of workplace health promotion interventions for increasing physical activity. $\mathrm{Br}$. J. Health Psychol. 19, 149-180. doi: 10.1111/bjhp.12052

Miller, W. R. (1983). Motivational Interviewing with problem drinkers. Behav. Psychother. 11, 147-172. doi: 10.1017/s0141347300006583

Miranda, H., Gore, R. J., Boyer, J., Nobrega, S., and Punnett, L. (2015). Health behaviors and overweight in nursing home employees: contribution of workplace stressors and implications for worksite health promotion. Sci. World J. 2015:10.

Moore, G. F., Audrey, S., Barker, M., Bond, L., Bonell, C., Hardeman, W., et al. (2015). Process evaluation of complex interventions: medical research council guidance. Br. Med. J. 350:h1258. doi: 10.1136/bmj.h1258

Ng, J. Y. Y., Ntoumanis, N., Thøgersen-Ntoumani, C., Stott, K., and Hindle, L. (2013). Predicting psychological needs and well-being of individuals engaging in weight management: the role of important others. Appl. Psychol. Health Well Being 5, 291-310. doi: 10.1111/aphw.12011

Nöhammer, E., Schusterschitz, C., and Stummer, H. (2010). Determinants of employee participation in workplace health promotion. Intern. J. Workplace Health Manag. 3, 97-110. doi: 10.1108/17538351011055005

O’Brien, N., McDonald, S., Araújo-Soares, V., Lara, J., Errington, L., Godfrey, A., et al. (2015). The features of interventions associated with long-term 
effectiveness of physical activity interventions in adults aged 55-70 years: a systematic review and meta-analysis. Health Psychol. Rev. 9, 417-433. doi: 10.1080/17437199.2015.1012177

Painter, J. E., Borba, C. P. C., Hynes, M., Mays, D., and Glanz, K. (2008). The use of theory in health behavior research from 2000 to 2005: a systematic review. Ann. Behav. Med. 35:358. doi: 10.1007/s12160-008-9042-y

Parfitt, G., Rose, E. A., and Burgess, W. M. (2006). The psychological and physiological responses of sedentary individuals to prescribed and preferred intensity exercise. Br. J. Health Psychol. 11, 39-53. doi: 10.1348/ $135910705 \times 43606$

Prestwich, A., Sniehotta, F. F., Whittington, C., Dombrowski, S. U., Rogers, L., and Michie, S. (2014). Does theory influence the effectiveness of health behavior interventions? Meta-analysis. Health Psychol. 33, 465-474. doi: 10. $1037 / \mathrm{a} 0032853$

Quested, E., Ntoumanis, N., Thøgersen-Ntoumani, C., Hagger, M. S., and Hancox, J. E. (2017). Evaluating quality of implementation in physical activity interventions based on theories of motivation: current challenges and future directions. Intern. Rev. Sport Exerc. Psychol. 10, 252-269. doi: 10.1080/ 1750984x.2016.1217342

Rao Hill, S., and Clarke, M. (2010). Linking employee wellbeing and stakeholder quality of life: The case of aged care, Paper Presented at ANZAM Conference, Adelaide, SA.

Rhodes, R. E., and Kates, A. (2015). Can the affective response to exercise predict future motives and physical activity behavior? A systematic review of published evidence. Ann. Behav. Med. 49, 715-731. doi: 10.1007/s12160-015-9704-5

Rollnick, S., and Allison, J. (2004). "Motivational interviewing," in The Essential Handbook of Treatment and Prevention of Alcohol Problems, eds N. Heather and T. Stockwell (Chichester: John Wiley \& Sons Ltd), 105. doi: 10.1093/med/ 9780190619954.003.0011

Rose, E. A., and Parfitt, G. (2008). Can the feeling scale be used to regulate exercise intensity? Med. Sci. Sports Exerc. 40, 1852-1860. doi: 10.1249/mss. 0b013e31817a8aea

Ryan, R. M., and Deci, E. L. (2000). Self-determination theory and the facilitation of intrinsic motivation, social development, and well-being. Am. Psychol. 55, 68-78. doi: 10.1037/0003-066x.55.1.68

Shepperd, S., Lewin, S., Straus, S., Clarke, M., Eccles, M. P., Fitzpatrick, R., et al. (2009). Can we systematically review studies that evaluate complex interventions? PLoS Med. 6:e1000086. doi: 10.1371/journal.pmed.1000086

Short, C. E., Vandelanotte, C., and Duncan, M. J. (2014). Individual characteristics associated with physical activity intervention delivery mode preferences among adults. Intern. J. Behav. Nutr. Phys. Activ. 11:25. doi: 10.1186/1479-5868-11-25
Sloan, R. P., and Gruman, J. C. (1988). Participation in workplace health promotion programs: the contribution of health and organizational factors. Health Educ. Q. 15, 269-288. doi: 10.1177/109019818801500303

Taylor, N., Conner, M., and Lawton, R. (2012). The impact of theory on the effectiveness of worksite physical activity interventions: a meta-analysis and meta-regression. Health Psychol. Rev. 6, 33-73. doi: 10.1080/17437199.2010. 533441

Trost, S. G., Owen, N., Bauman, A. E., Sallis, J. F., and Brown, W. (2002). Correlates of adults' participation in physical activity: review and update. Med. Sci. Sports Exerc. 34, 1996-2001. doi: 10.1097/00005768-200212000-00020

Vazou-Ekkekakis, S., and Ekkekakis, P. (2009). Affective consequences of imposing the intensity of physical activity: does the loss of perceived autonomy matter. Hellen. J. Psychol. 6, 125-144.

Weman-Josefsson, K., Lindwall, M., and Ivarsson, A. (2015). Need satisfaction, motivational regulations and exercise: moderation and mediation effects. Intern. J. Behavi. Nutr. Phys. Activ. 12, 1-11.

Wierenga, D., Engbers, L. H., Van Empelen, P., Duijts, S., Hildebrandt, V. H., and Van Mechelen, W. (2013). What is actually measured in process evaluations for worksite health promotion programs: a systematic review. BMC Public Health 13:1190. doi: 10.1186/1471-2458-13-1190

Williams, D. M. (2008). Exercise, affect, and adherence: an integrated model and a case for self-paced exercise. J. Sport Exerc. Psychol. 30, 471-496. doi: 10.1123/ jsep.30.5.471

Williams, D. M., Dunsiger, S., Ciccolo, J. T., Lewis, B. A., Albrecht, A. E., and Marcus, B. H. (2008). Acute affective response to a moderate-intensity exercise stimulus predicts physical activity participation 6 and 12 months later. Psychol. Sport Exerc. 9, 231-245. doi: 10.1016/j.psychsport.2007.04.002

Williams, G. C., Grow, V. M., Freedman, Z. R., Ryan, R. M., and Deci, E. L. (1996). Motivational predictors of weight loss and weight-loss maintenance. J. Pers. Soc. Psychol. 70, 115-126. doi: 10.1037/0022-3514.70.1.115

Conflict of Interest: The authors declare that the research was conducted in the absence of any commercial or financial relationships that could be construed as a potential conflict of interest.

Copyright (C) 2020 Lock, Post, Dollman and Parfitt. This is an open-access article distributed under the terms of the Creative Commons Attribution License (CC BY). The use, distribution or reproduction in other forums is permitted, provided the original author(s) and the copyright owner(s) are credited and that the original publication in this journal is cited, in accordance with accepted academic practice. No use, distribution or reproduction is permitted which does not comply with these terms. 
OPEN ACCESS

Edited by:

Llewellyn Ellardus Van Zyl,

Eindhoven University of Technology,

Netherlands

Reviewed by:

Lara C. Roll,

Lingnan University, China

Leah Dickens,

Kenyon College, United States

*Correspondence:

Ruut Veenhoven

veenhoven@ese.eur.nl

Specialty section:

This article was submitted to

Organizational Psychology,

a section of the journal

Frontiers in Psychology

Received: 25 December 2019

Accepted: 14 July 2020

Published: 17 November 2020

Citation:

Bergsma A, Buijt I and

Veenhoven R (2020) Will

Happiness-Trainings Make Us

Happier? A Research Synthesis Using

an Online Findings-Archive.

Front. Psychol. 11:1953

doi: 10.3389/fpsyg.2020.01953

\section{Will Happiness-Trainings Make Us Happier? A Research Synthesis Using an Online Findings-Archive}

\author{
Ad Bergsma1 , Ivonne Buijt ${ }^{1}$ and Ruut Veenhoven ${ }^{1,2 *}$ \\ ${ }^{1}$ Erasmus Happiness Economics Research Organization, Erasmus University Rotterdam, Rotterdam, Netherlands, ${ }^{2}$ Optentia \\ Research Program, North-West University, Vanderbijpark, South Africa
}

Most people want to be happy and many look out for opportunities to achieve a more satisfying life. Following a happiness training is an option, but the effectiveness of such training is being questioned. In this research synthesis we assessed: (1) whether happiness training techniques add to the happiness of their users, (2) how much happiness training techniques add to happiness, (3) how long the effect of happiness training lasts, (4) what kinds of training techniques work best, and (5) what types of groups of people profit from taking happiness training. We took stock of the available research and found 61 reports of effect studies on training techniques, which together yielded 179 findings. These findings are available in an online "findings archive," the World Database of Happiness. Using links to this source allows us to condense information in tabular overviews, while providing the reader with access to much detail. Happiness training techniques seem to do what they are designed to do: $96 \%$ of the studies showed a gain in happiness post intervention and at follow-up, about half of the positive results were statistically significant. Studies with cross-sectional designs and studies that used control groups showed more mixed results. The average effect of happiness training was approximately $5 \%$ of the scale range. We conclude that taking a form of happiness training is advisable for individuals looking for a more satisfying life. Since happier workers tend to be more productive, organizations would be wise to provide such training techniques for their workforce. Keywords: affect balance, happiness, happiness training, happiness awareness, life skills, life satisfaction,
positive psychology interventions, research synthesis

\section{INTRODUCTION}

\section{Call for Greater Happiness}

Most people want to be happy, and many of them look for opportunities to achieve a more satisfying life (Diener et al., 1998). This pursuit seems to be universal, but it is particularly pronounced in modern societies (Veenhoven, 2015). One reason for the heightened interest in happiness is the greater awareness that we have considerable control over our happiness. Happiness is no longer considered a matter of fate (Nes and Røysamb, 2017), but rather a condition that can actively be pursued, developed, and sustained (Sezer and Can, 2019) and that is a personal responsibility (Elliott and Lemert, 2009). Sheldon and Lyubomirsky (2019) argued that $40 \%$ of one's level of happiness is a function of purposeful and intentional action, although that may be 
an overestimation (Brown and Rohrer, 2019). Another reason for the call for greater happiness is the rising evidence of the positive effects of happiness on other areas of life such as health (Veenhoven, 2008) and civil behavior (Guven, 2008). Employers are keen to raise happiness in their workforce, particularly in view of the evidence that life satisfaction fosters productivity more than job satisfaction (Gaucher and Veenhoven, 2020; Bergsma and Veenhoven, 2020).

\section{Happiness Education}

The call for greater happiness is met in two ways: by improving external living conditions and by strengthening life skills that enable people to live in the upper range of their happiness potentials (Sheldon and Lyubomirsky, 2019). A new field of research and practice centers around structured training and educational initiatives designed to strengthen individuals' life skills. This field is aptly labeled "happiness education" and is comparable to, and often intertwined with, existing "health education." Happiness education can be found in a growing number of advisory books, on self-help websites, and at the mounting supply of (online) courses on happiness (Bergsma, 2008; Parks et al., 2013). Alongside such education, a practice of happiness coaching has developed (Grant and Spence, 2010; Freire, 2013). Professional life coaches offer advice on how to live a more rewarding life, and they have gained a greater share of the work of psychologists and social workers (Tarragona, 2015). These developments are inspired by the scientific fields of "positive psychology" and "positive education," which came into existence around the year 2000 and added scientific rigor to practices in the expanding training sector (Boniwell, 2012). Positive psychology interventions (PPIs) have been developed with the aim of strengthening people. These interventions typically consist of a combination of teaching and exercises. The common aims of such training techniques are to get individuals to see and seek meaning in their work and lives, to know who they are, and to foster positive feelings and self-reliance (Sin and Lyubomirsky, 2009).

\section{Happiness Training Techniques}

One kind of PPI focuses on increasing satisfaction with one's life. This kind is commonly presented as "happiness training" (Fordyce, 1977). These training techniques help an individual to gain insight into the sources of their happiness and to learn skills that are functional for living a happy life (Feicht et al., 2013). The focus of these training techniques is not on a specific life domain, such as work or marriage, but on one's life as a whole (Bergsma and Veenhoven, 2020). An advanced Google search on "happiness training" yielded 69,800 hits in December 2019. Some examples are the "Happiness Training Plan" (College of Well-being, n.d.), the Buddhist-inspired online course "A Life of Happiness and Fulfillment” (Indian School for Business, n.d.), and the Action for Happiness Course (Action for happiness, n.d.).

\section{Doubts About the Effectiveness of Happiness Trainings}

The majority of happiness training techniques focus on individuals. Happiness training techniques applicable to organizational contexts are still underdeveloped and not often utilized (Nielsen et al., 2017) since organizations focus on work-related skills and engagement rather than on wider life skills (Ivandic et al., 2017; Donaldson et al., 2019a,b; Roll et al., 2019). One of the reasons for this could be existing doubts about the effectiveness of happiness training interventions (Donaldson et al., 2019b). These doubts are rooted in theories of happiness and in reservations about PPIs in general and about happiness training in particular.

\section{Qualms About the Possibility of Greater Happiness}

There are doubts that the level of individual happiness can be raised because, among other concerns, happiness is believed to depend on social comparison. In this view, people are happier if they think they are better off than others, making happiness a zero-sum game (Brickman and Campbell, 1971). Others claim that happiness is part of a fixed genetic disposition and therefore determined by personality traits that remain constant (e.g., Omerod, 2012). A third reason is that the conscious pursuit of happiness may be self-defeating because higher expectations of happiness will lead to frustration if not realized (e.g., Ford and Mauss, 2014), which implies that the use of a happiness training technique will decrease one's happiness. A fourth reason is that the pursuit of happiness stimulates people in individualistic societies to focus on individual goals, whereas more socially engaged ways to seek happiness are deemed more effective (Ford et al., 2015). Looking for happiness may even increase loneliness (Mauss et al., 2012), and valuing happiness may give rise to depression (Ford et al., 2014). Chasing happiness may also be selfdefeating if people seek more positive effects directly, while, in contrast, aiming to fulfill basic psychological needs of relatedness, autonomy, and competence may yield better results (Sheldon and Lyubomirsky, 2019). Although most of these doubts have been discarded in the scientific literature (Veenhoven, 2010), they still live in public opinion. The dark sides of the pursuit of happiness, as well as the caveats and limitations, have a higher attentive value for the media than the stories with a happy ending (Soroka and McAdams, 2015).

\section{Limited Effects of Positive Psychological Interventions (PPIs) in General}

Three major meta-analyses on the effectiveness of PPIs have not yielded impressive effects. Sin and Lyubomirsky (2009) reported a modest effect (mean $r=+0.29$, median $r=+0.24$ ) on "wellbeing." These numbers are difficult to interpret because the studies covered different notions of well-being, most of which belong in the life-ability quadrant of Figure 1 (see below). Bolier et al. (2013) report a smaller effect $(d=+0.34)$ on subjective wellbeing that partly waned at follow-up $(d=+0.22)$ and after the removal of outliers $(d=+0.17)$. The authors were not very specific about the subjective well-being measures they included. Multicomponent PPIs have a small to moderate effect on subjective well-being (Hedges' $g=+0.34$ ), but again, the authors were not very specific on the subjective well-being measures they included. The removal of outliers or low-quality studies lowered the effect on well-being ( $g=+0.24$ without outliers, $g=+0.26$ for high-quality studies) (Hendriks et al., 2019). The modest 


\begin{tabular}{lll}
\hline & External Life Qualities & Internal Life Qualities \\
\hline Life Chances & Livability of environment & Life skills of the person \\
\hline Life Results & Utility of life & Satisfaction with life \\
\hline
\end{tabular}

FIGURE 1 | Four Qualities of Life. Source: Veenhoven (2000, 2019c).

effects of the meta-analyses we described may be too high because negative findings tend to be underreported in scientific literature. A recent re-analysis of the studies included in the first two metaanalyses mentioned above used an improved correction for small sample sizes and found an effect of 0.1 of PPIs on well-being (White et al., 2019).

\section{Reservations About Happiness Training Techniques in Particular}

In a recent Delphi study by Buettner et al. (2020), 14 leading scientists rated the effectiveness of "Ways to Greater Happiness" on a five-step scale. Their effectiveness rating for "Develop skills for greater happiness, using self-help or professional coaching" was 3.1, while their average rating for methods such as "Invest in friends and family" and "Get physical exercise" was about 4 .

The general public seems to have a mixed attitude toward happiness advice and training. There is much interest but also a lot of skepticism and grumbling about the "tyranny of positivity" (Held, 2002, 2018). One of the reasons may be that the term "happiness" is used to promote the particular trendy practices of the moment, such as meditation and veganism. This is part of the wider problem of the term "happiness" being increasingly used in sales communication as a "feel-good" term (e.g., Coca-Cola with its "Open Happiness" slogan). A shared definition of happiness is lacking, and this is another reason to question the message of happiness coaches and trainers.

\section{Research Questions}

Are these doubts about the effectiveness of happiness training techniques justified? In this study we seek to answer the following questions:

- Do happiness training techniques add to happiness?

- If so, how strong is the effect?

- If so, how long-lasting is the effect?

- What kind(s) of training techniques work best?

- What nature of training techniques works best?

- What modes of training techniques work best?

- What types of people profit most from joining a happiness training course?

\section{Concept of Happiness}

In answering these questions, we focus on happiness in the sense of "life satisfaction," which we will define in detail below. To our knowledge, the research literature on this subject has not been reviewed with that specific definition in mind.

\section{Meanings of the Word}

In a broad sense, the word happiness is used to denote a "good life" and used as a synonym for "quality of life" or "well-being." This meaning prevails in moral philosophy where it serves as a starting point for speculations about what qualities make the best life, such as the importance of "wisdom" (McMahon, 2018). In contemporary social sciences the term is increasingly used for one particular quality of life, that is, how satisfying one's life is. Since this is a measurable phenomenon, its determinants can be identified inductively using empirical research (Diener et al., 2015).

\section{Definition of Happiness}

Happiness is defined as the degree to which individuals judge the overall quality of their life as a whole favorably (Veenhoven, 1984). This definition fits the utilitarian tradition and is most closely associated with Bentham's (1789) view of happiness, which is described as "the sum of pleasures and pains" (Veenhoven, 2009). This concept is central in the World Database of Happiness, which we draw from for this research synthesis.

\section{Other Notions of Quality of Life and Satisfaction}

We realize that some readers will associate "happiness" with other notions of well-being, in particular readers with a background in positive psychology where the term "eudaimonic well-being" is currently used for positive mental health (Delle Fave et al., 2011). Therefore, we are expanding on this difference using Veenhoven (2000) classification of four qualities of life. This classification is based on two distinctions: vertical and horizontal. Vertically, there is a difference between opportunities and actual outcomes of life. This distinction is important because people can fail to use the life chances offered to them. The horizontal distinction refers to external qualities of the environment and internal qualities of the individual. Together, these two dichotomies produce four qualities of life, all of which have been denoted by the word "happiness."

In Figure 1, our concept of happiness is positioned in the right-bottom quadrant, as an inner outcome of life. Positive mental health (eudaimonic happiness) belongs in the top-right quadrant of Figure 1, that is, as a precondition for happiness. We only include measures of happiness that belong to the rightbottom quadrant. Our conceptual focus is sharper than that of earlier meta-analyses of positive psychological interventions, which included measures of well-being that also cover other quadrants of Figure 1. As such, our results are easier to interpret.

\section{Components of Happiness}

The overall evaluation of life draws on two sources of information: (1) how well we feel most of the time, and (2) to what extent we perceive that we are getting from life what we want from it. We refer to these sub-assessments as "components" of happiness, respectively called "hedonic level of affect" and "contentment" (Veenhoven, 1984). Diener et al. (1999) make a similar distinction between affective and cognitive appraisals of life, but do not conceptualize an overall evaluation in which these 

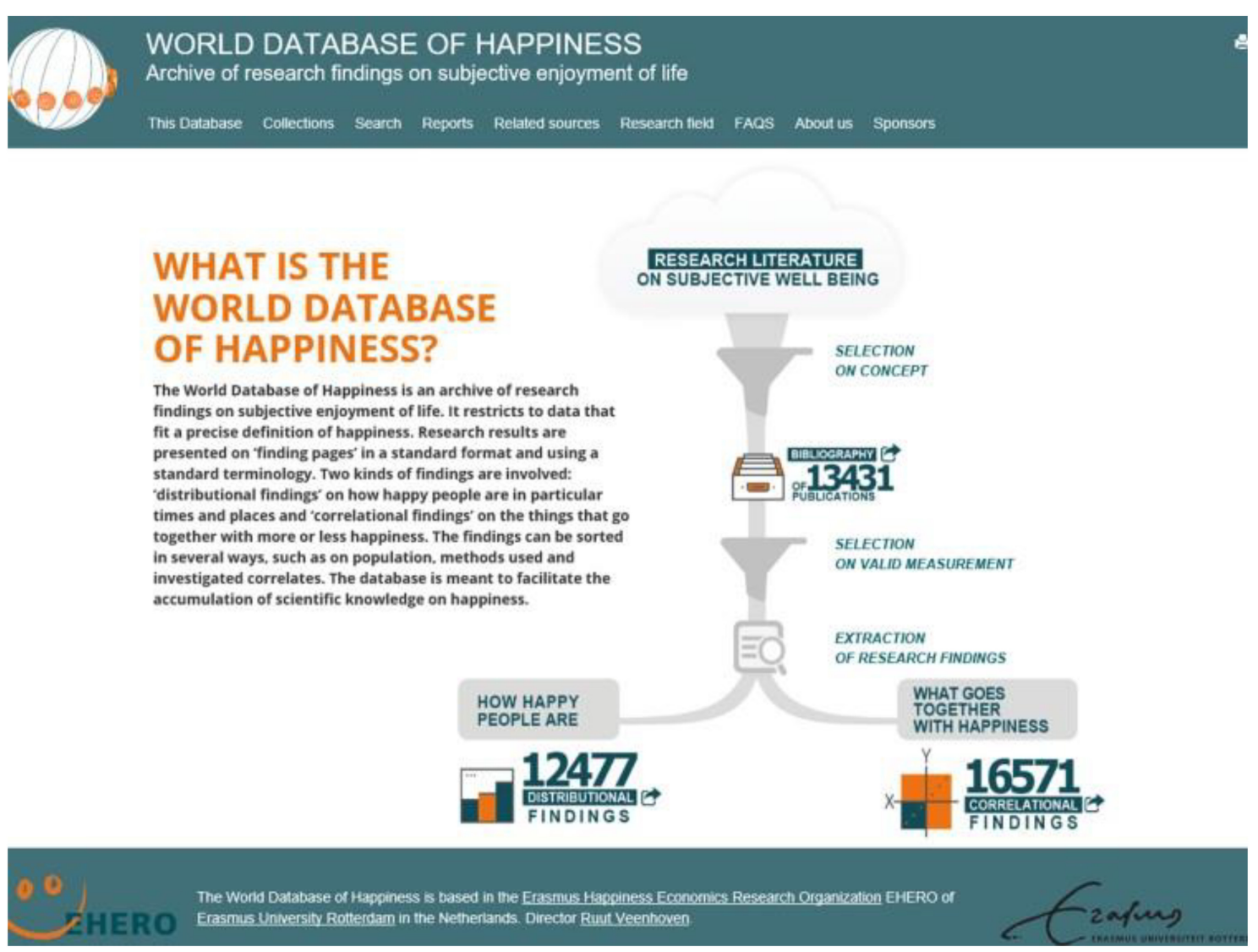

FIGURE 2 | Start page of the World Database of Happiness, showing the structure of this findings archive.

appraisals are merged. In this research synthesis we include all three variants, overall happiness and its two components.

\section{MATERIALS AND METHODS}

We seek answers to the research questions mentioned above in section "Research Questions" by taking stock of the available research findings. For this purpose, we draw on the World Database of Happiness (Veenhoven, 2019g, 2020). This is a "findings archive" that contains some 20,000 abstracts of observed correlations with happiness, presented on electronic "finding pages" in a standard format and terminology. The structure of this "finding archive" is presented on Figure 2. The finding pages are sorted by subject, and one of the subject categories is "happiness training," which contained 179 findings in December 2019. The World Database of Happiness restricts to findings obtained with measures of happiness that fit the above-mentioned definition of happiness, the selection of which is explained below. The use of this findings archive implies another way of gathering the available research findings than is usual in review studies and provides new ways for presenting the data. The technique is described in detail in Veenhoven (2020). We call it a "support system for research synthesis." In section "Advantages and Disadvantages of Using an Online Finding Archive," we discuss the advantages and disadvantages of this method. In section "Differences With MetaAnalysis," the differences of this research synthesis with metaanalysis are discussed.

\section{Search Strategy}

The World Database of Happiness, and hence this research synthesis, restricts to research findings on happiness as defined above. Publications on that matter have been gathered on a continuous basis since 1980 - at the outset, mainly with searches in abstract systems such as the Web of Science, and today by also tracking references in publications and using announcement services, such as New Economic Papers on Happiness (for detail Veenhoven, 2019b). Selected publications are entered in the Bibliography of Happiness and classified by main subject addressed, one of which is "happiness training" (Veenhoven, 2019a). We updated this latter collection with an additional literature search in Google Scholar and by tracking references in reviews of research on effects of PPIs.

\section{Eligibility Criteria Measurement of Happiness}

Since happiness is defined as something we subjectively experience, it can be measured using questioning. Not all 
questions used for measuring happiness studies fit the above definition of happiness. The World Database of Happiness, and hence this research synthesis, restricts to findings yielded with measures of happiness that have passed a face-validity test and are listed in the "Collection Measures of Happiness" in the World Database of Happiness (Veenhoven, 2019e).

\section{Rejected Happiness Scales}

Several multiple-item happiness scales failed this test because they include questions on other kinds of well-being than happiness as defined above. This is the case for two "happiness scales," that are often used in studies on the effects of happiness training techniques, the Satisfaction With Life Scale (SWLS) by Diener et al. (1985) and the Subjective Happiness Scale (SHS) by Lyubomirsky and Lepper (1999). Both are multipleitem questionnaires that contain one or more questions that does not fit our definition of happiness. In the case of the fiveitem SWLS, the statement "If I could live my life over again, I would change nothing." does not fit. Logically, one can be satisfied with life, but still be open for something else. The item is particularly inapt for measuring the effects of happiness training techniques since users of such techniques typically seek change in their lives. In the case of the four-item SHS, the problem is in the statement "Compared to other people, I consider myself less happy/more happy." Logically, one can think one might be happier than other people, but still be unhappy. Practically, we are often poorly informed of how happy "other" people are. In our view, this lack of substantive face validity cannot be offset by mathematical "tests" for concurrent validity or construct validity. Consequently, we excluded data yielded with these measures, sacrificing a number of findings to maintain a clear meaning of the remaining findings.

\section{Valid Measures Included}

Three types of accepted happiness measures are included in this research synthesis: (1) measures of overall "life satisfaction," (2) measures of "hedonic level of affect," that is, the affect balance scores and answers to the question about how happy one feels, and (3) mixed measures that combine questions about life satisfaction and affect level. The full text of these measures is available behind links in Table 1. Measures of "contentment" have not been used in any of the studies included in this research synthesis.

\section{Happiness Training}

Happiness training techniques are a kind of PPI. In practice, it is often difficult to see what particular training techniques precisely aim to improve. The first problem is in the naming of interventions; the use of the term "happiness" in the appellation does not always mean that happiness as defined above is targeted (e.g., this is not the case for the Happiness Course (The happiness course, n.d.), which is about strengthening religious communities). A second problem is that training techniques presented as a "happiness training" often aim to meet multiple goals, of which happiness is only one, and where "happiness" is seldom clearly defined. A third problem is that there are training techniques that focus on happiness, but do not use the word "happiness" in their name, as with, for example, the "Growth Training" developed by Sheldon et al. (2002).

We dealt with these problems in the following ways. First, we ignored the specific name used for a training technique. Instead, we looked at the instructions and materials to see what was actually trained. Another indication for the aim of the training was the outcome measures used in studies on its effects. This worked in most of the cases but was not always clear. This research synthesis may therefore not be complete, but it does offer a pragmatic grasp of studies.

\section{Studies Selected}

At the end of 2019, the World Database of Happiness included 61 studies in which the effects of happiness training on happiness had been assessed using a valid measure of happiness. These 61 studies were reported in 54 publications, which had been published between 1972 and 2019. Together, these 61 studies report 179 "findings," since several studies report more than one result. A list of these studies is presented in Table 1. The links in Table 1 lead to the specific happiness measures used and to the excerpts of the studies in the World Database of Happiness.

\section{People Investigated}

The people investigated in these studies were users of happiness training techniques. Most of them participated voluntarily and were recruited via websites, flyers, and using snowball sampling methods. Recruitment focused on students, patients, and working peoples. This resulted in self-selected samples, not random samples of all users of happiness training techniques. In our definition of self-selecting, we do not strictly refer to people who truly volunteered, but also to samples of college students who participated in the research for a study credit. Several studies forced people to take part in a happiness training technique, typically in the context of an educational course or as a therapy.

\section{Notation of Findings}

Observed effects of happiness training were summarized in a standard format and terminology on electronic finding pages, together with methodological characteristics of the study. Veenhoven (2019f) offers a description of that process.

\section{Analysis \\ Organization of the Findings}

We sorted the selected happiness training techniques by the nature of the intervention. The results are presented in Table $2^{1}$. Some of these techniques appear in more than one cell of the table. This is the case for a training that fits more than one category. The full classification of different natures and modes can be found on the WDH website ${ }^{2}$, (Veenhoven, 2019c).

\section{Presentation of the Findings}

In Table 3, we summarize the observed effects of happiness training on happiness using three possible signs: + for a positive

\footnotetext{
${ }^{1}$ https://worlddatabaseofhappiness.eur.nl/search-the-database/correlationalfindings/\#id=0zYMIXQB9uCjuYHDZDYa

${ }^{2}$ https://worlddatabaseofhappiness.eur.nl/search-the-database/correlational-
} findings/\#id=1DYPIXQB9uCjuYHDZTYe 
TABLE 1 | Studies included in this research synthesis.

\begin{tabular}{|c|c|c|c|c|c|}
\hline \multirow{2}{*}{$\begin{array}{l}\text { Target group: } \\
\text { Country and year }\end{array}$} & \multirow[t]{2}{*}{$\mathbf{N}$} & \multicolumn{2}{|c|}{ Happiness training } & \multirow{2}{*}{$\begin{array}{l}\text { Type of happiness } \\
\text { measure }^{\mathrm{a}}\end{array}$} & \multirow[t]{2}{*}{ Source $^{b}$} \\
\hline & & Named in WDH & Named by author & & \\
\hline \multicolumn{6}{|l|}{ Patients } \\
\hline Depressed adults, UK, 2009 & 55 & Goal setting training & $\begin{array}{l}\text { Self-help, positive goal-focused } \\
\text { intervention }\end{array}$ & $\begin{array}{l}\text { Affect balance } \\
\text { Life-satisfaction }\end{array}$ & Coote \& Macleod, 2012 \\
\hline $\begin{array}{l}\text { Medical patients with neuromuscular disease, } \\
\text { USA, } 1998\end{array}$ & 65 & Gratitude training & $\begin{array}{l}\text { Happiness training; gratitude } \\
\text { exercises }\end{array}$ & $\begin{array}{l}\text { Affect balance } \\
\text { Feel happy }\end{array}$ & $\begin{array}{l}\text { Emmons \& McCullough, } \\
2003\end{array}$ \\
\hline $\begin{array}{l}\text { Poor-health participants in a course of } \\
\text { mind-body therapies, Sweden, 2000-2001 }\end{array}$ & 152 & Meditation, mindfulness & Health self-management course & Affect balance & Fernros et al. 2008 \\
\hline Home-bound elderly, USA, 1982 & 51 & Life-review exercise & Life-review program & Affect balance & Haight, 1988 \\
\hline Distressed adults, Netherlands, 2005 & 57 & Meditation, mindfulness & Mindfulness based stress reduction & Affect balance & Nyklícek \& Kuijpers, 2008 \\
\hline $\begin{array}{l}\text { Patients on a waiting list for psychological } \\
\text { treatment, Australia, } 2012\end{array}$ & 48 & $\begin{array}{l}\text { 1) Gratitude training } \\
\text { 2) Kindness training }\end{array}$ & $\begin{array}{l}\text { Gratitude and kindness } \\
\text { interventions }\end{array}$ & $\begin{array}{l}\text { Feel happy } \\
\text { Affect balance }\end{array}$ & Kerr et al. 2015 \\
\hline \multicolumn{6}{|l|}{ Students } \\
\hline Psychology students, USA, 2005 & 180 & Life-review exercise & Positive reminiscence training & Feel happy & Bryant et al. 2005 \\
\hline Students, USA and South Korea, 2007 & 218 & Kindness training & $\begin{array}{l}\text { Performing acts of kindness with or } \\
\text { without and autonomy support }\end{array}$ & Affect balance & Della Porta, 2013 \\
\hline Students, USA, 1998 & 166 & Gratitude training & $\begin{array}{l}\text { Count blessings, thinking about five } \\
\text { hassles, social comparison }\end{array}$ & Affect balance & $\begin{array}{l}\text { Emmons \& McCullough, } \\
2003\end{array}$ \\
\hline Students in well-being course, USA, 2003 & 192 & $\begin{array}{l}\text { (1) Gratitude training } \\
\text { (2) Life-review exercise }\end{array}$ & Count blessings & & \\
\hline University students, Turkey, 2015 & 72 & $\begin{array}{l}\text { Practice retrospective sources of } \\
\text { happiness }\end{array}$ & $\begin{array}{l}\text { Increasing activities and } \\
\text { engagement }\end{array}$ & Affect balance & Eryilmaz, 2015 \\
\hline Students, USA, 1972 & 202 & Training for multiple mental skills & Happiness training & Feel happy & Fordyce, 1977 \\
\hline \multirow[t]{5}{*}{ University students, USA, 1980} & 57 & Training for multiple mental skills & $\begin{array}{l}\text { Program to increase personal } \\
\text { happiness, aiming to change } 14 \\
\text { fundamental behaviors }\end{array}$ & Feel happy & Fordyce, 1983 \\
\hline & 71 & & & & \\
\hline & 98 & & & & \\
\hline & 57 & & & & \\
\hline & 69 & Happiness education & & & \\
\hline Students, Italy, 2001 & 92 & Training for multiple mental skills & $\begin{array}{l}\text { Subjective well-being training } \\
\text { course }\end{array}$ & Feel happy & Goldwurm et al. 2003 \\
\hline Psychotherapy students, Italy, 2004? & 80 & Cognitive reframing & Subjective wellbeing training & Feel happy & Goldwurm et al. 2006 \\
\hline $\begin{array}{l}\text { Student participants in a savoring } \\
\text { exercise,USA, } 2011\end{array}$ & 193 & Savoring training & $\begin{array}{l}\text { Recalling positive events in the past } \\
\text { week }\end{array}$ & Affect balance & Hurley \& Kwon, 2012 \\
\hline Students,United Arab Emirates, 2015 & 267 & Training for multiple mental skills & PPI program & Affect balance & Lambert et al. 2019 \\
\hline
\end{tabular}




\begin{tabular}{|c|c|c|c|c|c|}
\hline \multirow{2}{*}{$\begin{array}{l}\text { Target group: } \\
\text { Country and year }\end{array}$} & \multirow[t]{2}{*}{$\mathbf{N}$} & \multicolumn{2}{|c|}{ Happiness training } & \multirow{2}{*}{$\begin{array}{l}\text { Type of happiness } \\
\text { measure }^{a}\end{array}$} & \multirow[t]{2}{*}{ Source $^{b}$} \\
\hline & & Named in WDH & Named by author & & \\
\hline $\begin{array}{l}\text { Students participating in happiness } \\
\text { training,USA, } 2014\end{array}$ & 139 & Lifestyle awareness training & Time scarcity training & Affect balance & Layous, et al. 2018 \\
\hline Psychology students,New Zealand, 1978 & 48 & $\begin{array}{l}\text { (1) Self-awareness training } \\
\text { (2) Positive thinking training }\end{array}$ & Cognitive retraining & Affect balance & Lichter et al. 1980 \\
\hline Psychology students, Germany, 2014 & 349 & Mood tracking & Use of Happiness Analyzer & $\begin{array}{l}\text { Affect balance } \\
\text { Feel happy } \\
\text { Life satisfaction }\end{array}$ & Ludwigs et al. 2018 \\
\hline Students,USA, 2006 & 96 & Life-review exercise & $\begin{array}{l}\text { Writing, talking, and thinking about } \\
\text { life's triumphs and defeats }\end{array}$ & Affect balance & Lyubomirsky et al. 2006 \\
\hline $\begin{array}{l}\text { Students and people from local education } \\
\text { center, UK, } 2008\end{array}$ & 64 & Goal setting training & Goal setting and planning training & Affect balance & MacLeod et al. 2008 \\
\hline Psychology students, Spain, 2010 & 105 & Gratitude training & Gratitude writing intervention & Feel happy & Martinez-Marti 2010 \\
\hline University students, South Korea, 2009 & 50 & $\begin{array}{l}\text { (1) Goal setting training } \\
\text { (2) Practice one's values }\end{array}$ & Well-being training & Affect balance & Nelson et al. 2014 \\
\hline Psychology students, USA, 2009 & 62 & Practice one's values & Self-affirmation & Affect balance & Nelson et al, 2014 \\
\hline Students, USA, 2004 & 360 & Training for multiple mental skills & Positive psychotherapy training & Life satisfaction & Parks, 2004 \\
\hline $\begin{array}{l}\text { Student participants in a happiness training, } \\
\text { USA, 2007-2008 }\end{array}$ & 267 & Training for multiple mental skills & Positive psychotherapy training & Life satisfaction & Parks 2009 \\
\hline Psychology students, USA, 2000 & 90 & Goal-setting training & $\begin{array}{l}\text { Goal training intervention, growth } \\
\text { training }\end{array}$ & Affect balance & Sheldon et al. 2002 \\
\hline \multicolumn{6}{|l|}{ School children } \\
\hline Middle school students, Netherlands, 2009 & 631 & Training for multiple mental skills & Lessons in happiness & Feel happy & Boerefijn \& Bergsma 2011 \\
\hline School children aged 9-11, UK, 2014 & 606 & Positive thinking training & Positive psychology intervention & Feel happy & Carter, 2016 \\
\hline Students aged 12-17, USA, 2006 & 221 & Gratitude training & Gratitude increasing intervention & Life satisfaction & Froh et al. 2008 \\
\hline Pupils of a parochial school aged 8-19, USA & 89 & Gratitude training & Gratitude intervention & Affect balance & Froh et al. 2009 \\
\hline Children aged 9-12, Netherlands, 2012 & 183 & Training for multiple mental skills & Happiness lessons & Feel happy & Leeuw, 2012 \\
\hline School children aged 10-12, USA, 2008 & 55 & Positive thinking training & Wellness program & Affect balance & Suldo et al 2014 \\
\hline \multicolumn{6}{|l|}{ Self-selected users of happiness trainings } \\
\hline Meditation trainees, Oman, 2001 & 45 & Meditation, mindfulness & Meditation course & Feel happy & AlHusani, 2001 \\
\hline \multirow[t]{2}{*}{$\begin{array}{l}\text { Users of the "Happiness Indicator" self-help } \\
\text { website }\end{array}$} & 5411 & $\begin{array}{l}\text { Comparison with the happiness of } \\
\text { similar people }\end{array}$ & Happiness comparer & Feel happy & Bakker et al. 2020 \\
\hline & & Mood awareness training & Happiness diary & & \\
\hline $\begin{array}{l}\text { Participants in a mindfulness meditation course, } \\
\text { USA, } 2008\end{array}$ & 69 & Meditation, mindfulness & Mindfulness training & $\begin{array}{l}\text { Life-satisfaction } \\
\text { combined with } \\
\text { Affect balance }\end{array}$ & Brown et al. 2009 \\
\hline
\end{tabular}


Target group: N

\section{Country and year}

Long-term meditators, Netherlands, 2009

Participants in a 9-day meditation retreat,

Netherlands, 2009

Healthy adult volunteers, USA, 2005

Users of an online training, 35 nations, 2012

Participants in a gratitude training, Poland, 2016

Adult volunteers, New Zealand, 1978

Participants in a savoring training, Spain, 2017 Users of a mood-tracking website, USA, 2010 Participants in a happiness training, USA, 2004 Users of online self-help program, USA, 2007

Participants in a 4-week psychological training Canada, 2011

Participants in a happiness training, USA, 2011

Participants in a happiness training, USA, 2004

Participants in a yoga course, Australia, 2007

\section{Miscellaneous groups}

School teachers, Hong Kong, 2007

Young adults, Spain, 201?

Self-selected employees, Germany, 2012

Managers participating in personality

development course, Germany, 2000

Self-selected older adults, UK, 2014

Employee well-being trainees, Australia, 2009
Happiness training

\section{Named by author}

Long-term meditation

9-day vipassana meditation retreat

Meditation, mindfulness

Psycho-education course on

positive psychology

Gratitude exercise

Course on happiness and positive

mental health

Appreciation of beauty

Frequent use of mood tracker

Positive psychotherapy training

"Live happy" online self-help

program

Gratitude inducing exercises

Hedonic adaptation prevention

(2) Life-review exercise

(1) Novelty training

(2) Goal setting training

List and practice perceived ways to

happiness

Meditation, mindfulness

Gratitude training

Lifestyle awareness training

Training for multiple mental skills

Empowerment training

Savoring training

Training for multiple mental skills

Change your actions not your

circumstances

Laughter yoga

Gratitude intervention program

Best possible self-Intervention

7-week web-based happines

training

Goal-setting training

Gratitude intervention

Well-being training program
Type of happiness

measure ${ }^{a}$

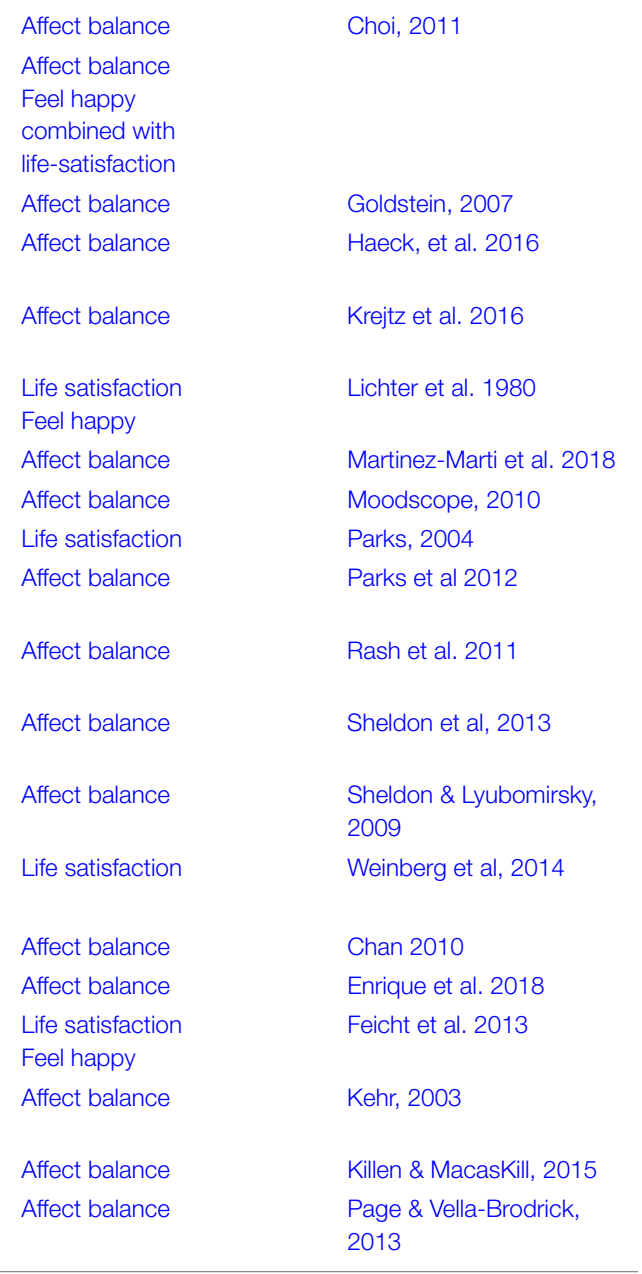


TABLE 2 | Classification of happiness trainings in the World Database of Happiness, collection of Correlational Findings, subject section Health: Psychological Treatment sub-subjects and number of finding-pages by December 2019.

\begin{tabular}{lr}
\hline Subject name & Number of fin \\
\hline Happiness training & \\
Best possible self-exercise & 2 \\
Cognitive reframing & 1 \\
Comparison with the happiness of similar people & 1 \\
Enlightenment about happiness & 5 \\
Goal setting training & 5 \\
Laughter yoga & 1 \\
List and practice perceived ways to happiness & 1 \\
- Practice retrospective sources of happiness & 1 \\
- Practice one's values & 2 \\
Meditation, mindfulness & 7 \\
Novelty trying & 1 \\
Life style awareness training & 1 \\
- Life-review exercise & 2 \\
- Mood awareness training & 4 \\
Positive thinking training & 3 \\
- Count blessings/curses & 7 \\
- Gratitude training & 10 \\
- Kindness training & 2 \\
- Recall of positive events & 5 \\
Savouring training & 1 \\
Trainings for multiple mental skills & 8 \\
- Enlightenment + exercises & 5 \\
Total & 74 \\
\hline
\end{tabular}

${ }^{1} A$ finding-page can report more than one separate research findings, such as obtained with different measures of happiness, different statistics and separate findings for experimental and control groups.

relationship, - for a negative relationship, and 0 for a nonrelationship. Statistical significance is indicated by printing the sign in bold $(p<0.05)$. Some of the findings are presented in a string of signs, for example, $+/+$ for studies that used more than one measure of happiness, or for studies that used more than one control group. In Table 4, we present the same data quantified in effect sizes as the change in percentage of the theoretical scale range of the happiness measure used. This method allows comparison across measures with different scale ranges and is relatively easy to interpret for a general public (Borenstein et al., 2009). In Tables 5-10, we summarize the same findings, sorted by different subgroups.

\section{Links to Online Detail}

As noted above, the World Database of Happiness is a collection of "finding pages" on which the results of empirical research on happiness are reported in a standard language and format. An example of a findings page is presented in Figure 3. In this paper we use links to such online finding pages. All the signs in Tables 3-10 link to finding pages in the World Database of Happiness, which serves as an online appendix for this article. If you click on a sign, the corresponding finding page will open and offer details of the observed relationship, such as on the people investigated, the sampling method used, the training technique, the happiness measure, and the statistical analysis. This technique allows us to present the main trends in the findings, while keeping this paper to a controllable size and, at the same time, allowing the readers to check detail.

\section{Indicators of Effect}

We considered three indicators of the effect of following a happiness training. A first indicator was the difference in happiness among people who have taken a happiness training course and people who have not. An evident weakness of this cross-sectional approach is that selectiveness can play us false, in particular because users of happiness training techniques are likely to be less happy than non-users.

A better indicator of how well a happiness training technique has worked is the change in happiness observed among users of a happiness training technique, both pre-test to post-test and in the long-term follow-up. A weakness of this longitudinal approach is that the observed effect may be due to being part of an intervention as such rather than its content. In clinical psychology this is known as the "placebo effect" and in industrial psychology as the "Hawthorne effect" (Franke and Kaul, 1978).

This problem can be solved using a control group that gets an equally credible intervention with another content or a place on a waiting list. The change in happiness of an intervention group compared with a change in a control group was our third indicator. It should be noted that the control groups used in the studies were heterogeneous, which makes the interpretation of the difference more complicated (Dickens, 2017).

\section{Advantages and Disadvantages of Using an Online Finding Archive}

There are pros and cons to the use of a findings archive such as the World Database of Happiness and plusses and minuses to the use of links to an online source.

\section{Advantages}

(1) Efficient gathering of research on happiness. (2) Sharp conceptual focus fitting a specific definition of happiness. (3) Uniform description of research findings. (4) Storage of findings pages in an easily searchable and freely available database. (5) Online availability of the database and the separate finding pages it contains. 6) Presentation of the available research findings in easy-to-view tables using links to online finding pages. (7) The technique is useful for ongoing harvesting of research findings on a particular subject. It is easy to update review papers of this kind by entering new signs in the tables.

\section{Disadvantages}

(1) The sharp conceptual focus cannot easily be changed. (2) Considerable investment is required to keep the archive up to date. (3) Links to online finding pages work only for electronic texts. (4) The standard information available in the excerpts is not always sufficient for judging the methodological quality, which is a hindrance, specifically, for the purposes of our research as links to the full text of the original research reports are required. (5) Using a finding archive such as the World Database of Happiness speeds up the process of finding all the relevant studies, but this 
TABLE 3 | 179 research findings on the effect of happiness trainings on happiness observed direction of change and statistical significance.

Longitudinal before versus after training

Cross-sectional had training versus did not have training

\begin{tabular}{lllll}
\multicolumn{2}{c}{ Change in treatment group only } & & \multicolumn{2}{c}{ Difference with change in control group } \\
\cline { 1 - 1 } \cline { 5 - 6 } Post-intervention $\quad$ After follow-up & & Post-intervention $\quad$ After follow-up
\end{tabular}

\section{Single kind of training}

Best possible self-exercise

Cognitive reframing

Comparison with similar people

Enlightenment about happiness

Goal-setting training

Laughter yoga

List and practice perceived ways to happiness

Practice retrospective sources of happiness

Live up to one's values

Meditation, mindfulness

Novelty trying

Lifestyle awareness training

Life-review exercise

Mood awareness training

Positive thinking training

- Count blessings and curses

- Gratitude training

- Kindness training

- Recall of positive events

Savoring training

\section{Multiple kinds combined}

Training of multiple mental skills

- Enlightenment + exercises

fter follow-up

Post-intervention

After follow-up

$\%$ independent studies positive

- all positive
- positive and significant $(p<0.05)$

$+/-$

Sifference. - negative difference, not significant. 
TABLE 4 | 150 research findings on the effect of happiness trainings on happiness in 55 studies effect sizes expressed in \% change on scale range.

Nature of happiness training $\quad$ Method of investigation

\begin{tabular}{|c|c|c|c|c|c|}
\hline & \multirow[t]{3}{*}{ Cross-sectional had training versus did not have training } & \multicolumn{4}{|c|}{ Longitudinal before versus after training } \\
\hline & & \multicolumn{2}{|c|}{ Change in treated group only } & \multicolumn{2}{|c|}{ Difference with change in control group } \\
\hline & & $\begin{array}{c}\text { Post- } \\
\text { intervention }\end{array}$ & $\begin{array}{c}\text { After } \\
\text { follow-up }\end{array}$ & $\begin{array}{c}\text { Post- } \\
\text { intervention }\end{array}$ & $\begin{array}{c}\text { After } \\
\text { follow-up }\end{array}$ \\
\hline \multicolumn{6}{|l|}{ Single kind of training } \\
\hline Best-possible-self exercise & & +5.1 & +1.6 & +0.5 & -2.3 \\
\hline Cognitive reframing & & +13.7 & & +12.5 & \\
\hline Enlightenment about happiness & & $+0.8+3.9$ & +3.2 & -2.9 & \\
\hline Goal-setting training & & $\begin{array}{l}+13.4 /+10.4 \mathrm{c} \\
+2.9+3.6 \\
+5.1 \mathrm{a}-1.3\end{array}$ & $\begin{array}{c}+11.9 /+10.4 \mathrm{c} \\
+1.1+1.6 \mathrm{a} \\
+3,6\end{array}$ & $\begin{array}{c}+8.6 /+9.5 c \\
+0.5 a+4.300\end{array}$ & $-2.3 \mathrm{a} 0$ \\
\hline Laughter yoga & & +8.6 & & +8.6 & \\
\hline List and practice perceived ways to happiness & & $+0.6 /+7.2 \mathrm{c}$ & & & \\
\hline Practice retrospective sources of happiness & & +12.5 & & +12.5 & \\
\hline Live up to one's values & & $+1.0+4.0$ & +2.5 & $+5.0+7.8$ & +5.8 \\
\hline Meditation, mindfulness & +2.9 & $\begin{array}{c}+4.1+13.2 \\
+4.6+18.0 \\
+8.7\end{array}$ & $\begin{array}{l}+5.0+5.6 \\
+17.6\end{array}$ & $\begin{array}{c}+8.0 \\
-0.6+18.0 \\
+9.0\end{array}$ & $-0.7+16.7$ \\
\hline Novelty trying & & $+3.6 \mathrm{a}$ & $+1.1 \mathrm{a}$ & 0 & 0 \\
\hline Life-review exercise & & & & & $-0.9 /-4.6 / 0 c$ \\
\hline Mood awareness training & & $+3.9 /+3.7 /+0.7 \mathrm{c}$ & $\begin{array}{c}+4.2 /+3.7 /+1.2 \mathrm{C} \\
+18.9 /+23.2 \mathrm{c}\end{array}$ & $+2.0 /+4.0 /+0.7 \mathrm{c}$ & $+0.4 /+1.1 /+1.1 \mathrm{c}$ \\
\hline Positive thinking training & & $\begin{array}{c}+2.4+13.7 \mathrm{a} \\
+4.0\end{array}$ & +7.0 & $\begin{aligned}-0.4 & +12.5 \mathrm{a} \\
& +5.0\end{aligned}$ & -2.9 \\
\hline - Count blessings and curses & $\begin{array}{l}+6.50 \\
-3.3 \mathrm{a}\end{array}$ & $+0.7+2.4 a$ & +1.5 & & \\
\hline
\end{tabular}


TABLE $4 \mid$ Continued

Nature of happiness trainin

Cross-sectional had training versus did not have training

Method of investigation

Longitudinal before versus after training

\begin{tabular}{cccccc}
\hline \multicolumn{2}{c}{ Change in treated group only } & & \multicolumn{2}{c}{ Difference with change in control group } \\
\cline { 1 - 1 } $\begin{array}{c}\text { Post- } \\
\text { intervention }\end{array}$ & $\begin{array}{c}\text { After } \\
\text { follow-up }\end{array}$ & & $\begin{array}{c}\text { Post- } \\
\text { intervention }\end{array}$ & $\begin{array}{c}\text { After } \\
\text { follow-up }\end{array}$
\end{tabular}

- Gratitude training

$+12.3-3.3+14.0 /+7.9 \mathrm{c}+5.4$

$+13.3 /+6.0 \mathrm{c}$

- Kindness training

- Recall of positive events

$+1.5+2.4$

$+0.6 /-2.9 \mathrm{c}$

$+1.9+0.7 \mathrm{a}$

$+3.0+4.9$

$+1.3$

$-0.7$

$-0.8$

$-0.2$

Savoring training

(1)

$+6.7+3.7+3.6$

$+7.8+5.9$

$+15.2 /+14.8 \mathrm{C}$

$+4.0$

- Enlightenment + exercises
$+3.5+1.5 a$

$+0.3$

$+1.6 /+1.10$

$+29.0 b+8.3$

+3.4
$+2.0+3.5$

$+15.8+0.4$

$+8.5$

$+11.8 /+14.8 \mathrm{c}$

$0+3.5$

$+23.8 /+23.4 \mathrm{~b}$

$+3.9$

$+8.7 /+10.9 /+18.50$

$+3.6 /+3.0 /+10.10$

$+21.6 /+46.1 \mathrm{~b}$

\section{Number of studies and participants}

Number of studies

$-2$

630

Mean $\mathrm{n}$

79

Median $\mathrm{n}$; range

61; 3-192

39

39

3,539

91

43; 10-606

22

2,126

2,126
97

31

$3,562 d$

73; 23-631

1,664

\section{Results}

Mean change

$+5.6 \%$

$+6.0 \%$

$+7.7 \%$

$+4.3 \%$

$+4.7 \%$

$+3.9 \%$

$+1.8 \%$

$+4.0 \%$

tincluded

Numbers denote \% change on scale range and link to a finding page in World Database of Happiness. Use control+click to view the page. a: Not in in a column. b: Not included in calculation of mean/median because of a huge decline in happiness in the control group (treated as outliers). c: Average value of multiple measures/multiple comparison groups used in calculation of mean/median. $d$ : Numbers of participants and controls added up. 
TABLE 5 | 66 research findings from 13 studies on the effect of happiness trainings on happiness, only studies with control group and follow-up measurement effect sizes expressed in \% change on scale range.

Nature of happiness training

Method of investigation

Longitudinal before versus after training

\begin{tabular}{|c|c|c|c|c|}
\hline \multicolumn{2}{|c|}{ Change in treated group only } & \multicolumn{2}{|c|}{ Difference with change in control group } & \multirow[t]{2}{*}{ Follow-up time } \\
\hline Post-intervention & After follow-up & Post-intervention & After follow-up & \\
\hline+5.1 & +1.6 & +0.5 & -2.3 & 2 months \\
\hline$+3.6+5.1 \mathrm{a}$ & $+1.1+1.6 \mathrm{a}$ & $0+0.5 a$ & $0-2.3 a$ & 2 weeks \\
\hline+4.0 & +2.5 & +7.8 & +5.8 & 2 weeks \\
\hline+4.6 & +5.6 & -0.6 & -0.7 & 6 weeks \\
\hline$+3.6 a$ & $+1.1 \mathrm{a}$ & Oa & $\mathrm{Oa}$ & \\
\hline$+3.9 /+3.7 /+0.7 \mathrm{c}$ & $+4.2 /+3.7 /+1.2 \mathrm{c}$ & $+2.0 /+4.0 /+0.7 \mathrm{c}$ & $+0.4 /+1.1 /+1.1 \mathrm{C}$ & 2 weeks \\
\hline+2.4 & +7.0 & -0.4 & -2.9 & 6 months \\
\hline+1.5 & -0.7 & -0.8 & -0.2 & 2 months \\
\hline+1.3 & +0.3 & $+1.6 /+1.1$ & $-0.2 /-0.1 c$ & 1 month \\
\hline $\begin{array}{c}+19.5+10.0 \\
+6.7+3.7 \\
+15.2 /+14.8 \mathrm{c}\end{array}$ & $\begin{array}{l}+13.9+30.8+15.8 \\
+0.4+11.8 /+14.8 \mathrm{c}\end{array}$ & $\begin{array}{c}+29.0 \mathrm{~b}+8.3 \\
+3.4+2.0 \\
+23.8 /+23.4 \mathrm{~b}\end{array}$ & $\begin{array}{l}+27.9 b+10.4 \\
+10.4-10.8 \\
+23.4 /+25.4 b\end{array}$ & $\begin{array}{c}6 \text { months } / 1 \text { year } \\
1 \text { year/3 months } \\
4 \text { weeks }\end{array}$ \\
\hline
\end{tabular}

\section{Number of studies and participants}

\begin{tabular}{lccc} 
Number of studies & 13 & 13 & 11 \\
Participants (n) & 945 & 933 & $1,441 d$ \\
Mean n & 73 & 42 & 131 \\
Median n; range & $43 ; 10-306$ & & $79 ; 37-360$ \\
\hline Results & $+6.2 \%$ & $+7.3 \%$ & $+2.2 \%$ \\
Mean change & $+4.0 \%$ & $+3.0 \%$ & $+1.4 \%$ \\
Median change & & $+0.9 \%$ \\
\hline Percentages change in upper part of the table link to finding page in World Database of Happiness. Click linked percentages in upper part of the table to view the page. a: not included in calculation of mean/median \\
because study appears twice in column. b: Not included in calculation of mean/median because of huge decline in happiness in control group. c: Average effect of multiple measures in study used in calculation of \\
mean/median. d: Numbers of participants and controls added up.
\end{tabular}


TABLE 6 | Observed \% change in happiness by nature of happiness training: single or multiple nature training Table 4 with nature of happiness training indicated in colors.

Nature of happiness training Method of investigation

\begin{tabular}{|c|c|c|c|c|c|}
\hline & \multirow[t]{3}{*}{ Cross-sectional had training versus did not have training } & \multicolumn{4}{|c|}{ Longitudinal before versus after training } \\
\hline & & \multicolumn{2}{|c|}{ Change in treated group only } & \multicolumn{2}{|c|}{ Difference with change in control group } \\
\hline & & Post-intervention & After follow-up & Post-intervention & After follow-up \\
\hline \multicolumn{6}{|l|}{ Single kind of training } \\
\hline Best-possible-self exercise & & +5.1 & +1.6 & +0.5 & -2.3 \\
\hline Cognitive reframing & & $+13.7 \mathrm{a}$ & & $+12.5 \mathrm{a}$ & \\
\hline Enlightenment about happiness & & $+0.8+3.9$ & +3.2 & -2.9 & \\
\hline Goal-setting training & & $\begin{array}{c}+13.4 /+10.4 \mathrm{c}+2.9 \\
+3.6+5.1 \mathrm{a}-1.3\end{array}$ & $\begin{array}{c}+11.9 /+10.4 \mathrm{c} \\
+1.1+1.6 \mathrm{a}+3.6\end{array}$ & $\begin{array}{l}+8.6 /+9.5 c+0.5 a \\
\quad+4.300\end{array}$ & $-2.3 \mathrm{a} 0$ \\
\hline Laughter yoga & & +8.6 & & +8.6 & \\
\hline List and practice perceived ways to happiness & & $+0.6 /+7.2 \mathrm{c}$ & & & \\
\hline Practice retrospective sources of happiness & & +12.5 & & +12.5 & \\
\hline Live up to one's values & & $+1.0+4.0$ & +2.5 & $+5.0+7.8$ & +5.8 \\
\hline Meditation, mindfulness & +2.9 & $\begin{array}{c}+4.1+13.2+4.6 \\
+18.0+8.7\end{array}$ & $+5.0+5.6+17.6$ & $\begin{array}{c}+8.0 \\
-0.6+18.0+9.0\end{array}$ & $-0.7+16.7$ \\
\hline Novelty trying & & $+3.6 \mathrm{a}$ & $+1.1 \mathrm{a}$ & 0 & 0 \\
\hline Life-review exercise & & & & & $-0.9 /-4.6 / 0 c$ \\
\hline Mood awareness training & & $+3.9 /+3.7 /+0.7 \mathrm{c}$ & $\begin{array}{c}+4.2 /+3.7 /+1.2 \mathrm{c} \\
+18.9 /+23.2 \mathrm{c}\end{array}$ & $+2.0 /+4.0 /+0.7 \mathrm{c}$ & $+0.4 /+1.1 /+1.1 \mathrm{c}$ \\
\hline Positive thinking training & & $+2.4+13.7+4.0$ & +7.0 & $-0.4+12.5+5.0$ & -2.9 \\
\hline - Count blessings and curses & $\begin{array}{l}+6.50 \\
-3.3 \mathrm{a}\end{array}$ & $+0.7+2.4 a$ & +1.5 & & \\
\hline - Gratitude training & $+12.3-3.3+14.0 /+7.9 \mathrm{c}+5.4$ & $+1.5+2.4$ & -0.7 & -0.8 & -0.2 \\
\hline - Kindness training & $+13.3 /+6.0 \mathrm{c}$ & $+0.6 /-2.9 \mathrm{c}$ & & $+3.6 /-4.0 \mathrm{c}$ & \\
\hline - Recall of positive events & & $\begin{array}{c}+1.9+0.7 a+3.0 \\
+4.9\end{array}$ & $+3.5+1.5 \mathrm{a}$ & $+4.0+3.3$ & \\
\hline Savoring training & & +1.3 & +0.3 & $+1.6 /+1.1 \mathrm{c}$ & $-0.2 /-0.1 \mathrm{c}$ \\
\hline
\end{tabular}


TABLE 6 | Continued

Nature of happiness trainin

Cross-sectional had training versus did not have training

Method of investigation

Change in treated group only

Post-intervention

Difference with change in control group
After follow-up

$+19.5+10.0+6.7$

$+3.7+3.6+7.8$

$+5.9+15.2 /+14.80$

Post-intervention

$+29.0 \mathrm{~b}+8.3+3.4$
$+2.0+3.5$
$+23.8 /+23.4 \mathrm{~b}$

After follow-up

\section{Multiple kinds combined}

Training of multiple mental skills

- Enlightenment + exercises
$+4.0+7.8 /+19.6 \mathrm{c}$

$\begin{aligned} &+0.4 \\ &+8.5 \\ & 11.8 /+14.8 \mathrm{c}\end{aligned}$

$+11.8 /+14.80$
$+27.9 b+10.4$

$+10.4$

$+23.4 /+25.4 b$

$+3.9$

$+3.6 /+3.0 /+10.10$

$+21.6 /+46.1 b$

\section{Participants and results*}

\section{All studies}

Nr of studies

Mean change

$8(630)$

$+5.6 \%$

$39(3,539)$

$+6.0 \%$

$22(2,126)$

$+7.7 \%$

31 (3,562d)

$+4.7 \%$

$14(1,664 d)$

Single nature

$\mathrm{Nr}$ of studies (n)

$8(630)$

$29(2,549)$

$16(1,647)$

$+4.9 \%$

$+5.4 \%$

$24(2,594 d)$

$+4.4 \%$

$11(1,146 d)$

Multiple kinds

10 (990)

6 (479)

7 (968d)

$+1.4 \%$

$\mathrm{Nr}$ of studies (n)

0

$+9.0 \%$

$+13.8 \%$

$+5.7 \%$

3 (518d)

Table 4 with nature of happiness training indicated in colors. Numbers denote \% change on scale range and link to a finding page in World Database of Happiness. Click percentages change in upper part of the table to view the page. a: Not included in calculation of mean/median because study appears twice in column. b: Not included in calculation of mean/median because of huge decline in happiness in control group (treated as outliers). c: Average value of multiple measures/multiple comparison groups used in calculation of mean/median. d: Numbers of participants and controls added up ${ }^{*}$ For detailed information on mean/median/range of sample size (see Supplementary Material). 
TABLE 7 | Observed \% change of happiness by mode of the training: online, offline Table 4 with mode of happiness training indicated in colors.

Nature of happiness training Method of investigation

Cross-sectional had training versus did not have training Longitudinal before versus after training

\begin{tabular}{ccccc}
\hline \multicolumn{2}{c}{ Change in treated group only } & & \multicolumn{2}{c}{ Difference with change in control group } \\
\cline { 1 - 1 } Post-intervention & After follow-up & & Post-intervention $\quad$ After follow-up \\
\hline
\end{tabular}

Single kind of training

Best-possible-self exercise

Cognitive reframing

Enlightenment about happiness

Goal-setting training

Laughter yoga

List and practice perceived ways to happiness

Practice retrospective sources of happiness

Live up to one's values

Meditation, mindfulness

Novelty trying

Life-review exercise

Mood awareness training

Positive thinking training

- Count blessings and curses

- Gratitude training

- Kindness training

- Recall of positive events

\section{$+5.1$}

$+13.7 \mathrm{a}$

$+0.8+3.9$

$+13.4 /+10.4 \mathrm{C}+2.9$

$+3.6+5.1 \mathrm{a}-1.3$

$+8.6$

$+0.6 /+7.2 \mathrm{C}$

$+12.5$

$+1.0+4.0$

$+4.1+13.2+4.6$

$+18.0+8.7$

$+3.6 \mathrm{a}$

\section{$+3.9 /+3.7 /+0.70$}

$+2.4+13.7+4.0$

$+0.7+2.0 \mathrm{a}$

$+1.5+2.4$

$+0.6 /-2.9 \mathrm{c}$

$+1.9+0.7 \mathrm{a}+3.0$

$+4.9$

$+1.3$

$+1.6$$$
+3.2
$$

$+1.1+1.6 \mathrm{a}+3.6$

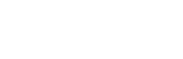

$\begin{aligned} & +2.5 \\ + & +5.0+5.6+17.6 \\ & +1.1 \mathrm{a}\end{aligned}$

$+4.2 /+3.7 /+1.2 \mathrm{C}$ $+18.9 /+23.2 \mathrm{C}$

$+7.0$

$+1.5$

$-0.7$

$+3.5+1.5 a$

$+0.3$

$+0.5$

+0.5
$+12.5 \mathrm{a}$

$-2.9$

$+8.6 /+9.5 \mathrm{c}+0.5 \mathrm{a}$

$+4.300$

$+8.6$

$+12.5$

$+5.0+7.8$

$+8.0$

$-0.6+18.0+9.0$

0

$+2.0 /+4.0 /+0.7 \mathrm{c}$

$-0.4+12.5+5.0$

$-0.8$

$+3.6 /-4.0 \mathrm{c}$

$+4.0+3.3$

$+1.6 /+1.1 \mathrm{c}$
$-2.3$

$-2.3 \mathrm{a} 0$

Savoring training
$+13.3 /+6.00$

-2.3
$-2.3 \mathrm{a} 0$


+5.8
$-0.7+16.7$
0
$-0.9 /-4.6 / 0$
$+0.4 /+1.1 /+1.1 \mathrm{c}$
-2.9
-0.2


TABLE 7 | Continued

Nature of happiness trainin

Cross-sectional had training versus did not have training

Method of investigation

Change in treated group only

Difference with change in control group
Post-intervention

After follow-up

$+19.5+10.0+6.7$

$+3.7+3.6+7.8$

$+5.9+15.2 /+14.80$

Post-intervention

$+29.0 \mathrm{~b}+8.3+3.4$
$+2.0+3.5$
$+23.8 /+23.4 \mathrm{~b}$

After follow-up

\section{Multiple kinds combined}

Training of multiple mental skills

- Enlightenment + exercises
$+4.0+7.8 /+19.6 \mathrm{c}$
$+27.9 b+10.4$

+10.4
-10.8

$+23.4 /+25.4 b$

$+3.9$

$8.7 /+10.9 /+18.5 c$

$+3.6 /+3.0 /+10.1 \mathrm{c}$

$+21.6 /+46.1 b$

\section{Participants and results*}

\begin{tabular}{|c|c|c|c|c|c|}
\hline \multicolumn{6}{|l|}{ All studies } \\
\hline Nr of studies (n) & $8(630)$ & $39(3,539)$ & $22(2,126)$ & $31(3,562 d)$ & $14(1,664 d)$ \\
\hline Mean change & $+5.6 \%$ & $+6.0 \%$ & $+7.7 \%$ & $+4.7 \%$ & $+1.8 \%$ \\
\hline \multicolumn{6}{|l|}{ Online e-training } \\
\hline Nr of studies (n) & 0 & $4(735)$ & $2(275)$ & 1 (349d) & 1 (349d) \\
\hline Mean change & & $+5.3 \%$ & $+12 \%$ & $+2.2 \%$ & $+0.9 \%$ \\
\hline \multicolumn{6}{|c|}{ Offline guided training } \\
\hline Nr of studies (n) & $8(630)$ & $35(2,804)$ & $20(1,851)$ & 30 (3213d) & $13(1,315 d)$ \\
\hline Mean change & $+5.6 \%$ & $+6.0 \%$ & $+7.3 \%$ & $+4.8 \%$ & $+1.9 \%$ \\
\hline
\end{tabular}

Table 4 with mode of happiness training indicated in colors. Numbers denote \% change on scale range and link to a finding page in World Database of Happiness. Use control+click to view the page. a: Not included in calculation of mean/median because study appears twice in a column. b: Not included in calculation of mean/median because of huge decline in happiness in control group (treated as outliers). c: Average value of multiple measures/multiple comparison groups used in calculation of mean/median. d: Numbers of participants and controls added up. ${ }^{*} F o r$ detailed information on mean/median/range of sample size) (see Supplementary Material). 
TABLE 8 | Observed change of happiness by context of the training Table 4 with context of happiness training indicated in colors.

Nature of happiness training Method of investigation

Cross-sectional had training versus did not have training Longitudinal before versus after training

\begin{tabular}{ccccc}
\multicolumn{2}{c}{ Change in treated group only } & & \multicolumn{2}{c}{ Difference with change in control group } \\
\cline { 1 - 1 } Post-intervention & After follow-up & & Post-intervention $\quad$ After follow-up \\
\hline
\end{tabular}

Single kind of training

Best-possible-self exercise

Cognitive reframing

Enlightenment about happiness

Goal-setting training

Laughter yoga

List and practice perceived ways to happiness

Practice retrospective sources of happiness

Live up to one's values

Meditation, mindfulness

Novelty trying

Life-review exercise

Mood awareness training

Positive thinking training

- Count blessings and curses

- Gratitude training

- Kindness training

- Recall of positive events

+5.1
$+13.7 \mathrm{a}$
$+0.8+3.9$
$+13.4 /+10.4 \mathrm{c}+2.9$
$+\mathbf{3 . 6}+5.1 \mathrm{a}-1.3$
$+\mathbf{8} .6$
$+0.6 / \mathbf{+ 7 . 2 c}$
+12.5
$+1.0+4.0$
$+\mathbf{4 . 1}+13.2+\mathbf{+ 4 . 6}$
$+18.0+\mathbf{8 . 7}$
$+3.6 \mathrm{a}$
$\mathbf{+ 3 . 9 / + 3 . 7 / + 0 . 7 c}$
$+2.4+13.7+4.0$
$+0.7+2.4 \mathrm{a}$
$+1.5+2.4$
$+0.6 /-2.9 \mathrm{c}$
$+1.9+0.7 \mathrm{a}+3.0$
+4.9
+1.3

+1.6
+3.2
$+11.9 /+10.4 \mathrm{c}$
$+1.1+1.6 \mathrm{a}+3.6$

+2.5
$+\mathbf{5 . 0}+\mathbf{5 . 6}+17.6$
$+1.1 \mathrm{a}$
$+\mathbf{4 . 2 / + 3 . 7 / + 1 . 2 c}$
$+\mathbf{1 8 . 9 / + 2 3 . 2 c}$
+7.0
+1.5
+0.7
$+3.5+1.5 \mathrm{a}$
+0.3

$\begin{array}{cc}+0.5 & -2.3 \\ +12.5 \mathrm{a} & \\ -2.9 & \\ +8.6 /+9.5 \mathrm{c}+0.5 \mathrm{a} & -2.3 \mathrm{a} 0 \\ +4.300 & \\ +8.6 & \\ +12.5 & \\ +5.0+7.8 & -0.7+16.7 \\ +8.0 & 0 \\ -0.6+18.0+9.0 & -0.9 /-4.6 / 0 \\ 0 & +0.4 /+1.1 /+1.1 \mathrm{c} \\ +2.0 /+4.0 /+0.7 \mathrm{c} & -2.9 \\ -0.4+12.5+5.0 & \\ & -0.2 \\ -0.8 & \\ +3.6 /-4.0 \mathrm{c} & \\ +4.0+3.3 & -0.2 /-0.1 \mathrm{c} \\ +1.6 /+1.1 \mathrm{c} & \end{array}$

Savoring training

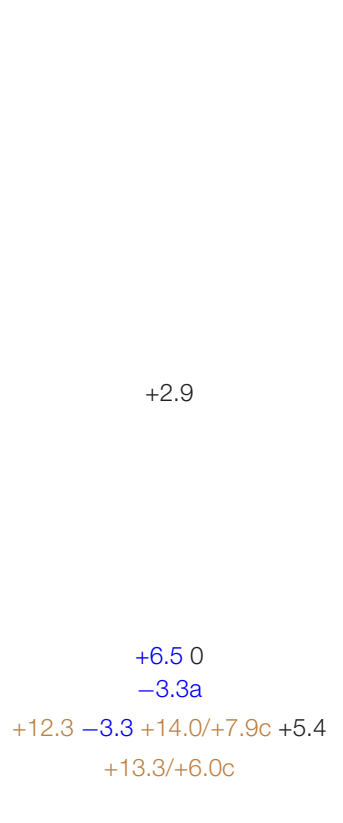


TABLE $8 \mid$ Continued

Nature of happiness training

Method of investigation

Cross-sectional had training versus did not have training

Longitudinal before versus after training

Change in treated group only Difference with change in control group

\begin{tabular}{|c|c|c|c|c|}
\hline & & \\
\hline & Post-intervention & After follow-up & Post-intervention & After follow-up \\
\hline \multicolumn{5}{|l|}{ Multiple kinds combined } \\
\hline Training of multiple mental skills & $\begin{array}{c}+19.5+\mathbf{1 0 . 0}+\mathbf{6 . 7} \\
\mathbf{+ 3 . 7}+3.6+\mathbf{7 . 8} \\
\mathbf{+} \mathbf{5 . 9}+15.2 /+14.80\end{array}$ & $\begin{array}{c}+13.9+\mathbf{+ 3 0 . 8}+\mathbf{+ 1 5 . 8} \\
+\mathbf{0 . 4} \\
+8.5 \\
+11.8 /+14.8 \mathrm{C}\end{array}$ & $\begin{array}{c}+29.0 \mathrm{~b}+\mathbf{8} .3+3.4 \\
+2.0+3.5 \\
+23.8 /+23.4 \mathrm{~b}\end{array}$ & $\begin{array}{c}+27.9 \mathrm{~b}+\mathbf{1 0 . 4} \\
+10.4 \\
-10.8 \\
+23.4 /+25.4 \mathrm{~b}\end{array}$ \\
\hline - Enlightenment + exercises & $+4.0+7.8 /+19.6 \mathrm{c}$ & & $\begin{array}{c}+3.9 \\
+8.7 /+10.9 /+18.5 \mathrm{c} \\
+3.6 /+3.0 /+10.1 \mathrm{c} \\
+21.6 /+46.1 \mathrm{~b}\end{array}$ & \\
\hline
\end{tabular}

\section{Participants and results}

\section{All studies}

udies (

$8(630)$

Care setting

Nr of studies ( $n$ )

Mean change

$+5.6 \%$

$39(3,539)$

$22(2,126)$

$+7.7 \%$

31 (3.562d)

$14(1,664 d)$

$3(127)$

$+11 \%$

$2(56)$

$2(107)$

$+4.7 \%$

$+1.8 \%$

Education setting

$\mathrm{Nr}$ of studies (n)

2 (322)

Mean change

$+1.6 \%$

$+12.6 \%$

$+14.4 \%$

2 (103d)

1 (152d)

Mean \% of change

$+1.6 \%$
+1.6

$15(1,623)$

7 (953)

$+4.8 \%$

$+3.6 \%$

$+8.5 \%$

$+16.7 \%$

ork setting

$\mathrm{Nr}$ of studies (n)

0

$+4.8$

$+3.6$

$14(2,011 d)$

$+5.0 \%$

4 (283d)

$+5.0$

Mean change

2 (64)

3 (163)

0

$+0.2$

Table 4 with context of happiness training indicated in colors. Numbers denote \% change on scale range and link to a finding page in World Database of Happiness. Click percentages change in upper part of the table to view the page. a: Not included in calculation of mean/median because study appears twice in a column. b: Not included in calculation of mean/median because of huge decline in happiness in control group (treated as outliers). c: Average value of multiple measures/multiple comparison groups used in calculation of mean/median. d: numbers of participants and controls added up. ${ }^{*}$ For detailed information on mean/median/range of sample size (see Supplementary Material). 
TABLE 9 | Observed change of happiness by mode of the training: participation voluntary, paid, obligatory Table 4 with mode of happiness training indicated in colors.

Nature of happiness training

Method of investigation

Cross-sectional had training versus did not have training

Longitudinal before versus after training

\begin{tabular}{ccccc}
\multicolumn{2}{c}{ Change in treated group only } & & \multicolumn{2}{c}{ Difference with change in control group } \\
\cline { 1 - 1 } Post-intervention & After follow-up & & Post-intervention $\quad$ After follow-up
\end{tabular}

Single kind of training

Best-possible-self exercise

Cognitive reframing

Enlightenment about happiness

Goal-setting training

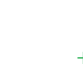

Laughter yoga

List and practice perceived ways to happiness

Practice retrospective sources of happiness

Live up to one's values

Meditation, mindfulness

Novelty trying

Life-review exercise

Mood awareness training

Positive thinking training

- Count blessings and curses

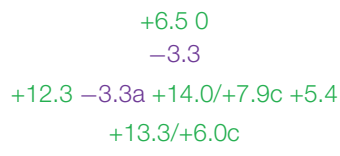

- Gratitude training

- Kindness training

Pt-intervention

After follow-up

- Recall of positive events

Savoring training

$\begin{array}{cc}+5.1 & +1.6 \\ +13.7 \mathrm{a} & +3.2 \\ +0.8+3.9 & +11.9 /+10.4 \mathrm{c} \\ +13.4 /+10.4 \mathrm{c}+2.9 & +1.1+1.6 \mathrm{a} \\ +3.6+5.1 \mathrm{a}-1.3 & +3.6\end{array}$

$+8.6$

$+0.6 /+7.2 \mathrm{C}$

$+12.5$

$+1.0+4.0$

$+4.1+13.2+4.6$

$+18.0+8.7$

$+3.6 \mathrm{a}$

$+3.9 /+3.7 /+0.7 \mathrm{c}$

$+2.4+13.7+4.0$

$+0.7+2.4 \mathrm{a}$

$+1.5+2.4$

$+0.6 /-2.9 \mathrm{c}$

$+1.9+0.7 \mathrm{a}+3.0$

$+4.9$
$+1.1+1.69 .0$
+3.6

$$
+2.5
$$

$+5.0+5.6+17.6$

$+1.1 \mathrm{a}$

$+4.2 /+3.7 /+1.20$

$+18.9 /+23.2 \mathrm{C}$

$+7.0$

$+1.5$

$-0.7$

$+3.5+1.5 a$

$+0.3$
$+0.5$

$+12.5 \mathrm{a}$

$-2.9$

$+8.6 /+9.5 \mathrm{c}+0.5 \mathrm{a}$

$+4.300$

$+8.6$

$+12.5$

$+5.0+7.8$

$+8.0$

$-0.6+18.0+9.0$

0

$+2.0 /+4.0 /+0.7 \mathrm{c}$

$-0.4+12.5+5.0$

$-0.8$

$+3.6 /-4.0 \mathrm{c}$

$+4.0+3.3$

$+1.6 /+1.1 \mathrm{C}$
$-2.3$

$-2.3 \mathrm{a} 0$

$+1.3$ 
TABLE 9 | Continued

Nature of happiness training Method of investigation

Cross-sectional had training versus did not have training

Longitudinal before versus after training

\begin{tabular}{|c|c|c|c|c|}
\hline & \multirow{2}{*}{\multicolumn{2}{|c|}{ Change in treated group only }} & & \\
\hline & & & \multicolumn{2}{|c|}{ Difference with change in control group } \\
\hline & Post-intervention & After follow-up & Post-intervention & After follow-up \\
\hline \multicolumn{5}{|l|}{ Multiple kinds combined } \\
\hline Training of multiple mental skills & $\begin{array}{c}+19.5+10.0+6.7 \\
+3.7+3.6+7.8 \\
+5.9+15.2 /+14.8 \mathrm{C}\end{array}$ & $\begin{array}{c}+13.9+30.8+15.8 \\
+0.4 \\
+8.5 \\
+11.8 /+14.8 \mathrm{c}\end{array}$ & $\begin{array}{c}+29.0 \mathrm{~b}+8.3+3.4 \\
+2.0+3.5 \\
+23.8 /+23.4 \mathrm{~b}\end{array}$ & $\begin{array}{c}+27.9 \mathrm{~b}+10.4 \\
+10.4 \\
-10.8 \\
+23.4 /+25.4 \mathrm{~b}\end{array}$ \\
\hline - Enlightenment + exercises & $+4.0+7.8 /+19.6 \mathrm{c}$ & & $\begin{array}{c}+3.9 \\
+8.7 /+10.9 /+18.5 \mathrm{c} \\
+3.6 /+3.0 /+10.1 \mathrm{c} \\
+21.6 /+46.1 \mathrm{~b}\end{array}$ & \\
\hline
\end{tabular}

\section{Participants and results*}

\begin{tabular}{|c|c|c|c|c|c|}
\hline \multicolumn{6}{|l|}{ All studies } \\
\hline Nr of studies (n) & $8(630)$ & $39(3,539)$ & $22(2,126)$ & $31(3,562 d)$ & $14(1,664 d)$ \\
\hline Mean change & $+5.6 \%$ & $+6.0 \%$ & $+7.7 \%$ & $+4.7 \%$ & $+1.8 \%$ \\
\hline \multicolumn{6}{|l|}{ Voluntary } \\
\hline Nr of studies (n) & $7(500)$ & $24(1,991)$ & $15(1,245)$ & $17(2,023 d$ & $10(1,440 d)$ \\
\hline Mean change & $+6.8 \%$ & $+6.4 \%$ & $+7.8 \%$ & $+4.0 \%$ & $+1.2 \%$ \\
\hline \multicolumn{6}{|l|}{ Paid/study credit } \\
\hline Nr of studies (n) & 0 & $5(122)$ & $2(49)$ & 5 (253d) & 2 (95d) \\
\hline Mean change & & $+4.4 \%$ & $+16.7 \%$ & $+6.1 \%$ & $+8.1 \%$ \\
\hline \multicolumn{6}{|l|}{ Mandatory } \\
\hline Nr of studies (n) & $1(130)$ & $10(1,426)$ & $5(832)$ & $9(1,286 d)$ & $2(129 d)$ \\
\hline Mean change & $-3.3 \%$ & $+5.7 \%$ & $+3.9 \%$ & $+5.2 \%$ & $-1.6 \%$ \\
\hline
\end{tabular}

Table 4 with mode of happiness training indicated in colors. Numbers denote \% change on scale range and link to a finding page in World Database of Happiness. Click percentages change in upper part of the table to view the page. a: Not included in calculation of mean because study appears twice in table. b: Not included in calculation of mean because of huge decline in happiness in control group (treated as outliers). c: Average value of multiple measures/multiple comparison groups used in calculation of mean. d: Numbers of participants and controls added up. *For detailed information on mean/median/range of sample size (see Supplementary Material). 
TABLE 10 | Size of changes in happiness among different users: children, university students, elderly Table $\mathbf{4}$ with users indicated in colors

Nature of happiness training

Method of investigation

Cross-sectional had training versus did not have training

Longitudinal before versus after training

\begin{tabular}{ccccc}
\hline \multicolumn{2}{c}{ Change in treated group only } & & \multicolumn{2}{c}{ Difference with change in control group } \\
\cline { 1 - 1 } Post-intervention $\quad$ After follow-up & & Post-intervention $\quad$ After follow-up
\end{tabular}

Single kind of training

Best-possible-self exercise

Cognitive reframing

Enlightenment about happiness

Goal-setting training

$+5$

$+13.7 \mathrm{a}$

$+0.8+3.9$

$+13.4 /+10.4 \mathrm{C}+2.9$

$+3.6+5.1 \mathrm{a}-1.3$

$+1.6$

Laughter yoga

List and practice perceived ways to happiness

Practice retrospective sources of happiness

Live up to one's values

Meditation, mindfulness

\section{Novelty trying}

Life-review exercise

Mood awareness training

Positive thinking training

- Count blessings and curses

- Gratitude training

- Kindness training

- Recall of positive events

Savoring training

$+8.6$

$+0.6 /+7.2 \mathrm{C}$

$+12.5$

$+1.0+4.0$

$+4.1+13.2+4.6$

$+18.0+8.7$

$+3.6 \mathrm{a}$

$+3.9 /+3.7 /+0.7 \mathrm{c}$

$-2.4+13.7+4.0$

$+0.7+2.4 \mathrm{a}$

$+1.5+2.4$

$+0.6 /-2.9 \mathrm{c}$

$+1.9+0.7 \mathrm{a}+3.0$

$+4.9$

$+1.3$
$+3.2$

$+11.9 /+10.4 \mathrm{c}$

$+1.1+1.6 \mathrm{a}$

$+3.6$

$+5.0+5.6+17.6$

$+1.1 a$

$+4.2 /+3.7 /+1.20$ $+18.9 /+23.2 \mathrm{c}$

$+7.0$

$+1.5$

$-0.7$

$+3.5+1.5 a$

$+0.3$

$-2.3$

+0.5
$+12.5 \mathrm{a}$

$-2.9$

$+8.6 /+9.5 \mathrm{c}+0.5 \mathrm{a}$

$+4.300$

$+8.6$

$+12.5$

$+5.0+7.8$

$+8.0$

$-0.6+18.0+9.0$

0

$+2.0 /+4.0 /+0.7 \mathrm{c}$

$-0.4+12.5+5.0$

$-0.7+16.7$

0

$-0.9 /-4.6 / 0$

$+0.4 /+1.1 /+1.1 \mathrm{c}$

$-2.9$

$-0.8$

$+3.6 /-4.0 \mathrm{c}$

$+4.0+3.3$

$+1.6 /+1.1 \mathrm{c}$

$-0.2 /-0.1 \mathrm{c}$ 
TABLE 10 | Continued

Nature of happiness training Method of investigation

Cross-sectional had training versus did not have training

Longitudinal before versus after training

Difference with change in control group

\begin{tabular}{|c|c|c|c|c|}
\hline & & \\
\hline & Post-intervention & After follow-up & Post-intervention & After follow-up \\
\hline \multicolumn{5}{|l|}{ Multiple kinds combined } \\
\hline Training of multiple mental skills & $\begin{array}{c}+19.5+10.0+6.7 \\
+3.7+3.6+7.8 \\
+5.9+15.2 /+14.8 \mathrm{c}\end{array}$ & $\begin{array}{c}+13.9+30.8+15.8 \\
+0.4 \\
+8.5 \\
+11.8 /+14.8 \mathrm{c}\end{array}$ & $\begin{array}{c}+29.0 \mathrm{~b}+8.3+3.4 \\
+2.0+3.5 \\
+23.8 /+23.4 \mathrm{~b}\end{array}$ & $\begin{array}{c}+27.9 b+10.4 \\
+10.4 \\
-10.8 \\
+23.4 /+25.4 b\end{array}$ \\
\hline - Enlightenment + exercises & $+4.0+7.8 /+19.6 \mathrm{c}$ & & $\begin{array}{c}+3.9 \\
+8.7 /+10.9 /+18.5 \mathrm{c} \\
+3.6 /+3.0 /+10.1 \mathrm{c} \\
+21.6 /+46.1 \mathrm{~b}\end{array}$ & \\
\hline
\end{tabular}

\section{Participants and results*}

All studies

\begin{tabular}{|c|c|c|c|c|c|}
\hline Nr of studies (n) & $8(630)$ & $39(3,539)$ & $22(2,126)$ & 31 (3,562d) & $14(1,664 d)$ \\
\hline Mean change & $+5.6 \%$ & $+6.0 \%$ & $+7.7 \%$ & $+4.7 \%$ & $+1.8 \%$ \\
\hline \multicolumn{6}{|l|}{ Children } \\
\hline Nr of studies (n) & $1(130)$ & $4(1,051)$ & $3(670)$ & $3(760 d)$ & 2 (129d) \\
\hline Mean change & $-3.3 \%$ & $+1.4 \%$ & $+2.6 \%$ & $-1.4 \%$ & $-1.5 \%$ \\
\hline \multicolumn{6}{|c|}{ University students } \\
\hline Nr of studies (n) & $2(297)$ & $19(1,370)$ & $8(840)$ & $20(2,251 d)$ & $8(1,100 d)$ \\
\hline Mean change & $+3.7 \%$ & $+5.0 \%$ & $+8.2 \%$ & $+4.8 \%$ & $+1.9 \%$ \\
\hline \multicolumn{6}{|l|}{ Elderly } \\
\hline Nr of studies (n) & 0 & $1(88)$ & $1(88)$ & 0 & 0 \\
\hline Mean change & & $+1.9 \%$ & $+3.5 \%$ & & \\
\hline
\end{tabular}

Table 4 with users indicated in colors. Numbers denote \% change on scale range and link to a finding page in World Database of Happiness. Click percentages change in upper part of the table to view the page. a: Not included in calculation of mean because study appears twice in table. b: Not included in calculation of mean because of huge decline in happiness in control group (treated as outliers). c: Average value of multiple measures/multiple comparison groups used in calculation of mean. d: Numbers of participants and controls added up. ${ }^{*}$ For detailed information on mean/median/range of sample size (see Supplementary Material). 
A WORLD DATABASE OF HAPPINESS

ARCHIVE OF RESEARCH FINDINGS ON SUBJECTIVE ENJOYMENT OF LIFE

Study Enrique et al. (2018): study ES 2015

Public: Young adults participating in a happiness training, Spain, 201?

Survey name: Unnamed study

Sample:

Respondents: $\quad \mathrm{N}=78$

Non Response:

Assessment: Questionnaire: paper

Correlate

Authors's label

Our Classification

Best Possible Self Intervention

HEALTH: PSYCHOLOGICAL TREATMENT 》 ... » Goal setting training

HEALTH: PSYCHOLOGICAL TREATMENT 》 ... » Voluntary, unsolicited

HAPPINESS: CAREER 》 ... 》 Actual changes in happiness

HEALTH: PSYCHOLOGICAL TREATMENT 》 ... 》 No particular setting, recruitment on interest

HEALTH: PSYCHOLOGICAL TREATMENT » ... »

HEALTH: PSYCHOLOGICAL TREATMENT 》 ... 》 One-time treatment

HEALTH: PSYCHOLOGICAL TREATMENT 》 ... » Mono sort

HEALTH: PSYCHOLOGICAL TREATMENT 》 ... 》 Best possible self exercise

Operationalization Participants were randomly assigned to:

1. TREATMENT. Best Possible Self program. Participants were asked to write about and imagine a future in which they have reached all their goals and developed all their potential in personal, professional, social and health domains. After a first session in the laborartory all the content in the participants' Book of Life was exported to the web platform so they could continue the practice exercise at home in the same format.

0. CONTROL. Daily activities programm. Participants were asked to think and write about everything they had done in the past $24 \mathrm{~h}$. They were told that it would help them to identify problematic areas in their lives and work on improving them.

In both groups participants were asked to continue the practice the exercise for 5 minutes a day during a period of 1 month.

B Observed Relation with Happiness



FIGURE 3 | Example of a findings page in the World Database of Happiness Correlational finding on Happiness and Best-Possible-Self exercise; Subject code: H16ad03a. 
comes at the cost of less control when determining the scope of the review and the questions it will address. (6) The new presentation may strike some readers as unfamiliar; the technique is not yet known under a particular name and not yet described in textbooks.

\section{Differences With Meta-Analysis}

Our research synthesis lacks three practices common in statistically more sophisticated meta-analysis. (1) Given the number and heterogeneity of the available findings, we did not assess statistical significance from the field taken as a whole. We restricted our findings to mentioning the percentage of significant results in each of the columns of Table $\mathbf{3}$ separately. For the same reason, we did not quantify the effects of moderator variables but presented these visually in Tables 6-10. (2) We did not correct for sample size because the large number of the online interventions would have out crowded the fewer face-toface trainings. (3) We did not take variance into account when calculating the average effect size using independent findings. We used an average "raw" percentage of the change in scale range instead. This is a consequence of the conceptual rigor in measuring the affective component of happiness. Almost half of the studies in the analysis used an affect balance scale, such as the PANAS (Watson et al., 1988), and reported the change in average positive and negative affect and the accompanying standard deviations separately, if at all. Yet, in isolation these scores do not fit our concept of hedonic level. You can experience much negative affect, but still be happy because you experience even more positive affect. Only the "Affect Balance Scores" are used in our analysis and, for that reason, we computed affect balance scores ourselves, subtracting reported average negative affect from average positive affect. This gave us group averages, but no individual scores and no information on the spread. This left us with effect sizes that can be described as "raw," in the sense that the dispersion around the mean is not taken into account. We sacrificed some of the statistical sophistication of common meta-analysis to report on as much data as possible that fits our definition of happiness. The advantage is that the effect size as a simple average change on the scale range used is intuitively meaningful (Borenstein et al., 2009).

Alongside these differences due to data availability, this research synthesis differs from common meta-analysis in the following ways: (1) The use of links to online finding pages provides the reader with far more detail than that which can be offered by standard reports of meta-analysis, while the standardized descriptions on the finding pages will also provide the analyst with a closer look at the research findings to be synthesized. (2) The presentation of research finding in tabular schemes, such as in Table 3, provides the reader with a visual overview from which the pattern of results can easily be recognized and from which differences in research methods used strike the eye. Moderators can also be visualized, using variant as of such tables in which differences in population or happiness measures are indicated using colors, as the reader will see in Tables 6-10. (3) As such, the method applied here tells the reader more about these heterogeneous and incomplete data than a common meta-analysis could have done with a reduction in numbers. (4) This research synthesis is conceptually more focused than the research syntheses of the effect of PPIs on "well-being" mentioned in section "Research Questions," and, as such, it generates new information.

\section{Publication Bias}

We study the distribution of effect sizes and perform a p-curve analysis to detect possible selective publishing and p-hacking of empirical studies that may have influenced our results.

\section{RESULTS}

Let us now revert to the research questions mentioned in section "Concepts of Happiness" and answer them one by one. Note that many of these results are tentative because of the limited availability of data.

\section{Do Happiness Training Techniques Add to Happiness?}

The answer to this question is presented in Table 3 on which + and - signs indicate whether or not the use of training had added to the average happiness of its users. In the table, we see mainly plusses, accounting for 149 of 179 or, roughly, $83 \%$. About half of these denote statistically significant effects as indicated in bold. The percentage of $83 \%$ is based on all findings and not just on independent studies. Taking a closer look and only counting independent studies in each of the columns in Table 3, we see in the bottom row that the proportion of studies with solely positive outcomes is highest (96\%) among studies that compared happiness before and after training and at follow-up, and lowest (56\%) among the cross-sectional studies, while the proportion of positive studies that compared the change in happiness to a control group is $87 \%$ post-intervention and $47 \%$ after followup. About half of the positive studies reported a statistically significant $(p<0.05)$ rise in happiness. So far, the available findings suggest that happiness training techniques typically work. A further first impression from Table $\mathbf{3}$ is that effects do not differ very much across different kinds of happiness training.

\section{How Strong Is the Effect of Following Happiness Training on Later Happiness?}

An answer to this question is found in Table 4, in which the sizes of the observed changes in happiness following happiness training are presented. Table 4 follows the same format as Table 3 but adds observed effect sizes to the + and - signs as much as the available data allow. We computed effect sizes as a percentage of the scale range (D\%sr) and calculated means and medians for each column of Table 4. In the table some studies appear twice because they fit two categories and some studies yielded more than one result (e.g., if more than one measure of happiness or more than one control group was used). Therefore, we calculated an average effect size for each individual study by averaging different happiness measures and/or control groups, 
and we did not count double studies twice. In this way, we ensured that only independent findings were used in calculating the overall mean and median effect sizes, as is recommended by Cheung (2019). We see a positive mean effect on happiness for all five indicators used, which is highest for absolute change in happiness at follow-up $(+7.7 \%)$ and lowest for difference with controls at follow-up $(+1.8 \%)$.

\section{Happiness of People Who Followed a Training Versus Non-users}

Looking at the columns in Table 4 individually, we first see the results of eight studies that compared people who had participated in happiness training with people who had not. The observed differences range between $-3.3 \%$ and $+14 \%$, with an average of $+5.6 \%$. As noted above, this method is likely to underestimate the effect of participating in happiness training since unhappy people may be more likely to take training. In this context, it is worth noting that seven of these eight studies were among self-selected participants.

\section{Happiness Before and After the Training}

The following two columns in Table 4 contain observed changes in happiness following participation in happiness training. The first of these columns consists of the change in happiness at the start of the training (pre-test) and right after (post-test). The second column consists of the change in happiness between pretest and later follow-up, typically some weeks or months later. The average gain in happiness is smaller right after the training $(6.0 \%)$ than at follow-up $(7.7 \%)$.

\section{Happiness of Treated and Controls}

The two right-hand columns in Table 4 consist of the findings of longitudinal studies that involved a control group and express the effect of following happiness training as the difference in change of happiness between users of such training techniques and non-users subjected to another form of intervention. Of the 36 studies included here, in just one $(2.5 \%)$ participants were randomly assigned to either a treatment or control condition, and in all other studies, non-probability samples were used ( $40 \%$ self-selected, $35 \%$ chunk, $8 \%$ purposive, and $1 \%$ accidental; a description of these sample types is found in Veenhoven (2019f). Control conditions were most often passive, just filling out happiness questionnaires (50\%). Less common were writing exercises (15\%), giving information about happiness (8\%), and some studies just compared different approaches to happiness, such as changing circumstances and activities.

A look at the bottom row of Table 4 shows that, on average, the treated gained more happiness than the controls, the difference at post-test being $4.7 \%$ and at follow-up $1.8 \%$. These gains are considerably smaller than the above-mentioned change in the treated. One of the reasons is the negative effects noted with a minus sign, where the gain in happiness was found to be higher in the control group than among the treated. A closer look at these 12 findings reveals that none of the negative effects were significant and the largest change $(-10.8 \%)$ was due to an unexplained increase in the happiness of the control group. The experimental group was slightly happier.

\section{Happiness Changes for Studies That Used Control Groups and Presented Data Before and After Intervention and at Follow-Up}

There is some heterogeneity in the studies included in these columns, since some report only a pre-post difference in happiness and other studies only the difference between pretest and follow-up. We present a selection from the findings of Tables 4, 5, with 66 research findings from 13 studies that (1) used a control group and (2) had measurements at pre-intervention, post-intervention, and follow-up. This selection gives a fairer insight into the observed differences at different measurements. The observed differences in the change in happiness between intervention and control groups ranged between $-0.8 \%$ and $+29 \%$. After the removal of two outliers with a strong negative trend in the happiness of the control group, the mean difference was $2.2 \%$ and the median $1.4 \%$. For these studies the effects of the intervention were higher without comparison with the control. The mean intervention effect was $6.2 \%$ post-intervention and $7.3 \%$ at follow-up.

\section{How Long-Lasting Is the Effect?}

We added a column on the length of the follow-up in Table 5, which varied between 2 weeks and one year. For follow-up periods of 2 weeks to 3 months, the observed change in happiness between pre-test and post-test is greater than the change between pre-test and follow-up, however, in two cases with a 6-month follow-up, hardly any difference was found. For the two cases of follow-up after a year, a larger change was found at follow-up than right after the training; this suggests a declining effect in the short run, but a sleeper effect in the long run.

\section{What Nature of Happiness Training Techniques Work Best?}

The data were not sufficient to answer this question because of a lack of data for most of the categories. The study on laughter yoga had promising results, but was the only one of its kind. Here are some tentative indications.

\section{Single Nature Training Techniques}

The greatest changes in happiness (>10\%) occurred after training that focused on either cognitive reframing, goal setting, laughter yoga, practicing retrospective sources of happiness, mood awareness training, or meditation. Most of the observed changes were smaller than 10\%. Greater gains in happiness compared to a control group were only found for meditation and mood awareness training.

\section{Multiple Nature Trainings}

The happiness trainings that used multiple techniques stand out as having high effects on happiness, with effect sizes that are almost double the average effect of single nature training techniques. See Table 6 in which interventions using a single technique are signaled in red and the multiple techniques in blue. Part of this effect may be due to the length of the training since the application of multiple techniques typically requires more sessions. The data do not allow a view of what mix of approaches 
works best since most of the courses used the same set of " 14 fundamentals" proposed by Fordyce (1977).

\section{What Modes of Trainings Work Best?}

Happiness training is given in different contexts and in different ways. Differences in effects on happiness appear to be small.

\section{Online Versus Offline}

From Table 7 we can see that no clear picture emerged. The online trainings can be recognized in the table by the color blue and the offline trainings by the color red. Online training yields smaller effects on happiness post-test, but larger effects at follow-up, if not compared to a control group. When differences with a control group are taken into account, the online effect is smaller than that for guided interventions, both post-test and at follow-up.

\section{Context of Happiness Training}

Happiness trainings are provided in the institutional context of care, in educational settings, and at work, but also sought independently by people interested in raising their happiness. The latter group is discussed in the following paragraph. The observed effects on happiness for these different contexts are presented in Table 8, with the color orange indicating a care setting, the color blue indicating an educational setting, and the color green indicating a work setting. The training techniques were least effective in the educational setting. Happiness in care settings yielded higher gains in happiness. Two of the three trainings in a work context had considerable effects, but none of these studies employed a control group.

\section{What Kinds of People Profit Most From Using a Happiness Training?}

Users of the happiness training techniques reviewed in this paper have much in common, namely that most live in an individualized modern society and most have received higher education.

\section{Initially Low on Trained Characteristics}

Training is likely to be more effective among people in need of improvement in their trained skills. This expectation was confirmed in three studies. Chan (2010) compared the effect of gratitude training on people who were high or low on gratitude. Not unexpectedly, the people low on gratitude experienced a significantly more positive affect after the intervention. The e-intervention by Bakker et al. (2020) yielded a greater gain in happiness among the initially least happy users. The level of happiness of the self-selected participants in this study was slightly lower than in the general population. Likewise, Coote and MacLeod (2012) report the largest change in happiness at follow-up in a depressed group at baseline.

\section{Self-Selected}

Happiness training techniques are likely to be more effective among people who participate voluntarily, typically because they are motivated to improve their happiness and hold positive opinions about psychological treatment. Self-selection is known to be a factor in effectiveness of psychotherapy (Le et al., 2014). We checked this expectation and show the results in Table 9, which is a variant of Table 4, but with changes in happiness among self-selected users indicated in green, changes among mandatory participants indicated in purple, and changes among paid participants indicated in blue. Indeed, happiness gains tend to be higher among voluntary participants than mandatory participants. Paid participation in the form of money or study credits also yielded favorable results, perhaps because this also can be considered a form of voluntary participation.

\section{Age Differences: Children and University Students}

Happiness training is likely to be more effective among users who are able to reflect on themselves and their lives and for that reason we expected greater effects among university students than among children in primary and secondary education. This expectation is confirmed by the average scores in the bottom rows of Table 10. There was only one study among elderly participants, with modest positive results. The studies with children are visible in orange, with the university students in blue and with the elderly in green.

\section{Publication Bias?}

This review is based on published reports of effect studies and we must be aware of the possibility of publication bias. Unwelcome research results are often not submitted for publication by investigators or are rejected by journals. The first thing to note in this context is that a substantial share of the findings in Table 3 are negative $(13 \%)$ or zero (4\%) and that only $40 \%$ of the findings are significant and positive. A more formal check for this "filedrawer" problem and "p-hacking" as the "sole explanation of the evidential value of a set of significant findings" is a p-curve analysis (Simonsohn et al., 2014). We performed such an analysis including 15 studies, which reported a statistically significant increase in happiness after completing a happiness training. In a p-curve analysis, only one finding from a particular study can be included. We used the follow-up measure if available and the post-treatment measure if a follow-up measure was lacking. If more than one happiness measure was reported, we chose overall happiness rather than affect balance or mixed measures. We excluded cross-sectional findings and treatment versus control comparisons because a reported difference does not necessarily mean that happiness increased or decreased within the treatment group. The statistically significant results of some studies had to be excluded from the analysis because the statistics were poorly reported. The $\mathrm{p}$-curve analysis supports the presence of evidential value $(p<0.01$ for binomial test and $Z=-9.91, p<0.001$ for continuous test). Thus, selective reporting and/or p-hacking is unlikely to be the sole explanation for the significant findings included in our research synthesis.

\section{DISCUSSION}

What does this all mean for individuals and organizations looking for possibilities to boost happiness? 


\section{Main Finding: Happiness Trainings Boost Happiness}

Together, our findings suggest that happiness training techniques usually have positive effects on happiness and that negative effects are uncommon. This appeared to be the case for different interventions, delivered in different ways, for different groups, in different settings. This can be seen as a confirmation of a basic tenet in positive psychology - that it is worthwhile not only to solve one's problems, but also to enhance strengths and life skills (Seligman and Csikszentmihalyi, 2000; Boniwell, 2012).

\section{How Strong Is the Effect?}

We estimate the real average gain at follow-up to be somewhere around 5\%. From the bottom rows of Tables 4, 5 we can see that gains in happiness following happiness training are smaller when the change in happiness in a control group is subtracted, the difference for all studies being $4.7 \%$ for gains at post-intervention and $1.8 \%$ at follow-up. This reduction is commonly seen as a placebo effect. But is it in this case?

Inevitably, awareness of their happiness has been raised among the controls, as they answered questions on their happiness during a pre-test, post-test, and follow-up. In the waiting list condition, the prospect of participation in happiness training will also have sharpened their awareness of their personal happiness. Below, we will see that raising awareness of how happy one feels tends to raise the level of one's happiness, probably by its effects on the choices people make. Another thing to keep in mind is that the control groups differed considerably, which makes it difficult to interpret the differences with the experimental group (e.g., Dickens, 2017). Some only used passive controls that filled in a survey while others received an alternative treatment, which is likely to have produced a gain in happiness by itself (e.g., in the case of doing a writing exercise). Expressive writing can be healing (Pennebaker, 2018). Together, this all means that we should not just take the lowest value at the bottom rows of Tables 4, 5 to be the best estimate.

\section{Should a 5\% Gain in Happiness Be Considered Modest or Much?}

At first sight, a 5\% gain in happiness does not impress as a great effect of following a happiness training. Yet, we are dealing with a small gain of a big thing - satisfaction with one's life as a whole which in its turn brings several other desirable things in its trail, such as a longer lifetime (Veenhoven, 2015). Next to this absolute impact on happiness of following happiness training, we can also look at its impact relative to other determinants.

\section{Financial Equivalence}

Analyses on the German Socio-Economic Panel Study (GSOEP) have yielded estimates of the effect of change in household income on happiness. Using this dataset over the years 2003 through 2008, Pfeifer (2013) reports that "Household income significantly increases life satisfaction on average by about 0.085 points per 1,000 Euros additional monthly net income in the pooled regressions and by about 0.039 points in the fixed effects regressions." Departing from the latter most conservative estimate of a 0.04 point rise on the 0-10 happiness scale per 1000 Euro additional monthly income, the 5\% (0.05) gain in happiness following a happiness training course equals a gain in monthly income of about $€ 1.250$, which was about one-third of the average household income in Germany at that time. Such income equivalences will differ across places, persons, and happiness variants, but are still considerable and comparable to amounts observed in studies on monetary compensation for losses in happiness, such as due to airport noise (Van Praag and Baarsma, 2005).

\section{Similarity to Impact of Life Events}

Bakker et al. (2020) compared the change in happiness following the use of their online Happiness Indicator with effects of real life events on happiness as observed in longitudinal studies. Getting married appears to raise happiness by some $5 \%$ and a gain of only $0.5 \%$ in happiness was found for winning a lottery. Becoming unemployed reduces happiness by $8 \%$ and the loss of one's spouse by $12 \%$. From this perspective, the average $5 \%$ gain in happiness after having followed a happiness training course is impressive.

\section{What Works for Whom?}

We can only provide provisional answers to the questions about what kind(s) of training techniques work best and what types of people profit most from joining a happiness training course. Multiple interventions seem to outperform single interventions, which is in line with the meta-analysis by Hendriks et al. (2019), which reports a higher effect size than the meta-analysis for single interventions that we mentioned above. The fact that multiple interventions seem to work better may have to do with the variety that is needed to prevent hedonic adaptation after improvements (Sheldon and Lyubomirsky, 2012). Another reason may be that happiness can be thought of as a signal that people are doing well in life and that a lot of different skills are necessary to achieve this (Veenhoven, 2008).

Other results are more tentative. As expected, happiness training seemed more effective for adults, probably because of their ability to reflect on their lives. Training also worked better for people participating voluntarily. Pursuing happiness requires effort and that may be in short supply if you are forced to participate, for example, in a classroom setting (Sheldon and Lyubomirsky, 2019). Personal involvement may also explain why offline training worked better directly after the training, whereas online training yielded superior results at follow-up. Online training requires more internal motivation to complete, and this may increase the likelihood that people keep expanding their life skills after training has ended.

We should stress that these conclusions are tentative because the different aspects of what works for whom are clearly related in our set of studies. An example is that mandatory participation was often in the classroom setting and the worse results may just as well have to do with the (school) age of the participants or with the lack of free choice. A weakness of our research synthesis is that it is less suited to answer the more specific questions. We lacked statistical possibilities to untangle the influence of covariates.

There is, however, an advantage of bringing together all the research of happiness training techniques We discovered that 
efforts to merely raise happiness awareness were quite effective in raising happiness. This discovery is not yet sufficiently recognized by the field (Ludwigs et al., 2018). Therefore, we discuss this in a separate paragraph.

\section{Raising Awareness Works}

Most happiness training techniques aim to foster specific life skills, such as planning for the future or seeing positive things in life. The idea behind these interventions is that such aptitudes help to make one's life more satisfying. Evident limitations of this approach are that (1) training is functional only when skills can be meaningfully improved, and (2) that the functionality of particular skills may not fit the context of the person to be trained (e.g., planning for the future may have more functionality for young adults than for fourth age pensioners).

A minority of the interventions listed in Table 2 are aimed at raising awareness of how one lives and feels. Techniques used for this purpose are mood tracking, activity diaries, and life reviews. The idea behind these approaches is that such awareness will help you to find a way of life that feels good for you, as explained in more detail in Bakker et al. (2020). The limitations are that (1) awareness of positive and negative moods does not automatically enable people to change their lives in a way that enables them to be happier more often, (2) the effect of greater awareness can backfire on happiness when change is not possible, as it only makes people more keenly aware about their misery, and 3) these interventions report high levels of attrition.

From Table 3 we observe that both of the kinds of interventions discussed above yield positive effects on happiness, and from Table 4 we can see that the resulting changes in happiness following raised awareness are in the range between 1 and $23 \%$, which is higher on average than the effects yielded by the other single-method training techniques listed in Table 4. If raising happiness awareness enables people to change their lives in ways so that they become happier, then this has important implications for all the studies used in the research synthesis. All training, and even all filling out surveys in a control group, will raise awareness of how happy one feels. Raising awareness may partly explain the effectiveness of other life skills training.

The fact that mood awareness is effective highlights that pursuing happiness has two sides to it. The first is the effort to milk as much positive affect out of interaction with the world, for example by increasing gratitude, savoring, or avoiding selfdefeating lines of reasoning. Positive psychology often aims to create positive feelings along this line of reasoning. Raising mood awareness starts out with the opposite. You can try to do more of what feels good and avoid what feels bad. After all, our emotions can also be thought of as a signal that we are

\section{REFERENCES}

Action for happiness (n.d.). The Action for Happiness Course. Available online at: https://www.actionforhappiness.org/the-action-for-happiness-course (accessed June 23, 2020). doing well or bad. Negative affect signals that we should try to change something, while positive affect signals that we are doing fine and that we can explore the world (Frijda, 1986). Pursuing happiness is just a much about listening to the messages of our emotions and moods and changing our behavior and the circumstances of life accordingly as it is about creating more pleasant feelings in our current interaction with the world (Bergsma, 2000, 2020).

\section{Similarity With Other Overview Studies on the Effect of PPIs}

If we compare our results with earlier work on the effects of PPIs on the wider subjective well-being, we can conclude that our results are in line with these. Sin and Lyubomirsky (2009), Bolier et al. (2013), and White et al. (2019) describe similar modest and positive effects, which suggests that the heterogeneous subjective well-being measures used in these meta-analyses have not changed the average effect.

\section{CONCLUSION}

Participation in a happiness training course is typically followed by a rise in happiness, in particular participation in training that focuses on multiple mental skills and/or happiness awareness techniques and by people voluntary looking to achieve greater happiness. Hence offering happiness training to employees is a good option for organizations that want to boost their productivity through employee happiness.

\section{AUTHOR CONTRIBUTIONS}

All authors listed have made a substantial, direct and intellectual contribution to the work, and approved it for publication.

\section{ACKNOWLEDGMENTS}

We would like to thank the two reviewers and editor Llewellyn van Zyl for significantly improving the manuscript, and Miranda Aldham-Breary for improving the English.

\section{SUPPLEMENTARY MATERIAL}

The Supplementary Material for this article can be found online at: https://www.frontiersin.org/articles/10.3389/fpsyg. 2020.01953/full\#supplementary-material

Al-Hussaini, A. A., Antony, S. X., and Dorvlo, A. S. (2001). Vipassana meditation: a naturalistic, preliminary observation in muscat. Med. Sci. 3, 87-92.

Bakker, A. B., Burger, M., Oerlemans, W., van Haren, P., and Veenhoven, R. (2020). Raise of happiness following raised awareness of how happy one feels: a 
follow-up of repeated users of the happiness indicator website. Intern. J. Appl. Posit. Psychol. doi: 10.1007/s41042-020-00032-w

Bentham, J. (1789). An Introduction to the Principles of Morals and Legislation. London: Batoche Books.

Bergsma, A. (2000). Transhumanism and the wisdom of old genes. Neurotechnology as source of future happiness? J. Happ. Stud. 1, 401-417. doi: 10.1023/a:1010016532529

Bergsma, A. (2008). Do self-help books help? J. Happ. Stud. 9, 341-360. doi: 10.1007/s10902-006-9041-2

Bergsma, A. (2020). "Paradoxen bij het streven naar werkgeluk," in Handboek Werkgeluk, eds A. Bergsma, E. Hamburger, and E. Klappe (Amsterdam: Boom), 317-328.

Bergsma, A., and Veenhoven, R. (2020). "Het rendement van geluk; het belang van levensgeluk voor werkprestaties," in Handboek Werkgeluk, eds A. Bergsma, E. Hamburger, and E. Klappe (Amsterdam: Boom), 130-144.

Boerefijn, J., and Bergsma, A. (2011). Geluksles verbetert schoolprestaties (Happiness training adds to school performance). Tijdschrift Voor Orthopedagogiek 50, 110-121.

Bolier, L., Haverman, M., Westerhof, G. J., Riper, H., Smit, F., and Bohlmeijer, E. (2013). Positive psychology interventions: a meta-analysis of randomized controlled studies. BMC Public Health 13:119. doi: 10.1186/1471-245813-119

Boniwell, I. (2012). Positive Psychology in a Nutshell: The Science of Happiness. New York, NY: McGraw Hill.

Borenstein, M., Hedges, L. V., Julian, P. T., Higgins, J. P. T., and Rothstein, H. R. (2009). Introduction to Meta-Analysis. Hoboken, NJ: Wiley.

Brickman, P., and Campbell, D. T. (1971). "Hedonic relativism and planning the good society," in Proceedings of the Adaptation Level Theory: A Symposium, ed. M. H. Appley (New York: Academic Press), 287-302.

Brown, K. W., Kasser, T., and Ryan, R. M. (2009). When what one has is enough: mindfulness, financial desire discrepancy, and subjective well-being. J. Res. Person. 43, 727-736. doi: 10.1016/j.jp. 2009.07.002

Brown, N. J., and Rohrer, J. M. (2019). Easy as (happiness) pie? A critical evaluation of a popular model of the determinants of well-being. J. Happ. Stud. 20, 1-17.

Bryant, F. B., King, S. P., and Smart, C. M. (2005). Using the past to enhance the present: boosting happiness through positive reminiscence. J. Happ. Stud. 6, 227-260. doi: 10.1007/s10902-005-3889-4

Buettner, D., Nelson, T., and Veenhoven, R. (2020). Ways to greater happiness: a delphi study. J. Happ. Stud. doi: 10.1007/s10902-019-00 199-3

Carter, P. J., Hore, B., and McGarrigle, L. (2012). Happy thoughts: enhancing wellbeing in the classroom with a positive events diary. J. Posit. Psychol. 13, 110-121. doi: $10.1080 / 17439760.2016 .1245770$

Chan, D. W. (2010). Gratitude, gratitude intervention and subjective well-being among chinese school teachers in Hong Kong. Educ. Psychol. 30, 139-153. doi: 10.1080/01443410903493934

Cheung, M. W. L. (2019). A guide to conducting a meta-analysis with nonindependent effect sizes. Neuropsychol. Rev. 29, 387-396. doi: 10.1007/s11065019-09415-6

Choi, Y. W. (2011). Pathways to Happiness. Doctoral dissertation, Radboud University, Nijmegen.

College of Well-being (n.d.). Happiness Training Plan. Available online at: http://collegeofwellbeing.com/happiness-training-plan/ (accessed June 23, 2020).

Coote, H. M. J., and MacLeod, A. K. (2012). A self-help, positive goal-focused intervention to increase well-being in people with depression. Clin. Psychol. Psychother. 19, 305-315. doi: 10.1002/cpp.1797

Della Porta, M. D. (2013). Enhancing the Effects of Happiness-Boosting Activities: The Role of Autonomy Support in an Experimental Longitudinal Intervention. $\mathrm{Ph}$. D. thesis, UC Riverside Electronic, California.

Delle Fave, A., Brdar, I., Freire, T., Vella-Brodrick, D., and Wissing, M. P. (2011). The eudaimonic and hedonic components of happiness: Qualitative and quantitative findings. Soc. Indic. Res. 100, 185-207. doi: 10.1007/s11205-010$9632-5$

Dickens, L. R. (2017). Using gratitude to promote positive change: a series of meta-analyses investigating the effectiveness of gratitude interventions. Basic Appl. Soc. Psychol. 39, 193-208. doi: 10.1080/01973533.2017.132 3638
Diener, E., Emmons, R. A., Larsen, R. J., and Griffin, S. (1985). The satisfaction with life scale. J. Pers. Assess. 49, 71-75.

Diener, E., Lucas, R. E., Smith, H. L., and Suh, E. M. (1999). Subjective well-being: three decades of progress. Psychol. Bull. 125, 276-230.

Diener, E., Oishi, S., and Lucas, R. E. (2015). National accounts of subjective well-being. Am. Psychol. 70:234.

Diener, E., Sapyta, J. J., and Suh, E. (1998). Subjective well-being is essential to well-being. Psychol. Inq. 9, 33-37.

Donaldson, S. I., Lee, J. Y., and Donaldson, S. I. (2019a). Evaluating positive psychology interventions at work: a systematic review and meta-analysis. Intern. J. Appl. Posit. Psychol. 4, 113-134.

Donaldson, S. I., Lee, J. Y., and Donaldson, S. I. (2019b). "The effectiveness of positive psychology interventions in the workplace: a theory-driven evaluation approach," in Theoretical Approaches to Multi-Cultural Positive Psychological Interventions, eds L. E. Van Zyl and S. Rothmann (Cham: Springer), 115-159. doi: 10.1007/978-3-030-20583-6_6

Elliott, A., and Lemert, C. (2009). The New Individualism: The Emotional Costs of Globalization. London: Routledge.

Emmons, R. A., and McCullough, M. E. (2003). Counting blessings versus burdens: an experimental investigation of gratitude and subjective well-being in daily life. J. Pers. Soc. Psychol. 84, 377-389. doi: 10.1037/0022-3514.84.2.377

Enrique, A., Bretón-López, J., and Molinari, G. (2018). Efficacy of An adaptation of the best possible self intervention implemented through positive technology: a randomized control trial. Appl. Res. Qual. Life 13, 671-689. doi: 10.1007/ s11482-017-9552-5

Eryilmaz, A. (2015). Positive psychology in the class: the effectiveness of a teaching method based on subjective well-being and engagement increasing activities. Intern. J. Instruct. 8, 17-32. doi: 10.12973/iji.2015.822a

Feicht, T., Wittmann, M., Jose, G., Mock, A., Von Hirschhausen, E., and Esch, T. (2013). Evaluation of a seven-week web-based happiness training to improve psychological well-being, reduce stress, and enhance mindfulness and flourishing: a randomized controlled occupational health study. Evid. Based Complement. Altern. Med. 2013, 1-14. doi: 10.1155/2013/67 6953

Fernros, L., Furhoff, A., and Wändell, P. E. (2008). Improving quality of life using compound mind-body therapies: evaluation of a course intervention with body movement and breath therapy, guided imagery, chakra experiencing and mindfulness meditation. Qual. Life Res. 17, 367-376. doi: 10.1007/s11136-0089321-x

Ford, B. Q., Dmitrieva, J. O., Heller, D., Chentsova-Dutton, Y., Grossmann, I., Tamir, M., et al. (2015). Culture shapes whether the pursuit of happiness predicts higher or lower well-being. J. Exper. Psychol. Gen. 144:1053. doi: $10.1037 / x g e 0000108$

Ford, B. Q., and Mauss, I. B. (2014). "The paradoxical effects of pursuing positive emotion: when and why wanting to feel happy backfires," in Positive Emotion: Integrating the Light Sides and Dark Sides, eds J. Gruber and J. Moskowitz (Oxford: Oxford University Press), 363-381. doi: 10.1093/acprof: oso/9780199926725.003.0020

Ford, B. Q., Shallcross, A. J., Mauss, I. B., Floerke, V. A., and Gruber, J. (2014). Desperately seeking happiness: valuing happiness is associated with symptoms and diagnosis of depression. J. Soc. Clin. Psychol. 33, 890-905. doi: 10.1521/ jscp.2014.33.10.890

Fordyce, M. W. (1977). Development of a program to increase personal happiness. J. Counsell. Psychol. 24, 511-521. doi: 10.1037/0022-0167.24.6.511

Fordyce, M. W. (1983). A program to increase happiness: further studies. J. Counsell. Psychol. 30, 483-498. doi: 10.1037/0022-0167.30.4.483

Franke, R. H., and Kaul, J. D. (1978). The hawthorne experiments: first statistical interpretation. Am. Sociol. Rev. 43, 623-643.

Freire, T. (2013). "Positive psychology approaches," in The Wiley-Blackwell Handbook of the Psychology of Coaching and Mentoring, eds J. Passmore, D. Peterson, and T. Freire (West Sussex: Wiley-Blackwell), $426-442$.

Frijda, N. H. (1986). The Emotions. Cambridge: Cambridge University Press.

Froh, J. J., Emmons, R. A., and Sefick, W. J. (2008). Counting blessing in early adolescents: an experimental study of gratitude and subjective well-being. J. Sch. Psychol. 46, 213-233. doi: 10.1016/j.jsp.2007.03.005

Froh, J. J., Kashdan, T. B., and Ozimkowski, K. M. (2009). Who benefits the most from a gratitude intervention in children and adolescents? examining 
positive affect as a moderator. J. Posit. Psychol. 4, 408-422. doi: 10.1080/ 17439760902992464

Gaucher, R., and Veenhoven, R. (2020). The happy productive worker thesis refined: productivity depends more on life-satisfaction than on job-satisfaction. Paper Presented at the Erasmus Happiness Economics Research Organization, Rotterdam.

Goldstein, E. D. (2007). Sacred moments: implications on well-being and stress. J. Clin. Psychol. 63, 1001-1019. doi: 10.1002/jclp.20402

Goldwurm, G. F., Baruffi, M., and Colombo, E. (2003). Improving subjective wellbeing for the promotion of health: the Milan project. Homeostasis 42, $157-162$.

Goldwurm, G. F., Baruffi, M., and Colombo, F. (2006). "Subjective well-being training to increase happiness," in Dimensions of Well-Being, ed. A. DelleFave (Milano: Franco Angeli), 441-454.

Grant, A. M., and Spence, G. B. (2010). "Using coaching and positive psychology to promote a flourishing workforce: a model of goal-striving and mental health," in Oxford Handbook of Positive Psychology and Work, eds P. A. Linley, S. Harrington, and N. Page (Oxford: Oxford University Press), $175-188$.

Guven, C. (2008). Are happier people better citizens? Paper Presented at the School Working Papers, Economic Series, SWP 2009/4, (also SOEP Paper no. 199, DIW, 2009), Melbourne.

Haeck, C., Parks, A. C., and Schueller, S. M. (2016). Impact of psycho-educational content delivered online to a positive psychology aware community. J. Posit. Psychol. 11, 270-275. doi: 10.1080/17439760.2015.1048819

Haight, B. K. (1988). The therapeutic role of a structured life review process in homebound elderly subjects. J. Gerontol. 43, 40-44.

Held, B. S. (2002). The tyranny of the positive attitude in america: observation and speculation. J. Clin. Psychol. 58, 965-992.

Held, B. S. (2018). Positive psychology's a priori problem. J. Hum. Psychol. 58, 313-342. doi: 10.1177/0022167817739409

Hendriks, T., Schotanus-Dijkstra, M., Hassankhan, A., de Jong, J., and Bohlmeijer, E. (2019). The efficacy of multi-component positive psychology interventions: a systematic review and meta-analysis of randomized controlled trials. J. Happ. Stud. 20, 1-34.

Hurley, D. B., and Kwon, P. (2012). Results of a study to increase savouring the moment: differential impact on positive and negative outcomes. J. Happ. Stud. 13, 579-588. doi: 10.1007/s10902-011-9280-8

Indian School for Business (n.d.). A Life of Happiness and Fulfillment. Available online at: https://www.classcentral.com/course/happiness-2860 (accessed June 23, 2020).

Ivandic, I., Freeman, A., Birner, U., Nowak, D., and Sabariego, C. (2017). A systematic review of brief mental health and well-being interventions in organizational settings. Scand. J. Work Environ. Health 43, 99-108. doi: 10. 5271/sjweh.3616

Kehr, H. M. (2003). Goal conflicts, attainment of new goals, and well-being among managers. J. Occup. Health Psychol. 8, 195-208. doi: 10.1037/1076-8998.8. 3.195

Kerr, S. L., O’Donovan, A., and Pepping, C. A. (2015). Can gratitude and kindness interventions enhance well-being? J. Happ. Stud. 16, 17-36. doi: 10.1007/ s10902-013-9492-1

Killen, A., and MacasKill, A. (2015). Using a gratitude intervention to enhance well-being in older adults. J. Happ. Stud. 16, 947-964. doi: 10.1007/s10902014-9542-3

Krejtz, I., Michnicka, A., and Nezlek, J. B. (2016). Counting One's blessings can reduce the impact of daily stress. J. Happ. Stud. 17, 25-39. doi: 10.1007/s10902014-9578-4

Lambert, L. T., Joshanloo, M., and Passmore, H. A. (2019). A positive psychology intervention program in a culturally-diverse university: boosting happiness and reducing fear. J. Happ. Stud. 20, 1141-1162. doi: 10.1007/s10902-018-9993-z

Layous, K., Chancellor, J., Kurtz, J. L., and Lyubomirsky, S. (2018). Reframing the ordinary: imaging time as scarce increases in wellbeing. J. Posit. Psychol. 13, 301-308. doi: 10.1080/17439760.2017.1279210

Le, Q. A., Doctor, J. N., Zoellner, L. A., and Feeny, N. C. (2014). Cost-effectiveness of prolonged exposure therapy versus pharmacotherapy and treatment choice in posttraumatic stress disorder (the optimizing PTSD treatment trial): a doubly randomized preference trial. J. Clin. Psychiatry 75, 222-230. doi: 10.4088/jcp. $13 \mathrm{~m} 08719$

Leeuw, S. (2012). The Happy Factor. Lessons in Happiness: Can They Affect WellBeing, Classroom Climate and Academic Achievement? Master thesis, Leiden University, Leiden.

Lichter, S., Haye, K., and Kammann, R. (1980). Increasing happiness through cognitive retraining. New Zeal. Psychol. 9, 57-64.

Ludwigs, K., Burger, M., and Lucas, R. E. (2018). How does more attention to subjective well-being affect subjective well-being? Appl. Res. Q. Life 13, 1055-1080. doi: 10.1007/s11482-017-9575-y

Lyubomirsky, S., Dickerhoof, R., and Sousa, L. A. (2006). The costs and benefits of writing, talking, and thinking about life's triumphs and defeats. J. Pers. Soc. Psychol. 90, 692-708. doi: 10.1037/0022-3514.90.4.692

Lyubomirsky, S., and Lepper, H. (1999). A measure of subjective happiness: preliminary reliability and construct validation. Soc. Indic. Res. 46, 137-155.

MacLeod, A. K., Coates, E., and Hetherton, J. (2008). Increasing well-being through teaching goal-setting and planning skills: results of a brief intervention. J. Happ. Stud. 9, 185-196. doi: 10.1007/s10902-007-9057-2

Martinez-Marti, M. L., Avia, M. D., and Hernández-Lloreda, M. J. (2010). The effects of counting blessings on subjective well-being: a gratitude intervention in a spanish sample. Span. J. Psychol. 13, 886-896. doi: 10.1017/ s1138741600002535

Martínez-Martí, M. L., Avia, M. D., and Hernández-Lloreda, M. J. (2018). Effects of an appreciation of beauty randomized-controlled trial web-based intervention on appreciation of beauty and wellbeing. Psychol. Aesthet. Creat. Arts 12, 272-283. doi: 10.1037/aca00 00164

Mauss, I. B., Savino, N. S., Anderson, C. L., Weisbuch, M., Tamir, M., and Laudenslager, M. L. (2012). The pursuit of happiness can be lonely. Emotion 12:908. doi: $10.1037 / \mathrm{a} 0025299$

McMahon, D. M. (2018). "From the paleolithic to the present: three revolutions in the global history of happiness," in Handbook of Well-Being, eds E. Diener, S. Oishi, and L. Tay (Salt Lake City, UT: DEF Publishers).

Moodscope (2010). Mood Management Through Self-Tracking and Peer Support. Available online at: www.moodscope.com (accessed April 1, 2019).

Nelson, S. K., Fuller, T., and Lyubomirsky, S. (2014). Beyond self-protection: selfaffirmation benefits hedonic and eudaimonic well-being. Person. Soc. Psychol. Bull. 40, 1-14.

Nes, R. B., and Røysamb, E. (2017). Happiness in behavior genetics: an update on heritability and changeability. J. Happ. Stud. 18, 1533-1552. doi: 10.1007/ s10902-016-9781-6

Nielsen, K., Nielsen, M. B., Ogbonnaya, C., Känsälä, M., Saari, E., and Isaksson, K. (2017). Workplace resources to improve both employee well-being and performance: a systematic review and meta-analysis. Work Stress 31, 101-120. doi: 10.1080/02678373.2017.1304463

Nyklícek, I., and Kuijpers, K. F. (2008). Effects of mindfulness-based stress reduction intervention on psychological well-being and quality of life: is increased mindfulness indeed the mechanism? Ann. Behav. Med. 35, 331-340. doi: 10.1007/s12160-008-9030-2

Omerod, P. (2012). "The folly of wellbeing in public policy," in And the Pursuit of Happiness; Wellbeing and the Role of Government, ed. P. Booth (London: Institute of Economic Affairs), 39-57.

Page, K. M., and Vella-Brodrick, D. A. (2013). The working for wellness program: RCT of an employee well-being intervention. J. Happ. Stud. 14, 1007-1031. doi: 10.1007/s10902-012-9366-y

Parks, A. C. (2009). Positive Psychotherapy: Building a Model of Empirically Supported Self-Help. Ph. D. thesis, University of Pennsylvania, Philadelphia, PA.

Parks, A. C., Della Porta, M. D., Pierce, R. S., Zilca, R., and Lyubomirsky, S. (2012). Pursuing happiness in everyday life: the characteristics and behaviors of online happiness seekers. Emotion 12, 1222-1234.

Parks, A. C., Schueller, S. M., and Tasimi, A. (2013). "Increasing happiness in the general population: empirically supported self-help," in The Oxford Handbook of Happiness, eds S. A. David, I. Boniwell, and A. C. Ayers (Oxford: Oxford University Press), 901-914.

Pennebaker, J. W. (2018). Expressive writing in psychological science. Perspect. Psychol. Sci. 13, 226-229. doi: 10.1177/1745691617707315 
Pfeifer, C. (2013). Life satisfaction and the consumption values of partners and friends: Evidence from German panel survey data. Econ. Bull. 33, 31313142 .

Rash, J. A., Matsuba, M. K., and Prkachin, K. M. (2011). Gratitude and well-being: who benefits the most from a gratitude intervention? Appl. Psychol. Health Well Being 3, 350-369. doi: 10.1111/j.1758-0854.2011.01 058.x

Roll, L. C., Van Zyl, L. E., and Griep, Y. (2019). "Brief positive psychological interventions within multi-cultural organizational contexts: a systematic literature review," in Theoretical Approaches to Multi-Cultural Positive Psychological Interventions, eds L. E. Van Zyl and S. Rothmann (Cham: Springer), 523-544. doi: 10.1007/978-3-030-20583-6_24

Seligman, M. E. P., and Csikszentmihalyi, M. (2000). Positive psychology; an introduction. Am. Psychol. 55, 5-14.

Sezer, S., and Can, E. (2019). School happiness: a scale development and implementation study. Euras. J. Educ. Res. 79, 167-190.

Sheldon, K. M., Boehm, J. K., and Lyubomirsky, S. (2013). "Variety is the spice of happiness: the hedonic adaptation prevention model," in The Oxford Handbook of Happiness, eds S. A. David, I. Boniwell, and A. C. Ayers (Oxford: Oxford University Press), 901-914.

Sheldon, K. M., Kasser, T., and Smith, K. (2002). Personal goals and psychological growth: testing an intervention to enhance goal attainment and personality integration. J. Pers. 70, 5-31. doi: 10.1111/1467-6494.00176

Sheldon, K. M., and Lyubomirsky, S. (2009). "Change your actions, not your circumstances: an experimental test of the sustainable happiness model," in Happiness, Economics and Politics, Chap. 12, eds A. K. Dutt and B. Radcliff (Cheltenham: Edward Elgar Publishing).

Sheldon, K. M., and Lyubomirsky, S. (2012). The challenge of staying happier: testing the hedonic adaptation prevention model. Person. Soc. Psychol. Bull. 38, 670-680. doi: 10.1177/0146167212436400

Sheldon, K. M., and Lyubomirsky, S. (2019). Revisiting the sustainable happiness model and pie chart: can happiness be successfully pursued? J. Posit. Psychol. doi: 10.1080/17439760.2019.1689421

Simonsohn, U., Nelson, L. D., and Simmons, J. P. (2014). P-curve: a key to the file-drawer. J. Exper. Psychol. Gen. 143, 534-547. doi: 10.1037/a00 33242

Sin, N. L., and Lyubomirsky, S. (2009). Enhancing well-being and alleviating depressive symptoms with positive psychology interventions: a practicefriendly meta-analysis. J. Clin. Psychol. 65, 467-487. doi: 10.1002/jclp.20593

Soroka, S., and McAdams, S. (2015). News, politics, and negativity. Polit. Commun. 32, 1-22. doi: 10.1080/10584609.2014.881942

Suldo, S. M., Mercer, S. H., and Savage, J. A. (2014). Increasing middle school students' life satisfaction: efficacy of a positive psychology group intervention. J. Happ. Stud. 15, 19-42. doi: 10.1007/s10902-013-9414-2

Tarragona, M. (2015). "Positive psychology and life coaching," in Positive Psychology in Practice, ed. S. Joseph (Hoboken, NJ: John Wiley \& Sons), 249-264. doi: 10.1002/9781118996874.ch15

The happiness course (n.d.). Available online at: https://livability.org.uk/resources/ happiness-course/ (accessed June 23, 2020).

Van Praag, B. M., and Baarsma, B. E. (2005). Using happiness surveys to value intangibles: the case of airport noise. Econ. J. 115, 224-246. doi: 10.1111/j.14680297.2004.00967.x

Veenhoven, R. (1984). Conditions of Happiness. Dordrecht: Reidel.

Veenhoven, R. (2000). The four qualities of life: ordering concepts and measures of the good life. J. Happ. Stud. 1, 1-39.

Veenhoven, R. (2008). Healthy happiness: effects of happiness on physical health and the consequences for preventive health care. J. Happ. Stud. 9, 449-464.

Veenhoven, R. (2009). "How do we assess how happy we are?" in Happiness, Economics and Politics: Towards a Multi-Disciplinary Approach, eds A. K. Dutt and B. Radcliff (Cheltenham: Edward Elger Publishers), 45-69.
Veenhoven, R. (2010). Greater happiness for a greater number. is that possible and desirable? J. Happ. Stud. 11, 605-629. doi: 10.1007/s10902-010-9204-z

Veenhoven, R. (2015). "Happiness: history of the concept," in International Encyclopaedia of Social and Behavioural Sciences, ed. J. Wright (Amsterdam: Elsevier), 521-525. doi: 10.1016/b978-0-08-097086-8.03086-5

Veenhoven, R. (2019a). Bibliography of Happiness. World Database of Happiness. Rotterdam: Erasmus University Rotterdam. Available online at: https://worlddatabaseofhappiness.eur.nl/collections/bibliography/what-isthis-bibliography-of-happiness/

Veenhoven, R. (2019b). Collection of Scientific Publications on Happiness. World Database of Happiness, Erasmus University Rotterdam. Introductory Text to the Bibliography of Happiness. Chap. 4. Available online at: https://worlddatabaseofhappiness.eur.nl/wp-content/uploads/2020/08/ Introtext-MeasuresOfHappiness-Chapter4.pdf (accessed December 21, 2019).

Veenhoven, R. (2019c). Correlates of Happiness. World Database of Happiness, Erasmus University Rotterdam. Available online at: https: //worlddatabaseofhappiness.eur.nl/collections/correlational-findings/what-isthis-collection- of-correlational-findings-on-happiness/ (accessed December 21, 2019)

Veenhoven, R. (2019d). Correlational Findings on Happiness and Health: Psychological Treatment. Rotterdam: Erasmus University Rotterdam. Available online at: https://worlddatabaseofhappiness.eur.nl/search-the-database/ correlational-findings/\#id=1DYPIXQB9uCjuYHDZTYe

Veenhoven, R. (2019e). Measures of Happiness. World Database of Happiness. Rotterdam: Erasmus University Rotterdam. Available online at: https://worlddatabaseofhappiness.eur.nl/collections/measures-of-happiness/ what-is-this-collection-measures-of-happiness/

Veenhoven, R. (2019f). Notations of Findings. World Database of Happiness. Rotterdam: Erasmus University Rotterdam. Available online at: https://worlddatabaseofhappiness.eur.nl/wp-content/uploads/2020/08/ Introtext-CorrelationalFindings-Chapter3.pdf

Veenhoven, R. (2019g). World Database of Happiness: Archive of Research Findings on Subjective Enjoyment of Life. Rotterdam: Erasmus University Rotterdam. Available online at: https://worlddatabaseofhappiness.eur.nl

Veenhoven, R. (2020). "World database of happiness: a 'findings archive," in Handbook of Wellbeing, Happiness and the Environment, eds H. Welsch, D. Maddison, and K. Rehdanz (Cheltenham: Edward Elger Publishing), 25-45. doi: 10.4337/9781788119344.00009

Watson, D. C., Lee, A., and Tellegen, A. (1988). Development and validation of brief measures of positive and negative affect: The PANAS scales. J. Pers. Soc. Psychol. 54, 1063-1070. doi: 10.1037/0022-3514.54.6.1063

Weinberg, M. K., Cummins, R. A., and Hammond, T. G. (2014). The impact of laughter yoga on subjective well-being: a pilot study. Eur. J. Humour Res. 1, 25-34.

White, C. A., Uttl, B., and Holder, M. D. (2019). Meta-analyses of positive psychology interventions: the effects are much smaller than previously reported. PLoS One 14:e0216588. doi: 10.1371/journal.pone.021658

Conflict of Interest: The authors declare that the research was conducted in the absence of any commercial or financial relationships that could be construed as a potential conflict of interest.

Copyright (c) 2020 Bergsma, Buijt and Veenhoven. This is an open-access article distributed under the terms of the Creative Commons Attribution License (CC BY). The use, distribution or reproduction in other forums is permitted, provided the original author(s) and the copyright owner(s) are credited and that the original publication in this journal is cited, in accordance with accepted academic practice. No use, distribution or reproduction is permitted which does not comply with these terms. 


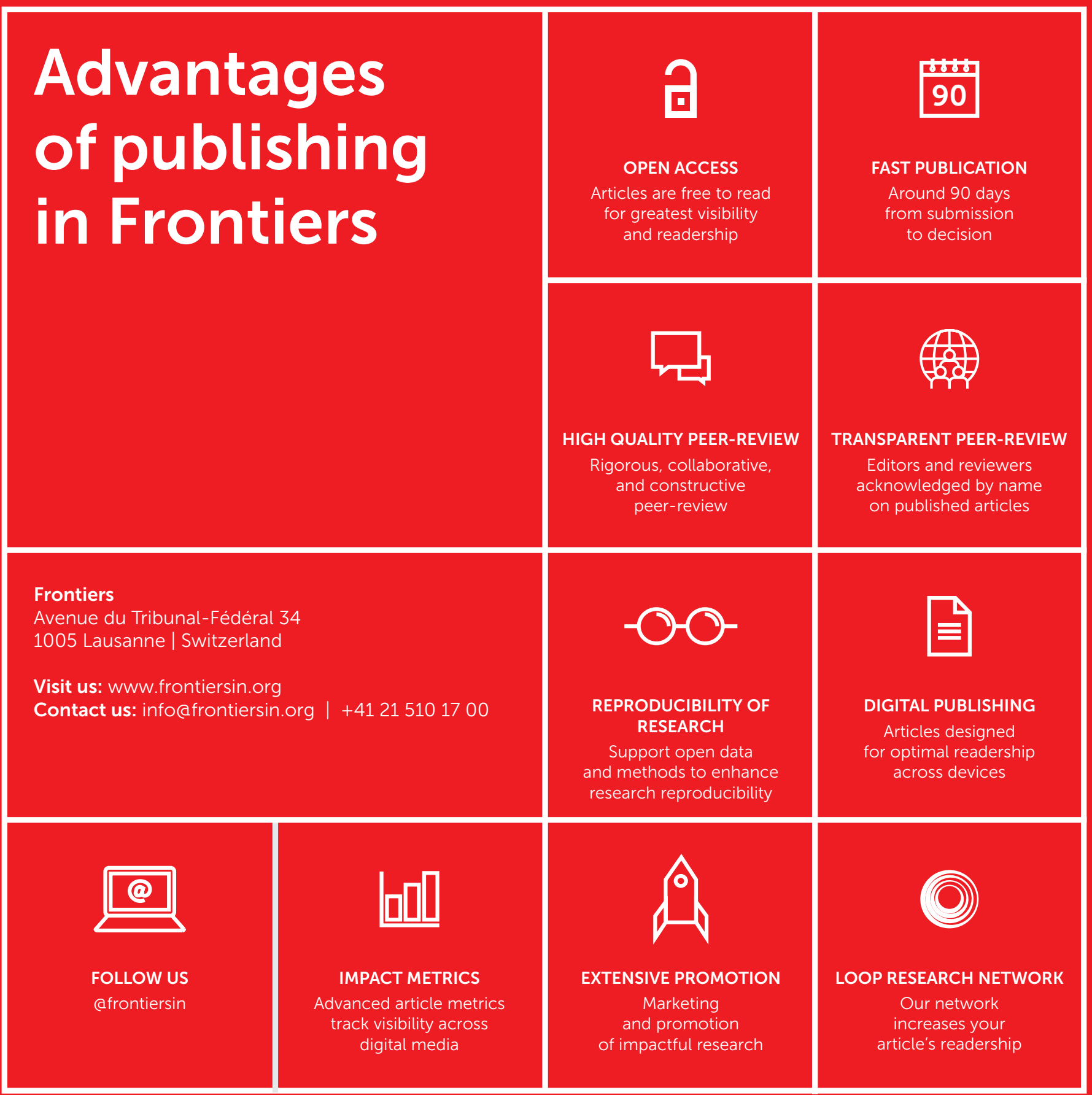

